\title{
Federal Geothermal Research Program Update Fiscal Year 1997
}

\section{Prepared for:}

\author{
U.S. Department of Energy \\ Assistant Secretary for Energy Efficiency and \\ Renewable Energy \\ Office of Geothermal Technologies \\ Washington, DC 20585 \\ Compiled By:
}

Princeton Economic Research, Inc. Rockville, MD 20852

March 1998

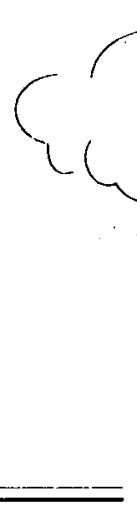




\section{DISCLAIMER}

This report was prepared as an account of work sponsored by an agency of the United States Government. Neither the United States Government nor any agency Thereof, nor any of their employees, makes any warranty, express or implied, or assumes any legal liability or responsibility for the accuracy, completeness, or usefulness of any information, apparatus, product, or process disclosed, or represents that its use would not infringe privately owned rights. Reference herein to any specific commercial product, process, or service by trade name, trademark, manufacturer, or otherwise does not necessarily constitute or imply its endorsement, recommendation, or favoring by the United States Government or any agency thereof. The views and opinions of authors expressed herein do not necessarily state or reflect those of the United States Government or any agency thereof. 


\section{DISCLAIMER}

Portions of this document may be illegible in electronic image products. Images are produced from the best available original document. 
NOTICE

"This report was prepared as an account of work sponsored by an agency of the United Sates Government. Neither the United States Government nor any agency thereof, nor any of their employees, makes any warranty, express or implied, or assumes any legal liability or responsibility for the accuracy, completeness, or usefulness of any information, apparatus, product, or process disclosed, or represents that its use would not infringe privately owned rights. Reference herein to any specific commercial product, process, or service by trade name, trademark, manufacturer, or otherwise, does not necessarily constitute or imply its endorsement, recommendation, or favoring by the United States Government or any agency thereof. The views and opinions of authors expressed herein do not necessarily state or reflect those of the United States Government or any agency thereof." 
TABLE OF CONTENTS

EXECUTIVE SUMMARY

$1-1$

\section{EXPLORATION TECHNOLOGY}

\section{GeOPHYSICAL METHODS}

ARCHIVE OF GEOTHERMAL EXPLORATION DATA

John K. Costain

FRACTURE PERMEABILITY IN GEOTHERMAL SYSTEMS

Dennis L. Nielson

THE HISTORY OF HYDROTHERMAL MINERALIZATION IN THE VOLCANIC-HOSTED GEOTHERMAL SYSTEM AT TIWI, PHILIPPINES

Joseph N. Moore, Matthew T. Heizler, David I. Norman, and Carol Bruton . . . . . 2 2 - 15

GEOLOGIC STUDY OF THE COSO FORMATION

Diane L. Kamola and J. Douglas Walker

THE AWIBENGKOK, INDONESIA, GEOTHERMAL RESEARCH PROJECT

Jeffrey B. Hulen

\section{GeOCHEMiCAL MeThOdS}

GEOTHERMAL CHEMISTRY/EXPLORATION

Fraser Goff and Cathy J. Janik

ISOTOPE GEOCHEMISTRY IN GEOTHERMAL RESEARCH

B. Mack Kennedy, Donald J. DePaolo, and Alfred H. Truesdell

MAGMATIC-HYDROTHERMAL AQUEOUS EXSOLUTION

P.A. Candela and P.M. Piccoli 
THERMODYNAMICS AND PHASE RELATIONS OF SYNTHETIC GRANITE MELTS AND ASSOCIATED AQUEOUS FLUIDS

J. G. Blencoe, L. M. Anovitz, D. R. Cole and J. Horita

\section{Geological Methods}

MT/CSAMT ELECTRICAL METHODS RESEARCH

Philip E. Wannamaker and John A. Stodt .

SP MODELING

Alan C. Tripp and Howard P. Ross

ELECTROMAGNETIC METHODS FOR GEOTHERMAL EXPLORATION

Ki Ha Lee

UPDATE ON THE GEOTHERMAL EXPLORATION PROGRAM AT THE

EL HOYO GEOTHERMAL AREA, NICARAGUA

Tsvi Meidav and Bill Teplow

GEOTHERMAL EXPLORATION

IN THE RYE PATCH GEOTHERMAL FIELD

Tsvi Meidav and Bill Teplow $2-81$

GEOPHYSICAL STUDIES OF THE

COVE FORT-SULPHURDALE, UTAH GEOTHERMAL SYSTEM

Howard P. Ross

GEOTHERMAL RESOURCE/RESER VOIR INVESTIGATIONS

BASED ON HEAT FLOW AND THERMAL GRADIENT DATA

FOR THE UNITED STATES

David D. Blackwell, Kenneth W. Wisian, and John L. Steele $2-93$

LIST OF CONTACTS FOR EXPLORATION TECHNOLOGY $2-99$ 


\section{DRILLING TECHNOLOGY}

DEVELOPMENT OF ADVANCED SYNTHETIC-DIAMOND

DRILL BITS FOR HARD-ROCK DRILLING

Jack L. Wise and David W. Raymond

$3-1$

LOST CIRCULATION TECHNOLOGY DEVELOPMENT PROJECT

LOSS-ZONE CHARACTERIZATION HARDWARE AND SOFTWARE

George E. Staller and Arthur J. Mansure

\section{LOST CIRCULATION TECHNOLOGY DEVELOPMENT PROJECT}

DOWNHOLE TOOLS AND MATERIALS FOR TREATING LOSS ZONES

George E. Staller

HIGH-TEMPERATURE INSTRUMENTATION

Randy A. Norman \& Joseph A. Henfling

SLIMHOLE DRILLING FOR GEOTHERMAL EXPLORATION

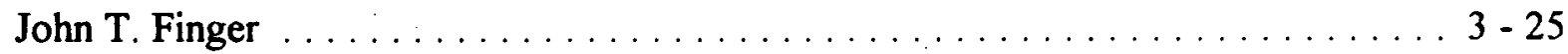

WIRELESS DATA TELEMETRY

Douglas S. Drumheller and Steven D. Knudsen $\ldots \ldots \ldots \ldots \ldots \ldots \ldots \ldots \ldots \ldots$

GEOTHERMAL DRILLING ORGANIZATION

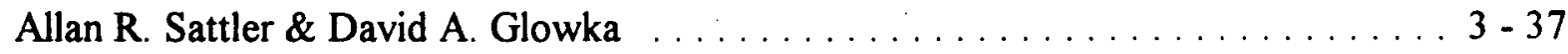

GEOTHERMAL SYSTEMS STUDIES

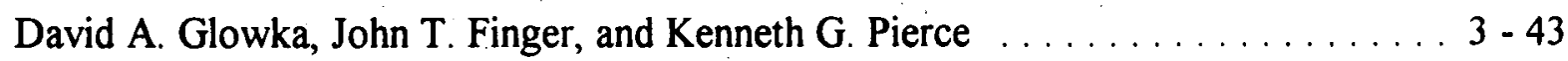

LIST OF CONTACTS FOR DRILLING TECHNOLOGY $\ldots \ldots \ldots \ldots \ldots \ldots \ldots \ldots$

\section{RESERVOIR TECHNOLOGY}

\section{RESERVOIR CHEMISTRY}

GEOCHEMICAL STUDIES OF GEOTHERMAL SYSTEMS

Gregory J. Nimz and Carol J. Bruton. 
TABLE OF CONTENTS (continued)

GEOCHEMISTRY OF ALUMINUM IN HIGH TEMPERATURE BRINES

Donald A. Palmer, Pascale Benezeth, and David J. Wesolowski . . . . . . . . . . 4 - 9

VOLATILITY OF CHLORIDES AND THE THERMODYNAMICS OF BRINES DURING BRINE DRYOUT

J. Michael Simonson, Donald A. Palmer, S. L: Marshall, M. S. Gruszkiewicz, and R. E. Mesmer

STABLE ISOTOPE PARTITIONING IN BRINE-GAS-MINERAL SYSTEMS RELEVANT TO GEOTHERMAL RESOURCES

Juske Horita, David R. Cole, and David J. Wesolowski

TRACING FLUID FLOW IN GEOTHERMALRESERVOIRS

Peter E. Rose and Michael C. Adams

CHEMICAL MODELS FOR OPTIMIZING

GEOTHERMAL ENERGY PRODUCTION

Nancy M $\phi l l e r$, John H. Weare, Zhenhao Duan and Jerry P. Greenberg

\section{Reservoir PHYSICS}

WATER ADSORPTION

Miroslaw S. Gruszkiewicz, Juske Horita, J. Michael Simonson, and

Robert E. Mesmer

\section{RESERVOIR SIMULATION}

CERRO PRIETO FIELD CASE STUDY

Marcelo J. Lippmann, Alfred H. Truesdell, and Héctor Gutiérrez Puente . . . . . . . 4 - 53

HIGHER-ORDER DIFFERENCING SCHEMES FOR

GEOTHERMAL RESERVOIR SIMULATION

Curtis M. Oldenburg and Karsten Pruess

T2SOLV: AN ENHANCED PACKAGE OF SOLVERS

FOR THE TOUGH2 FAMILY OF CODES

George J. Moridis and Karsten Pruess 
TABLE OF CONTENTS (continued)

FURTHER DEVELOPMENTS IN MULTIPHASE INVERSE MODELING

Stefan Finsterle, Karsten Pruess, and Alfredo Battistelli . . . . . . . . . . . . . . . 4 - 69

DECLINE CURVE ANALYSIS OF VAPOR-DOMINATED RESERVOIRS

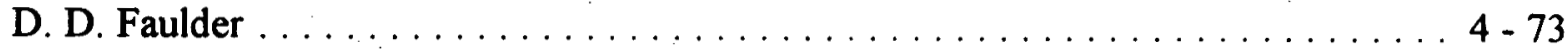

NUMERICAL MODELING OF THE

GEYSERS UNIT 18 COOPERATIVE INJECTION PROJECT

K. K. Bloomfield, G. M. Shook, and D. D. Faulder

ELECTRICAL GENERATING CAPACITIES OF GEOTHERMAL SLIM HOLES

John W. Pritchett

INTEGRATED RESERVOIR STUDY OF THE BEOWAWE

HYDROTHERMAL SYSTEM

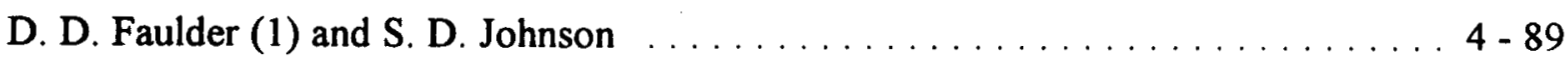

GEOTHERMAL DATA CONVERSION PROJECT

Jeffrey L. Wagoner and Oscar Nazario .

\section{The GeYSERS Field STUdies}

HEAT-FLOW STUDIES IN THE AREA OF THE

GEYSERS GEOTHERMAL FIELD, CALIFORNIA

Colin F. Williams

$4-97$

THERMAL HISTORY AND AGE OF THE FELSITE UNIT, THE GEYSERS

GEOTHERMAL FIELD, FROM THERMAL MODELING OF ${ }^{40} \mathrm{Ar} /{ }^{39} \mathrm{Ar}$

INCREMENTAL HEATING DATA

G. Brent Dalrymple

$4-103$

MICROSEISMIC MONITORING AT THE GEYSERS

A. Kirkpatrick, E.L. Majer and J.E. Peterson, Jr. 
A COMPREHENSIVE STUDY OF FRACTURE PATTERNS AND DENSITIES

IN THE GEYSERS GEOTHERMAL RESER VOIR USING

MICROEARTHQUAKE SHEAR-WAVE SPLITTING TOMOGRAPHY

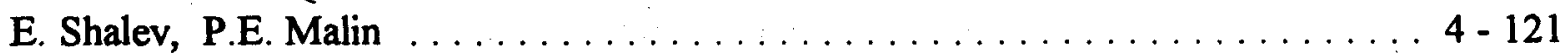

CHARACTERIZATION OF FRACTURE PATTERNS AND DENSITIES IN THE GEYSERS GEOTHERMAL RESERVOIR BY ANALYZING SHEAR-WAVE SPLITTING FROM MICRO-EARTHQUAKES

J.A. Rial . . . . . . . . . . . . . . . . . . . . . . . . . . . . . . . . 4 425

ESTIMATED RELATIVE PERMEABILITY CURVES FOR

CORE PLUGS FROM THE GEYSERS WELL SB-15-D

Peter Persoff and Stefan Finsterle

FRACTURE ANALYSIS AT THE GEYSERS

Dennis L. Nielson $\ldots \ldots \ldots \ldots \ldots \ldots \ldots \ldots \ldots \ldots \ldots \ldots \ldots \ldots \ldots, 4-143$

THE APPLICATION OF FLUID-INCLUSION GASES TO TRACING

FLUID SOURCES AND RESERVOIR PROCESSES:

A CASE STUDY OF THE GEYSERS, CALIFORNIA

Joseph N. Moore, David I. Norman, B. Mack Kennedy . . . . . . . . . . . . . . 4 - 149

THE MECHANISM AND TIMING OF THE TRANSITION

FROM HOT-WATER- TO VAPOR-DOMINATED CONDITIONS

AT THE GEYSERS

Jeffrey B. Hulen, Joseph N. Moore, Matthew T. Heizler, and Jeffrey C. Quick . . . 4 4 - 153

AGE, PETROGENESIS, AND EMPLACEMENT OF FELSIC PLUTONIC

AND VOLCANIC ROCKS AT THE GEYSERS:

NEW AND CONFIRMED CONSTRAINTS ON THE INCEPTION AND

EVOLUTION OF THE GEYSERS HYDROTHERMAL SYSTEM

Jeffrey B. Hulen, James A. Stimac, Matthew T. Heizler

RESISTIVITY DURING BOILING IN THE SB-15-D CORE FROM

THE GEYSERS GEOTHERMAL FIELD: THE EFFECTS OF CAPILLARITY

Al Duba, Jeff Roberts, Brian Bonner, and Paul Kasameyer

$4-177$ 
TABLE OF CONTENTS (continued)

\section{Dixie Valley Field Studies}

STRUCTURAL AND TECTONIC SETTING OF

THE DIXIE VALLEY GEOTHERMAL FIELD, NEVADA

Gabriel L. Plank, Richard A. Schweickert, Ardyth M. Simmons, and

Dick Benoit

$4-181$

FRACTURE PERMEABILITY AND IN SITU STRESS

IN THE DIXIE VALLEY, NEVADA, GEOTHERMAL RESERVOIR

Stephen Hickman, John Sass, Colin Williams, Roger Morin, Colleen Barton,

Mark Zoback, and Dick Benoit

SEASONAL VARIATION IN BIG GREASEWOOD SPECTRAL BLUE SHIFTING, DIXIE VALLEY, NEVADA

Gregory D. Nash

ALTERATION HISTORY OF JURASSIC RESERVOIR ROCKS

IN THE DIXIE VALLEY GEOTHERMAL FIELD, NEVADA

Susan J. Lutz and Joseph N. Moore

$4-207$

LIST OF CONTACTS FOR RESERVOIR TECHNOLOGY

$4-211$

\section{CONVERSION TECHNOLOGY}

Geothermal Materials DevelopMent

$\mathrm{CO}_{2}$-RESISTANT CEMENTS IN GEOTHERMAL WELLS

Toshifumi Sugama

THERMALLY CONDUCTIVE COMPOSITES

FOR HEAT EXCHANGER TUBING

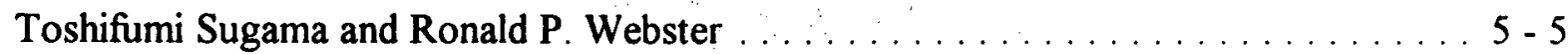

COATINGS FOR HIGH TEMPERATURE APPLICATIONS

Toshifumi Sugama . . . . . . . . . . . . . . . . . . . . . . . . . . 5 5 
COATINGS FOR PROTECTION OF EQUIPMENT FOR BIOCHEMICAL PROCESSING OF GEOTHERMAL RESIDUES

M.L. Allan

THERMALLY CONDUCTIVE CEMENTITIOUS GROUTS FOR GEOTHERMAL HEAT PUMPS

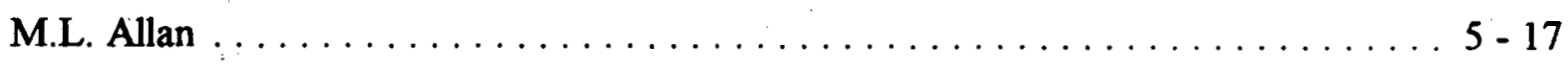

ADVANCED BIOCHEMICAL PROCESSES

FOR GEOTHERMAL BRINES

Eugene T. Premuzic

GEOTHERMAL BIOCORROSION

P. A. Pryfogle

\section{Heat Cycle Research}

IMPROVEMENTS IN BINARY CYCLE PERFORMANCE

SUPERSATURATED TURBINE EXPANSION

G. L. Mines

BINARY CYCLE PERFORMANCE IMPROVEMENT FROM

REAL-TIME PROCESS CONTROL

B. W. Brown, G. L. Mines, and M. M. Plum $\ldots \ldots \ldots \ldots \ldots \ldots \ldots \ldots \ldots 5-37$

TRILATERAL CYCLE FOR LOW-TEMPERATURE RESOURCES

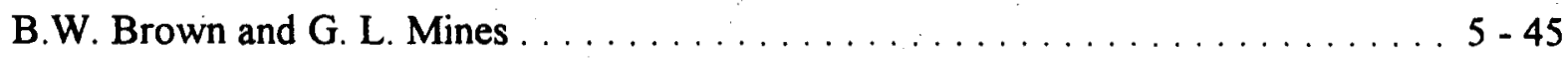

REAL-TIME $\mathrm{H}_{2} \mathrm{~S}$ MONITOR FOR APPLICATION

IN GEOTHERMAL PLANTS

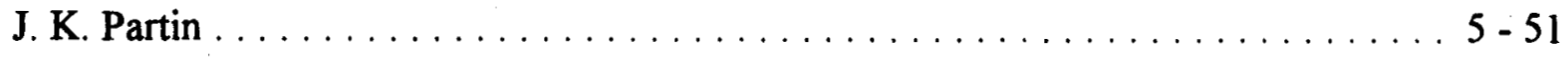

\section{GEOTHERMAL ENERGY CONVERSION}

INVESTIGATION OF GEOTHERMAL POWER SYSTEMS USING MULTI-COMPONENT WORKING FLUIDS

Desikan Bharathan .............................. 5 - 55 
TABLE OF CONTENTS (continued)

MODEL DEVELOPMENT AND ANALYSIS OF ADVANCED BINARY CYCLES

Vahab Hassani and Keith Gawlik ... . . . . . . . . . . . . . . . . . . . . . 5 - 57

FIELD TESTING OF THERMALLY-CONDUCTIVE, CORROSION-RESISTANT HEAT EXCHANGER LINERS

Keith Gawlik and Vahab Hassani

DEVELOPMENT AND TESTING OF ADVANCED

DIRECT-CONTACT CONDENSERS

Desikan Bharathan

REDUCTION OF OPERATING AND MAINTENANCE COSTS

AT GEOTHERMAL POWER PLANTS

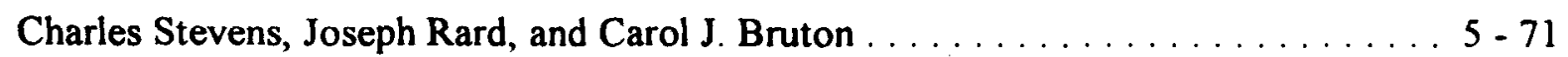

LIST OF CONTACTS FOR CONVERSION TECHNOLOGY

$5-75$

\section{ENVIRONMENT}

GEOTHERMAL DIRECT-HEAT UTILIZATION ASSISTANCE

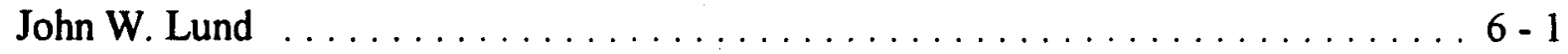

GEOTHERMAL HEAT PUMP TECHNOLOGY TRANSFER

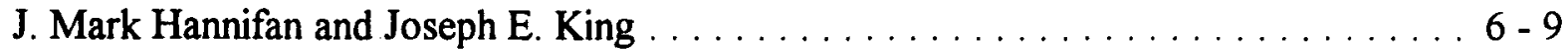

SOUTHEAST GEYSERS EFFLUENT PIPELINE PROJECT

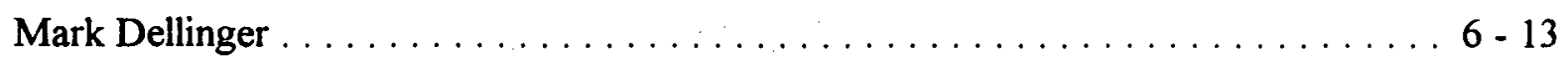

GEOTHERMAL HEAT PUMP TECHNOLOGY TRANSFER

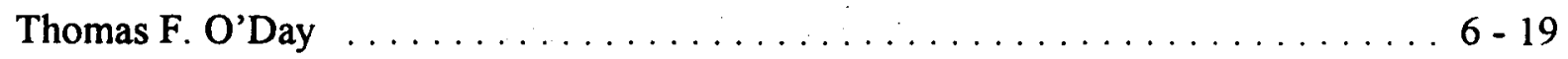

LIST OF CONTACTS FOR ENVIRONMENT $\ldots \ldots \ldots \ldots \ldots \ldots \ldots \ldots \ldots \ldots . \ldots \ldots$

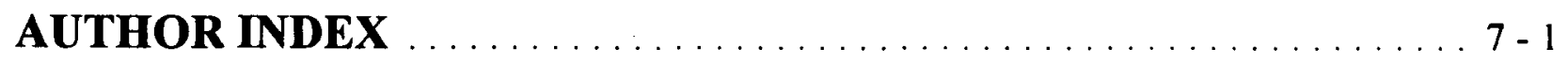

KEYWORD INDEX $\ldots \ldots \ldots \ldots \ldots \ldots \ldots \ldots \ldots \ldots \ldots \ldots, \ldots \ldots \ldots$ 


\section{EXECUTIVE SUMMARY}

\section{OVERVIEW}

The Department of Energy (DOE) and its predecessors have conducted research and development (R\&D) in Geothermal Energy since 1971. To develop the technology needed to harness the Nation's vast geothermal resources, DOE's Office of Geothermal Technologies oversees a network of national laboratories, industrial contractors, universities, and their subcontractors. The following mission and vision statements guide the overall activities of the Office of Geothermal Technologies.

\section{Mission}

To work in partnership with U.S. industry to establish geothermal energy as a sustainable, environmentally sound, economically competitive contributor to the U.S. and world energy supply.

\section{Vision}

By the year 2010, geothermal energy will be the preferred alternative to polluting energy sources throughout the world.

This Federal Geothermal Research Program Update reviews the specific objectives, status, and accomplishments of DOE's Geothermal Research Program for Federal Fiscal Year (FY) 1997. The information contained in this Research Program Update illustrates how the mission and vision of the Office of Geothermal Technologies are reflected in each R\&D activity. The Geothermal Research Program, from its guiding principles to the most detailed research activities, is focussed on expanding the use of geothermal energy.

\section{RESEARCH FOCUS}

In accordance with the mission and vision, the Geothermal Research Program serves two broad purposes: 1) to assist industry in overcoming near-term barriers by conducting cost-shared research that allows geothermal energy to compete in today's aggressive energy markets; and 2) to undertake fundamental research with potentially large commercial payoffs.

Since the inception of the Geothermal Program, the federal government and private industry have worked closely together - in pursuing promising research directions, and in overcoming difficult technical barriers - to establish an extensive geothermal knowledge base. Over the past two decades, industry, in turn, has succeeded in creating an infrastructure that translates research results into marketplace applications. The DOE/industry partnership guides the DOE research program towards more cost-competitive power generation from geothermal resources. This partnership assesses the value of long-term research options as well. Private-sector inputs to DOE's planning process are critical to a logical, balanced strategy for the Geothermal Research Program. This joint strategy serves to increase geothermal energy's role in the U.S. energy sector. 
The five categories of work used to distinguish the research activities of the Office of Geothermal Technologies reflect main components of real-world geothermal projects (Figure 1). These categories are described briefly here and form the main sections of the project descriptions in this Research Program Update.

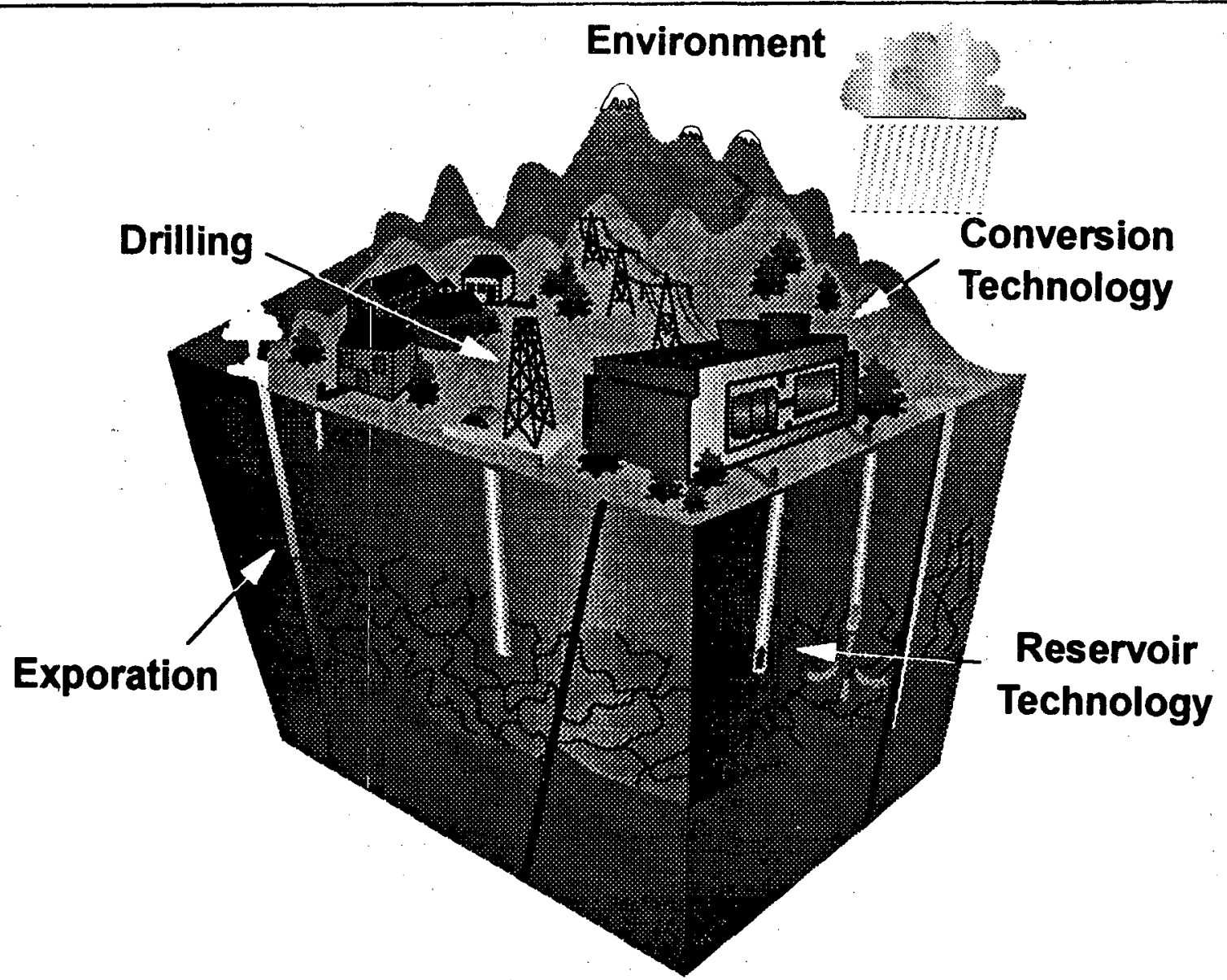

Figure 1. Schematic Diagram of a Geothermal System and its Component Technologies

\section{Exploration Technology}

Most of the U.S. hydrothermal systems with obvious surface manifestations have been explored. New hydrothermal discoveries will require exploration in frontier areas where the reservoirs are either concealed or lie at greater depths. The Exploration Technology research focusses on developing instruments and techniques to discover hidden hydrothermal systems and to explore the deep portions of known systems.

Research in geophysical and geochemical methods is expected to yield increased knowledge of hidden geothermal systems. Improved exploration techniques and data interpretation methods will facilitate expanding the geothermal resource base. 


\section{Drilling Technology}

Drilling and completion of wells for exploration, production, and injection account for 25 to 50 percent of the cost of generating electricity from geothermal resources. Current geothermal drilling and completion technology derives primarily from the oil and gas industry. This technology is often unsuitable for the high temperatures, hard rock, and highly corrosive fluids found in the hostile geothermal environment. The Drilling Technology projects focus on developing improved, economic drilling and completion technology for geothermal wells.

Ongoing research to avert lost circulation episodes in geothermal drilling is yielding positive results. Field testing of prototype packer elements is underway to confine and regulate cementing operations for recovering from lost circulation. Flow meters capable of measuring flow rates into and out of a well are being field tested. Advanced drill bits are under development. Slimhole drilling, which might reduce exploration drilling costs by up to 50 percent, will facilitate reservoir confirmation. Cost-shared efforts to develop memory-based logging instruments and an acoustic telemetry system for downhole measurements are also in progress.

\section{Reservoir Technology}

The geothermal industry has made progress in devising techniques for characterizing and developing hydrothermal reservoirs. Nevertheless, reservoir technology still suffers from several major uncertainties, such as those encountered in assessing reservoir productivity and sustainability, and in assessing the extent of field reserves. These uncertainties may lead to overproduction in a field and premature pressure and production declines. The Reservoir Technology research combines laboratory and analytical investigations with equipment development and field testing to establish practical tools for resource development and management for both hydrothermal and hot dry rock reservoirs.

Research in various reservoir analysis techniques is generating a wide range of information that facilitates development of improved reservoir management tools. Improved geothermal tracer chemicals and tracer data interpretation techniques will optimize injection strategies and increase resource longevity. Capabilities for predicting scaling and corrosion have improved markedly with the ongoing research in brine chemistry. Efforts are also underway to minimize reservoir depletion at The Geysers geothermal reservoir in California and extend the resource lifetime.

\section{Conversion Technology}

The three conversion technologies in current use for electricity generation are: 1) Dry steam conversion, such as that used at The Geysers since 1960; 2) Flash steam plants, favored for liquid-dominated or two-phase resources when the resource temperature is over $180^{\circ} \mathrm{C}\left(360^{\circ} \mathrm{F}\right)$; and 3) Binary cycles, favored for moderate resource temperatures in the range of $100^{\circ}$ to $180^{\circ} \mathrm{C}\left(212^{\circ} \mathrm{F}\right.$ to $\left.360^{\circ} \mathrm{F}\right)$. Dry steam and flash steam plants are mature technologies generating cost-competitive electricity in some situations. Binary cycle power plant technology is less mature, only recently coming into general use as an economic conversion alternative. The Conversion Technology research focuses on reducing costs and improving binary conversion cycle efficiency, to permit greater use of the more abundant moderate-temperature geothermal resource; and on the development of materials that will improve the operating characteristics of many types of geothermal energy equipment.

Increased output and improved performance of binary cycles will result from investigations in heat cycle research. High-temperature, scale-resistant, corrosion-resistant, and thermally-conductive liner materials are being developed for fluid transport systems, heat exchanger applications, and energy conversion processes. $\mathrm{CO}_{2}-$ resistant well cements able to withstand the aggressive chemistry of certain geothermal fluids are also under 
development. Biotechnology solutions for geothermal waste disposal are being refined.

\section{Environment}

This category covers aspects of environmental, health, and safety research.

Construction of the Southeast Geysers Effluent Pipeline and Injection Project began in October 1995. This project will contribute to sustaining power capacity at The Geysers. In another project, new applications are being found for silica wastes from geothermal power plants.

The Department of Energy and other partners initiated the Geothermal Heat Pump Consortium (GHPC) in late 1994. The GHPC is a partnership of utilities, geothermal manufacturers, HVAC vendors, and public agencies whose objective is to overcome market barriers to the widespread deployment of geothermal heat pumps.

\section{MAJOR RESEARCH ACCOMPLISHMENTS IN FY 1997}

\section{Exploration Technology}

Research is being conducted to test and verify new exploration technologies at developed geothermal fields where well drilling has defined the resource. Scientists demonstrated the utility of combining rapid, broad spectrum fluid-inclusion gas analyses with analyses of the noble-gas contents as a means of tracing the sources and quantifying the effects of fluid mixing and boiling at The Geysers. Petrographic and fluid inclusion studies can be conducted on core or cuttings from exploration wells, and work at Dixie Valley, Nevada, revealed six major mineral assemblages representing alteration events associated with the early stages of the Basin and Range extension and the evolution of the geothermal system.

Magnetotelluric (MT/CSAMT), self potential (SP) and ground magnetic surveys were completed for the El Hoyo - Monte Galan, Nicaragua, and Rye Patch, Nevada, geothermal fields as part of an overall effort to develop an integrated geoscientific exploration strategy. To test the use of seismic shear wave splitting as an exploration method to identify major fracture directions in the reservoir, more than 1,100 split shear waves from seismic events within The Geysers were analyzed and the split shear wave paths with clear polarization directions were plotted. Results indicate that shear-wave splitting is mainly caused by pervasive, north-northeast aligned anisotropy at the northwest Geysers. Methods to identify open and permeable fractures in exploration core drilling were tested in an analysis of the hydrothermal mineralogy, vein paragenesis, and fluid inclusions of the Tiwi geothermal system in the Philippines.

\section{Drilling Technology}

Researchers completed three-dimensional numerical analyses for ten different claw-cutter bit configurations featuring various groove widths, groove spacing, groove depths, and diamond thicknesses under typical hard rock operating conditions. The potential for fabricating superhard rock cutters using explosive compaction techniques was evaluated. During field tests, the second generation Rolling Flow Meter demonstrated enhanced sensitivity, accuracy and robustness. The Sandia-developed pressure/temperature tool, equipped with a spinner from Pruett Industries, is now commercially available, either on a logging-service basis or for sale as a stand-alone item. Correlations of productivity and injectivity indices between large and small wells, using data from more than 200 Japanese slimholes and production wells, show that most of the slimholes are good predictors of performance for production wells drilled into the same reservoir. A high-temperature, high-pressure valve-changing tool has 
been successfully field tested. A patent application has been filed for a new line-shaft pump monitor, which measures the alignment of the pump rotor with the pump housing.

\section{Reservoir Engineering}

A major focus of reservoir researcher is to develop numerical reservoir simulators that provide accurate predictions of geothermal field response to fluid production and injection. A model of the Beowawe hydrothermal system was produced to assist in forecasting future cooling from cold water injection and to develop reservoir management strategies to mitigate cooling of deep production zones. The response to injection was predicted in model studies using data collected during The Geysers Unit 18 injection test with Unocal, NCPA, and Calpine. The model produced very good matching of production rates and wellhead pressures for all 43 wells in the area. As a tool for industry use, the Fetkovich decline type-curve analytic method has been modified to handle pressure declines in vapor-dominated geothermal systems. Initial measurements were conducted to determine the amount of water adsorbed on rock surfaces in low pressure geothermal systems, and the phenomenon of adsorption appears to control a significant quantity of water.

\section{Conversion Technology}

Researchers elucidated the interactions taking place at polymer cement linings (PCL) - or polymer-scale interfaces, to get a better understanding and selection of corrosion resistant coatings. Studies are underway to develop well cementing materials produced by acid-based reactions between flyash-blended calcium aluminate cements and phosphate-containing compounds. Ceramic sealed NiAl composite and flyash-derived glass ceramic were laboratory and field tested for use as corrosion/oxidation/abrasion-resistant coatings for mild carbon steel, stainless steel, $\mathrm{Ni}-\mathrm{Cr}$ steel, and $\mathrm{Ti}$-based alloys. Investigations are underway for use of polyaromatic hydrocarbons as viable liquid phase tracers under the most demanding $\left(>300^{\circ} \mathrm{C}\right)$ hydrothermal conditions. Research is underway to develop high thermal conductivity cementitous grouts that can reduce GHP borehole length requirements and installation costs while improving GHP performance. An evaluation of the electrical generating capacities of slimholes confirmed that they have considerable promise for supplying small off-grid steam turbogenerators, even without downhole pumps. Development and demonstration of a real-time hydrogen sulfide $\left(\mathrm{H}_{2} \mathrm{~S}\right)$ gas detection and monitoring system for geothermal plants is underway. Testing of an ideal expansion of isobutane through a converging-diverging nozzle produced supersaturated vapor with equilibrium moisture levels of $5 \%$ to $6 \%$, without degrading turbine efficiency. Model studies were conducted to optimize the thermodynamic performance and economics of binary plants with different plant configurations and mix of working fluids. A newly developed computer code permits modeling the thermal performance, scavenging of non-condensible gases, and accompanying chemical-reactions in direct contact condensers.

\section{Environment}

The Geo-Heat Center handled 725 requests for technical and development assistance on geothermal direct use projects and published a "Comprehensive Greenhouse Developers Package" and a guide for "Well Pumping in Commercial Ground Water Heat Pump."

The entire 29-mile Southeast Geysers pipeline has been installed and successfully tested, with the project culminating with its dedication on October 16, 1997. 


\title{
ARCHIVE OF GEOTHERMAL EXPLORATION DATA
}

\author{
John K. Costain \\ Virginia Tech, Department of Geological Sciences
}

\section{KEY WORDS}

geothermal exploration, Eastern United States, temperature gradients, thermal conductivity, radiogenic model, geophysical exploration, exploration methods for geothermal energy, low-temperature applications

\section{PROJECT BACKGROUND AND STATUS}

This project was started in 1995 to make available to the public the extensive geothermal database for the southeastern United States that was generated between 1976-1982 as part of DOE Contracts E-(40-1)-5103, ET78-C-05-5648, and DE-AC05-78ET-27001 to Virginia Polytechnic Institute and State University. That geothermal program was entitled Evaluation and Targeting of Geothermal Resources in the Southeastern United States. Methodology is described in Costain and others (1980). It was decided that the widest exposure to the basic data gathered during this program would be obtained if that data were placed on the World Wide Web. To date, data from Virginia, North Carolina, South Carolina, Georgia, Delaware, and Maryland have been placed on the WWW. The work is on schedule, and the project should be completed on August 15, 1998. Progress to date can be viewed at web site http://rglsunl.geol.vt.edu. No figures have been included in this report because they can all be viewed on the web site.

\section{PROJECT OBJECTIVES}

In addition to detailed (latitude, longitude, and 7.5' quadrangle) location maps and reflection seismic data, this format allows the posting of all individual temperature values for each hole logged, as well as each value of thermal conductivity, a degree of data accessibility that would not be possible using conventional publication channels. Previously published results can thus be reproduced, or the data can be used for purposes other than geothermal applications, i.e., for global climate studies. The objective of this project is to make the Virginia Tech web site a valuable source of basic data for low-temperature, non-electric power, geothermal applications in the southeastern United States.

\section{Technical Objectives}

- Make basic geothermal data available to the public and private sector.

- Strict adherence to developing Hypertext Markup Language (HTML) standards. The data can be viewed and downloaded using any standard web browser.

- Provision for links to related geothermal sites, including those of the Department of Energy.

\section{Expected Outcomes}

- Encouragement of increased use of groundwater heat pumps for space heating as the public is made aware of cost efficiencies that can be realized for individual dwellings and industrial complexes. The potential areas of application in the southeastern United States are widespread. 
- Summary of geophysical techniques used by Virginia Tech to explore for optimum sites for lowtemperature geothermal applications in the southeastern United States.

- An easily accessed and efficiently cross-referenced source of basic geothermal data for public and private planning purposes.

- Economic value: Providing the data base decreases the need for additional exploration in areas where data are already available, and accelerates planning for geothermal applications.

\section{APPROACH}

The vintage of some of our temperature log data is such as to require scanning for conversion to an alphanumeric digital format for placement on the Web. Most of the log data, however, is being formatted for dirct viewing via the HTML source language and standard browser viewers. All temperature data are placed on the web as tables that can be downloaded by the user. In addition, all temperature data have been plotted and displayed as temperature versus depth and geothermal gradient versus depth. For each state or sub-area, temperature profiles have been plotted on the same graph to the same scale for ease of comparison. Some of the seismic data are being converted to Society of Exploration Geophysicists SEG-Y format so that they can be downloaded, viewed, and studied using user seismic data processing software.

\section{RESEARCH RESULTS}

Making basic geothermal data available on a Web site is essentially a form of advertising. Our geothermal web site at Virginia Tech advertises and promotes the use of an alternate energy source -geothermal energy -in the southeastern United States. If the basic data can be packaged in such a way that they are easy to access and view, then they are more likely to promote a positive response from a potential user. This we have attempted to do.

Although this archival project was not initially targeted to produce new research resuits, it is accomplishing that. The rule of thumb generally followed by hydrologists from the early 1900 s to the mid 1980s was to not drill greater than about 75 to 100 meters (Ellis, 1906) in the Piedmont. In the Atlanta, GA, area, however, Cressler and others (1983) found that many wells with large yields penetrated horizontal openings at depths of 120 to 190 meters below the surface. Cressler and others $(1983$, p. 19) interpreted these openings as stress-relief fractures that formed as a result of erosional unloading. They noted that the chance of obtaining large well yields from stress-relief fractures is significantly increased by drilling to about 190 meters The next major advance in knowledge of the Piedmont groundwater system resulted from a statistical analysis by Daniel (1989) of more than 6,000 well records from the Piedmont and Blue Ridge Provinces of North Carolina. Daniels found that well yields increase with depth to a much greater depth than previously thought, and that well yields increase dramatically as well diameter increases.

During the Virginia Tech part of the drilling program associated with the NSF-sponsored ADCOH (Appalachian UltraDeep Core Hole) Project in 1986 (Hatcher and others, 1988), four holes were drilled into the crystalline rocks of the Piedmont of South Carolina. Heat flow values were determined at each site. It was subsequently (last year) realized by us that the same fracture zone was encountered at the same depth interval $(170-200 \mathrm{~m})$ in each hole. This is further documentation for the widespread occurrence of sub-horizontal deep fracture permeability in crystalline rocks. The results of this new research are in preparation for publication by Costain and Hatcher (1998). 


\section{FUTURE PLANS}

Areas related to low-temperature geothermal applications include the recognition of and exploration for deep fracture permeability in crystalline rocks. It is well known that the best currently available downhole techniques to identify the locations of fracture zones in crystalline rocks depend upon the measurement of some thermal parameter such as temperature or heat flow. The temperature-depth profiles and their derivatives provide a direct indication of those fracture zones that conduct water. The exploration for new groundwater resources is considered by many to be the new frontier in the general field of hydrology. The availability of adequate groundwater resources in fractured rocks is a major concern in many areas of the eastern United States as well as in other parts of the world. A geothermal data base can therefore become an important source of basic data that can be used to help characterize the nature and extent of hydraulic conductivity in fractured rocks. We plan to continue to augment our web site (http://rglsunl.geol.yt.edu) with new geothermal data as the data become available, and to advertise the increasing residential uses of geothermal energy in the eastern United States.

\section{INDUSTRY INTEREST AND TECHNOLOGY TRANSFER}

Although we have not yet started to document the number of hits on our geothermal web site, calls and requests for data and advice continue to come in from industry as well as from educational institutions where students are discovering low-temperature applications and the advantages of geothermal energy.

\section{REFERENCES}

Costain, J.K., Keller, G.V., and Crewdson, R.A., 1976, Geological and geophysical study of the origin of the warm springs in Bath County, Virginia, Final Report TID-28271 to the U.S. Department of Energy, 184 pp.

Costain, J. K., L. Glover, III and A. K. Sinha, 1980, Low-temperature geothermal resources in the eastern United States, EOS, Amer. Geophys. Union, vol. Gl, no. 1.

Costain, J.K., and Decker, E.R., 1987, Heat flow at the proposed Appalachian Ultradeep Core Hole (ADCOH) site: Tectonic Implications, Geophysical Research Letters, v. 14, No. 3, p. 252-255.

Hatcher, Jr., R.D., Williams, R.D., Edelman, S.H., Costain, J.K., Coruh, C., Phinney, R.A., Roy-Chowdury, K., Decker, E.R., Zoback, M.D., Moos, D., and Anderson, R.N., 1988, The Appalachian Ultradeep Core Hole $(\mathrm{ADCOH})$ Project, in Deep Drilling in Crystalline Bedrock, v. 2, edited by A. Boden and K.G. Eriksson, Springer-Verlag, p. 117-154.

Heath, R.C., 1989, The Piedmont Groundwater System, in Proceedings, Conference on Ground Water in the Piedmont of the Eastern United States, published by Clemson University, Clemson, SC 29634-0357, (803) 6564073.

Lambiase, J. J., S. S. Dashevsky, J. K. Costain, R. J. Gleason, and W. S. McClung, 1980, Moderate-temperature geothermal resource potential of the northern Atlantic Coastal Plain, Geology, v. 8, 447-449.

Loiselle and Evans, 1995, Fracture density distributions and well yields in Coastal Maine, Ground Water, v. 33, No. 2, March-April, p. 190-196.

Perry, L.D., Costain, J.K., and Geiser, P.A., 1979, Heat flow in western Virginia and a model for the origin of thermal springs in the Appalachians, J. Geophysical Research, v. 84, No. B12, p. 6875-6883. 


\title{
FRACTURE PERMEABILITY' IN GEOTHERMAL SYSTEMS
}

\author{
Dennis L. Nielson \\ Energy \& Geoscience Institute \\ University of Utah
}

\section{KEY WORDS}

fault scaling, borehole imaging logs, structural classification, fault zone architecture

\section{PROJECT BACKGROUND AND STATUS}

Economic development of geothermal systems requires production of high-volumes of fluids from single or multiple fractures. Exploration for these highly permeable fractures is difficult as evidenced by the high ranking that fracture detection and mapping has received from numerous industry workshops (Wright, 1997). Fractures are extremely variable in character resulting both from different modes of formation and influence by secondary processes such as sealing, dissolution and continued brecciation.

Often, the variable character of fracturing results from different tectonic settings. It is not surprising that the fracturing associated with a Basin \& Range system should be different from that at The Geysers. When fracture zones are mapped in detail, it becomes clear that there is a great deal of complexity both from the standpoint of geometry and fluid flow. Borehole imaging tools are available to aid in the mapping of fractures in the subsurface. These tools are being widely applied in the geothermal industry, but much improvement is possible in their interpretation. A variety of studies have shown that fault zones often display predicable geometric relationships that have the potential of explaining the locations of highly permeable zones. The research project outlined below has four different components that address these important factors in geothermal exploration and development.

Work has begun on all the components of the project described here. Additional aspects of our fracture investigations are described in the Update on Fracture Analysis at The Geysers (Nielson, this volume).

\section{PROJECT OBJECTIVES}

The overall objective of this project is to increase the efficiency of geothermal exploration and development. We intend to accomplish this by developing models for the fluid-flow architecture of fracture systems and by improving borehole imaging interpretation techniques for the mapping of fractures in geothermal wells.

\section{Technical Objectives}

- Establish a framework for a structural classification of hydrothermal systems that is supported by detailed studies of a number of geothermal systems.

- Utilize drill core and outcrop mapping to compile data on character and orientation of fractures that make up different categories of fracture systems.

- Evaluate different logging tools to demonstrate improvements in interpretation techniques and procedures. 
- Demonstrate the application of fault scaling relationships for evaluating the fluid-flow architecture of faults.

\section{Expected Outcomes}

- A structural classification of geothermal systems that aids in decision making and data collection in the evaluation of fracture controls

- Completion of a series of detailed structural analyses of fractures in geothermal environments that will result in improved exploration and reservoir simulation models

- Increased application of borehole logging in geothermal system exploration and development

- Establishment of valid fault-scaling relationships that are of use in predicting permeability along faults

\section{APPROACH}

\section{Structural Classification of Geothermal Systems}

Classifications of geothermal systems generally concentrate on the character of the fluid phase. White et al: (1971) classify systems as hot water versus vapor-dominated. Henley and Ellis (1983) differentiate between systems associated with silicic volcanic provinces and those associated with calc-alkaline stratovolcanos. Wohletz and Heiken (1992) have also taken a volcanological approach to the characterization of geothermal systems. Henley (1985) has classified geothermal systems on the basis of their plate tectonic setting and principal sources of heat. Heald et al. (1987) did a detailed study of sixteen volcanic-hosted epithermal deposits and distinguished two types of epithermal deposits based principally on vein and alteration mineralogy. They classified these two types of systems as Acid-Sulfate and Adularia-Sericite. These system classes have also been termed High-Sulfidation and Low-Sulfidation.

The above classification schemes are very useful and have served as a basis for understanding and communicating the character of geothermal systems. However, when the objective of a drilling program is the intersection of fracture permeability, it may be more practical to consider a classification based on structural setting and on the character of faulting and jointing in geothermal systems. Initial work on this topic suggested that sufficient data was not available to publish these ideas without additional detailed work on individual systems. Often, fault zones are poorly characterized even in systems that have been producing for long periods of time.

However, we can present a preliminary structural classification of geothermal systems (Table 1). Most geothermal systems in the world are found in tectonic zones characterized by either normal or strike-slip faulting. The simplest case is developed when there is a single fault or family of faults. As an example, the Dixie Valley geothermal system is formed along a range-front fault and present fracture (Forster et al., 1997) and stress (Hickman and Zoback, 1997) orientations are consistent with that normal faulting. This is contrasted with the setting at Roosevelt Hot Springs where there is a strong presence of normal faulting consistent with the present regional stress environment, but there is also an orthogonal fault set that is presently seismically active, is consistent with in situ stress orientations within the geothermal system and appears to control much of the geothermal fluid flow (Nielson, 1989). Similarly, The Geysers is located within the strike-slip environment of the San Andreas fault, but important fluid pathways are along structural orientations that have apparently been inherited (Nielson and Nash, 1997): 


\section{Fault Zone Architecture}

Little research has been done on the complexity of fracture systems and their control on fluid flow. Initial models of permeability structure have been established (Caine et al., 1996), and detailed surface mapping near the Dixie Valley geothermal system (Forster et al., 1997) has demonstrated our approach. Additional detail on fluid flow in fractures is being gleaned from logging of core from geothermal systems in conjunction with the borehole imaging studies discussed below. Petrographic techniques can also be utilized to investigate the permeability along geothermal fractures (Nielson et al., 1993, 1995). We also visualize that the character of fracture permeability will change with depth in the geothermal environment as shown in Figure 1.

Fracturing in geothermal and hydrocarbon systems originates from a variety of processes. The fractures are then susceptible to modification by another wide variety of processes (Table 2). As an example, we have completed detailed studies of the character of fractures in a number of cores from geothermal systems. Figure 2 shows a fault zone with slickenlined surfaces that accumulated drilling mud demonstrating that it was permeable. Other fractures in the same well are extensional in nature (Fig. 3), but show no indication that they had any permeability, although they obviously contributed a great deal of porosity to the reservoir. We are working with the imaging logs to improve our ability to recognize such fractures. In addition, we are looking at the distribution of different types of fractures to test models of fault zones.

Much of the detailed work we are presently doing is in evaluating fracture permeability in gold mines in Nevada. These are former intermediate-temperature geothermal systems. The work is being done as a study of fractured petroleum reservoirs and is being sponsored both by DOE/Fossil and corporate clients.

\section{Borehole Image Log Interpretation}

Both acoustic and electrical borehole imaging are very powerful tools for the determination of fracture orientation and character in geothermal systems. Many companies now consider it standard practice to run these logs, particularly at the initiation of projects. Although the logs can be interpreted to show the orientation of fractures, little work has been done on understanding the character of fractures.

The interpretation of image logs remains a difficulty; it is seldom that logs are interpreted to the full extent of their potential largely due to the time-intensive nature of the interpretation process. Most interpretation centers on the determination of fracture orientation. However, the structural analysis should also apply concepts from the old Statistical Curvature Analysis Technique (SCAT) that considers changes in orientation of bedding across faults to also understand structural character (Bengtson, 1981). Using this approach, it is possible to draw conclusions concerning fault geometry and calculate percent extension. To a first approximation, the greater the percent extension; the greater the permeability. However, this generalization soon falls apart when fault systems are inspected in detail; permeability may have as much to do with how the extension is distributed as with the amount.

As part of this research, we are working with Sandia National Laboratory on the development of a slim-hole hightemperature televiewer. This tool would be more transportable than existing imaging log devices. In addition, it could be used in core- and other slim holes to improve the information base collected from heat flow, exploratory and observation wells.

Imaging log technology can also be a powerful tool in understanding the character and distribution of lost circulation zones. Mansure and Glowka (1995) report that lost circulation can account for $10 \%-20 \%$ of the cost of drilling a typical geothermal well. Most of the lost circulation occurs in the upper parts of wells where 
intergranular permeability attributed to sedimentary and volcanic processes may be as, or more, significant than fracture permeability (Nielson, 1997). Part of our effort in image log interpretation is directed to the characterization of lost circulation zones. Another component of this is the documentation of lost circulation from EGI's extensive collection of core from geothermal systems. This core provides the opportunity to measure the size and geometry of holes in different types of rocks.

There are two over-ridding issues for addressing industry's need with respect to the development of a slim-hole televiewer. The first is convincing the industry of the usefulness of this tool. The second is improving the resolution of televiewer technology to make the output more consistent with the types of information that can be derived from the electrical imaging logs:

\section{Fault Scaling Research}

The structural geology community has recently done a great deal of work in the general category of fault scaling. This topic concerns both the geometric relationships of faults as well as the generalization of conclusions from measurements at one scale to larger scales. I include within this topic the discussion above concerning the relationship between percent extension and permeability.

Research suggests that there are a number of aspects of faults that exhibit scale independence. In addition, it is often clear that the geometric relationships within individual, and perhaps classes, of faults can be defined mathematically. A variety of studies have examined faults of numerous scales and suggest that there is a nearlinear correlation between the length and displacement (Clark and Cox, 1996) and between the thickness and displacement (Hull, 1988) of a fault. These fault dimensions appear to be related by a power-law, which reflects the growth sequence of the fault (Walsh and Watterson, 1988). There are also power-law distributions to fault lengths (Claudous and Marrett, 1996) and fault displacement (Pickering et al., 1997).

There is a great deal of discussion in the literature about the confidence that can be attributed to these relationships. The relationship between the fault characteristics may not be truly linear, although it does appear to be close for most datasets (Walsh and Watterson, 1988; Nicol et al., 1996). In regions of constant displacement, faults often have variable thicknesses (Blenkinsop, 1989; Evans, 1990), which may be 2 orders of magnitude. Also, there are many properties related to the faulting that can influence the relationship between the size of a fault and it's displacement, such as the lithology of the faulted rock, variations in the stress state (Knott et al., 1996), and propagation rates (Peacock and Sanderson, 1996). Although the correlations between fault characteristics may not be consistent for large populations, they appear to be fairly robust for subpopulations of faults (Hull, 1988; Fossen and Romes, 1996; Nicol et al., 1996).

Most of the published work to date on fault scaling has been in the context of hydrocarbon production and migration. The scaling laws of faults are of importance in geothermal research as well. The dimensions of these producing zones are often difficult to estimate, due mainly to the absence of core or image logs. Research into the character of scaling relationships has the potential for defining the zones of highest permeability along faults and can serve as an important guide for development of high-temperature geothermal systems.

\section{FUTURE PLANS}

The continuation of work on a structural classification of geothermal systems will involve detailed mapping and evaluation in variety of geothermal systems. We are planning to continue to do detailed studies of geothermal systems in which there is both core and borehole imaging logs. The detailed mapping of faults will also contribute to testing of fault scaling relationships in geothermal systems 
A borehole imaging workshop will be conducted in association with Sandia National Laboratory. This workshop is planned to be held this year with the GRC meeting in San Diego.

\section{REFERENCES}

Blenkinsop, T.G., 1989, Thickness-displacement relationships for deformation zones: Discussion: Journal of Structural Geology, v. 11, p. 1051-1053.

Bengtson, C. A., 1981, Statistical curvature analysis techniques for structural interpretation of dipmeter data: American Association of Petroleum Geologists Bulletin, v. 65, p. 312-332.

Caine, J. S., Evans, J. P., and Forster, C. B., 1996, Fault zone architecture and permeability structure: Geology, v. 24 , p. $1025-1028$.

Cladouhos, T.T. and Marrett, R., 1996, Are fault growth and linkage models consistent with power-law distributions of fault lengths?: Journal of Structural Geology, v. 18, p. 281-293.

Clark, R.M. and Cox, S.J.D., 1996, A modern regression approach to determining fault displacement-length scaling relationships: Journal of Structural Geology, v. 18, p. 147-152.

Evans, J.P., 1990, Thickness-displacement relationships for fault zones: Journal of Structural Geology, v. 12, p. 101-1065.

Forster, C. B., Caine, J. S., Shultz, S. and Nielson, D. L., 1997, Fault zone architecture and fluid flow: an example from Dixie Valley, Nevada: Proceedings, $22^{\text {nd }}$ Workshop on Geothermal reservoir Engineering, Stanford University, SGP-TR-155, p. 123-130.

Fossen, H. and Rørnes, A., 1996, Properties of fault populations in the Grullfaks Field, northern North Sea: Journal of Structural Geology, v. 18, p. 179-190.

Heald, P., Foley, N. K. and Hayba, D. O. 1987, Comparative anatomy of volcanic-hosted epithermal deposits: acid-sulfate and adularia-sericite deposits: Economic Geology, v. 82, p. 1-24.

Henley, R. W., 1985, The geothermal framework of epithermal deposits, in Berger, B. R. and Bethke, P. M. (Eds.) Geology and geochemistry of epithermal systems: Reviews in Economic Geology, v. 2, p. 1-24.

Henley, R. W. and Ellis, A. J., 1983, Geothermal systems ancient and modern: a geochemical review: Earth Science Reviews, v. 19, p. 1-50.

Hickman, S. and Zoback, M., 1997, In-situ stress in a fault-hosted geothermal reservoir at Dixie Valley, Nevada: Proceedings, $22^{\text {nd }}$ Workshop on Geothermal reservoir Engineering, Stanford University, p. 141-146.

Hull, J., 1988, Thickness-displacement relationships for deformation zones: Journal of Structural Geology, v. 10, p. 431-435.

Knott, S.D., Beach, A., Brockbank, P.J., Brown, J.L., McCallum, J.E., and Wedbon, A.I., 1996, Spatial and mechanical controls on normal fault populations: Journal of Structural Geology, v. 18 p. 359-372. 
Mansure, A. J. and Glowka, D. A., 1995, Progress toward using hydraulic data to diagnose lost circulation zones: Geothermal Resources Council Transactions, v. 19, p. 111-115.

Nicol, A., Watterson, J., Walsh, J.J., and Childs, C., 1996, The shapes, major axis orientations and displacement patterns of fault surfaces: Journal of Structural Geology, v. 18, p. 235-248.

Nielson, D. L., 1989, Stress in geothermal systems: Geothermal Resources Council Transactions, v. 13, p. 271276.

Nielson, D. L., 1997, Rock permeability in high-temperature geothermal systems: Proceedings, Intersociety Energy Conversion Engineering Conference, Honolulu, p. 1837-1839.

Nielson, D. L., Barton, C. and Keighley, K. E., 1998, Comparative study of fractures in core and borehole televiewer in well VC-2B, Valles caldera, New Mexico: Proceedings, $23^{\text {rd }}$ Workshop on Geothermal reservoir Engineering, Stanford University, in press.

Nielson, D. L. and Nash, G. D.,1997, Structural fabric of The Geysers: Geothermal Resources Council Transactions, v. 21, p. 643-649.

Nielson, D.L., Nash, G., Hulen, J.B., Tripp, A.C., 1993, Core image analysis of matrix porosity in the Geysers reservoir: Proceedings $18^{\text {th }}$ Workshop on Geothermal Reservoir Engineering, Stanford University, p. 45-52.

Nielson, D.L., Nash, G.D., and White, W.S.,1995, Reservoir characterization using image analysis of coreexamples from The Geysers geothermal field: Proceedings World Geothermal Congress, p. 3017-3021.

Peacock, D.C.P. and Sanderson, D.J., 1996, Effects of propagation rate on displacement variations along faults: Journal of Structural Geology, v. 18, p. 311-320.

Pickering, G., Peacock, D. C. P., Sanderson, D. J., and Bull, J. M., 1997, Modeling tip zones to predict the throw and length characteristics of faults: American Association Petroleum Geologists Bulletin, v. 81, p. 82-99.

Walsh, J.J. and Watterson, J., 1988, Analysis of the relationship between the displacements and dimensions of faults: Journal of Structural Geology, v. 10, p. 239-247

White, D. E., Muffler, L. J. P. and Truesdell, A. H., 1971, Vapor-dominated hydrothermal systems compared with hot water systems: Economic Geology, v: 66, p. 75-97.

Wohletz, K. and Heiken, G., 1992, Volcanology and geothermal energy: University of California Press, Berkeley and Los Angeles, $432 \mathrm{p}$.

Wright, P. M., 1997, Summary of GEA workshops - review of DOE's Geothermal R\&D Program: Proceedings Geothermal Program Review XV, DOE/EE-0139, p. 1-21 to 1-24. 


\begin{tabular}{|l|l|l|}
\hline \multicolumn{3}{|c|}{ Table 1 - Preliminary Structural Classification of Geothermal Systems } \\
\hline & Normal Faulting & Strike-Slip Faulting \\
\hline Simple & Dixie Valley & $\begin{array}{l}\text { Imperial Valley (?) } \\
\text { Tongonan } \\
\text { Sarulla }\end{array}$ \\
\hline Composite & $\begin{array}{l}\text { Roosevelt Hot Springs } \\
\text { Tiwi } \\
\text { Larderello (?) }\end{array}$ & The Geysers \\
\hline
\end{tabular}

Table 2 - Origin of Fracture Permeability and Modifiers

\begin{tabular}{|c|c|}
\hline Primary Process & Modifiers \\
\hline $\begin{array}{l}\text { Faulting (Modes II and III) } \\
\text { Core } \\
\text { Damage Zone } \\
\text { Joints (Mode I) } \\
\text { Extension accommodation } \\
\text { Cooling } \\
\text { Uplift } \\
\text { Fold-related } \\
\text { Depositional Breccias }\end{array}$ & $\begin{array}{l}\text { Mineral Precipitation } \\
\text { Dissolution } \\
\text { Igneous Injection (dikes and sills) } \\
\text { Hydrothermal Brecciation } \\
\text { Healing without Mineral Precipitation }\end{array}$ \\
\hline
\end{tabular}




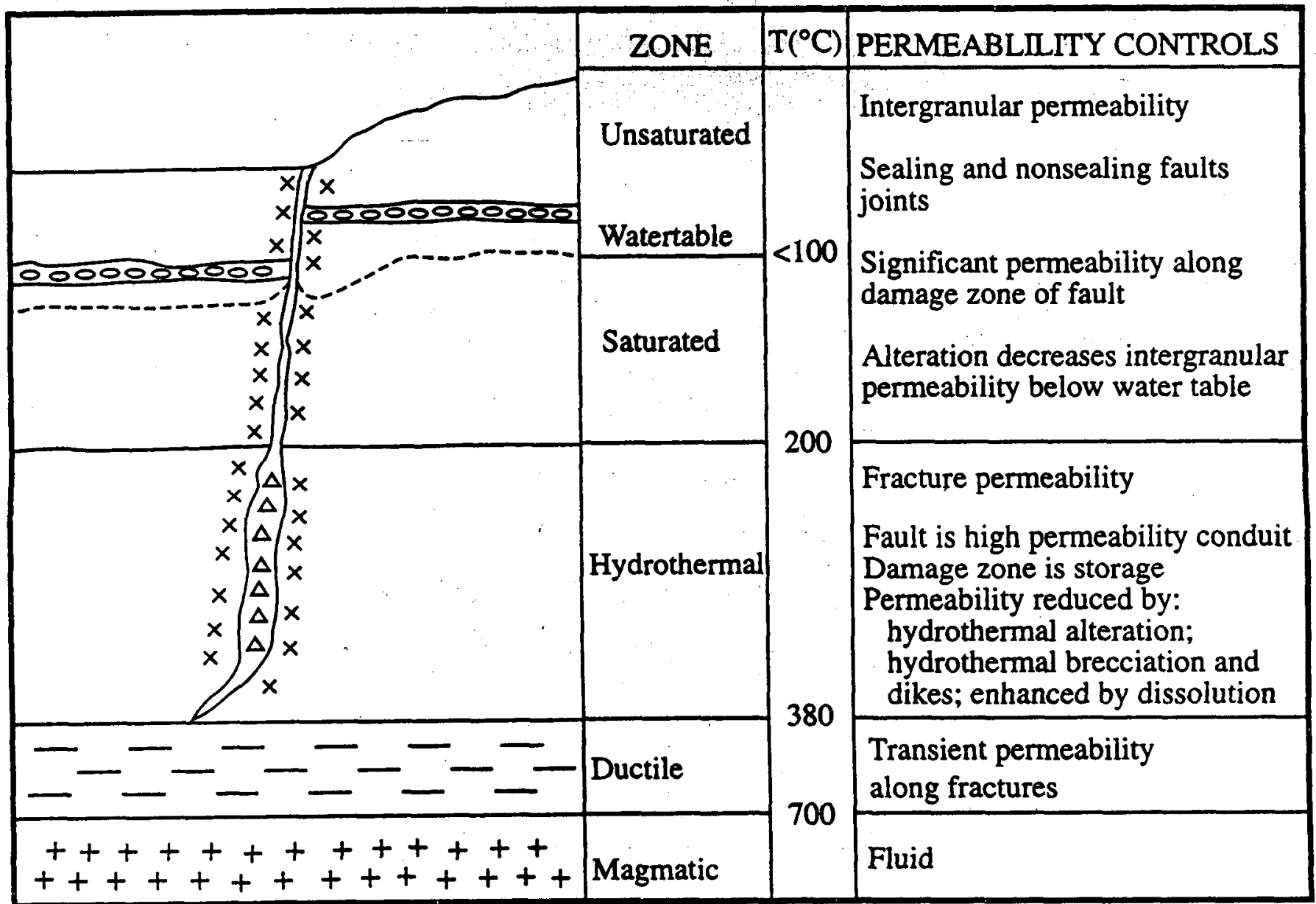

Figure 1 -- Model of permeability controls and vertical zonation of geothermal system (Nielson, 1997) 


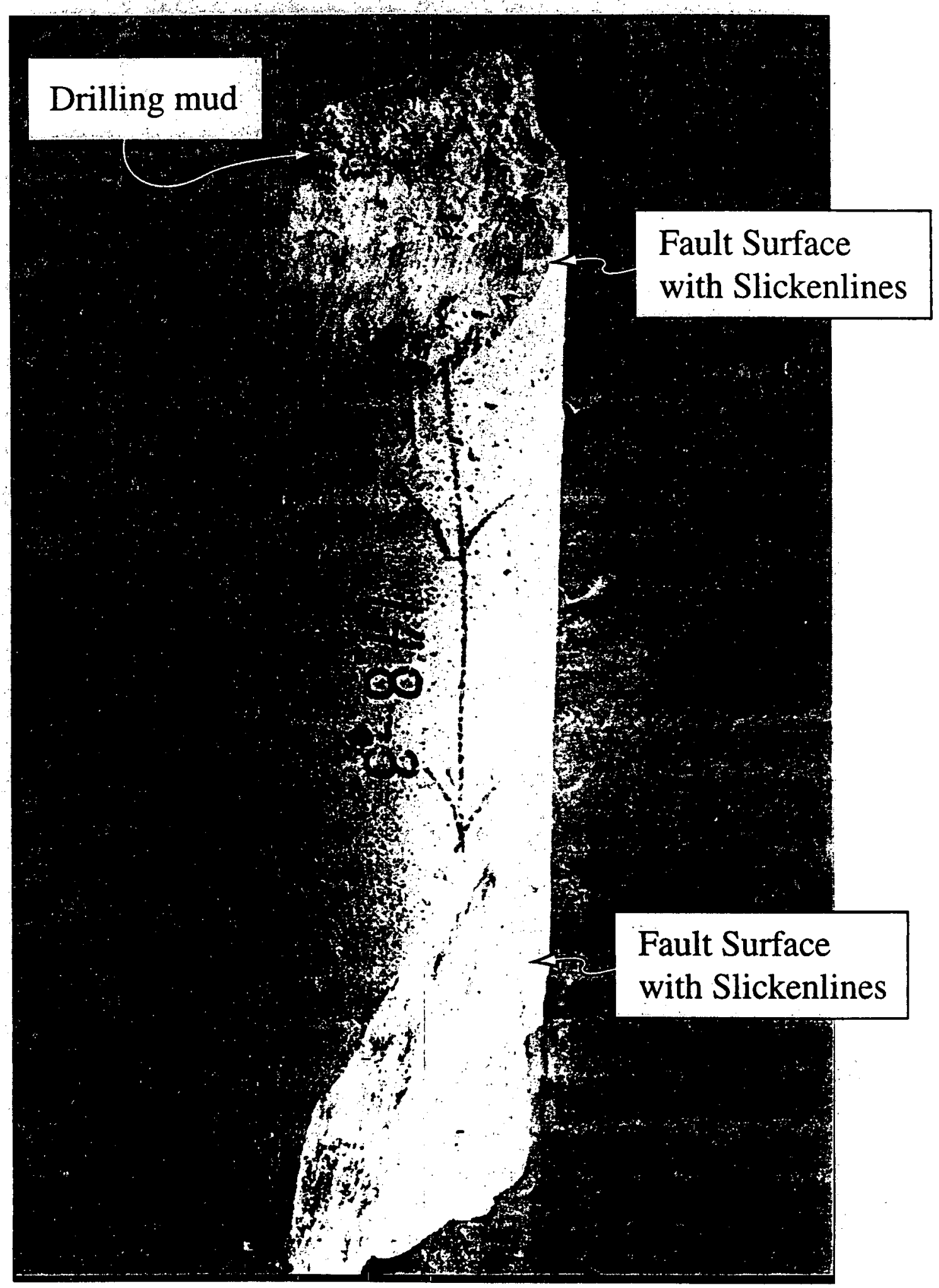

Figure 2 -- Two faults in core from VC-2b, Sulphur Springs area, Vallez Caldera, New Mexico. 


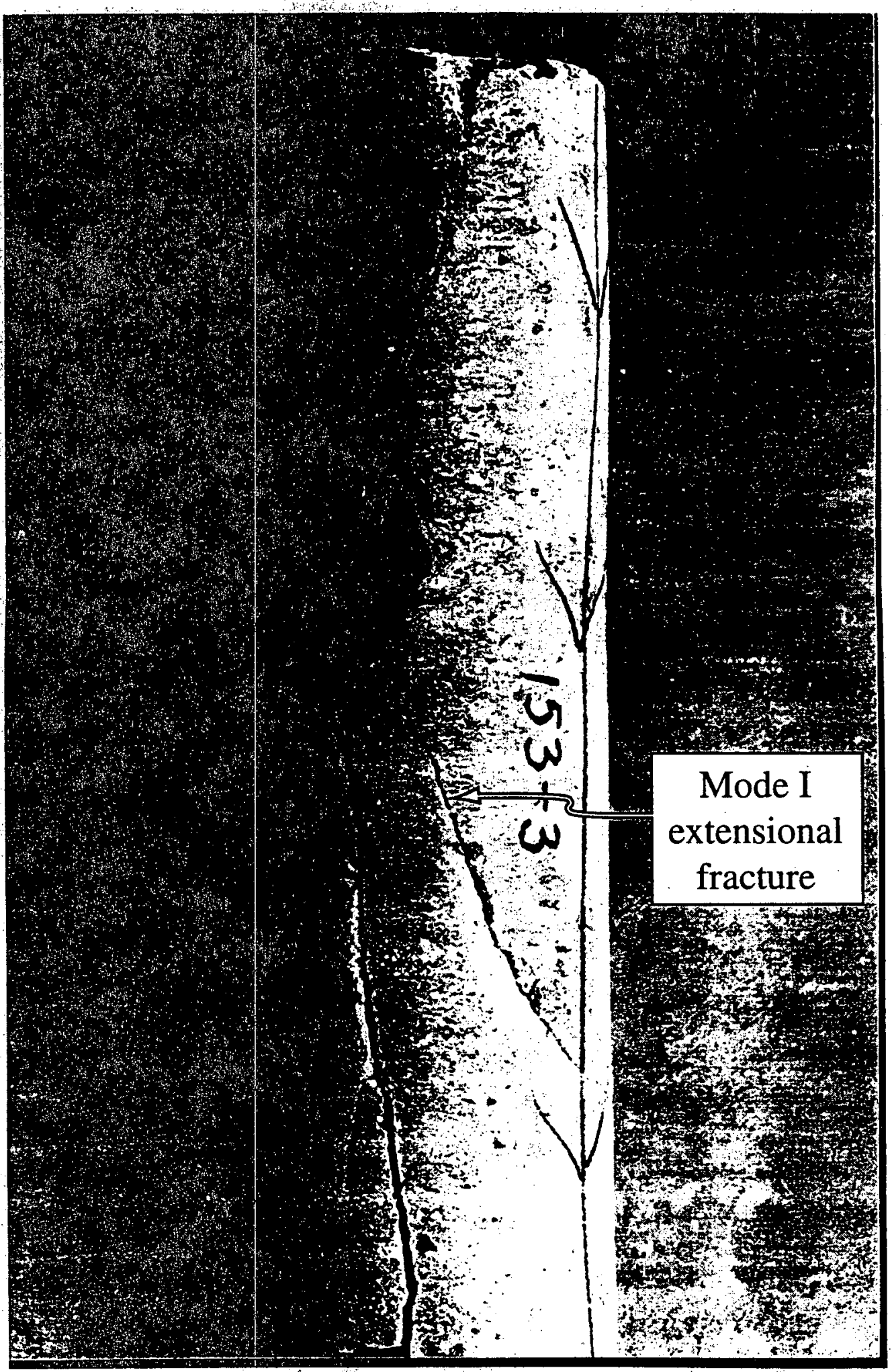

Figure 3 - Mode I extensional fracture in core from VC-2b, Sulphur Springs area, Valley Caldera, New Mexico. 


\title{
THE HISTORY OF HYDROTHERMAL MINERALIZATION IN THE VOLCANIC-HOSTED GEOTHERMAL SYSTEM AT TIWI, PHILIPPINES
}

\author{
Joseph N. Moore', Matthew T. Heizler', David I. Norman', and Carol Bruton \\ 'Energy and Geoscience Institute, University of Utah \\ ${ }^{2}$ New Mexico Tech \\ ${ }^{3}$ Lawrence Livermore National Laboratory
}

\section{KEY WORDS}

Tiwi, Philippines, hydrothermal alteration, fluid inclusions, gas geochemistry, ${ }^{40} \mathrm{Ar} /{ }^{\beta 9} \mathrm{Ar}$ dating

\section{PROJECT BACKGROUND AND STATUS}

Most of the world's geothermal production is linked to volcanic-hosted geothermal systems. Tiwi is a large system located on Luzon Island in the Philippines. The field is developed on the flanks of Mt. Malinao which has been active for the last $0.5 \mathrm{Ma}$. Tiwi has an installed capacity of $330 \mathrm{Mw}$ and in the early 1990 's, provided $11 \%$ of Luzon's electricity (Gambill and Baraquit, 1993).

Despite more than 25 years of exploration and development, only a few scattered pieces of core were available from the reservoir until 1992 when Unocal drilled Matalibong-25 in the western part of the field. The well recorded temperatures that reached $270^{\circ} \mathrm{C}$. Core was recovered from $789-2439 \mathrm{~m}$ with $95 \%$ recovery. Our study of the hydrothermal mineralization, the fluid inclusions they contain, and the timing of thermal activity is part of a broader program to characterize the geology and geochemistry of the Tiwi field. As part of this program, Nielson et al. (1996) characterized the fractures within the core. Bruton et al. (1997) performed geochemical modeling simulations to evaluate the chemical and physical processes responsible for the deposition of the observed secondary minerals. The hydrothermal mineralogy and vein parageneses, compositions and temperatures of the fluid inclusions, and the thermal history of the system have been described by Moore et al. $(1997,1998)$ and Norman et al. (1997).

The results of these studies have been surprising and unexpected. They have demonstrated that the Tiwi system has had a much more complex history than was previously thought. We have now recognized two major cycles of hydrothermal activity and have established the time-temperature histories of each. As a result of this work, the thermal history of Tiwi is among the best documented of any active geothermal system.

\section{PROJECT OBJECTIVES}

\section{Technical Objectives}

- Document the mineralogy and paragenesis of the hydrothermal alteration minerals and relate them to the distribution of permeable fracture zones.

- Determine which minerals are in equilibrium with the present-day fluids.

- Establish the time-temperature history of the thermal system. 
- Determine the origin of the hydrothermal fluids and the importance and characteristics of any magmatic contributions.

\section{Expected Outcomes}

- Detailed conceptual models are needed at all stages of development and exploration. Concepts developed at Tiwi will be applicable to many other volcanic-hosted geothermal systems in the Philippines, Indonesia, Japan, and elsewhere.

- An understanding of the interrelationships between the hydrothermal fluids and the mineral assemblages they produced will help developers, who use mineralogy as a exploration guide, in the targeting of new wells.

- High-temperature acid fluids are a common occurrence in volcanic systems. Understanding the sources of the hydrothermal fluids and the influence of a magmatic component may help develop strategies that avoid these zones.

- Detailed mineralogic and fracture studies are necessary for the understanding and evaluation of the permeability structure within a geothermal system. The mineralogic investigations conducted at Tiwi will provide data for developing appropriate permeability models.

- Although techniques for analyzing the compositions of fluid inclusions by quadrapole mass spectrometry has improved during the last few years, our ability to interpret the data is far from perfect. Comparison of gas data with data from other sources (e.g. production fluids, fluid-inclusion salinities) will result in improved interpretations.

\section{APPROACH}

The time-temperature-composition models developed from this study have been based on a careful characterization of the hydrothermal mineralogy and mineral parageneses in the core from Matalibong- 25 . Standard thin section petrography, supplemented by X-ray diffraction studies were applied to characterize the rocks. The temperatures and salinities of more than 57.5 fluid inclusions were determined from heating and freezing measurements. Gas compositions were determined by quadrapole mass spectrometry after the gases were liberated by crushing or thermal decrepitation. Particular efforts have been made to test interpretations based on gas data against results obtained by other techniques. For example, the application of broad-spectrum gas analyses for tracing fluid sources are being compared to the results of noble-gas analyses (Kennedy, DePaolo, and Truesdell, this volume). ${ }^{40} \mathrm{Ar} /{ }^{39} \mathrm{Ar}$ spectrum dating was conducted on hand-picked samples of adularia to date the thermal events that have affected Tiwi. Modeling of the age spectra, combined with Ar kinetic data for the Tiwi adularia and fluid-inclusion and downhole temperatures has allowed us to construct a time-temperature history of the system.

\section{RESEARCH RESULTS}

More than 50 samples of veins were studied petrographically. We have recognized nine stages of alteration and vein mineralization on the basis of crosscutting relationships. Stage 1 is characterized by chalcedony and clays. Veins of sericite and chlorite were deposited during stage 2 . Stage 3 veins contain quartz \pm pyrite \pm epidote. Stage 4 veins consist of blocky, often coarse-grained anhydrite that is locally brecciated, and minor rhombohedral calcite. These veins are crosscut by veins dominated by epidote or quartz \pm adularia (stage 5 ). Veins deposited 
during stage 5 are the most diverse, with mineral abundances varying markedly even among individual fractures in the same thin section. Rarely, veins assigned to this stage consist of quartz and bladed calcite. Stage 6 veins are characterized by rhombohedral calcite and minor anhydrite. Veins deposited during stage 7 contain wairakite \pm epidote \pm quartz. However, wairakite-bearing veins are present only in the upper part of the well. Stage 8 is represented by calcite that replaces wairakite and fills open spaces in stage 7 veins. The final stage of mineralization (stage 9 ) is characterized by illite \pm chlorite that forms radiating aggregates in open spaces or replaces earlier calcite, although some late-stage sericite was also deposited between stages 6 and 7 .

Fluid inclusions in veins quartz, calcite, and anhydrite yielded homogenization temperatures that ranged from $332^{\circ}$ to $191^{\circ} \mathrm{C}$ while salinities varied from 4.5 to 0.0 weight percent $\mathrm{NaCl}$ equivalent. In general, the maximum temperatures are close to the boiling point to depth curve, whereas the minimum temperatures below a depth of about $1524 \mathrm{~m}$ are nearly constant at $230^{\circ} \mathrm{C}$.

There is an overall increase in the maximum salinities of the fluid inclusions with depth. Below $1600 \mathrm{~m}$, the maximum salinities ranged from 3.1 to 4.5 weight percent $\mathrm{NaCl}$ equivalent, indicating that the hydrothermal fluids were dominated by seawater. At shallower depths the salinities do not exceed 1.7 weight percent $\mathrm{NaCl}$ equivalent. Temperature-salinity relationships suggests that these shallow fluids were composed mainly of steam-heated meteoric fluids. For comparison, the reservoir fluid produced by Matalibong- 25 has a salinity of 1.2 weight percent $\mathrm{NaCl}$ equivalent.

The mineralogic and fluid-inclusion data demonstrate that veins in Matalibong-25 formed under a variety of conditions and flow regimes. Bruton et al. (1997) determined the saturation state of the vein minerals with respect to the modern reservoir fluids and simulated the effects of boiling, cooling, heating, and the addition of $\mathrm{CO}_{2}$-rich steam on their deposition. The models suggest that assemblages consisting of quartz \pm epidote \pm adularia \pm wairakite (stages 3,5 , and 7) formed in response to boiling, but that monomineralic veins of wairakite could also have formed by conductive cooling. The only process that favors deposition of calcite + anhydrite (stages 4,6 , and 8 ) is conductive heating. Crystals of calcite in these veins typically have a blocky habit whereas calcite deposited as a result of boiling is often bladed and intergrown with quartz. Taken together, the vein parageneses document periods of upflow that oscillated with the incursion of cooler fluids during stages 4,6 , and 8. Fluid-inclusion temperatures, however, demonstrate that the maximum temperatures during stages 4,5 , and 6 exceeded $300^{\circ} \mathrm{C}$ throughout most of the well. Even though we were unable to obtain fluid-inclusion data on minerals clearly related to stages 3 and 7 , the presence of epidote in these veins indicates that temperatures were above $240^{\circ} \mathrm{C}$ while post-stage 8 actinolite at $996 \mathrm{~m}$ provides evidence of temperatures above $300^{\circ} \mathrm{C}$ (Henley and Ellis, 1983).

Late-stage sericite (stage 9) is commonly associated with corroded calcite. Bruton et al. (1977) demonstrated that the modern reservoir fluid produced by Matalibong- 25 is slightly acidic with a pH of 5.3 compared to a neutral $\mathrm{pH}$ of 5.6 at $270^{\circ} \mathrm{C}$. The $\mathrm{pH}$ of this fluid, which may reflect the addition of $\mathrm{CO}_{2}$-rich steam, favors the deposition of sericite and can lead to corrosion of calcite. Thus, the occurrence of sericite as the latest alteration phase is consistent with the chemistry of the modern fluids. A similar mechanism may account for the formation of the stage 1 sericite veins.

The gas compositions of fluid inclusions in more than 15 samples of vein calcite, quartz, and anhydrite from depths ranging from 1113 to $2428 \mathrm{~m}$ were measured by quadrapole mass spectrometry after being liberated by crushing or thermal decrepitation. The principal component of the inclusions was water, which accounted for 70 to 99.8 mole percent of the analysis. $\mathrm{CO}_{2}, \mathrm{CH}_{4}, \mathrm{H}_{2}, \mathrm{~N}_{2}, \mathrm{Ar}, \mathrm{H}_{2} \mathrm{~S}, \mathrm{SO}_{2}$, and hydrocarbons $\left(\mathrm{C}_{2-7}\right)$ were also detected, with $\mathrm{CO}_{2}$ and $\mathrm{CH}_{4}$ dominating. Most samples have $\mathrm{N}_{2} / \mathrm{Ar}$ ratios ranging from air-saturated water (36) to 232 . $\mathrm{N}_{2} /$ Ar ratios up to about 80 can be explained by boiling (Norman et al.,1997). Higher $\mathrm{N}_{2}$ contents imply 
contributions from either cnustal rocks beneath the reservoir or a diluted magmatic fluid. The high $\mathrm{CH}_{4}$ contents are markedly different from the present-day fluids which are $\mathrm{CH}_{4}$ poor. This argues that the fluid inclusions trapped gases generated during the early stages of the system's evolution.

$\mathrm{N}_{2} /$ Ar ratios of less than 15 in Tiwi fluid inclusions require either the loss of $\mathrm{N}_{2}$ or the addition of radiogenic $\mathrm{Ar}$ (Norman et al., 1997). At Tiwi, loss of $\mathrm{N}_{2}$ is demonstrated by a comparison of $\mathrm{N}_{2}$ and Ar distributions. The most likely cause of this loss is the incorporation of ammonia into clay minerals.

${ }^{40} \mathrm{Ar} /{ }^{39} \mathrm{Ar}$ spectrum dating of adularia from depths of 1809,1849 , and $1852 \mathrm{~m}$ has yielded an age of approximately $0.30 \mathrm{Ma}$ for stage 5 mineralization. Fluid inclusions in quartz intergrown with adularia, from a depth of $1849 \mathrm{~m}$, demonstrate that the temperatures during this mineralization were close to $330^{\circ} \mathrm{C}$. Modeling of the age spectra combined with Ar kinetic data for the Tiwi adularia leads to three important conclusions regarding the timing of subsequent events. First, the models indicate that temperatures could have remained above $300^{\circ} \mathrm{C}$ until about $0.2 \mathrm{Ma}$ or that the rocks were heated above $300^{\circ} \mathrm{C}$ at this time. Fluid-inclusion homogenization temperatures above $300^{\circ} \mathrm{C}$ in stage 6 minerals and the presence of post-stage 8 actinolite constrain the age of the main mineralization (stages 2-8) to more than $0.2 \mathrm{Ma}$. Secondly, the models indicate that significant cooling to temperatures below $250^{\circ} \mathrm{C}$ must have occurred between $0.2 \mathrm{Ma}$ and the recent past. This cooling is reflected in fluid-inclusion temperatures that are as low as $191^{\circ} \mathrm{C}$. Finally, the models show that the present-day temperatures of $270^{\circ} \mathrm{C}$ could not have been maintained for more than the last $0.05 \mathrm{Ma}$. Thus, the data record a relatively long period of cooling between the initial magmatic pulse that generated the hydrothermal system and recent, renewed magmatic activity.

\section{FUTURE PLANS}

We plan to complete our interpretation of the fluid-inclusion gas compositions, refine the thermal models of the system based on the ${ }^{40} \mathrm{Ar}{ }^{\beta 9} \mathrm{Ar}$ spectrum dating, and evaluate the relationship between the chemistries of the hydrothermal minerals and fluids. Particular emphasis will be placed on integrating the broad-spectrum and noble-gas data and on obtaining a better understanding of the effects of fluid mixing and boiling on the gas compositions.

The compositions of the major mineral phases will be determined by electron microprobe at Lawrence Livermore National Laboratory. Evaluation of these data will be undertaken by Dr. Bruton.

It is anticipated that the results of the preliminary results of these studies will be presented at the $9^{\text {th }}$ International Water-Rock Conference (New Zealand, 1998), and at the Pan American Conference on Research on Fluid Inclusions (Las Vegas, 1998). A peer-reviewed paper detailing these results will also be prepared.

\section{INDUSTRY INTEREST}

Our studies of Tiwi represent a combined effort between Unocal and various research organizations including the Energy and Geoscience Institute, Lawrence Berkeley Laboratory, Lawrence Livermore National Laboratory, and New Mexico Tech. However, the geothermal community as a whole will benefit because of the current world wide interest in volcanic-hosted geothermal systems. Interest in similarly detailed studies of other geothermal fields has been expressed by Califomia Energy Co. Inc., Calpine, and Unocal. These opportunities will be considered and undertaken as they become available. 


\section{REFERENCES}

Bruton, C. J., Moore, J. N., and Powell, T. S., 1997, Geochemical analysis of fluid-mineral relations in the Tiwi geothermal field, Philippines: Twenty-sccond Workshop on Geothermal Reservoir Enginecring. Stanford University, p. 457-463.

Gambill, D. T. and Beraquit, D. B., 1993, Development history of the Tiwi geothermal field, Philippines: Geothermics, v. 22, p. 403-416.

Henley, R. W., and Ellis, A. J., 1983, Geothermal systems ancient and modern: a geochemical review: Earth Science Reviews, v. 19, p. 1-50.

Moore, J. N., Powell, T. S., Norman, D.I., and Johnson, G., 1997, Hydrothermal alteration and fluid-inclusion systematics of the reservoir rocks in Matalibong-25, Tiwi, Philippines: Twenty Second Workshop on Geothermal Reservoir Engineering, Stanford University, p.

447-456.

Moore, J. N., Powell, T. S., Bruton, C. J., Norman, D. I, and Heizler, M. T., 1998: Thermal and Chemical Evolution of the Tiwi geothermal system, Philippines: $9^{\text {th }}$ International Water-Rock Conference, in press.

Nielson, D. L., Clemente, W. C., Moore, J. N., and Powell, T. S., 1996, Fracture Permeability of the Matalibong25 Corehole, Tiwi geothermal system, Philippines: Twentieth Workshop on Geothermal Reservoir Engineering, Stanford University, p. 209-216.

Norman D. I., Moore J. N., and Musgrave, J., 1997, More on the use of fluid inclusion gaseous species as tracers in geothermal systems: Twenty-second Workshop on Geothermal Reservoir Engineering, Stanford University, p. 419-426. 


\title{
GEOLOGIC STUDY OF THE COSO FORMATION
}

\author{
Diane L. Kamola and J. Douglas Walker \\ University of Kansas
}

\begin{abstract}
KEY WORDS
geologic studies, extensional basins, facies analysis, geochronology, Coso Range

\section{PROJECT BACKGROUND AND STATUS}

There have been great advances in the last 20 years in understanding the volcanic, structural, geophysical, and petrologic development of the Coso Range and Coso geothermal field. These studies have provided a wealth of knowledge concerning the geology of the area, including general structural characteristics and kinematic history. One element missing from this dataset is an understanding of the sedimentology and stratigraphy of well-exposed Cenozoic sedimentary strata - the Coso Formation.

The Coso Formation is loosely defined to include all sedimentary and pyroclastic rocks between pre-Tertiary basement and the voluminous late Pliocene to recent volcanic rocks (Schultz, 1937). Sedimentary facies include lacustrine, fanglomerate, volcaniclastic and, locally, volcanic tuffs. The history of the Coso Formation has received limited treatment in the geologic literature (e.g., Bacon et al., 1982; Grant, 1986; Stinson, 1964; Duffield et al., 1986). The Coso Formation merits study for the following reasons: 1) it provides a look at events older than most of the volcanic rocks in the area, and 2) it can give detailed insights into paleogeographic and structural development on the local and regional scale. Other sedimentary rocks in the area, principally the White Hills Formation, are neither well exposed nor represent the time interval of the Coso Formation.

The relation between exposures of Coso Formation in the northern Coso Range and those in the southern part of the range is somewhat uncertain. For example, correlation of rocks exposed in the northern Coso Range adjacent to Owens Lake with those in the western part of the range are problematic: northern exposures of the Coso Formation are Mio-Pliocene in age (Bacon et al., 1982) whereas the bulk of the formation adjacent to Rose Valley is either middle to late Pliocene (Bacon et al., 1982) or early Pliocene (Grant, 1986) in age. In addition, whether these areas are related sedimentologically or structurally is unclear. Understanding the connection between these exposures will give significant new insights into the paleogeographic and structural development of the Coso Range and surrounding areas. On a broader scale, it is known that Panamint Valley started opening during the late Miocene because of motion on west-dipping normal faults on the western part of the Panamint Mountains. The timing and mechanisms of formation for Rose Valley and Indian Wells Valley are less well known: a better understanding of the stratigraphy and sedimentology of the Coso Formation will add new data concerning the development of these valleys.

The Coso Formation owes its present structural configuration to the tectonics of Rose and Owens valleys. Numerous folds and faults cut the Coso Formation in its various exposures (Stinson, 1977a, 1977b; Duffield and Bacon, 1981). Some of these faults may be syndepositional, controlling stratigraphic patterns. Other faults may be wholly post-Coso in age. Understanding these structures could give great insight into the relative roles of strike-slip and normal faulting in the development of the Rose-Owens Valley system, and give new knowledge about the late Miocene to present structural development of the area. This is only possible using the Coso Formation. 
The study was initiated in cooperation with CalEnergy Company, Inc., the U.S. Navy Geothermal Program Office and DOE to better understand the geologic development of Basin and Range structure around the Coso geothermal field. This understanding of Coso and Basin and Range structure and kinematics should be useful in developing exploration models for the Coso region and Basin and Range.

\section{PROJECT OBJECTIVES}

The main aim of this study is to better understand the development of the Coso Range, east-central California. Pliocene to Holocene volcanic rocks of the area are fairly well understood. Recent work on the bedrock geology of the area (Whitmarsh, 1997) is complete. The last remaining unknown aspect of the Coso Range history is the latest Miocene to middle Pliocene ( -6 to $3 \mathrm{Ma}$ ) structural and paleographic development of the area. A study of the Coso Formation will fill this gap in our knowledge.

\section{Technical Objectives}

- Construct detailed geologic maps of the Coso Formation to delineate the stratigraphy and structural configurations of the unit.

- Perform depositional analysis of the Coso Formation and establish stratigraphic relations across its exposures.

- Determine ages of various exposures of the Coso Formation to aid in correlation within the Coso Range, the Indian Wells Valley, and the southern Inyo Mountains.

\section{Expected Outcomes}

- An understanding of the spatial and temporal variations in paleostructural and paleogeographic development of the Coso Formation. This will allow for a quantification of the relative amounts of extension and strike-slip deformation involved with construction of the Coso Formation basin.

- Elucidation of the position and formation of the Coso geothermal area in the context of the development of the southwestern Basin and Range Province. This may aid in developing models for exploration of geothermal resources in other areas of the Basin and Range.

\section{APPROACH}

Field work follows normal practices of geologic mapping and stratigraphic efforts. Geologic mapping is done by walking the area and employing topographic maps aided by photographic or satellite images to delineate important geologic features. Stratigraphic studies are conducted by preparing several carefully measured stratigraphic sections through the Coso Formation. These sections form the basis for a stratigraphic/paleogeographic framework for the unit. Samples are collected where needed for dating by the Ar/Ar method. Where available, fault zone structures such as slickenside lineations and fault grooves are used to determine fault motions.

Data collected will be compiled into an existing GIS database constructed at the University of Kansas for the Coso Range and Indian Well Valley area. This database contains many geologic maps, compilation of ages determined for various rocks, remote sensing data, and numerous other geologic datasets. 


\section{RESEARCH RESULTS}

\section{Stratigraphic Studies}

Four locations were selected for detailed facies analysis and described in detail: Haiwee Ridge; north of Haiwee Ridge; Vermillion Canyon; and west of Sugarloaf. The vertical successions at Haiwee Ridge, the section north of Haiwee Ridge, and the section west of Sugarloaf are similar. At Haiwee Ridge, four distinct depositional settings have been identified and are described below. The outcrop exposure does not reveal a continuous vertical sequence, but a complete section is seen across a $3 \mathrm{~km}$ transect. At the eastern extent of exposure, the Coso Formation onlaps basement rock and consists of conglomeratic alluvial fan deposits. This conglomerate consists of granitic, subangular to subrounded clasts, although many clasts are flat or elongate. Clasts are up to $70 \mathrm{~cm}$ in length, with an average clast size of $20 \mathrm{~cm}$. This coarser conglomerate alternates with a finer grained conglomerate, where clast size averages $1 \mathrm{~cm}$ in diameter. The conglomerates are matrix supported, where the matrix is predominantly very coarse sandstone. The conglomerate is composed of a series of beds $1.5-7 \mathrm{~m}$ in thickness. Beds are sharp based, with crudely defined graded bedding, and occasional large scale planar cross stratification. Strata are interpreted to represent a series of bars migrating through a braided stream system in an alluvial fan complex.

The conglomerates interfinger with and are replaced laterally by a pebble-rich; arkosic sandstone of fluvial origin. This facies consists of poorly sorted, orange-stained, ferruginous/uranium-bearing pebbly arkosic sandstone-to-sandy pebble conglomerate (maximum clast size of $.5-1 \mathrm{~cm}$ ) and contains compound, complex cross sets and planar tabular bedding punctuated by low angle scour surfaces. Upsection, this unit is predominantly an arkosic sandstone, characterized by $5-20 \mathrm{~cm}$ thick sandstone beds, occasionally alternating with thin beds of conglomeratic sandstone. Bedding here is crudely developed. Scour surfaces and planar bedding also occur. These sandstones and pebbly sandstones are interpreted to represent fluvial deposits at the distal end of a braid plain. Caliche beds are interbedded with the orange-stained sandstone and may represent lacustrine influence.

The arkosic sandstone is overlain by a thick interval of volcanic ashes interbedded with lacustrine deposits. The ashes consist of distinct beds of tuffaceous volcanic ash, ranging from a few meters to $30 \mathrm{~m}$ in thickness The lacustrine beds consist predominantly of reworked volcanic ash and sand. Based on field evaluation, each ash bed within a measured section is mineralogically distinct; but not distinct enough for confident correlation of ash beds between measured sections. Individual ash beds exhibit a great deal of lateral variability. For example, the $30 \mathrm{~m}$ ash ranges from a bomb-dominated tuff, to a well bedded volcanic deposit exhibiting inversely graded beds, to a fine grained, bedded unit with well-developed large scale foresets. This lateral variability reflects the different modes of deposition for this ash, ranging from proximal ash fall deposits to more distal surges. Interbedded with the distinct ash beds are lacustrine units composed of reworked ash. The thickest section of lacustrine deposits shows a marked, vertical zonation. The lower half of this unit is a well bedded, somewhat resistant unit, while the upper lacustrine deposits are more of a slope former. The lower lacustrine deposits are composed of well-developed upward-shallowing packages, averaging 4 to $7 \mathrm{~m}$ in thickness, interpreted as parasequences. Parasequences are repetitive, or cyclic deposits and display a predictable succession of sedimentary structures. Seven parasequences are recognized at Haiwee Ridge. Each parasequence consists either of basinward inclined foresets of small, prograding deltas, or thin beds of wave-rippled volcanic sands and reworked ash. Each parasequence is capped by a bioturbated bed, overlain by a clean, coarser-grained, well-cemented sandstone. Laterally, these parasequences can show significant soft sediment deformation characterized by chaotically arranged elongate "clasts" of brecciated volcanic sands greater than $0.5 \mathrm{~m}$ in length. Upsection, parasequences are not well developed, but the lacustrine section still consists of thin bedded, wave-rippled volcanic sands and reworked ash. We interpret these as shallow water deposits. The thickness of 
the upper section, over $30 \mathrm{~m}$, suggests slow subsidence of the basin allowing time to maintain the shallow water depths of deposition for these deposits.

Each well-developed parasequence is terminated by a rapid flooding event, indicating a sudden deepening event in the basin. These sudden deepening events could represent cyclic climatic change, but we think they more likely represent episodic faulting within the basin. In foreland basins, parasequence architecture has been suggested to record the history of thrust sheet movement in the corresponding fold and thrust belt. In the Coso Formation, parasequence development is postulated to reflect the fault history associated with the opening of the Indian Wells/Rose Valley. The 4 to $7 \mathrm{~m}$ thickness of each of the parasequences is consistent with possible magnitudes of throws on faults bounding and within the basin. The presence of significant soft-sediment deformation supports the interpretation of a tectonic driving force for the development of the parasequences. Because subsidence events are not rapid enough and distinct enough to create well developed parasequences in the upper portion of the lacustrine deposits, we interpret the change in faulting style; basin subsidence during deposition of the upper lacustrine deposits appears to be more gradual and uniform rather than punctuated. Elucidating this difference in subsidence style for the Haiwee section provides an example of how the detailed facies and stratigraphic analysis can be used to interpret fault and tectonic history of the basin.

The thick lacustrine section is capped by another ash which shows marked lateral changes in thickness. Its thickness ranges from $12 \mathrm{~m}$ to less than $7 \mathrm{~m}$. Internally, this ash is dominated by the presence of bombs. Internal stratification or bedding is absent. This ash is overlain by interbedded conglomerate and sandstone. The conglomerate contains both reworked clasts of basement rocks and reworked volcanics and contains numerous scour surfaces and planar bedding. The sandstone is texturally and compositionally more mature than the underlying volcanic sands. It also contains numerous scour surfaces and large scale planar tabular cross bedding and trough cross bedding. Both are interpreted as a fluvial in origin. The reintroduction of basement clasts into this fluvial unit indicates renewed uplift and displacement of the lacustrine environment by a high-energy fluvial system. The remainder of this section, due to structural dip, is buried beneath Haiwee reservoir and Highway 395.

The Sugarloaf section, at the northern end of the Coso Range, shows a different vertical succession than the southern Coso exposures. The thick lacustrine deposits which dominate much of the sections to the south are absent from the Sugarloaf section. While this section also begins with a conglomerate/sandstone interval, this unit contains a significant amount of reworked volcanic ash. Individual beds of conglomerate are thin (averaging less than $.5 \mathrm{~m}$ ) and interbedded with thicker beds of sandstone. Sharp based beds, crudely defined graded bedding and occasional large scale planar cross stratification occur, along with thick intervals of structureless (volcanic) sandstone. Localized scouring and graded bedding indicates fluvial transport. The conglomerate/sandstone interval is abruptly overlain by an eolian sandstone with cross beds averaging $2 \mathrm{~m}$ in thickness. This eolian unit is then overlain by a thick succession $(\sim 180 \mathrm{~m})$ of sand sheet/sand flat deposits consisting of horizontally laminated sandstone and low angle, inclined foresets. These are interpreted to represent a transitional facies between dune, interdune and non-eolian deposits. Small cut and fill structures and low angle inclined foresets suggest this interval was subjected to both fluvial transport and wind reworking. Proximal to the basement uplift, small growth faults occur in this interval, with syndepositional displacement averaging $2 \mathrm{~m}$. The sand sheet/sand flat deposits are overlain by an ash-rich horizon. Much of the ash-rich bedding shows evidence of water reworking, preserved either as fluvial or (?) lacustrine deposits. In places, the ash appears clean (i.e., not reworked): volcanic bombs were collected from these selected intervals for age dating. This interval is overlain by a thin coarse grained deposit of fluvial origin, indicating renewed uplift. 
The presence of a thick lacustrine suite in the three measured sections in the southern exposures of the Coso Formation and its absence in the northern section in the Sugarloaf area suggests a structural divide may have been present between the Vermillion Canyon and Sugarloaf localities.

Samples were collected from all ash deposits from the four stratigraphic sections. These were collected to resolve the controversy concerning the age of the Coso Formation and to aid in the correlation of ashes between measured sections.

\section{Geologic Mapping and Structural Studies}

A significant portion of the Coso Formation outcrop in the Haiwee Ridge area and the area north of Haiwee Ridge has been mapped in detail using 1:12,000 scale air photos. Five mappable units were identified based on the detailed measured sections, and are listed from oldest to youngest: (1) basal conglomerate, (2) arkosic sandstone, (3) lacustrine suite, (4) upper ash, (5) upper sandstone/conglomerate. Previous geologic maps (i.e. Stinson, 1977a, 1977b; Duffield and Bacon, 1981) which include the Coso Formation are not based on an established stratigraphic framework of mappable units, but rather map lithofacies which are not defined or placed in stratigraphic hierarchy. These previous attempts often map the same stratigraphic unit as multiple units, and sometimes combined different aged stratigraphic units as the same mappable unit.

Mapped structural features include a series of north-south trending faults, in both the Haiwee Ridge area and the area north of Haiwee Ridge. Offset along these faults is limited to 30 meters, with many of the smaller faults displaying offsets of only 5 meters. These smaller faults, however, are often within a fault series which collectively show offsets of around 20-30 meters. A number of east-west trending, broad open folds were identified and mapped.

Approximately 13 relict springs were mapped in the area north of Haiwee Ridge. The relict springs occur along north-south trending faults, either as isolated units, or in a linear arrangement of three or more small spring deposits. Individual relict springs range from a few meters to more than 5 meters in diameter. The exact nature of fluids emanating from these springs in uncertain, but may represent relatively hot ground water fluxing into the fluvio-lacustrine setting of the Coso Formation. The springs are significant because they suggest geothermal activity may have been present in the latest Miocene to earliest Pliocene time in the Coso Range.

\section{FUTURE PLANS}

Geologic mapping of the Coso Formation will continue. These studies will extend mapping using the newly established stratigraphic framework to remaining exposures of the Coso Formation. Ages will be determined on samples collected to this point in the study, and additional samples for age determinations will be collected if needed. Detailed structural studies to examine fault kinematics (using striations and grooves on fault surfaces) will be conducted. The geologic maps and stratigraphic information will be compiled into a series of paleogeographic and paleostructural maps. All of the geologic studies will be compiled and integrated with existing interpretations for the Coso Range. 


\section{INDUSTRY INTEREST}

\section{Organization}

CalEnergy Company

U.S. Navy Geothermal Program Office,

China Lake

\section{Type and Extent of Interest}

Geology and stratigraphy of the Coso Range

This project is supported by the Department of Energy (DOE) and the Geothermal Technology Organization (GTO). Funding is provided by GTO members (U.S. Navy and CalEnergy) and DOE.

\section{REFERENCES}

Bacon, C. R., Giovannetti, D. M., Duffield, W. A., Dalrymple, G. B., and Drake, R. E., 1982, Age of the Coso Formation, Inyo County, California: United States Geological Survey Bulletin 1527, 18 pp.

Duffield, W.A., and Bacon, C.R., 1981, Geologic map of the Coso volcanic field and adjacent areas, Inyo County, California: U.S. Geological Survey, Map I-1200.

Duffield, W. A., Bacon, C. R., and Delaney, P. T., 1986, Deformation of a poorly consolidated sediment during shallow emplacement of a basalt sill, Coso Range, California: Bulletin of Volcanology, v. 48, p. 97-107.

Grant, M. J., 1986, The chronologic and stratigraphic evolution of the Coso Range, Inyo County, California [M.S. thesis]: University of Southern California, Los Angeles.

Schultz, J. R, 1937, A late Cenozoic vertebrate fauna from the Coso Mountains, Inyo County, California: Carnegie Institution of Washington Publication, v. 487, p. 75-109.

Stinson, M. C., 1964, A trip to a vertebrate fossil locality: California Division of Mines and Geology Mineral Information Service, v. 17, p. 160-163.

Stinson, M.C., 1977a, Geology of the Haiwee Reservoir 15' Quadrangle, Inyo County, California: California Division of Mines and Geology, Map Sheet 378.

Stinson, M.C., 1977b, Geology of the Keeler 15' Quadrangle, Inyo County, California: California Division of Mines and Geology, Map Sheet 38.

Whitmarsh, R.S., 1997, Structural development of the Coso Range and adjacent areas of eastern California [Ph.D. dissertation]: University of Kansas, Lawrence. 


\title{
THE AWIBENGKOK, INDONESIA, GEOTHERMAL RESEARCH PROJECT
}

\author{
Jeffrey B. Hulen \\ Energy \& Geoscience Institute (EGI) \\ University of Utah
}

\section{KEY WORDS}

Awibengkok, Gunung Salak, West Java, Indonesia, core, high-temperature, geothermal system, porosity, permeability, fluid migration and storage

\section{PROJECT BACKGROUND AND STATUS}

In mid-1997, the U.S. Department of Energy's (DOE) Office of Geothermal Technology, working through EGI, finalized negotiations with Unocal Geothermal Indonesia (UGI) to obtain more than $1.1 \mathrm{~km}$ of continuous core from the heart of the large (330 MW at this writing), high-temperature (up to at least $300^{\circ} \mathrm{C}$ ) Awibengkok geothermal system in West Java, Indonesia. The core, with complementary wireline logs and other information provided by UGI, will serve as the (cylindrical) cornerstone of an intensive, multidiscliplinary, DOE-sponsored geothermal research effort during the next several years. Briefly stated, the governing objective of this project is to improve significantly our understanding of reservoir controls not only at Awibengkok but in similar composite-volcanic-hosted geothermal systems worldwide. Such systems are certain to provide an increasingly larger proportion of the Earth's geothermal power well into the 21 st century, and the more we know about them, the easier they will be to find and develop at reasonable cost.

The corehole, Awibengkok ("Awi" for short) 1-2, was drilled by UGI late in 1995. EGI personnel (J. Hulen and D. Nielson) were on site to monitor the drilling and make a preliminary description of each 10-m core section immediately upon its liberation from the wireline-retrieved "inner tube". These brief descriptions and corresponding one prepared by UGI wellsite geologists, are essential insurance against later disruption of the core during handling, shipment, and sampling.

The core, a substantial $8 \mathrm{~cm}$ in diameter, spans the depth range 762-1829 $\mathrm{m}$, and core recovery (Tonto Drilling Company, Salt Lake City, UT) was close to $100 \%$. This is one of only two such cores (from the interiors of composite-volcanic-hosted systems) which is not only of great length and completeness, but is also selectively available for non-proprietary research -- the other core, possession of which Unocal retains, is from drillhole MAT-25 in the Tiwi system, Philippines. Negotiations for acquisition of the Awi 1-2 core were complicated and lengthy, with final agreement reached in mid-1997, about a year and a half after drilling. Boxing and marking the DOE half (longitudinal)-split of the core was done at Awibengkok in late November 1997, and at this writing, the core has arrived by sea in Long Beach, CA, where it should clear U.S. Customs for trucking to Salt Lake City by early February 1998.

The Awibengkok geothermal system was discovered in 1983 by UGI working in partnership with the Indonesian organizations PERTAMINA and PLN, the latter of which is the Indonesian State Electrical Corporation. After an intensive geological, geochemical, and geophysical evaluation, Awibengkok ("bent bamboo" in one of several Javanese languages) was found beneath a fumarole field on the western flank of Gunung (Mount) Salak, one of numerous Quaternary volcanoes (many still vigorously active) of the Sunda arc. 
The Sunda volcanic arc, created in response to magmatism and tectonism above the northward subducting IndoAustralian plate, is one of the world's richest geothermal resource areas. The arc boasts 177 volcanic centers, 88 of which have active surface thermal features -- solfataras, hot springs, mud pots, and fumaroles -- and several of which are currently producing electrical power (Radjah, 1990; Rachman et al., 1995). Large-scale power production in Indonesia commenced at the vapor-dominated Kamojang field in 1983. Kamojang and Amoseas' nearby, smaller but similar Darajat field as of late 1997 were producing, respectively, 140 and $55 \mathrm{MW}$ of electrical power (P.M. Wright, pers. comm., 1998). At $330 \mathrm{MW}$ of installed electrical generating capacity, however, the Awibengkok field is at this writing by far Indonesia's largest. Through the efforts of DOE-OGT and the cooperation of Unocal Geothermal (particular thanks to Research Coordinator Tim Anderson), we are fortunate to have secured for focused research a virtually unique continuous rock sample extending from the upper reaches of this important resource deep into its productive, high-temperature interior.

\section{PROJECT OBJECTIVES}

\section{Technical Objectives}

- Governing -- Through detailed study of the continuous Awi 1-2 core and ancillary data, significantly improve understanding of reservoir controls in a large but otherwise probably typical, island-arc composite-volcanic-hosted, high-temperature geothermal system. Compare and contrast the new information obtained from this study with (to the extent possible) corresponding data from other such systems around the world.

- Determine the origins, measure and map the configurations, and establish the interrelationships of fractures, breccias, dissolution cavities, vesicles, and other voids which singly or in combination serve as geothermal-fluid conduits or storage sites. Study the relative influence of regional vs local controls on development of these features. For example, to what extent are fractures and breccias formed in response to far-field stresses, and to what extent they are the products of local forces.

- Determine lithologic controls on configuration of the geothermal system's key components (e.g. caprock vs productive reservoir; aquifers and aquicludes in the reservoir proper). In so doing, establish a detailed volcanic stratigraphy potentially of use in indirect three-dimensional mapping of discordant conduits such as fractures and pebble dikes.

- Ascertain the effects of penetrated igneous intrusions on the geometry of the geothermal system, and on the compositions and textures of the reservoir rocks these igneous bodies invade.

- Map in detail hydrothermal alteration mineralogy and zoning, not only in a gross vertical sense with respect to the reservoir as a whole but also locally, for example selvages bordering veins as well as rims and rinds on clasts and phenocrysts. Examine this information for correlations with other rock and reservoir properties. For example, do certain alteration mineral assemblages and zoning sequences show a systematic relationship to active thermal-fluid conduits? Are impermeable hydrothermal breccias differently altered than their permeable vuggy counterparts? Investigate the utility of secondary-mineral zoning and paragenetic sequences in targeting remotely as well as mapping potentially productive thermal-fluid conduits.

- Compare characteristics and controls of the Awibengkok system with those observed and inferred for several late Cenozoic volcanic-hosted precious-metal deposits in the immediate vicinity, especially the 2,000,000-oz, 8 m.y.-old Pongkor deposit (Basuki et al., 1994) just a few kilometers northwest of Awi 
- Reconstruct the hydrothermal history of the portion of the Awibengkok geothermal system penetrated by the corehole. If possible, utilize this information to help predict changes in reservoir characteristics with time and progressive depletion. As a particularly important module of this task, investigate the possibility that a noncondensible gas cap had accumulated above this shallowest portion of the geothermal reservoir.

- Measure multiple physical and mineralogic properties of the penetrated rocks, not only under ambient conditions but also under simulated reservoir pressures and temperatures to the extent these parameters can be determined. Examine the utility of this information in constraining interpretations of surface- and borehole-based geophysical surveys of these and similar geothermal-reservoir rocks and the fluids they contain.

\section{Expected Outcomes}

- With the new information obtained from this investigation: (1) improve the odds of finding similar volcanic-hosted geothermal systems anywhere in the world; (2) help reduce operators' costs in exploiting those systems already secured, including Awibengkok itself; and (3) enable those operators to prolong the systems'. productive lives through more informed long-term development strategies.

- A detailed picture of the Awibengkok geothermal system's evolution since inception, especially: (1) the nature and timing of events specifically linked to the creation, enhancement or occlusion of porosity and permeability; (2) fluid sources, volumes, pathways, chemical transformations, and thermal histories.

\section{APPROACH}

After numerous difficulties, the securely packaged and carefully marked and documented DOE split of the Awi 1-2 core has arrived, via ocean voyage, in the United States. It is presently on the dock in Long Beach, California, being processed by a shipping broker for transmittal by truck to EGI's Geothermal Sample Library in Salt Lake City, Utah. Once there, it will be readily accessible for observation and judicious sampling by investigators with specific research initiatives.

The core will serve as the framework for a one- or two-day workshop in Salt Lake City (probably early April 1998) at which an earlier-distributed draft Science Plan for the project will be debated and refined. Copies of the finalized Plan will be distributed to all within two months of the workshop. Chief Scientist for the project will be J. Hulen of EGI. In order to maximize the project's scientific yield, Hulen will maintain close contact not only with the research team, but with key Unocal personnel most familiar with Awibegkok, especially Research Coordinator Tim Anderson, Chief Development Geologist Glenn Melosh, and Senior Geologist Jim Stimac. The Awi research plan as presently envisioned will be a modification and expansion of the one successfully applied on The Geysers Coring Project but of course tailored to the different geologic, geochemical, and hydrologic setting at Awibengkok.

Fundamental studies for the Awi 1-2 project will be those which have proven value in the characterization of high-temperature geothermal systems and their "fossil" counterparts, the epithermal mineral deposits. These will include, but will not necessarily be limited to the following:

- Detailed geologic logging of the core at a nominal scale of $1 "=10 \mathrm{ft}$. This work will complement the very preliminary logs prepared on site as the core was being retrieved, but will focus more closely on those features critical to the storage and transmission of thermal fluids in the subsurface -- fractures, 
faults, breccias, veins, vugs, dissolution cavities, vesicles, intergranular pores. Lithologic units will be scrutinized to determine their roles as aquifers and hydrologic seals. A detailed stratigraphy will be established for comparison, ultimately, with the geologic sections penctrated elsewhere in the rescrvoir. The stratigraphic section and its rock components will be compared with wireline log responses so that if necessary similar units can be identified with greater confidence even in the absence of borehole rock samples.

- Studies of hydrothermal alteration mineralogy and zoning as well as vein mineralogy and paragenesis will provide detailed information critical for constraining the hydrothermal history of Awibengkok. Methods to be employed in this undertaking include the detailed geologic logging mentioned above; petrographic analysis; X-ray diffraction; X-ray fluorescence and other geochemical analytical techniques; stable-isotope geochemistry; electron-microbeam geochemical analysis of individual minerals; claymineral geothermometry; argon-argon incremental-heating age dating and thermal-history modeling, fluid-inclusion microthermometry and geochemical analysis (especially trapped gases); numerical geochemical modeling.

- Characterization and measurement of porosity and permeability at the scale of the core. At The Geysers, investigators were able to measure even vanishingly small permeabilities .- on the order of a few nanometers -- confirming that fluid storage in the steam reservoir must be largely in secondary voids. As part of the Awi 1-2 data package, Unocal has provided routine plug porosity and permeability measurements for the entire core, and these data will be invaluable for comparison with the more detailed results obtained by the envisioned higher-precision porosity and permeability studies.

- Monitoring of changes in permeability, porosity, and other rock properties of the core (for example, electrical and acoustic) at varying simulated reservoir conditions. This information will be useful in forecasting reservoir behavior, and for predicting the responses of various rock units and alteration assemblages during surface-and borehole-based geophysical surveys.

\section{RESEARCH RESULTS}

As the Awibengkok core research project is just getting underway, there are no research results to report at this writing.

\section{FUTURE PLANS}

The pre-workshop, pre-debate, site-specific Science Plan for the Awibengkok coring project will be presented at the 1998 Stanford Geothermal Reservoir Engineering Conference. The site-specific Awi 1-2 workshop will be held in Salt Lake City, probably in early April 1998. The resulting site-specific Science Plan will be published shortly thereafter as a guide to the overall research effort. Individual research projects are envisioned to span 1-3 years. Updates on research progress will be provided to all interested parties at the annual Stanford Conference and Geothermal Resources Council Meeting; we are investigating the possibility of further distributing information on the project and its results electronically via a world-wide-web site.

\section{INDUSTRY INTEREST}

The new information to be gained from this exciting undertaking of course will be of immediate use in optimizing production and expansion at the Awibengkok geothermal system. More importantly, Awibengkok is really a 
proxy for all andesitic volcanic-hosted, liquid-dominated hydrothermal systems. Accordingly the results of this investigation will be applicable in any such setting worldwide.

\section{REFERENCES}

Basuki, A., Sumanagara, D.A., and Sinambela, D., 1994, The Gunung Pongkor gold-silver deposit, West Java, Indonesia: Journal of Geochemical Exploration, v. 50, p. 371-391.

Ganda, S., Sunaryo, D., Hantono, D., and Tampubolon, T., 1992, Exploration progress of high-enthalpy geothermal prospect[s] in Indonesia: Geothermal Resources Council, Transactions, v. 16, p. 83-88.

Hochstein, M.P., and Sudarman, S., 1993, Geothermal Resources of Sumatra: Geothermics, v. 22, p. 181-200.

Rachman, A., Lubis, L.I., Boedihardi, M., Suroto, and Mulyono, A., 1995, Geothermal prospects in Indonesia -Prospect status and development opportunity: Florence, Italy, World Geothermal Congress, Proceedings, p. 531535.

Radja, V.T., 1990, Review of the status of geothermal development and operation in Indonesia, 1985-1990: Geothermal Resources Council, Transactions, v. 14, p. 127-145. 


\title{
GEOTHERMAL CHEMISTRY/EXPLORATION
}

\author{
Fraser Goff (1) and Cathy J. Janik (2)
}

(1) Los Alamos National Laboratory

(2) U.S. Geological Survey

\section{KEY WORDS}

fluid geochemistry, gas composition, water composition, isotope composition, Dixie Valley geothermal system, The Geysers-Clear Lake geothermal region, reservoir models, scaling, recharge, fumaroles

\section{PROJECT BACKGROUND AND STATUS}

The current project is a modification of work funded annually since FY91 to provide chemical analyses, bulk gas analyses, and isotope analyses for DOE geothermal efforts. To date, these analyses have been performed on samples for U.S. Geological Survey projects at Cerro Prieto, Mexico; The Geysers-Clear Lake, California; Steamboat Springs, Nevada; for a University of Nevada-Reno project on Geothermal Modeling of Productive Geothermal Resources in Nevada; for Los Alamos National Laboratory projects in The Geysers-Clear Lake region, California and for small private contractors concerned with resource assessments in the domestic and international geothermal arenas. We have routinely analyzed about 100 to 120 samples on an annual basis.

In FY97, we became active in geothermal exploration and research aspects of selected areas for which we provided analyses and interpretive expertise. We continued our investigations of carbon isotope systematics and carbon flux in The Geysers-Clear Lake geothermal region. We completed a research project on K/Ar dating of hydrothermal illite in the SB-15-D corehole in The Geysers. We completed a thermal modeling study of the Clear Lake region. We began a new study on scaling of injection wells at the Dixie Valley geothermal system, Nevada. We planned a campaign of new studies in Dixie Valley for FY98 to 1) monitor temporal geochemical changes in production fluids, 2) investigate recharge to the system, and 3) determine growth rate of the new fumaroles north of the power plant (the "dead zone").

\section{PROJECT OBJECTIVES}

The primary objectives of this task are to: 1) provide comprehensive major/trace element analyses, bulk gas analyses, and isotope analyses of geothermal waters and gases on samples collected for geothermal projects sponsored by the U.S. Department of Energy; 2) provide geothermal/geochemical exploration, modeling, and monitoring expertise for the above projects as required.

\section{Technical Objectives}

- Provide high-quality analyses for DOE-sponsored geothermal projects.

- Continue study of carbon isotope systematics and carbon flux at The Geysers-Clear Lake region, California. A regional inventory of carbon isotopes in gas; water, and rock samples across The Geysers-Clear Lake area will provide the necessary data to determine the source or sources of copious $\mathrm{CO}_{2}$ emissions associated with the local geothermal systems. Estimation of the total flux of $\mathrm{CO}_{2}$ to the atmosphere will be accomplished 
by determination of the $\mathrm{CO}_{2}$ flux at target sites (springs and vents) combined with flux measurements along several traverses between target sites.

- Completed draft manuscripts on carbon isotope systcmatics, $K$-Ar dating of illite, and thermal modeling at The Geysers-Clear Lake region, Califormia (Bergfeld et al., 1998, WoldeGabriel et al., 1998; Stimac et al., 1997, 1998).

- Published paper on Mont-Dore geothermal system, France (Pauwels et al., 1997).

- Began study on chemical scaling in injection wells at the Dixie Valley geothermal system, Nevada. Injection lines and injection wells at Dixie Valley grow a silica-rich scale that must be routinely removed by mechanical means ("pigging"). We initiated a combined geochemical sampling-thermodynamic modeling study to advise the field operator (Oxbow Power Services, Inc.) on appropriate dilution, mixing, or additive scenarios for their injection scheme. We are working cooperatively with Oxbow, Lawrence Livermore Laboratories, and Earth Sciences \& Resources Institute on this project.

\section{Expected Outcomes}

- About 150 analyses performed for several DOE-sponsored projects.

- Three above mentioned journal manuscripts on work in The Geysers-Clear Lake region are in review. Publication date not yet determined.

- Final analysis of fluids from Steamboat Hills geothermal system, Nevada will be completed.

- Determination of $\mathrm{CO}_{2}$ provenance and estimation of $\mathrm{CO}_{2}$ flux in The Geysers-Clear Lake region. To date, no study has determined the provenance of carbon sources on a regional basis although topical studies were conducted by Lambert and Epstein (1992) and by Goff and Janik (1993). Kerrick et al. (1995) attempted an estimate of carbon flux for this region $\left(10^{10} \mathrm{~mol} / \mathrm{yr}\right)$. The present investigations are part of the Ph.D. dissertation requirements for Deborah Bergfeld, University of New Mexico. The results will be published in refereed journals. Bergfeld is now working as a Graduate Research Assistant (GRA) at LANL and has an Associated Western Universities (AWU) grant to work at the USGS in Menlo Park.

- A preliminary report on the Dixie Valley scaling project was published (Bruton et al., 1997).

\section{APPROACH}

\section{General Statement}

We determine reservoir parameters such as fluid properties, production-related processes, reservoir lifetime, scaling/corrosion potential, etc., determine if newly explored sites justify exploration drilling, and define boundary conditions such as reservoir age and fluid sources. We discover new geothermal systems, characterize reservoir geochemistry, help improve reservoir performance (energy output), and obtain basic knowledge of existing systems using geochemical techniques (i.e., Janik and Goff, 1996). Our work provides US geothermal industry with data and interpretations to increase domestic profits and to improve their competitive edge abroad. 


\section{Carbon Isotope and Flux Study}

Gas samples collected by Bergfeld, Janik, and Goff will provide the foundation for understanding natural variations in the carbon isotope composition of $\mathrm{CH}_{4}$ and $\mathrm{CO}_{2}$ across The Geysers-Clear Lake region. Isotopic analyses of two generations of calcite veins (Chyd and $\mathrm{C}_{\mathrm{Fran}}$ ) and organically derived carbon $\left(\mathrm{C}_{\text {org }}\right)$ from Franciscan greywacke and argillite samples in core from upper portions of The Geysers reservoir have been performed to investigate the role they play in $\mathrm{CO}_{2}$ production. Similar analyses from outcrop samples across The Geysers-Clear Lake region will be used to examine the isotopic composition of carbon sources unperturbed by recent geothermal fluids.

Measurements of gas flux at target locations have been made as a preparatory means for determining a value for the regional $\mathrm{CO}_{2}$ flux. These values will be significantly refined by collecting data for the soil $\mathrm{CO}_{2}$ flux using a Li-Cor $\mathrm{CO}_{2}$ analyzer along several traverses oriented across areas related to local geothermal systems and fault zones. One field season of $\mathrm{Li}$-Cor data has been obtained and another data set will be gathered in late fall, 1997.

\section{Dixie Valley Investigations}

The project on injection scales is continuing. Due to our rapid response to this need, we have been encouraged to begin three new projects at Dixie Valley: 1) monitoring of temporal geochemical changes in production fluids, 2) determination of recharge sources and ages of the geothermal reservoir fluids, and 3) investigation of dimensions and growth rate of the zone of new fumaroles north of the power plant.

\section{RESEARCH RESULTS}

\section{Carbon Isotope Systematics and Flux, The Geysers-Clear Lake Region}

Analyses of 50 gas samples have produced the largest data set available on the carbon isotope composition of $\mathrm{CH}_{4}$ for the region (Bergfeld et al., 1996a; 1996b, 1998). These data show considerable variability at Clear Lake locations and more constrained values within The Geysers. In general, the isotopes indicate an organic source for the methane. Detailed isotopic analyses of The Geysers SB-15-D core show a significant shift in the carbon isotopic composition of calcite veins compared with the isotopic composition of veins from rocks unaffected by recent geothermal fluids. If subsurface lithologies across the Clear Lake area are similar to what we have found in The Geysers core, then the stable isotope data generated thus far indicate either low-temperature $\left(190^{\circ} \mathrm{C}\right)$ equilibration between the $\mathrm{CO}_{2}$ and calcite, or that some of the $\mathrm{CO}_{2}$ evolves via oxidation of an isotopically depleted source such as $\mathrm{C}_{\text {org }}$ or $\mathrm{CH}_{4}$.

Although the flux study is still in progress, our measurements of $\mathrm{CO}_{2}$ flux from 53 springs and vents across a $>1500 \mathrm{~km}^{2}$ area indicate that $>1600$ tons/year $\mathrm{CO}_{2}$ are emitted from the Clear Lake region alone (Bergfeld et al., 1997a, 1997b).

\section{Dixie Valley Scale}

Modeling shows that low-pressure brine and injection fluids are saturated with respect to amorphous silica as determined by chemical analyșis and XRD. Shallow groundwater near the power plant is a mixture of meteoric recharge and geothermal brine. This groundwater is supersaturated with respect to calcite and modeling indicates the injection of this fluid would precipitate calcite in the reservoir. Mixing of existing injectate with reservoir fluid can have a variety of consequences depending on where and at what temperature mixing occurs (Bruton et al., 1997). 


\section{FUTURE PLANS}

In FY98 we are continuing the carbon isotope and flux study in The Geysers-Clear Lake region. We have enlarged the flux study to investigate zones between major faults, off major thermal areas, and over the Clear Lake volcanic field by obtaining a Li-Cor $\mathrm{CO}_{2}$ soil gas analyzer (joint study, LANL-USGS-Univ. New Mexico).

We are enlarging the scope of our investigations at Dixie Valley geothermal system Nevada, as described above. We will obtain fluid/solid samples, analyze samples for their chemical and isotopic composition, and model results to determine scaling processes and to offer solutions to prevent scaling/corrosion. The data will be used to determine fluid sources and effects of injection/production (joint study, LANL-USGS- LLL- EGI-Oxbow Power Services, Inc.).

\section{INDUSTRY INTEREST}

\section{Organization}

Union Geothermal Co.

Environmental Protection Agency

Caithness Power, Inc.

Oxbow Power Services, Inc.

SB Geo, Inc.

California Energy Co.

Southwest Tech. Devel. Inst.

\section{Type and Extent of Interest}

Land access; permission to use data/cores

Geochemistry of Sulphur Bank Mine

Samples for analysis, Nevada assessment

Active participation in scaling/corrosion study

System modeling; tracer studies

Information on Medicine Lake Highlands

Analyses for Fort Bliss geothermal project

\section{REFERENCES}

Bergfeld, D., Goff, F., and Janik, C.J., 1996a, Fluid-rock interaction and $\mathrm{CO}_{2}$ generation within The GeysersClear geothermal region of northern California, in (J.B. Hulen, ed.) Research results from The Geysers Coring Project: Univ. Utah Rept. ESRI-27495-96/3, $4 \mathrm{pp}$.

Bergfeld, D., Goff, F., and Janik, C.J., 1996b, Fluid-rock interaction and $\mathrm{CO}_{2}$ generation within The GeysersClear geothermal region of northern California: Geol. Soc. Amer. Abst. w/Prog., 1996 Annual Meeting, Denver CO, Oct. 27-30, 1996.

Bergfeld, D., Janik, C.J., and Goff, F., 1997a, $\mathrm{CO}_{2}$ degassing from point-source locations in The Geysers-Clear Lake region of northern California: EOS, Trans. AGU, v. 78, p. S328.

Bergfeld, D., Goff, F., and Janik, C.J., 1997b, Carbon dioxide flux and carbon reservoirs in The Geysers-Clear Lake geothermal region of northern California: Trans AGU, Fall 1997 meeting, San Fran., CA, Dec. 15, 1997.

Bergfeld, D., Goff, F., and Janik, C.J., 1998, Carbon isotope systematics and $\mathrm{CO}_{2}$ sources in The Geysers-Clear Lake region, northern California: submitted to Geothermics. 
Bruton, C.J., Counce, D., Bergfeld, D., Goff, F., Johnson, S.D., Moore, J.N., and Nimz, G., 1997, Preliminary investigation of scale formation and fluid chemistry at the Dixic Valley geothermal ficld, Nevada: Geotherm. Resourc. Counc. Trans., v. 21, p. 157-164.

Goff, F., and Janik, C.J., 1993, Gas geochemistry and guide for geothermal features in the Clear Lake region, Califormia, In: J.J. Rytuba, ed., Active geothermal systems and gold-mercury deposits in the Sonoma-Clear Lake volcanic fields, California: Soc. Econ. Geol. Guidebk., v. 16, p. 207-261.

Janik, C.J., and Goff, F., 1996, Reservoir geochemistry from flow tests of scientific core holes, Sulphur Springs, Valles Caldera, in (F. Goff, B. Kues, M.A. Rogers, L. MacFadden, and J.N. Gardner, eds) The Jemez Mountains Region: New Mexico Geological Society 47th Field Conference, Sept. 25-28, p. 52-52.

Kerrick, D.M., McKibben, M.A., Seward, T.M., and Caldiera, K., 1995, Convective hydrothermal $\mathrm{CO}_{2}$ emission from high heat flow regions: Chem. Geology, v. 121, p. 285-293.

Lambert, S.J., and Epstein, S., 1992, Stable isotope studies of rocks and secondary minerals in a vapor-dominated hydrothermal system at The Geysers, Sonoma County, California: Jour. Volcanol. Geotherm. Res., v. 53, p. 199 226.

Pauwels, H., Fouillac, C., Goff, F., and Vuataz, F.-D., 1997, The isotope and chemical composition of $\mathrm{CO}_{2}$-rich thermal waters in the Mont-Dore region (Massif Central, France), Applied Geochemistry, v. 12, p. 411-427.

Stimac, J.A., Goff, F., and Wohletz, K., 1997, Thermal modeling of the Clear Lake magmatic system, California: Implications for conventional and hot dry rock geothermal development: Los Alamos Nat'l. Lab. Rept. LA12778-MS, $38 \mathrm{pp}$.

Stimac, J.A., Goff, F., and Wohletz, K., 1998, Thermal modeling of the Clear Lake magma-hydrothermal system: Implications for conventional and hot dry rock geothermal development: submitted to Geothermics.

WoldeGabriel, G., Goff, F., Hulen, J.B., and Aronson, 1998, Mineralogical and K-Ar geochronology of mixedlayered illite/smectite from The Geysers coring project, California: submitted to Geothermics. 


\title{
ISOTOPE GEOCHEMISTRY IN GEOTHERMAL RESEARCH
}

\author{
B. Mack Kennedy (1), Donald J. DePaolo (2), and Alfred H. Truesdell (3)
}

(1) Lawrence Berkeley National Laboratory

(2) University of California, Berkeley (3) Consultant

\section{KEY WORDS}

magmatic gas, fluid inclusions, noble gases, isotopes, heat content, The Geysers, Dixie Valley, Basin and Range Province, Tiwi, Awibengkok

\section{PROJECT BACKGROUND AND STATUS}

\section{The Geysers}

The source of steam and noncondensable gas, and the temporal evolution of The Geysers vapor-dominated reservoir are not well understood; complicating attempts to understand and predict production-induced changes in pressure, steam flow, gas content, and composition. In prior studies (e.g., Kennedy and Truesdell, 1996) we have shown that the high noncondensable gas component in the high-temperature vapor-dominated reservoir of the northwest Geysers is magmatic and that there is an active present-day flux of magmatic gases into geothermal system. High ${ }^{3} \mathrm{He} /{ }^{4} \mathrm{He}$ ratios in steam from the southeast Geysers suggest that the influence of this magmatic gas flux may extend underneath much of the geothermal field. Fluid inclusion studies (Moore and Gunderson, 1995) have revealed the existence of a liquid-dominated geothermal system that predates the present vapor-dominated reservoir. From analyses of noble gases from fluid inclusions, we have determined that the early liquid-dominated system was also widely influenced by magmatic gases, but connate or metamorphic fluids were also present.

\section{Tiwi}

The Tiwi geothermal field is related to a young volcanic system along the southern coast of Luzon, Philippines. It is a major producer of electricity in the Philippines, with an installed capacity of $330 \mathrm{MWe}$. Development of the field began in the early 1960 s and in 1992 a continuous core through the reservoir became available when Unocal drilled well Matalibong-25 in the western portion of the field. We have begun a study of the temporal evolution of this field with analyses of fluid inclusions from the MAT-25 core.

\section{Basin and Range Province}

Over the last 10-15 Ma the northern Basin and Range Province has experienced intense extension (up to about $250 \mathrm{~km}$ in an approximate east-west direction; Wernicke et al., 1988) and is presently characterized by high regional average heat flow $\left(\sim 100 \mathrm{~mW} / \mathrm{m}^{2}\right.$; e.g., Sass, 1995). The geothermal industry produces about $510 \mathrm{MW}$ of electricity from geothermal power plants within the northern Basin and Range (Benoit, 1996). The regional high heat flow is variable on a local scale and all of the geothermal power plants are located within or near local heat flow highs $\left(>100 \mathrm{~mW} / \mathrm{m}^{2}\right)$. Some of the power plants, such as Coso and Long Valley, are clearly associated with recent (Holocene) intrusive activity. Most, however, are located in regions lacking any evidence of recent volcanic activity and many believe the heat is derived from deep circulation of fluids in high heat flow regions (e.g., Sass, 1995). However, the fluids in these systems often carry a mantle helium signature implying the involvement of active magmatic systems (Welhan et al.; 1988; Kennedy et al., 1996). Extension and rifting of 
continental crust is usually accompanied by igneous activity. Isotopic, trace element and petrologic data for continental volcanics support the hypothesis that magma sources change during the various stages of rifting. Coupled variations between trace and minor element concentrations, Nd isotopic compositions, and the age of the erupted volcanics implies that magma contributions from an upwelling asthenosphere become more dominant over lithospheric sources with progressive rifting (Daley and DePaolo, 1992). Where and when this occurs throughout the Basin and Range will have a significant impact on heat sources, heat flow patterns, and the potential location of hidden (i.e.," "blind") geothermal systems.

\section{PROJECT OBJECTIVES}

The project is aimed at critically assessing the value of isotope ratio measurements for characterizing geothermal reservoirs. Our objective is to develop a set of isotopic parameters, based on measurements of fluids, fluid inclusions, and rocks and minerals, that will help identify past and present fluid sources in geothermal systems and to estimate their extent, heat content, and lifetime.

\section{Technical Objectives}

- The Geysers: Develop a more thorough understanding of how and when The Geysers evolved from a liquid-dominated to a vapor-dominated system and what role the flux of magmatic gases has played over the course of this evolution.

- Tiwi: Use noble gases in fluid inclusions to develop a better understanding of the temporal evolution of the geothermal reservoir.

- Basin and Range Province: Generate a more comprehensive understanding of the relationship between extension rates, melt intrusion, magma sources, and heat flow leading to improved models for the origin and evolution of the Basin and Range geothermal systems, such as Dixie Valley.

\section{Expected Outcomes}

- The Geysers: Better and more comprehensive models of the origin and evolution of the vapor-dominated reservoir will enable steam producers to more confidently predict the decline in steam flow, the future concentrations of non-condensable gases, the possible appearance of corrosive $\mathrm{HCl}$, and the positive or adverse effects of injection.

- Tiwi: A better understanding of the relationship between recent, renewed magmatic activity and earlier initial activity and the temporal evolution of the system.

- Basin and Range Province: A better understanding of the origin, extent, heat content, lifetime and potential location of productive geothermal systems in this Province and similar tectonic environments.

\section{APPROACH}

The temporal evolution of geothermal fluids is investigated by comparing the compositions of fluid inclusions of different paragenetic histories with each other and with present-day production fluids. The isotopes of the chemically inert noble gases ( $\mathrm{He}, \mathrm{Ne}, \mathrm{Ar}, \mathrm{Kr}$, and $\mathrm{Xe}$ ) provide long-lasting tracers of fluid sources. These tracers include large ${ }^{3} \mathrm{He}$ enrichments of deep fluids originating in the mantle and introduced into crustal fluids through magma degassing or deep fluid circulation, enrichment in radiogenic ${ }^{4} \mathrm{He},{ }^{40^{*}} \mathrm{Ar}\left({ }^{40^{*}} \mathrm{Ar}=\right.$ radiogenic $\left.{ }^{40} \mathrm{Ar}\right)$ and 
nucleogenic components of crustal fluids, and enrichment in ${ }^{36} \mathrm{Ar}$ of atmospheric fluids. Noble gases can be analyzed in fluid samples collected from producing wells, surface hydrothermal features, fluid inclusions, and in the rocks and minerals related to the geothermal system.

A combined study of noble gas, $\mathrm{Sr}$, and $\mathrm{Nd}$ isotopic compositions of volcanics will be used to trace relative contributions from lithospheric versus asthenospheric mantle in basalt source regions as a function of time. A better understanding of the time-dependent contributions to the magma source will lead to a better understanding of the relationship between extension rates, melt intrusion, magma sources, and heat flow.

\section{RESEARCH RESULTS}

\section{The Geysers}

To establish a better understanding of the temporal evolution of The Geysers geothermal system, in collaboration with Joe Moore (EGI, University of Utah) and David Norman (New Mexico Tech.), we have analyzed noble gases extracted from fluid inclusions in hydrothermal minerals from core samples (Moore et al., 1997). The selection of samples for noble gas analyses was based on a survey study of fluid inclusion bulk gas chemistry conducted by David Norman using a quadrupole mass spectrometer. This system has the advantage that numerous samples can be analyzed quickly. This provides a comprehensive picture of the variations in bulk gas chemistry among samples of various paragenetic histories from which specific samples can be selected for more detailed isotopic studies. Although in some cases, gas chemistries can provide insight into fluid source, the noble gas isotopes can provide definitive evidence.

The fluid inclusions record a zoned halo of decreasing temperature and salinity with distance away from the 1.31.4 Ma felsite intrusion and are, therefore, likely to be related to the intrusion of the felsite (Moore and Gunderson, 1995). In a suite of samples selected to provide a representative section of the temperature-salinity halo, the bulk gas chemistry of the fluid inclusions suggest mixing between three different fluids: one indistinguishable from air-saturated water (in some cases modified by phase separation or air contamination), a second that is strongly enriched in $\mathrm{N}_{2}$ and believed to be magmatic, and a third that is enriched in $\mathrm{CH}_{4}$ with a nearly constant $\mathrm{N}_{2} / \mathrm{CH}_{4}$ ratio $(\sim 0.05-0.10)$ suggesting a crustal source. In all samples, except one, noble gases extracted from the fluid inclusions are enriched in magmatic helium with a nearly constant ${ }^{3} \mathrm{He} /{ }^{4} \mathrm{He}$ ratio of $\sim 6$ $\mathrm{Ra}$, significantly less than that observed in present-day production steam from the high-temperature vapordominated reservoir ( $\sim 8 \mathrm{Ra}$; Kennedy and Truesdell, 1996). The enrichment in magmatic helium confirms the suspected influence that the felsite intrusion had on the evolution of the liquid system, and the nearly constant ${ }^{3} \mathrm{He} /{ }^{4} \mathrm{He}$ ratios document a widespread flux of magmatic gas throughout the liquid dominated hydrothermal system. However, the degree of enrichment is independent of location within the zoned halo of decreasing temperatures and salinities and independent of the bulk gas chemistry, but is inversely correlated with the amount of air-derived ${ }^{36} \mathrm{Ar}$. The latter suggests mixing between the magmatic gases and meteoric waters. The exception (L'esperance-2) is vein material from the margin of the high-temperature reservoir of the northwest Geysers. Noble gases in fluid inclusions from these veins are strongly enriched in $\mathrm{He}$ but with a low helium isotopic composition ( $0.5 \mathrm{Ra})$, suggesting overprinting of the magmatic signature by connate or metamorphic fluids or that these veins contain fluids that predate the felsite intrusion.

\section{Tiwi}

Fluid inclusion studies of the MAT-25 core identified nine stages of water-rock alteration and vein mineralization. The majority of the stages (2-8) reflect repeated cycles of boiling, pressure drawdown and dilution with cooler fluids. Stage 9 reflects renewed heating related to recent magma intrusion. The bulk gas composition and 
salinities of the fluid inclusions suggests that the hydrothermal fluids were mixtures of meteoric and seawater that had been altered by the addition of primarily crustal and possibly magmatic gases (Moore et al, 1998). We have analyzed the noble gases extracted from fluid inclusions in a suite of hydrothermal minerals from MAT-25, supplied by Joe Moore. The samples, from stages 4-6, contain air-derived noble gas abundances consistent with meteoric water. All of the samples are enriched in ${ }^{4} \mathrm{He}$ relative to the air noble gases, contain significant contributions of magmatic ${ }^{3} \mathrm{He}$, and both the ${ }^{4} \mathrm{He}$ enrichment factors and ${ }^{3} \mathrm{He} /{ }^{4} \mathrm{He}$ ratios appear to increase with depth in the reservoir. To fully appreciate the implications of the noble gas results a more comprehensive suite of inclusions should be analyzed and compared with the composition of present day production fluids.

\section{Basin and Range Province}

Steam supplied to the Dixie Valley geothermal plant is characterized by helium isotopic compositions (0.70-0.76 $\mathrm{Ra}$ ) elevated relative to that expected for radiogenic production in the crust $(0.02-0.10 \mathrm{Ra})$ and indicate that as much as $\sim 7.5 \%$ of the helium in the reservoir fluid is magmatic or mantle-derived (Kennedy et al., 1996). Although this mantle signature is not very strong when compared to other geothermal systems, it is enigmatic due to a lack of recent igneous activity in the Dixie Valley region. One possibility is that the high heat and ${ }^{3} \mathrm{He}$ fluxes in the area are driven by a deep melt zone (e.g., Jarchow et al., 1993) related to asthenospheric upwelling and magma formation (e.g., Daley and DePaolo, 1992). To better understand the complicated relationship between shallow manifestations of deeper processes related to tectonic extension and associated magma generation, we have conducted a combined noble gas, $\mathrm{Sr}, \mathrm{Nd}$, and major and trace element study of Basin and Range volcanics. Based on the analyses of 30 basalts, we have found a strong correlation between $\mathrm{He}, \mathrm{Nd}$, and $\mathrm{Sr}$ isotopic compositions (Dodson et al., 1997). The nature of the correlations allow individual flow systems within volcanic provinces to be characterized, in both space and time, according to their relative contributions from asthenospheric versus lithospheric melts. It is expected that regions presently dominated by shallow asthenospheric melts will be characterized by higher heat and ${ }^{3} \mathrm{He}$ fluxes.

\section{FUTURE PLANS}

\section{The Geysers}

(1) Acquisition of additional noble and bulk gas $\left(\mathrm{N}_{2}, \mathrm{Ar}\right.$, and $\left.\mathrm{CH}_{4}\right)$ data from fluid inclusions with an emphasis on evaluating the degree of heterogeneity of fluid composition within individual compositional zones and correlations between bulk gas compositions and magmatic contributions;

(2) Extend sampling coverage of steam from the northwest Geysers to generate a better understanding of the distribution of magmatic gases associated with the high-temperature reservoir; and

(3) A systematic study of injection fluids to further our understanding of the composition of atmospheric noble gases in the production fluids. In steam from the high-temperature reservoir, the atmospheric noble gases are decoupled from the magmatic component, are unlike the composition of air-saturated water at expected natural recharge temperatures, and may be a proxy for either the degree of water saturation or the influence of injection fluids.

\section{Tiwi}

(1) Conduct a more comprehensive study of noble gas compositions in fluid inclusions from MAT-25 as a function of reservoir depth and mineralization stage. 
(2) Analyze noble gases in present-day production fluids to compare to the fluid inclusion data.

\section{Basin and Range Province}

(1) Develop a model which can evaluate the heat content of an existing or potential geothermal system based upon a correlation between ${ }^{3} \mathrm{He}$ content of the reservoir fluids and the mass influx rate of asthenospheric melt to a magma chamber, as derived from the observed correlations between $\mathrm{He}, \mathrm{Nd}$, and $\mathrm{Sr}$ isotopes of associated volcanics.

\section{Awibengkok}

We will conduct a comprehensive isotopic study, that will include noble gases, light stable isotopes, $\mathrm{Sr}$, and $\mathrm{Nd}$, of vein and host minerals in a core from the Awibengkok field which will become available to us during FY 1998.

\section{INDUSTRY INTEREST}

\section{Organization}

Calpine Corp. N.C.P.A., Unocal Geothermal

Unocal Geothermal and other companies

Oxbow Energy Co.

\section{Type and Extent of Interest}

Origin of production gas, potential for Unocal Geothermal production of corrosive steam in SE Geysers.

Sources and potential for production of chemically hostile fluids in geothermal systems closely associated with active volcanoes.

Origin of heat and size of resource at Dixie Valley, and use of injection tracers.

\section{REFERENCES}

Benoit, D. (1996), A review of geothermal power generation in the Basin and Range Province in 1995. Geothermal Resources Council Bull., 25, 197-201.

Daley, E.E. and DePaolo, D.J. (1992), Isotopic evidence for lithospheric thinning during extension: Southeastern Great Basin. Geology, 20, 104-108.

Dodson, A., DePaolo, D.J., and Kennedy, B.M. (1997), Helium isotopes in lithospheric mantle: evidence from Tertiary basalts of the western U.S. Paper submitted to Geochim. Cosmochim. Acta.

Jarchow, C.M., Thompson, G.A., Catchings, R.D., and Mooney, W.D. (1993), Seismic evidence for active magmatic underplating beneath the Basin and Range Province, Western United States. J. Geophys. Res., 98 , 22,095-22,108.

Kennedy, B.M. and Truesdell, A.H. (1996), The Northwest Geysers high-temperature reservoir: evidence for active magmatic degassing and implications for the origin of The Geysers geothermal field. Geothermics, 25 , 365-387. 
Kennedy, B.M., Benoit, D., and Truesdell, A.H. (1996), A preliminary survey of noble gases at Dixie Valley, Nevada. Geothermal Resources Council Trans., 20, 815-819.

Moore, J.N. and Gunderson, R.P. (1995), Fluid inclusion and isotopic systematics of an evolving magmatichydrothermal system. Geochim. Cosmochim. Acta, 59, 3887-3907.

Moore, J.N., Norman, D.I., Kennedy, B.M., and Adams, M.C. (1997), Origin and chemical evolution of The Geysers, California, hydrothermal fluids: implications from fluid inclusion gas compositions, Geothermal Resources Council Trans., 21, 635-642..

Moore, J.N., Powell, T.S., Bruton, C.J., Norman, D.I., and Heizler, M.T. (1998), Thermal and chemical evolution of The Tiwi geothermal system, Philippines. Proc. 9th International Symposium on Water-Rock Interaction, March 30-April 3, 1998, Taupo, New Zealand (in press).

Sass, J.H. (1995), Mining the Earth's heat in the Basin and Range. Geothermal Resources Council Bull., 24, 125-129.

Welhan, J. A., Poreda, R. J., Rison, W., and Craig, H. (1988), Helium isotopes in geothermal and volcanic gases of the western United States, I. Regional variability and magmatic origin. J. Volc. Geotherm. Res. 34, 185-199.

Wernicke, B., Axen, G.J., and Snow, J.K. (1988), Basin and Range extensional tectonics at the latitude of Las Vegas, Nevada. Geol. Soc. Am. Bull. 100, 1738-1757. 


\title{
MAGMATIC-HYDROTHERMAL AQUEOUS EXSOLUTION
}

\author{
P.A. Candela and P.M. Piccoli \\ Department of Geology \\ University of Maryland at College Park
}

\section{KEY WORDS}

geothermal, aqueous phase, vapor, brine, exsolution, magma, texture, volatiles, volcanic

\section{PROJECT BACKGROUND AND STATUS}

The aim of this research is to develop a model to explain the behavior of volatile species (such as $\mathrm{H}_{2} \mathrm{O}, \mathrm{HCl}$ and $\mathrm{S}$-bearing gases) and other magmatically derived chloride-complexed species (such as $\mathrm{NaCl}, \mathrm{KCl}$, and $\mathrm{FeCl}_{2}$ ) in silicic volcanic and plutonic systems associated with geothermal systems. Shallow felsic magmas evolve volatile phases (MVP) which can transport heat and solutes to high levels in geothermal systems. Magmatic volatiles contribute to both the acidity and total dissolved solids of geothermal fluids, and are often become fixed in mineral alteration products (scale) in these systems. Further, as magmatic fluids cool, they become corrosive. Both scaling and corrosion can affect the exploitation of a geothermal reservoir.

\section{PROJECT OBJECTIVES}

This project involves experimental, modeling, and field research. The results of this research can be used in natural state modeling to calculate the concentration of $\mathrm{HCl}$ in the magmatic component of a geothermal fluid as a function of the depth of the magma chamber, the estimated $\mathrm{Cl} /$ water ratio in the magma, and silicate melt compositions in the regional magma system. This work will yield important geothermal exploration information on how the chemistry of recent proximal volcanics and/or recent shallow plutons intersected by drilling in geothermal areas may affect the aqueous contributions of magmas to the geothermal systems. The results can be used to predict how magmatic-aqueous fluids may contribute to the alteration of both natural and technogenic materials in these systems.

\section{Technical Objectives}

- Evaluate alteration equilibria in natural systems through experimentation

- Extract thermodynamic data pertinent to alteration associated with some high temperature geothermal systems

- Integrate experimental data with field observations to produce a model which can be used as a predictive tool to estimate the $\mathrm{HCl}$ and $\mathrm{Cl}$ generated from magmatic system

\section{APPROACH}

To develop an integrated model of the deep magmatic inputs to geothermal systems; the following three part approach is being utilized: 
1) Experimental Investigations: we are performing experiments on the partitioning of $\mathrm{HCl}$, total chlorine, and other elements among silicate melts, two phase (vapor and brine) mixtures of chloride-bearing aqueous fluids, and minerals, and how the evolved chloride-bearing aqueous fluids effect alteration of both natural and technogenic materials in geothermal systems.

2) Physical and Chemical Modeling: we are modeling aspects of the chemistry (in the systems high silica melt-aqueous phase and high silica melt-aqueous brine-low salinity vapor) and the physics of aqueous phase exsolution in plutonic systems; and

3) Field Investigations: we are investigating igneous apatite chemistry as a function of magmatic textures in the fossil remains of several localized, shallow magmatic-geothermal systems of the high Sierra of California (to constrain any physico-chemical model of accession of magmatic volatiles into geothermal systems).

\section{RESEARCH RESULTS}

\section{Select Experimental Results}

In order to understand the role played by high salinity aqueous phases in the shallow magmatic environment, we examined quartz-present mineral/aqueous phase equilibria in a vapor-undersaturated high-salinity portion of the system $\mathrm{Al}_{2} \mathrm{O}_{3}-\mathrm{SiO}_{2}-\mathrm{H}_{2} \mathrm{O}-\mathrm{HCl}-\mathrm{KH}_{-1}$.

Previous studies have emphasized dominantly the low-salinity portion of the aqueous phase volume. From our study, updated values of the $\log$ of the equilibrium quotient $\left[\log _{10}(\mathrm{~K} / \mathrm{H})\right]$ (expressed in terms of the analytical concentration of $\mathrm{KCl}$ and $\mathrm{HCl}$ ), with uncertainties (in parenthesis) presented as half-widths of the reversal brackets, have been obtained. For the Kfs-Ms-Qtz (K-feldspar-muscovite-quartz) equilibrium, $\left[\log _{10}(\mathrm{~K} / \mathrm{H})\right]=$ $1.6(0.1), 0.81(0.06), 0.54(0.04)$ and $0.42(0.08)$ at $400^{\circ} \mathrm{C} @ 25 \mathrm{MPa}, 450^{\circ} \mathrm{C} @ 40 \mathrm{MPa}, 500^{\circ} \mathrm{C} @ 50 \mathrm{MPa}$, and $550^{\circ} \mathrm{C} @ 60 \mathrm{MPa}$ (run T \& P's), respectively. For the And-Ms-Qtz equilibrium, $\left[\log _{10}(\mathrm{~K} / \mathrm{H})\right]=0.63(0.1)$, $0.063(0.06), 0.17(0.05)$ and $0.25(0.08)$ at the nun $T$ and $P^{\prime} s$, respectively. We determined $\mu_{x H_{-1}}^{\circ}$ where $\mu_{X H_{-1}}^{0}=\Delta \bar{G}_{f, K C l}^{0}-H C l+\mu_{X E H_{-1}}^{\alpha x}$ for the high salinity aqueous phase. By using this variable, the equilibrium constant,

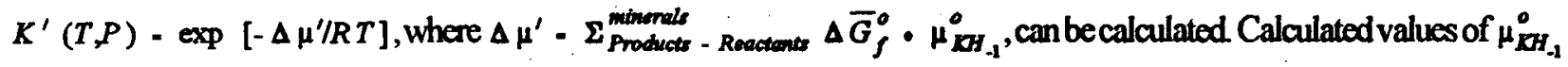
(kJ/mole) are -291, -284, -284, and -288 at nu T \& P's, respectively, for Kfs-Ms-Qtz, and -264, -248, -245, and -240 , for And(andalusite)-Ms-Qtz at run T \& P's, respectively. The equilibria are shifted to lower K/H (at a given $T$ and $P$ ) relative to those involving a lower salinity phase. This shift may be attributed to pressure effects and the physical properties of the phases.

Acidic geothermal fluids are responsible for the mineralogical alteration of rocks near hydrothermally active areas. On the order of half of the acid found in deep geothermal brines can due to sulfate in the form $\mathrm{H}_{2} \mathrm{SO}_{4}$. Therefore, we are also studying equilibria of the type:

$$
\begin{gathered}
\underset{\text { water }}{4 \mathrm{H}_{2} \mathrm{O}}+\underset{\mathrm{KMg}_{3} \mathrm{Si}_{3} \mathrm{AlO}_{10}(\mathrm{OH})_{2}}{\text { phlogopite }}+\underset{\text { quartz anhydrite }}{24 \mathrm{SiO}_{2}}+6 \mathrm{CaSO}_{4}= \\
\underset{\text { tremolite }}{3 \mathrm{Ca}_{2} \mathrm{Mg}_{5} \mathrm{Si}_{8} \mathrm{O}_{22}(\mathrm{OH})_{2}}+\underset{\mathrm{KAlSi}_{3} \mathrm{O}_{8}}{5}+\underset{\text { perthite sulfuric acid }}{6 \mathrm{SO}_{4}}
\end{gathered}
$$


Experimental examination of his equilibrium will allow us to constrain the concentration of $\mathrm{H}_{2} \mathrm{SO}_{4}$ in some geothermal fluids.

The current experimental procedure entails loading a specific set of minerals and a hypersaline solution into a gold capsule. The minerals include perthite, tremolite, and quartz; the hypersaline solution consists of $\mathrm{H}_{2} \mathrm{O}$, $\mathrm{H}_{2} \mathrm{SO}_{4}, \mathrm{NaCl}, \mathrm{KCl}$, and $\mathrm{Na}_{2} \mathrm{SO}_{4}$. The perthite and tremolite are added as small grains $(\sim 0.5 \mathrm{~mm}-1 \mathrm{~mm}$ in diameter). Inclusion-free $\mathrm{Brazilian}_{\text {quartz }}$ is added to provide $\mathrm{a} \mathrm{SiO}_{2}$ source for the reaction in addition to trapping fluid inclusions during the experimental run. These inclusions will be analyzed to insure that the experiment was conducted (under the correct geothermal conditions) in the brine field of the $\mathrm{NaCl}$ equivalent $-\mathrm{H}_{2} \mathrm{O}$ system. Initial experiments are being conducted at $500^{\circ} \mathrm{C}$ and $50 \mathrm{MPa}$ with a $42 \mathrm{wt} . \% \mathrm{NaCl}$ equivalent brine. The amount of each species of salt added to the brine is calculated by using predetermined initial ratios of $\mathrm{K}^{+} / \mathrm{Na}^{+}$and $\mathrm{Cl}^{-} /\left(\mathrm{SO}_{4}\right)^{-2}$, while the ratio of $\mathrm{K}^{+} / \mathrm{H}^{+}$was varied for each experiment. Results to date show that all brines have produced only anhydrous run products at the stated conditions.

Note that the high salinity phases in our experiments were not vapor-saturated; further, the lower salinity phases ( 1 molal total $\left.\mathrm{Cl}^{-}\right)$of previous investigators were not brine-saturated. Therefore, these results, and the results of lower salinity experiments should not be considered as representative of the properties of a coexisting vapor and brine.

\section{Select Modeling Results}

Estimation of the concentration of $\mathrm{Cl}$ and $\mathrm{HCl}$ in the magmatic volatile phase is critical to the evaluation of the deep input to geothermal systems, and the chemistry of volcanic volatiles. We have calculated these parameters in two ways. The first method uses the ASI of an aplite melt at the aplite intrusion P \& $T$, together with our recent experimental data relating $\mathrm{HClNaCl}$ and $\mathrm{HCl} / \mathrm{KCl}$ to melt $\mathrm{ASI}$, to calculate a maximum $\mathrm{HCl} /($ total $\mathrm{Cl}$ ) in the magmatic vapor phase. Further, if brine saturation is assumed, we can calculate a model $\mathrm{HCl}$ concentration in brine-saturated magmatic vapor. The second method uses apatite $(\mathrm{Cl} / \mathrm{OH})$ in conjunction with thermodynamic data to calculate the fugacity ratio of $\mathrm{HCl} / \mathrm{H}_{2} \mathrm{O}$; if the ASI of the melt is known, then $\mathrm{HCl} /($ total $\mathrm{Cl}$ ) can be used with apatite chemistry to calculate the total $\mathrm{Cl}$ concentration of the magmatic vapor. Each method requires an aplite intrusion $\mathrm{P} \& \mathrm{~T}$; $\mathrm{P}$ can be estimated from the aplite bulk composition relative to the pressure-dependent $\mathrm{H}_{2} \mathrm{O}$-saturated granite minima compositions, and $\mathrm{T}$ (apatite saturation temperature $\sim$ aplite intrusion temperature) can be estimated from the $\mathrm{P}_{2} \mathrm{O}_{5}$ and $\mathrm{SiO}_{2}$ concentrations in the aplite: see Piccoli \& Candela, 1994).

In this study, we examined the aplites and apatites of the Rush Creek (RC) quartz monzodiorite (Sierra Nevada Batholith, USA) given $P=50 \mathrm{MPa}$ (from aplite composition) and $850^{\circ} \mathrm{C}$ (close to the apatite saturation temperature of $820^{\circ} \mathrm{C}$ ). The ASI of the residual melt, calculated from the bulk composition of the $\mathrm{RC}$ aplites, was 1.02. From our experimental data (Williams et al., 1997), we calculate $\log \mathrm{KCl} / \mathrm{HCl}(-$ $0.022)$ and $\log \mathrm{NaCl} / \mathrm{HCl}(-0.056)$ in the magmatic vapor, yielding $\mathrm{HCl} /($ total $\mathrm{Cl})=0.35$ for the vapor in equilibrium with $\mathrm{RC}$ aplite. Assuming a total $\mathrm{Cl}=0.07$ molal (brine-saturated vapor), we can calculate a maximum $\mathrm{HCl}$ concentration in the magmatic vapor of 0.02 molal.

Alternatively, we can calculate $\mathrm{HCl} / \mathrm{H}_{2} \mathrm{O}$ directly from the composition of apatite at $\mathrm{P} \& \mathrm{~T}$. Rush Creek aplites contain apatite with $3.26 \mathrm{wt} \% \mathrm{~F}\left(X_{p p p}^{\phi p}=0.865\right)$ and $0.05 \mathrm{wt} . \% \mathrm{Cl}\left(X_{\mathcal{C} p}^{\phi p}=0.007\right)$. At $820^{\circ} \mathrm{C}$ and 50 $\mathrm{MPa}$, these apatites would be in equilibrium with a vapor with $\mathrm{HCl} \sim 0.02$ molal. If both apatite composition and melt ASI are available, they can be combined to yield a total chloride concentration; in this case, we calculate a total $\mathrm{Cl}$ concentration in the vapor phase of $0.06(0.35 \mathrm{wt} . \% \mathrm{NaCl}$ eq. $)$. Note that this is the total $\mathrm{Cl}$ concentration of a vapor that is at or near saturation with a brine in the system $\mathrm{NaCl}-\mathrm{H}_{2} \mathrm{O}$. That is, given 
apatite data and aplite ASI, we can demonstrate that a vapor in equilibrium with the RC aplite melt was at, or close to, saturation with brine. We suggest that these techniques be used to predict the concentration of $\mathrm{HCl}$ and $\mathrm{Cl}$ in magmatic volatile phases associated with a given volcanic or plutonic system. These data can be used to estimate the potential magmatic contributions of chloride-complexed dissolved solids and chloride acidity to a given geothermal system under exploration, given melt ASI and/or apatite composition data.

\section{FUTURE PLANS}

We will continue our experiments on brines and other fluids present in the geothermal environment, from magmatic temperatures to near-earth surface temperatures, involving the interactions of these fluids with minerals, melts and technogenic material.

\section{INDUSTRY INTEREST}

In our site visits at geothermal facilities and other conversations with people in the industry, we have discussed issues of corrosion and scaling, and how our work might be used to aid to lessen the impact of these factors.

\section{REFERENCES}

Frank, M.R., Candela, P.A. and Piccoli, P.M. (1996) Thermodynamics of alteration equilibria in a high salinity, quartz-saturated portion of the system $\mathrm{Al}_{2} \mathrm{O}_{3}-\mathrm{SiO}_{2}-\mathrm{H}_{2} \mathrm{O}-\mathrm{HCl}-\mathrm{KH}_{-1}$. Accepted for the Geological Society of America Abstracts with Programs, v. 28, p. 153.

Piccoli, P.M. and Candela, P.A. (1994) Apatite in felsic rocks: a model for the estimation of initial halogen contents in the Bishop Tuff (Long Valley) and Tuolumne Intrusive Suite (Sierra Nevada Batholith) Magmas. American Journal of Science, v. 294, p. 92-135.

Piccoli, P.M., Candela, P.M. and Williams, T.J. (1996) Constraints on $\mathrm{HCl}$ and $\mathrm{Cl}$ in the magmatic volatile phase: calculations based on aluminum saturation index of aplites, and apatite composition. Geological Society of America Abstracts with Programs, v. 28, p. 402. Invited.

Williams, T.J., Candela, P.A. and Piccoli, P.M. (1997) Hydrogen-alkali exchange between silicate melts and two-phase aqueous mixtures: an experimental investigation. Contributions to Mineralogy and Petrology, $v$. 128, p. 114-126. 


\title{
THERMODYNAMICS AND PHASE RELATIONS OF SYNTHETIC GRANITE MELTS AND ASSOCIATED AQUEOUS FLUIDS
}

\author{
J. G. Blencoe, L. M. Anovitz, D. R. Cole and J. Horita \\ Chemical and Analytical Sciences Division, Oak Ridge National Laboratory
}

\section{KEY WORDS}

silicate melts, geothermal fluids, fluid-rock interactions, thermodynamics, phase equilibria, modeling, granite

\section{PROJECT BACKGROUND AND STATUS}

Geothermal resources are genetically linked to silicic magmatism in numerous localities worldwide. Two important manifestations of this link are heat transfer from the magmas to superjacent geothermal systems, and mixing of magmatic fluids with meteoric waters. In mixed-fluid systems it is known that: (1) the initial chemical compositions of magmatic fluids are strongly influenced by the bulk composition and thermodynamic mixing properties of the magma, (2) incompatible melt components are preferentially partitioned into the aqueous fluids that separate from silicic magmas, and (3) geochemical reactions can potentially produce significant changes in the compositions of magmatic fluids prior to and during mixing with meteoric waters. These and other magmahydrothermal processes have been understood semi-quantitatively for many years; to characterize these systems more rigorously, new thermodynamic and kinetic models are needed.

A comprehensive thermodynamic model for granitic magmas would facilitate quantitative geochemical investigations of granite-hosted, magma-hydrothermal systems. With such a model, crystallization paths for the melts could be calculated. These paths correlate with release of latent heat, which is an important factor in the overall heat budget of the system. They also define both the P-T-X conditions at which an aqueous fluid begins separating from the magma, and the composition of that fluid.

Granitic magmas contain numerous minor and trace components. Consequently, it is impractical to experimentally quantify all of the thermodynamic characteristics of these melts. Fortunately, a great deal can be learned by investigating analog systems. The "haplogranite" system $\mathrm{NaAlSi}_{3} \mathrm{O}_{8}$ (albite), $\mathrm{KAISi}_{3} \mathrm{O}_{8}$ (sanidine), $\mathrm{Si}_{4} \mathrm{O}_{8}$ (quartz) and $\mathrm{H}_{2} \mathrm{O}$ (water) is widely regarded as an excellent analog for granites and granitic pegmatites. Thus, we are conducting systematic investigations of the thermodynamics and phase relations of haplogranitic melts. Currently, our attention is focused on measuring the mutual solubility of haplogranite melt and water, and re-evaluating the available data for the system albite-water.

\section{PROJECT OBJECTIVES}

This project is part of the program "Physical Chemistry of Geothermal Systems" at the Oak Ridge National Laboratory (ORNL). The immediate goal of the research is to perform laboratory experiments which elucidate the phase relations and thermodynamic mixing properties of haplogranitic melts and associated aqueous fluids. The resulting fundamental thermochemical data can be applied in quantitative modeling of heat and fluid flow in geothermal systems associated with silicic magmas. The ultimate aim of the work is to develop thermodynamic models for silicic magmas and high-temperature geothermal fluids. 


\section{Technical Objectives}

- Determine the alkali aluminosilicate composition of aqueous fluid in equilibrium with haplogranitic melt at $680-1000^{\circ} \mathrm{C}, 500-2500$ bars.

- Determine the solubility of water in haplogranitic melts at $680-1000^{\circ} \mathrm{C}, 500-2500$ bars.

- Re-evaluate the reliability of available thermodynamic data for the system albite-water.

- Acquire new and more accurate data on the boundaries of melt-crystal phase fields in haplogranitic systems at $680-1000^{\circ} \mathrm{C}, 500-2500$ bars.

- Measure the chemical potential of water in haplogranitic melts at $1000^{\circ} \mathrm{C}, 500$ bars.

\section{Expected Outcomes}

The new experimental data will be used to develop thermodynamic equations of state for:

- Predicting the solubility of granitic components in geothermal fluids;

- Calculating the solubility of water in silicic melts;

- Modeling the $\mathrm{H}_{2} \mathrm{O}$-undersaturated hypersolidus phase relations of silicic igneous systems; and

- Estimating the quantities and compositions of magmatic fluids in geothermal systems associated with silicic intrusions.

\section{APPROACH}

The integral thermodynamic mixing properties of hydrous haplogranitic melts can be determined if sufficient, accurate experimental data are obtained on the hypersolidus phase relations of haplogranitic systems; the chemical potential of water in haplogranitic melts and the free energies of fusion of stoichiometric silicate components $\left(\mathrm{NaAlSi}_{3} \mathrm{O}_{8}, \mathrm{KAISi}_{3} \mathrm{O}_{8}, \mathrm{Si}_{4} \mathrm{O}_{8}\right.$ ). To obtain these data, experiments are being performed in an internally-heated pressure vessel, and in cold-seal hydrothermal apparatus. These are some of the unique laboratory devices at ORNL for studies of chemical equilibria, thermodynamics of brine systems, liquid-vapor molecular and isotopic partitioning, and other phase behavior.

\section{RESEARCH RESULTS}

\section{A. Fluid-Composition Experiments}

A number of factors have limited the ability of previous researchers to determine the composition of aqueous fluid coexisting with haplogranitic melt. The most serious is that the high P-T composition of the fluid is not retained on quenching. Silicate materials precipitate as films and "quench roe" (amorphous silica-rich spheres). This prevents direct analysis of the high P-T fluid. The tendency of the silicate to precipitate on the glass further complicates the analysis. 
We have developed a method that overcomes many of these difficulties, and are currently determining the compositions of aqueous fluids equilibrated with haplogranitic melts. These experiments establish the $\mathrm{Na}, \mathrm{K}$, $\mathrm{Si}$, and $\mathrm{Al}$ composition, as well as $8 \mathrm{D}$ and $8^{18} \mathrm{O}$, of an aqueous fluid coexisting with haplogranitic melt. The method uses a triple Pt capsule. Hydrous haplogranite glass is placed in two identical inner capsules, which are welded on the bottom only. The top of each capsule is filled with a ball of fine $\mathrm{Pt}$ mesh. These inner capsules are loaded, along with water, into a larger outer capsule. During an experiment, the water has easy access to the melt through the mesh but the mass of water in each inner capsule is small. Thus, after quenching, essentially all of the precipitate is found in the outer capsule, easily separable from the glass.

Hydrous haplogranitic glasses of known chemical and isotopic composition were synthesized as starting materials for the experiments. Nine anhydrous compositions were prepared: five in the $\mathrm{NaAlSi}_{3} \mathrm{O}_{8}-\mathrm{KAlSi}_{3} \mathrm{O}_{8}-\mathrm{SiO}_{2} \mathrm{system}$, three on the bounding binaries (2500-bar minimum melt compositions), and albite. Both water-oversaturated and undersaturated glasses were prepared to permit reversal of the equilibrium water content of the melt. To date, experiments have been performed at $950^{\circ} \mathrm{C}, 2500$ bars, for periods ranging from 1 to 11 days.

A major challenge in this project has been development of analytical techniques. The following steps are required: (1) opening the capsules, (2) processing the precipitate for analysis, (3) analysis of the precipitate, (4) dehydrating the glasses to measure water contents, and (5) isotopic measurements of both the free water and the glass. Capsules are opened by puncturing under vacuum. Heat tape on the puncturer prevents water precipitation in its upper section, and a heat gun is used to drive water out of the capsule and into a break-seal tube cooled by liquid nitrogen. Excessive heating is avoided to prevent partial dehydration of the haplogranitic glass. The vacuum distillation process separates the water from the precipitate, and leaves any remaining dissolved material in the capsule. The break-seal tube is then sealed and the water saved for isotopic analysis. The difference in the weight of the capsule before and after puncturing gives the amount of free water present during the run.

To prepare the precipitate for analysis the inner capsules are removed and checked for precipitate. Comparison of the weight of the outer capsule to its initial weight yields one estimate of the amount of precipitate, and thus of the total solubility at $\mathrm{P}$ and $\mathrm{T}$. A second estimate is obtained by measuring the weight change in the inner capsules and correcting for dissolved water (the difference between the water added to the outer capsule and that recovered on puncturing) to determine the amount of weight lost, which is assumed to be precipitate. The capsule is then filled with Li-borate and heated to $1000^{\circ} \mathrm{C}$ to dissolve the silicate precipitate in the flux.

Analysis of the sample requires that it.be dissolved in aqueous solution. To do this, known amounts of $\mathrm{Ca}$ and $\mathrm{Mg}$ standards and $\mathrm{HNO}_{3}$ are weighed into small bottles. The capsules containing the fluxed samples are then added, and the materials heated at $60^{\circ} \mathrm{C}$ for $2-3$ weeks. The capsules are then removed and checked for complete sample dissolution. A third weight-change estimate of the total amount of precipitate is obtained at this stage by comparing (1) the current weight of the capsule with the flux and precipitate removed with (2) the weight of the outer capsule immediately after the inner capsules were removed. The dissolved samples are analyzed by ICP. Dilution factors calculated from the $\mathrm{Ca}$ and $\mathrm{Mg}$ analyses convert the $\mathrm{Na}, \mathrm{K}, \mathrm{Al}$, and $\mathrm{Si}$ analyses to amounts of material present to calculate the total amount of solid in solution. The analysis of each element yields its relative concentration.

For each sample, one of the two inner capsules can be dehydrated to determine its water content, thereby constraining the solubility of water in the melt (see below). Difficulties encountered in analyzing the water contents of hydrous glasses are well known. Our method avoids many of the pitfalls described by previous investigators. Dehydration tubes were designed in which haplogranitic glass can be slowly heated to $1300^{\circ} \mathrm{C}$. The tube is evacuated and sealed before heating. A single openable fitting minimizes leakage. Evolved water is trapped in a breakseal tube and analyzed with high precision by U-fumace manometry. While this approach 
solves the problem of measuring the mass of water in the glass, it cannot be used to distinguish dissolved water from that in trapped inclusions. No technique based on heating to remove water, regardless of the postdehydration analysis technique, can do this. Thus, it is advisable to make high precision standards for SIMS anatysis of the haplogranitic glasses. A cross-section of one of the inner capsules can then be cut and analyzed for water content, isotope ratios, and major element content, (by SIMS and electron microprobe), and to check for homogeneity.

To date, data have been collected on the solubility of a Si-poor haplogranite reacted at $950^{\circ} \mathrm{C}, 2500$ bars, for 1 , $2,4,8$ and 11 days. This work was reported at the annual meeting of the Geological Society of America, and was very well received (Anovitz and Blencoe, 1997b). Results suggest that: (1) the total solubility of this haplogranite in water is $1.60 \pm 0.1 \mathrm{wt}$. \%; (2) dissolution is incongruent, with a significant increase in $\mathrm{Si}$ in the fluid over that in the melt; (3) $\mathrm{Al}$ is mobile in aqueous fluids, even in the absence of halide anions, and (4) significant $\mathrm{Na} / \mathrm{K}$ partitioning occurs between the water and melt.

Table 1 gives the calculated weight percent precipitate obtained from the chemical analyses, as well as from the three weight-loss techniques. It is apparent that there is considerable scatter in the weight-loss measurements. This is not surprising, as each involves a number of assumptions and accumulated errors. Of the three methods, however, that which compares the weight of the capsule before fluxing, and after the acid bath, appears to be the most consistent.

\begin{tabular}{|c|c|c|c|c|}
\hline & Chem. Analysis & & Weight Loss & \\
\hline Water W4 & $\begin{array}{c}\text { wt \% } \\
\text { Precipitate }\end{array}$ & $\begin{array}{l}\text { wt } \% \text { est from } \\
\text { capsule weight }\end{array}$ & $\begin{array}{l}\text { wt } \% \text { est from } \\
\text { capsule weight } \\
\text { post flux }\end{array}$ & $\begin{array}{l}\text { wt } \% \text { est from } \\
\text { water weight }\end{array}$ \\
\hline $\begin{array}{l}1 \text { day } \\
2 \text { day } \\
4 \text { day } \\
8 \text { day } \\
11 \text { day }\end{array}$ & $\begin{array}{l}1.264 \\
1.345 \\
1.225 \\
1.546 \\
1.654\end{array}$ & $\begin{array}{l}1.648 \\
1.480 \\
2.100 \\
1.731 \\
1.750\end{array}$ & $\begin{array}{c}-0.411 \\
1.763 \\
1.865 \\
1.917\end{array}$ & \\
\hline \multicolumn{5}{|l|}{ Water W6 } \\
\hline $\begin{array}{l}1 \text { day } \\
2 \text { day } \\
4 \text { day } \\
8 \text { day } \\
11 \text { day }\end{array}$ & & $\begin{array}{l}0.978 \\
1.300 \\
1.562 \\
2.333 \\
2.261\end{array}$ & $\begin{array}{l}0.903 \\
1.162 \\
1.496 \\
1.567\end{array}$ & $\begin{array}{l}1.304 \\
1.714 \\
2.144 \\
2.333 \\
2.833\end{array}$ \\
\hline
\end{tabular}


Table 2 shows the analyses of the precipitates obtained from the experimental samples compared with those of the starting material. Both the ICP-analyzed and weighed-in compositions for this starting material are given. It is apparent from these analyses that the concentrations vary with time. We therefore plan to run one additional experiment, lasting up to $\mathbf{3 0}$ days, to ascertain whether a final equilibrium composition has been achieved.

\begin{tabular}{|l|l|c|c|c|c|}
\hline \multicolumn{7}{|c|}{ Table 2. Precipitate analyses (water W4) } \\
\hline Sample & & Na wt \% & K wt \% & Al wt \% & Si wt \% \\
\hline \multirow{3}{*}{ 1 day } & & 3.02 & 1.30 & 2.34 & 42.04 \\
2 day & & 3.10 & 1.29 & 2.58 & 41.79 \\
4 day & & 3.23 & 1.23 & 2.56 & 41.75 \\
8 day & & 2.91 & 1.69 & 2.88 & 41.42 \\
I1 day & & 2.91 & 2.01 & 3.78 & 40.44 \\
\hline \multirow{3}{*}{ Si-poor } & & 3.62 & 3.79 & 6.84 & 36.28 \\
starting & analysis 1 & 3.89 & 4.24 & 7.153 & 35.592 \\
material & analysis 2 & 3.75 & 3.86 & 7.06 & 35.98 \\
& weighed in & 3.75 & 3.96 & 7.02 & 35.95 \\
\hline
\end{tabular}

\section{B. Water-Solubility Experiments}

The solubility of water in haplogranitic melts is being determined by reversing the bivariant reaction "melt $\sim$ melt + vapor" in the same experiments as those used to determine the solubility of the melt in water. Reaction reversal is demonstrated by obtaining water-increasing and water-decreasing half reversals. A water-increasing half reversal is obtained by reacting water-undersaturated haplogranitic melt with an amount of water that is more than sufficient to saturate the melt. During the experiment, some of the "free" water dissolves in the melt. Afterwards, the vacuum extraction/manometry technique described above or SIMS analysis is used to measure the water content of the hydrous glass obtained from the reacted sample. This measurement yields a minimum solubility of water in the melt. A water-decreasing half-reversal is obtained by reacting wateroversaturated haplogranitic melt at experimental P-T conditions. During experimentation some of the water dissolved in the melt exsolves to form a separate aqueous fluid. Measuring the water content of this glass yields a maximum solubility of water in the melt.

In addition to the haplogranite experiments, we have measured the solubility of water in albitewater and albitequartz-water melts. Solubilities for albite-water melts are slightly higher than those measured by previous investigators. Data for albite-quartz-water melts indicate that: (1) $\mathrm{H}_{2} \mathrm{O}$ solubility is nearly independent of albite/quartz ratio between 740 and $800^{\circ} \mathrm{C}$, but decreases slightly with decreasing albite/quartz ratio at $900^{\circ} \mathrm{C}$; and (2) $\mathrm{H}_{2} \mathrm{O}$ solubility decreases from $\sim 55$ mole $\%$ at $740^{\circ} \mathrm{C}$ to $\sim 50$ mole $\%$ at $900^{\circ} \mathrm{C}$. These results are in good agreement with data obtained by previous investigators, except at near-eutectic temperatures, where our data indicate that water solubilities are slightly higher than those measured by earlier investigators. 


\section{Evaluation of Phase Equilibria for the System Albite-Water}

Any model of the thermodynamic properties of haplogranite melts needs to take into account the existing experimental database describing phase equilibria for haplogranites. To begin this work, and to provide a basis for the expansion of the preliminary model reported by Blencoe et al. (I 994), we are carefully re-examining data from experiments on the albite-water system. This system has been extensively investigated, and work on it dates back to Goranson (1936).

Our analysis shows that, despite the amount of research completed, the system is, in fact, very poorly known. In the dry system neither the reversed experimental data, nor the thermodynamic data, strongly constrain the melting of albite as a function of pressure and temperature. We have derived new thermodynamic data for this reaction, including realistic uncertainties for the various parameters.

Re-examination of hydrous phase relations in the albite-water system has further pointed out the need for reversed experiments, of which there are very few in the literature. Many of the apparent inconsistencies amongst various experimental data sets disappear when only carefully reversed data are considered. Unfortunately, as in the case of the water-free system, this evaluation shows that our knowledge of this system is far poorer than is commonly believed. Our work on the hydrous part of this system was reported this year at the spring meeting of the American Geophysical Union (Anovitz and Blencoe, 1997a). A first draft of a manuscript on the dry melting of albite has been completed, and is currently undergoing pre-submission revisions.

\section{Measurement of the Chemical Potential of Water in Haplogranitic Melts}

Two experimental methods have been developed to measure $\mu_{\mathrm{H} 2 \mathrm{O}}-\mathrm{X}_{\mathrm{H} 2 \mathrm{O}}$ relations for hydrous haplogranitic melts: the "mixed-volatile" and "controlled- $f_{\mathrm{H} 2 \mathrm{O}}$ " methods (Blencoe and Anovitz, 1995). Each permits quantification of the chemical potential of water $\left(\mu_{\mathrm{H} 2 \mathrm{O}}\right)$ in an aqueous fluid coexisting with melt (mixed-volatile method) or dissolved in the melt (controlled- $f_{\mathrm{H} 2 \mathrm{O}}$ method). In mixed-volatile experiments, an aqueous fluid containing an "inert" diluent gas $\left(\mathrm{CO}_{2}, \mathrm{~N}_{2}\right.$ or Xe) reacts with hydrous melt, causing the water content of the melt to change. After experimentation the masses of water and gas in the fluid are determined manometrically, and the mass of water in the quenched melt measured by vacuum extraction/manometry. The resulting data yield values for $\mu_{\mathrm{H} 2 \mathrm{O}}$.

In controlled- $f_{\mathrm{H} D \mathrm{O}}$ experiments, the oxygen fugacity $\left(f_{\mathrm{O} 2}\right)$ in each sample is set by an internal oxygen buffer (Ni$\mathrm{NiO}$ ), and hydrogen fugacity $\left(f_{\mathrm{H} 2}\right)$ is fixed by controlling the concentration of $\mathrm{H}_{2}$ in the $\mathrm{Ar}-\mathrm{H}_{2}$ gas surrounding the samples. During experimentation mass transfer of $\mathrm{H}_{2}$ occurs across the wall of each $\mathrm{Pt}$ or Ag-Pd capsule. Depending on the P-T- $f_{\mathrm{O} 2}-f_{\mathrm{H} 2}$ conditions and the initial water content of the melt, water is either generated or consumed by the reaction $\mathrm{H}_{2}+\mathrm{NiO} \sim \mathrm{Ni}+\mathrm{H}_{2} \mathrm{O}$, and the water content of the melt is measured after the experiment. An experimentally based value for $f_{\mathrm{H} 2}$ is obtained by measuring the pressure of hydrogen in the membrane (Shaw, 1963; Shaw and Wones, 1964).

In both types of experiments, data will be collected at closely-spaced $\mathrm{X}_{\mathrm{H} 2 \mathrm{O}}$ intervals, and anhydrous bulk compositions selected to ensure that the thermodynamic mixing properties of the melts are determined accurately for a wide range of silicate compositions. These experimental strategies are essential because the measured thermodynamic mixing properties of water in the melts are needed to calculate the thermodynamic mixing properties of the silicate components. 


\section{FUTURE PLANS}

The immediate future goals of our research are to continue our work on the mutual solubility of haplogranite melt and water, and to complete our evaluation of the albite-water system. Our research on the composition of aqueous fluid coexisting with haplogranitic melt has emphasized analysis of experimental data obtained at $950^{\circ} \mathrm{C}$, 2500 bars. Future work in this research area will emphasize analysis of data obtained from melt-fluid experiments performed at $\mathrm{T}<950^{\circ} \mathrm{C}, 2500$ bars, and $800 \leq \mathrm{T}\left({ }^{\circ} \mathrm{C}\right) \leq 1000, \mathrm{P}<2500$ bars. Time permitting, we will also begin testing the method outlined in section (D) for measuring the chemical potential of water in haplogranitic melts.

\section{INDUSTRY INTEREST}

To perform our research, we have developed laboratory techniques for acquiring highly precise and accurate data on the volatile contents and bulk chemical compositions of very small masses of aluminosilicate material. These methods have numerous potential practical applications in geothermal R\&D. We have started reporting the results of our work at technical meetings (Anovitz et al., 1995; Anovitz and Blencoe, 1997b). After further refinement, the methods will be described in detail in articles written for leading geochemical journals. Researchers and technologists interested in the progress of our research are encouraged to contact us for further information.

\section{REFERENCES}

Anovitz L. M., Blencoe J. G., Horita J., and Cole D. R., 1995, An Experimental Method for Determining Compositions of Aqueous Fluids Coexisting with Silicate Melts. U.S. Geol. Surv. Circ. 1129, p. 10-1 1.

Anovitz L. M. and Blencoe J. G., 1997a, Re-analysis of the albite-water system. EOS.

Anovitz L. M. and Blencoe J. G., 1997b, Experimental determination of the compositions of aqueous fluids coexisting with silicate melts. GSA Abst. w. Prog. 29, A394.

Blencoe J. G. and Anovitz L. M., 1995, Methods for Determining the Thermodynamic Mixing Properties of Hydrous Haplogranitic Mefts: Progress, Problems and Prospects. U.S. Geol. Surv. Circ. 1 129, p. 24-25.

Blencoe J. G., Anovitz L. M., Joyce D. B. and Burch T. E., 1994, A new thermodynamic model for albitewater melts, Eos, v. 75, p. 693.

Goranson R. W. (I 93 6) Silicate-water: the solubility of water in albite melt. Amer. Geophys. Union Trans. 17, 257-259.

Thinger P. D., Hervig R. L. and McMillan P. F., 1994, Analytical methods for volatiles in glasses, in Carroll M. R. and Holloway J. R. (eds), Volatiles in Magmas (Reviews in Mineralogy, Volume 3 0), 67-12 1, Mineralogical Society of America, Washington, D.C.

Shaw H. R, 1963, Hydrogen-water vapor mixtures: Control of hydrothermal atmospheres by hydrogen osmosis, Science, 139, 1220-1222.

Shaw H. R, and Wones D. R, 1964, Fugacity coefficients for hydrogen gas between 0 and 1000 C, for pressures up to $3000 \mathrm{~atm}$, Amer. J. Sci., 262, 918-929. 


\title{
MT/CSAMT ELECTRICAL METHODS RESEARCH
}

\author{
Philip E. Wannamaker and John A. Stodt \\ Energy \& Geoscience Institute (EGI) \\ University of Utah
}

\section{KEY WORDS \\ electromagnetics, magnetotellurics, CSAMT, instrumentation, algorithms \\ PROJECT BACKGROUND AND STATUS}

EGI (formerly UURI) has maintained a long-term (over 15 years) effort devoted to upgrading MT data acquisition and interpretation, and has received support from the Department of Energy (DOE) and the National Science Foundation (NSF) for this effort. EGI has developed and field-tested a wideband MT system which includes simultaneous, dual-site measurement utilizing digital FM telemetry and coherence-based data quality sorting in real time. In addition to defining a platform for instrumentation research, our MT system has been intended as insurance against the often fragile stability of MT contractors in the unsteady petroleum and geothermal exploration markets.

Our research group also has taken a lead role in the development of more efficient and accurate algorithms for interpreting electrical and electromagnetic (including MT/CSAMT) data for the geothermal, petroleum and mining industries. Particular emphasis, has been placed on developing two-dimensional (2-D) finite element and three-dimensional (3-D) integral equations methods for modeling and inversion, but 1-D methods remain useful and have been advanced also. Finally, we have provided new understanding of the relationship of resistivity models to structure and physico-chemical state in the Earth as a result of the large, field-based component of our research.

The anticipated benefits of this research are reduced drilling costs (through increased drilling success) and better evaluation of reservoir potential which reduces front end costs and facilitates better plant design. Reduced exploration costs and environmental impact stimulates regional-scale exploration which will also facilitate integrated planning for power lines and markets. We estimate an additional power-on-line of $500 \mathrm{MW}$ and an additional 200 acres of greenhouse development could be achieved by the year 2010 within the Basin and Range and Southern Rio Grande Rift if significant cost and risk reduction could be achieved. Electrical geophysical advances by EGI and UURI are implemented by many users worldwide.

EGI at the University of Utah has achieved state-of-the-art in MT field instrumentation but seeks new advances in data acquisition efficiency and field noise reduction. Instrumentation concepts to this time have proven highly successful based on survey results in diverse environments. Both $2-D$ and 3-D numerical interpretation developments are producing structural interpretations with detail and reliability not achieved in the recent past. We will continue research which incorporates a significant component of field data acquisition from other funding sources because this has been very instructive as to interpretation needs.

\section{PROJECT OBJECTIVES}

The general objectives of this project are to improve the methodology and interpretation of electrical geophysical techniques by making them more accurate, more efficient, and easier to implement so that they will be available 
for increased use by the geothermal industry and researchers. EGI has chosen to address the magnetotelluric (MT) method and its controlled source analog CSAMT, in particular, because of their importance in geothermal exploration.

\section{Technical Objectives}

- Improve interpretation of MT/CSAMT data through new algorithm development and response characterization.

- Improve the quality of MT field data through improved instrumentation and field techniques.

- Demonstrate the improved capabilities of MT and CSAMT through carefully selected field studies.

\section{Expected Outcomes}

- Demonstrate improved data quality and structural resolution.

- Increase use of the MT/CSAMT techniques by industry, which will result in large savings in exploration and drilling costs.

\section{APPROACH}

EGI will continue to concentrate on the development of electrical geophysical techniques since they have broad applicability to mapping geothermal resources on both regional and detailed scales. EGI will continue to test existing methods, to improve techniques and equipment for gathering field data, and to improve interpretation algorithms and computer codes. Integrated geoscience interpretations will provide additional insight into these methods. Field surveys in varying field conditions identify method limitations and practical resolution limits. DOE research support for instrumentation and algorithm development has been complemented strongly by NSF support for MT field programs which test the method.

\section{RESEARCH RESULTS}

The year 1997 to a large degree was devoted to electrical geophysical research supported by the NSF, but these have substantial overlap with DOE/GT interests and complement the DOE-supported components. Significant progress has been made in the areas of MT field instrumentation, 2-D and 3-D numerical analysis methods, and in interpretation methodology for the CSAMT technique. These will be detailed below in turn.

\section{Magnetotelluric Instrumentation}

We are in the process of redesign of our MT system to incorporate improvements made feasible by new technology, and to replace our aging system with new hardware to improve both performance and reliability in the field (Figure 1). Our goals and plans have not changed fundamentally from those discussed in the 1996 year-end report. Briefly, they were to incorporate use of $24 \mathrm{bit} A / \mathrm{D}$ converters, provide simultaneous low- and mid- band data acquisition through separately optimized analog data paths, provide a subsystem for concurrent high frequency data collection, increase the overall system bandwidth, decrease power consumption and size, provide for synchronization via GPS timing, provide a data logging mode, provide integrated system calibration, and improve digital radio telemetry for both faster and longer range communications. An additional part of the planning for this new system is to migrate from our current obsolete DESQview operating system environment 
to the Windows 95 environment for near real-time control and data processing tasks, to provide a long term software upgrading path. Progress towards our goals in 1997 was achieved in the following areas.

Samples of Burr-Brown's 24 bit A/D converter were obtained and tested for noise floor and cross-talk performance; this part performs exceptionally well and has been selected as the converter to implement low- and mid-band data acquisition paths. High frequency data ( $>100 \mathrm{~Hz}$ or so ) could be acquired more accurately with a different product, although 20 bit accuracy can still be achieved up to sample rates of $1 \mathrm{Khz}$. We will make a final decision on a converter for high frequency data collection when we finalize the design of the high frequency subcomponent of the system. Analog designs have been developed to condition MT signals separately and allow simultaneous mid- and low-band data acquisition, using the Burr-Brown A/D. We are still exploring design approaches for high-frequency data acquisition, and for interfacing to recently designed existing equipment.

Simultaneous data acquisition across multiple bands requires increased systems communications bandwidth and processing capability. We have identified a new embedded controller for overall system control, and a microprocessor for individual channel cards to interface between the A/D converters and the system controller. We are designing an interface using the ECP parallel port specification, to provide adequate internal system communications bandwidth. The ECP interface will be implemented in a Field Programmable Gate Array (FPGA), along with other system logic tasks. We are exploring products from Motorola, and also recently from Altera, to implement this interface. Data logging capabilities will be implemented with the embedded system controller, with storage most likely provided through a PCMCIA interface using Flash Disk PC cards.

We have identified and acquired GPS timing hardware to implement timing synchronization via the GPS IPPS pulse. The equipment we have acquired provides the ability to synchronize to within $100 \mathrm{nS}$, which means we can maintain phase accuracy in recordings from different sites to within a degree, up to approximately $25 \mathrm{khz}$. This equipment provides capability for self-contained site synchronization, a necessary capability for effective implementation of a data logging mode of opcration. We have also identified and acquired new radio/modems which promise both increased operating range and data communications rates. We will integrate these into our system to provide increased capability for our near real-time operations using digital radio communications.

Some additional effort was expended this past year to maintain our current MT system. Specifically, connecter interfaces and wiring harnesses were reworked in the last of our three existing MT system controller units, and radio/modem malfunctions were diagnosed and repaired. The overhall of the third system controller was similar to work performed on our other two system controllers in 1996, which has greatly improved the reliability of the system for the near term.

\section{Magnetotelluric Surveying}

Finalized and published this year were two papers on crustal structure, deep thermal state and geothermal significance of the central and eastern tectonic subprovinces of the Great Basin (CGB and EGB). Wannamaker et al. (1997a) established the importance of non-thermal crustal structures in defining the conductivity of the upper crust in the eastern Great Basin. Specifically, graphitized organic sediments, deformed during both overthrust and extensional orogeny, dominate the high conductivity regions at these levels. The apparent uniformity of the deep crustal conductor over regional distances implies that it holds relatively little value for anything but the most broad-scale; reconnaissance exploration for geothermal resources. MT perhaps is more fruitfully applied later in the exploration sequence for more detailed structural imaging. Wannamaker et al. (1997b) compared deep thermal states of the quiescent CGB with the active EGB of western Utah. The EGB shows a thick, high-conductivity layer in its lower crust correlated with high temperature brines and partial melt over regional distances. In contrast, the lower crust of the CGB is less in conductance by at least a factor of four 
and the conductor lies deeper. The latter results are consistent with fluid percolation models where fluid input from basaltic underplating ceased about $10 \mathrm{Ma}$ when CGB rifting subsided, but is still active under the EGB today.

Field surveying was de-emphasized this year in favor of analysis of existing data sets. Our work in the central and eastern Great Basin has just been described. Also, under NSF support; our MT transect of the New Zealand Southern Alps has been modeled in a preliminary fashion. A spectacular deep crustal conductor develops beneath the area of maximum, present-day crustal thickening, presumably due to prograde fluid release (Davey et al., 1996; Stern et al., 1996). We have just received word from the NSF that our followup proposal to close the 30 km data gap through the high Alps is going to be funded. Moreover, on November 10, 1997, Wannamaker, Stodt and coworkers depart to attempt an MT transect of South Pole station, Antarctica, under NSF/OPP funding. This was funded in large part due to our collection of high-quality results previously from central West Antarctica, the first ever from that continent's interior. These are examples where our leveraging DOE-supported instrumentation research with non-DOE funding for field programs has been an effective means of proving system performance.

Wannamaker completed a paper on the current understanding of the EM induction community on the causes of crustal conductivity in thermal regimes and their ancient analogues. This paper is written as a comment on the recent publication "The petrologic case for a dry lower crust" by B. Yardley and J. Valley, J. Geophys. Res., June, 1997. The petrological discussion, the essence of which is the impossibility of crustal conductors being due to fluids in typical crustal compositions, is a seriously flawed and outdated representation of the current state of knowledge of EM researchers. Specifically, probable temperatures for the whole suite of conductivity models are far from uniform and this should be considered when advocating conductivity mechanisms (e.g., Figure 2). Second, the conductivity structure of older, stable regimes can be highly variable laterally even though lateral temperature variations appear quite small. Finally, deep conductive zones in regions long stable are largely, perhaps mostly, in rocks of brittle or semi-brittle rheology and appropriate mechanisms deserve greater consideration.

Wannamaker is being forwarded final hardcopy proofs (galleys) for an invited paper for publication in the SEG Investigations in Geophysics series (Wannamaker, 1997a). This was an outcome of the First International Symposium on Three-Dimensional Electromagnetics hosted by Schlumberger-Doll Research in Ridgefield, CT, in October of 1995. The paper is entitled "Magnetotelluric surveying one can afford: interpretation of MT profiling data from natural environments". The subject matter addresses the need for adequate sampling of the MT response both in space and frequency, but balanced by the need for the data to be reliably interpretable and affordable. Included in the paper is a new, 3-D interpretation of the Long Valley MT profile taken several years ago by our group and displayed in last year's annual report. Finite strike extents for both shallow caldera conductors and the mid-crustal conductor under the west moat were suggested in our original interpretation, and this has now been verified through explicit 3-D simulations using our own integral equations code.

\section{Algorithm Development}

The implementation of the adjoint method (reciprocity) in obtaining parameter sensitivities (Jacobians) for the 2-D MT/CSAMT inversion problem programmed by former graduate student P. P. de Lugao (de Lugao and Wannamaker, 1996) has been completely reworked by Wannamaker. The adjoint approach is necessary for regularized or minimum-structure inversion to curtail spurious model structure not demanded by the field data. The approach reduces the computational need for these derivatives to about the price of the original forward problem, rather than several tens of forward problems, which has been required by existing perturbational approaches. The new pertinent sections of the code are about one-third the original length, have undergone top- 
down, structured programming, bugs removed, and accuracy verified for both first and second-order auxiliary field derivatives, and for topography and bathymetry. Results compare exactly with the original perturbation approach and within 1-2\% with finite differencing of similar forward problems. It is programmed within the framework of program PW2D, which we have distributed literally hundreds of copies of, and which is the computational engine for the state-of-the-art Occam-2 minimum structure inversion code. Occam-2, however, utilizes the older perturbation method of derivatives. Furthermore, Wannamaker derived a regularization mesh for defining the inverted resistivity distribution in the Earth whose elements (pixels) grow both laterally and vertically with depth. This preserves pixel influence on the response at the surface, thereby improving the condition of the parameter inverse matrix and substantially speeding its solution.

This year, Wannamaker continued development of our 3-D integral equations algorithm for simulating EM responses from diverse sources such as MT, CSAMT, dipole-dipole resistivity, and central loop and short-offset loop-loop EM calculations including airborne and downhole EM arrays (Wannamaker, 1995; Figure 3). The integral equations algorithm has formed the basis for time-domain simulations and rapid approximate solutions at the University of Arrhus (Denmark) and University of California at Berkeley. It has been used in modeling of MT and CSAMT field data sets from Long Valley (in press) and Valles Caldera (published, below). In particular, he implemented the localized non-linear approximation (LNLA) into the code to handle large, complex structures quickly with good accuracy. This approximation is based on original work by $\mathrm{T}$. Habashy at Schlumberger-Doll Research (Habashy et al., J. Geophys. Res., 1993). The approximation was cast into a classic method-of-moments (MOM) description used for numerical simulations generally. This revealed that the LNLA treats the entire body as a single pulse basis function, with point matching carried out sequentially at the locations of each individual cell. Comparison between the LNLA and a full solution over a simple prism structure with an offset loop source is shown in Figure 4.

\section{CSAMT Research}

This year saw publication of Wannamaker's two-part paper on tensor CSAMT surveying of the Sulphur Springs thermal area, Valles caldera, NM, in Geophysics (Wannamaker, 1997b, c). Data acquisition was funded by DOE/OBES but much of the interpretation has been supported by DOE/GD. Two-dimensional modeling of the plane-wave regime CSAMT data augmented by sparse MT soundings and layered-earth, tensor CSAMT inversion was carried out for four data profiles. Modeling revealed that almost all fault displacement in the area lies on the NE-trending Sulphur Creek fault. Toward the SE side of the prospect, surveying also discovered a major, down-to-SE normal fault here named the Redondo Border fault. No especially high resistivities are associated with an inferred shallow vapor zone in the thermal area. Existing MT soundings and the resistivity model allowed us to understand controlled-source effects in the CSAMT data using our 3-D interpretation methods (Wannamaker, 1997c). In short, if the thickness of conductive sediments in skin-depths exceeds the transmitter-receiver separation in resistive basement skin-depths, then one cannot obtain plane-wave regime information about structures in the basement, due to near-field behavior. When heterogeneity is important, significant departures between scalar and tensor CSAMT data can be expected, and are exacerbated when the source field is poorly coupled to the sensors.

Wannamaker presented a review paper on imaging of earth structure using controlled source planar EM waves at the Symposium on Underground Imaging using longwave electromagnetic fields, sponsored by the United States Air Force and Phillips Laboratories. The Valles Caldera data set also has been donated to the student research program of the Consortium for Electromagnetic Modeling, directed by Prof. M. Zhdanov of the Dept. of Geology and Geophysics. There, some methods from the Soviet school of EM forward modeling and inversion will be applied for comparison with models derived in Wannamaker (1997b, c). Finally, Wannamaker served on the M.S. committee of Carl Nettleton of San Diego State University, who successfully defended this month. 
The thesis was entitled "Magnetotelluric modeling of the Valles Caldera, New Mexico". Forty-one MT soundings donated by Unocal (arranged by Wannamaker) or collected in the SAGE program were modeling using 2-D smooth inversion and some simple 3-D forward models. Inversion suggests a deep crustal conductor dipping to the west follows the pattern of projected crustal isotherms from heat flow data. Upper crustal structure of the caldera is complex, but the regional trends follow more closely that of the Rio Grande Rift (N-S) than that of the Jemez Lineament (NE-SW). No particular conductor associated with the resurgent Redondo Peak was resolved, but this may be due in part to limited sampling and the need for 3-D modeling.

\section{FUTURE PLANS}

A letter of recommendation for funding from NSF/EAR/IF has been received to establish the University of Utah/EGI as a national instrument facility for MT, in cooperation with the University of Washington and the University of California at Riverside. This award will substantially complement DOE/GT support for instrumentation support at EGI by providing multiple site modules and incorporating our high-impedance electrometer design into a modernized overall platform. Joining the facility, to be maintained and operated by us under NSF support, will be three, five-channel MT-24 units made by EMI, Inc., and twenty long-period MT recorders for deep crust and upper mantle surveying made by Phoenix Geophysics.

We will continue to maintain older hardware to address upcoming projects in the interim until new hardware can be brought online. Our goals remain the same as last year's, namely to provide and maintain state-of-the-art research MT instrumentation with unique capabilities not available in the commercial market, even from the new generation of $24 \mathrm{bit}$ MT systems now entering the marketplace. Our capability to handle high impedance environments is unmatched, as is our unique combination of digital data telemetry and near real-time robust data reduction, which provides an operator the feedback necessary to actively optimize data acquisition in the fickle MT measurement environment.

With completion of the adjoint method for parameter sensitivities, we will produce a new regularized, 2-D inversion algorithm for MT/CSAMT data profiles. At present, we prefer regularization with apriori models because it allows ready incorporation of constraints. Three-dimensional model development will include improved high-frequency simulation as well as time-domain modeling through a discrete Fourier transform technique. We intend to pursue the local non-linear approximation introduced by $\mathrm{T}$. Habashy as the basis of an iterative, accurate solution for modeling and inversion of large data sets and structures. The LNLA will be cast in the classic method-of-moments framework and related to the Galerkin technique of estimating the unknown scattered field quantities.

\section{INDUSTRY INTEREST}

\section{Organization(s)}

National Science Foundation

Unocal - Geothermal Division, Trans-Pacific Geothermal

Mining, Petroleum and Geothermal Research Consortium, U. of Utah

\section{Type and Extent of Interest}

Crustal-scale MT surveys; MT equipment upgrades

MT/CSAMT interpretation and equipment

MT/CSAMT and finite-source EM interpretation 


\section{REFERENCES}

Davey, F. J., Henyey, T., Holbrook, W. S., Okaya, D., Stern, T. A., Eberhart-Phillips, D., McEvilly, T., Urhammer, R., Anderson, H., Jiracek, G. R., Wannamaker, P. E., Caldwell, G., and Christiansen, N., 1997, Preliminary results from a geophysical study across a modern, continent-continent collisional plate boundary the Southern Alps, New Zealand: Tectonophysics, Special Issue on VIIth Int. Symp. Deep seismic profiling of the continents, in press.

de Lugao, P. P., and Wannamaker, P. E., 1996, Calculating the two-dimensional magnetotelluric Jacobian in finite elements using reciprocity: Geophys. J. Int., 127, 806-810.

Mareschal, M., R. L. Kellett, R. D. Kurtz, J. N. Ludden, S. Ji, and R. C. Bailey, 1995, Archean cratonic roots, mantle shear zones and deep electrical anisotropy: Nature, 375, 134-137.

Stern, T. A., Wannamaker, P. E., Eberhart-Phillips, D., Okaya, D., Davey, F. J., and the South Island working group, 1997, Crustal Structure experiments across the Southern Alps of New Zealand: EOS Article, Trans. AGU, $78,329,335-336$.

Wannamaker, P. E., 1995, EMIE3D-v2.1: algorithm for integral equations modeling of electromagnetic responses of three-dimensional earth structure: Program documentation, report to Consortium for Electromagnetic Interpretation, University of Utah, 62 p.

Wannamaker, P. E., J. A. Stodt, and S. L. Olsen, 1996, Dormant state of rifting in Byrd subglacial Basin, central west Antarctica, implied by magnetotelluric profiling: Geophys. Res. Lett., 23, 2983-2986.

Wannamaker, P. E., 1997a, Magnetotelluric surveying one can afford: interpretation of MT sounding profiles from natural environments, in Three-dimensional electromagnetics, ed. by M. Oristaglio and B. Spies, Soc. Explor. Geophys., Invest. Geophys., Tulsa, in press.

Wannamaker, P. E., 1997b, Tensor CSAMT survey of the Sulphur Springs thermal area, Valles Caldera, New Mexico, Part I: implications for structure of the western caldera: Geophysics, 62, 451-465.

Wannamaker, P. E., 1997c, Tensor CSAMT survey of the Sulphur Springs thermal area, Valles Caldera, New Mexico, Part II: implications for CSAMT methodology: Geophysics, 62, 466-476.

Wannamaker, P. E., Johnston, J. M., Stodt, J. A., and Booker, J. R., 1997a, Anatomy of the southern Cordilleran hingeline, Utah and Nevada: implications from deep electrical resistivity profiling: Geophysics, 62, 1069-1086.

Wannamaker, P. E., W. M. Doerner, J. A. Stodt, and J. M. Johnston, 1997b, Subdued state of tectonism of the Great Basin interior relative to its eastern margin based on deep resistivity structure: Earth Planet. Sci. Lett., 150, 41-53.

Wannamaker, P. E., 1997, Comment on "The petrologic case for a dry lower crust", by Yardley, B. W. D., and Valley, J. W., J. Geophys. Res., 102, 12,173-12,185, 1997. 


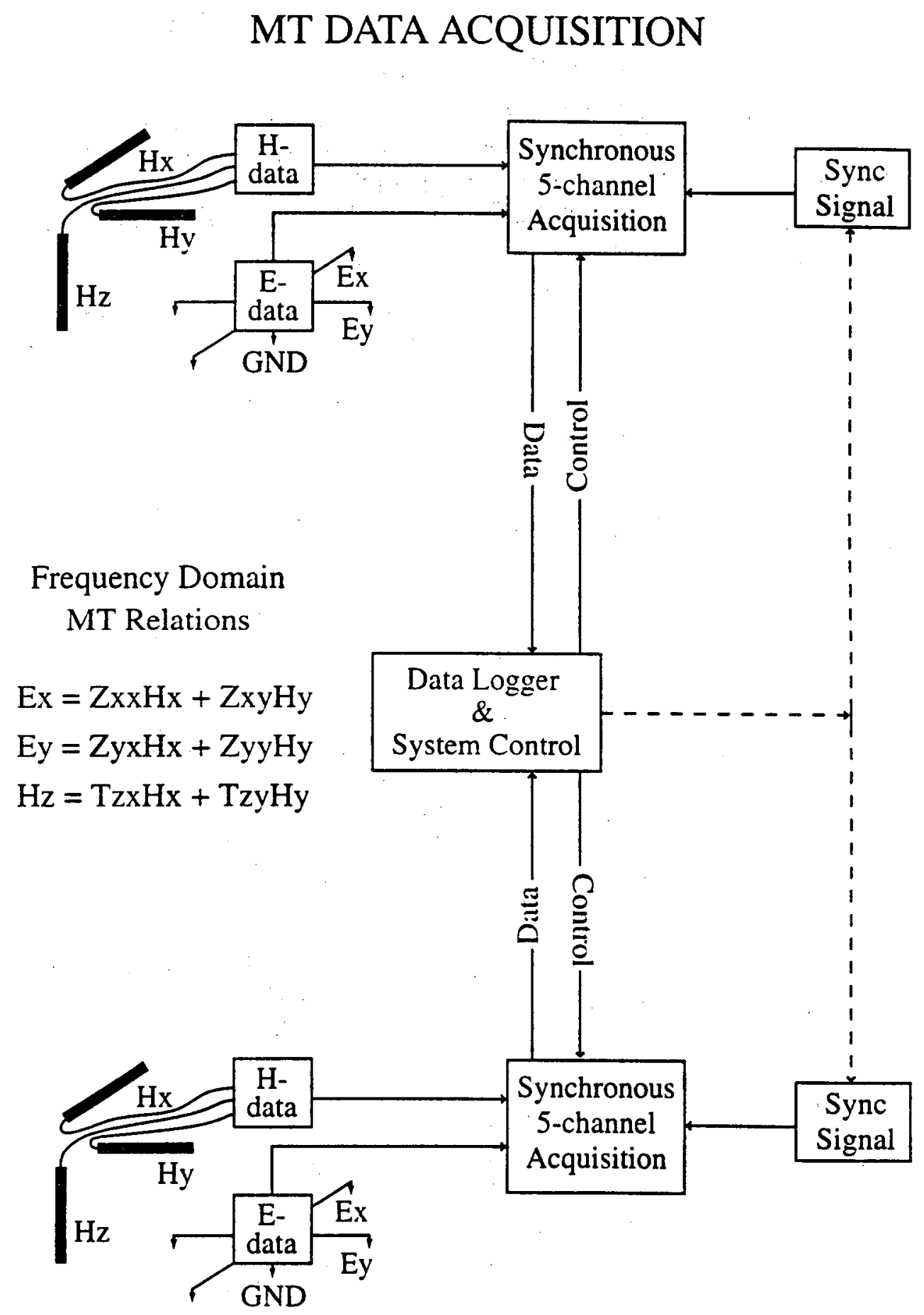

Figure 1 - Key elements of present MT field system design. Current efforts included consolidation of function modules given newer components and the simultaneous acquisition of mid-and low-band data. 


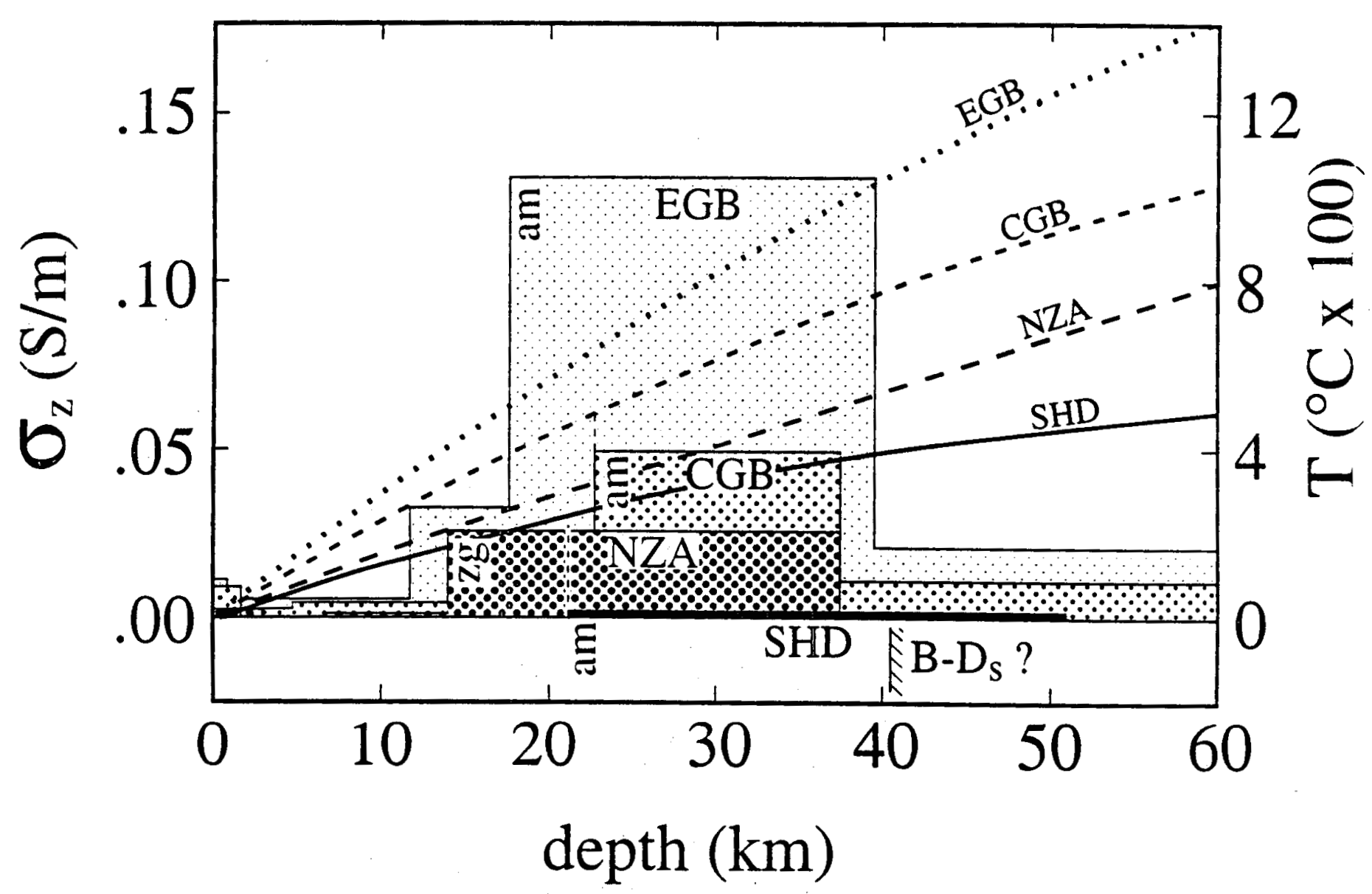

Figure 2 - Sample conductivity profiles from diverse tectonic environments derived using MT measurements, compared to coincident geotherms computed from surface heat flow and thermal models. Regimes include the extensional eastern and central Great Basin areas (EGB and CGB; Wannamaker et al., 1997a,b), the New Zealand Southern Alps (Stern et al., 1997; Davey et al., 1997), and the Pontiac Archean terrane (Mareschal et al., 1995). Horizontal dashed lines connect the New Zealand and Archean conductor tops with their geotherms for clarity. 


\section{Electromagnetic Modeling Using Integral Equations}

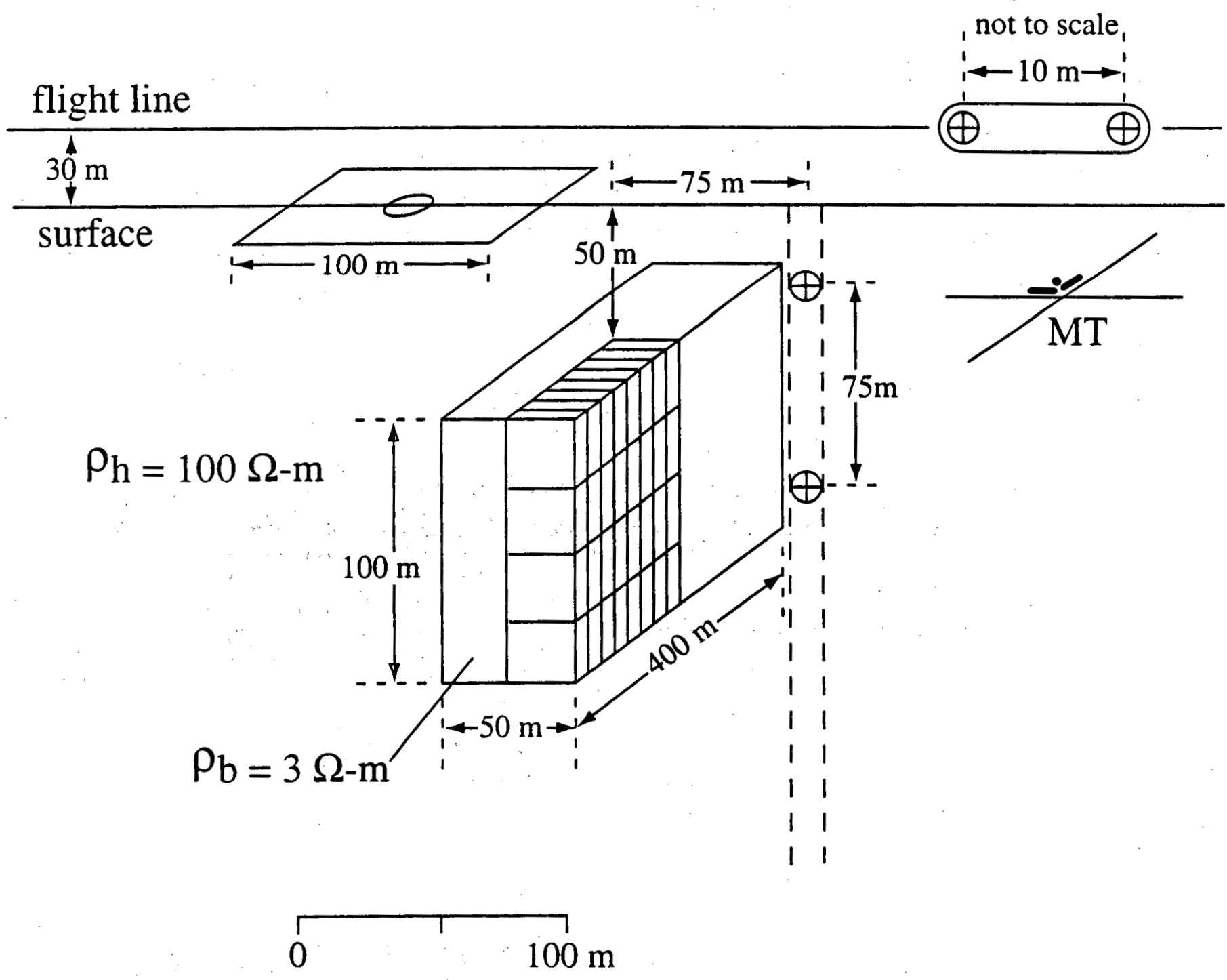

Figure 3 - Schematic depiction of multi-source modeling capability with integral equations code. This code has capability for MT, CSAMT, dipole-dipole resistivity/IP, central loop, and short-offset airborne and downhole arrays. 

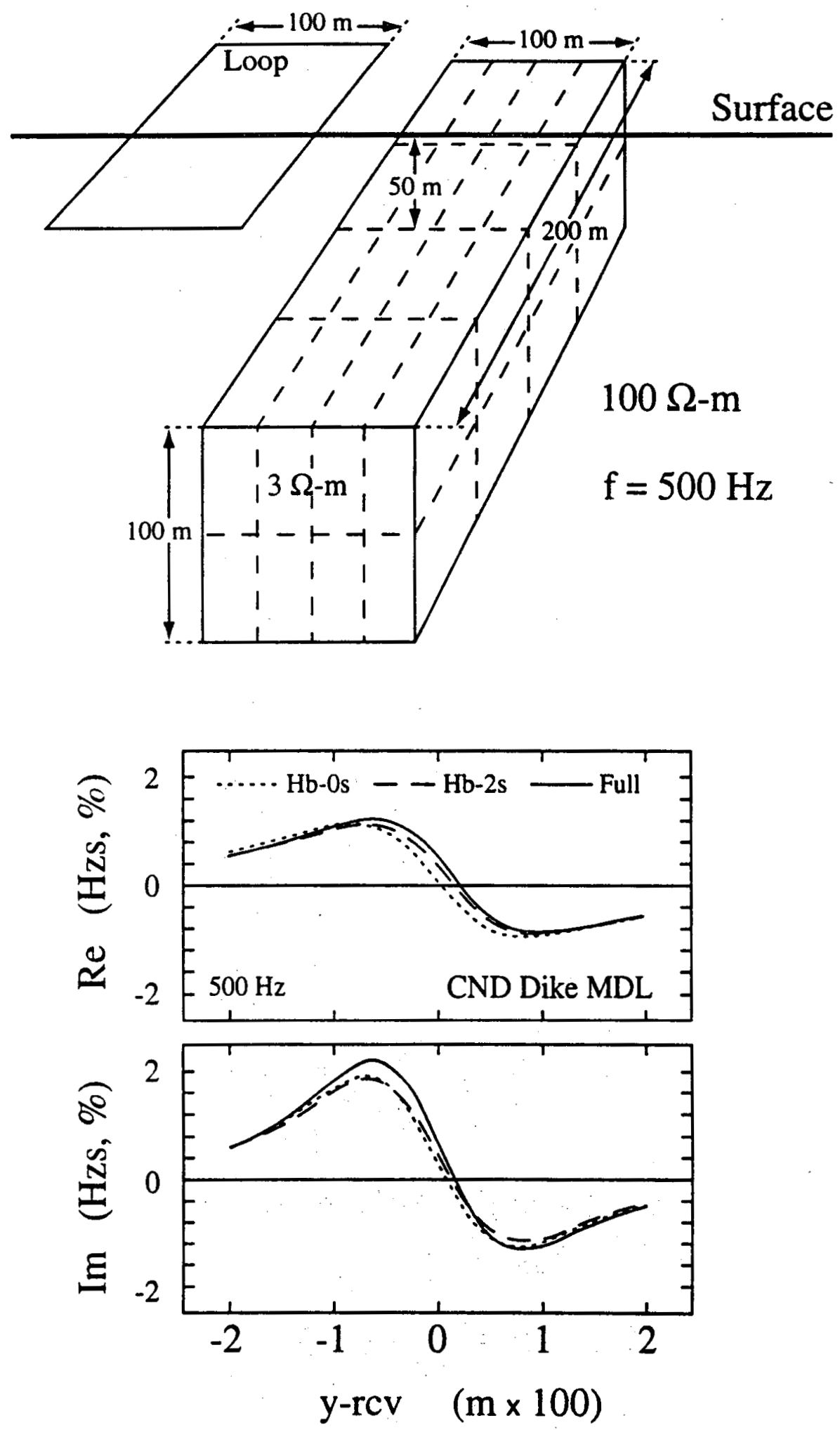

Figure 4 - Simple, prismatic conductor in a resistive half-space (left) simulated for offset horizontal loop source at $\mathrm{f}=500 \mathrm{~Hz}$ (right). Solid curves are full I.E. solution, short dashes are LNLA for arbitrary geometries, and long dashes are LNLA assuming two planes of symmetry in the body. 


\title{
SP MODELING
}

\author{
Alan C. Tripp and Howard P. Ross \\ Energy \& Geoscience Institute ( EGI) \\ University of Utah
}

\section{KEY WORDS \\ self-potential, geophysics, numerical modeling \\ PROJECT BACKGROUND AND STATUS}

The spontaneous potential (SP) method measures the electrical manifestation of primary flows, such as heat flow or fluid flow. As such, it has been often mentioned as a method of detecting or monitoring geothermal systems. One problem with such applications is that interpreting SP data has always been daunting due to the number of degrees of freedom in the SP interpretation problem and to the scarcity of versatile numerical interpretation algorithms.

Investigation of three-dimensional modeling of SP data was initiated at EGI in the Spring of 1996. An initial effort concentrated on using the approach of Sill ( 1982) with a fully three - dimensional electrical modeling code. The objectives of this phase were to test our understanding of the Sill approach to SP modeling and to modify a suitable 3D electrical code to accept equivalent sources at depth. The code used was an integral equations algorithm, originally described by Hohman (1975). The research effort mainly involved reviewing Sill's approach, placing the equivalent electrical sources at depth, and developing appropriate presentations for the subsequent potentials. This phase was completed during the last fiscal year, with the successful generation of SP responses to 3D flows such as those examined by Sill.

Sill ( 1982) illustrated his equivalent source concept using a parameterized 2D convection model originally suggested by Combarnous and Bories (1975). Although such parameterized models are useful in illustrating concepts and might find a use in interpretation of SP data, a consideration of them alone cannot provide the insight into the SP response which was one of the primary objectives of the SP modeling project. To provide this insight, a much more general algorithm for calculating flows is needed. Since cross-coupling coefficients are necessary for generating the SP response, it is essential to understand their range and functional dependence on reservoir parameters. Subsequent efforts have concentrated on achieving the capability of computing general flows and in understanding linkage of cross-coupling coefficients and reservoir parameters.

Since any approach to SP modeling depends on a realistic estimation of the cross-coupling coefficients, an initial effort in FY 97 was a review of the cross-coupling literature and a compilation of existing pertinent data. Both review and data compilation have been summarized in a draft document (Tripp and Ross, 1997). This document has been subjected to internal review and figures are now being drafted.

Flow modeling for complex geometries will depend on two general flow modeling packages. The first is TOUGH2 , discussed, for example, in the proceedings of the TOUGH ' 95 Workshop (1995) and by Pruess (1991). The second is an algorithm discussed by López and Smith $(1995 \mathrm{a}, \mathrm{b})$. Both of these packages are written in Fortran. The López - Smith algorithm has been placed on a Pentium II platform with a Windows NT operating system. The algorithm has been compiled successfully and will be used for SP modeling of fault 
controlled flow. A test of this algorithm in the context of SP modeling will involve modeling the SP data gathered over the Newcastle system as an example of the SP response of a forced convection system.

We are also working on a paper which presents a theoretical and numerical discussion of the SP response of a free convection system, including boiling at depth.

\section{PROJECT OBJECTIVES}

\section{Technical Objectives}

- Demonstrate the applicability of the Sill approach to SP modeling for 3D geothermal flows.

- Perform a critical review of the cross-coupling literature, emphasizing functional relationships between the coefficients and reservoir properties.

- Assemble a collection of 3D flow modeling algorithms for generating equivalent electric sources for substitution into the 3D electrical algorithm. Place these algorithms on a PC platform.

- Model SP data over geothermal reservoirs using 3D algorithms.

- Investigate theoretically and numerically the use of SP for reservoir description.

\section{Expected Outcomes}

- Technical outcomes should be equivalent to technical objectives.

- The practical outcome of this research should be an increased level of appraisal and use of SP on the industrial level for reservoir detection, delineation, and description.

\section{APPROACH}

The technical approach has been outlined in the Background and Status section above.

\section{RESEARCH RESULTS}

A compilation of cross-coupling coefficients has been completed and forms the basis of a critical review, now in revised draft form.

A collection of 3D coupled flow algorithms has been assembled. An algorithm written by López and Smith has been placed and compiled on a Pentium II platform.

A theoretical analysis of the SP response of a freely convecting boiling system has begun.

Numerical modeling of SP data gathered over the Newcastle geothermal system has begun. 


\section{FUTURE PLANS}

Future plans include the following: Complete Newcastle modeling and prepare publication; Complete free convection paper; Send cross-coupling compilation paper to a journal; Identify and interpret other SP data sets over geothermal systems. At least one data set should be over a system with a steam cap. The Cove Fort data set has been considered for interpretation.

\section{INDUSTRY INTEREST}

All Fortran software used in the project will be placed on a Pentium II platform under a Windows NT operating system, and hence will be readily usable by industry.

All research is to be discussed in relevant industry and technical journals.

Active involvement of industry in identifying applications of SP in reservoir description and delineation is sought.

\section{REFERENCES}

Combarnous, M.A. and Bories, S.A., 1975, Hydrothermal convection in saturated porous media: in Advances in Hydroscience, 10, ed. V.T. Chow, Academic Press.

López, D.L. and L. Smith, 1995a, Fluid flow in fault zones: Analysis of the interplay of convective circulation and topographically driven groundwater flow: Water Resources Research, 31, 1489 - 1503.

López, D.L. and L. Smith, 1995b, Fluid flow in fault zones: Influence of hydraulic anisotropy and heterogeneity on the fluid flow and heat transfer regime: Preprint.

López, D.L. and L. Smith, 1995c, Fluid flow and heat transfer within connected, range-bounding faults: A possible example at Leach Hot Springs, Nevada: Preprint.

Hohmann, G.W., 1975, Three-dimensional induced polarization and electromagnetic modeling: Geophysics, 40, $309-324$.

Pruess, K., 1991, TOUGH2 - A general purpose numerical simulator for multiphase fluid and heat flow: Lawrence Berkeley Laboratory Report, LBL-29400, Berkeley, California.

Sill, W.R., 1982, Self-potential effects due to hydrothermal convection-velocity cross-coupling: DOE/DGE Report, Contract DE-AC07-80ID12079, Department of Geology and Geophysics.

Sill, W.R., 1983, Self-potential modeling from primary flows: Geophysics, 48, 76 - 86.

TOUGH '95 WORKSHOP : Proceedings, Lawrence Berkeley Laboratory, March 20 -22, 1995.

Tripp, A.C. and Ross, H.P., 1997, SP heat and fluid flow cross-coupling coefficients - A compilation: In preparation. 


\title{
ELECTROMAGNETIC METHODS FOR GEOTHERMAL EXPLORATION
}

\author{
$\mathrm{Ki} \mathrm{Ha} \mathrm{Lee}$ \\ Lawrence Berkeley National Laboratory
}

\section{KEY WORDS}

magnetotellurics, controlled source magnetotellurics, source effect, geothermal, electrical conductivity

\section{PROJECT BACKGROUND AND STATUS}

The application of electromagnetic (EM) methods to geothermal exploration is not new. The task reported here was initiated in 1993 when Trans-Pacific Geothermal Corporation (TGC) approached DOE/LBNL requesting the evaluation of Controlled Source Magnetotellurics (CSMT) data collected near Vale, Oregon. We interpreted the TGC data using the state-of-the-art two-dimensional Magnetotelluric (MT) inversion code developed at LBNL. Since then the inversion code has been upgraded continuously, and we are now considering implementing a countermeasure to handle source effects.

TGC has been developing the El Hoyo-Monte Galán field in Nicaragua where the CSMT technique is used as a main geophysical exploration tool. We examined the CSMT and MT data collected at this site and which had been processed by Zonge Engineering. The total line coverage was $39 \mathrm{~km}$. Line 3, an 8-km-long traverse in the middle of the survey area, was then selected for full analysis. The analysis included two-dimensional inversion. The results have been delivered to TGC for evaluation and a meeting for consultations is scheduled in early FY1998. Upon integrating seismic, joint hydrology and self-potential; and CSMT survey results, potential drill sites will be selected. We plan to assist TGC's effort by interpreting the CSMT data using the improved interpretational tool being developed with DOE's support.

One very practical concern with the CSMT method, however, is the source effect. So we are not certain of the interpreted results at depth. The study on the source effects in CSMT has been continued using the wavenumber analysis. This method is compared with the pseudo-analytic approach in which the 'apparent resistivity' is derived using fields that would exist in uniform half-space. In this approach near fields are used directly for the calculation of resistivities.

\section{PROJECT OBJECTIVES}

\section{Technical Objectives}

- Evaluate current magnetotelluric (MT) methods for: (a) Exploration of geothermal fields, and (b) Characterization and monitoring of reservoirs at a regional scale.

- Demonstrate the utility of the controlled-source magnetotelluric (CSMT) method when used in conjunction with the MT method.

\section{Expected Outcomes}

- Provide improved means for interpreting MT and CSMT data. 
- Help establish guidelines for efficient and cconomic CSMT survey design.

- Improved general reservoir characterization

\section{APPROACH}

There is an essential difference between MT and CSMT methods in terms of the nature of the source field. The MT source is natural and the resulting electromagnetic field is a plane-wave. The plane-wave is incident on the earth surface with an incident angle, but travels vertically once it gets transmitted into the earth. The CSMT source field is man-made and consist of a spectrum of many wavenumbers. Electric to magnetic field ratio in regions near the source deviates from plane-wave impedance, so straightforward application of plane-waveanalysis results in erroneous conclusions. We approximate the controlled source fields by terms at a few appropriately-chosen horizontal wavenumbers. The objective is to develop a simple correction of near-source effects. We are also investigating combination of electric and magnetic sources to achieve reduced source effects.

The other promising approach is to use the closed form solutions for the EM impedance on the surface of a uniform half-space. The resistivity of the half-space can be derived approximately from the impedance, and it can be referred to as the 'apparent resistivity.'

\section{RESEARCH RESULTS}

The finite wavenumber approach leads to an asymptotic expression between the impedance and the various field components. Initial results using a few chosen wavenumbers to approximate fields by finite sources shows limited success. By first estimating the 'complex' horizontal wavenumber using vertical fields, and then using this information to correct for plane-wave impedance, we obtain better estimation of plane-wave impedance. We are in the process of comparing this result with the one generated by the apparent resistivity approach. Initial results show that each method has its own merit depending on the source configuration and polarization.

\section{FUTURE PLANS}

A rigorous evaluation of the finite wavenumber approach and the apparent resistivity approach is planned. It is reasonable to expect that a combination of these two methods may increase the chance of improving the overall efficiency of the CSMT technique. No additional computational complexity is expected in these approaches.

\section{INDUSTRY INTEREST}

CSMT methods have been widely used in geothermal exploration in hostile environments. Presently, this project is a joint TGC-LBNL/DOE effort. In the future, other companies might participate. TGC will provide field support, CSMT data, and other relevant geophysical and geological information. Meetings are held periodically to discuss research directions and priorities.

\section{REFERENCES}

Ward, S.H., and Hohmann, G.W., 1988, Electromagnetic theory for geophysical applications, in M.W. Nabighian, Ed., Electromagnetic Methods in Applied Geophysics-Theory: vol. I., Society of Exploration Geophysicists, Tulsa. 


\title{
UPDATE ON THE GEOTHERMAL EXPLORATION PROGRAM AT THE EL HOYO GEOTHERMAL AREA, NICARAGUA
}

\author{
Tsvi Meidav and Bill Teplow \\ Trans-Pacific Geothermal Corporation
}

\section{KEY WORDS}

geothermal exploration, El Hoyo, Nicaragua, remote sensing, geophysical exploration, MT/CSAMT, resistivity, self potential, temperature measurements

\section{PROJECT BACKGROUND AND STATUS}

Trans-Pacific Geothermal Corporation (TGC) owns the geothermal concession of the El Hoyo-Monte Galán geothermal field in Nicaragua. Despite vigorous volcanic manifestations in the entire region, drilling success rate in that active volcanic belt, as in other promising volcanic regions in the world, has not been spectacular. For example, in the nearby San Jacinto-Tizate prospect, only two wells out of seven turned out to be productive despite intense geothermal exploration which preceded the drilling. Similar problems have been encountered in other volcanic belts in southeast Asia and elsewhere.

The geoscientific exploration phase of the project is now complete. We are actively analyzing the data and plan to conclude that effort by year end. The next phase of the project will be to carry out exploration drilling which will indicate how successful we have been in carrying out the research program that we have just concluded.

\section{PROJECT OBJECTIVES}

The overarching objective of this research program is to increase the competitiveness of geothermal electricity in an intensely competitive market place, where fossil fuels dominate the market. We expect to drill exploration holes in the next phase of this project. We wish to reduce the number of failures ("dry holes") to a reasonable minimum.

\section{Technical Objectives}

- Identify likely faults and areas of hydrothermal alteration from Landsat and radar satellite imagery.

- Map precisely the vertical and horizontal distribution of electrical resistivity to a depth of two km or more.

- Conduct detailed self potential measurements which might identify active convection along faults.

- Carry out detailed ground magnetic measurements, to identify possible fault zones, as well evidence, if any, for hydrothermal alteration of magnetic mineral into less magnetic minerals which might be associated with geothermal convection over time.

Carry out shallow (1 meter) temperature measurements which might indicate shallow high temperature rock occurrence or low level fumarolic activity. 
- Collect gas samples wherever possible to determine the last equilibration temperature of those gases prior to their travel to the surface.

- Conduct all surveys on identical lines as much as possible to permit cross correlation of physical parameters, thereby reducing interpretation ambiguity.

- Develop a followup drilling exploration strategy.

\section{Expected Outcomes}

The most important outcome of this research program is that it would lead to an informed selection of drilling targets. The success of this strategy in delimiting the best target areas for drilling would result in the reduction of cost of geothermal field exploration and development in similar terrains both in Central America and in other regions of the world characterized by similar geology.

The central objective of this research effort is to reduce the cost of geothermal field drilling exploration costs. Assuming that this integrated geoscientific exploration does improve the success ratio of the expected follow-on drilling program, the objective of cost reduction

of drilling would be attained.

\section{APPROACH}

The variability of subsurface rocks, permeability and porosity patterns in a volcanic terrain are notoriously problematic in designing a high success drilling program. We expect that as a result of carefully executed, multi-parameter, high-density data gathering, it would be possible to reduce the exploration risk substantially. We expect that a substantial improvement in the success ratio of exploration drilling in volcanic terrain is likely to result from this program.

\section{RESEARCH RESULTS}

In this preliminary report we show a sample of the various geophysical surveys that were carried out within the El Hoyo prospect along Line 3 which transects the area from NNW to SSE (Figure 1). This profile transects El Hoyo and Cerro Colorado, the two main volcanic and hydrothermal features within the prospect. The different geophysical parameters along that profile demonstrate the correlation of features that can be used to identify drilling targets.

\section{Results of the Surveys}

Geophysical Profile Line 3 (Figure 1) was chosen because it transects the two main volcanic and hydrothermal features within the prospect, El Hoyo and Cerro Colorado. The overlay of geophysical profiles shown in Figure 1 demonstrates the correlation of features that can be used to identify drilling targets.

The MT/CSAMT survey was conducted along a 9-km profile, from the peak of the El Hoyo volcano in the west to a point east of the Cerro Colorado cinder cone. Because of the dense spacing of the depth soundings, the cross section precisely locates lateral changes in resistivity. A significant resistivity low occurs in the area surrounding the peak of the El Hoyo volcano, with a sharp discontinuity to the east, the Picacho Fault. Another distinct lateral discontinuity occurs at the Westside Fault, which is associated with a high temperature gradient hole. A remarkable resistivity anomaly occurs within the Cerro Colorado Volcano, where resistivities decrease to below 
one ohm-meter. The Cerro Colorado anomaly is bounded by sharp lateral resistivity discontinuities to the west and east.

A 1-meter temperature survey was carried out for about $6.5 \mathrm{~km}$, covering the area from the valley to the peak of El Hoyo and beyond. A dramatic rise in ground temperature was mapped from the Picacho Fault eastward across the fumarolic area of El Hoyo.

The SP survey showed two distinct anomalous areas, one in the Picacho-El Hoyo area and the other in Cerro Colorado. The SP anomaly on El Hoyo is a composite of several features, with a total amplitude of about 300 $\mathrm{mV}$. An additional anomaly, with an amplitude of about $100 \mathrm{mV}$, occurs along the Westside Fault at the eastern base of El Hoyo. This feature is associated with hot ground water circulation as evidenced by gradient drilling.

High magnetometer data density allowed for effective data smoothing which in turn revealed significant magnetic anomalies. The anomalies correlated very closely with the SP and resistivity surveys and therefore served to refine hydrothermally active fault locations.

\section{Preliminary Interpretation}

Several strong correlations of geophysical and geologic features occur along Profile Line 3. The combination of the high ground temperature on the upper slopes of El Hoyo (above $600 \mathrm{~m} \mathrm{MSL}$ ), visible steam leakage and hydrothermal alterations, the low resistivity to a substantial depth, and the very strong SP anomaly, combine to suggest that active, near vertical, deep hydrothermal convection is currently taking place in that area. Likewise, the combination of fumarolic activity, high indicated gas geochemistry, very low resistivity and well-defined SP anomalies suggest that Cerro Colorado is also an attractive target for exploratory drilling.

The final interpretation of data derived from the integrated program will provide well-defined drilling targets for the next phase of exploration which will consist of slimhole exploration wells drilled to a depth of $1000 \mathrm{~m}$. Results of the drilling will provide a direct measure of the efficiency of the integrated geophysical program.

\section{FUTURE PLANS}

The object of this research effort was to develop a methodology for reducing drilling exploration risk. Upon completion of the data analysis, we intend to select drilling targets, which will establish the success of the approach utilized in this program.

\section{INDUSTRY INTEREST}

The problems identified here are common to all geothermal developers who work in similar volcanic terrains. We intend to publish the results of this survey and the follow-on drilling, with the expectation that the cost of drilling exploration will be reduced as a result of this effort.

\section{REFERENCES}

Amason, K. and O.G. Flovenz, 1992, Evaluation of Physical methods in geothermal exploration of rifted volcanic crust, GRC Trans., Vol 16:207-214. 
Ross, H.P, Blacket, R.E., Shubat, M.A . and Mackelprang, C. E., 1990, Delineation of fluid upflow and outflow plume with electrical resistivity and self-potential data, Newcastle geothermal area, Utah: GRC Trans. V. 14:1531-1536.

Wilt, M., W. Teplow, and T. Meidav, 1993, Low cost exploration at Amedee Hot Springs, using self potential and magnetics, GRC Trans. V. 17, pp. 459-463.

Yasukawa, K., G. Bodvarsson, and M.J. Wilt, 1993, A coupled self potential and mass-heat flow code for geothermal applications, GRC Trans. V.17:203-207. 


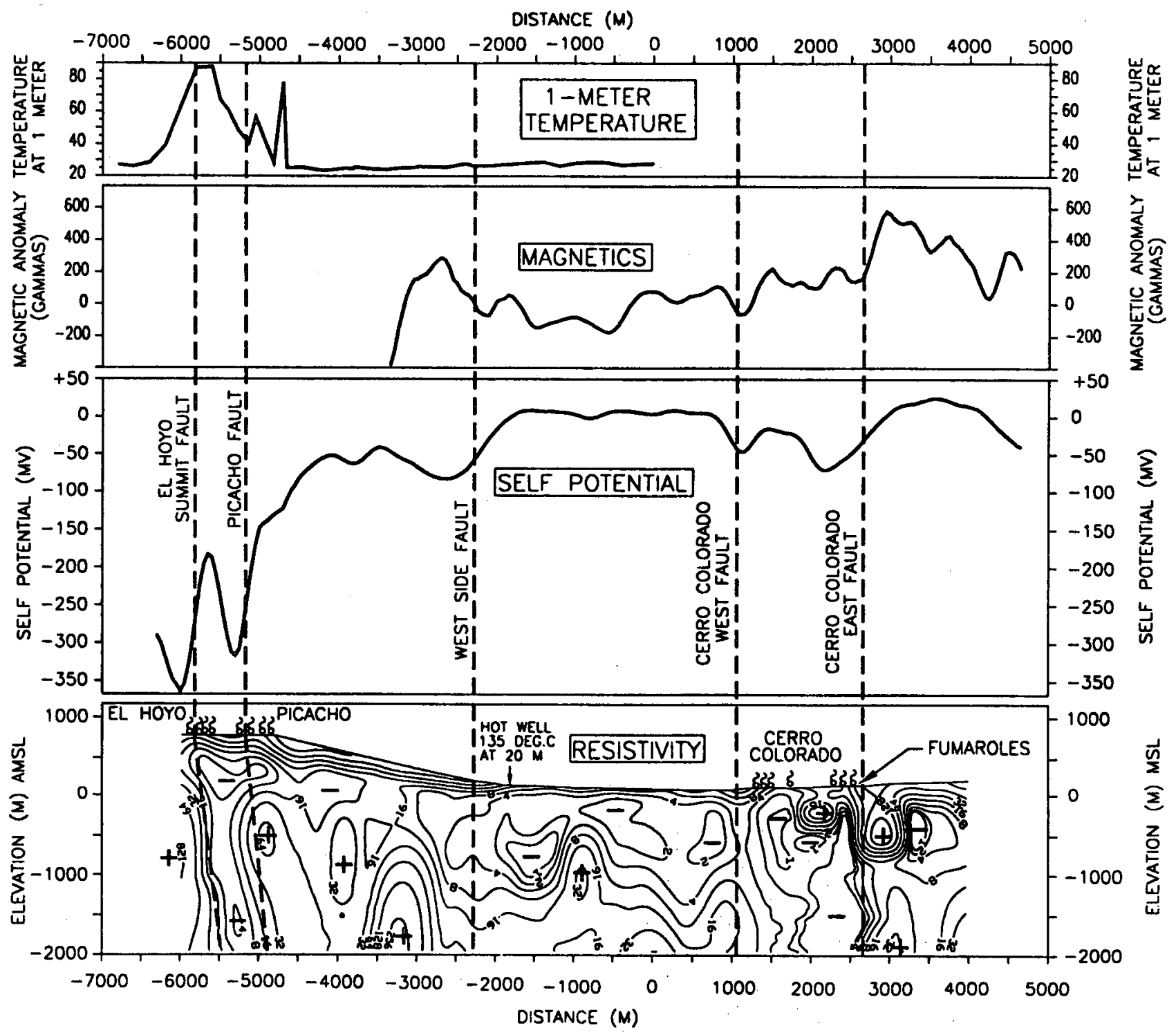

FIGURE 1: CORRELATION OF GEOPHYSICAL SURVEYS, PROFILE 3 


\title{
GEOTHERMAL EXPLORATION IN THE RYE PATCH GEOTHERMAL FIELD
}

\author{
Tsvi Meidav and Bill Teplow \\ Trans-Pacific Geothermal Corporation
}

\section{KEY WORDS}

Rye Patch, Basin and Range, geophysical exploration, geological exploration, 3-D seismic reflection, MT/CSAMT, self potential, magnetometry, vertical seismic profiling, integrated data analysis, drilling success

\section{PROJECT BACKGROUND AND STATUS}

The Industrial Company (TIC) is the owner of leases and a non-operating geothermal power plant in the Rye Patch geothermal field in Nevada. Initial drilling of three wells confirmed the existence of a geothermal reservoir and proved enough geothermal brine capacity for about $6 \mathrm{MW}$. Based upon the data obtained, a $12 \mathrm{MW}$ geothermal plant was constructed. However, the drilling of another 5 wells failed to discover additional commercial production, even though those new wells were drilled in close proximity to previously drilled wells. As a result, the contract for the purchase of electricity by the local utility was canceled and the project was suspended.

This disappointing result cast a cloud of doubt regarding the ability of the industry to locate commercial production in the often complex geology of the Basin and Range Province of Nevada, despite the evidence that substantial shallow hydrothermal systems are found in the region. Failure to map commercial production in an otherwise promising geothermal area is likely to put a damper on future geothermal exploration in the region. The overall aim of this research effort is to improve the technology of identifying potentially productive structures and stratigraphy within a known geothermal system.

The project was started by TIC, who retained Trans-Pacific Geothermal Corporation (TGC) as its contractor for planning and executing an innovative exploration program, with the hope that this would unlock the geologic puzzle of defining additional commercial production in an area that appeared to be quite promising at its earlier stage of exploration.

In coordination with, and under the direction of TIC, TGC developed a comprehensive, integrated exploration program aimed at defining more precisely the nature of the geothermal system in the Rye Patch area and providing drilling targets that are likely to be more successful than some of the previous ones. The Lawrence Berkeley Laboratory, under the direction of Dr. Emie Majer, was contracted to provide planning, and management of the seismic reflection component of the program. Dr. Jim McNitt of GeothermEx was retained to assist in the geological interpretation of the structure and stratigraphy of the area. The program began on July 15, 1997, and is expected to be completed within less than one year from that date.

The program is basically on time and on budget with its geological component, the MT/CSAMT survey, magnetics and self potential. It is about two months behind schedule in its 3-D seismic exploration program, due to legal issues related to the rights to enter existing wells for vertical seismic profiling. Those problems have now been resolved, and it is expected that the seismic reflection work will be started in mid-December 1997. 


\section{PROJECT OBJECTIVES}

The proposed program aims to improve the success of drilling for geothermal resources in the Basin and Range.

\section{Technical Objectives}

- Develop a comprehensive geological model of the Rye Patch area by integrating borehole lithologic data with surface geology.

- Carry out closely spaced MT/CSAMT, ground magnetic, and SP surveys over the area of interest, utilizing identical survey lines as much as possible. Cross correlation of different geophysical techniques reduces ambiguity of interpretation. Closely-spaced measurements reduce the risk of aliasing which comes about when station spacing approaches the wavelength of the features which they are intended to measure.

- Conduct a preliminary Vertical Seismic Profile (VSP) survey in any one of the existing geothermal wells to develop a velocity profile of the subsurface and establish reflectivity of key formations. This would improve the quality of the 3-D seismic reflection survey data processing, and increase the confidence in the processed depth sections.

- Conduct a simultaneous VSP and 3-D seismic reflection survey over the area, to define the structure and stratigraphy as well as possible. Seismic reflection has hardly been utilized in geothermal exploration because it was considered to be too expensive for the results that it would provide. However, the efficacy of 3-D seismic reflection surveys for geothermal exploration has not, to the best of our knowledge, been tested before in the Basin and Range.

- Carry out a joint interpretation of all data sets to refine the stratigraphy and structure of the geothermal prospect.

- Identify the likeliest targets for drilling, if such targets are clearly identifiable from this program.

\section{Expected Outcomes}

The expected outcomes are both general and site-specific:

- Demonstrate the realm of applicability of 3-D seismic reflection under geological conditions of the Basin and Range.

- Reduce failure rate of drilling exploration in the Basin and Range, thereby reducing geothermal field cost development and increase of confidence in the evolving exploration technology.

- Unlike the case of mechanical improvement in for example, turbine blade efficiency, exploration risk reduction cannot be quantitatively described. It will vary with the area, and the specific subset of issues that the explorationist must resolve. However, the over-arching goal is the reduction in cost of field development drilling. 


\section{APPROACH}

The approach is:
- Examine possible geological models of the structure and stratigraphy to design the geophysical program which will help in narrowing down the likely model which approaches the actual earth model as closely as possible.
- Being cognizant of the possibility of sharp lateral discontinuities, which are of great importance in locating permeable fractures, carry out geophysical measurements at appropriately close spacing.
- Measurement of different geophysical parameters on identical lines reduces the level of ambiguity of interpretation.

TIC is contributing substantial amount of previously confidential borehole data to this program, which would make the interpretation much more meaningful, and would permit the geothermal industry to evaluate the program based upon real data, rather than hypothetical models.

The Lawrence Berkeley Laboratory is participating in this program as manager of the seismic reflection program. LBL has amassed substantial experience in conducting seismic reflection studies in The Geysers field and elsewhere. The Zonge Engineering company conducted the MT/CSAMT survey as a subcontractor.

Lettis and Associates will utilize simulated annealing optimization velocity modeling and Kirchoff migration for imaging laterally complex structure derived from the $3-\mathrm{D}$ survey data. This process is similar to that utilized on the 2-D seismic data of Dixie Valley, with the expectation that this would result in a further refinement of the interpretation of the 3-D structure and stratigraphy of the area.

\section{RESEARCH RESULTS}

This is a progress report of an effort that has not been completed as yet. Hence, only preliminary observations may be made.

So far, we have completed the MT/CSAMT survey, the SP and ground magnetics work, as well as a small part of the geological component, and are about to commence the seismic reflection phase.

The MT/CSAMT resistivity survey (the layout of which is shown in Figure 1) identified some distinct lateral discontinuities which appear to be related to the high temperature zone encountered in production well 44-28. These features also correlate closely with discontinuities identified in the magnetic and SP surveys. A sharp resistivity discontinuity aligned N-S approximately 30,0 west of well 44-28 may be a localized permeability channel, which is transporting the $400+$ deg F fluid and therefore represents a distinct target for 3-D seismic survey delineation.

Figure 2 shows a contour map of the ground magnetic data. It is characterized by a steep magnetic gradient of the same trend as the Rye Patch Fault.

Figure 3 shows a contour map of the SP data gathered in the survey. The contour map displays a very distinct and isolated negative SP anomaly near the intersection of Profile 0 and Profile $1 W$. This anomaly correlates closely with an isolated resistivity low observed in the $500^{\prime}$ depth slice obtained from the resistivity data (not 
shown here). If this anomaly represents a shallow leakage from a permeable segment of the underlying Rye Patch Fault, it could be considered a separate exploration target. No drilling has taken place in the vicinity of that anomaly before now. However, it deserves a closer examination during the follow-on exploration phase.

\section{FUTURE PLANS}

The additional activity yet to be carried out in the field is the VSP and 3-D seismic exploration work. In parallel, the geologic analysis will be completed, and the entire data set will be jointly interpreted. Mr. Bill Honjas of Lettis and Associates will conduct a simulated annealing and Kirchoff migration on the seismic data similar to that which he and his associates carried out on the Dixie Valley data (Honjas, et al, 1997). That approach offers a substantial improvement in the interpretation of seismic reflection and refraction data in steeply dipping rock areas.

\section{INDUSTRY INTEREST}

Companies which seek to develop geothermal resources in the Basin and Range would be interested in the methodology and results of this program. Moreover, if the simulated annealing methodology proves to be predictive, it would be a significant advance for the industry as a whole, in whatever geothermal terrain that any company seeks to explore.

\section{REFERENCES}

Honjas, William, Satish K. Pullammanappallil, Jeffrey R. Unnuh, and Gabriel L. Plank; Effectiveness of simulated annealing velocity modeling and Kirchoff migration for imaging laterally complex geologic environments within the Dixie Valley Geothermal Field, Nevada;Geothermal Resources Council Annual Meeting, October 14, 1997. 


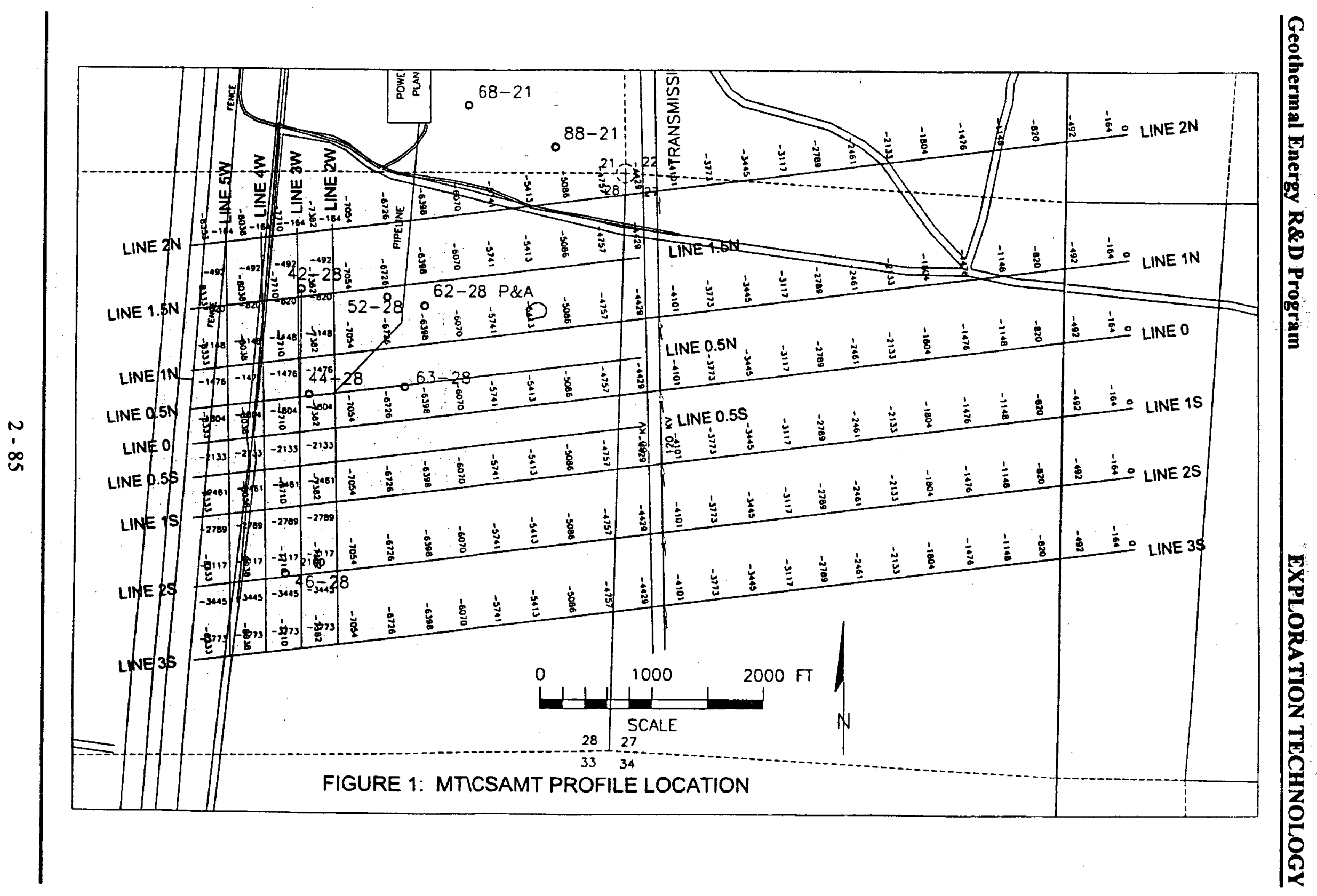




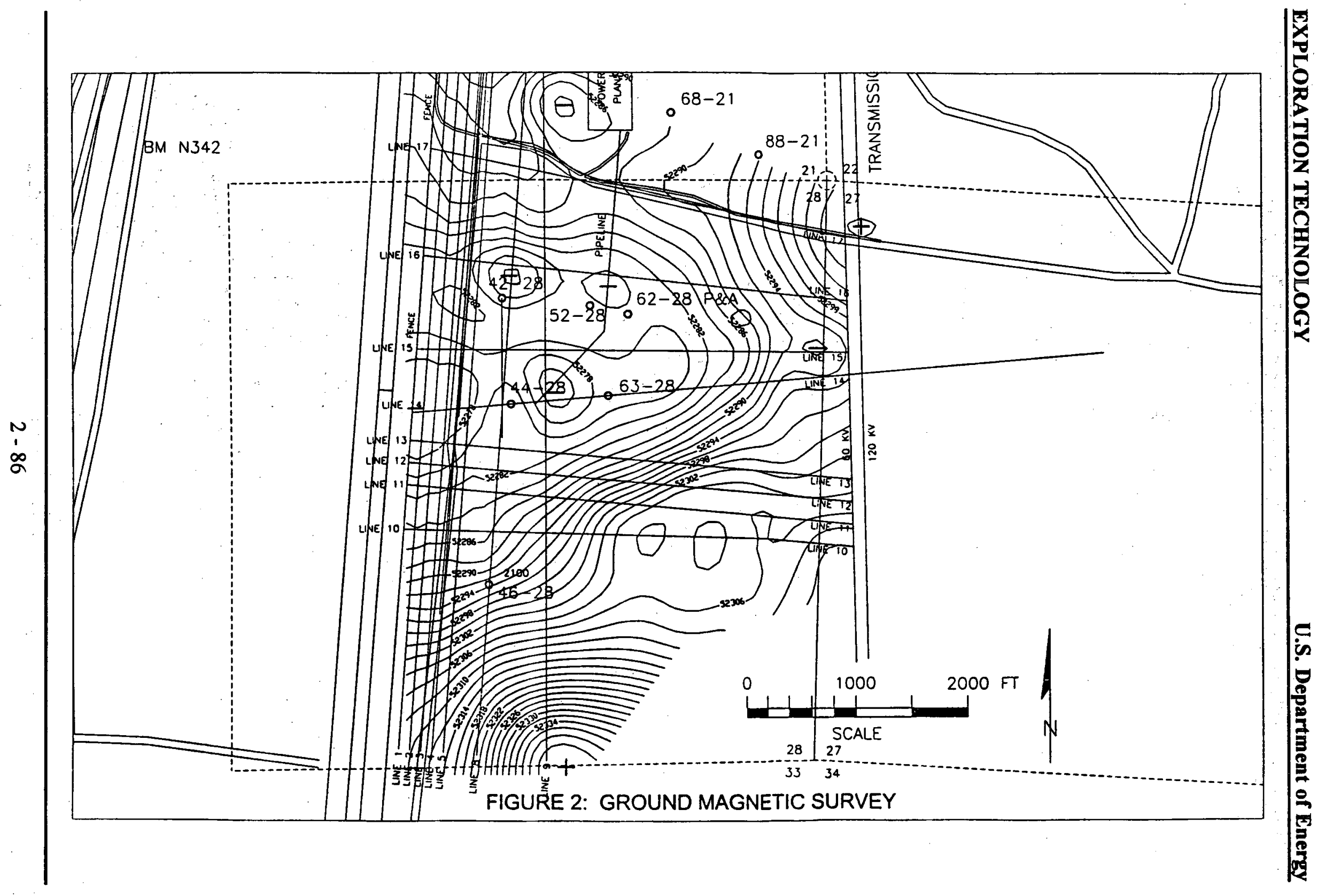

| 


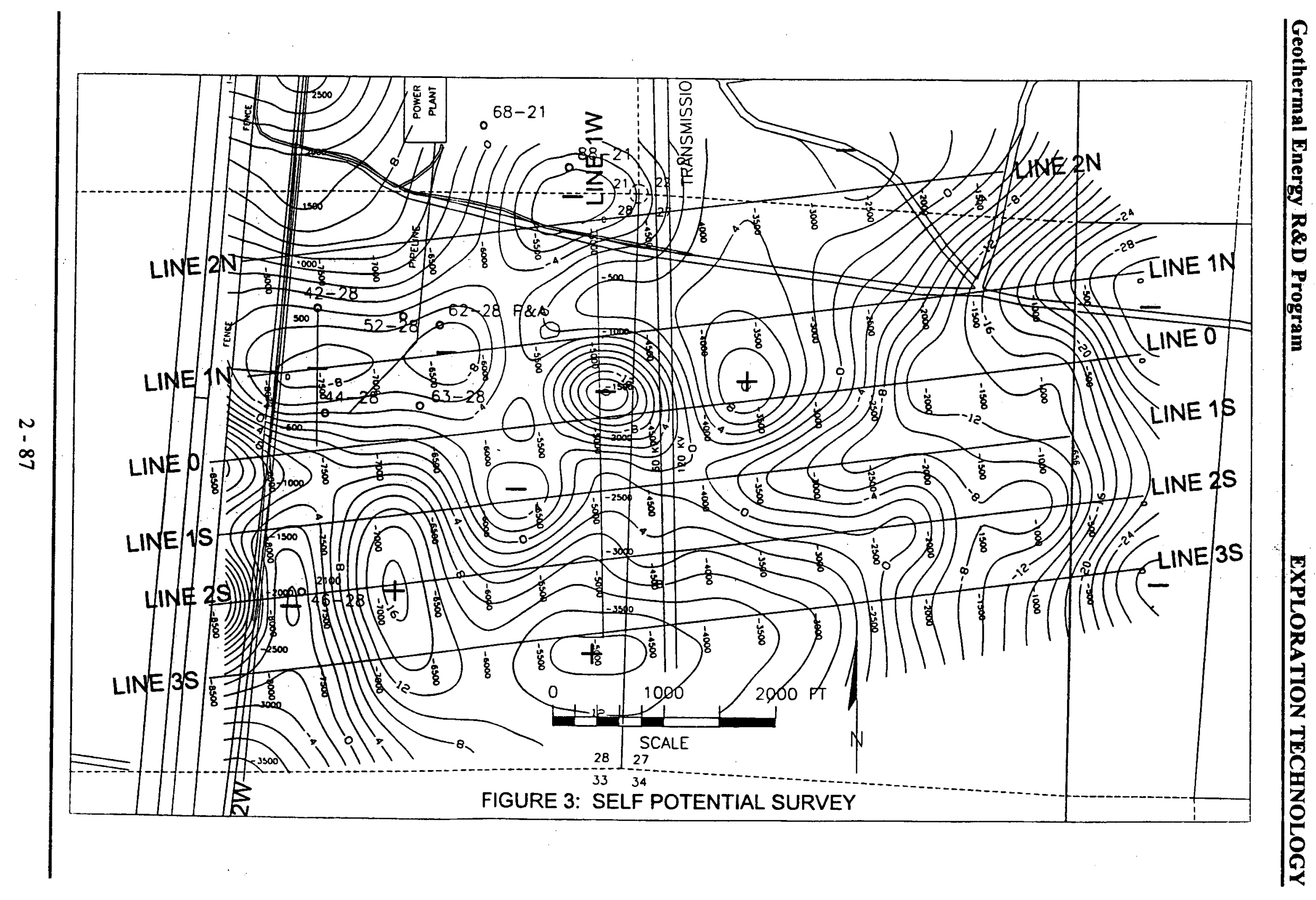




\title{
GEOPHYSICAL STUDIES OF THE COVE FORT-SULPHURDALE, UTAH GEOTHERMAL SYSTEM
}

\author{
Howard P. Ross \\ Energy \& Geoscience Institute \\ University of Utah
}

KEY WORDS

Cove Fort, geophysics, self-potential, electrical resistivity

\section{PROJECT BACKGROUND AND STATUS}

The Cove Fort-Sulphurdale geothermal area, located in the Transition zone where the Basin and Range Province meets the Colorado Plateau in central Utah, is part of one of the largest thermal anomalies in the western United States. Exploration for geothermal energy began here in the early 1970's, and Unocal proved the presence of a moderate-temperature resource in 1977 with the drilling of well CFSU 42-7 which recorded temperatures of $178^{\circ} \mathrm{C}$. Mother Earth Industries (MEI) later acquired the geothermal leases and discovered a "dry" steam cap during the drilling of well 34-7 in October 1983. Production from the steam cap has continued since 1985, but increased production has resulted in a pressure decline in producing wells. In 1994 the Utah Municipal Power Agency (UMPA), operator of the power plant, acquired the MEI geothermal leases and surface rights.

In 1995, the Energy \& Geoscience Institute (EGI) at the University of Utah, the Utah Geological Survey (UGS) and UMPA began new studies to evaluate the status of the reservoir after ten years of production. These studies include the geochemistry of geothermal fluids, geobotanical spectral studies, and geophysical studies. This summary is limited to geophysical studies of the Cove Fort-Sulphurdale area. A detailed self-potential survey of the known resource area was conducted during the 1995 and 1996 field seasons, with some repeat measurements and additional survey lines in 1997. These data were merged with existing geologic information and existing and new electrical resistivity data to obtain a preliminary geophysical interpretation. A more complete integration with borehole results and quantitative resistivity data continues. We estimate that the present study is 60 percent complete, and that this project will terminate when the present Right of Entry Agreement between EGl and UMPA ends in May 1999.

\section{PROJECT OBJECTIVES}

The objectives of this project are to document the geophysical expression of this major geothermal resource area, and to interpret and understand the geophysical data sets. This understanding will contribute to a refined model for the geothermal system, including the location and nature of the deep, primary geothermal reservoir which feeds the secondary steam reservoir. Such information could lead to increased production and long-term sustainable use of the Cove Fort-Sulphurdale geothermal system.

\section{Technical Objectives}

Complete a detailed self-potential (SP) survey which includes but extends beyond the known reservoir area, which will document the SP expression of this important geothermal resource. 
- Locate thermal fluid upflow and outflow zones which may help indicate the presence of the primary hot-water reservoir:

Interpret electrical resistivity, aeromagnetic and gravity data to refine existing models of the geothermal system, and to help identify the primary geothermal reservoir.

\section{Expected Outcomes}

- Improved reservoir model for the geothermal system.

- Identify targets for future drill testing which could expand production and sustainable production of this geothermal resource.

\section{APPROACH}

The objectives will be obtained by completing a detailed SP survey and examining the data for any anomalies which may relate to fluid upflow or outflow zones. A large database of drill hole results, temperature data, reservoir studies, and geophysical data were acquired by MEI from 1985 to 1995 , and these data are now available for study by EGI through the UMPA-EGI Right of Entry Agreement. EGI will study these data and integrate them with extensive electrical resistivity, aeromagnetic, and gravity data obtained by Unocal and UURI during the Industry Coupled Program of 1977-1982. New geochemical and geomatics studies by EGI will be integrated with the geophysical studies to refine existing reservoir models.

\section{RESEARCH RESULTS}

Howard Ross and Robert Blackett (Utah Geological Survey, UGS) completed a detailed SP survey which totaled 892 observations (about $30 \%$ repeat and tie line stations) on 41.1 line-km of survey profiles. The survey extends from Interstate 15 on the west to the hillside perhaps $600 \mathrm{~m}$ east of the power plant and producing steam zone, an area of about $6.32 \mathrm{~km}^{\wedge} 2$. A low-amplitude bipolar anomaly $(+29 \mathrm{mV},-25 \mathrm{mV})$ characterizes the known steam reservoir, but this is an area of numerous drill holes, pipelines and other grounded structures. High-amplitude readings near drill holes and grounded structures were removed from the data set, but some contribution from these features may be included in the dipolar anomaly: Potentially more important are three coherent negative anomalies of -25 to $-34 \mathrm{mV}$ which occur north and west of the known steam field. These anomalies all occur along faults or fault intersections identified from geologic mapping, gravity and magnetic data, and are thought to indicate fluid upflow zones. All anomalies occur in a broad area of $<5 \mathrm{ohm}-\mathrm{m}$ electrical resistivity interpreted from existing resistivity surveys.

Figure 1 shows the location of SP anomalies, low-resistivity zones, and major faults interpreted from gravity and aeromagnetic data. The structural interpretation is supported by geologic mapping (Moore and Samberg, 1979) and numerical modeling (Ross and Moore, 1985). North-trending structures interpreted from gravity data and a northeast-trending fault which cuts Cinder Crater define the northern limit of the Beaver-Cove Fort graben.

The low-resistivity area shown in Figure 1 corresponds to the intrinsic electrical resistivity for depths of 460-600 $\mathrm{m}$, as determined by numerical modeling. This area has been extended to the west by Line HEC 3 , which trends northwest through SP anomaly F. Permission to use these data, part of a proprietary survey by Hunt Energy Company, has been given by Roger Bowers. Additional resistivity information comes from a detailed, but very limited CSAMT survey (Zonge Engineering \& Research Organization (1987) which is part of the UMPA database acquired from MEI. The resistivity data from Line HEC 3 and the $4 \mathrm{~Hz}$ CSAMT data exhibit some of 
the lowest electrical resistivities observed in the region. The low electrical resistivities, SP anomalies, interpreted faults and surface geology all support one model for the geothermal system which calls for a primary hot-water reservoir south and west of the known steam reservoir. The thermal fluids move north and east along major structures and feed the steam cap and thermal occurrences located by other drill holes.

The results of studies to date were reported by Ross, Blackett, and Sperry in a paper "Self-potential and electrical resistivity studies of the Cove Fort-Sulphurdale geothermal system, Utah" presented at the 1997 Geothermal Resources Council Annual Meeting. An abstract titled "Geophysical characterization of the Cove FortSulphurdale, Utah geothermal system" by Ross, Blackett, and Moore has been submitted for presentation at the 1998 AAPG Annual Meeting in Salt Lake City.

\section{FUTURE PLANS}

Plans for FY-98 include continued study of geologic and geophysical data in the UMPA database, and the integration of these data with ongoing geochemical, geomatics, and geophysical studies by EGI. Although there is relatively little interest in exploration drilling of new geothermal areas in the western United States, a power plant and market are already in place for this resource, and sustainable future production may depend upon production from the primary hot-water reservoir.

\section{INDUSTRY INTEREST}

\section{Organization}

Utah Municipal Power Agency

Terracon, Inc., Arlington, Texas

\section{Type and Extent of Interest}

Geothermal reservoir model for the resource

Geophysical and drilling database for the area

\section{REFERENCES}

Moore, J.N., and Samberg, S.M., 1979, Geology of the Cove Fort-Sulphurdale KGRA: Univ. Utah Res. Inst., Earth Science Lab., rep. 18, 44 p.

Ross, H.P., and Moore, J.N., 1985, Geophysical investigations of the Cove Fort-Sulphurdale geothermal system, Utah: Geophysics, v.50, 1732-1745.

Ross, H.P., Blackett, R.E., and Sperry, T.L., 1997, Self-potential and electrical resistivity studies of the Cove Fort-Sulphurdale geothermal system, Utah: Geothermal Resources Council Transactions, v. 21, p. 255-261

Ross, H.P., Blackett, R.E., and Moore, J.N., 1998, Geophysical characterization of the Cove Fort-Sulphurdale, Utah geothermal system: abs., submitted for presentation at the 1998 AAPG Annual Convention, Salt Lake City, May. 


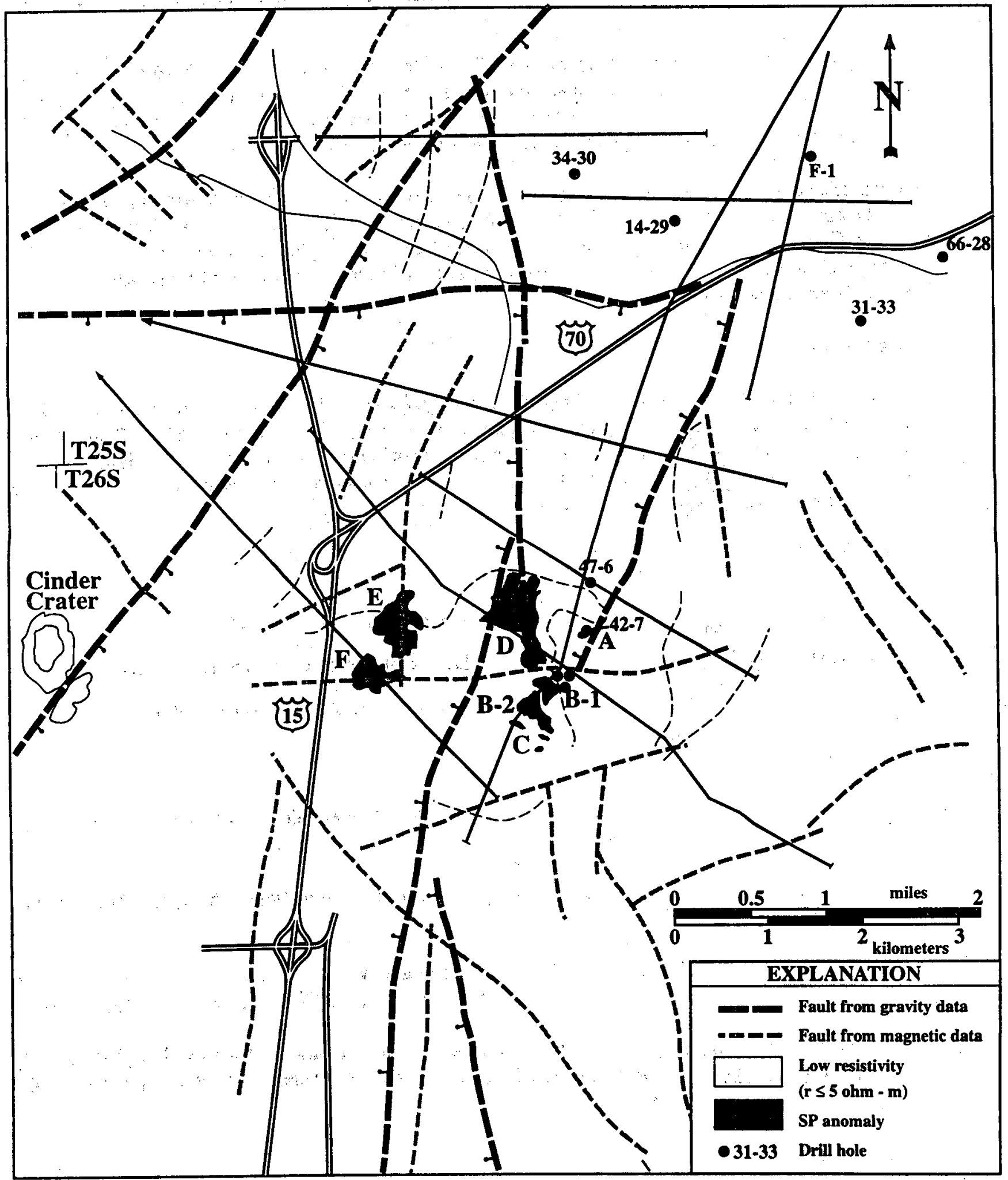

GEOT9725.003

Figure 1 - Geophysical data summary showing SP anomalies, low-resistivity zones, major structures interpreted from aeromagnetic and gravity data and geological mapping. The producing steam field occurs at SP anomalies $\mathrm{B} 1$ and $\mathrm{B} 2$. 


\title{
GEOTHERMAL RESOURCE/RESERVOIR INVESTIGATIONS BASED ON HEAT FLOW AND THERMAL GRADIENT DATA FOR THE UNITED STATES
}

\author{
David D. Blackwell, Kenneth W. Wisian, and John L. Steele \\ Department of Geological Sciences, Southern Methodist University
}

\section{KEY WORDS}

Eastern U.S., Western U.S., geothermal potential, temperature, heat flow, thermal conductivity, geothermal gradient, heat mining

\section{PROJECT BACKGROUND AND STATUS}

This project extends the early geothermal resource evaluations of Muffler (1979), and Reed (1985). The detailed geothermal data base developed for the Geological Society of America Decade of North American Geology (DNAG) Geothermal Map of North America (Blackwell and Steele, 1992; Blackwell et al., 1989, 1991) was expanded and updated in a previous project (Blackwell et al., 1996). Publications on the status of the previous project are contained in Blackwell et al. $(1992,1993,1994,1995,1996)$. This project was initiated in January, 1997 and is focused on specific area heat flow and geothermal data sets in the western United States. The change in focus is due to the different nature of the geothermal resource in the high heat flow areas of the western U.S.

\section{PROJECT OBJECTIVES}

The general objectives of this project are to a) increase the precision and accuracy of geothermal resource estimates and assessments and b) to characterize regional geothermal resources in the United States.

\section{Technical Objectives}

The general objectives will be met by the specific technical objectives:

- Develop a data base of, and make available for the process of resource evaluation site specific heat flow, geothermal gradient, and thermal conductivity information for western United States,

- Use results to develop generalized models for the site specific evaluation of resource potential,

- Maintain heat flow, geothermal gradient and ancillary (thermal conductivity, sediment thickness, surface temperature, etc.) data bases and maps based on published thermal data for the U.S., and

- Develop and maintain an Internet home page with results of the project available in the form of downloadable data and map summaries of results.

\section{Expected Outcomes.}

- First, develop the specifications and data for a site specific heat flow and geothermal gradient data base for the westem U.S., 
- Second, new exploration and evaluation models for Basin and Range geothermal systems,

- Third, a digital representation of the heat flow for the western U.S.,

- Fourth, an updated heat flow data base and a series of digital data bases designed to estimate temperature in the depth range 3 to $5 \mathrm{~km}$ at a horizontal resolution of about $5 \mathrm{~km}$ over the U.S., and

- Fifth, an Internet home page: the address is http://www.smu.edu/ geothermal.

The results should increase the accuracy of regional resource estimates by at least $25 \%$ compared to previously available information due to the increased spatial detail and the inclusion of additional geothermal variables.

\section{APPROACH}

This project is at the beginning of a multiyear effort to evaluate the geothermal conditions at depths of several $\mathrm{km}$ in the U.S., expanding the focus of the project to the more complex geothermal conditions in the Cordillera from the eastern U.S. focus in the previous study. The data to be used in resource analysis in the western U.S. are being collected from a variety of published and unpublished sources. A large number of formerly unavailable company temperature gradient and heat flow exploration data are being collected, compiled, and will be synthesized in addition to the public domain data in papers and open-file reports.

Geothermal resource estimates and assessments by this and other projects are supported by making available for the process the most up to date heat flow, geothermal gradient, and thermal conductivity information in useful digital formats. Distribution of the results in digital form via the Internet is part of the project.

\section{RESEARCH RESULTS}

\section{Heat Flow and Thermal Properties Data Base}

A data base of all available heat flow measurements in the United States was prepared and published by Blackwell et al. (1989). The heat flow data base was used in the preparation of the (DNAG) 1:5,000,000 Geothermal Map of North America (Blackwell and Steele, 1992, see also Blackwell et al., 1991, 1992). That heat flow data base has been updated as of September, 1996 with an additional 256 high quality heat flow sites (and 456 total sites) that have become available since compilation of the 1989 data list of 1735 sites. The entry for each site includes location, thermal gradient, and other pertinent data as described in previous reports. The new data fill in some gaps in the existing heat flow data distribution, however, large gaps in heat flow measurements remain in some areas such as the Gulf Coast, the southern Great Plains, and the Northcentral region (Ohio, Indiana, and Kentucky). The site information is available on the Internet home page in spreadsheet form.

As a second part of this first task, a $5 \mathrm{~km}$ interval digitized version of the revised heat flow map has been prepared. The digital form of the heat flow map allows quantitative analysis of the heat flow on a geographically weighted basis as opposed to the somewhat biased analysis based on data sites alone. This information was used to produce a new geothermal gradient map that is shown in Figure 1. This map represents the mean gradient over a depth interval of 1 to $3 \mathrm{~km}$ and thus, when added to the surface temperature, gives a good indication of the mean temperature at various depths. This display focuses on 
regional variations rather than local anomalies. The distribution of geothermal gradient has been discussed in detail in the references mentioned above.

One of the main project results is planning and initial development of the geothermal system specific, thermal well, data base. A map is shown (Figure 2) that gives the location of sites where multiple wells in individual geothermal systems are available to us at the present time (pluses). About 1/2 of these data are in reports and open-file reports that have not been generally available in the past (see below). In addition the location of individual wells in our database that are classed as "geothermal" are shown (triangles).

The information on each geothermal gradient/heat flow exploration site will consist of the number, temperature, and depth range of wells, the area location, a thermal gradient or heat flow map of the area, a reference (or references) to the results and to the original thermal data, Ultimately we plan to include individual well identification, location and thermal data of the areas if possible.

The first inventory result is summarized on Figure 2 . We have collected the data from a number of different sources including material published in the GRC Transactions and related publications; material published in the open literature; thermal wells in the published data base described above, unpublished DOE technical reports and open-file reports (Industry Coupled data releases for example), USGS open-file reports, and unpublished thermal data in the SMU archives. The data in the first three categories are fairly readily available whereas the others are relatively less available. The locations of wells in these categories by area are shown by symbols on Figure 2 for the western U.S., where all but a few of the points lie. The total number of wells is about 3,260 . We have attempted to remove the major duplications but undoubtedly some still exist. Areas where the symbols overlap are areas with multiple studies that include both duplicate and/or spatially overlapping thermal data sets. We have the list of data areas from the GEO data base (Renner, personnel communication, 1997) and the data set compiled by Larry Garside for the state of Nevada (1997). These have not yet been folded into the total data set.

\section{FUTURE PLANS}

In the future there are plans to maintain the regional thermal properties data base and to keep updated results available by operating the home page on the Internet with the up-to-date information available there. The data base of exploration heat flow wells in the western U.S. will be developed and expanded. The regional resource evaluation and exploration methodology used in the earlier studies, with appropriate modifications, will be applied to the western U.S. Local evaluation procedures will be developed using the data.

\section{INDUSTRY INTEREST}

We have had inquires from numerous individuals and companies for local information on temperature and geothermal gradient. Specific larger projects using regional data base that we know about are shown on the next page. 


\section{Organization}

INEEL

NASA

Geoheat Center

Energy Laboratory, MIT

\section{Type and Extent of Interest}

Geothermal Education

Geothermal Resource Evaluation

Geothermal Gradients in U.S.

Temperature for Heat Mining Economic Analysis

\section{REFERENCES}

Blackwell, D.D., and J.L. Steele, editors, DNAG geothermal map of North America, 1:5,000,000, 4 sheets, Geol. Soc. Amer., Boulder, Co., 1992.

Blackwell, D.D., J.L. Steele, and L.S. Carter, Heat flow data base for the United States, in Geophysics of North America CD-ROM, ed. A.M. Hittleman, J.O. Kinsfather, and H. Meyers, NOAA, Natl. Geophys. Data Center, 1989:

Blackwell, D.D., J.L. Steele, and L.S. Carter, Heat flow patterns of the North American Continent; A discussion of the geothermal map of North America, p. 423-437, in Neotectonics of North America, ed. D.B. Slemmons, E.R., Engdahl, M.D. Zoback, and D.D. Blackwell, Geol. Soc. Am. Decade of North Am. Geol., Decade Map V. 1, 498 pp., 1991.

Blackwell, D.D., J.L. Steele, and L.S. Carter, Heat flow patterns of the United States: a key component of geothermal resource evaluation, Trans. Geothermal Resources Council, 16, 119-124, 1992

Blackwell, D.D., J.L. Steele, and L.S. Carter, Geothermal resource evaluation for the eastern United States based on heat flow and thermal conductivity distribution, Trans. Geothermal Resources Council, 17, 97-103, 1993

Blackwell, D.D., J.L. Steele, and K.W. Wisian, Results of geothermal resource evaluation for the eastern United States, Trans. Geothermal Resources Council, 18, 161-164, 1994.

Blackwell, D.D., K.W. Wisian, and J.L. Steele, Geothermal regime in the central and eastern United States east of the Rocky Mountains, pp. 649-653, in Proc. World Geothermal Cong. 1995, ed. E. Barbier, G. Frye, E. Iglesias, and G. Palmason, V. 1, 665 pp., 1995.

Blackwell, D.D., K.W. Wisian, and Maria Richards, Geothermal resources of the United States based on heat flow and gradient information, Final Report DOE contract C91-103450, 75 pp., 1996

Muffler, L.J.P., ed, Assessment of Geothermal Resources of the United States--1978, U. S. Geol. Surv. Circ. 790, 163 pp., 1979.

Reed, M.J., ed., Assessment of low-temperature geothermal resources of the United States-1982, U. S. Geol Surv. Circ. 892, 73 pp, 1983. 


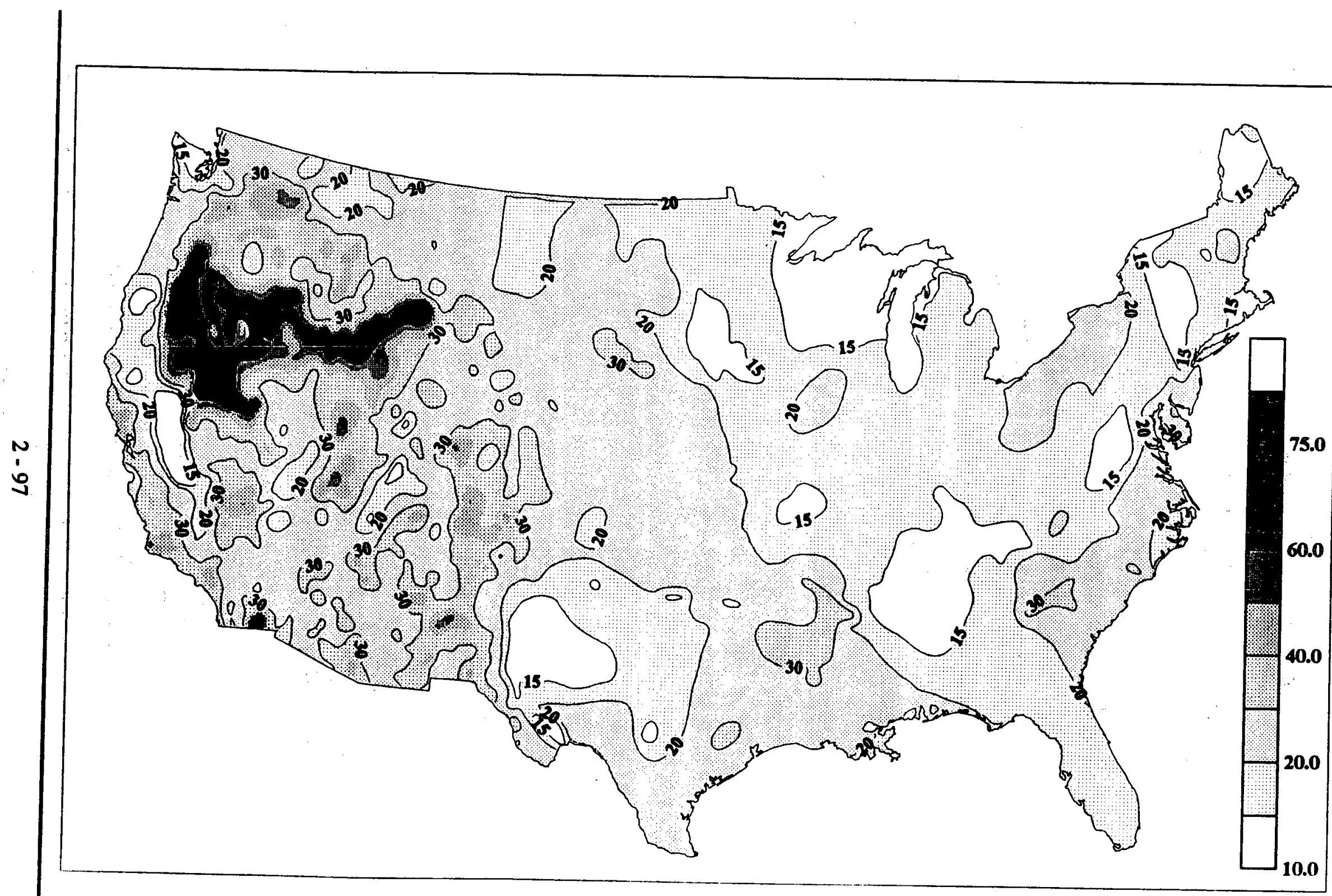




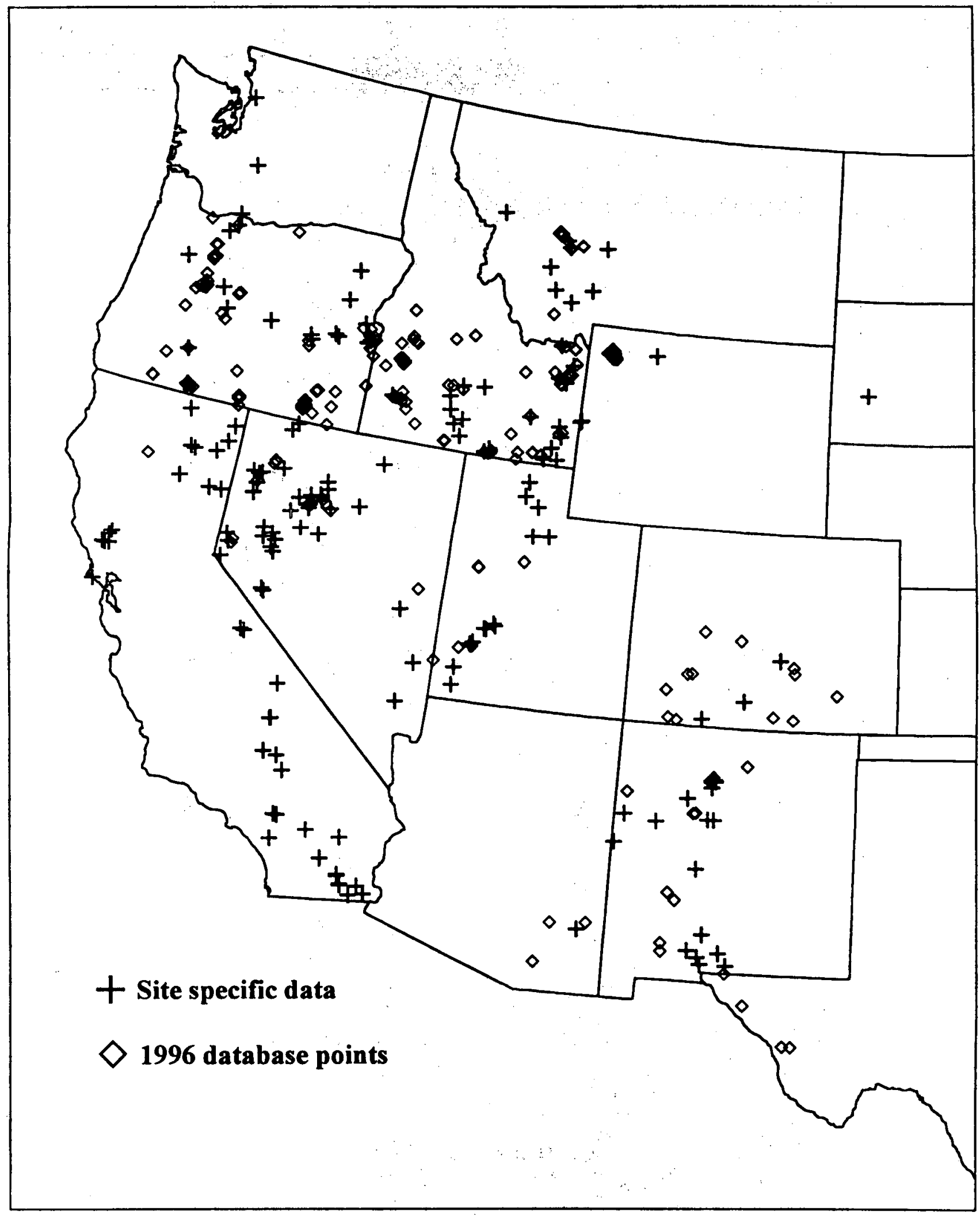

Figure 2 -- Location of site specific heat flow and geothermal gradient data in the western U.S. 


\section{LIST OF CONTACTS FOR EXPLORATION TECHNOLOGY}

Timothy D. Anderson

Unocal Geothermal

1300 N. Dutton Avenue

Santa Rosa, California

Phone: (707) 521-7611

Fax: (707) 521-7604

e-mail: tanderson@unocal.com

Lawrence M. Anovitz

Chemical and Analytical Sciences Division

Oak Ridge National Laboratory

P.O. Box 2008, Bldg. 4500S, MS-6110

Oak Ridge, TN 37831-6110

Phone: (423) 574-5034

Fax: (423) 574-4961

David D. Blackwell

Department of Geological Sciences

Southern Methodist University.

Dallas, TX 75275

Phone: (214) 768-2745

Fax: (214) 768-2701

e-mail: blackwel@passion.isem.smu.edu

James G. Blencoe

Chemical and Analytical Sciences Division

Oak Ridge National Laboratory

P.O. Box 2008, Bldg. 4500S, MS-6110

Oak Ridge, TN 37831-6110

Phone: (423) 574-7041

Fax: (423) 574-4961

Peggy Brookshier

U. S. Department of Energy

Idaho Operations Office

785 DOE Place, MS 1220

Idaho Falls, ID 83401-1563

Phone: (208) 526-1403

Fax: (208) 526-5964
Philip A. Candela

Department of Geology

University of Maryland at College Park

College Park, MD 20742-4211

Phone: (301) 405-2783

Fax: (301) 314-9661

e-mail: candela@geol.umd.edu

David R. Cole

Chemical and Analytical Sciences Division

Oak Ridge National Laboratory

P.O. Box 2008, Bldg. 4500S, MS-6110

Oak Ridge, TN 37831-6110

Phone: (423) 574-5473

Fax: (423) 574-4961

John K. Costain

Professor of Geophysics

Department of Geological Sciences

Virginia Tech

Blacksburg, VA 24061

Phone: (540) 231-8912

Fax: (540) 231-3386

e-mail: costain@vt.edu

Robert J. Creed Jr.

U. S. Department of Geothermal Energy

Idaho Operations Office, MS 1220

850 Energy Drive

Idaho Falls, Idaho 83401

Phone: (208) 526-9063

Fax: (208) 526-6249

e-mail: creedrj@inel.gov

Donald J. DePaolo

Department of Geology and Geophysics

University of California

Berkeley, CA 94720

Phone: (510) 643-5063

Fax: (510) 486-5496 
Fraser Goff

EES-1, MS D462

Los Alamos National Laboratory

Los Alamos, NM 87545

Phone: (505) 667-8060

Fax: (505) 665-3285

e-mail: fraser@lanl.gov

Juske Horita

Chemical and Analytical Sciences Division

Oak Ridge National Laboratory

P.O. Box 2008, Bldg. 4500S, MS-6110

Oak Ridge, TN 37831-6110

Phone: (423) 576-2750

Fax: (423) 574-4961

Jeffrey B. Hulen

Energy and Geoscience Institute

423 Wakara Way

Salt Lake City, UT 84108

Phone: (801) 581-8497.

Fax: (801) 585-3540

e-mail: jhulen@egi.utah.edu

Cathy J. Janik

MS 910

US Geological Survey

345 Middlefield Rd.

Menlo Park, CA 94025

Phone: (415) 329-5213

Fax: (415) 329-5203

e-mail: cjanik@mojave.wr.usgs.gov

Diane L. Kamola

KU Center for Research, Inc. and Department of

Geology

University of Kansas

Lawrence, KS 66045-2124

Phone: (785) 864-7712

Fax: (785) 864-7789

B. Mack Kennedy

Lawrence Berkeley National Laboratory

Earth Sciences Division, MS 70A-3363

Berkeley, CA 94720

Phone: (510) 486-6451

Fax: (510) 486-5496
Ki Ha Lee

Earth Sciences Division

MS 90-1116

Lawrence Berkeley National Laboratory

Berkeley, CA 94720

Phone: (510) 486-7468

Fax: (510) 486-5686

Dr. Tsvi Meidav

Trans-Pacific Geothermal Corporation

1901 Harrison, Suite 1590

Oakland, CA 94612

Phone: (510) 763-7812

Fax: (510) 763-2504

e-mail: tgcorp@california.com

Glenn Melosh

Unocal Geothermal Indonesia

Ratu Plaza Office Tower, 3rd Floor

Jl. Jend. Sudirman, Jakarta, INDONESIA

Phone: 021-571-0525

Fax: 021-720-5153

e-mail: gmelosh@unocal.com

Joseph Moore

Energy and Geoscience Institute

423 Wakara Way

Salt Lake City, UT 84108

Phone: (801) 585-6931

Fax: (801) 585-3540

e-mail: jmoore@egi.utah.edu

Dennis L. Nielson

Energy \& Geoscience Institute

University of Utah

423 Wakara Way

Salt Lake City, UT 84108

Phone: (801) 585-6855

Fax: (801) 585-3540

e-mail: dnielson@egi.utah.edu

Philip M. Piccoli

Department of Geology

University of Maryland at College Park

College Park, MD 20742-4211

Phone: (301) 405-6966

Fax: (301) 314-9661

e-mail: piccoli@geol.umd.edu 
Marshall Reed

U. S. Department of Geothermal Energy

Office of Geothermal Technology, EE-12

1000 Independence Avenue, SW

Washington, D. C. 20585-0121

Phone: (202) 586-8076

Fax: (202) 586-8185

e-mail: marshall.reed@hq.doe.gov

Joel L. Renner

Idaho National Engineering and Environmental

Laboratory

P.O. Box 1625

Idaho Falls, ID 83415-3830

Phone: (208) 526-9824

Fax: (208) 526-0969

e-mail: rennerjl@inel.gov

Howard P. Ross

Energy \& Geoscience Institute

University of Utah

423 Wakara Way, Suite 300

Salt Lake City, Utah 84108

Phone: (801) 581-5184

Fax: (801) 585-3540

e-mail: hross@egi.utah.edu

James Stimac

Unocal Geothermal

1300 North Dutton Avenue

Santa Rosa, California 95401

Phone: (707) 521-7600

Fax: (707) 521-7604

e-mail: jstimac@unocal.com

Bill Teplow

Trans-Pacific Geothermal Corporation

1901 Harrison, Suite 1590

Oakland, CA 94612

Phone: (510) 763-7812

Fax: (510) 763-2504

e-mail: tgcorp@california.com

\author{
Alan C. Tripp \\ Department of Geology and Geophysics \\ University of Utah \\ 2634 KRC \\ Salt Lake City, UT 84112 \\ Phone: (801) 581-4664 \\ Fax: (801) 581-7065 \\ e-mail: actripp@mines.utah.edu \\ Alfred H. Truesdell
700 Hermosa Way \\ Menlo Park, CA 94025 \\ Phone: (650) 322-6135 \\ Fax: (650) 324-4009 \\ J. Douglas Walker \\ Department of Geology \\ University of Kansas \\ Lawrence, KS 66045-2124 \\ Phone: (785) 864-2735 \\ Fax: (785) 864-5276 \\ Philip E. Wannamaker \\ Energy and Geoscience Institute \\ 423 Wakara Way \\ Salt Lake City, UT 84108 \\ Phone: (801) 581-3547 \\ Fax: (801) 585-3540 \\ e-mail: pewanna@egi.utah.edu
}




\section{DRILLING TECHNOLOGY}




\title{
DEVELOPMENT OF ADVANCED SYNTHETIC-DIAMOND Drill Bits for Hard-Rock Drilling
}

\author{
Jack L. Wise and David W. Raymond \\ Sandia National Laboratories
}

\section{KEY WORDS}

polycrystalline diamond compact (PDC), synthetic-diamond bits, impregnated-diamond bits, thermally stable polycrystalline (TSP), hard-rock drilling, geothermal drilling, single-cutter testing, cutter wear testing

\section{PROJECT BACKGROUND AND STATUS}

If the life and penetration rate of bits used in geothermal drilling could both be doubled, a $15 \%$ reduction in geothermal well costs would result. Technology development in the field of synthetic-diamond bit design has the potential for providing such improvements. Based on Sandia's prior history with the development of polycrystalline diamond compact (PDC) bits, Sandia renewed its program in this area in $1992^{1.2}$.

A large number of companies were contacted and a comprehensive program proposal on synthetic-diamond drill bit technology development was written. The proposal was presented to the Drilling Engineering Association for review and evaluation in February 1993. After favorable review, the DOE Office of Fossil Energy approved funding for the program under the Natural Gas and Oil Technology Partnership (NGOTP). This funding was received in August 1993. Joint-work, cost-shared contracts were placed with each company, and the program was begun at the end of October 1993. Additional funding was received from the DOE Office of Geothermal Technologies in FY94. Overall funding for the program was shared equally by industry, DOE Fossil Energy, and DOE Geothermal in FY95. The NGOTP funding was depleted in FY95, but funding by DOE Geothermal has continued. The current projects are all expected to be completed in FY98 or FY99.

\section{PROJECT OBJECTIVES}

The hard, abrasive, and fractured rock formations drilled to access geothermal reservoirs are generally considered beyond the capabilities of current synthetic-diamond drag bit technology. However, the inherent cutting efficiency and lack of moving parts of drag bits make them an ideal prospect for future increases in penetration rate and bit life in hard formations. The hard-rock drill bit program is a national laboratory-industry cooperative research and development program aimed at developing drag bits capable of more economically drilling into hard-rock formations.

\section{Technical Objectives}

- Reduce geothermal drilling costs by increasing penetration rates and bit life over those attainable with current roller-cone bits.

- Extend the range of application of drag bit technology into harder formations. 


\section{Expected Outcomes}

- Develop an optimized PDC claw cutter design combining the abrasion resistance of diamond and the impact resistance of tungsten carbide.

- Develop advanced thermally-stable polycrystalline (TSP) drill bits capable of handling the higher temperatures associated with hard-rock geothermal drilling.

- Optimize a Track-Set PDC bit, effectively reducing lateral vibrations and impacts in hard rock.

- Develop advanced impregnated-diamond bits utilizing new diamond coating technology and specifically developed to increase penetration rates in hard rock.

- Develop a mudjet-augmented PDC drill bit that employs low-pressure mudjets to augment the drag cutting action.

- Develop an improved understanding of cutter chatter and bit dynamics as they affect the design and operation of PDC bits in hard-rock formations.

- Determine the feasibility of fabricating wear-resistant drag cutters by explosively compacting boron suboxides.

\section{APPROACH}

Several drill bit companies, drag-cutter companies, and universities have teamed with Sandia National Laboratories to work on different projects as part of a cooperative effort to advance the state of the art in drag bit design and manufacture. Each project explores a different approach to cutter and bit design and builds on each respective companies' capabilities and current product interests. Sandia's role is to assure integration of the individual projects into a coherent program and to provide unique testing and analytical capabilities where needed.

Research and development is being conducted in the design of PDC cutters and bits, impregnated-diamond bits, thermally-stable polycrystalline (TSP) bits, and explosively compacted boron-suboxide cutters. The objective of each project is to develop drill cutters and bits that drill faster and last longer in hard-rock formations. The development of these hard-rock bits would mean lower-cost and faster drilling in natural gas, oil, and geothermal reservoirs.

The companies and universities that have teamed together with Sandia to work on these projects are listed below with the corresponding projects.

- Dennis Tool Company is optimizing the design of the claw cutter by combining single-cutter wear testing with thermal and stress numerical modeling. The project will result in a claw cutter that has been optimized for hard rock drilling.

- Security DBS is optimizing the design of their Track-Set drill bit. A variety of cutter tests will be performed to analyze the track-set cutting structure. The results of the tests will be utilized in a force/wear bit model for Track-Set bit design. 
- Hughes Christensen Company is improving impregnated-diamond bit performance in hard rock. A mechanistic drilling model for impregnated bits is being developed with the aid of laboratory drilling tests. The final model will be used to develop bit designs for specific hard-rock applications.

- Maurer Engineering and Slimdril International are improving the design of TSP drill bits in hard rock by using results from single-cutter wear testing to design and fabricate three different TSP bits. The bits will be evaluated both in the laboratory and in the field.

- Amoco Production Research participates in the program by providing expertise related to field testing and use of PDC bits and by making available their Catoosa Test Facility for use in evaluating concepts related to hard-rock synthetic-diamond bit design.

- Security DBS, Dynaflow, and Terra Tek participate in a project to develop a mudjet-augmented PDC bit.

- University of Southwestern Louisiana is conducting a study of PDC cutter chatter using Sandia's rockcutting facilities.

- New Mexico Institute of Mining and Technology is conducting two studies related to rock drilling: an experimental and theoretical study of PDC bit dynamics and wear; and a separate study on the explosive compaction of boron suboxide to fabricate rock cutters.

Sandia plays a role in each of the above projects, ranging from technical program management to comparative cutter wear testing, linear testing of cutting force and rock/cutter interaction, and numerical thermal and mechanical stress analysis.

\section{RESEARCH RESULTS}

Work conducted on each project in FY97 is described below. Previous work on some of these projects in described in Reference 3.

\section{Claw Cutter Optimization}

Sandia provided continuing technical assistance to Dennis Tool Company during FY97 to support efforts to optimize PDC claw cutter designs. This assistance included both analytical and experimental activities. Specifically, Sandia completed a parametric, three-dimensional numerical analysis for ten different claw-cutter configurations under typical operating conditions. The claw-cutter geometries being studied featured various groove widths, groove spacing, groove depths, and diamond thicknesses. In FY97, separate thermal-stress and mechanical-stress computational results obtained previously were superimposed to determine the net overall stress distribution for each cutter design, thereby identifying the optimal configuration on the basis of minimal peak stresses. Wear tests have been initiated to validate this assessment.

The relevant wear investigations utilize the Sandia Cutter Wear Test Facility (CWTF), a laboratory drilling machine, to comparatively evaluate the wear performance of cutters in an actual drilling environment with realistic fluid flow and cutter speeds, forces, and interactions. To date, several older claw-cutter designs have been tested that have a very coarse diamond grain size as compared to the standard (GE 2741) PDC cutter formulation that has been used to establish a baseline wear rate. For the sake of a meaningful comparison, new 
claw cutters with the "standard" PDC diamond grain size are currently being manufactured by Dennis Tool Company for upcoming tests.

\section{Track-Set Bit Optimization}

During FY97, Sandia augmented the track-set bit development work in progress at Security DBS by maintaining and expanding its database of cutter force-component measurements acquired with the SNL Linear Cutter Test Facility (LCTF). Existing test results were interpreted for incorporation in the Security DBS bit-design code which is an adaptation of the Sandia-developed PDCWEAR code. In addition, new parametric studies were completed to determine the operating forces characteristic of a new "super chamfer" cutter design when used in different rock types (Berea Sandstone and Sierra White Granite) with various combinations of backrake, siderake, and depth-of-cut settings. Planning was initiated for an FY98 test program that will employ the LCTF to measure triaxial cutting forces as a function of depth-of-cut for dual-cutter, track-set geometries that involve assorted lateral and circumferential cutter spacing.

\section{TSP Bit Optimization}

Maurer Engineering continued to promote the thermally-stable polycrystalline (TSP) diamond cutter technology during FY97 for application to hard-rock drilling by identifying promising cutter designs and obtaining samples for performance evaluation in the Sandia CWTF. In particular, Maurer focused attention on a new cutter design concept that features small TSP cutters embedded in a tungsten-carbide matrix which is sintered via a proprietary low-temperature process. Samples of this cutter have been provided to Sandia for testing in FY98.

\section{Impregnated-Diamond Bit Optimization}

Sandia administered DOE funding to Hughes Christensen Company for ongoing mechanistic modeling and laboratory testing of impregnated-diamond drill bits incorporating various diamond and matrix-material combinations. Specifically, comparative performance and wear data were obtained for three types of hard rock using bits that featured different diamond grit sizes, diamond qualities, diamond concentrations, and matrix types. Testing of this nature was completed during FY97 to guide upcoming (FY98) activities aimed at the design, fabrication, and possible field demonstration of one or more bits designed for geothermal drilling. As a result of this joint project with Sandia, Hughes Christensen has significantly expanded its impregnated-diamond research effort.

\section{PDC Bit Field Testing}

After a number of years of research aimed at improvements in PDC bit performance for hard-rock applications, Sandia began to formulate plans during FY97 for the demonstration of the latest technology by means of field tests involving bits that are to be designed and built by several manufacturers specifically for geothermal drilling. These tests will be accomplished in cooperation with one or more geothermal operators to allow assessment of the merits of each design approach under actual, and nominally identical, drilling conditions. At least one geothermal operator has agreed in principle to test the bits in their geothermal wells. 


\section{Brazing Process for Attachment of TSP Diamond to a Substrate}

Working under a project sponsored by the National Advanced Drilling and Excavation Technologies (NADET) Institute, Sandia began testing late in 1997 to evaluate the viability of a new microwave brazing process for bonding TSP cutters to tungsten-carbide substrates. This is a cooperative, multidisciplinary effort that also involves Technology International; Inc., the Jet Propulsion Laboratory, and the Colorado School of Mines.

The Sandia tests utilized the CWTF to ascertain bond integrity in a realistic drilling environment, and to obtain TSP wear-resistance data for comparison to standard PDC performance. Initial drilling results showed no evidence of bond failure, and indicated a wear resistance for the TSP cutter that was quantitatively consistent with that for a baseline PDC cutter. Additional tests are planned for FY98.

\section{Drill Bit Technology Assessment}

Sandia provided general consulting and laboratory test services to industry in the development of candidate hardrock drill bit technology. Using PDCWEAR, a computer code developed at Sandia, analysis has been conducted to predict the performance of an 8-3/4" Jammer Bit currently under development at Novatek. The bit is intended to penetrate hard-rock formations using percussive-type drilling action. The Jammer Bit has $\mathbf{4 1}$ polycrystalline diamond cutters distributed on five blades and includes multiple mud jets. Using experimentally derived penetrating force-depth of cut data provided to Sandia by Novatek for two rock types, Missouri Red Granite and Holston Limestone, PDCWEAR predicted the individual cutter forces in addition to integrated bit performance parameters such as weight-on-bit, drilling torque, and bit imbalance. These predictions will be used to modify the design for improved individual cutter performance, increased drilling efficiency and extended bit life.

Using the Sandia-developed Cutter Wear Test Facility (CWTF), Sandia provided wear testing to several companies developing advanced PDC cutter technology. As previously mentioned, the CWTF is a laboratorybased drill rig which is used to evaluate the performance of polycrystalline diamond cutter blanks under controlled conditions. The CWTF accommodates research in PDC bit wear by using a replaceable-cutter coring bit to drill multiple boreholes through a small rock sample to simulate deep penetrations in an actual hard-rock drilling environment. By drilling a series of holes with a bit configured with identical cutters, a "baseline" performance for the CWTF is established. Comparative type testing can then be conducted by replacing the test cutter, installing new gage cutters identical to those used in the baseline, and repeating the testing under the same conditions. This allows the performance of other cutter specimens to be evaluated with respect to the baseline.

The CWTF baseline has been established using GE 2741-DTC (diamond table chamfer) polycrystalline diamond cutter blanks manufactured by General Electric. To establish the baseline, the CWTF is operated at a constant rate of penetration of 30 feet per hour in Sierra White Granite with constant rotary speed of $100 \mathrm{rpm}$ and water as a drilling fluid. Cutter wear is measured after a test using high resolution optical magnification equipment.

Wear testing has been conducted on five (5) types of polycrystalline diamond claw cutters currently under development at Dennis Tool Company. As described before, this data will be used along with numerical analysis data to optimize the claw cutter design. Sandia has also tested proprietary cutters under development at Hughes Christensen. Testing will continue for both of these companies, in addition to others, in FY98.

\section{Mudjet-Augmented PDC Bit}

This NADET project incorporates the cooperative efforts of Security DBS, Dynaflow, Terra Tek and Sandia to develop a PDC bit which uses high pressure, resonating, cavitating, jet nozzles to augment several PDC cutters 
on an existing bit design. Work began in the last quarter of FY97 after funding was secured and the necessary contracts placed. The project will continue into FY 98 using its remaining FY97 funds.

An existing Security DBS PDC bit has been selected for modification to include the mudjet nozzles. Sandia has made predictions using PDCWEAR to identify the cutters which would be best suited for mudjet-augmentation. A nozzle design study is currently underway . In FY98, the design of the prototype nozzles and bit will be completed, manufactured, and tested at Terra Tek.

\section{Self-Induced PDC Bit Vibrations}

Testing commenced in the Sandia LCTF during FY97 to support a study of self-induced PDC cutter vibration (i.e., chatter) that has been undertaken by the University of Southwestern Louisiana. This is a cost-shared project, with funding provided by Unocal, Baker Hughes Inteq, Hughes Christensen Company, and DOE Geothermal. To date, previous cutting-force measurements from the LCTF database have been reviewed to assess rock cutting stiffness, the bandwidth of the data acquisition system has been significantly expanded, a more compliant support frame for rock samples has been fabricated and installed to permit rock flexure, mechanical transfer functions have been determined for the cutter and mounting hardware, and initial vibration data have been acquired during linear cutting under different conditions and have been subjected to spectral analysis. This work will resume during the summer of 1998 to study process damping and cutting stability.

\section{Cutter Force Modeling for Hard-Rock Drilling}

Sandia administered FY97 DOE funding to the New Mexico Institute of Mining and Technology (New Mexico Tech) in support of analytical studies of cutter/rock interactions, including cutting-force and rock-fragmentation phenomena. A single-cutter force model was developed based on the rock fragmentation process and statistical analyses of cutter force-component measurements extracted from the Sandia LCTF database that was mentioned previously in conjunction with the track-set bit development activities at Security DBS. This model is applicable to continuing efforts, at New Mexico Tech and elsewhere, to better define the downhole dynamic behavior, including shock response, of a PDC drill bit.

\section{Explosively-Compacted Drag Cutters}

New Mexico Tech conducted additional DOE-funded research under contract with Sandia in FY97 to evaluate the potential for fabrication of superhard rock cutters using explosive compaction techniques. Initial experiments produced boron sub-oxide materials with a hardness approaching that of synthetic diamond, and a fracture toughness greater than that of tungsten carbide. Early testing at Sandia showed promise for this material as a rock-cutting agent. Efforts to optimize the explosive compaction process continued at New Mexico Tech during FY97 with the object of supplying sample cutters to Sandia during FY98 for LCTF and CWTF testing.

\section{Bi-Center PDC Bits}

During FY97, a plan was formulated by Sandia and Montana Tech of the University of Montana for a project to model and develop bi-center PDC bits for geothermal applications. Under this plan, complementary analytical and experimental activities will culminate in the development of a fully three-dimensional model for bi-center bits that will permit calculation of the orientation and magnitude of the reactive bit forces and moments. Furthermore, mechanisms contributing to unusual cutter wear patterns will be studied, and a concept will be pursued for optimizing drilling parameters on the basis of downhole conditions (e.g., rock properties and/or bit wear) derived from force and moment measurements at the bit. Ultimately, a prototype bi-center bit design will be developed, 
fabricated, and field tested to validate the modeling effort. Diamond Products International, a bit manufacturer, and Midgard Energy Company, an independent operator, will participate in the project with hardware, salary, and in-kind services related to laboratory and field tests of the prototype bit.

\section{PDC Cutter Forces in Uncycled and Pressure-Cycled Sierra White Granite}

In support of research and development activities at Waterjet Technology, Inc., Sandia performed a series of LCTF tests during FY97 to quantify the force components experienced by a PDC cutter as it scored a slab of Sierra White Granite that had been previously pressure cycled in water to 4000 psi for 24 hours. Comparison of the results from these tests to those obtained previously for uncycled SWG indicated that hydrostatic pressure cycling had no significant influence on the force components affecting a PDC cutter.

\section{FUTURE PLANS}

The contracts with the industry partners were extended for two additional years in FY96. This will allow the work outlined in the original program plan to be completed. Upon completion, the projects will be evaluated to determine the bit design approaches that have the greatest potential for improving hard-rock drilling. Additional work may then be initiated to further advance the technology related to those approaches.

\section{INDUSTRY INTEREST}

\section{Organization}

Dennis Tool Company

Maurer Engineering, Inc./Slimhole Int']

Security DBS

Hughes Christensen Company

Technology International

Colorado School of Mines

Jet Propulsion Laboratory

Dynaflow, Inc.

Terra Tek, Inc.

Waterjet Technology, Inc.

Novatek, Inc.

University of Southwest Louisiana

New Mexico Tech

Montana Tech

\section{Type and Extent of Interest}

Cost-shared partner

Cost-shared partner

Cost-shared partner, NADET partner

Cost-shared partner

NADET project partner

NADET project partner

NADET project partner

NADET project partner

NADET project partner

Technical assistance

Technical assistance

Cost-shared partner

Contract partner

Cost-shared partner 


\section{REFERENCES}

Glowka, D.A. and Schafer, D.M.: "Program Plan for the Development of Advanced Synthetic-Diamond Drill Bits for Hard-Rock Drilling," Report SAND93-1953, Sandia Natl. Laboratories, Albuquerque, NM (September, 1993).

Schafer, D.M. and Glowka, D.A.: "An Overview of the Department of Energy's Advanced Synthetic-Diamond Drill Bit Program," presented at ASME Energy-Sources Technology Conference, New Orleans, LA, January 24-26, 1994 (PD-Vol. 56), 175-180.

Glowka, D.A.; Dennis, T.; Le, P.; Cohen, J.; and Chow, J.: "Progress in the Advanced Synthetic-Diamond Drill Bit Program," Transactions, ASME Energy Week Conference '96, Houston, TX, January 30-February 1, 1996. 


\title{
LOST CIRCULATION TECHNOLOGY DEVELOPMENT PROJECT Loss-Zone Characterization Hardware and Software
}

\author{
George E. Staller and Arthur J. Mansure \\ Sandia National Laboratories
}

\section{KEY WORDS}

drilling fluid hydraulics measurement system, rolling float meter, Doppler flow meter, expert system

\section{PROJECT BACKGROUND AND STATUS}

Lost circulation accounts for $10-20 \%$ of the cost of a typical geothermal well. If the driller and drilling engineer had more knowledge about a lost-circulation zone that had been encountered, decisions as to how to best treat the loss zone could be made quicker and more accurately. The current industry practice of monitoring drilling fluid pit levels to detect and quantify lost circulation zones is inadequate because of low resolution and slow response. A technique based on comparing the inflow and outflow rates of the drilling fluid would provide much faster response and more useful data. The goal of this project is to develop such a technique and the associated hardware and software.

This project began when it was observed that geothermal drillers did not have an effective means for detecting and evaluating lost circulation zones. The idea of the rolling float meter for measuring drilling fluid outflow rates was conceived and reported to a geothermal industry advisory board, which enthusiastically supported its development. Design and laboratory testing proceeded, and a prototype rolling float meter was field tested in the Long Valley Exploratory Well in 1991. Improvements in the manufacture of the float and bearing assembly were undertaken to correct problems encountered in the field test. Two conference papers and a comprehensive report were written that describe the rolling float meter and its development ${ }^{1-3}$. A loan program was set up in which eight rolling float meters were loaned to various service companies in the geothermal and petroleum drilling industries. Results of the evaluations were discussed in the FY95 annual report.

One of the results of the rolling float meter testing program was the realization that a better technique for measuring drilling fluid inflow rates was also needed. Acoustic Doppler flow meters were thought to be ideal for this application because they are non-intrusive, having transducers that clamp onto the outside of the rig standpipe. Testing of a commercially available Doppler flow meter was done on a core rig in the Steamboat Geothermal Field in 1993. It was shown that rig noise was too intense for the meters unless further signal processing could be done.

In 1994, a new type of Doppler flow meter was introduced to the marketplace by Peek Measurements, Inc. This meter performs advanced signal processing that can be used to separate rig noise from the Doppler signal. This type of flow meter has been evaluated, with good results, on nearly a dozen different geothermal drill rigs since FY95 ${ }^{4}$. Results of testing completed in the past year are discussed in this report.

It was also realized during field testing of the rolling float meter and Doppler. flow meters that some type of realtime inflow/outflow data analysis software would be extremely useful for interpreting the sometimes confusing data that are gathered from the various sensors on the drill rig. It was recognized that a cost-effective approach to developing such software would be to build on the Well Site Advisor (WSA) expert system developed by 
Tracor, Inc., for gas kick detection in oil and gas wells. A project to do that was initiated in FY96 as a Geothermal Drilling Organization (GDO) project. Details of the progress to date are discussed in this report.

All development work related to the rolling float meter and the Doppler flow meter has been completed, although technology transfer efforts continue. The expert system development will require two more years to complete.

\section{PROJECT OBJECTIVES}

The objective of this project is to develop and transfer to industry a reliable and accurate method for measuring and analyzing the inflow and outflow rates of fluid flow in geothermal wells while drilling. More accurate measurement of these flow rates would allow lost circulation to be more quickly recognized and characterized. This would allow more rapid and accurate diagnosis of loss zones, leading to better decisions on treating the loss zones, thereby saving rig time and reducing drilling costs and, therefore, the costs of on-line geothermal power. It would also allow steam kicks to be detected and circulated through more effectively and safely, making underbalanced drilling and its attendant benefits more attractive for geothermal drilling.

\section{Technical Objectives}

- Reduce geothermal drilling costs by making more informed and timely decisions on lost circulation control.

- Develop and document the rolling float meter and demonstrate its usefulness in measuring drilling fluid outflow rates in geothermal drilling. Develop procedures for the proper use of the rolling float meter on drill rigs.

- Verify the advantage of using commercial acoustic Doppler flow meters to accurately measure drilling fluid inflow rates in geothermal drilling. Develop procedures for the proper use of Doppler flow meters on drill rigs.

- Develop an expert system, operating procedures, and data acquisition algorithms for monitoring, recording, and analyzing drilling fluid inflow and outflow rates for the purpose of identifying and characterizing lost circulation zones.

- Demonstrate tó industry how accurate inflow/outflow measurements and analysis can be used to reduce rig time and make more informed decisions. Advise geothermal service and operating companies interested in using this technology on their drill rigs.

\section{Expected Outcomes}

Reduced down time and costs associated with lost circulation are the expected outcomes of this project. With a rig rate of $\$ 300-500 / \mathrm{hr}$ and a single cement treatment (including rig time) costing over $\$ 10,000$, small improvements in the efficiency of dealing with loss zones can have a significant effect on total wellbore costs. For example, circulating to confirm a drilling fluid loss by monitoring mud pit levels, the standard practice, may require more than one hour of time for each loss zone, whereas the technology under development in this project is able to detect such fluid loss as soon as it occurs. This allows the location of the loss zone to be accurately determined if the loss zone is on bottom. Also, by knowing exactly when fluid losses begin, it is possible to make sure that at least ten additional feet of hole are drilled in order to uncover the loss zone fully before cementing. Premature cementing can waste cement plugs because the loss zone may leak further when it is fully drilled through later. The expert system, when carried through to its ultimate configuration, will provide drillers with 
assistance in detecting and analyzing anomalies throughout the drilling process. This could substantially reduce the down time associated with the non-drilling parts of the process, thereby improving overall efficiencies and reducing well costs ${ }^{5}$.

\section{APPROACH}

The approach taken in this project has been: concept development, hardware design, procurement, and laboratory testing at Sandia; and field testing in cooperation with industry. This approach allows first-hand field-operation feedback from industry to be directly incorporated into the hardware design. By loaning rolling float meters to industry participants willing to test them, data about their expected performance under a wide variety of conditions have been obtained. In addition, several suggestions from potential industry users have been incorporated into the rolling float meter design, as well as modifications resulting from Sandia's direct experience during field testing, to produce a robust user-friendly tool. By testing the Doppler flow meters under a variety of drilling conditions, we have identified their strengths and limitations. This knowledge will be useful in developing the expert system, which will have to use data from a large number of sensors in order to accurately diagnose drilling problems.

\section{RESEARCH RESULTS}

\section{Rolling Float Meter}

The second generation Rolling Float Meter (RFM) design was thoroughly evaluated at the SNL Wellbore Hydraulics Flow Facility prior to initiating new field tests in FY97. Field testing was completed on four exploratory slim hole wells ( 7.5 weeks total operating time) and two large diameter geothermal wells (13.5 weeks total operating time). These tests demonstrated that our design improvements enhanced the sensitivity and accuracy as well as the robustness of the RFM. No major problems were uncovered during the field tests. Postfield-test inspections of the RFM revealed some minor damage to a few float wheel fins (slight bending) caused by flow surging during a gas kick, but this did not adversely affect RFM performance. Data from the RFM was used extensively by both drillers and company men during drilling operations. The final report on the RFM was begun and contacts to transfer this technology to interested industry manufacturers and potential users have been initiated.

\section{Ultrasonic Doppler Flow Meter Testing}

Ongoing evaluations were conducted on various commercial instruments that have potential applications for geothermal drilling operations. Laboratory tests were completed at the SNL Wellbore Hydraulics Flow Facility on: a Doppler flow meter made by Peek Measurements, Inc., and a Doppler flow meters transit-time meter made by Controlotron, all for measuring mud inflow; a Micro Motion, Inc., Coriolis meter for measuring combined mud inflow and mud density; and a Gulton-Statham differential-pressure meter for real-time monitoring of mud densities while drilling. All instruments showed good promise during laboratory evaluations.

In cooperation with CalEnergy, Nabors Drilling, Epoch and Tecton Geologic logging companies, field tests were completed using Doppler and transit-time flow meters for mud inflow measurements while drilling large-diameter geothermal wells. In addition, the transit-time meter was also evaluated for use in non-intrusive measurement of injection-well fluid-flow rates and possibly for use in determining the thickness of internal-pipe scale buildup. Results of these tests are still being evaluated. A field evaluation of the Gulton-Statham mud-density meter was also completed. This instrument provided accurate real-time mud density information while drilling. 
Market surveys for advanced instruments that show new or improved capabilities for geothermal well instrumentation are continually being conducted, and promising equipment is being evaluated in our laboratory for possible field applications.

\section{Expert System for Lost Circulation Control}

The first phase in the development of the expert system was completed as a Geothermal Drilling Organization (GDO) project in FY97. Data provided by CalEnergy and Sandia were used to develop and demonstrate the use of the resulting software system. The demonstration showed how the expert system would have reacted to the various real anomalies in the data. Lost circulation, mud-pump problems, and flow sensor problems were all correctly diagnosed by the system. The potential of the system was clearly demonstrated with the recorded data set $^{6}$.

The demonstration was given to the members of the GDO, both at a GDO meeting in July and in individual meetings with interested parties throughout the year. These events helped to build support for the project. At the end of FY97, the expert-system project participants were preparing to organize the industry cost-sharing required to conduct the second phase of the project in FY98.

\section{FUTURE PLANS}

Additional field tests of the rolling float meter, Doppler flow meter, and mud-density meter were planned in cooperation with Epoch Well Logging. Epoch will evaluate the instruments for use in their commercial well logging operations.

The second phase of the expert system will be developed if approved by the GDO. This phase will entail fullscale development of the system to include detection of not only mud circulation problems but other drilling problems as well. Tracor and Sandia will work with geothermal industry participants to integrate the system into their operations and to tailor the expert advise module to fit their procedures.

\section{INDUSTRY INTEREST}

\author{
Organization \\ CalEnergy Company \\ Tecton Geologic, Inc. \\ Epoch Well Logging, Inc. \\ Nabors Drilling
}

\section{Type and Extent of Interest}

Rolling float meter testing, Doppler flow meter testing, transit-time meter testing

Rolling float meter testing, Doppler flow meter testing

\section{REFERENCES}

1. Schafer, D.M., Loeppke, G.E., Glowka, D.A., Scott, D.D., and Wright, E.K.: "An Evaluation of Flowmeters for the Detection of Kicks and Lost Circulation During Drilling," paper IADC/SPE 23935, presented at 1992 IADC/SPE Drilling Conference, New Orleans, LA, February 18-21, 1992. 
2. Glowka, D. A., Schafer, D. M., Scott, D. D., Wernig, M. D., and Wright, E. K.: "Development and Use of a Return Line Flowmeter for Lost Circulation Diagnosis in Geothermal Drilling," (Oct. 1992), Trans. Geothermal Resources Council, 16, 39-46.

3. Loeppke, G.E., Schafer, D.M., Glowka, D.A., "Development and Evaluation of a Meter for Measuring Return Line Fluid Flow Rates During Drilling," Report SAND91-2607, Sandia Natl. Laboratories, Albuquerque, NM (June, 1992).

4. Whitlow, G.L., Glowka, D.A., and Staller, G.E., "Development and Use of Rolling Float Meters and Doppler Flow Meters to Monitor Inflow and Outflow While Drilling Geothermal Wells," (Oct. 1996), Trans. Geothermal Resources Council, 20, 515-521.

5. Glowka, D.A., "The Role of R\&D in Geothermal Well Costs Reduction," (Oct. 1997), Trans. Geothermal Resources Council, 21, 405-410.

6. Harmse, J.E., Wallace, R.D., Glowka, D.A., and Mansure, A.J.: “Automatic Detection and Diagnosis of Problems in Drilling Geothermal Wells," (Oct. 1997), Trans. Geothermal Resources Council, 21, 107112. 


\title{
LOST CIRCULATION TECHNOLOGY DEVELOPMENT PROJECT Downhole Tools and Materials for Treating Loss Zones
}

\author{
George E. Staller \\ Sandia National Laboratories
}

\section{KEY WORDS}

downhole tools and materials for treating lost circulation zones, drillable straddle packer, Engineered-Lithology Test Facility

\section{PROJECT BACKGROUND AND STATUS}

Lost circulation accounts for $10-20 \%$ of the cost of a typical geothermal well. Conventional methods for treating lost circulation include the use of lost circulation materials (LCMs) added to the drilling mud and cementing operations. If more efficient materials and techniques could be developed, significant geothermal drilling cost reductions would result. This project with the development of unique laboratory facilities for testing lost circulation materials (LCMs) for geothermal drilling environments. Many types of materials were tested under high-temperature, high-pressure conditions. A number of materials were identified that are suitable for moderately high temperatures and could be used to advantage in a wide variety of drilling environments. Mathematical models were developed that describe the LCM plugging process and describe the effects of numerous variables on the plugging capability of a given material, such as size, shape, elastic modulus, and

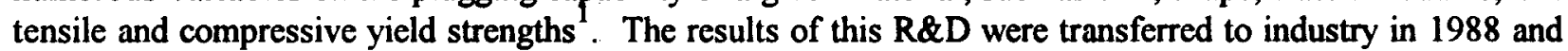
provide a basis for industry selection of LCMs for a wide variety of drilling applications. Materials such as ground walnut shells, ground rubber tires, and mineral fiber are widely available and used by the industry. The designs of our LCM laboratory testing hardware and procedures were also provided to industry and were duplicated by at least two companies for use in their LCM development efforts.

The LCM testing and modeling also indicated that if the aperture of a loss zone fracture is very large (larger than the drill bit nozzles), it cannot be plugged with LCM materials that are simply added to the drilling mud. This, not temperature, is the reason why most loss zones in geothermal drilling are plugged with cement rather than LCMs. It is therefore necessary, in order to reduce lost circulation costs, to improve upon the conventional cementing operation.

The concept of the drillable straddle packer was reported to a geothermal industry advisory board, which enthusiastically supported its development. The packer consists of an assembly that is attached to the bottom of an open-end drill pipe and has two flexible fabric bags that straddle a loss zone and inflate as cement is pumped downhole. The bags provide low-pressure seals against the wellbore wall that confine the cement flow to the region between the bags. In this manner the cement is directed into the loss zone while at the same time restricting the flow of drilling fluid into the zone where it would dilute the cement. After a given volume of cement is pumped, the drillstring is withdrawn from the wellbore, leaving the packer assembly behind. The packer assembly is then drilled through after the cement sets. Refs. 2-4 further describe the drillable straddle packer concept and its development history.

A laboratory facility for testing the drillable straddle packer components was designed and constructed, and testing of various designs of the packer's inflatable was initiated. All key-component testing for the packer was completed as reported in the FY94 annual progress report. 
Because of the unconventional approach of the drillable straddle packer, it was deemed necessary to test the packer under full-scale conditions with cement prior to taking it to the field. Accordingly, the Engineered-Lithology Test Facility (ELTF) was constructed in FY.94-95 for this purpose. This outdoor facility allows large-scale, simulated loss and production zones to be constructed in a clay bed that can be excavated after a cementing test to determine the location of cement and the effectiveness of any techniques or hardware (such as the drillable straddle packer) in directing the cement flow where it is needed. The facility became operational in FY95 and has been used for several full-scale tests of the drillable straddle packer. In addition to drillable straddle packer tests, studies are being conducted with conventional cementing practices to learn more about the characteristics of cement flowing from an open-end drill pipe into a large-diameter wellbore.

In 1993, we were approached by Halliburton Services and CalEnergy for assistance in evaluating a cementitious lost circulation material developed by Halliburton to treat lost circulation zones. During FY95, this project was initiated as a Geothermal Drilling Organization (GDO) project, and work continued into FY96. In FY97, the project was expanded to include field testing of nitrogen-foam cement.

\section{PROJECT OBJECTIVES}

The objective of this project is to develop and transfer to industry tools and materials for treating lost circulation zones in a more economical manner than conventional cementing operations. The purpose of these tools and materials is to increase the effectiveness of the plugging operation. This would reduce or eliminate the need for multiple treatments in the same loss zone, thereby saving rig time and reducing drilling costs and, therefore, the cost of on-line geothermal power.

\section{Technical Objectives}

- Reduce geothermal drilling costs by improving the effectiveness of lost-circulation treatment methods.

- Develop a drillable straddle packer to improve the plugging efficiency of cementing operations, eliminating the need for multiple cement plugs in a single loss zone.

- Foster the development of alternative treatments for lost circulation control by participating in laboratory and field testing of new materials and techniques.

\section{Expected Outcomes}

Reduced down time and costs associated with lost circulation are the expected outcomes of this project. With a rig rate of $\$ 300-500 / \mathrm{hr}$ and a single cement treatment (including rig time) costing over $\$ 10,000$, small improvements in the efficiency of sealing loss-zones can have a significant effect on total wellbore costs. For example, some loss zones require ten or more cement plugs to seal them; many require at least two plugs. A technique capable of reliably plugging loss zones with a single treatment would greatly reduce geothermal drilling costs.

\section{APPROACH}

Significant industry interaction has taken place during the life of this project. In some cases, we have transferred technology we have developed to industry, such as LCM test data and test equipment designs. In other cases, we have participated in field testing industry's ideas and materials in the laboratory and in the field. 


\section{RESEARCH RESULTS}

\section{Drillable Straddle Packer}

Tests of the drillable straddle packer were completed prior to FY97 with full-scale simulated wellbores emplaced in clay and gravel beds. In FY97, we conducted a tests series to examine the cementing process by conducting identical tests in full-scale transparent wellbores to enable video documentation. To accomplish this objective, we completed the design, procurement, fabrication, and installation of a two-level work mezzanine and two structural steel support towers in the Engineered-Lithology Test Facility (ELTF). These towers can be rotated from vertical to horizontal orientation for test bed installation and removal.

The test bed emplaced in each tower was a transparent wellbore (TW) constructed of acrylic. For the first test, we completed the design, procurement, fabrication, and installation of two 8" (7.5" ID simulated wellbore) TW assemblies. To provide production and loss zone access to the wellbore, these assemblies included three acrylic boxes simulating these zones, in series with sections of the sixteen foot high 8 " acrylic wellbore. Cement was pumped into each wellbore by Halliburton using the same techniques employed during a standard lost circulation well treatment. Cement was pumped into one wellbore through an open-end drill pipe (OEDP), and into the other through the drillable straddle packer (DSP). Results indicated that a standing plug was formed in the 7.5" wellbore with the OEDP, and most of the cement was forced into the loss zone. In the other wellbore, nearly all of the cement was forced into the loss zone by the DSP. After the tests, we removed both test beds for further evaluation, and the DSP test bed was also cut along its longitudinal axis. This sectioned test bed shows clearly that the cement was captured in the DSP bags, between the bags and in the loss zone box.

We next completed the design, procurement, fabrication, and installation of two 16" (15" ID simulated wellbore) TW assemblies. Tests in these larger simulated wellbores were scheduled for early FY98. The purpose of these tests is to determine the effect of wellbore diameter on the likelihood of setting a balanced cement plug in a wellbore (one that does not migrate downward because of density differences between the cement and the wellbore fluid).

\section{Field Testing of Alternative Lost-Circulation Cements}

Sandia's active participation in this project is considered to be part of the lost circulation project; however, because this work was performed entirely under a GDO project, it is described in the GDO section of this report.

\section{FUTURE PLANS}

Testing of the drillable straddle packer in the ELTF will be completed this year with a final series of tests in transparent wellbores. In these tests, the effects of fluid produced at one wellbore interval and flowing into the simulated loss zone will be tested. Following these tests, the project will focus on demonstrating the use of the drillable straddle packer in the field. One or more field tests will be scheduled for FY99 if possible. In addition, other applications for the drillable straddle packer bag technology will be sought. One possible application is for setting a drillable bridge plug on a wireline.

Plans for the alternative lost circulation cement testing project are discussed in the GDO section of this report. 


\section{INDUSTRY INTEREST}

Organization

CalEnergy Company

Halliburton Services

Unocal Geothermal

\section{Type and Extent of Interest}

Alternative LC cement testing; drillable straddle packer

Drillable straddle packer

\section{REFERENCES}

1. Loeppke, G.E., Glowka, D.A., and Wright, E.K.: "Design and Evaluation of Lost Circulation Materials for Severe Environments," Journal of Petroleum Technology (March 1990) 328-337.

2. Glowka, D.A.: "Lost Circulation Technology Development Projects," presented at DOE Geothermal Program Review VIII, San Francisco, CA, April 18-20, 1990.

3. Glowka, D.A., Schafer, D.M., Loeppke, G.E., and Wright, E.K.: "Progress in the Lost Circulation Technology Development Program," presented at DOE Geothermal Program Review IX, San Francisco, CA, March 19-21, 1991.

4. Glowka, D.A.: "A Drillable Straddle Packer for Lost Circulation Control in Geothermal Drilling," Proceedings of the World Geothermal Congress, Florence, Italy, May 18-31, 1995. 


\title{
HIGH-TEMPERATURE INSTRUMENTATION
}

\author{
Randy A. Norman \& Joseph A. Henfling \\ Sandia National Laboratories
}

\section{KEY WORDS}

logging, logging tools, slimhole tools, high-temperature tools, downhole measurements, memory tools, pressure, temperature, spectral gamma, fluid/gas sampler, core-tube memory logger, silicon-on-insulator

\section{PROJECT BACKGROUND AND STATUS}

If more cost-effective techniques for obtaining downhole logging data were available, the geothermal industry would undoubtedly run more logs, and more knowledge of geothermal reservoir characteristics would be available for efficient reservoir management. The objective of Sandia's high-temperature instrumentation program is to develop such techniques.

Sandia's involvement with downhole instrumentation dates from the mid ' 70 s when work was centered on the development of a high-temperature acoustic borehole televiewer and the establishment of a list of hightemperature component parts such as resistors, microchips, and sensors. This work evolved into the development of memory logging devices for the US Continental Scientific Drilling Program. These tools were of low cost and very easy to use. Their deployment resulted in scientific advancement in understanding geothermal formations, and a thrust of the current program is to move memory tools from the scientific realm to the commercial environment.

The present Sandia Memory Tool Program was initiated in 1990. There have been three principal tools developed for measuring pressure/temperature $(\mathrm{P} / \mathrm{T})$, spectral gamma, and capturing borehole steam or fluid samples. Working prototypes have been built and field tested for each of these three memory tools. The P/T tool has had over forty successful geothermal log runs and was transferred to industry in FY97. A project to develop a core-tube data logger using the same design approach was initiated in FY96 and continued in FY97.

A new project was initiated in FY97 to examine the potential for using silicon-on-insulator integrated chip technology to design unshielded electronics for high-temperature applications, up to $300^{\circ} \mathrm{C}$. As described in this report, this work is very promising and could potentially lead to significant advances in the well logging industry.

\section{PROJECT OBJECTIVES}

Downhole measurement tools are used by the hydrocarbon industry to calibrate surface geophysical experiments, to establish reservoir parameters, and to provide engineering data for drilling and production. Such measurements are not as common to the geothermal industry. It is not that suitable tools cannot be built, but rather that a lack of market has stymied progress. Sandia's objective is to foster the development and commercial availability of suitable high-temperature logging tools for the geothermal industry. 


\section{Technical Objectives}

The objective of this project is to develop and demonstrate the utility of a suite of geothermal logging tools with the following characteristics:

- Low cost, yet possess a pedigree for data quality.

Two inches in diameter or less to be suitable for slim, diamond-cored holes.

- Transportable by common air carrier.

- Operation to $400^{\circ} \mathrm{C}\left(750^{\circ} \mathrm{F}\right)$.

- Operate on a "slick line", not an electric wireline.

- Be programmable for different operations and operating conditions.

\section{Expected Outcomes}

- Establish a viable downhole measurements service industry or driller-owned capability.

- Provide downhole data for drilling, reservoir evaluation, and remediation.

- Establish a bridge between the hydrocarbon and geothermal logging industries.

\section{APPROACH}

Three memory tools form the backbone of the initial Sandia tool suite. These tools meet the temperature and size criteria noted above: Each of these tools is a microprocessor controlled, memory-based, measurement system protected by a thermal flask housing. At the surface before a log is run; a lap top PC communicates with the tool, downloading logging instructions and synchronizing clocks. The tool and depth encoder readings are synchronized in time. The log is then run, with the memory tool operating on its own. Data recording can be initiated either at pre-selected times or at pre-selected levels attained by one or more of its sensors, such as pressure or temperature. After completion of the logging exercise, the depth and tool measurements are correlated, resulting in a $\log$ of measured data $v s$ depth.

All of the tool PC software was written as a Microsoft Windows ${ }^{\infty}$ application. This allows for tool data to be directly downloaded into a lap top while running other Windows applications. Data can be easily imported into Lotus $123^{\circ}$ or MS Excel .

Pressure/temperature measurements are necessary for the evaluation of geothermal reservoirs, and they are relatively simple to make. Thus, the initial Sandia program concentrated on such a tool, and it has been successfully used in the field many times without a single failure. This tool has now been commercialized and forms the basis for other tools since many engineering principles were proven in its evolution.

The second tool in the Sandia suite measures the gamma ray emissions from formation materials. These emissions originate in the decay of potassium, and uranium and thorium daughter products. Each element produces gamma rays of a characteristic energy, and the tool resolves the overall spectrum into its component 
parts. Thus an assay for a few elements is available. Past work by the hydrocarbon industry has tied these assays into useful geologic information. Such work remains to be done in geothermal formations.

The third tool in the initial Sandia suite collects specimens of borehole fluids and gases. This tool is based on the pressure/temperature tool in that many component parts are identical. The programming capabilities of the former tool are used to "trip" the sampler at appropriate states in the borehole. The development of this tool was supported by the Department of Energy/Basic Energy Sciences. The current fielding stage is supported by the present program.

Development of a fourth tool was initiated in FY96. The core-tube data logger is an instrument that attaches to the top of the core tube used in wireline coring operations. When retrieved with the core tube, the instrument downloads data that it acquired while on bottom, thus providing a "free" log in terms of rig time spent. Immediate uses for this instrument are for measuring bottomhole temperature and borehole inclination. A technique for recording core orientation is also under development.

All of the above tools employ dewared flasks to shield the electronics from the hot wellbore for a limited time. These flasks are the most expensive component in many of these tools. Having electronics that could survive high temperatures without shielding would thus reduce the cost of logging tools and allow the electronics to stay downhole longer. This is the motivation behind the silicon-on-insulator project described begun in FY97 and described below.

\section{RESEARCH RESULTS}

\section{PTS Tool}

In late FY96, an ad was placed in the Commerce Business Daily offering to the public the opportunity to commercialize the Sandia-developed Pressure/Temperature Tool. There were some 22 respondents, all of whom were sent follow-up information and in some cases phone conversions.

Because of the limited size of the geothermal market and limited funding for technology transfer, a procedure was written and followed to ensure that the best possible candidates for commercialization were chosen. Pruett Industries was selected as the commercialization partner. Pruett Industries and Sandia created an extension of the partnership by adding an existing Pruett spinner to the tool, making it a PTS tool. The spinner modification was easily accomplished and created a much more versatile tool.

The PTS tool was built and successfully field tested in Nevada in FY97. Following these results, Pruett now offers the tool as a commercial item, either on a logging-service basis or for sale as a stand-alone tool. Sandia will continue to monitor and assist in the commercialization process in FY98.

\section{Spectral Gamma Memory Tool}

The spectral tool project experienced difficulties in FY97 in the fabrication of a new tool using a larger, more sensitive detector. The delivery time for the crystal was supposed to be four months, but it actually took eleven months for a suitable crystal to be delivered.

On a more positive note, the smaller existing tool worked extremely well at a Rincon, New Mexico, well with a maximum temperature of approximately $200^{\circ} \mathrm{F}$. In that test, gamma measurements from a commercial, lowtemperature gamma tool could be compared with those from the Sandia tool. The two measurements were 
virtually identical. This data, along with explanations of spectral gamma processing algorithms, were given in a paper presented at the 1997 GRC conference'.

In the interim, waiting for the new detector, we developed faster gamma-capturing electronics. The older design took between 80-220 $\mu \mathrm{S}$ for each gamma conversion and was unable to account for dead time. (Dead time is the time spent converting gamma peaks to energy and not capturing new gamma.) This loss of time created calibration problems at high gamma count rates. The faster design requires a fixed $60 \mu \mathrm{S}$ per conversion and measures tool dead time for auto-correcting count rates. This change was important because the larger crystal will have a counting rate 4.5 times higher than the older design. Also developed was an algorithm for compensation of spectral readings within production wells of differing sizes. This development is critical for logging production wells.

The existing tool was also modified to use the same battery pack as the PTS tool. This modification eliminated the need for the expensive custom batteries previously used and will increase reliability. The PTS display software was modified to also display the spectral gamma data. Both tools now have a compatible interface.

\section{Downhole Steam Sampler}

The Downhole Steam Sampler was again tested at a UNOCAL well in The Geysers outside Santa Rosa, Ca. The sample data was compared to surface sample data taken using standard sampling techniques. This data was very comparable, giving UNOCAL good reason to continue development with Sandia. A UNOCAL-sponsored proposal to DOE was funded through Sandia contracting in FY97.

We now have data from six sampler tests. From these tests a number of lessons have been learned. For example, the steam sampler valve should be replaced every forth test, at a cost of approximately $\$ 100$. This will increase reliability and confidence in the sample. Another lesson was to provide the tool with 5 or more minutes to temperature-stabilize within the well before deployment of the valve for sample capture. This increases the accuracy of the $\mathrm{Cl}$ measurement.

Testing the proposed solenoid valve for high-pressure liquid (as opposed to steam) capture proved the valve was not suitable for liquid-sampling at high-temperatures. Discussing this valve performance problem with the manufacturer revealed that the valve cannot live up to the manufacturer's claims of 8,000 psi for both flow directions, (both before sampling and then after). A second valve using gas actuation was considered and designed. This valve is only a one-time-use-only valve, but it has already been tested to $335^{\circ} \mathrm{C}$ by weapon designers.

A paper was presented at the 1997 GRC conference on the performance of the current tool in steam sampling ${ }^{2}$.

\section{Core-Tube Data Logger}

This instrument was designed and tested in Nevada while drilling with Tonto Drilling. These tests were so successful that two additional, improved tools were built for use in drilling with Boart Longyear at Fort Bliss, TX/NM. The Core-Tube Data Logger was successfully deployed over 40 times while drilling geothermal exploratory slimholes at Fort Bliss ${ }^{3}$.

Boart Longyear saw the commercial opportunity in this type of instrument. They have contacted Sandia and are presently planning to make this tool commercially available for wireline core drilling operations in both geothermal and mineral exploration. 


\section{High-Temperature SOI Electronics}

Sandia has acquired early production units of Honeywell silicon-on-insulator (SOI) electronics. In 1997 we received the (HT83C51) SOI microprocessor and accompanying 128-kbyte SOI memory along with SOI operational amplifiers and digital switches. To date, the amplifiers and switches have been tested at $315^{\circ} \mathrm{C}$ $\left(600^{\circ} \mathrm{F}\right)$ for extended periods of time.

The simple act of placing electronics within an oven operating at $300^{\circ} \mathrm{C}+$ required solving a number of technical issues. For example, solder no longer works for lead attachment, so several alternatives were evaluated, including laser welding, mechanical attachment, and adhesives. Mechanical attachment works well for development testing, while laser welding may be the answer for production building. Sandia is not only looking at a method for testing in the oven but how to move this high-temperature technology into higher production volumes.

A computer program for testing the HT83C51 for testing in the oven has been written in FY97. Before the microprocessor with memory could be placed in the oven, however, additional devices had to be tested. Some of these devices were not available in SOI at that time. Using Sandia's $200^{\circ} \mathrm{C}$ technology list, supplemental devices were tested to fill in the gap. One of the missing elements was the microprocessor clock. The Sandia clock operated at $250^{\circ} \mathrm{C}$ for 24 hours and then at $300^{\circ} \mathrm{C}$ for another 24 hours. However, when the temperature was pushed to $315^{\circ} \mathrm{C}$, the clock failed after a few hours. Another non-SOI device is the address latch for increasing the microprocessor's electronic data storage for use within the memory tool. This latch was tested and passed operating at $300^{\circ} \mathrm{C}$ and then $315^{\circ} \mathrm{C}$ continuously for several days without failure.

Another thrust of the high-temperature instrumentation program is the development of high-temperature batteries. The Sandia effort is to adapt weapon thermal batteries by making them operate at cooler temperatures (thermal batteries normally operate between $300-650^{\circ} \mathrm{C}$ ). In this effort, Sandia constructed a test battery to use in oven testing for comparison to computer modeled performance. The test concluded that the computer model is not exact but is useable for predicting future performance. Sandia researchers have studied alternative chemical salts for low-temperature battery operation and improved means of thermal heating. One such salt operates at $40^{\circ} \mathrm{C}$ but may not produce the needed energy. Another operates starting at $150^{\circ} \mathrm{C}$ and is a likely candidate for additional testing.

\section{High-Temperature Slimhole Televiewer}

Over the past year, Sandia has explored the industry interest and feasibility of a next-generation, high-temperature slimhole televiewer for geothermal exploration. Such a tool could be extremely valuable in mapping fractures and other structural features in geothermal reservoirs. Sufficient industry and academic interest has been identified to warrant its development. A proposal for funding the construction of the televiewer was written in FY97. 


\section{FUTURE PLANS}

Work will continue to field test all four downhole memory tools under development at Sandia. Simultaneously, work will continue to transfer the technology embodied in the tools to industry where it can be commercialized. We will work directly with several companies in FY97 to accomplish this commercialization.

Work will also expand in the area of ultra-high-temperature electronics. The feasibility of building unshielded electronics to operate at temperatures as high as $300^{\circ} \mathrm{C}$ will be explored. Oven testing of components will be continued, and a workshop will be conducted in FY98 to develop plans for the rapid development and demonstration of logging tools employing these components.

\section{INDUSTRY INTEREST}

Organization

Pressure/Temperature Tool

Unocal

Cal Energy

Spectral Gamma Tool

Unocal

California Energy

Hydrocarbon Companies

Fluid/Gas Sampler

Unocal

Calpine

\section{Core-Tube Data Logger}

Boart Longyear

Tonto Drilling

\section{Type and Extent of Interest}

Slim-hole measurements in remote locations, Reservoir evaluation

Lost circulation evaluation

Fracture identification, mineralogy

Tracer studies using decaying isotopes

Acid corrosion in the Geysers

Downhole drilling fluid temperatures, borehole orientation, core orientation

\section{REFERENCES}

1. Normann, R.A. and Henfling, J.A.: "Considerations for Geothermal Spectral Gamma Well Logging," (Oct. 1997), Trans. Geothermal Resources Council, 21, 219-226.

2. Normann, R.A. and Henfling, J.A.: “Subsurface Steam Sampling," (Oct. 1997), Trans. Geothermal Resources Council, 21, 629--633.

3. Henfling, J.A., Normann, R.A. and Drumheller, D.S.: "Core-Tube Data Logger," (March, 1997), Proc. Geothermal Program Review XV, U.S. Department of Energy, San Francisco, CA, March 24-26, 1997. 


\title{
SLIMHOLE DRILLING FOR GEOTHERMAL EXPLORATION
}

\author{
John T. Finger \\ Sandia National Laboratories
}

\section{KEY WORDS \\ geothermal, exploration, slimhole, drilling costs \\ PROJECT BACKGROUND AND STATUS}

Geothermal exploratory drilling is expensive and, because it comes early in the project, must usually be financed by the operator with a long period of debt service before costs can be recovered from power sales. The success rate for geothermal wildcat wells is only $25-40 \%$, so a reduction of the exploratory drilling costs, which run $\$ 1-3$ million for a production-sized well, would be a major incentive for increased development. Industry representatives have been generally enthusiastic about the concept of lowering these costs with slimhole drilling and are strongly in agreement that the technique needs adequate demonstration. Three Sandia/industry costshared drilling projects ${ }^{1-4}$ have shown that slimholes reduce exploration cost by $40 \%$ to $60 \%$. Furthermore, reservoir production estimates based on slimhole testing are starting to gain credibility ${ }^{5-9}$ and be considered by financial institutions in evaluating financing of geothermal projects.

The principal work to date in this program comprises: drilling three cost-shared exploratory slimholes (Steamboat Hills, Nevada; Vale, Oregon; and Newberry Crater, Oregon); in-house analysis of flow data and comparison of that data with several numerical flow simulators; contracts with Maxwell Technologies (formerly S-Cubed) to collect and examine data from slimholes and production wells in five different Japanese geothermal fields; and technology transfer by joint sponsorship with the Geothermal Resources Council of a Slimhole Workshop in July, 1996.

\section{PROJECT OBJECTIVES}

In broadest terms the research objective is to demonstrate that lower-cost slimhole drilling will allow industry to increase exploration and expand proven geothermal reserves. Two crucial questions must be resolved: 1) Can slimholes provide sufficient data to evaluate a geothermal reservoir? and;2) What are the costs of slimhole exploration compared to conventional methods? Answering those questions requires achieving the following objectives:

\section{Technical Objectives}

- Reduce geothermal exploration costs by providing a solid basis for employing slimhole drilling and testing techniques to explore for geothermal resources.

- Collect data from slimhole and production wells in existing geothermal fields, including international developments where available.

- Correlate production and injection test data between slimholes and production size wells. 
- Develop and validate a coupled wellbore-reservoir flow simulator that can be used with slimhole flow data to yield a reservoir evaluation.

\section{Expected Outcomes}

- Demonstrate correlation between reservoir-evaluation data from slimholes and production-size wells.

- Use cost data to demonstrate economies of slimhole drilling, compared to production-size wells drilled in the same conditions.

- Publish all results and transfer slimhole exploration-drilling technology to industry so that it becomes an accepted method for geothermal reservoir identification and evaluation.

\section{APPROACH}

We have used a coordinated working group including personnel from Sandia, Maxwell Laboratories, Lawrence Berkeley National Laboratory, University of Utah Research Institute, US Geological Survey, geothermal operators, and independent consultants focused on this program. In addition to the Geothermal Research Department staff directing this program, other Sandia organizations such as the Incompressible Fluid Dynamics and Thermal Sciences Departments are providing significant support.

\section{RESEARCH RESULTS}

Principal activities during FY97 were: publication of the final report on drilling and testing operations at the Newberry slimhole; major progress on writing a Geothermal Slimhole Handbook; and continuing analysis of data from Japanese geothermal fields.

\section{Slimhole Handbook}

The Slimhole Handbook is a collection of results from work done and sponsored by Sandia in the Slimhole Drilling Program, which aims to show that geothermal exploration costs can be drastically reduced by using smaller, cheaper wells which still give enough information to evaluate the potential reservoir. The Handbook comprises: case histories of Sandia's and other field drilling projects; compilation of test data from Sandia projects and a synopsis of data from Japanese wells; descriptions of in-house and other analyses of the data set; descriptions of drilling, logging, and testing equipment available for slimholes; guidelines for designing, drilling, completing, and testing geothermal slimholes; and a bibliography. Draft copies of the Handbook will be distributed for comment to people in the industry, and the final version will be published as a Sandia Report.

Approximately $80-85 \%$ of the Handbook was completed in FY97, with the remaining portion expected to be completed in the first quarter of FY98.

\section{Fort Bliss Exploratory Drilling}

Under a Work-for-Others (WFO) contract, the Geothermal Research Department at Sandia assisted the U. S. Army with planning, instrumentation, data analysis, and on-site project management during an exploratory drilling project at the Fort Bliss McGregor Range in southern New Mexico. The project included four slimholes, ranging in depth from 2,018 to 3,961 feet in depth, to assess the potential for geothermal direct-use and/or power generation at this location. More than 10,000 total feet of hole were successfully drilled at a cost of 
approximately $\$ 73 /$ foot, and the slimholes were as informative for reservoir evaluation as conventional rotarydrilled holes would have been. The slimholes had the additional value of continuous coring, providing a complete lithologic record of the formations in the area.

Drilling operations were completed in April, 1997, although temperature logging in the holes continued through the summer, and the final report was delivered to the Army in August, 1997. This work will also be documented in a SAND Report to be published in the first quarter of FY98.

\section{Analysis of Kirishima, Japan, Data}

Maxwell Technologies, under contract to Sandia, has negotiated the release of data -- comprising drilling, production, and injection records from more than 50 slimholes and production wells -- from the Kirishima geothermal field. These data -- drilling records, downhole pressures and temperatures, water level -- have been entered into a geothermal data-management system (GEOSYS) and have been analyzed to determine feed zone locations, temperatures, and pressures.

A few of the Kirishima wells have two-phase flow, but for statistical validity, it is important to gather a larger data set (see Okuaizu, Japan, project below) and use all available field records to test a model of discharge capacity in boreholes with two-phase flow, which is being developed on this contract. Analysis of the Kirishima data is complete, development of the discharge model will be complete in the first quarter of FY98, and a final report on these tasks will be delivered to Sandia about February 1998.

\section{Analysis of Okuaizu, Japan, Data}

Maxwell Technologies has gathered and analyzed data from a total of more than 200 Japanese slimholes and production wells, and has correlated productivity and injectivity indices between the large and small wells. This analysis has shown that most of the slimholes are good predictors of performance for production wells drilled into the same reservoir.

Most wells analyzed to date, however, have had liquid-phase feed zones, but hotter wells in Japan and many of those being developed in Indonesia and the Philippines have two-phase feed zones which may not follow the same correlations already established. To examine this possibility, Maxwell personnel traveled to Japan and negotiated the release of data from the Okuaizu geothermal field, which has predominantly two-phase feeds. Maxwell will use this data to complete testing of the discharge-capacity model of boreholes with two-phase feed zones. Sorting and analyzing the Okuaizu data, with the on-going comparison to the two-phase discharge model, will continue during FY98 with completion and publication of results in FY99. The Okuaizu contract also includes a separate task for evaluation of existing wellbore models; using all the Japanese data; this task will be completed and a report on the work published in FY98.

\section{Long Valley Exploratory Well}

After two major drilling phases, one workover, and numerous scientific experiments, the LVEW in California is at a depth of 7,188 feet. In FY96, control of the location was transferred to the USGS, and Sandia has assisted them in pursuing funding for a third drilling phase to approximately 11,500-12,000 feet. That extension of the hole would have payoffs in at least the following areas: evaluation of the potential for conventional hydrothermal development; acquisition of data applicable to development of long-range energy technologies such as magma and hot dry rock; development and testing of very-high-temperature drilling technology; establishment of a volcano/earthquake hazard monitoring station; and scientific investigation of a young silicic caldera. Combining 
promised contributions from USGS, DOE, and the International Continental Drilling Program (ICDP), we established the required cost match to apply for a $\$ 1$ million grant from the California Energy Commission (CEC). The CEC granted a positive decision on the application in the first quarter of FY98, and drilling was planned to take place from approximately June through September, 1998.

\section{FUTURE PLANS}

For slimhole exploration to become widely useful, it must be applicable to different reservoir types and must be accessible to the small, independent geothermal developer. The best strategy for demonstrating applicability combines statistically-valid analysis of slimhole/production well data (such as that acquired from Japanese fields) and cost-shared drilling projects with domestic industry, which are invaluable for creation of guidelines on drilling practices and on potential technology developments. The projects listed above will be continued and several of them completed in FY98.

\section{INDUSTRY INTEREST}

\section{Organization}

Geo Hills Associates

Maxwell Technologies

U.S. Army

USGS, ICDP, CEC
Type and Extent of Interest

Contract partner, Geothermal Slimhole Handbook

Contract partner, Japanese well analysis

Sponsor, Fort Bliss exploratory drilling

Project partners, Long Valley Exploratory Well

\section{REFERENCES}

1. Finger, R. D. Jacobson, C. E. Hickox, R. R. Eaton, "Steamboat Hills Exploratory Slimhole: Drilling and Testing," Report SAND94-055 1, October 1994, Sandia National Laboratories, Albuquerque, NM, 871851033.

2. Finger, R. D. Jacobson, C. E. Hickox, R. R. Eaton, "Slimhole Drilling for Geothermal Exploration"; presented at the World Geothermal Congress (and in Proceedings), Florence, Italy; May 1995.

3. Finger, R. D. Jacobson, C. E. Hickox, "Vale Exploratory Slimhole: Drilling and Testing", Report SAND961396, June 1996, Sandia National Laboratories, Albuquerque, NM, 87185-1033.

4. Finger, J.T. Jacobson, R.D., and Spielman, P.B.: "Newberry Exploratory Slimhole," (Oct. 1997), Trans. Geothermal Resources Council, 21, 97-102.

5. Finger, J.T. Jacobson, R.D., and Hickox, C.E.: "Newberry Exploratory Slimhole: Drilling and Testing," Report SAND97-2790, Sandia National Laboratories, November 1997.

6. Garg, S., J. Combs, M. Abe: “A Study of Production/Injection, Data from Slim Holes and Production Wells at the Oguni Geothermal Field, Japan"; Report SAND94-2870/1 Sandia National Laboratories, March 1995. 
7. Garg, S., J. Combs, M. Abe: "Appendices to A Study of Production/Injection Data from Slim Holes and Production Wells at the Oguni Geothermal Field, Japan", Report SAND94-2870/2, Sandia National Laboratories, March 1995.

8. Garg, S., J. Combs; "Production/Injection Characteristics of Slim Holes and Large-Diameter wells at the Sumikawa Geothermal Field, Japan"; Presented at the Twentieth Stanford Workshop on Geothermal Reservoir Engineering, Stanford University, Stanford, CA, January 24-26, 1995.

9. Garg, S., J. W. Pritchett, J. L. Stevens, L. Luu, J. Combs, " Development of a Geothermal Resource in a Fractured Volcanic Formation: Case Study of the Sumikawa Geothermal Field, Japan", Sandia National Laboratories Contractor Report SAND96-2556, November 1996.

10. Garg, S., J. Combs, Fumio Azawa, Hiroki Gotoh, " A Study of Production/Injection Data from Slim Holes and Large-Diameter Wells at the Takigami Geothermal Field, Kyushu, Japan", Sandia National Laboratories Contractor Report SAND96-2555, November 1996. 


\title{
WIRELESS DATA TELEMETRY
}

\author{
Douglas S. Drumheller and Steven D. Knudsen \\ Sandia National Laboratories
}

\section{KEY WORDS}

acoustic telemetry, wireless telemetry, measurement while drilling (MWD), waveguides, communications, production monitoring, pump monitoring, core-tube monitoring

\section{PROJECT BACKGROUND AND STATUS}

Effective techniques for transmitting data from a downhole location to the surface are needed in several geothermal applications. Retrieving data from the bottom of a wellbore is never a trivial matter, particularly if downhole conditions are hostile. The use of downhole memory tools is one solution that works in many applications. In other applications, data are either needed in real time, or the application does not allow the use of any type of wireline. In such cases, an alternative way to retrieve data from downhole is by sending the data up the steel tubulars in the form of sound waves.

Acoustic data transmission is a highly developed science that has thus far seen little application in drilling operations. Technical challenges include designing and building downhole devices that survive the ambient conditions and convert the downhole data to stress waves that can travel uphole in the drill pipe or production tubing. Sandia has several patents on such a device ${ }^{1-6}$. Deciphering the signal received on the surface to extract the actual signal from the rig noise is another challenge: Sandia has developed data acquisition and reduction capabilities for this purpose ${ }^{7,8}$. The technology is, therefore, ready for use in a variety of applications.

Much of this technology evolved under a joint industry project to develop an acoustic measurement-while-drilling (MWD) system that sends data up the drillstring at higher rates than current MWD mud-pulse systems. That project was canceled when the industry partner was sold and the new owner had different business priorities. The technology that was developed is useful, however, in other acoustic data transmission applications.

There are, in fact, less rigorous geothermal environments where acoustic technology can be more easily applied than in drilling. The production environment is one, in which the production tubing can be used to transmit the acoustic signal. Drilling applications that do not require a downhole acoustic source are also favorable applications. We are applying acoustic data transmission technology to three such applications: a core-tube latching detector, an alignment system for line-shaft pumps, and a wireless telemetry system for production monitoring. Each of these projects is nearing completion.

The primary benefit of acoustic data transmission technology is the consequent availability of useful data that are otherwise unavailable or more expensive to obtain. How the data can be used to reduce costs depends on the application. Based on the acoustic technology projects we currently have under way, a $5 \%$ well cost-reduction goal is reasonable. This would reduce overall geothermal power project costs by about $2 \%$. 


\section{PROJECT OBJECTIVES}

Communications hardware has been developed that will both transmit data and passively listen to stress-wave signals in well tubulars. This includes new data communication links for measurement-while-drilling operations and for monitoring production operations.

\section{Technical Objectives}

- Provide measurement-while-drilling technology for geothermal drilling.

- Provide wireless data link for production-monitoring technology.

- Provide wireless data link for geothermal line-shaft pumps.

- Provide passive listening device for wireline-core drilling.

\section{Expected Outcomes}

- Reduced drilling costs - Mud pulse telemetry is the only commercial data telemetry system available to the drilling industry. It is slow, expensive, and limited to rotary drilling in liquid-filled, low-temperature wells. Our goal is to develop high-temperature, less expensive communication tools for a broader range of applications. Wireless telemetry will work at higher data rates and does not require the use of drilling mud. It can also be used to passively monitor drilling operations. The potential savings offered by this technology are enormous.

As an example, both banking and industry sources have estimated that successful deployment of an MWD system with increased data capacity would double or triple the MWD industry's gross revenues over a few years. This is a potential payoff of $\$ 1$ to 2 billion in short-term growth of annual revenues to an industry that is critical to the future reduction of geothermal drilling costs.

- Improved reservoir management -- Currently, production monitoring tools are rarely deployed and then only with hard-wired connections. Installation requires several extra days of costly rig time. Moreover, the wireline represents $80 \%$ of the tool cost and $85 \%$ of the tool failure. Wireless telemetry can eliminate these problems while providing a less expensive tool to a broader segment of the market. We have recently licensed one of our tools to Baker Oil Tools. This tool is convenient to install and costs less than the previously used cabling. Baker feels that this tool will have broad applications in many other aspects of reservoir production.

- Reduced pumping costs -- Line shaft pumps are used extensively throughout the geothermal industry. These pumps are oversized to compensate for misalignment of the downhole pump rotor. By providing measurement and active control of alignment, smaller and less expensive pumps can be used in deep wells. This is an important factor for the continued production from many domestic geothermal resources.

\section{APPROACH}

In our past work, we augmented the empirical approach of industry with a more systematic program directed at the fundamentals of acoustic telemetry. We assembled computer simulations, experimental data, and field test results that demonstrate the existence of acoustic transmission bands strongly correlated to theoretical predictions. 
We also tested transducer arrays that were capable of directionally projecting and measuring acoustic energy in a drill string.

Several MWD devices have been designed, built, patented, and licensed to an industrial partner, Baker Hughes/INTEQ. Recently, our work has branched into several other applications of wireless telemetry. We have developed a wireless telemetry tool with another industrial partner, Baker Oil Tools. This tool monitors reservoir temperature and pressure. It is designed as an inexpensive, low-data-rate tool for monitoring reservoir parameters in a production well. Costs are being shared between the Oil Technology Partnership (DOE) and Baker Oil Tools.

Another project under development is a telemetry system for monitoring the alignment of pump components in a geothermal well. This unique system adds only one additional moving part and no electronics to the downhole assembly. It will operate in very harsh, high-temperature environments while continuously sending data to the surface. Our partner in this project is Johnston Pump Company. We have also assembled a prototype passivelistening system for core drilling. This system is used on wireline drilling platforms to detect the latching of coretube assemblies at the drill bit. Boart-Longyear has expressed interest in fielding this tool.

We originally conceived this project because of our familiarity with wave propagation in solids with periodic structure. We quickly realized that physical concepts, computer algorithms, and experimental methods that had been developed for studying stress wave phenomena in missile heat shields could be directly applied to the telemetry problem. Throughout this work, exceptional correlations between this model and field test data have been demonstrated, and significant advances have been made. Our work on an advanced transducer design continues. We will use these new tools to test signal modulation methods in the field. Future work will build upon our existing system analysis methods, our 1400-feet surface simulation facility, and our mobile instrumentation laboratory.

\section{RESEARCH RESULTS}

\section{Wireless Production Monitor}

The prototype transmitter for the production monitor has been successfully tested in three wells and licensed to our industrial partner, Baker Oil Tools. We have received a patent on this device, and we have submitted a technical paper to an industry journal reporting our results. This tool has proven to be more robust, easier to assemble, and more energy efficient then the original transducer which we designed for Teleco (now Baker/Hughes INTEQ). We expect system efficiencies of conversion of battery power to acoustic power to exceed 30 percent. Baker Oil Tools expects the commercialization of this tool to have broad impact across many aspects of its worldwide market.

\section{Line-Shaft Pump Alignment System}

We have filed a patent application on a new monitor for a line-shaft pump. This novel and simple system measures the alignment of the pump rotor with the pump housing. The measurement is transmitted via the drive shaft to the surface. Typical lengths of these shafts range between 800 and 1800 feet. Johnston Pumps has fabricated our design, and we are currently nearing completion of a bench testing program to optimize the tool. Upon completion of this program, we will proceed with an installation in a customer well. 


\section{High-Data-Rate Geothermal Drilling Telemetry}

The transmission of high-speed downhole drilling data to the surface with a technique known as surface area modulation (SAM) telemetry was also field tested. The technique employs a method for transmitting electrical signals along the drill pipe back to the surface. The downhole electronics required to implement SAM technology is relatively simple; thus, it is anticipated that if sensors can be temperature hardened, so can the entire SAM package. Furthermore, SAM technology should readily integrate into a Dewared/thermoelectrically cooled system. Thus, the focus of FY97 efforts were on determining the data rates achievable as a function of depth, rather than high-temperature issues.

A field test was conducted at RMOTC incorporating both bare and insulated tubulars. Tests were made with the SAM telemetry package up to $1391 \mathrm{ft}$ below the standing fluid level in the well. As anticipated, the bare tubular signal was attenuated according to the well-known skin depth formula that limits current EM telemetry systems. The apparent skin depth of the insulated tubular was a factor of ten larger than predicted based on the resistivity of the surrounding formation (effective resistivity 100 times larger). At a depth of $730 \mathrm{ft}$ the system was able to transmit data at 9600 baud. Unfortunately at a depth of $1391 \mathrm{ft}$ for some unknown reason, the system was not able to acquire spectral data or tell the SAM telemetry package to change the baud rate from the default rate of 110 baud. Spectral data from $382 \mathrm{ft}$ and $730 \mathrm{ft}$ are being analyzed to determine the depth and data rates SAM telemetry can achieve.

\section{FUTURE PLANS}

The prototype tool for production monitoring is completed. We will continue to act in an advisory capacity to ensure timely commercialization of this tool through our license agreement with Baker Oil Tools.

Instrumentation for the passive latch detector is assembled. We expect to find opportunities to field test this technology with Boart-Longyear.

A prototype of the geothermal line-shaft pump has been fabricated and bench tested. We plan to field test this system in the next year and assist Johnston Pumps with commercial development of this instrumentation.

We have initiated development of a high-temperature MWD system for geothermal drilling. We plan to investigate high-temperature electronic designs and transducer assemblies in the next year. We are pushing the operating envelope of these components, and extensive laboratory testing will be required to establish their usefulness at these extreme temperatures.

\section{INDUSTRY INTEREST}

\section{Organization}

Baker Hughes/INTEQ

Baker Oil Tools

Tonto Drilling

Johnston Pumps

\section{Type and Extent of Interest}

Patent license, loan of equipment and test data

Active prototype-tool development, fabrication of hardware, field test support, engineering design

Field test support, engineering design, prototype testing

Engineering design, fabrication of components, support for prototype testing 


\section{REFERENCES}

1. D. S. Drumheller, "Analog Circuit for Controlling Acoustic Transducer Arrays" U.S. Patent No. 5,056,067, 1991.

2. D. S. Drumheller, "Acoustical Telemetry in a Drill String Using Inverse Distortion and Echo Suppression", U. S. Patent No. 5,128,901, 1992.

3. D. S. Drumheller, "Electromechanical Transducer for Acoustic Telemetry System", U. S. Patent No. $5,222,049,1993$.

4. D. S. Drumheller and D. D. Scott, "Digital Circuit for Echo and Noise Suppression in a Drill String," U. S. Patent No. 5,274,606, 1993.

5. D.S. Drumheller, "Downhole Pipe Selection for Acoustic Telemetry," U. S. Patent No. 5,477,505, 1995 a.

6. D. S. Drumheller, "Acoustic Transducer", U. S. Patent No. 5,703,836, 1997.

7. D. S. Drumheller and S. D. Knudsen, "The Propagation of Sound Waves in Drill Strings", J. Acoustical Society of America, Vol. 97, No. 4, ppl 16-126, April 1995.

8. D. S. Drumheller, "Introduction to Wave Propagation in Nonlinear Fluids and Solids", Cambridge University Press, New York, 1998. 


\title{
GEOTHERMAL DRILLING ORGANIZATION
}

\author{
Allan R. Sattler \& David A. Glowka \\ Sandia National Laboratories
}

\section{KEY WORDS}

Geothermal Drilling Organization (GDO), drilling technology, cost sharing, joint DOE/industry ventures, industry partners

\section{PROJECT BACKGROUND AND STATUS}

The Geothermal Drilling Organization (GDO) was organized in 1982 as a joint DOE-industry organization devoted to jointly developing and funding near-term technology development projects for reducing geothermal drilling costs. Sandia administers DOE funds to the private entities performing the technical work and generally provides some technical assistance in each project. The types of projects usually considered by this organization are those where the basic research and development has already been completed, and all that remains before possible commercialization is applications development and field testing. These projects most often are used to provide assistance to technologies under development by private industry but occasionally build upon Sandia work. Equal cost-sharing between DOE and industry is a requirement for each project.

The GDO consists of the following organizations:

Baker Hughes Inteq

Calpine Corporation

Halliburton Services

Nabors Drilling USA, Inc.

Santa Fe Geothermal

Unocal Geothermal

APS Technology

Drill Cool Systems
Boart Longyear Company

Layne Christensen Corp.

Los Alamos National Labs

Pajarito Enterprises

Smith Drilling \& Completion

Tonto Drilling Services, Inc.

Novatek

\section{CalEnergy}

Geo Hills Associates

M-I Drilling Fluids Co.

Sandia National Labs

Thermasource

Weatherford Enterra

Resource Group

The GDO serves a very useful purpose in encouraging commercialization of emerging cost-reducing technologies and fostering a spirit of cooperation among the various segments of the geothermal industry toward reducing drilling costs. For Sandia, the GDO also serves as a mechanism for learning of the industry's drilling problems as well as a forum for transferring the technology we develop in our program.

Several GDO projects have been successfully completed, including projects to develop a high-temperature borehole televiewer, high-temperature rotating head rubbers, and a retrievable whipstock. New projects are continually being proposed. Current ongoing projects are described below.

\section{PROJECT OBJECTIVES}

\section{Technical Objectives}

- Reduce geothermal drilling costs by developing and commercializing new tools, materials, and techniques in cost-shared projects with industry. 


\title{
Expected Outcomes
}

- DOE/industry jointly-funded technologies that reduce cost and improve the drilling process.

\begin{abstract}
APPROACH
The GDO is composed of geothermal operators and service companies. Potential projects are screened by an executive committee with the criterion that completion should result in a new product or service in the near term. Project proposals are then presented to the members at periodic (quarterly) meetings or by mail. Projects require at least two industry members participating with the Department of Energy (DOE). Cost sharing by industry is at least $50 \%$, almost invariably in the form of in-kind services or, on occasion, in cash. Most of the development work is accomplished by industry.
\end{abstract}

\section{RESEARCH RESULTS}

\section{Insulated Drill Pipe}

The Geothermal Drilling Organization approved a new project in FY97 with Drill Cool Systems and CalEnergy to develop and test insulated drill pipe (IDP). Compared to conventional drill pipe (CDP), the IDP will deliver cooler fluid to the bottom of the hole, thereby improving tool life, preserving drilling fluid properties, and enabling the use of downhole electronics when drilling in high-temperature formations.

During FY97 Sandia provided instrumentation and assistance for two tests - thermal and mechanical - carried out at Drill Cool's plant in Bakersfield, CA. In the thermal test, a piece of IDP was placed in a test chamber with hot water circulating through the pipe and cold water through the annulus between the pipe and chamber. Inflowand-outflow water temperature measurements gave the heat transfer through, and thus the conductivity of, the IDP wall. These measurements, even including the un-insulated connections between two joints of pipe, showed that the overall conductivity of the IDP is less than $10 \%$ that of conventional drill pipe.

The mechanical test used strain gauges inside and outside the IDP to measure deflections when the inside of the pipe was pressurized; it therefore showed how much support the liner pipe got from the insulating material between the two tubes. The liner tube began to yield at a pressure of 9,000-10,000 psi, but that pressure capability, included in the combined stresses due to pipe weight, allows the IDP to be used in its present configuration for 15,000 foot wells. Since the test, the proppant used for insulation has been changed to a stronger material, which should increase the depth capability even more.

Finally, we did a sensitivity analysis using a thermal computer code to examine the effect of using IDP for only part of a drill string. The sample case used $4,000^{\prime}$ of IDP in a 10,000' drill string, with the IDP placed at the top, the bottom, and in the middle. Placing the IDP at the top of the drill string is the best choice from both thermal and strength standpoints, because it is almost as effective as a complete string of IDP. A summary of these results is given below. 


\begin{tabular}{|l|c|c|c|c|c|}
\hline & All CDP & All IDP & $\begin{array}{c}\text { 4K' of IDP } \\
\text { @ top }\end{array}$ & $\begin{array}{c}\text { 4K' of IDP } \\
\text { @ bottom }\end{array}$ & $\begin{array}{c}\text { 4K' of IDP } \\
\text { in middle }\end{array}$ \\
\hline Returns temp., F & 163 & 196 & 182 & 170 & 175 \\
\hline BH fluid temp., F & 401 & 165 & 232 & 278 & 250 \\
\hline Max fuid temp., F & 406 & 215 & 244 & 306 & 261 \\
\hline
\end{tabular}

\section{Alternative Lost Circulation Cements for Lost Circulation Control}

In FY97, the GDO's cementitious mud evaluation project was expanded to include nitrogen-foam cements and other alternative cements that show potential for lost circulation control. Nitrogen-foam cement was evaluated on a CalEnergy well at the Coso Geothermal Field. Sandia's role in the operation was to provide lost circulation instrumentation (drilling fluid in and out of the borehole) to characterize lost circulation zones and the effects of the cement treatments. Prior to treating with foam cement to stem lost circulation, Sandia personnel also observed, helped interpret, and paid for pressure/temperature/spinner logs and an imaging log to further diagnose the loss zone.

A Halliburton foam cement plug was to be set if the opportunity arose. Criteria for setting a foam cement plug was that (total) circulation losses in a zone had to be persistent enough to merit at least two standard, unsuccessful cement plug treatments.

A commercial Doppler flow meter was used to measure fluid going into the hole, and Sandia's rolling float meter was used to monitor returned drilling fluid. A commercial differential-pressure mud-density meter was used to monitor drilling fluid density. Overall, the performance of the three meters was excellent. There was complete correlation of density meter output with Doppler flow meter anomalies and with visual observation of the, often foamy, drilling fluid in the mud pit. Invariably, when the density meter indicated that the drilling fluid was less dense than water, the Doppler flow meter did not function property.

During the course of drilling, a lost circulation zone was found. This intermittent, but persistent, loss zone was treated four times (unsuccessfully) by standard cement plugs.

A pressure/temperature/spinner log and an imaging log were nun to obtain further information about the loss zone. The temperature log showed a temperature reversal at the loss zone, indicative of drilling fluid entering and cooling what was at that time presumed to be a fractured formation. The pressure log indicated a perturbation at this zone, and the spinner log failed to operate. The image of the loss zone showed multiple fractures over an approximate 200 -foot interval centered about the persistent loss zone.

The Halliburton foam cement operation to treat lost circulation was run over the 200-foot interval. The packer was set on the basis of two caliper logs showing a 10-foot interval where the hole was in gage, a gamma ray log indicating little-to-no argillite in the interval, a mud log showing no drilling break, and a field print of the FMS $\log$ indicating few borehole anomalies in that interval. (However, the FMI $\log$, delivered later, did show a greater number of borehole anomalies over the zone in which the packer was set. In fact, there seemed to be fractures almost everywhere in the vicinity.)

During the Halliburton foam treatment, the McAllister packer (or, as likely, the formation surrounding the packer) failed at pressures between 1300 to 1600 psi. The pressure gradient went as high as $0.85 \mathrm{psi} / \mathrm{ft} v s$ a normal frac gradient of $0.70 \mathrm{psi} / \mathrm{ft}$ for that portion of the field. 
It was estimated that approximately $20 \mathrm{bbl}$ of foam cement entered the loss zone. The packer could not be removed easily, and had to be fished out: Examination of the packer did not provide conclusive evidence as to whether damage was caused by failure of the packed-off zone to hold pressure or the efforts to extricate the packer from the wellbore. During the drill-out of the horizon where the packer had been set, only partial losses were encountered in this heretofore persistent, total-loss zone.

Even though the operation was, by any yardstick, considered a failure (there was a pressure failure and a fishing job accompanying the foam treatment), it appears, however, that the foam cement treatment (or the cuttings and material in the wellbore which were forced into the fracture system during the treatment) did stem the losses from this persistent loss zone. Furthermore, a subsequent temperature log no longer indicated a temperature reversal over this interval. Thus there may indeed have been some noteworthy scientific accomplishments from this economically failed operation.

\section{Percussive Mud Hammer for Geothermal Drilling}

In 1996, under a GDO project, Novatek undertook the development of an improved mud hammer for drilling 121/4 to 13-1/2 inch holes in order to improve geothermal drilling rates with less weight on bit. An initial series of tests was accomplished with a modified existing mud hammer for drilling 7-3/4 inch holes in Terra Tek in early FY 96. As a result of those tests, an improved version of the 7-3/4 inch hammer was fabricated, with the main thrust of the design being: more weight on hammer to match the impedance of the bit/bit sub-assembly; a lengthened hammer stroke for more blow energy impact; a decreased hammer frequency; and rerouting the exhaust through the bit.

A second series of rock penetration tests was conducted at Terra Tek in late FY96/early FY97. This time there was a $70 \%$ increase penetration rate of the mud hammer over that of an ordinary drill bit at 300 psi borehole pressure. This improvement decreased with increased borehole pressure to about $20 \%$ improvement at $1000 \mathrm{psi}$ borehole pressure, however, and the hammer assembly froze up after the initial series of tests because of clogging by the drilling fluid.

Modifications to the hammer assembly were made in early FY97. Additional tests were conducted at Terra Tek in mid and late FY97. One thrust of these tests, and indeed, a focus of the future work, is removing sources of hammer inefficiencies. One major source of hammer inefficiencies is leakage through the hammer valve. A second major source of hammer inefficiencies involves the transmission of impact stress into the rock.

The first source of these inefficiencies was addressed by adjusting the timing of the hammer valve to decrease leakage and improve impact velocity. During one series of atmospheric pressure tests, changes to valve timing (stop position) were simulated by moving the hammer "bit" through a range of positions relative to the stroking hammer. By doing so, the relative impact position of the valve could be adjusted without making hardware changes, i. e., without adjusting the valve stops. The second source of these inefficiencies was addressed by using a solid-bodied bit instead of a relatively compliant roller cone bit.

The ensuing test on hammer efficiency/valve timing showed no improvement over the earlier tests, those in late FY96. As before, there were significantly improved penetration rates at low simulated borehole pressures, but much smaller improvements at higher borehole pressures. A separate test of the fixed cutter bit for the hammer showed no improvement to even negative effects on drilling rates for increasing weight-on-bit. At this time it is concluded that the reasons for these unexpected and disappointing results is that simulating the valve timing changes may not give equivalent hammer performance changes as adjusting the valve stops, and/or use of the fixed-cutter bit may attenuate any further gains. 
Another thrust of the tests and of the future work is to assure adequate life of critical hammer components. Better coating processing techniques and better component design have therefore been investigated to address this problem. The hammer valve has been redesigned to avoid crack patterns in the valve-coating due to stress or highvelocity drilling fluid flow. Other components also have had some degree of redesign. Future study will focus specifically on differences between simulated and actual hardware changes to valve timing, and more work is needed to optimize bit/cutter structure and hammer energy transfer for true rotary-percussive drilling. Along with this, the development of a robust sensor to reliably detect hammer position has begun. Finally arrangements are being made for temporary and permanent test facilities.

\section{Valve-Changing Tool}

A GDO project on a high-temperature, high-pressure valve-changing tool was initiated in late December, 1996, and has now undergone successful field testing in Hawaii. The tool is essentially a high-pressure packer that is run into the casing of a well below the master valve. Its purpose is to shut off the flow of a geothermal well so that the master valve can be repaired or replaced. Commercially available valve-changing tools are typically rated at $1,000 \mathrm{psi}$ and $400^{\circ} \mathrm{F}$. The new tool, designed for $6,000 \mathrm{psi}$ and $600^{\circ} \mathrm{F}$, is necessary for high-temperature, high-pressure fields such as those found in Hawaii.

An operator on the Big Island, Puna Geothermal Ventures (PGV), needed such a tool to allow repairs to be made to corroding master valves. Other geothermal operators were also interested in the tool and encouraged its development under a GDO project. The new tool was designed, fabricated, and tested by Smith International under a GDO contract with Sandia.

After a series of laboratory tests, tool component redesign, and retesting, the tool was shipped to the operator's site in Hawaii. After some preliminary casing scraping, both packers were run through the lubricator, set, and successfully pressure-tested in the well. Both packers were retrieved in turn and redressed. The next day, both packers were again run through the lubricator, set, and left in place while the wellhead equipment was successfully changed out. The packers were retrieved along with the dismantled hydraulic extension rod clamp, rotating extension rod clamp, and the rod packing gland. The first field test and operation were completely successfully.

At the end of the fiscal year, a milling capability was being added to the tool assembly. Thus equipped, the tool will be used in the plug-and-abandon operations for a number of old wells at The Geyser. This capability will be tested in early FY98. Smith currently markets lower-temperature, lower-pressure tools of this type and will also market the new tool now when its development and field testing are complete.

\section{Development of an Expert System to Detect Lost Circulation}

This GDO project is described under the lost circulation technology section describing loss-zone characterization hardware and software.

\section{Positive Displacement Air Motor for High Temperatures}

Test opportunities to evaluate the air motor in the field are still being sought. Because of the limited market for the tool size that has been built, locating a suitable test site has not yet been accomplished. 


\section{FUTURE PLANS}

The industry is taking an extremely active role in identifying future projects for funding. Several new projects have been proposed for FY98. These include Phase 2 of the expert system, development and testing of new technology for high-temperature mud motors, construction and testing of a new type of drilling air/mud/solids separator, development and testing of high-temperature drill pipe protectors, and development of remedial casing repair techniques at The Geysers.

\section{INDUSTRY INTEREST}

Following are the names of specific present collaborators with the DOE and their particular interests. However, it should be emphasized that the entire membership of the Geothermal Drilling Organization is interested in improving the overall geothermal drilling operation while cutting costs.

\section{Organization}

Baker Hughes INTEQ

Smith International, Puna Geothermal Ventures

California Energy Co.

Novatek, Unocal, Mobil, Amoco

Tracor

Drill-Cool

\section{Type and Extent of Interest}

Positive displacement air motor

High-temperature, pressure valve changing tool Rotating head, stripper rubbers

Evaluation of alternative cements, percussive mud hammer, expert system, insulated drill pipe

Construction and testing of an improved mud hammer for geothermal use

Expert system to detect lost circulation

Insulated drill pipe 


\title{
GEOTHERMAL SYSTEMS STUDIES
}

\author{
David A. Glowka, John T. Finger, and Kenneth G. Pierce \\ Sandia National Laboratories
}

\section{KEY WORDS}

drilling systems, well costs, resource evaluation, geothermal markets, geothermal exploration

\section{PROJECT BACKGROUND AND STATUS}

This program area examines other geothermal well-related activities at Sandia that do not fall into one of the other program areas. Activities described here cover a wide range, from drilling system studies to geothermal resource evaluation. These activities often drive activities in other technology areas because they examine technical issues from a more global perspective. Well costs, for example, are studied in one of the projects listed below. This study is expected to identify technology areas that can have the greatest impact on geothermal well costs, which in turn will influence which technical projects are given the highest priority.

\section{PROJECT OBJECTIVES}

The objective of this project is to examine geothermal energy, particularly the well-related aspects, from a systems viewpoint and to develop an understanding that helps direct Sandia's technology development programs toward maximum well-cost reduction.

\section{RESEARCH RESULTS}

\section{Hydrothermal Drilling Cost Study}

An adaptable, modular well-costing code is being developed and used for sensitivity analysis, trade-off studies, case studies, and life-cycle analysis of selected geothermal projects. These analyses will use the code to develop information needed by DOE, the industry, and the geothermal research community in focusing on high-payoff research and development with the greatest potential impact on the industry. Sandia is developing the code with assistance from Livesay Consultants.

This study was initiated in FY97. The costing code was almost developed by the end of the fiscal year. Additional work on the code and then use of the code to perform sensitivity analyses will be completed in FY98. Technologies or technical solutions that could have the greatest effects on the cost of geothermal energy will be identified and the effects quantified. The code will also be released to industry as a comprehensive, flexible tool for independently conducting drilling, completion, and well life-cycle cost studies.

\section{Systems Analysis of Novel Wellbore-Lining Methods}

Sandia and Livesay Consultants are working in partnership to examine novel (that is, not conventional casingand-cement) methods of lining a wellbore. This analysis, which is looking at such concepts as casing while drilling, drilling with casing, and formed-in-place casing, will be applicable to lost circulation and wellbore stability problems, as well as potential cost savings through using fewer casing strings. 
Because funding for this project was received late in FY97, work to date has been primarily devoted to literature searches and development of a contact list of previous and current researchers in this general topic area. Project completion, including two conceptual lining-system designs, will take place during FY98.

\section{Compact Rig Study}

Geothermal Management Company, Inc. has conducted two studies concerning development of a compact drill rig rated for 10,000 -ft geothermal production wells. The first survey contacted geothermal operators, drilling consultants, rig manufacturers, and others in the industry to determine whether there is a need for such a rig and, if so, to define its requirements. Having concluded that a need exists, GMC did a second survey to compare currently available rigs to the requirements derived from the first survey. A rig built by IDECO was found to be very close to the target specifications, and a detailed design and cost estimate for this rig in geothermal configuration was done. An economic analysis of using this rig for production drilling was then done, and annual cost savings of $\$ 1.5 \mathrm{M}$ in a 4-well/year program were estimated.

Reports on the two surveys were combined and will be published as a Sandia Report in early FY98 ${ }^{2}$. GMC will further transfer the technology by individual meetings with operators to brief them on details of the rig and to acquaint them with possible cost savings from its use.

\section{Micro-Seismic Detection System}

In November, 1996, Sandia deployed a three-axis accelerometer package in an abandoned Unocal well at the Geysers. These instruments took data for approximately two days and gave better high-frequency data, and thus better resolution for mapping fractures, than conventional geophones. Accurate fracture detection and mapping would be extremely valuable in geothermal reservoirs because most production is fracture-dominated, not through a permeable matrix, and knowledge of the fractures' orientation would enable operators to intersect more fractures per well.

The accelerometer package was a spin-off from technology development funded by the Gas Research Institute (GRI) for use in gas exploration, and its electronic components are only qualified for use up to a temperature of approximately $300^{\circ} \mathrm{F}$. The full array designed for GRI has five accelerometer packages, spaced $200 \mathrm{ft}$ apart, which gives much more information than single-level systems. To test the five-level system in a realistic geothermal reservoir, however, requires a relatively cool, deep well in which to insert the array. The immediate priority for this project is to test the GRI five-level array in a geothermal reservoir to evaluate its ability to locate and map fractures in this kind of formation. If that is the case, then we will begin efforts to upgrade the accelerometers and electronics to operate at geothermal temperatures. Efforts to identify a potential test site will continue through the first quarter of FY98.

Configuration of a five-level package's installation in or alongside a geothermal well must also be defined, with one possibility being to contain the array in an auxiliary pipe embedded in the cement around a casing annulus. A simple two-dimensional, finite-element model of this kind of pipe, which is similar to a parasite injection string, was used to analyze stresses in the cement during thermal cycling. Although minor crushing was predicted to occur around the auxiliary pipe, it does not appear that introduction of this perturbation into the annulus would cause serious degradation in the cement compared to conventional practice. 


\section{Geothermal Resource Survey of Russia, Ukraine, and China}

Under an on-going contract with Sandia, Bob Lawrence \& Associates (BLA) conducted a survey of potential geothermal resources in Russia and Ukraine and published a report that includes for each region: maps of the geothermal sites, their current usage, and thermodynamic properties such as pressure, temperature, and flow rate.

Most of the resources in Russia and Ukraine are low-enthalpy, primarily suited to direct use, but in China the situation is considerably different. The Chinese govermment is committed to installing 170 gigawatts of electrical generation in the next 10 years, and geothermal can play a significant role in that expansion. BLA suggests that the U. S. government's role with respect to China should be to monitor activities there and to report opportunities to the U. S. geothermal industry.

Since completion of the regional surveys, BLA have focused their efforts on development of a strategic plan for identifying and financing opportunities for U. S. companies. Most of the work has been devoted to creation of a Financing Workbook, which will contain three case studies of geothermal development projects and will be used by geothermal companies seeking project-development money. Another major activity is selection of up to ten international sites with market potential which will receive further detailed study and description. Results of this work will not only be reported to Sandia and DOE but will be available on a Web site, although the site will incorporate security procedures which limit access to U. S. companies. The Workbook will be available in the second quarter of FY98.

\section{FUTURE PLANS}

Existing projects in this area will continue in FY98, as described above. Additional system studies will be initiated as needed to address global issues associated with geothermal energy evaluation and extraction.

\section{REFERENCES}

1. Pierce, K.G., Bomber, T.M., and Livesay, B.J." "Well Cost Estimates in Various Geothermal Regions," (Oct. 1997), Trans. Geothermal Resources Council, 21, 119-122.

2. Huttrer, G.W.: "Technical and Economic Evaluation of Selected Compact Drill Rigs for Drilling 10,000Foot Geothermal Productions Wells," Report SAND97-2872, Sandia National Laboratories, Albuquerque, NM, November 1997. 


\section{LIST OF CONTACTS FOR DRILLING TECHNOLOGY}

Douglas S. Drumheller

Sandia National Laboratories

Geothermal Research Dept. 6211

Albuquerque, NM 87185

Phone: (505) 844-8920

Fax: (505) 844-3952

e-mail: dsdrumh@sandia.gov

John T. Finger

Sandia National Laboratories

Geothermal Research Dept. 6211

Albuquerque, NM 87185

Phone: (505) 844-8089

Fax: (505) 844-3952

e-mail: jtfinge@sandia.gov

David A. Glowka, Manager

Sandia National Laboratories

Geothermal Research Dept. 6211

Albuquerque, NM 87185

Phone: (505) 844-3601

Fax: (505) 844-3952

e-mail: daglowk@sandia.gov

Paul Grabowski

Office of Geothermal Technologies

U. S. Dept. of Energy

Forrestal Bldg., EE-12

1000 Independence Ave SW

Washington, DC 20585

Phone: (202) 586-0478

Fax: (202) 586-8185

Joseph A. Henfling

Sandia National Laboratories

Geothermal Research Dept. 6211

Albuquerque, NM 87185

Phone: (505) 844-6720

Fax: (505) 844-3952
Steven D. Knudsen

Sandia National Laboratories

Geothermal Research Dept. 6211

Albuquerque, NM 87185

Phone: (505) 857-6841

Fax: (505) 844-3952

e-mail: sdknuds@sandia.gov

Arthur J. Mansure

Sandia National Laboratories

Geothermal Research Dept. 6211

Albuquerque, NM 87185

Phone: (505) 844-9315

Fax: (505) 844-3952

e-mail: ajmansu@sandia.gov

Randy A. Normann

Sandia National Laboratories

Geothermal Research Dept. 6211

Albuquerque, NM 87185

Phone: (505) 845-9675

Fax: (505) 844-3952

e-mail: ranorma@sandia.gov

Kenneth G. Pierce

Sandia National Laboratories

Geothermal Research Dept. 6211

Albuquerque, NM 87185

Phone: (505) 844-9176

Fax: (505) 844-9293

e-mail: kgpierc@sandia.gov

Lew Pratsch

Office of Geothermal Technologies

U. S. Dept. of Energy

Forrestal Bldg., EE-12

1000 Independence Ave SW

Washington, DC 20585

Phone: (202) 586-1512

Fax: (202) 586-8185 
David W. Raymond

Sandia National Laboratories

Geothermal Research Dept. 6211

Albuquerque, NM 87185

Phone: (505) 844-8026

Fax: (505) 844-3952

Marshall Reed

Office of Geothermal Technologies

U. S. Dept. of Energy

Forrestal Bldg., EE-12

1000 Independence Ave SW

Washington, DC 20585

Phone: (202) 586-8076

Fax: (202) 586-8185

Allan R. Sattler

Sandia National Laboratories

Geothermal Research Dept. 6211

Albuquerque, NM 87185

Phone: (505) 844-1019

Fax: (505) 844-0240

e-mail: arsattl@sandia.gov

George E. Staller

Sandia National Laboratories

Geothermal Research Dept. 6211

Albuquerque, NM 87185

Phone: (505) 844-9328

Fax: (505) 844-3952

e-mail: gestall@sandia.gov

Jack A. Wise

Sandia National Laboratories

Geothermal Research Dept. 6211

Albuquerque, NM 87185

Phone: (505) 844-6359

Fax: (505) 844-3952

e-mail: jlwise@sandia.gov 


\title{
GEOCHEMICAL STUDIES OF GEOTHERMAL SYSTEMS
}

\author{
Gregory J. Nimz and Carol J. Bruton \\ Lawrence Livermore National Laboratory (LLNL)
}

\section{KEY WORDS}

geochemistry, isotopes, magmatic fluids, geochemical modeling, reinjection, Coso, Dixie Valley, Awibengkok

\section{PROJECT BACKGROUND AND STATUS}

The geothermal industry has many unresolved exploration and development issues related to its incomplete understanding of geothermal systems. We are applying two LLNL capabilities to increase our knowledge of these systems: (1) the measurement of low-abundance natural and anthropogenic isotopes using accelerator mass spectrometry, and (2) computer modeling of geochemical fluid-rock interactions. We are collaborating in isotopic studies at (1) Coso Hot Springs with California Energy Company, (2) Dixie Valley with Oxbow Power Services, Inc., and (3) Awibengkok, Indonesia, with Unocal Geothermal Corp. Working with Oxbow, we are applying our geochemical modeling capabilities to the Dixie Valley geothermal system.

\section{Coso}

The Coso geothermal field is located in the southernmost portion of Owens Valley in eastern California. The geothermal activity is associated with the Coso volcanic field, which is composed of basaltic-to-rhyolitic rocks erupted between 6 million and 40 thousand years ago (Duffield et al., 1980; Duffield and Bacon, 1981). The hydrothermal production zone is within granitoid basement rocks. The Coso geothermal field is operated by the California Energy Company, and currently has a production capacity of $240 \mathrm{MW}$. The origin of corrosive solutes within Coso geothermal waters, the regional circulation of that water, and the temporal variations in circulation are not clearly known and are the primary emphases of our investigations at Coso.

\section{Dixie Valley}

The Dixie Valley Geothermal Field occurs in a typical Basin and Range tectonic setting in north-central Nevada. The geothermal activity is associated with the high regional heat flow of the Battle Mountain region (Sass et al., 1971). The production zone is adjacent to the Stillwater Fault, which is a late-Cenozoic normal fault separating dominantly granitoid rocks to the west from Tertiary volcanic and Paleozoic marine sequences to the east. The producing zone occurs at a depth of about 2800 to $3050 \mathrm{~m}$ and about $250^{\circ} \mathrm{C}$. The wide variety of rock types occurring in this setting are extensively altered by geothermal fluids (Lutz et al., 1997a and b). The 62-MW field is owned and operated by Oxbow Power Services, Inc. Scaling occurs in flow lines and injectors, which require periodic cleaning. Oxbow currently reinjects low-pressure brine at the margins of the field. To maintain reservoir pressure, future plans call for reinjecting the reservoir with a mixture of low-pressure brine and local groundwater. We are collaborating with Oxbow to determine the following: the relationship between regional hydrology and geothermal fluids, the effect of plant operations on regional hydrology, and the role of geologic faulting on hydrology and geothermal circulation. This project is in collaboration with Los Alamos National Laboratory, the U.S. Geological Survey, the University of Utah Energy and Geoscience Institute, and Oxbow Power Services, Inc. 


\section{Awibengkok}

The Awibengkok geothermal field is located in West Java, Indonesia, approximately $60 \mathrm{~km}$ south of Jakarta. The geothermal activity is associated with the magmatism of the Gunung Perbakti-Gagak volcanic complex (Mt. Salak), a $<1 \mathrm{Ma}$ andesitic stratovolcano. This complex is part of the Indonesian subduction-related volcanic arc that sits on Tertiary oceanic sedimentary strata. The Awibengkok geothermal field is operated by the Unocal Geothermal Corp., and currently has a production of about $300 \mathrm{MW}$. We are collaborating with Unocal to determine the pathways by which meteoric water can enter the geothermal system, and whether subduction-related isotopes can be used as exploration tools.

\section{PROJECT OBJECTIVES}

Our overall objective is to use geochemical modeling of fluid-rock interactions and the measurement of low-abundance natural and anthropogenic isotopes to better understand the hydrology of geothermal systems and the fluid-rock interactions that occur during the evolution of geothermal systems. Our focus is on the origin of solutes and fluids within the system, the flow of hydrothermal fluids and related regional waters, and chemistry-related problems during production and reinjection (e.g., scale, corrosive fluids).

\section{Technical Objectives}

Coso

- Determine the source of solutes in the geothermal fluids.

- Determine the residence time of geothermal fluids within the field.

- Determine on a regional basis the flow patterns of the geothermal fluids surrounding the production field.

- Determine the feasibility of using isotopic indicators to understand the relationship between fluid inclusions in Coso drillcore samples and the geothermal fluids currently circulating in the hydrothermal system.

Dixie Valley

- Determine the hydrologic connection between the "shallow" meteoric groundwater system in the geothermal reservoir and the "deep" hydrothermal system.

- Determine the role of the Stillwater fault in the geothermal circulation: does the fault act as a conduit of fluids or a barrier to fluid flow?

- Determine what role, if any, mantle-derived fluids have in Basin and Range type geothermal systems.

- Determine (1) the effects of reinjection on the circulation of the geothermal fluids, and (2) the potential that, over time, reinjection fluids will damage the reservoir by reacting with reservoir fluids and rocks, and thereby disturbing groundwater flow within Dixie Valley:

Awibengkok

- Determine the flow paths of cold meteoric water into the geothermal system. 
- Determine the source of solutes in the geothermal fluids, especially slab vs. mantle-derived sources, in order to select "fingerprints" for future exploration in similar geologic environments.

- Determine circulation depths for the geothermal fluids based on isotopic source signatures.

\section{Expected Outcomes}

Coso

- Determine the origin of solutes and corrosive $\mathrm{HCl}$ in the geothermal system, and use this information to help mitigate corrosion problems.

- Develop isotopic means to test hydrothermal circulation models and models for hydrologic flow adjacent to the field so that the appropriate models can be used to site drillholes.

- Develop isotopic geothermal exploration tools for the region.

Dixie Valley

- Better define the hydrologic system affecting this system and its response to continued production and reinjection.

- Determine the effect of the Stillwater fault on the flow of geothermal fluids, and use this information to help site future production and monitoring holes.

- Provide information allowing Oxbow Power Services, Inc., to better design reinjection strategies, maintain injectivity, and understand the long-term effects of pressure changes in the field on hydrothermal water movement.

Awibengkok

- Determine the pathways by which cold meteoric water can enter the geothermal system, and use this information to help site future production holes.

- Determine a characteristic isotopic fingerprint for geothermal fluids in a subduction setting, and use this isotopic signature as a tool in future exploration in the circum-Pacific region.

\section{APPROACH}

To determine the sources of solutes in the fluids, we examine low-abundance natural and anthropogenic isotopes of rare nuclides in geothermal fluids, meteoric waters, and host rocks. Our primary facility for isotopic analysis is the LLNL Center for Accelerator Mass Spectroscopy (CAMS), where we measure nuclides such as ${ }^{14} \mathrm{C},{ }^{36} \mathrm{Cl}$, and ${ }^{129} \mathrm{I}$ in small samples of fluid and rock from geothermal systems. This determination provides information concerning the origins; ages, and circulation pathways for fluids within geothermal systems. We also model fluid-fluid and fluid-rock interactions using various computer models, including reactive transport simulators, to evaluate the effects of production and reinjection. By combining existing fluid analyses and rock samples from a geothermal field with thermodynamic modeling of the dynamic interactions among them, we can obtain a more complete description of reservoir and regional processes both past and present. 


\section{RESEARCH RESULTS}

\section{Coso}

The ${ }^{36} \mathrm{Cl} / \mathrm{Cl}$ values for several geothermal water samples and reservoir host rock samples from the Coso geothermal field have been measured (Figure 1). Because the values for the granitoid rocks, which are the dominant lithology, are different from those of the water, they indicate that most of the chlorine is not derived from the rocks that host the geothermal system. Calculated ${ }^{36} \mathrm{Cl} / \mathrm{Cl}$ values for rocks of the Sierran Province, to which Coso belongs, indicate that the values measured at Coso are typical for the Province. But the ${ }^{36} \mathrm{Cl} / \mathrm{Cl}$ values within the Coso waters are truly unlike those of the rocks within the Province (Figure 2).

Three other potential sources for the chlorine could be suggested: (1) meteoric input from groundwater recharge, (2) migration of chloride and/or water into the granitic rocks from adjacent sedimentary units, and (3) migration of chloride into the geothermal system from magmatic sources. If the chlorine was originally input into the Coso subsurface through meteoric recharge, the input occurred at least 1 to 1.25 million years ago. This is the time it would take for the radioactive ${ }^{36} \mathrm{Cl}$ to decay to the currently observed values, beginning at the regional meteoric value of about $250 \mathrm{E}-15$ (Bentley et al., 1986). There is no independent evidence to suggest that the Coso water is not simply very old groundwater, although a mechanism for concentrating the solutes to their present levels is required (e.g., $>2000 \mathrm{ppm}$ chloride). Sedimentary rocks typically have low uranium concentrations, which produce time-integrated low ${ }^{36} \mathrm{Cl} / \mathrm{Cl}$ ratios in the rock, similar in value to those measured in the Coso waters (Andrews et al., 1986). Therefore, the Coso geothermal waters could represent connate waters derived from sedimentary formations, presumably underlying or adjacent to the granitic rocks. A connate origin for the water would be consistent with the $\partial \mathrm{D} / \partial^{18} \mathrm{O}$ values observed in Coso waters (Fournier and Thompson, 1980). Further work is required to rule out this possibility. The third possibility, that the chlorine is magmatic in origin, also requires further investigation, but is clearly in agreement with the ${ }^{36} \mathrm{Cl} / \mathrm{Cl}$ ratios measured in the Coso water. The $\partial \mathrm{D} / \partial^{18} \mathrm{O}$ values in Coso waters are not those of magmatic fluids, so it should be emphasized that in this model it is not the water that migrates into the geothermal system, but only the chlorine (plus or minus other solutes).

Neutrons released during the natural spontaneous fission of $\mathrm{U}$ and $\mathrm{Th}$ produce ${ }^{36} \mathrm{Cl}$ in rock and water by neutron activation of stable chlorine. This causes a constant build-up of ${ }^{36} \mathrm{Cl}$ that will reach an equilibrium maximum concentration, offset by the constant radioactive decay of ${ }^{36} \mathrm{Cl}$. The magnitude of the equilibrium concentration ${ }^{36} \mathrm{Cl} / \mathrm{Cl}$ value is a function of the number of neutrons available, which is directly related to the local $\mathrm{U}$ and $\mathrm{Th}$ concentrations. Any system older than about 1.5 million years $\left(5\right.$ times the ${ }^{36} \mathrm{Cl}$ half-life, the time it takes for equilibrium to be reached) will have a characteristic and fixed ${ }^{36} \mathrm{Cl} / \mathrm{Cl}$ ratio that is a function primarily of the $U$ and $\mathrm{Th}$ concentrations of that system. Because the ${ }^{36} \mathrm{Cl} / \mathrm{Cl}$ ratios in the Coso waters are lower than those in the rock, the chlorine has not reached equilibrium with the rock environment. This permits us to make an estimate of the maximum residence time for the Coso water samples, that is, how long the build-up could have been occurring in that U-Th environment. Figure 3 shows the results of these calculations based on a uranium concentration of $6 \mathrm{ppm}$ and a Th/U ratio of 3.2 (the Sierran averages). A maximum residence time would be given by the circumstance where the original ${ }^{36} \mathrm{CV} / \mathrm{Cl}$ ratio (before entering into the granitoid rocks) was zero. This would be about 180,000 years (Figure 3). If instead, the original equilibrium ${ }^{36} \mathrm{Cl} / \mathrm{Cl}$ ratio was $6.0 \mathrm{E}-15$ (an appropriate value for water from typical limestones and sandstones), the maximum residence time would be about 110,000 years. Any significant amount of leaching of $\mathrm{Cl}$ from the granitoids would lower the calculated residence time even further. Phillips et al., (1995) have suggested, based on chlorine mass-balance arguments, that waters within the Mono Basin to the north of the Coso field received a significant input of chlorine between 100,000 and 450,000 years ago. This is strikingly similar to our findings at Coso. 


\section{Dixie Valley}

We thermodynamically reconstructed the chemistry of production, domestic, and power plant fluids under operating and subsurface conditions. The analyses were used to (1) identify trends in fluid chemistry from producers to injectors, (2) determine relations between regional recharge and shallow groundwater, and (3) identify potentially adverse mineral reactions during reinjection. Geochemical analysis showed that the low-pressure brine and injection waters are saturated with respect to amorphous silica. The ongoing scale problem thus correlates with the precipitation of silica necessary to maintain equilibrium with a phase similar to amorphous silica. Scale control, therefore, becomes fundamentally one of controlling silica scale.

According to multiple lines of evidence (including fluid chemistry, ${ }^{36} \mathrm{Cl} / \mathrm{Cl}$ ratios, and temperature-affinity diagrams), shallow groundwater from a nearby well contains about $15 \%$ geothermal brine mixed with regional recharge. The elevated $\mathrm{Ca}, \mathrm{Mg}$, and $\mathrm{HCO}_{3}$ content of the groundwater and its equilibrium with respect to calcite suggests that carbonate precipitation may occur if the groundwater is reinjected and its temperature increases. Computer simulations of the heating of the shallow groundwater suggest that calcite and anhydrite and perhaps $\mathrm{Mg}$-bearing silicates will tend to precipitate in response to increased temperature.

Downhole reservoir fluids are close to equilibrium with the latest vein mineral assemblage of quartz-calcite (Lutz, 1997b) when monomeric Al concentrations are used. [Note: Bruton et al. (1997) had to use total Al to match an earlier interpretation of vein mineral assemblage in Lutz (1997a). The use of monomeric Al, which is normally considered the appropriate quantity, yields quartz-calcite equilibria that correspond to the newest interpretation in (Lutz, 1997b).] Preliminary geochemical simulations of the reinjection of low-pressure brine into the reservoir suggest that the region near the wellbore is affected much differently than the region farther away. Mineral saturation states are controlled mainly by temperature during mixing rather than variations in $\mathrm{pH}$ caused by mineral precipitation/dissolution. However, $\mathrm{Mg}$-bearing silicates such as $\mathrm{Mg}$-chlorite are especially sensitive to changes in $\mathrm{pH}$ caused by changing temperature and ongoing mineral precipitation/dissolution reactions (Bruton et al., 1997).

\section{Awibengkok}

Our isotopic research results at Awibengkok are still very preliminary and reconnaissance in character. They suggest that certain isotopic systems are sensitive to mixing between geothermal fluids and meteoric waters at this site. Significantly, isotopic indicators of a slab component, which we anticipated, were not present. This is distinct from other young subduction-related volcanic systems where such a signature was observed in rocks using other isotopic systems (Edwards et al., 1993).

\section{FUTURE PLANS}

\section{Coso}

The isotopic signature of the production waters at Coso is very distinct. We plan to examine both geothermal and cold waters in the region to define the geographical and, potentially, the three-dimensional distribution of these signatures. Through our ongoing collaboration with the University of Utah Energy and Geoscience Institute, we hope to work on the adjacent U.S. Navy China Lake lands, in cooperation with the U.S. Navy. 


\section{Dixie Valley}

An understanding of the relationship between regional hydrologic flow and local geothermal circulation is critical at Dixie Valley because the system appears to be driven by regional heat flow rather than point-source magmatic activity. We plan to continue our isotopic and chemical characterization of the regional hydrology in collaboration with the Oxbow Power Services, Inc., Los Alamos National Laboratory, and the U.S. Geological Survey. Once the hydrology is better understood at the valley (groundwater basin) scale, the isotopic indicators can be used as field-development and field-management tools during the drilling of future holes, monitoring, reinjection, and production. We will continue to make reactive transport simulations of fluid-rock interactions during reinjection into the reservoir to evaluate its long-term effects on the reservoir.

\section{Awibengkok}

We plan to continue our work with Unocal Corp. to isotopically characterize the waters and solutes in arc-related geothermal fields. Of central importance in this work is making the transition from the characterization of isotopic signatures to their use as exploration tools in similar circum-Pacific subduction-related complexes.

\section{INDUSTRY INTEREST}

\author{
Organization \\ California Energy Company
}

Oxbow Power Services, Inc.

Unocal Geothermal Corp.

\section{Type and Extent of Interest}

Provides samples for analysis on collaborative basis with the University of Utah Energy and Geoscience Institute.

Participates directly in (1) research to develop isotopic tools for the Basin and Range Province, (2) production and monitoring well access, and (3) access to Dixie Valley chemical and geological data; provides logistical support to field work within Dixie Valley.

Provides samples for analysis on collaborative basis; provides information on industry needs in Indonesia.

\section{REFERENCES}

Andrews, J.N., Fontes, J-Ch., Michelot; J-L., and D. Elmore (1986), "In-situ neutron flux, ${ }^{36} \mathrm{Cl}$ production and groundwater evolution in crystalline rocks at Stripa, Sweden," Earth Planet. Sci. Lett. 77, 49-58.

Bentley, H.W., Phillips, F.M., and S.N. Davis (1986), "Chlorine-36 in the terrestrial environment," Handbook of Environmental Geochemistry (P. Fritz and J.-Ch. Fontes, eds.), Elsevier, Amsterdam, pp. 427-480.

Bruton, C.J., Counce, D., Bergfeld, D., Goff, F., Johnson, S.D., Moore, J.N., and G. Nimz (1997), "Preliminary investigation of scale formation and fluid chemistry at the Dixie Valley Geothermal Field, Nevada," Geothermal Resources Council Trans. 21, 157-164.

Duffield, W.A., and C.R. Bacon (1981), Geologic map of the Coso volcanic field and adjacent areas, Inyo County, California: Scale 1:50,000: Misc. Geol. Field Invest. Map 1-1200, U.S. Geological Survey. 
Duffield, W.A., Bacon, C.R., and G.B. Dalrymple (1980), "Late Cenozoic volcanism, geochronology, and structure of the Coso Range, Inyo County, California," J. Geophys. Res. 85, 2381-2404.

Edwards, C.M.H., Morris, J.D., and M.F. Thirlwall (1993), "Separating mantle from slab signatures in arc lavas using $\mathrm{B} / \mathrm{Be}$ and radiogenic isotope systematics," Nature 362, 530-533.

Fournier, R.O., and J.M. Thompson (1980), The recharge area for the Coso, California, geothermal system deduced from $D$ and ${ }^{18} O$ in thermal and non-thermal waters in the region, U.S. Geological Survey Open-file Report 80-454.

Lutz, S.J., Moore, J.N., and D. Benoit (1997a), "Geologic framework of Jurassic reservoir rocks in the Dixie Valley Geothermal Field, Nevada: Implications from hydrothermal alteration and stratigraphy," Proc. 22nd Workshop on Geoth. Reserv. Eng., Stanford University Report SGP-TR-155, Stanford, CA, Jan. 27-29, 1997, $8 \mathrm{p}$.

Lutz, S.J., Moore, J.N., and D. Benoit (1997b), "Integrated alteration mineralogy and fluid inclusion study at the Dixie Valley Geothermal Field, Nevada," Abstract submitted to 23rd Workshop on Geoth. Reserv. Eng., Stanford University, Jan. 26-28, 1998.

Phillips, F.M., Rogers, D.B., Dreiss, S.J., Jannick, N.O., and D. Elmore (1995), "Chlorine-36 in Great Basin waters: Revisited,"Water Res. Research 31, 3195-3204.

Sass, J.H., Lachenbruch, A.H., Munroe, R.J., Greene, G.W., and T.H. Moses, (1971), "Heat flow in the western United States,"J. Geophys. Res. 76, 6376-6413. 


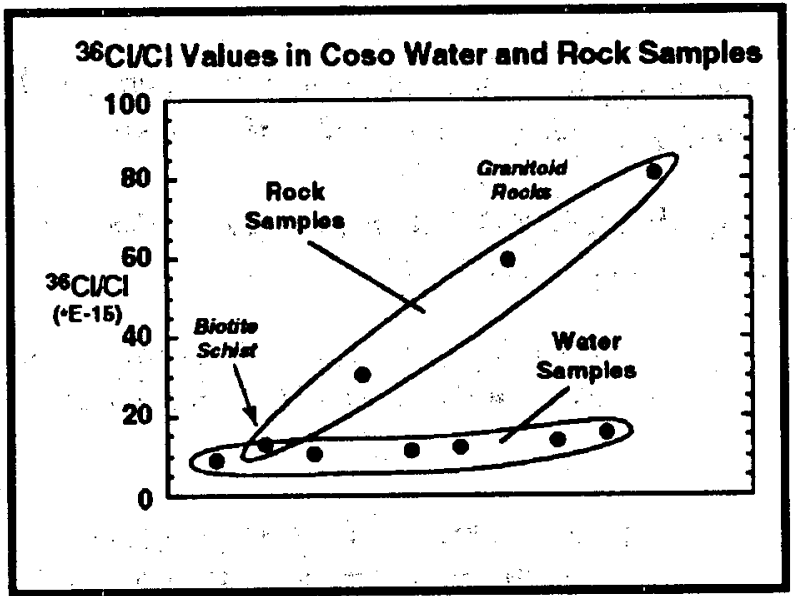

Figure 1

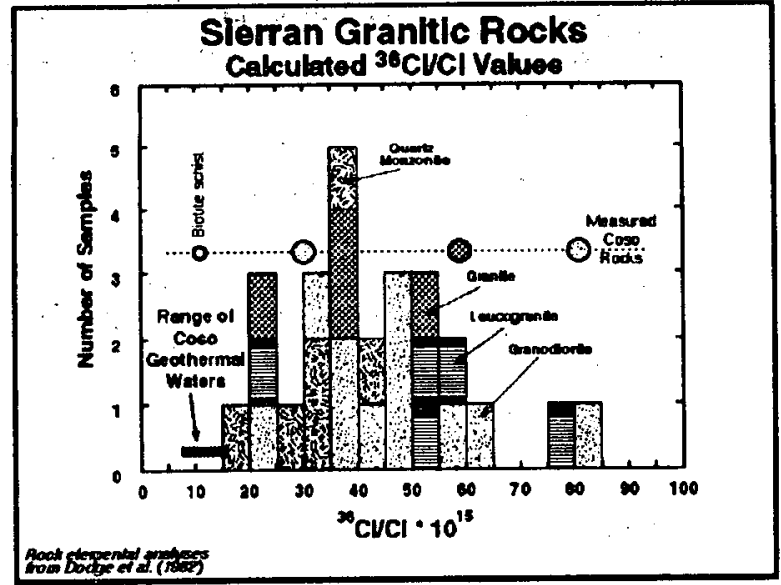

Figure 2

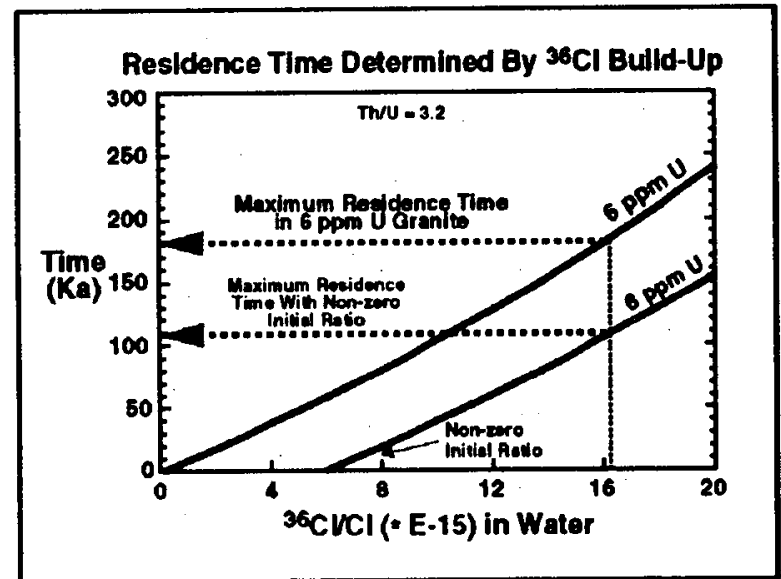

Figure 3 


\title{
GEOCHEMISTRY OF ALUMINUM IN HIGH TEMPERATURE BRINES
}

\author{
Donald A. Palmer, Pascale Benezeth, and David J. Wesolowski \\ Chemical and Analytical Sciences Division, Oak Ridge National Laboratory
}

\section{KEY WORDS}

aluminum, solubility, potentiometry, permeability, alteration, aluminosilicates, modeling

\section{PROJECT BACKGROUND AND STATUS}

In geothermal systems, the ability to model accurately the composition of the reservoir fluid from observed mineral assemblages and the effects of fluid temperature and composition on the dissolution/precipitation rates and equilibrium mineral assemblages, will provide more reliable determinations of fluid sources and system hydrodynamics. Accurate models will also help to predict the onset of corrosion and aluminosilicate scale formation and the effects of geothermal fluid extraction and spent fluid reinjection, on reservoir porosity and permeability.

The original research in this program began with a systematic study of gibbsite solubility in $\mathrm{NaCl}$ solutions to 5 molal at low and high $\mathrm{Ph}$ to $80^{\circ} \mathrm{C}$, which yielded the stabilities of the two end-member species, $\mathrm{Al}^{3+}$ and $\mathrm{Al}(\mathrm{OH})_{4}^{-}$. The resulting solubility quotients were modeled with empirical equations, as well as by the Pitzer ioninteraction treatment. An intensive and time-consuming solubility study followed in the intermediate $\mathrm{pH}$ range $\left(0.1\right.$ molal $\mathrm{NaCl}$ and $\left.50^{\circ} \mathrm{C}\right)$ by the same batch method using various buffers to control the $\mathrm{pH}$. The stabilities of the $\mathrm{Al}(\mathrm{OH})^{2+}, \mathrm{Al}(\mathrm{OH})_{2}{ }^{+}$, and $\mathrm{Al}(\mathrm{OH})_{3}{ }^{0}$ were obtained from the resulting solubility profile, which was found to be in excellent agreement with the extrapolated solubilities determined from the previous end-member investigations. Based only on the measured solubility quotients for $\mathrm{Al}^{3+}, \mathrm{Al}(\mathrm{OH})^{2+}$ (Palmer and Wesolowski, 1993) and $\mathrm{Al}(\mathrm{OH})_{4}^{-}$, the solubility profile could be simulated over the whole range of salinities (to 5 molal or $226,000 \mathrm{ppm})$, temperature $\left(0\right.$ to $\left.100^{\circ} \mathrm{C}\right)$, and $\mathrm{pH}$ to within $0.3 \log$ units in total aluminum concentration at the solubility minimum where $\mathrm{Al}(\mathrm{OH})_{2}{ }^{+}$and $\mathrm{Al}(\mathrm{OH})_{3}{ }^{0}$ are significant species. Moreover, by invoking the "isocoulombic" approach to estimate solubility constants based on the measured values at $50^{\circ} \mathrm{C}$, determination of these two remaining species was made possible over the full range of conditions.

A thorough study of the thermodynamics of aqueous aluminum at temperatures above $100^{\circ} \mathrm{C}$ required a different approach, because predictions based on extrapolation of our lower-temperature data were found to conflict with some recent studies reported in the literature (Castet et al., 1993; Bourcier et al., 1993), which also disagreed with one another. This conflict extended from mildly acidic to near neutral $\mathrm{pH}$ conditions corresponding to the solubility minimum of boehmite, $\mathrm{AlOOH}$, which is the stable phase of aluminum above $100^{\circ} \mathrm{C}$. Note that the published studies relied on the measured $\mathrm{pH}$ at $25^{\circ} \mathrm{C}$ for calculation of $\mathrm{pH}$ at temperature. The stability of the dominant aluminate species in neutral to basic solutions is well established. Increasing temperature favors increased hydrolysis of all metal ions, thereby broadening the stability field of $\mathrm{Al}(\mathrm{OH})_{4}{ }^{\circ}$. On the other hand. increased ionic strength drives the solubility minimum to higher $\mathrm{pH}$, thereby widening the stability field of $\mathrm{Al}^{3+}$ at the expense of the hydrolyzed species. This influence of salinity on speciation is substantial and directly relevant to geothermal environments, a subject not addressed in any of the previous high temperature studies. The current program has focused on the solubility of boehmite in the $100-290^{\circ} \mathrm{C}$ range at ionic strengths of 0.03 to 5 molal ( $27.5 \mathrm{wt} \%$ ) using a potentiometric cell which allows continuous $\mathrm{pH}$ monitoring in conjunction with periodic sampling and analysis of aluminum in the aqueous phase. 
This effort benefits substantially from three projects funded by the DOE Office of Basic Energy Sciences, namely two from the Geoscience Research Program entitled "Fundamental Geochemistry of Geothermal Systems", and "Experimental Studies of Hydrothermal Processes Employing In Situ pH Measurements", as well as the project entitled "Basic Aqueous Chemistry to High Temperatures and Pressures", funded by the Chemical Sciences Division. These programs permit more detailed, fundamental studies of certain aspects of aluminum chemistry, such as complexation by organic and inorganic ligands occurring in natural and experimental solutions.

\section{PROJECT OBJECTIVES}

The objective of this research is to provide quantitative data on the principal aqueous species and the properties of aluminum minerals required to model the changes in permeability and brine chemistry associated with fluid/rock interactions in the recharge, reservoir, and discharge zones of active geothermal systems.

\section{Technical Objectives}

- Aluminosilicates are the dominant mineral phases controlling permeability and brine chemistry in geothermal systems. In order to understand the chemistry invoking changes in these fundamental reservoir characteristics, a precise knowledge of the aqueous speciation of aluminum in aqueous brines is required, spanning the temperature and fluid composition ranges encountered in active systems.

- Detailed solubility measurements of aluminum minerals utilizing potentiometric and conventional methods are in progress to constrain the speciation and stability constants of dissolved aluminum species. Particular emphasis is placed on our ability to control and measure solution $\mathrm{pH}$ in situ to high temperatures. An additional goal is to apply this technique to the study of the kinetics of dissolution/precipitation reactions.

\section{Expected Outcomes}

- A consistent set of thermodynamic parameters will be generated which will identify and quantify the prevalent aqueous aluminum species, as well as the chemical composition of solutions in equilibrium with rock-forming minerals at geothermal reservoir conditions.

- The results will be treated to allow them to be readily incorporated into chemical reaction and transport computer codes in common use by the geothermal industry.

- Topics to be addressed in the near future include dissolution/precipitation kinetics and solubilities of aluminosilicates, and problems associated with brine reinjection, scaling, and corrosion in down-hole and in-plant systems.

\section{APPROACH}

The thermodynamic properties at infinite dilution and the activity coefficients of $\mathrm{Al}(\mathrm{OH})_{y}^{3 . y}(y=0-4)$ in 0.03 to 5 molal $\mathrm{NaCl}$ brines were measured using a variety of solubility and potentiometric methods. Experimental studies have focused on the solubility of gibbsite and boehmite, and independent potentiometric measurements of the hydrolysis of $\mathrm{Al}^{3+}$ over a wide range of temperatures and salinities. Initial modeling efforts to help understand problems of aluminosilicate scale formation and reservoir permeability changes associated with reinjection at the Dixie Valley geothermal system were also initiated in collaboration with Joe Moore at the Energy and Geoscience Institute, University of Utah, Fraser Goff at Los Alamos National Laboratory, and Dick Benoit of Oxbow Geothermal. 


\section{RESEARCH RESULTS}

The aqueous geochemistry of $\mathrm{Al}$ (III) is dominated by the interaction of $\mathrm{Al}^{3+}$ with water to form hydrolytic species, which profoundly influence the solubility of any aluminum-bearing mineral as a function of $\mathrm{pH}$. Aluminum concentrations vary by orders of magnitude from the stability field of $\mathrm{Al}^{3+}$, where the solubility increases threefold for a unit increase in $\mathrm{H}^{+}$concentration, to the field of stability of $\mathrm{Al}(\mathrm{OH})_{4}$, where the solubility is linearly dependent on the inverse of $\mathrm{H}^{+}$concentration. At intermediate $\mathrm{pH}$ values typical of many geothermal reservoirs, all aluminum minerals exhibit solubility minima, the position and depth of which are strong functions of temperature and salinity. The $\mathrm{pH}$ ranges over which the minima occur correspond to the stability field of the aqueous $\mathrm{Al}(\mathrm{OH})_{3}{ }^{0}$ species with aqueous aluminum concentrations in the sub-ppb range or lower for many clays, micas, and feldspars. Determination of the aqueous speciation of aluminum at elevated temperatures is crucial in modeling reservoir and geothermal fluid characteristics, but the insolubility of aluminum silicates represents a severe experimental challenge. Therefore, we have studied the solubility of gibbsite and boehmite in order to determine the thermodynamics of the aqueous aluminum species prevalent under geothermal conditions.

Many replicate boehmite solubility experiments were performed in a large capacity (working volume of $500 \mathrm{~mL}$ capacity), hydrogen-electrode, concentration cell in solutions of 0.03 molal $\mathrm{NaCl}(100,150,200,250$, and $290^{\circ} \mathrm{C}$ ). Considerable effort was expended conducting further solubility measurements aimed at verifying the lower solubility minima found at temperatures $\geq 150^{\circ} \mathrm{C}$, than are predicted from either of the two previous investigations reported in the literature. The occurrence of inexplicably low solubilities on the basic side of the solubility minima at temperatures $>150^{\circ} \mathrm{C}$ was corrected by installing a platinum mesh frit on the high temperature end of the solution sample tube to prevent boehmite particles from entering the tube and providing nucleation sites. Moreover, the introduction of 0.003 molal ammonia into the suspended boehmite $/ \mathrm{NaCl}$ solution mixture within the cell had the desired effect of preventing precipitation in the sample tube by increasing the $\mathrm{pH}$ of the solution as it cooled while being withdrawn up the sample tube.

Acidic and basic titrants were metered into the cell to affect a change in the $\mathrm{pH}$ of the solution and to reverse the direction of approach to the equilibrium saturation state and thereby ensure that the system was reversible thermodynamically. A least-squares regression of the results obtained at this low ionic strength was performed at each temperature to determine the molal solubility products $\left(Q_{80}\right.$ to $\left.Q_{34}\right)$ of boehmite. Typically five titrations had been performed at each temperature with small variations in ionic strength and temperature and the combined results were regressed iteratively with corrections applied to give a constant temperature and ionic strength to each entire data set. Following this procedure, experimental solubility values were rejected that manifested abnormally high solubilities above the fitted solubility curves, as such values are deemed to have been contaminated. A final regression was then performed at eàch condition.

Five solubility quotients were extracted from the curve at $101.5^{\circ} \mathrm{C}$ and each value was very consistent with those published by Castet et al. (1993) based on their "smoothed". constants reported at infinite dilution and adjusted to 0.03 molal ionic strength using the appropriate Pitzer Debye-Hückel extended limiting law expressions. At $152.5^{\circ} \mathrm{C}$ the solubility minimum is shifted sufficiently to lower $\mathrm{pH}$ that it was impossible to determine all five quotients unambiguously and therefore the fist hydrolysis quotient for $\mathrm{Al}^{3+}$ was fixed at the value from Palmer and Wesolowski (1993. The resulting quotients were found to be in good agreement with those of Castet et al., except for the value of $Q_{23}$ which was significantly smaller in the present analysis (i.e., consistent with the observed lower solubility minimum. This trend continues through $290^{\circ} \mathrm{C}$ with closer agreement being found at this extreme temperature, although the solubility is dominated by the aluminate anion at this condition such that values of $Q_{30}, Q_{31}$ and $Q_{32}$ were not needed to describe the present results. Note that in the present study, the equilibrium solubility is approached from supersaturation at the solubility minimum, so that the observed lower solubility cannot be a kinetic effect. 
Further comparisons can now be made at $290^{\circ} \mathrm{C}$ with additional data from Bourcier et al. (1993), who worked in the range of 150 to $250^{\circ} \mathrm{C}$. Good agreement was found at high pH between the three studies, where the solubility is relatively high and the $\mathrm{pH}$ can be determined readily from the free hydroxide ion molality. However, a substantial discrepancy with the calculated curve based on the smoothed $\mathrm{K}_{\mathrm{m}}$ values of Bourcier et al. becomes apparent at low $\mathrm{pH}$. On the other hand, there is generally good agreement with the Castet et al. model, with the lower solubility minimum found in the present study being due to the lower predicted stability of the $\mathrm{Al}(\mathrm{OH})_{3}{ }^{\circ}$ species.

The solubility of boehmite was also studied at $152.4^{\circ} \mathrm{C}(0.1,0.3,1.0$, and $5.0 \mathrm{molal} \mathrm{NaCl})$, and in acidic solutions at 203 and $250^{\circ} \mathrm{C}(1.0$ molal $\mathrm{NaCl})$. In general at $152.4^{\circ} \mathrm{C}$, the values of $Q_{80}$ and $Q_{84}$ were derived readily from linear regressions ( $\log \mathrm{m}_{\text {todal } \mathrm{Al}}$ versus $\mathrm{pH}$ ) on either side of the solubility curve. Analytical difficulties in measuring aluminum concentrations at the intermediate $\mathrm{pH}$ range with aluminum concentrations $<10^{-6}$ molal in the presence of high brine concentrations precluded useful derivation of the intermediate solubility quotients. Therefore, as in the case of gibbsite, the total aluminum in solution was estimated based only on the two endmember quotients $\left(Q_{30}\right.$ and $\left.Q_{34}\right)$ and the values of $Q_{H I}$ (Palmer and Wesolowski, 1993) determined from independent potentiometric measurements in homogeneous solutions of the hydrolysis of $\mathrm{Al}^{3+}$ to form $\mathrm{Al}(\mathrm{OH})^{2+}$. The remaining two solubility quotients, $Q_{32}$ and $Q_{33}$, were estimated from the isocoulombic extrapolation of the corresponding constants found at 0.03 molal ionic strength. Inclusion of these two estimated values raised the solubility minimum by only $0.4 \mathrm{log}$ units such that, given the experimental uncertainty in any aluminum analysis at these low levels, it would seem adequate for most purposes to either ignore $\mathrm{Al}(\mathrm{OH})_{2}{ }^{+}$and $\mathrm{Al}(\mathrm{OH})_{3}{ }^{\circ}$, or to rely on a method such as the isocoulombic approach to estimate their stabilities at high ionic strength. The values of the logarithm of $Q_{30}$ and $Q_{34}$ at $152.4^{\circ} \mathrm{C}$ were fitted to functions of ionic strength (including the appropriate Debye-Hückel term and the activity of water) that gave a precise description of these quotients from infinite dilution to 5 molal $\mathrm{NaCl}$.

In conclusion, our solubility data in dilute brines are generally in good agreement with those of Castet et al. and Bourcier et al. in basic solutions, but are lower than these measurements and the predictions of Pokrovskii and Helgeson (1995) near the solubility minimum as the temperature increases. The stabilities of the intermediate hydrolyzed species become more confined with respect to $\mathrm{pH}$ at moderate to high salinities, but can be estimated adequately from low ionic strength data using the isocoulombic treatment. Final treatment of the solubility data in terms of step-wise hydrolysis quotients is now near at hand and these values will fit smoothly and consistently with the corresponding lower temperature $\left(<100^{\circ} \mathrm{C}\right)$ gibbsite data to give a thermodynamic description of aluminum aqueous chemistry from 0 to $300^{\circ} \mathrm{C}$ and to 5 molal ionic strength at $150^{\circ} \mathrm{C}$. Time does not permit an extension of these measurements to high salinities at temperatures in excess of $150^{\circ} \mathrm{C}$, but adequate predictions of aluminum aqueous chemistry to these conditions are now possible based on the combined results of this program.

\section{FUTURE PLANS}

As a logical extension of the solubility studies on boehmite in $\mathrm{NaCl}$ brines nearing completion in this project, we will conduct a number of solubility studies in tetramethylammonium chloride (TMACl) (or some other large cation-containing salt) solutions at moderately basic $\mathrm{pH}$ 's in the $100-290^{\circ} \mathrm{C}$ range. The large, singly-charged $\mathrm{TMA}^{+}$cation is known to form very weak ion pairs with singly-charged aqueous anions. We will use this approach to determine the extent of ion pairing between the aluminate anion $\mathrm{Al}(\mathrm{OH})_{4}{ }^{-}$and $\mathrm{Na}^{+}$, the most abundant cation in geothermal brines. Recent literature studies provide conflicting information on this interaction, suggesting much higher stabilities for the ion pair than our solubility results would suggest. Since many high temperature geothermal brines are buffered at near-neutral $\mathrm{pH}$ 's, the aluminate anion is the dominant aqueous 
aluminum species, and a knowledge of its interactions with other solution components is critical in modeling reservoir permeability changes associated with aluminosilicate dissolution and precipitation.

The hydrogen-electrode, concentration cell approach is entirely amenable to studies of the rates and equilibrium constants of mineral transformation reactions, such as the hydrolysis of feldspars via reactions like the alteration of potassium feldspar to muscovite and quartz:

$$
3 \mathrm{KAlSi}_{3} \mathrm{O}_{8}+2 \mathrm{H}^{+} \mathrm{KAl}_{3} \mathrm{Si}_{3} \mathrm{O}_{10}(\mathrm{OH})_{2}+2 \mathrm{~K}^{+}+6 \mathrm{SiO}_{2}
$$

If these phases react sufficiently rapidly to achieve equilibrium in a few weeks at temperatures of $200-300^{\circ} \mathrm{C}$ in our cells, which are magnetically stirred with high efficiency promoting rapid attainment of solid/liquid equilibrium, then the equilibrium constant for reaction (l) can be precisely determined. This will aid in predicting the $\mathrm{pH}$ and steam corrosivity in geothermal systems. Furthermore, by first establishing an equilibrium $\mathrm{K}^{+} / \mathrm{H}^{+}$ ratio, then quickly changing this ratio by titration of acid, base, or potassium into a solution in equilibrium with the mineral assemblage, and observing the rate of change of the $\mathrm{pH}$ back to an equilibrium value, we can obtain the rates of reaction, both at near-equilibrium and far-from equilibrium conditions, as a function of temperature, $\mathrm{pH}$, salinity, and mineral grain size.

Future studies will involve equilibrium solubility and dissolution/precipitation rate determinations of a number of aluminosilicate phases prevalent in geothermal reservoirs. The only limiting factor in the use of these cells will be the formation of additional phases during an experiment. Therefore, we will initiate studies of aluminosilicate solubility equilibria and kinetics by first determining the dissolution/precipitation rates of boehmite, then examining the equilibrium solubilities and dissolution/precipitation kinetics of increasingly complex aluminosilicates, including kaolinite/dickite, alkali feldspars, pyrophyllite and vermiculite, and eventually smectites and chlorites. In conjunction with these investigations, a thorough analysis of the solid phases initially placed in the cell and those retrieved after the experiments will be carried out. Changes in phases, morphology, grain size and surface mineralogy will be characterized using a wide variety of in-house techniques that are currently being exploited for our work on boehmite and more complex phases in research for other funding agencies.

\title{
INDUSTRY INTEREST
}

\author{
Organization \\ CalEnergy Company, Inc. \\ Oxbow Geothermal Co.
}

Type and Extent of Interest

Corrosion problems in Imperial Valley plants

Aluminosilicate scale formation

Unpublished results of this program are frequently provided to John Weare at Scripps Institute of Oceanography and Everett Shock of Washington University for immediate incorporation into chemical reaction codes utilized by the geothermal community.

\section{REFERENCES}

Benezeth P., Palmer D.A., and Wesolowski D.J. (1997) The aqueous chemistry of aluminum. A new approach to high temperature solubility measurements. Geothermics, $26,465-481$. 
Bourcier W.L., Knauss K.G., and Jackson K.J. (1993) Aluminum hydrolysis constants to $250^{\circ} \mathrm{C}$ from boehmite solubility measurements. Geochim. Cosmochim. Acta, 57, 747-762.

Castet S., Dandurand J.L., Schott J., and Gout R. (1993) Boehmite solubility and aqueous aluminum speciation in hydrothermal solutions $\left(90-350^{\circ} \mathrm{C}\right)$ : Experimental study and modeling. Geochim. Cosmochim. Acta, 57, 4869. 4884.

Palmer D.A. Benezeth P., and Wesolowski David J. (1995) A new-experimental approach to solubility measurements equilibria and kinetics: Boehmite solubilities as a test case. Geological Society of American Annual Meeting, Abstr. Prig., 27, no. 6, p. A-93.

Palmer D.A., Wesolowski D.J., and Benezeth P. (1996) The aqueous chemistry of aluminum. A new approach to high temperature solubility measurements. Proc. 21 st Annual Workshop: Geothermal Reservoir Engineering, Stanford, CA., 201-208.

Palmer D.A. and Wesolowski D.J. (1992) Aluminum speciation and equilibria in aqueous solution. II. The solubility of gibbsite in acidic sodium chloride solutions from 30 to $70^{\circ} \mathrm{C}$. Geochim. Cosmochim. Acta, 56, 1093 1111 .

Palmer D.A. and Wesolowski D.J. (1993) Aluminum speciation and equilibria in aqueous solution. III. Potentiometric determination of the formation constants of $\mathrm{Al}(\mathrm{OH})^{2+}$ in $0-5 \mathrm{~m} \mathrm{NaCl}$ solutions from 25 to $125^{\circ} \mathrm{C}$. Geochim. Cosmochim. Acta, 57, 2929-2938.

Pokrovskii V.A. and Helgeson H.C. (1995) Thermodynamic properties of aqueous species and the solubilities of minerals at high pressures and temperatures: The system $\mathrm{Al}_{2} \mathrm{O}_{3}-\mathrm{H}_{2} \mathrm{O}-\mathrm{NaCl}$. Amer. J. Sci., 295, 1255-1342.

Wesolowski D.J. (1992) Aluminum speciation and equilibria in aqueous solution. I. The solubility of gibbsite in $\mathrm{Na}-\mathrm{K}-\mathrm{Al}(\mathrm{OH})_{4}-\mathrm{OH}-\mathrm{Cl}$ from $0-100^{\circ} \mathrm{C}$. Geochim. Cosmochim. Acta, 56, 1065-1091.

Wesolowski D.J. and Palmer D.A. (1994) Aluminum speciation and equilibria in aqueous solution. V. Gibbsite solubility at $50 \mathrm{EC}$ and $\mathrm{pH} 3$ to 9 in $0.1 \mathrm{molal} \mathrm{NaCl}$ solutions, a general model for aluminum speciation: analytical methods. Geochim. Cosmochim. Acta, 58, 2947-2969. 


\title{
VOLATILITY OF CHLORIDES AND THE THERMODYNAMICS OF BRINES DURING BRINE DRYOUT
}

\author{
J. Michael Simonson, Donald A. Palmer, S. L. Marshall, M. S. Gruszkicwicz, and R. E. Mesmer \\ Chemical and Analytical Sciences Division, Oak Ridge National Laboratory
}

\section{KEY WORDS}

hydrochloric acid, volatility, corrosion, The Geysers, modeling, thermodynamics, acidity, chloride, brine, steam

\section{PROJECT BACKGROUND AND STATUS}

Corrosive solutes in geothermal steam can limit or prevent economic production of steam from relatively hightemperature geothermal resources. Some wells in a high-temperature $\left(>300^{\circ} \mathrm{C}\right)$, vapor-dominated resource at the Northwest Geysers, California, have produced high levels of chloride at the wellhead, with observed levels greater than $100 \mathrm{ppm}$ in some cases. This chloride-bearing steam is extremely corrosive to piping and well casings, leading in severe cases to loss of production within a few days. In addition to the current problem, the question of potential production of acidic steam in older wells at The Geysers as the reservoir dries out with continued production is of great long-term significance in the operation of the resource. Questions of acid chloride partitioning from brines to steam have also been raised in conjunction with other geothermal systems. Examples include the observation of elevated chloride in steam on steam-cap formation during production at Los Azufres, and the effects of surface processes ( $\mathrm{pH}$ modification through acid injection) at plants in the Salton Sea geothermal resource.

The high volatility of hydrochloric acid and the observed nonstoichiometry of chloride with cations in steam (e.g., $\mathrm{Na}$ ) lead to the hypothesis that the observed chloride at The Geysers is due to hydrochloric acid. A laboratory study of the partitioning of acid chlorides over both single electrolyte solutions and over brines likely to be encountered in the reservoir was undertaken to address the problem of acidic steam production, particularly in the deeper, hotter wells in the Northwest Geysers, and the projected behavior of the 'normal' reservoir with further production. Early results, including measurements of the partitioning of $\mathrm{HCl}$ from liquid to vapor in pureacid solutions and $\mathrm{NaCl}(\mathrm{aq})$ brines, indicated that $\mathrm{HCl}$ was unlikely to be the sole source of chloride in steam due to the low brine $\mathrm{pH}$ required to give high $\mathrm{HCl}$ concentrations in steam. Calculations based on the results of these measurements, and on primary volatility data obtained for aqueous ammonium chloride in a program at this laboratory sponsored by the Electric Power Research Institute, indicate that $\mathrm{NH}_{4} \mathrm{Cl}(\mathrm{aq})$ volatility could give high chloride levels in steam over near-neutral high-temperature brines containing high concentrations of $\mathrm{NaCl}(\mathrm{aq})$. [Simonson et al., 1995, 1997] Furthermore, recent measurements have shown that, for temperatures $\leq 300^{\circ} \mathrm{C}$, the volatility of $\mathrm{NaCl}$ over very concentrated (to halite saturation) $\mathrm{NaCl}(\mathrm{aq})$ brines is significantly lower than predicted from recently-developed equations of state for $\mathrm{NaCl}+\mathrm{H}_{2} \mathrm{O}$. These new measurements are consistent with very low sodium ion concentrations found in wellhead condensate samples having high chloride as a result of $\mathrm{HCl}+\mathrm{NH}_{4} \mathrm{Cl}$ partitioning at high temperatures. Measurements have also been made of the partitioning of solutes to steam over $\mathrm{NaCl}(\mathrm{aq})$ brines in the presence of finely-ground samples of reservoir rocks (well MLM-3) from The Geysers. Analyses of these condensed-steam samples showed that the chloride concentration in steam was not significantly enhanced by the presence of the rock sample. Although the rock sample was treated with hydrochloric acid prior to beginning the volatility measurements, relatively high concentrations of ammonia have been found in these condensate samples. Other ions found in significant quantity included thiosulfate ion. Efforts to identify and fully quantify these other volatile species were hindered by the high levels of ammonia and thiosulfate found in the condensed vapor samples. However, it was clear that there was no enhancement of 
chloride in steam above those levels expected on the basis of $\mathrm{NaCl}$ partitioning, and, consistently, that the high levels of ammonia observed indicated that the rock was imposing a pH in solution near or slightly above neutral. Noting that the rocks used in these initial studies were characteristic of cap rock from the 'normal' reservoir of the Central Geysers [J. Moore, Energy and Geoscience Institute, University of Utah, personal communication], we have carried out over the last year a number of equilibrations of vapor with $\mathrm{NaCl}(\mathrm{aq})$ in contact with core samples from the high-temperature reservoir of the Northwest Geysers (well L'Esperance \#2) for further studies of the partitioning of chloride from brine to steam in the presence of reservoir rocks.

\section{PROJECT OBJECTIVES}

The goals of this project are to determine likely sources of highly corrosive steam from high-temperature geothermal wells and to suggest appropriate mitigation procedures based on the thermodynamics of liquid-vapor partitioning of corrosive solutes. A further objective is to enable calculations to be made of the compositions of coexisting brines and steam over the full range of conditions (reservoir to surface equipment) encountered in the production of electricity from geothermal steam. This research is of particular importance to the control of chloride in the steam produced from the vapor-dominated reservoir at The Geysers geothermal field in California. However, the fundamental approach taken makes the results of this program generally applicable to a variety of geothermal-plant operating problems arising from partitioning of solutes between brine and steam.

\section{Technical Objectives}

- Carry out precise laboratory measurements of the partitioning of corrosive solutes to steam over ranges of temperature and brine composition appropriate to geothermal reservoirs, including equilibrations of brine in contact with rock samples from The Geysers.

- Represent the experimental data quantitatively, using sound thermodynamic models, in order to provide the means for reliable calculation of the composition of coexisting brine and steam under both reservoir and surface (e.g., piping and turbine) conditions.

- Propose and validate methods for mitigation of the production of corrosive steam from geothermal reservoirs based on the experimental and modeling results.

\section{Expected Outcomes}

- The primary products of this research will be new data on the partitioning of potentially corrosive solutes between brine and steam over wide ranges of temperature and composition characteristic of various geothermal systems, and a quantitative method for calculating the composition of coexisting phases at various points in the geothermal steam cycle.

- In collaboration with personnel from companies operating geothermal power plants, these experimental results will be used to develop methods for the mitigation of problems (corrosion; solids deposition) encountered in energy production from geothermal resources.

\section{APPROACH}

The problem is addressed through laboratory measurements of liquid-vapor partitioning equilibria. The partitioning of chlorides to the vapor phase has been measured at temperatures to $350^{\circ} \mathrm{C}$ over pure $\mathrm{HCl}(\mathrm{aq})$, from aqueous mixed brines at concentrations ranging to salt saturation, and from brines in contact with rock samples 
from The Geysers. These experiments provide the data needed to develop quantitative models for the partitioning of solutes to steam from the mixed electrolyte brines encountered in geothermal reservoirs.

This project is part of the program "Physical Chemistry of Geothermal Systems" at ORNL. Significant contributions to the general objectives of this program are provided by other closely-related programs in progress at ORNL, including research in fundamental aqueous chemistry at high temperatures and measurements of solute volatilities important in fossil-fired and nuclear steam cycle chemistry.

\section{RESEARCH RESULTS}

A special apparatus has been constructed for these measurements of the partitioning of chloride between liquid and vapor phases, using a thin platinum liner within a stainless-steel pressure vessel to permit studies to high temperatures on these very corrosive solutions. Samples of both the liquid and vapor phases are obtained at temperature through chemically-inert tubing and valves, with condensed vapor-phase samples withdrawn at a precisely controlled rate in order to prevent disturbing equilibrium conditions and to minimize sample contamination by entrained liquid droplets. Sample compositions are determined quantitatively using methods appropriate for the solutes in a particular sample. Where practical, experiments are carried out over wide ranges of ionic strength and acidity/salinity ratios at each temperature, to insure that the correct thermodynamic equilibrium constant is obtained from the analysis of the results.

The thermodynamic equilibrium constant for the partitioning reaction may be written as $\mathrm{K}=$ $m_{v}(M C l) /\left\{m_{1}(M) m_{1}(C l) \gamma_{ \pm}^{2}(M C l)\right\}$, where $m_{v}$ and $m_{1}$ are molalities of the components in the vapor and liquid phases and $\gamma_{ \pm}$is the stoichiometric mean ionic activity coefficient for $\mathrm{MCl}$ in the liquid phase. These activity coefficients, which are significantly different from unity at the conditions investigated, are known or can be estimated reliably from previous studies in this Laboratory; the activity coefficient for the neutral $\mathrm{MCl}$ molecule in the vapor phase is assumed to be unity. The invariance of $K$ with observed liquid and vapor phase compositions and sampling rates serves as a check for the absence of mechanical carryover of solute, and of the accuracy of the activity coefficients.

The values of $\mathrm{K}$ for $\mathrm{HCl}$ have been represented as a simple function of temperature and solvent (water) density for purposes of interpolation and extrapolation of the results to the solvent critical temperature $\left(374^{\circ} \mathrm{C}\right)$. The observed partitioning of $\mathrm{NaCl}$ is somewhat more complex: at constant temperature, values of $\mathrm{K}$ decrease with the decreasing density of steam as the brine becomes more concentrated. We have shown that for $\mathrm{t} \geq 300^{\circ} \mathrm{C}$ and $\mathrm{pH} \geq 3$, the volatility of $\mathrm{HCl}$ alone is not sufficient to give high $(\sim 100 \mathrm{ppm})$ chloride concentrations in steam, even over highly saline brines. Additional measurements of the compositions of coexisting phases have been made to $350^{\circ} \mathrm{C}$ for aqueous brines containing $\mathrm{MgCl}_{2}, \mathrm{MgCl}_{2}+\mathrm{NaCl}$, and $\mathrm{CaCl}_{2}$. It is clear from these experiments that while $\mathrm{HCl}$ is produced by hydrolysis of cations in these solutions, the total amounts of $\mathrm{HCl}$ generated are again too small to account for the high levels of chloride observed in steam from the hightemperature reservoir at The Geysers.

The production of corrosive, high-chloride steam at The Geysers is often accompanied by relatively high levels of ammonia (to $1000 \mathrm{ppm}$ ). We have combined these field observations with our laboratory measurements on volatilities of $\mathrm{HCl}$ and $\mathrm{NaCl}$ carried out in this program and our measurements of $\mathrm{NH}_{4} \mathrm{Cl}$ partitioning supported by the Electric Power Research Institute to outline a mechanism for the formation of corrosive steam having high levels of both chloride and ammonia. In a mixed brine containing $\mathrm{HCl}, \mathrm{NH}_{3}, \mathrm{NH}_{4} \mathrm{Cl}$ and $\mathrm{NaCl}$, all four solutes partition from the brine to steam. The $\mathrm{pH}$ within the reservoir of a brine (predominantly $\mathrm{NaCl}$ ), which is in equilibrium with steam having the observed wellhead concentrations of chloride and ammonia, can be calculated from the partitioning results coupled with values of hydrolysis constants and activity coefficients of the solutes 
in the brine. The results of these calculations indicate that high concentrations of chloride can partition to steam (as $\mathrm{HCl}+\mathrm{NH}_{4} \mathrm{Cl}$ ) from highly concentrated $\mathrm{NaCl}$ brines at a near-neutral $\mathrm{pH}$, with minimal sodium concentrations in the steam. These results are consistent with observed solute concentrations in condensate samples from some wells in the Northwest Geysers. Similar calculations can be made of the extent of desuperheating of steam (to partial condensation under equilibrium conditions) required to yield steam with the desired low chloride concentrations, including indications of chloride concentrations in steam for which plants could be operated reliably without desuperheating. With primary support from another program in this Laboratory, a computer model incorporating many of the features of these calculations has been written and tested.

Measurements of solute volatilities from brines in contact with Geysers reservoir rock samples (MLM-3) were carried out at 250,300 , and $350^{\circ} \mathrm{C}$. Analyses of condensed-steam samples from equilibrations with $\mathrm{NaCl}(\mathrm{aq})$ and these reservoir rocks indicated the presence of significant concentrations of additional solutes (i.e., other than sodium, hydrogen ion, and chloride); these solutes included significant concentrations of ammonia and thiosulfate ion. The presence of these solutes also complicated the determination of sodium and chloride concentrations in the samples. While it was not possible to quantify fully the concentrations of all solutes in the condensed vapor samples, it was clear that no enhancement of the chloride concentration over that expected for $\mathrm{NaCl}$ partitioning was observed in these experiments.

Equilibrations have been carried out at 250 and $300^{\circ} \mathrm{C}$, and liquid and condensed vapor samples obtained for $\mathrm{NaCl}(\mathrm{aq})$ in contact with rock samples from L'Esperance \#2. Particularly at higher $\mathrm{NaCl}(\mathrm{aq})$ concentrations at $250^{\circ} \mathrm{C}$, the observed levels of both chloride and sodium in condensed vapor samples were higher than expected for $\mathrm{NaCl}$ based on our earlier measurements on $\mathrm{NaCl}(\mathrm{aq})$ without rock present in the system, the difference between sodium and chloride in the condensate samples, while small, was reproducible across the brine composition range and indicated some enhancement of chloride over sodium in the vapor. A corresponding cation required to achieve charge balance of the observed excess of chloride has not yet been identified. Further samples have been obtained for this system at both 250 and $300^{\circ} \mathrm{C}$, and equilibrations at $350^{\circ} \mathrm{C}$ are currently in progress. Analyses for anion concentrations in the condensed vapor phase sample by ion chromatography for those samples obtained at $300^{\circ} \mathrm{C}$ indicated a strong peak, nearly coincident with, and significantly larger than, the peak for chloride in the chromatograms. Tests against standard solutions containing bisulfide and bicarbonate ions indicated that these ions did not elute at the position of the unknown peak. Further efforts will be made to identify and quantify this anionic species in the vapor phase using a new ion chromatograph system recently purchased. The higher sensitivity and greater peak separation offered by the new chromatograph should permit identification and quantification of this peak.

Our results for $\mathrm{NaCl}$ volatility in the two-phase (brine + steam) region [Simonson et al., 1994] did not appear to extrapolate smoothly to the published values for $\mathrm{NaCl}$ content in steam along the three-phase line (brine + steam + halite). Given the importance of $\mathrm{NaCl}$ in the high-temperature reservoir as indicated by fluid inclusion studies and the implications of $\mathrm{NaCl}$ partitioning for development of a model for overall chloride partitioning from brines to steam, it was considered crucial to investigate in detail the partitioning of $\mathrm{NaCl}$ brine concentrations extending to halite saturation. An initial series of measurements on unbuffered solutions gave results which indicated that $\mathrm{HCl}$ partitioning due to the autoionization of water at high temperature resulted in chloride concentrations in steam condensate samples which were significantly higher $(>1$ order of magnitude) than the corresponding sodium levels. These experiments were consistent with the expected solution $\mathrm{pH}$ and the known partitioning of $\mathrm{HCl}$, but were not sufficiently precise to quantify the actual partitioning of $\mathrm{NaCl}$ from these brines. A second series of measurements on this system was carried out with a small amount of $\mathrm{NaOH}$ added to suppress the partitioning of $\mathrm{HCl}$. These experiments gave good agreement of the concentrations of sodium and chloride in the condensed steam samples and appear to extend smoothly from our previous results at lower 
$\mathrm{NaCl}$ (aq) molalities to the three-phase condition. This study provides the first measured values for $\mathrm{NaCl}$ partitioning to steam along the three-phase line at temperatures below $300^{\circ} \mathrm{C}$, and will be an important component of a complete description of chloride partitioning to steam in geothermal systems.

\section{FUTURE PLANS}

Measurements of the partitioning of chloride to steam over $\mathrm{NaCl}(\mathrm{aq})$ brines equilibrated with core samples from the Northwest Geysers are expected to be concluded in the next reporting period. We expect that new information on a number of volatile components arising from the rocks, in addition to chloride, will be available from these studies. Additional studies of the solubility of $\mathrm{NaCl}$ in steam, both with and without rock samples as the solid phase-component, may be undertaken in order to resolve completely the question of $\mathrm{NaCl}$ transport to steam under three-phase (halite + brine + steam) conditions. Further, some confirmatory measurements of the partitioning of chlorides from brine to steam in the system $\left\{\mathrm{NH}_{4} \mathrm{Cl}+\mathrm{NaCl}\right\}(\mathrm{aq})$ are anticipated to demonstrate the applicability of the calculations carried out previously for ammonium chloride volatility in mixed brines at high temperatures.

The experimental techniques and modeling approaches developed in this program and complementary programs in this Laboratory have applications to geothermal systems beyond the original problem of corrosive-steam production at The Geysers. It is anticipated that this work will be extended to similar problems encountered in other geothermal systems (e.g., corrosion in process units at California Energy company sites in California and increasing chloride in steam from two-phase wells at Los Azufres), including liquid-dominated as well as vapordominated resources.

It is apparent that the application of measured equilibrium constants to the wide range of conditions (temperature, pressure, brine composition) encountered in geothermal systems requires a broad and accurate knowledge of the thermodynamic properties of solutes in brines at high temperatures, including homogeneous reactions (e.g., ion association) and excess properties (i.e., activity coefficients). We expect that further quantitative modeling of the volatility results, and applications to field observations from geothermal systems, will indicate that some closely-targeted experimental measurements of these properties under clearly defined conditions could contribute significantly to an overall understanding of liquid-vapor phase behavior of solutes in geothermal systems. Isopiestic (vapor pressure) measurements aimed toward an understanding of the activity of carbonates in aqueous solutions at high temperature could give important new information related to the problem of carbonate scale formation in geothermal systems. Similarly, calorimetric experiments on $\left\{\mathrm{NaCl}+\mathrm{CO}_{2}\right\}$ aqueous mixtures, and on the less-basic carbonate and bicarbonate mixtures inaccessible to isopiestic measurements, could advance materially our understanding of the thermodynamics of $\mathrm{CO}_{2}$-containing fluids under both reservoir and surfaceequipment conditions.

\section{INDUSTRY INTEREST}

Technology transfer has been an integral component of this program from its inception. Results have been communicated frequently to the geothermal industry through both periodic, focused update meetings and participation in geothermal conferences of broader scope. Direct contact and consultation on the application of these results to problems arising from volatility of solutes are continuing with the organizations listed below. We intend to extend these contacts in the next year through direct discussions of the full results of the volatility and modeling studies of chloride transport with interested parties operating at The Geysers. 


\section{Organization}

UNOCAL, other Geysers operators

California Energy Company

Electric Power Research Institute

Pacific Gas and Electric Company

\section{Type and Extent of Interest}

Geysers geothermal field applications

Salton Sea geothermal field process applications

Fossil-fired and nuclear steam cycle applications

Guidelines for operation of corrosion-mitigation equipment

\section{REFERENCES}

Simonson J. M. and Palmer D. A. (1993) "Liquid-vapor partitioning of $\mathrm{HCl}(\mathrm{aq})$ to $623 \mathrm{~K}$," Geochim. Cosmochim. Acta, 57, 1-7.

Simonson J. M., Palmer D. A., and Carter R. W. (1994) "Liquid-vapor partitioning of $\mathrm{NaCl}(\mathrm{aq})$ from concentrated brines at temperatures to $350^{\circ} \mathrm{C}$," Proceedings of the 19th Stanford Geothermal Reservoir Engineering Workshop, 19, 245-251.

Simonson J. M. and Palmer D. A. (1994) "Vapor-liquid equilibrium of chlorides in aqueous systems to high temperatures: Application to the Geysers geothermal field," Geothermal Resources Council Transactions, 18, 347-352.

Simonson J. M. and Palmer D. A. (1995) "Partitioning of solutes between liquid water and steam in the system $\left\{\mathrm{Na}-\mathrm{NH}_{4}-\mathrm{NH}_{3}-\mathrm{H}-\mathrm{Cl}\right\}$ to $350^{\circ} \mathrm{C}$," Physical Chemistry of Aqueous Systems: Meeting the Needs of Industry (Proceedings of the 12th International Conference on the Properties of Water and Steam), 677-684.

Simonson J. M. and Palmer D. A. (1995) "Liquid-vapor partitioning in the system Na- $\mathrm{H}-\mathrm{NH}_{4}-\mathrm{NH}_{3}-\mathrm{OH}-\mathrm{Cl}-\mathrm{H}_{2} \mathrm{O}$ to $350^{\circ} \mathrm{C}$," Proceedings of the World Geothermal Congress 1995, 969-974.

Joyce D. B., Simonson J. M., and Palmer D. A. (1995) "Vapor liquid partitioning of aqueous sodium chloride to $350^{\circ} \mathrm{C}$," Geological Society of America: Abstracts with Programs, v. 27.

Simonson J. M. and Palmer D. A. "Volatility of $\mathrm{HCl}$ and the thermodynamics of brines during brine dryout," Proceedings:" Geothermal Program Review XV, "The Role of Research in the Changing World of Energy Supply." Springfield, VA: National Technical Information Service, 1997, pp. 2-25 - 2-31. 


\title{
STABLE ISOTOPE PARTITIONING IN BRINE-GAS-MINERAL SYSTEMS RELEVANT TO GEOTHERMAL RESOURCES
}

\author{
Juske Horita, David R. Cole, and David J. Wesolowski \\ Chemical and Analytical Sciences Division, Oak Ridge National Laboratory
}

\begin{abstract}
KEY WORDS
isotope, oxygen, hydrogen, brine, steam, mineral, partitioning, tracers, geothermometer
\end{abstract}

\section{PROJECT BACKGROUND AND STATUS}

The distribution of the stable isotopes of oxygen, hydrogen, carbon, and other light elements, which partition as a function of temperature and the bonding characteristics of individual phases, has been widely studied in geothermal systems in order to constrain the time-temperature history of geothermal systems, the sources and fluxes of fluids, the extent of boiling and mineral deposition from the fluids, and the temporal relationship among alteration minerals. Numerous investigations of isotope partitioning at room temperature have demonstrated that there exist composition-dependent salt effects on the partitioning of $\mathrm{D} / \mathrm{H}$ and ${ }^{18} \mathrm{O} /{ }^{16} \mathrm{O}$ ratios between brines and coexisting phases, such as steam, other volatiles $\left(\mathrm{CO}_{2}, \mathrm{CH}_{4}\right)$, and alteration minerals. However, at elevated temperatures encountered in geothermal systems, there are insufficient experimental data or theoretical models to predict salt effects on isotope partitioning. The limited data available at elevated temperatures are conflicting, but indicate potentially significant isotope salt effects in the 100 to $300^{\circ} \mathrm{C}$ range, leading to large errors in calculated temperatures and gross misinterpretation of fluid sources and fluxes, particularly in highly saline geothermal systems such as the Salton Sea and the Guaymas Basin. Even in less-saline geothermal systems, the boiling processes associated with steam separation and mineral precipitation can produce deep-seated, highly saline fluid reservoirs. In order to model isotope partitioning during boiling/condensation and mineral precipitation/alteration involving brines, accurate knowledge of the salt effect on isotope partitioning is required. In addition, recent theoretical works predicted that pressure may affect significantly isotope partitioning between water and coexisting phases at geothermal conditions. To date, pressure has been largely neglected as a potentially important variable in isotope partitioning.

The current project started several years ago, together with complementary experimental programs at Oak Ridge National Laboratory, funded by DOE's Office of Basic Energy Sciences/Geosciences program. Recently, substantial progress has been made on liquid-vapor equilibration experiments of salt solutions up to $350^{\circ} \mathrm{C}$, and emphasis is being shifted toward hydrothermal experiments in mineral-water systems at temperatures to $500^{\circ} \mathrm{C}$ to examine the isotope salt and pressure effects. An effort to model the isotopic behavior of geothermal systems has been initiated.

\section{PROJECT OBJECTIVES}

The objectives of this research are: (1) to provide precise experimental data on the partitioning of oxygen and hydrogen isotopes between geothermal waters and other phases (steam, gases, and alteration minerals formed in geothermal reservoirs) at elevated temperatures, and the effect of dissolved salts and pressure on the isotope partitioning, and (2) to investigate the importance of the salt and pressure effects on isotope partitioning for isotopic studies of geothermal systems through modeling of the isotopic evolution of fluids (steam and gases) and minerals at various physical and chemical conditions. 


\section{Technical Objectives}

- Determine precisely the effects of common dissolved salts $\left(\mathrm{NaCl}, \mathrm{KCl}, \mathrm{CaCl}_{2}\right.$ etc.) and pressure on oxygen and hydrogen isotope partitioning in the systems water liquid-vapor and mineral-water at temperatures to $500^{\circ} \mathrm{C}$.

- Establish simple, empirical equations based on experimental results for calculating the isotope salt and pressure effects in natural, complex geothermal brines over wide ranges of temperature and chemical composition.

- Investigate the importance of the isotope salt and pressure effects for the interpretation of isotopic data from geothermal systems through modeling at various physical and chemical conditions.

\section{Expected Outcomes}

- A set of internally consistent, precise experimental results on the partitioning of oxygen and hydrogen isotopes among geothermal materials (waters, brines, steam, gases, and minerals) at elevated temperatures as a function of the composition of water and pressure, that can be directly used to better characterize geothermal reservoirs (temperatures, origin and residence time of fluids, phase separation, and water-rock interaction) and to trace injected fluids to production sites for estimating the quantity of production that is derived from injection.

- Isotopic models of geothermal systems, which can be used to investigate geochemical processes of geothermal fluids and rocks at various physical and chemical conditions.

\section{APPROACH}

Utilizing the unique experimental facilities and expertise at Oak Ridge National Laboratory, we measured salt and pressure effects on isotope partitioning by means of salt solution-water vapor equilibration and salt solutionmineral exchange methods at temperatures up to $500^{\circ} \mathrm{C}$ at various pressures. Changes in the partitioning of $\mathrm{D} / \mathrm{H}$ and ${ }^{18} \mathrm{O} /{ }^{16} \mathrm{O}$ between liquid water, and water vapor or minerals as a function of the concentration of dissolved salts and pressure are modeled in terms of the activity coefficient ratios of the isotopic water molecules in the brines, in order to construct simple empirical equations for predicting the isotope salt and pressure effects in natural, complex brines over a wide range of temperature and pressure.

This project benefits substantially from the program "Fundamental 'Geochemistry of Geothermal Systems" funded by the Geosciences Program of the DOE Office of Basic Energy Sciences, in which more detailed, complementary studies and modeling are performed. This project is part of a program "Physical Chemistry of Geothermal Systems" at ORNL. The general objective of this program is to conduct laboratory experimental research utilizing unique facilities and expertise at ORNL for studies of selected chemical equilibria, thermodynamics of brine systems, liquid-vapor solute and isotopic partitioning, and other phase behavior.

\section{RESEARCH RESULTS}

A better technique was developed for hydrogen isotope analysis of hydrous minerals. A few mg of brucite, $\mathrm{Mg}(\mathrm{OH})_{2}$, were loaded into a small, pre-roasted quartz cup, which was in turn slid into a 3/8" OD quartz dehydration tube. The samples were then evacuated and heated with an electrical-resistance furnace at about $150^{\circ} \mathrm{C}$ overnight to remove adsorbed water. After the drying, the samples were heated to above $900^{\circ} \mathrm{C}$ for about 
one hour to extract structural water completely from the samples, and the water liberated was collected in a trap at liquid nitrogen temperature. Advantages of the new technique over the previous one are: 1) samples were not exposed to ambient air after drying and before dehydration (in situ drying), and 2) precise control of temperature and slow heating of the sample. The precision of $\mathrm{D} / \mathrm{H}$ measurements of a starting brucite with the new dehydration method improved; $\pm 0.6 \%(1 \sigma, n=6)$ compared to $\pm 1.5 \%(1 \sigma, n=9)$ with the previous technique. With this dehydration technique, $\mathrm{D} / \mathrm{H}$ ratios of run products were redetermined from a series of hydrothermal experiments examining the effects of $0-5$ molal $\mathrm{NaCl}$ and $0-3$ molal $\mathrm{MgCl}_{2}$ solutions on oxygen and hydrogen isotope partitioning between the mineral brucite, $\mathrm{Mg}(\mathrm{OH})_{2}$, and water in the temperature range from 200 to $500^{\circ} \mathrm{C}\left(200^{\circ} \mathrm{C}\right.$ and 21 bars for 180 days, $300^{\circ} \mathrm{C}$ and 100 bars for 90 days, $400^{\circ} \mathrm{C}$ and 500 bars for 47 days, and $500^{\circ} \mathrm{C}$ and 800 bars for 28 days). The results of remeasurements were basically the same as the previous analyses. Both dissolved $\mathrm{NaCl}$ and $\mathrm{MgCl}_{2}$ increased $\mathrm{D} / \mathrm{H}$ fractionations between brucite and water up to $5 \%$. At 200 and $300^{\circ} \mathrm{C}$, the magnitude of the effect on the $\mathrm{D} / \mathrm{H}$ partitioning was very similar to our results from liquid-vapor water equilibration to $350^{\circ} \mathrm{C}$. However, the magnitude of $\mathrm{NaCl}$ effect on $\mathrm{D} / \mathrm{H}$ fractionation between brucite and water dropped at $400^{\circ} \mathrm{C}$ and increased again at $500^{\circ} \mathrm{C}$. This somewhat complex trend is different from our results obtained from liquid-vapor water equilibration to $350^{\circ} \mathrm{C}$, which show an increase in the magnitude of $\mathrm{NaCl}$ effects on $\mathrm{D} / \mathrm{H}$ partitioning from 200 to $350^{\circ} \mathrm{C}$. This apparent discrepancy in $\mathrm{NaCl}$ effects on D/H partitioning between the two different systems (liquid-vapor and mineral-water) is conspicuous, and its cause probably lies in changes in isotopic properties of water at elevated temperatures and pressures.

In the liquid-vapor experiments, the pressure and density of water vapor in equilibrium with pure water and $\mathrm{NaCl}$ solutions are not the same at a given temperature. With increasing temperature, water vapor becomes increasing non-ideal, and the formation of water clusters (dimer, trimer, etc.) becomes significant. Thus, the speciation of water vapor in equilibrium with pure water and $\mathrm{NaCl}$ solutions becomes increasingly different with increasing temperature and $\mathrm{NaCl}$ molality. Recently, Driesner (1997) proposed, on the basis of molecular dynamics and $a b$ initio calculations, that the formation of water clusters in the vapor phase accompanies large $\mathrm{D} / \mathrm{H}$ fractionation compared to water monomer. Thus, measured effects of $\mathrm{NaCl}$ on liquid-vapor water isotope partitioning reflect not only the isotope salt effect in liquid water, but also differences in the isotopic properties of water vapor due to different densities of water vapor in equilibrium with pure water and salt solutions. Furthermore, Polyakov and Kharlashina (1994) and Driesner (1997) suggested, on the basis of thermodynamic and statistical mechanical calculations, that pressure measurably affects isotopic properties of pure liquid and supercritical waters, thus also $\mathrm{D} / \mathrm{H}$ isotope partitioning between minerals and pure water at elevated temperatures.

We are finishing measurements of $\mathrm{D} / \mathrm{H}$ isotope partitioning between brucite, $\mathrm{Mg}(\mathrm{OH})_{2}$, and pure water at 200$500^{\circ} \mathrm{C}$, and 20-800 bars. Satake and Matsuo (1984) conducted similar experiments in the same temperature range, but at higher pressures (mostly at 1000 bars). A close examination of the two sets of results suggests that our results of the D/H fractionations appear a few \%o lower than those of Satake and Matsuo (1984), consistent with the results of the above calculations.

Our experiments of liquid-vapor isotope partitioning of $\mathrm{NaCl}$ solutions conducted from 50 to $350^{\circ} \mathrm{C}$ were recently reexamined by several investigators: Berndt et al., 1996, 400-450 ${ }^{\circ} \mathrm{C}, \mathrm{D} / \mathrm{H}$ only; Driesner and Seward, $1996,200-400^{\circ} \mathrm{C}, \mathrm{D} / \mathrm{H}$ and ${ }^{18} \mathrm{O} /{ }^{16} \mathrm{O}$; and Shmulovich et al., 1996, 350-500 ${ }^{\circ} \mathrm{C}, \mathrm{D} / \mathrm{H}$ only. Their results confirmed our experimental results and the prediction that substantial oxygen and hydrogen fractionations exist between vapor and liquid $\mathrm{NaCl}$ solutions even at these high temperatures. The fractionation factors smoothly approach zero at the critical temperature of a given $\mathrm{NaCl}$ solution.

Our study on isotope fractionation was extended to other minerals. Chlorite is a common alteration phase found at moderate to high temperatures in numerous geothermal systems. A knowledge of the oxygen isotope fractionation factors between chlorite and water would prove useful in estimating down-hole temperatures and 
delineating the source of fluids in deep aquifers. Variations in the oxygen isotopic composition of biotites altered to chlorite have been monitored as a function of time from 16 hydrothermal granite-fluid experiments conducted at the following conditions: $\mathrm{T}=170$ to $300^{\circ} \mathrm{C}, \mathrm{P}=100-300$ bars, $\mathrm{NaCl}$ molality $=0.1-1.0$, fluid/biotite mass ratios $=1-60$, run durations $=200-840 \mathrm{hr}$. Detailed thin section, $S E M$, and $X R D$ studies demonstrate that biotite is altered exclusively to chlorite in 11 of the 16 experiments. The amounts of chlorite, quantified through point counting, increased with increasing temperature as well as time. For times exceeding 600 hours, the weight percent of biotite altered to chlorite averaged approximately $90-100 \%, 60-80 \%$, and $35-50 \%$ for temperatures of 300,250 , and $200^{\circ} \mathrm{C}$, respectively. The isotopic compositions of chlorite were calculated from mass balance, and compared with final measured $\delta^{18} \mathrm{O}$ of the fluids. The $1000 \ln \alpha$ (chlorite-water) values average $0.23,1.16$, $3.16 \%$ for 300,250 , and $200^{\circ} \mathrm{C}$, respectively. The errors become progressively larger with decreasing temperature because the calculated final chlorite isotope value is more sensitive to errors in point counting as the extent of reaction becomes less. We estimate that the errors are at least $\pm 0.5 \%$ at 250 and $300^{\circ} \mathrm{C}$, and as much as $\pm 1 \%$ at $200^{\circ} \mathrm{C}$. Despite the drawbacks to the use of empirical estimates, our data are in excellent agreement with the curves given by Wenner and Taylor (1971), Savin and Lee (1988), and Onuma et al. (1972).

However, below about $200^{\circ} \mathrm{C}$, our new data tend to predict somewhat larger fractionations compared to a number of other studies.

\section{FUTURE PLANS}

Measurements of oxygen and hydrogen isotope partitioning between vapor and liquid water will be continued for the system Na-K-Mg-Ca-Cl-SO 4 to $350^{\circ} \mathrm{C}$, including several mixed salt solutions resembling natural geothermal brines (i.e., Salton Sea). Highly concentrated acid waters are encountered in mine drainages, crater lakes, volcanic emanations, and some andesitic geothermal systems. It is known that $\mathrm{HCl}$ and $\mathrm{H}_{2} \mathrm{SO}_{4}$ have large oxygen isotope effects at room temperature, and we plan to examine the effect of these acids at elevated temperatures. It is likely that there exist measurable effects of these salts and acids on liquid-vapor isotope partitioning as found for $\mathrm{NaCl}$ to $350^{\circ} \mathrm{C}$.

It has been suggested that isotope partitioning between water and coexisting phase (minerals, gases) is substantially affected by pressure as the density of aqueous fluids changes significantly. If this is true, isotope partitioning is determined not only by temperature $(\mathrm{T})$ and the composition of aqueous fluids $(\mathrm{X})$, but also by pressure $(\mathrm{P})$, as are chemical reactions. Such findings have profound implications for isotope geochemistry in general, where temperature has been considered the sole variable in determining equilibrium isotope partitioning. We initiated isotope exchange experiments in the system brucite-water at $380^{\circ} \mathrm{C}$ and at pressures from 100 to 2000 bars, in order to examine possible isotope pressure effects. Ranges of temperature and pressure, where the largest pressure effects are predicted on $\mathrm{D} / \mathrm{H}$ isotope partitioning between minerals and water, are from 300 to $400^{\circ} \mathrm{C}$, and 100 to 1000 bars. These temperature and pressure ranges are well within those encountered in natural geothermal systems, and the outcome of possible pressure effects has significant impacts on the interpretation of isotopic data obtained from geothermal systems. We plan to conduct a few scoping experiments in the system mineral-water-salt to gain knowledge on the isotope salt and pressure effects at select T-P-X conditions. Possible pressure effects on oxygen isotope partitioning will also be investigated. Minerals being employed are calcite, strontianite, brucite, and epidote, with which we already have extensive experience and good knowledge of isotope partitioning.

Aside from the isotope salt and possible pressure effects on isotope partitioning between water and other phases, fractionation factors for a number of important phases are simply lacking. The temperature dependency of stable isotope partitioning provides geochemists with a particularly large number of geothermometers, but most of the reliable equilibrium fractionation factors have been obtained experimentally at temperatures well above those 
appropriate for geothermal systems. We plan to investigate the equilibrium oxygen and hydrogen isotope partitioning between common hydrous minerals (e.g., kaolinite, chlorite, epidote) and water, and the carbon and hydrogen equilibrium exchange among $\mathrm{C}-\mathrm{O}-\mathrm{H}$ gas species at temperatures below $500^{\circ} \mathrm{C}$. These will be directly applicable to many problems encountered in geothermal systems.

\section{INDUSTRY INTEREST}

Organization

UNOCAL

EGI, Univ. of Utah

\section{Type and Extent of Interest}

Using our results to monitor injection

Using our results for the interpretation of geochemical data from The Geysers

\section{REFERENCES}

Horita J., Wesolowski D. J., and Cole D. R. (1993) The activity-composition relationship of oxygen and hydrogen isotopes in aqueous salt solutions: I. Vapor-liquid equilibration of single salt solutions from 50 to $100^{\circ} \mathrm{C}$, Geochimica et Cosmochimica Acta, 57, 2797-2817.

Horita J., Cole D. R., and Wesolowski D. J. (1993) The activity-composition relationship of oxygen and hydrogen isotopes in aqueous salt solutions: II. Vapor-liquid equilibration of mixed salt solutions from 50 to $100^{\circ} \mathrm{C}$ and geochemical implications, Geochimica et Cosmochimica Acta 57, 4703-4711.

Horita J. and Wesolowski D. J. Liquid-vapor fractionation of oxygen and hydrogen isotopes of water from the freezing to the critical temperature. (1994) Geochimica et Cosmochimica Acta 58, 3425-3437.

Horita J., Cole D. R. and Wesolowski D. J. (1994) Salt effects on stable isotope partitioning their geochemical implications for geothermal brines. Proceedings of the 19th Annual Workshop on Geothermal Reservoir Engineering, Stanford University, p285-290.

Horita J., Cole D. R., and Wesolowski D. J. (1995) The activity-composition relationship of oxygen and hydrogen isotopes in aqueous salt solutions: IIl. Vapor-liquid equilibration of $\mathrm{NaCl}$ salt solutions to $350^{\circ} \mathrm{C}$. Geochimica et Cosmochimica Acta 59, 1139-1151.

Horita J., Cole D. R., Wesolowski D. J., and Fortier S. M. (1996) Salt effects on isotope partitioning and their geochemical implications: An overview. Proceedings of Todai International Symposium on Cosmochronology and Isotope Geoscience, p33-36. 


\title{
TRACING FLUID FLOW IN GEOTHERMAL RESERVOIRS
}

\author{
Peter E. Rose and Michacl C. Adams \\ Energy \& Gcoscience Institute \\ University of Utah
}

\section{KEY WORDS}

tracers, tracer tests, geothermal, fluorescein, polyaromatic sulfonates, reservoir simulation

\section{PROJECT BACKGROUND AND STATUS}

Injection of produced fluids is essential to prudent geothermal reservoir-management strategies, both as a means of disposing of an environmental pollutant as well as a method of maintaining reservoir pressures. The judicious location of the injection wells within the three-dimensional network of fractures that forms the reservoir is crucial to the successful exploitation of the field. Proper well location leads to increased power production due to enhanced pressures, less reservoir scaling from boiling around the production wells, and reduced thermal breakthrough. Unfortunately, prior to the field start-up, only the pressure relationships within the hydro-geologic connections are known, not the pathways and velocities that the injection fluid will take between wells. The latter data can only be obtained from fluid-chemistry data, and such data are not available in the early stages of production when reservoir-management strategies are being formulated. Introduction of tracers into the injectionproduction loops is the fastest and most effective method of obtaining data that describe the flow of injected fluids.

At the inception of the tracer development program in 1982, there were very few tracers in use by the geothermal industry. In addition, an insufficient knowledge of the thermal stability of these known tracers produced a lack of confidence in the results of tracer field tests. Surveys of the geothermal industry by the DOE indicated a strong belief that tracer research and development would be very valuable if stable geothermal tracers could be developed. It was on this basis that the tracer development project was founded. And, whereas a significant number of tracers has subsequently been developed and field-tested (Adams et al., 1992; Adams and Davis, 1991; Adams et al., 1990; Adams et al.; 1989; Rose et al., 1995; Rose and Adams, 1994), the need persists for new tracers that are relatively inexpensive and that are mutually compatible.

\section{PROJECT OBJECTIVES}

The primary objective of this research project is to identify and test candidate compounds for use as tracers in both liquid-dominated and vapor-dominated geothermal reservoirs. An ideal tracer is nontoxic, environmentally benign, thermally stable (or possessing a quantifiable and reasonably slow rate of decay under geothermal conditions), detectable at very low concentrations, fairly nonreactive with the reservoir rock and relatively inexpensive. As many of these compounds as possible should be identified because of the need for identifying individual injector/producer flow paths in reservoirs containing multiple injection wells. A secondary objective of this project is to develop improved methods for the design of tracer tests as. well as for the interpretation of tracer return-curve data. 


\section{Technical Objectives}

- Prove the stability of several candidate compounds for use as geothermal tracers. Use both laboratory and field tests to provide the evidence of stability. As many of these compounds as possible should be identified because of the need for the simultaneous use of multiple tracers in reservoirs containing many injection wells and, as a result, multiple injection-production flow paths.

- Develop numerical-simulation techniques for modeling the flow of tracers along injection-production pathways. A properly calibrated model can provide such valued test-design information as the appropriate amount of tracer required to realize chemical breakthrough, as well as an indication of where and when tracer breakthrough is expected. And; by combining a model of the thermal-decay kinetics with a numericalsimulation flow model, candidate tracers can be screened in advance of the actual field test and eliminated from consideration if they are not sufficiently stable. Finally, a properly calibrated numerical simulation model can provide estimates of such important reservoir information as fracture density, fracture porosity, effective permeability and reservoir-fluid volume, which can subsequently be used to predict thermal breakthrough and reservoir longevity.

\section{Expected Outcomes}

- A minimum of ten affordable, easily detectable tracers that are stable in geothermal reservoirs with temperatures to $300^{\circ} \mathrm{C}$.

- Numerical modeling techniques for evaluating candidate tracers and improving tracer-test designs.

\section{APPROACH}

Our approach to the development of new tracers for the geothermal industry has been, first, to search the literature for promising candidates. Since good liquid-phase geothermal tracers have all of the qualities of good groundwater tracers in addition to the attribute of reasonable thermal stability, the groundwater-tracer literature is the likely place to begin the search. Next, the candidate compounds are screened for thermal stability and adsorption, based upon thermodynamic and kinetic data found in the literature. The surviving candidates are then subjected to a series of laboratory experiments using high-pressure autoclaves to create an environment of temperature, pressure, and solution matrix that simulates the reservoir environment. Upon completion of the laboratory phase, candidate tracers are field-tested in geothermal reservoirs. The results of the field tests are then compared to the results of the laboratory tests to refine the laboratory-derived parameters. Finally, the results of the laboratory experiments and field tests are published in the open literature. These methods provide for rapid evaluation of candidate compounds and immediate, up-to-date access of our results to the geothermal community.

\section{RESEARCH RESULTS}

\section{Liquid-Phase Tracer Development}

In order for candidate tracers to qualify for use in the geothermal industry, they must be environmentally benign, affordable, detectable, thermally stable, and resistant to adsorption on reservoir rock. Unfortunately, very few nonradioactive compounds are both very detectable and thermally stable under the rigors of a hydrothermal environment at $300^{\circ} \mathrm{C}$. We have begun a systematic approach to the identification of viable tracers by looking within a class of compounds that is known to possess these qualitites--the polyaromatic hydrocarbons. 
The first column in Figure 1 shows the chemical structures of three common polyaromatic hydrocarbons, naphthalene, anthracene, and pyrene. It is their condensed aromatic ring structure with significant double-bond character that renders these compounds very thermally stable. Likewise, this condensed aromatic ring structure accounts for their fluorescence, which, in turn explains their excellent detectability. These compounds, however, would not qualify for use as hydrothermal tracers, since they are extremely toxic, relatively insoluble in water and strongly adsorbent on reservoir-rock surfaces.

Shown in column 2 of Figure 1 are various sulfonate derivatives of the 2-, 3-, and 4-ring polyaromatic hydrocarbons. The simple addition of sulfonate groups renders the polyaromatic hydrocarbons nontoxic, water soluble, and strongly resistant to adsorption on negatively charged reservoir rock, without diminishing their thermal stability. These compounds are excellent candidates for use as tracers under the most demanding $\left(>300^{\circ} \mathrm{C}\right)$ hydrothermal conditions. Under laboratory conditions that simulate a geothermal reservoir, $2-$ naphthalene sulfonate, 2,6-naphthalene disulfonate, 1,3,6-naphthalene trisulfonate, and pyrene tetrasulfonic acid showed no evidence of decomposition when exposed to $295^{\circ} \mathrm{C}$ for one week. Unfortunately, the polyaromatic sulfonates are moderately expensive and not readily available in bulk.

Shown in column 3 of Figure 1 are some examples of amino- and hydroxy-substituted sulfonated polyaromatic hydrocarbons. The addition of the amino or hydroxy substituent renders the polyaromatic sulfonates more fluorescent but somewhat less thermally stable than the polyaromatic sulfonates. More importantly, the compounds in column 3 are much more readily available and affordable than the unsubstituted polyaromatic sulfonates. In addition, the amino- and hydroxy-substituted sulfonated polyaromatic hydrocarbons decay by losing the amino and hydroxy substituents. The end-products of decay are therefore the unsubstituted polyaromatic sulfonates, which are thermally stable at $295^{\circ} \mathrm{C}$. As a result, the less stable but more affordable substituted polyaromatic sulfonates are transformed under demanding reservoir conditions to the stable, but still detectable, unsubstituted polyaromatic sulfonates. The substituted polyaromatic sulfonates are therefore useful in both intermediate- $\left(-250^{\circ} \mathrm{C}\right)$ and high-temperature $\left(\sim 300^{\circ} \mathrm{C}\right)$ reservoirs.

In order to sort out distinct flow paths in reservoirs containing many injection and production wells, a chemically distinct tracer is required for each injection well in the reservoir. To facilitate the task of simultaneously analyzing for multiple tracers, our laboratory recently obtained a high-performance liquid chromatograph (HPLC). Using this instrument, a mixture of compounds can be separated chromatographically as well as spectrally. We have developed methods for the simultaneous analysis of a large number of fluorescent tracers, including the polyaromatic sulfonates and the amino-substituted polyaromatic sulfonates described above. With the HPLC, it is now possible to analyze many fluorescent compounds simultaneously and thereby determine the injection-production pathways in reservoirs containing many injection wells.

Whereas laboratory experiments are required for testing candidate tracers under controlled conditions of time, temperature, pressure and solution chemistry, the tracer qualification process is incomplete without field testing. In two tracer tests initiated this year at the geothermal reservoir at Dixie Valley, Nevada, we tested the polyaromatic sulfonate, pyrene tetrasulfonate, and the amino-substituted polyaromatic sulfonate, amino $G$. Amino $G$ was used in a tracer test initiated in 1996 at Dixie Valley, but it was detected only in concentrations close to its detection limit. In the test initiated this year at Dixie Valley; however, we injected a sufficient quantity of amino $G$ to observe its deaminated decay product, which was shown in laboratory experiments to be a very stable naphthalene sulfonate, 1,3-naphthalene disulfonate. In large reservoirs with sufficiently hot water, amino $\mathrm{G}$ is converted completely to the thermally stable 1,3-naphthalene disulfonate, which is a reasonably fluorescent and, therefore, moderately detectable compound. This approach allows for the use of amino $G$ in hightemperature $\left(300^{\circ} \mathrm{C}\right.$ or hotter) geothermal reservoirs. 
In addition to the evaluation of new candidate compounds for use as geothermal tracers, a basic objective of this project is to develop improved methods for the design of tracer tests as well as for the interpretation of tracer return-curve data. We have been conducting a tracer test at the Beowawe, Nevada, geothermal reservoir over the past three years in order to study the long linear tailing portion of the return curves, as measured by the concentration over time of the tracer at the production wells.

Figure 2 reveals that the 3-well average return curve attains a remarkably constant decay rate after about 550 days. From an analysis of this return-curve tail, we have been able to estimate such valuable parameters as overall reservoir fluid volume and maximum fluid exchange rate between the reservoir and surrounding aquifers. In addition, we used the numerical simulation code TETRAD (Vinsome, 1995) to model the flow process and to verify our analytical results.

\section{Vapor-Phase Tracer Development}

For the last decade the three operators in the Southeast Geysers, NCPA, Calpine, and Unocal, have been engaged in cooperative projects with DOE that are designed to examine and augment the efficiency of injection at The Geysers. A lack of produced liquid at The Geysers lowers the amount of water available to be injected back into the reservoir. Injection is a crucial factor in extending the power-producing lifetime of the reservoir because there is much more heat than water in geothermal systems. Much effort has been exerted to increase the amount of injected water, including power plant modifications and the injection of outside sources of water from creeks. Efficient use of the water requires knowledge of where, how much, and how fast the injection water travels from the injection wells to the production wells.' This is a complex problem at The Geysers because of the hundreds of production wells and the complex three-dimensional network of fractures in the reservoir. Another problem is that the injected water changes state from liquid to steam at some point between the injection and production wells.

The most empirical method of detecting the pathways of the injected water is to detect some of its unique components in the produced steam. This requires that the components pass unhindered through the liquid-steam transition as the injected water boils in the reservoir. Thus, traditional methods such as dye tracers or chloride increases cannot be used because these compounds generally reside only in the liquid phase. Several methods have been developed that take advantage of changes induced in the water composition by power production in the surface facilities. Unfortunately, these methods suffer from high natural backgrounds of the compounds and from the changes in the power plants operating conditions. The most reliable method found to date is to add compounds to the injected water that will act as tracers, avoiding the problems of natural and man-made variations that affect the outcome of the other methods.

Recent developments at The Geysers have created a need for more tracer field tests. The most significant is the Southeast Geysers Effluent Pipeline Project, sponsored by DOE and industry, that will bring nearly 5,000 gpm of water from the Lake County Wastewater Treatment Plant and Clear Lake. New vapor-phase tracers will be needed to quantify the benefits of this cooperative venture between DOE and industry because tracers originally developed by EGI for The Geysers are either scarce or have increased significantly in cost. We are currently examining the possibility of using fluorocarbons or hydrofluorocarbons as substitutes for the chlorofluorocarbons. To this end, we will screen a variety of these compounds for the purpose of determining such needed tracer parameters as detectability and thermal stability. 


\section{FUTURE PLANS}

Our plans for the forthcoming year include the continued evaluation of candidate liquid-phase and vapor-phase geothermal tracers. Additional fluorescent compounds from among the polyaromatic sulfonates and aninosubstituted polyaromatic sulfonates will be tested for thermal stability and detectability in the laboratory under conditions that simulate high-temperature liquid-dominated geothermal reservoirs. In addition, we will seek opportunities to test these tracers in high-temperature $\left(300^{\circ} \mathrm{C}\right.$ or hotter) liquid-dominated hydrothermal systems.

We will continue the tracer tests that we have initiated at Dixie Valley, Nevada, in order to verify the predicted laboratory results of the liquid-phase tracer candidates amino $\mathrm{G}$ and pyrene tetrasulfonate. In the event that we are unable to test the high-temperature candidate tracers in a high-temperature $\left(300^{\circ} \mathrm{C}\right.$ or hotter) geothermal reservoir, we will attempt to conduct further tracer testing in this moderately hot $\left(250^{\circ} \mathrm{C}\right)$ hydrothermal system.

We will continue the numerical simulation studies to model the performance of tracers in geothermal settings, using either Tetrad (Vinsome, 1995) or TOUGH2 (Pruess, 1991). Starting with the model that was developed and verified this year, we will model the flow of tracer injected through proposed injection wells at Dixie Valley. Based upon the results of the study, we will determine appropriate tracer quantities and predict tracer-flow patterns. At the end of the tracer test, the predicted flow patterns will be compared to the measured data, and the results of our study will be published in the open literature. The use of tracer return-curve data as a means of calibrating numerical simulation models will hopefully provide operators of geothermal reservoirs with greater confidence in the accuracy of their models as tools in reservoir management.

\section{INDUSTRY INTEREST}

All of our field tests are designed to maximize the collection of reservoir information as well as data on tracer stability. Because of this balance between research and application, industry is willing to cost-share our field tests. The following table lists the name of the company as well as the type and extent of interest that it has demonstrated:

\section{Organization}

Far West Capital Inc.

Oxbow Power Services Inc.

Beowawe Geothermal Power Company

Oxbow Power Services Inc.

Calpine Corporation

Northern California Power Agency

Unocal Energy Resources

Pacific Gas \& Electric
Type and extent of interest

Cost-shared tracer test at Steamboat Hills

Cost-shared tracer test at Dixie Valley

Cost-shared tracer test at Beowawe

Cost-shared tracer test at The Geysers

\section{REFERENCES}

Adams, M. C. (1995) Vapor, liquid, and two-phase tracers for geothermal systems: Proceedings of the World Geothermal Congress, 3, p. 1875-1880. 
Adams, M. C., Moore, J. N., Fabry, L. and Ahn, A. H. (1992) Thermal stabilities of aromatic acids as geothermal tracers: Geothermics, 21, p. 323-339.

Adams, M.C., and Davis, J. (1991) Kinetics of fluorescein decay and its application as a geothermal tracer: Geothermics, 20, p. 53-66.

Adams, M. C., Fabry, L. and Moore, J. N. (1990) Comparative study of high performance liquid chromatographic parameters used for the analysis of carboxylic and sulfonic acid geothermal tracers: University of Utah Research Institute, Earth Science Laboratory Rept., ESL-89013-TR, DOE/ID/12489-48.

Adams, M. C., Benoit, W. R., Doughty, C., Bodvarrson, G. S., and Moore, J. N., (1989) The Dixie Valley, Nevada tracer test: Transactions, Geothermal Resources Council, 14, p. 215-220.

Pruess, K. (1991) TOUGH2--a general-purpose numerical simulator for multiphase fluid and heat flow. Lawrence Berkeley Laboratory, Earth Sciences Division, LBL-29400.

Rose, P.E., Adams, M.C., and Benoit, W.R. (1995) A tracer test at the Beowawe geothermal field, Nevada, using fluorescein and tinopal CBS, Transactions, Geothermal Resources Council, 19, 217-221.

Rose, P.E., Adams, M.C. (1994) The application of rhodamine WT as a geothermal tracer, Transactions, Geothermal Resources Council, 18, 237-240.

Vinsome, K. (1995) Tetrad user's manual, version 11.5, ADA International Consulting Ltd., Alberta, Canada. 


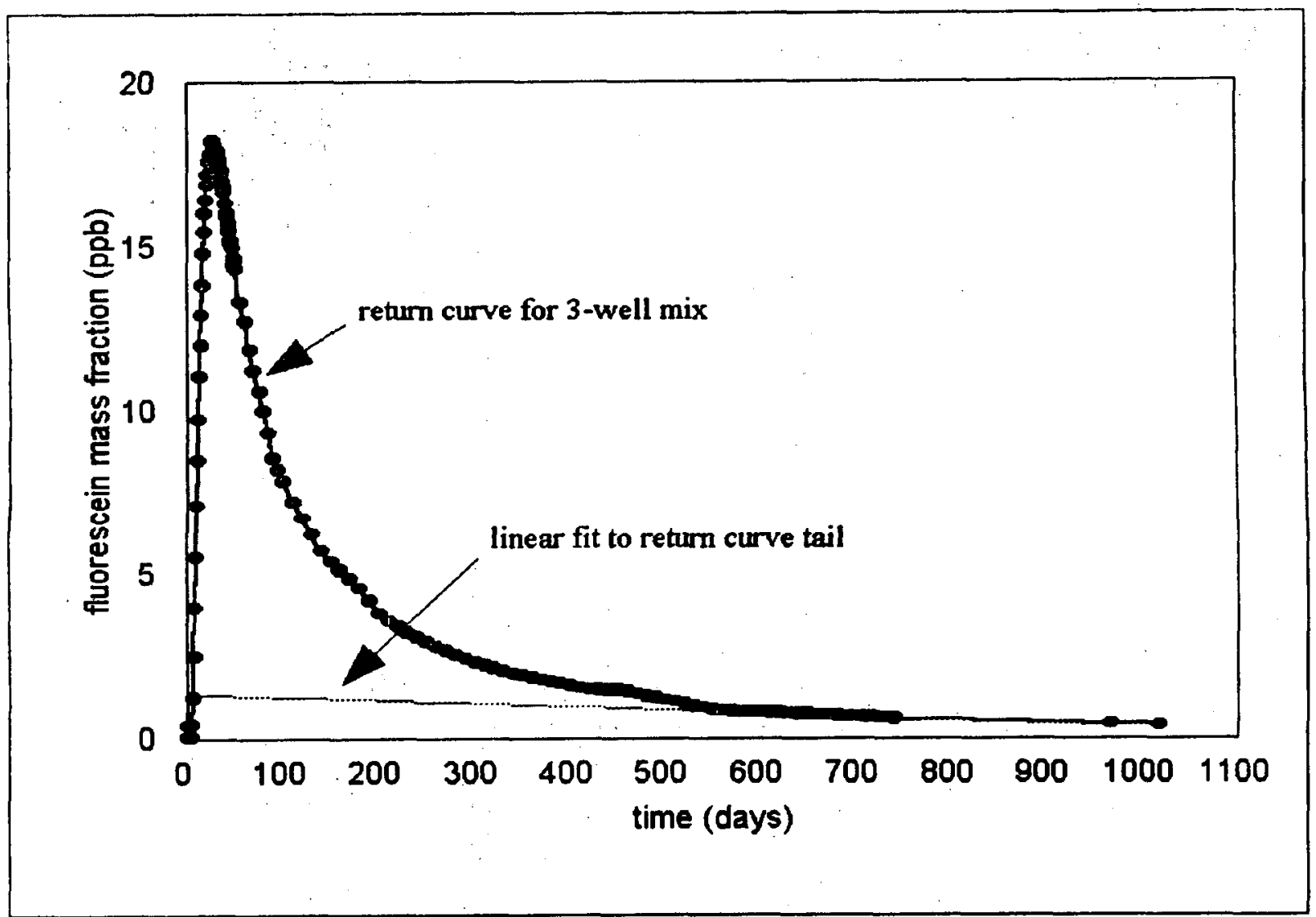

Figure 2. Combined 3-well return curve for a tracer test at Beowawe, Nevada, showing the constantly sloping section of the curve after about 550 days. 


\title{
CHEMICAL MODELS FOR OPTIMIZING GEOTHERMAL ENERGY PRODUCTION
}

\author{
Nancy Mфller, John H. Weare, Zhenhao Duan and Jerry P. Greenberg \\ Chemistry Department (0340), University of California at San Diego
}

\section{KEY WORDS}

breakout, brines, chemistry, computer models, energy, enthalpy, EOS, Equilibrium, gases, geothermal, pH, phase transitions, reservoir, rock/water interactions, scaling, simulation, solubility, steam fraction, thermodynamic data

\section{PROJECT BACKGROUND AND STATUS}

Many of the most significant problems limiting the economical development of geothermal energy (e.g., scale formation, gas breakout, permeability losses) result from the thermochemical behavior of the natural brines from which the energy is extracted. Because of the complexity of the physical and chemical interactions within the fluids, this behavior is difficult to predict from tables or past experience. However, in many situations, it can be calculated from equilibrium thermodynamics via the free energy of the system. To develop a sufficiently general description of a geothermal system, the variation of the free energy with pressure, temperature and composition of all the phases present in the system must be modeled.

In 1980, Harvie and Weare showed that the semi-empirical equations of Pitzer $(1973,1987)$ describing the free energy of electrolyte solutions could be used to accurately predict complex solubility relationships in the Na-K$\mathrm{Ca}-\mathrm{Mg}-\mathrm{Cl}-\mathrm{SO}_{4}-\mathrm{H}_{2} \mathrm{O}$ system. Since that time, with funding primarily from the Department of Energy (DOE), this modeling approach has been expanded to include additional species, such as the carbonate system and $\mathrm{SiO}_{2}$, gas solubility, acid-base reactions and variable temperature $\left(\mathrm{T}<300^{\circ} \mathrm{C}\right.$ ) (see, for example, Harvie et al. (1984), Weare (1987), Mфller, (1988), Greenberg and Mфller, (1989), Mфller, (in prep)). Good agreement is found when these models are applied to interpret geothermal field problems.

With support from the DOE Geothermal Program, our research efforts have led to significant breakthroughs in developing new phenomenology for predicting the behavior of complex solid-liquid-vapor mixtures. Using this phenomenology, we produced an EOS model of the gas $\mathrm{CO}_{2}-\mathrm{CH}_{4}-\mathrm{H}_{2} \mathrm{O}$ system which accurately predicts phase equilibria and PVT properties from 0 to $1000^{\circ} \mathrm{C}$ and from 0 to 1200 bars (Duan et al. (1992a), (1992b)). This was the first model which could successfully predict both the single and two phase behavior of mixtures. Accurate multiple phase EOS models of the $\mathrm{NaCl}-\mathrm{CO}_{2}-\mathrm{H}_{2} \mathrm{O}$ and $\mathrm{NaCl}-\mathrm{CH}_{4}-\mathrm{H}_{2} \mathrm{O}$ ternaries and of the $\mathrm{NaCl}-\mathrm{CH}_{4}-$ $\mathrm{CO}_{2}-\mathrm{H}_{2} \mathrm{O}$ quaternary system were recently constructed. Development of the latter model depended heavily on our new simulation technology which was used to generate reliable PVT data. These EOS models accurately predict the phase equilibria and PVT properties from 0 to 2000 bars and from $50^{\circ}$ to $1000^{\circ} \mathrm{C}$. These models allow reliable simulation of both the single and two phase behavior in gas-containing brines from the subcritical to supercritical regions. The new phenomenology allows us to significantly improve our predictions of gas breakout in highly pressurized systems and of the heat and work content (e.g., enthalpies) of complex brine systems. 


\section{PROJECT OBJECTIVES}

Our objective is to improve the productivity and efficiency of geothermal operations and exploration by providing user-friendly computer models of the thermochemical and thermophysical properties of geothermal brines and their associated noncondensible phases as well as reservoir behavior. These models provide reliable means to predict the chemical and physical consequences of plant operations (e.g., scaling and breakout) and the chemical, thermal and energy properties of the reservoir. They, thereby, offer plant operators, engineers and consultants the ability to rapidly analyze potential problems and to test strategies for their abatement. Our objective also includes effective communication with the geothermal community in order to improve technology transfer and to increase the relevance of the models to the problems of the industry.

\section{Technical Objectives}

- To construct thermodynamic models for predicting energetic and chemical behaviors such as brine and steam phase enthalpies, scaling, breakout and steam fractions and reservoir degradation created by the extraction of energy from geothermal brines.

- To develop new modeling technology for improved representation of the thermodynamic behavior of natural fluids from subcritical to supercritical T,P conditions.

- To develop user-friendly application software for mainframe and personal computers to facilitate the transfer of modeling technology to industrial operators, consultants and engineers as well as the academic community.

\section{Expected Outcomes}

- TEQUIL APPLICATION PACKAGE: Models providing variable temperature $\left(\mathrm{T}<300^{\circ} \mathrm{C}\right)$ solubilities of geothermal brines. Reservoir-brine interactions, scaling and gas-breakout as well as mixing, $\mathrm{pH}$, reinjection effects can be calculated using this package.

- GEOFLUIDS APPLICATION PACKAGE: Models for calculating the PVT properties and salt/vapor/liquid equilibrium of brines and other natural fluids from subcritical to supercritical temperatures and pressures.

- GEOHEAT APPLICATION PACKAGE: Models calculating the specific heat, heat of solution and enthalpy of complex brine/gas mixtures. They allow the rapid estimation of steam fractions, available heat and work, etc.

- GEOPHASE APPLICATION PACKAGE: This package (under development) provides visualization capabilities to aid in the interpretation of complex gas/liquid/solid phase relations under variable T,P conditions.

- RELIABLE SUMMARY OF MANY GEOCHEMICAL DATA SETS FOR GEOTHERMAL BRINE/SOLID/GAS SPECIES: Our chemical modeling methods include correlation and evaluation of many data points for model parameterization and comprehensive model validation by comparison to both laboratory and field data. 


\section{APPROACH}

To have the predictability required for geothermal applications, highly accurate models of the chemical behavior and physical properties of the resource formation and working fluids and their interactions are necessary. Using recent developments in the chemistry of fluids and gases, we have developed computer models, with careful attention to parameterization and validation, that accurately reproduce measured solubilities, solid/liquid/vapor equilibria and heat contents of both liquids and gases. Our EOS modeling approach can reproduce the PVT properties in solid-liquid-gas mixtures as well as vapor-liquid coexistence. These EOS have been integrated to provide highly accurate models of the enthalpy and free energy of natural fluids. In addition, we have carried out a program of first principles simulations (i.e., molecular dynamics) which can be used to develop even more general descriptions of geothermal fluids. The models we have developed have been applied to well-determined production situations with remarkable success.

As new models are developed, they are included in user-friendly application packages called TEQUIL, GEOFLUIDS, GEOHEAT and GEOPHASE. These can be loaded from diskettes to personal computers. Also we are making our codes available over the World Wide Web. Periodically, workshops are given in the use of these programs to treated problems of interest to the geothermal community.

Our modeling technology has wide application in other industries. For example, they have been used in the development of chemical processing, stripping tower design, solar pond engineering and in waste isolation problem solving. As a result, in addition to the support from the DOE Geothermal program, we have received support from other government agencies, such as: NSF-EAR, NSF-OCE, ACS-PRF, the DOE-Nuclear waste program and the UC Water Research Institute as well as from industrial sources, such as UNOCAL and Potash Corporation of Saskatchewan, Canada.

\section{RESEARCH RESULTS}

The goal of our research program is to develop new technologies which can be reliably used to understand and control problems related to the chemistry, phase equilibria and available heat of geothermal fluids.

\section{TEQUIL: Brine/Solid Phase Models, $T<300^{\circ} \mathrm{C}$}

Most geothermal energy production sites encounter brines and formation rocks composed of the seawater components: $\mathrm{Na}, \mathrm{K}, \mathrm{Ca}, \mathrm{Mg}, \mathrm{Cl}, \mathrm{SO}_{4}, \mathrm{CO}_{2}$ as well as $\mathrm{SiO}_{2}$ and aluminum and temperatures ranging from about $25^{\circ} \mathrm{C}$ (reinjection and surface operations) to $250^{\circ} \mathrm{C}$. TEQUIL includes our chemical models, based on the Pitzer equations, which can be used to predict the complicated solid-liquid-gas equilibria in these systems. The agreement between the models and the data, both experimental and field, is excellent.

TEQUIL presently includes the calcite scaling model which predicts solubilities in the $\mathrm{Na}-\mathrm{K}-\mathrm{H}-\mathrm{Ca}-\mathrm{Cl}-\mathrm{HCO}_{3}$ $\mathrm{CO}_{3}-\mathrm{SO}_{4}-\mathrm{SiO}_{2}-\mathrm{H}_{2} \mathrm{O}-\mathrm{CO}_{2}$ (gas) system to $250^{\circ} \mathrm{C}$ and high ionic strength. Table (1) compares predictions of this model, together with GEOFLUIDS and GEOHEAT, with new geothermal well data for steam fractions and downhole calcium compositions recently supplied by Ted DeRocher. The predicted steam fraction is calculated with the assumption of constant enthalpy expansion using GEOFLUIDS and GEOHEAT. We note that the measured value is lower than would be predicted from a constant enthalpy expansion, possibly indicating a small loss in heat to the formation. Using measured well head compositions and temperature $\left(171^{\circ} \mathrm{C}\right)$, we predict calcite undersaturation at the well head $(S R=39)$. At $227^{\circ} \mathrm{C}$ (the well bottom temperature), the well head brine would be supersaturated $(\mathrm{SR}=2.2)$ with respect to calcite due to the loss of $\mathrm{CO}_{2}$. In order to replicate the downhole conditions, we recombined the reported $\mathrm{CO}_{2}$ in the gas phase at the well head into the brine component. Now 
the brine is predicted to be undersaturated $(\mathrm{SR}=3)$ at the downhole temperature. To reproduce downhole conditions in the presence of antiscalent, this brine was then reequilibrated with the formation calcite. This resulted in a predicted well bottom $\mathrm{Ca}$ value of .000201 . In the table, this value is compared to the measured value of .000243 taken in the presence of antiscalent. The higher measured concentration may reflect the elevated well bottom pressure ( 87 bar) which increases calcite solubility.

Phase equilibria models of the $\mathrm{Na}-\mathrm{K}-\mathrm{H}-\mathrm{Ca}-\mathrm{Mg}-\mathrm{Cl}-\mathrm{HCO}_{3}-\mathrm{CO}_{3}-\mathrm{HSO}_{4}-\mathrm{SO}_{4}-\mathrm{H}_{2} \mathrm{O}-\mathrm{CO}_{2}$ (gas) system $\left(25^{\circ} \mathrm{C}\right)$ and of the carbonate-free seawater system $\left(-55^{\circ} \mathrm{C}\right.$ to $\left.25^{\circ} \mathrm{C}\right)$ are also in TEQUIL. The low temperature model can be used to determine the brine composition of fluid inclusions and is therefore useful for reservoir evolution studies. Our variable temperature $\left(0-250^{\circ} \mathrm{C}\right)$ model of the carbonate-free seawater system will be added in the near future. Predictions of mineral paragenesis in this complicated system (see, for example, Fig. (1)) are very sensitive to small changes in chemical potentials $(<.001 \mu / \mathrm{RT}$ units in some cases.). Therefore careful attention was paid to establishing temperature functions for the chemical potentials which would yield detailed phase transition information in good agreement with the data.

Inclusion of aluminum species in the seawater models will greatly broaden their application to reservoir studies. The development of accurate chemical models for predicting the behavior of aluminum-bearing scales in geothermal systems is complicated by the many complexation reactions involving aluminum and hydroxide ions. Using the data collected in literature searches (e.g., Bourcier et al. (1993); Wesolowski and Palmer (1994)), we are starting the construction of a preliminary model of aluminum hydrolysis from $0^{\circ} \mathrm{C}$ to $250^{\circ} \mathrm{C}$. Since these reactions vary with $\mathrm{pH}$ and salinity, we are using the variable temperature calcite scaling model as a base (see Future Plans). The addition of the aluminum species to the calcite model required some modification to the fitting and equilibrium codes because of the large increase in the number of potential interaction parameters needed. This work is now completed.

Several of the TEQUIL models have been incorporated into other widely distributed modeling codes (e.g., EQ3/6, FREZCHEM). In addition, there have been many requests to use TEQUIL in a wide variety of geochemical studies, both industrial and academic (see CONTACTS for geothermal related requests).

\section{GEOFLUIDS: Multiple Phase EOS Models, $50^{\circ} \mathrm{C}<T<1000^{\circ} \mathrm{C}$}

Many geothermal brines contain noncondensible gases including both $\mathrm{CO}_{2}$ and $\mathrm{CH}_{4}$. The solubilities of these gases greatly influence the breakout characteristics of geothermal wells. Furthermore, there is potential economic value in the $\mathrm{CH}_{4}$ contained in highly pressured systems. Therefore, one of our research goals is to develop accurate Equation of State (EOS) models for the quaternary $\mathrm{NaCl}-\mathrm{H}_{2} \mathrm{O}-\mathrm{CO}_{2}-\mathrm{CH}_{4}$ system which will predict thermodynamic properties, PVTX, immiscibility, phase equilibria, etc. in $\mathrm{NaCl}$ brines from the subcritical region to very high temperatures $\left(1000^{\circ} \mathrm{C}\right)$ and pressures.

This year, building on work accomplished in the last three years, we achieved this research goal. Previously, we developed highly accurate EOS for the salt-free ternary: $\mathrm{CH}_{4}-\mathrm{CO}_{2}-\mathrm{H}_{2} \mathrm{O}\left(0-1000^{\circ} \mathrm{C}\right.$ and $0-8000$ bar $)$ and for the salt-containing ternary: $\mathrm{NaCl}-\mathrm{H}_{2} \mathrm{O}-\mathrm{CO}_{2}\left(300^{\circ} \mathrm{C}<\mathrm{T}=1000^{\circ} \mathrm{C} ; 0-6000\right.$ bar $)$. This year, using the same phenomenology, EOS for the $\mathrm{NaCl}-\mathrm{H}_{2} \mathrm{O}-\mathrm{CH}_{4}$ ternary and for the $\mathrm{NaCl}-\mathrm{H}_{2} \mathrm{O}-\mathrm{CO}_{2}-\mathrm{CH}_{4}$ quaternary were constructed. We believe that these EOS models, which are included in the GEOFLUIDS package, are the only ones available which are able to predict phase equilibria and PVTX properties in these systems over such broad $T, P$ ranges. These capabilities are very important for many geothermal applications to mixed gas-brines systems, such as prediction of boiling pressures (see Fig. (2)), gas fugacities and solubilities, densities or volumetric properties and homogenization pressures of fluid inclusions. 
A new version of GEOFLUIDS with substantially improved user-friendly interfaces was prepared this year. Currently this version includes the $\mathrm{EOS}$ models for the $\mathrm{NaCl}-\mathrm{CH}_{4}-\mathrm{CO}_{2}-\mathrm{H}_{2} \mathrm{O}$ system. The silica geothermometer and $\mathrm{EOS}$ models for the $\mathrm{NaCl}-\mathrm{H}_{2} \mathrm{~S}-\mathrm{H}_{2} \mathrm{O}$ ternary $\left(4-320^{\circ} \mathrm{C} ; 0-300 \mathrm{bar}\right)$ and for the $\mathrm{NH}_{3}-\mathrm{H}_{2} \mathrm{O}$ binary $\left(50-400^{\circ} \mathrm{C}\right.$; 1-1200 bar), which were included in the original GEOFLUIDS code, need to be added as options to the new version. There have been a large number of requests for the individual EOS models and for the GEOFLUIDS (I and II) code package.

\section{Simulation Studies}

When possible, our models are based on high quality data obtained in the laboratory. However, the ranges of composition, temperature and pressure variables that can be encountered in geothermal applications are extremely large. It is unlikely that sufficient data to completely parameterize models covering these ranges will ever exist. Furthermore, while there has been progress in the development of appropriate equations to describe the thermodynamics of complex mixtures, there is still much that we don't know about solutions at high temperatures. Therefore, one of our research goals is to develop first principles technology which can be used to generate both data and appropriate equations for model correlations at high temperature and pressure.

The results of our molecular dynamics (MD) and Monte Carlo (MC) simulations have been very positive. Our EOS model of the $\mathrm{CH}_{4}-\mathrm{CO}_{2}-\mathrm{N}_{2}-\mathrm{H}_{2} \mathrm{O}$ system for high temperatures and pressures was generated from PVT data (see above). Recent comparisons with new experimental data have shown it to be considerably more accurate than other competing EOS. Simulations are more difficult for brine systems. However, the results of our 1-1 electrolyte $(\mathrm{NaCl}$ and $\mathrm{KCl})$ simulations, which use a simple parameterization of the intermolecular potentials, have accuracies close to that of experiments for a large range of $T$ and $P$, both above and below the critical values for water. More recently, we have begun calculations for 2-1 and 2-2 electrolytes $\left(\mathrm{CaCl}_{2}\right.$ and $\left.\mathrm{CaSO}_{4}\right)$ which seem to indicate that similar accuracy may be obtained in these more strongly interacting systems. Comparisons with data, indicate that the simulated results are within $2-3 \%$ of the measured volumes. The success of these simulations suggests that many properties, including those that are difficult to measure experimentally, can be simulated. This simulation technology can be very useful for such geothermal applications as studies of the effect of inhibitors on mineral precipitation and the effect of small pores on solution thermodynamics.

We have also begun a study to quantify the accuracy of simulation-based water thermodynamics. The most important data for geological application involve the free energy of aqueous systems (e.g., phase equilibria). A system's free energy is very difficult to simulate because this involves integration over intensive variable changes from a known state (e.g., ideal gas) to the state of interest. To do this requires many simulation points. Although a great deal of experimental thermodynamic data exist for the pure water system, there has been only one simulation to date that attempts to compare free energy predictions. This simulation uses a rather primitive water model, and the results show only qualitative agreement with experimental data. We have made good progress using our Watts water potential. We have shown that this potential provides higher quality predictions of properties (such as enthalpy, liquid structure, etc.) than other models of the water-water interaction. Preliminary calculations, however, suggest that there may be some problems in the prediction of liquid -vapor coexistence even with this highly accurate model. We are presently trying to solve these problems. When completed, this study will be highly valuable for estimating errors in the simulated properties of aqueous systems for geothermal applications.

\section{GEOHEAT}

Accurate estimates of the available heat in the working fluid are essential for the economic exploitation of a geothermal resource. Unfortunately, with the exception of the pure water system, there are very little enthalpy 
data for the pressure and temperature ranges of geothermal operations. Therefore, it is common in the industry to use pure water enthalpy information to predict fluid behavior (e.g., in the prediction of steam fractions). However, geothermal fluids are typically solutions with high concentrations of ionic species and insoluble gases. The enthalpy of such solutions is a complex function of composition, temperature and pressure. As a result, predictions of important geothermal information (such as steam fractions) from pure water enthalpies can have significant errors.

In prior work, we developed a model of the enthalpy of the $\mathrm{H}_{2} \mathrm{O}-\mathrm{CO}_{2}-\mathrm{CH}_{4}$ system for temperatures in the two phase region well below the critical point of water to roughly $2000^{\circ} \mathrm{C}$. We also developed a model for the more complex system, $\mathrm{H}_{2} \mathrm{O}-\mathrm{CO}_{2}-\mathrm{CH}_{4}-\mathrm{N}_{2}-\mathrm{H}_{2} \mathrm{~S}-\mathrm{O}_{2}-\mathrm{H}_{2}-\mathrm{CO}$-Ar, for application above the critical point of water. With the development of our EOS technology for the mixed brine/gas $\mathrm{NaCl}-\mathrm{CH}_{4}-\mathrm{CO}_{2}-\mathrm{H}_{2} \mathrm{O}$ system (see above), we now have a comprehensive new tool for the analysis of geothermal processing. Since heat data are not available for this system, the model relies heavily on the use of PVT data (see above) and ideal gas heat data to produce a very accurate free energy function. From this equation, the enthalpy can be obtained from the van't Hoff equation. This model can also be used to calculate steam fractions, partial enthalpy, heats of solution, etc. An example of a temperature-pressure-density-enthalpy diagram calculated with the model is given in Fig. (3).

A test version of this model has been implemented in the GEOHEAT software package. In order to require a minimum of information from the user, the GEOHEAT program can establish the state of the system independent of user control. This required a considerable effort to improve the performance of the GEOFLUIDS algorithm and implement the software within the GEOHEAT program.

\section{GEOPHASE}

A UCSD Chemical Geology Group (CGG) web page is being developed which gives users access to our webbased TEQUIL and GEOFLUIDS software. A GEOPHASE program has been developed which can successfully calculate the complex phase diagrams predicted by the TEQUIL models. This program, which plots complex phase diagrams directly from model calculations without user intervention, is a powerful new tool for effective utilization of our modeling technology. The program scans the entire composition space, adding salts at each point and printing the equilibrium compositions. A new plotting program ("phaseplot") sorts out invariant and univariant points. Univariant points are fitted to quadratic curves and invariant points are plotted as points. Plots can be depicted as triangles (with, for example, $\mathrm{SO}_{4}{ }^{2-}$ and $\mathrm{K}_{2}{ }^{2+}$, and $\mathrm{Mg}^{2+}$ as vertices; see Fig. (1) or as polythermal $1-d$ plots with selected salt scales. These calculations are computer intensive: typically over 150,000 equilibrium points are calculated for each temperature but run very fast on an IBM RS/6000 ( $<10$ minutes). This important new capability, which is only available over the Internet, promotes rapid visualization of modeling results.

The web-based GEOFLUIDS program currently accessed from the CGG page is computationally more intense than TEQUIL. We are now working on a GEOPHASE program to use in conjunction with GEOFLUIDS. The problem is that even the binary phase relations in the $\mathrm{NaCl}-\mathrm{CO}_{2}-\mathrm{H}_{2} \mathrm{O}$ system are very complicated. Also, the most interesting and difficult to understand occur in the transition from the subcritical tot he supercritical region.

\section{FUTURE PLANS}

In the future, we plan to improve our modeling technology by expanding system components and variable ranges. Specifically, we will concentrate on enlarging the number of species in the current calcite scaling model. The addition of the aluminum system will be given top priority so that we can develop models which can predict the chemical behavior of the important aluminum silicate minerals and scales. The GEOFLUIDS EOS model of the 
quaternary brine-gas-liquid system $\left(\mathrm{NaCl}-\mathrm{CO}_{2}-\mathrm{CH}_{4}-\mathrm{H}_{2} \mathrm{O}\right)$ needs to be expanded to include previously studied species (e.g., $\mathrm{H}_{2} \mathrm{~S}$ and $\mathrm{NH}_{3}$ ) as well as new species. As EOS models of higher order systems are developed, they will be added to the GEOHEAT package. We will continue our first principles simulation studies by first completing our simulations of the $\mathrm{CaCl}_{2}-\mathrm{H}_{2} \mathrm{O}$ system and of the full free energy water surface.

Ongoing improvement of previously developed models is expected as new data become available and new simulation techniques are created. Since visualization of model calculations (e.g., phase relationships) is so helpful in understanding the chemical processes of interest to geothermal operations, emphasis will be also placed on improving our graphic capabilities both within the web-based GEOPHASE and in our nonweb visualization programs.

In addition, we will continue applying our technology to geothermal problems both directly and indirectly by assisting others working in the field. Our modeling technology is widely used by the geothermal community (see Contacts) as well as by other industrial and academic groups. Suggestions offered by these users have proven valuable in making improvements to our software. When the web site is in full use, there will be even more user feedback. This process of interactive technical transfer yields highly reliable and relevant chemical modeling application packages for use in geothermal energy operations and in other technologies.

\section{TECHNOLOGY TRANSFER: INDUSTRY, AGENCY, ACADEMIC}

\section{Geothermal Related Contacts, FY97}

Ben Holt Co., Pasadena, CA:

CalEnergy International, Ltd.

ENEL, Italy

Energetski Inst., Croatia

Hyundai Engineering Co.

(geothermal), Korea

Kluwer Publications

Los Alamos Nat'l. Lab.

Massey Univ., New Zealand

Orme Geothermal, Inc.

Paradis, Ray,

Geothermal Consultant, NV

Yankee/Caithness, NV
Requested the new version of TEQUIL.

Requested TEQUIL and GEOFLUIDS.

Requested access to modeling software on the web.

Requested TEQUIL.

Requested GEOFLUIDS and TEQUIL.

Requested review of chapter on a geothermal model.

Requested application of models to reinjection data.

Requested geothermal brine chemistry papers.

Requested access to our Internet programs.

Requested scale removal information.

Requested assistance analyzing geothermal data with models.

\section{Technical Meetings, FY 97}

March 25: DOE Geothermal Program Review, San Francisco.

April 27-30: DOE-BES review, Oak Ridge.

March 26 - April 16: Z: Duan visited China (other funding) to collaborate with Professor $\mathrm{Hu}$, Nanjing University. April 30 - May 1; GRC meeting, San Francisco.

May: J. Weare and N. Mфller, attended the DOE field trip and workshop, Dixie Valley.

June 2-6: J. Weare chaired session and gave presentation at the $7^{\text {th }}$ Annual Goldschmidt Conference, Tucson, Arizona.

Aug. 26-27: J. Weare attended Dixie Valley workshop, Reno, NV;

Sept. 24 - Oct. 15:Z. Duan visited China (other financial support) to give invited presentation at the Asia Fluid Inclusion conference. 


\section{Technical Papers, FY97}

Phase Equilibria and Solubility Prediction in the Na-K-Mg-Cl-SO $-\mathrm{SO}_{4} \mathrm{O}$ System to High Concentration from $0^{\circ} \mathrm{C}$ to $250^{\circ} \mathrm{C}$. Mфller, N. (in prep.).

Phase Equilibria and Solubility Prediction in the Carbonate-Free Seawater system, $\mathrm{Na}-\mathrm{K}-\mathrm{Ca}-\mathrm{Mg}-\mathrm{Cl}-\mathrm{SO}_{4}-\mathrm{H}_{2} \mathrm{O}$, to High Concentration from $0^{\circ} \mathrm{C}$ to $250^{\circ} \mathrm{C}$. Mфller, N. (in prep.)

Prediction of the Solubility of $\mathrm{H}_{2} \mathrm{~S}$ in $\mathrm{NaCl}$ Aqueous Solutions- An Equation of State Approach. Z. Duan, N. Mфller, and J. Weare, Chemical Geology 130, 15-20 (1996)

A General Equation of State for Supercritical Fluid Mixtures and Molecular Dynamics Simulation of Mixture PVTX Properties. Z. Duan, N. Mфller, and J. Weare, Geochim. Cosmochim. Acta 60, 1209-1216 (1996).

Prediction of Phase Separation, PVT Properties, Enthalpy and Fugacity of Supercritical Fluids in the $\mathrm{H}_{2} \mathrm{O}-\mathrm{CO}_{2}$ $\mathrm{CH}_{4}-\mathrm{N}_{2}$ System Up to $2000^{\circ} \mathrm{K}$ and $100 \mathrm{~K}$ bar. Z. Duan, N. Mфller, and J. Weare (in prep.).

Enthalpy Model of Geological Fluid Mixtures to High Temperature and Pressures. Z. Duan, N. Mфller, and J. Weare (in prep.).

Phase Separation and Thermodynamical Properties for Natural Fluids Under Deep Crustal and Mantel Pressure and Temperature Conditions. Z.Duan, N. Mфller, and J. Weare (in prep.).

Molecular Dynamics Simulation of the Thermodynamic Transport and Structural Properties of the System NaCl$\mathrm{H}_{2} \mathrm{O}$ Up to High Temperatures and Pressures. Z. Duan, N. Mфller, and J. Weare (in prep.).

Monte Carlo Gibbs Ensemble Simulation of phase Equilibria of the System: $\mathrm{CO}_{2}-\mathrm{CH}_{4}-\mathrm{N}_{2}$. Z. Duan, N. Mфller, and J. Weare (in prep.).

\section{REFERENCES}

Bourcier W.L., Knauss K.G. and Jackson K.J. (1993) Aluminum hydrolysis constants to $250^{\circ} \mathrm{C}$ from boehmite solubility measurements. Geochim. Cosmochim. Acta 57, 747-762.

Duan Z., Mфller, N. and Weare J.H. (1992a) An equation of state for the $\mathrm{CH}_{4}-\mathrm{CO}_{2}-\mathrm{H}_{2} \mathrm{O}$ system: I. Pure systems from 0 to $1000^{\circ} \mathrm{C}$ and 0 to 8000 bar. Geochim. Cosmochim. Acta 56, 2605-2617.

Duan Z., Mфller, N. and Weare J.H. (1992b) An equation of state for the $\mathrm{CH}_{4}-\mathrm{CO}_{2}-\mathrm{H}_{2} \mathrm{O}$ system: II. Mixtures from 50 to $1000^{\circ} \mathrm{C}$ and 0 to 1000 bar. Geochim. Cosmochim. Acta 56, 2619-2631.

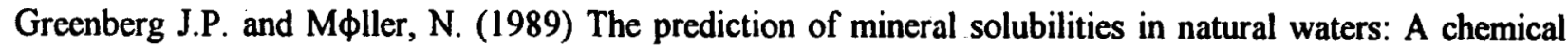
equilibrium model for the $\mathrm{Na}-\mathrm{K}-\mathrm{Ca}-\mathrm{Cl}-\mathrm{SO}_{4}-\mathrm{H}_{2} \mathrm{O}$ system from $0^{\circ}$ to $250^{\circ} \mathrm{C}$. Geochim. Cosmochim. Acta 53; 2503-2518.

Harvie C.E. and Weare J.H. (1980) The prediction of mineral solubilities in natural waters: The Na-K-Mg-Ca-Cl$\mathrm{SO}_{4}-\mathrm{H}_{2} \mathrm{O}$ system from zero to high concentration at $25^{\circ} \mathrm{C}$. Geochim. Cosmochim. Acta 44, 981-997 
Harvie C.E., Mфller, N., and Weare J.H. (1984) The prediction of mineral solubilities in natural waters: The Na$\mathrm{K}-\mathrm{Mg}-\mathrm{Ca}-\mathrm{H}-\mathrm{Cl}-\mathrm{SO}_{4}-\mathrm{OH}-\mathrm{HCO}_{3}-\mathrm{CO}_{3}-\mathrm{CO}_{2}-\mathrm{H}_{2} \mathrm{O}$ system to high ionic strengths at $25^{\circ} \mathrm{C}$. Geochim. Cosmochim. Acta 48, 723-751.

Mфller, N., (1988) The prediction of mineral solubilities in natural waters: A chemical equilibrium model for the $\mathrm{Na}-\mathrm{Ca}-\mathrm{Cl}-\mathrm{SO}_{4}-\mathrm{H}_{2} \mathrm{O}$ system to high temperature and concentration. Geochim. Cosmochim. Acta 52, 821-837.

Pitzer K.S. (1973) Thermodynamics of electrolytes: I. Theoretical basis and general equations. J. Phys. Chem. 77, 268-277.

Pitzer K.S. (1987) Thermodynamic model for aqueous solutions of liquid-like density. Reviews in Mineralogy 17, 97-142.

Weare J. H. (1987) Models of mineral solubility in concentrated brines with application to field observations. Reviews in Mineralogy 17, 143-176.

Wesolowski D.J. and Palmer D.A. (1994) Aluminum speciation and equilibria in aqueous solution: V. Gibbsite solubility at $50^{\circ} \mathrm{C}$ and $\mathrm{pH} 3-9$ in 0.1 molal $\mathrm{NaCl}$ solutions (a general model for aluminum speciation; analytical methods). Geochim. Cosmochim. Acta 58, 2947-2969.

Table 1. Calcite Scale Prediction in a Geothermal Well

\begin{tabular}{|c|c|c|c|c|c|}
\hline & $\begin{array}{c}\text { Steam } \\
\text { Fraction }\end{array}$ & $\begin{array}{c}\mathrm{CaCO}_{3} \mathrm{SR}^{\mathrm{a}} \\
\text { Well Head }\end{array}$ & $\begin{array}{c}\mathrm{CaCO}_{3} \mathrm{SR}^{\mathrm{a}} \\
\text { Well Head }\end{array}$ & $\begin{array}{c}\mathrm{CaCO}_{3} \mathrm{SR}^{\mathrm{b} .} \\
\text { Well Head }\end{array}$ & $\begin{array}{c}\text { Ca Concentration } \\
(\mathrm{m})^{\mathrm{c}} \text {. Well Bottom }\end{array}$ \\
\hline Measured & $9 \%$ & - & - & - & .000243 \\
\hline Prediction & $12 \%$ & .39 & 2.2 & .3 & .000201 \\
\hline
\end{tabular}

a.) Brine $-\mathrm{CO}_{2}$. b.) Brine $+3183 \mathrm{ppm} \mathrm{CO}_{2}(\mathrm{aq})$. c.) Antiscalent Conditions 


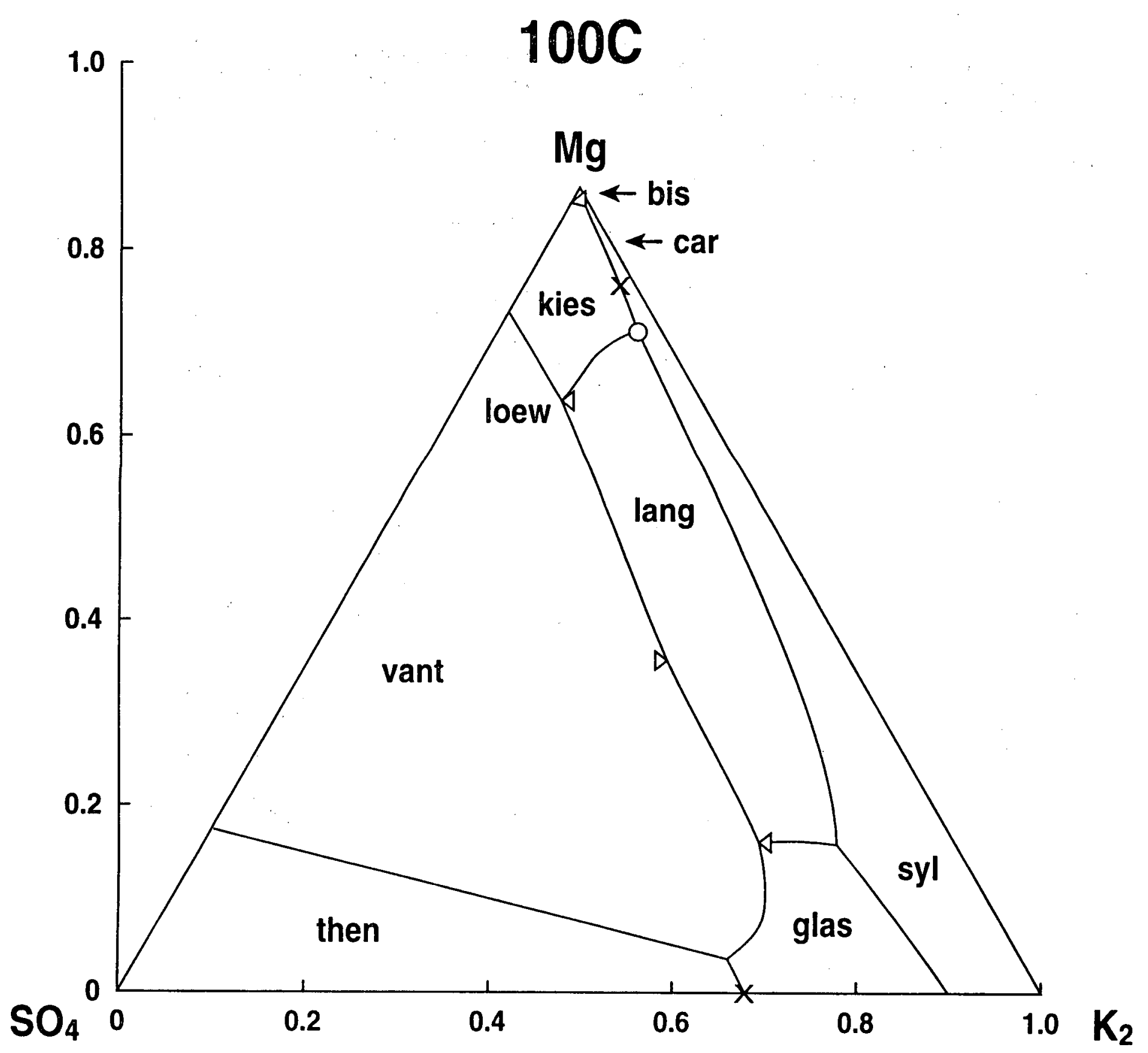

Figure 1 - Janecke projection of the $100^{\circ} \mathrm{C}$ Isotherm for the Five-Component, Na-K-Mg-Cl-SO ${ }_{4}-\mathrm{H}_{2} \mathrm{O}$, at $\mathrm{NaCl}$ Saturation. This phase diagram is generated directly from the seawater model without user intervention employing the new "phaseplot" plotting program. 


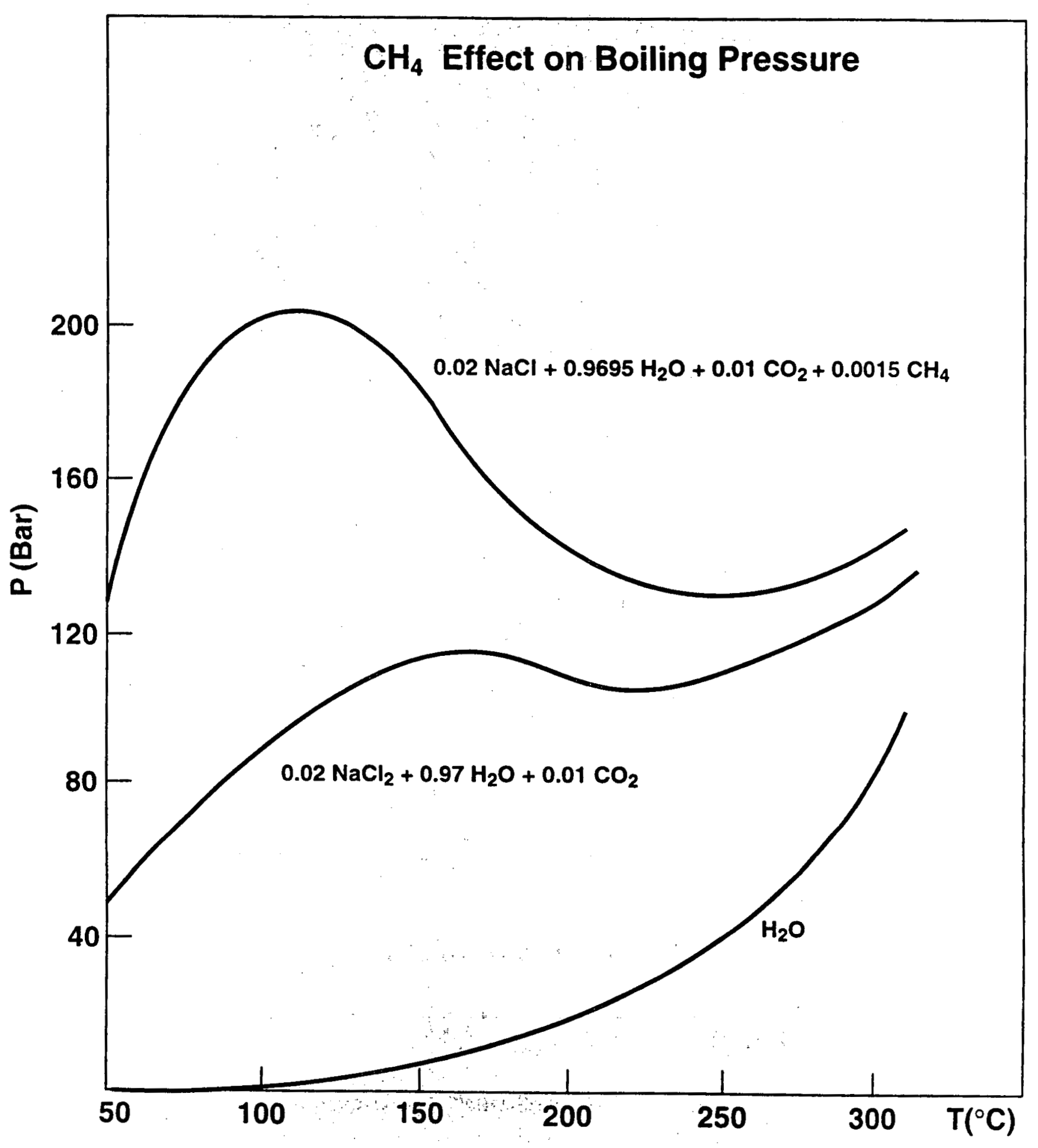

Figure 2 -- The Effect of $\mathrm{CH}_{4}$ on Boiling Pressure as a Function of Temperature. Using the quaternary EOS model, boiling pressure predictions for a NaCl brine are compared in the presence of various gases $\left(\mathrm{H}_{2} \mathrm{O}, \mathrm{CO}_{2}\right.$ and $\mathrm{CH}_{4}$ ) as a function of temperature. 


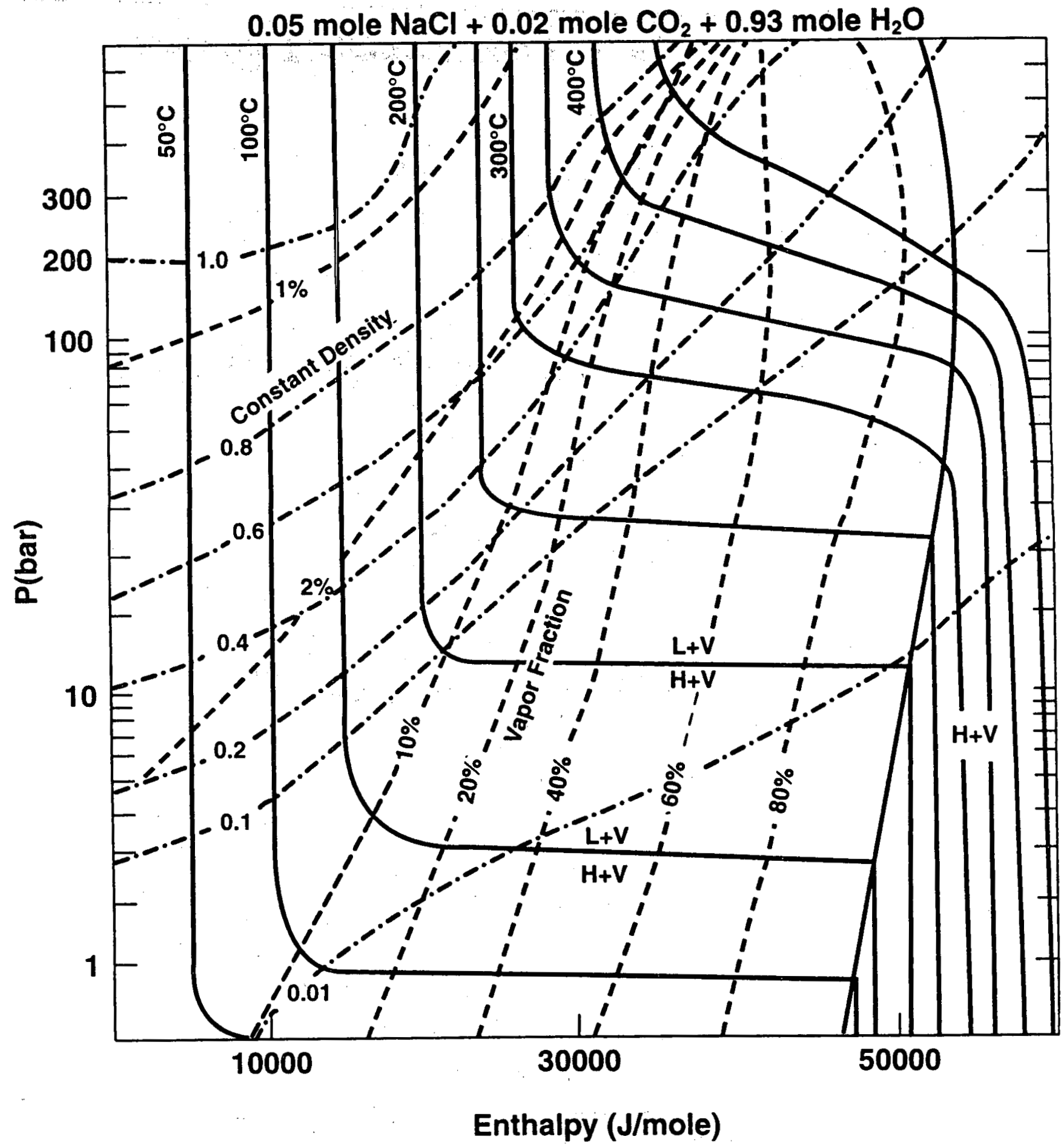

Figure 3 - A Temperature-Pressure-Density-Enthalpy Diagram for the Ternary System: 0.05 mole $\mathrm{NaCl}+0.02$ mole $\mathrm{CO}_{2}+0.93$ mole $\mathrm{H}_{2} \mathrm{O}$ Calculated Using the GEOHEAT and Updated GEOFLUIDS Programs. These programs incorporate our current EOS models. 


\title{
WATER ADSORPTION
}

\author{
Miroslaw S. Gruszkiewicz, Juske Horita, J. Michael Simonson, and Robert E. Mesmer \\ Chemical and Analytical Sciences Division, Oak Ridge National Laboratory
}

\section{KEY WORDS}

geothermal reservoir, adsorption, The Geysers, rocks, porous materials

\section{PROJECT BACKGROUND AND STATUS}

Any reliable model of the behavior of vapor-dominated geothermal reservoirs must include information about the amount of water retained by the rocks as a function of temperature and pressure. All porous materials, including rocks, can retain water as multi-layer adsorbate on all of their internal surface, as pore-filling adsorbate in the micropores (widths up to about $20 \AA$ ) and as multi-layer adsorbate and capillary condensate in the mesopores and macropores (widths up to about $1000 \AA$ ). This retained water has a density close to the density of liquid water even if the temperature and pressure in the reservoir are in the superheated steam region, indicating that only low-density steam should exist in the absence of surface effects. This means that the term 'vapordominated reservoir' refers to the equilibrium state of the steam present in large rock fractures and the steam produced in the wells, but does not reflect the fact that water is also stored in such reservoirs in a high-density condensed state. To estimate the size of the available resource and to predict pressure changes during operation it is important to know what fraction of the water is present as adsorbed layers and capillary condensate with an equilibrium vapor pressure lower than that of bulk water. Operating experience suggests that adsorbed and pore water may act as either a source or a potential sink directly influencing the response to reinjection processes. This response may be influenced by the phenomena that cause adsorption/desorption hysteresis.

Since the physicochemical complexity of rocks makes it impossible to predict with a reasonable certainty the water retention at different temperatures and pressures, the most useful data would be those obtained at temperatures in the vicinity of the actual reservoir temperatures. The temperature in most of The Geysers reservoir is approximately $240^{\circ} \mathrm{C}$, and a higher temperature reservoir is found in the northwest area of the field. The experimental measurements of water adsorption published in the literature have been limited to about $150^{\circ} \mathrm{C}$, with most of the experiments conducted at $120^{\circ} \mathrm{C}$ or $130^{\circ} \mathrm{C}$ and below (Shang et al., 1995; Satik et al, 1995,1996 ). Bertani et al. (1996) reported water adsorption isotherms (with no hysteresis information, since the desorption branches were not measured) for 10 samples including The Geysers NEGU-17 and MLM-3 wells in the temperature range $170-200^{\circ} \mathrm{C}$.

This project was undertaken in order to significantly expand the knowledge of the adsorption/desorption processes useful for operating geothermal reservoirs. The following work was completed in this project:

- Rock cores were obtained and samples in three grain size fractions were prepared. Initial BET surface area analyses were made using nitrogen and krypton at $77 \mathrm{~K}$. These analyses yielded surface areas and total pore volumes of the samples. Densities were also determined by the helium displacement method.

- The Oak Ridge National Laboratory (ORNL) isopiestic apparatus was extensively overhauled and modifications were made to achieve the highest possible weighing accuracy.

- The densities of the samples were measured using the effect of buoyancy in compressed argon gas. 
- The $150^{\circ} \mathrm{C}, 200^{\circ} \mathrm{C}$ and $250^{\circ} \mathrm{C}$ adsorption and desorption isotherms in the relative pressure range from vacuum to saturation were determined for 12 rock samples taken from three wells at the Geysers geothermal system, in three grain size fractions and for four pure minerals.

- Mercury intrusion porosimetry and low temperature nitrogen adsorption/desorption analyses were performed on representative samples by Micromeritics laboratories. BET specific surface areas, pore size distributions and total porosities of the samples before and after high temperature adsorption measurements were obtained.

- The experimental data were reduced by fitting isotherms to empirical correlations of the amount of water retained as a function of relative pressure. Approximate pore size distributions were calculated from the water adsorption/desorption isotherms.

- A manuscript describing the results was prepared for publication.

\section{PROJECT OBJECTIVES}

\section{Technical Objectives}

- Experimental determination of water retention capacities on rocks from The Geysers geothermal field as a function of vapor pressure at temperatures from $150^{\circ} \mathrm{C}$ to $250^{\circ} \mathrm{C}$ when pressure is increasing ('adsorption' isotherms) and decreasing ('desorption' isotherms).

- Characterization of the rocks from The Geysers using the data obtained by us, mineralogical descriptions, and low temperature nitrogen adsorption.

- Correlation of the water retention phenomena in the reservoirs with rock characteristics and T-p conditions.

\section{Expected Outcomes}

- Obtain accurate and reliable water retention data for representative samples of The Geysers rocks at the reservoir temperature (for the first time). These data, including hysteresis behavior, will be available for use in reservoir models and in injection/production simulations.

- Resolve the issue of the temperature dependence of the amount of water retained.

- Expand the knowledge about the structure of The Geysers rocks and about rock-water interactions. Gain an insight into the type of rock surface-water interactions that are present, both chemical and physical.

\section{APPROACH}

The ORNL high-temperature isopiestic apparatus (Holmes et al., 1978) is a unique facility capable of precise and accurate measurements of the change of mass of a sample under high temperature-high pressure conditions. This ability makes it suitable for measurements of adsorption by materials characterized by small specific surface areas. The parameter measured is the mass of the solid as a function of vapor pressure. The sorptometers used by other investigators for measuring adsorption on geothermal reservoir rocks rely on measurements of vapor pressure in a chamber of known volume containing the sample. The total volume of the instrument is kept small to increase its sensitivity to relative pressure changes, but the small volume also makes the instrument more sensitive to leaks, temperature variation, and errors in calibration of the internal volumes. In the isopiestic 
apparatus the mass is measured by comparison with a set of standard weights placed inside the pressure vessel together with the samples. The densities of the samples, which have to be known in order to correct the results for the effect of buoyancy, are measured inside the isopiestic apparatus by weighing the samples in vacuum and then in the atmosphere of a compressed gas (e.g. Ar) of known density. The large volume of the isopiestic vessel (about $28 \mathrm{~L}$ ) makes the method less sensitive to leaks. These characteristics of the isopiestic apparatus make it relatively easy to evaluate the time needed for reaching equilibrium, as the samples may be left under the same vapor pressure for many days and the change of mass with time can be monitored. The isopiestic apparatus is capable of, and has been previously used for, measurements at $250^{\circ} \mathrm{C}$ and $40 \mathrm{bar}$.

In conjunction with the high temperature water adsorption measurements, multipoint BET surface area analyses using nitrogen adsorption measurements at $77 \mathrm{~K}$, and mercury porosimetry analyses were performed by Micromeritics on the same rock samples in order to obtain specific surface, total pore volume, and pore size distribution information. With pressure range from vacuum to 60000 psia the mercury intrusion technique covers pores from $3 \mathrm{~nm}$ to over $100 \mu \mathrm{m}$, while low temperature adsorption is a well developed standard method for determination of specific surfaces and provides the most accurate information about pores up to roughly $50 \mathrm{~nm}$.

\section{RESEARCH RESULTS}

The measurements were performed on cores taken from the producing steam reservoir. Well numbers and approximate depths are as follows (from Dr. Jeff Hulen of the Energy and Geoscience Institute, who supplied the samples): NEGU-17, 8530-8530.5 ft; PRATI-STATE 12, 6261.7-6261.8 ft; MLM-3, 4336-4336.3 ft.

The differences in depth and the known variability of rock characteristics along the cores must be taken into account when comparing the results on these three samples. The rocks were crushed and sieved. Three fractions were prepared of each core with the following grain sizes: $2.00-4.25 \mathrm{~mm}$ ('coarse'), $0.355-2.00 \mathrm{~mm}$ ('medium'), and $<0.355 \mathrm{~mm}$ ('fine'). The surface areas as determined by PMI ranged from 0.64 to $3.52 \mathrm{~m}^{2} / \mathrm{g}$.

Four samples of each rock were loaded in the titanium cups of the isopiestic apparatus (the medium fraction of each of the rocks was loaded in two cups, so that the repeatability of the measurements could be verified). Four of the remaining cups contained pure minerals (silica gel, chlorite, magnetite, and anatase). The data obtained on anatase compared well with literature results on the same material.

Although the samples are labeled with the well names, the differences in depth and the known variability of rock characteristics along the cores must be taken into account when comparing the results. The amounts of water adsorbed on the rock samples at $\mathrm{p} / \mathrm{p}_{0}=0.8 \mathrm{ranged}$ from 1 to nearly $4 \mathrm{mg} / \mathrm{g}$. The capacity of the cores investigated for water adsorption increased in the sequence Prati-State $12<$ NEGU- $17<$ MLM-3. This order was different from the one corresponding to nitrogen adsorption capacities (or BET specific surface areas); Prati-Statel $2<$ MLM-3 < NEGU-17. The differences in nitrogen specific surface areas of the three cores were much more pronounced than the differences in water adsorption capacity. Both nitrogen adsorption and mercury intrusion results for NEGU-17 metagraywacke showed a significant shift in the pore volume distribution towards smaller pores in comparison with the other two wells. Possible microporosity in NEGU-17 samples could also be inferred from pore size distributions derived from high temperature water adsorption results. The presence of very narrow pores resulted in an enhancement of nitrogen adsorption (and correspondingly larger calculated BET surface areas) for NEGU-17, but it had little influence on water adsorption capacity. These results indicate that BET specific areas obtained from nitrogen adsorption cannot be considered a reliable estimator of hightemperature water adsorption capacities of rocks.

Since isotherms were obtained over a wide range of temperatures, $\left(150-250^{\circ} \mathrm{C}\right)$ it was possible to observe the narrowing of the hysteresis loop which occurred above $200^{\circ} \mathrm{C}$. This is apparently the result of the decrease of 
the surface tension of water with increasing temperature, which makes it possible to differentiate between temperature-independent multilayer adsorption and temperature-dependent capillary condensation. As the hysteresis loop flattens, the decrease in the amount of water present on the surfaces on the desorption branches of the isotherms is proportional to the fraction of water present which is retained by the capillary condensation mechanism. At the reservoir temperature, most (probably more than $90 \%$ ) of the water present on the surface of the reservoir rocks is condensed by the multilayer adsorption mechanism which does not depend on the presence of microscopic radius liquid-water interface curvature. It was found that as the temperature increases the amount of water adsorbed may remain nearly constant or it may decrease, as the conditions for vapor pressure lowering due to surface curvature become less favorable, and some of the capillary condensate, present at lower temperatures, evaporates. No evidence of an increase of adsorption with temperature was found. Virtual invariability with temperature of the adsorption branches is in agreement with the results of Bertani et al. (1996) in the range $170-200^{\circ} \mathrm{C}$. The reduction of the hysteresis loop has to be taken into account if water adsorption results at temperatures lower than the reservoir temperature are to be used for estimation of the sorption capacities of reservoir rocks. Low temperature isotherms, especially their desorption branches, are biased by the excess capillary condensate which may not be present at the reservoir temperature.

The shape of the isotherms and the hysteresis loops (type H3 according to the IUPAC recommended classification) is consistent with a pore system composed of open parallel slits (which produce flat isotherms with hysteresis) and wedges closed on the narrow side (which produce sloping isotherms without hysteresis). The adsorption on the rock samples was reversible. The relative pressure at the closure point of the hysteresis loop of the NEGU-17 isotherms corresponded to a pore diameter in the micropore range (calculated using the Kelvin equation). As the temperature increased, the hysteresis loop closing point moved towards higher relative pressures. Most Prati-State 12 and MLM-3 samples showed low-pressure hysteresis (hysteresis present at relative pressures which correspond to the Kelvin equation pore diameters of molecular and submolecular dimensions. Such hysteresis can not be caused by capillary condensation. It may be associated with minerals that have layered structures and can intercalate water molecules in very narrow spaces, or can change dimensions, (swell) with creation of new adsorption sites, when exposed to excess water. There are significant differences in the mineral compositions of the three cores, which at least qualitatively explain some of the results. Metagraywacke from the NEGU-17 core, which showed nearly no low pressure hysteresis and had the smallest average pore diameter, had also much higher content of chlorite relative to quartz and feldspars. It had the highest content of carbonized organic matter and did not contain calcite, which can show low pressure hysteresis (Gregg and Gammage, 1972).

One of the consequences of the presence of hysteresis loops is that the well pressure does not in itself determine the amount of the resource available. For example for the NEGU-17 rocks, with the same total amount of water retained, the equilibrium vapor pressure (reservoir pressure) may be either $0.7 \mathrm{p}_{0}$ or $0.95 \mathrm{p}_{0}$. It is more desirable to remain on the adsorption branch, where at constant water content the equilibrium pressure is higher. If after the injection the system is on the desorption branch, the amount of water retained which is necessary to maintain the same pressure (e.g. $\left.\mathrm{p} / \mathrm{p}_{\mathrm{o}}=0.8\right)$ may significantly exceed the amount required on the adsorption branch This is particularly true if the temperature drops causing an increase in surface tension, and some amount of water is retained by the capillary condensation mechanism.

It was found that the strikingly different water retention behavior of the fine grain size fraction samples, reported earlier, was an artifact due to the presence in these samples of iron (steel) originating from the mill used to crush the samples. The observed significant and largely irreversible mass changes, quite different from the behavior of either coarse or medium fractions, were initially thought to be due to chemical changes on fresh surfaces created during grinding. However, these mass changes can be explained by the formation of oxides/hydroxides 
on the impurity iron. The differences in water retention between the coarse and medium grain size samples which did not contain elemental iron were not significant.

\section{FUTURE PLANS}

The cycle of high temperature adsorption measurements on the three core samples was completed, and the results were processed and described. A paper was prepared for publication in the special issue of Geothermics focused on The Geysers Coring Project. In parallel to the industry interest, we are planning to extend the adsorption study to the cores obtained from the geothermal fields in Indonesia and from the Northwest Geysers (well L'Esperance\#2). We are also considering the possibility of investigating high temperature water sorption properties of some naturally occurring zeolites in cooperation with the group of Prof. Barnes at the Pennsylvania State University.

\section{INDUSTRY INTEREST}

Partial results of this study were presented at the Twenty-First Annual Stanford Geothermal Reservoir Engineering Workshop in Stanford, California, January 22-24, 1996 and published in the workshop Proceedings. They were also presented during the DOE Geothermal Program Review XV, March 1997. Complete results will be presented at the Twenty-Third Workshop (January 26-29, 1998). The results are expected to be of interest to companies operating vapor dominated geothermal reservoirs. The knowledge of the adsorption/desorption isotherms and of the hysteresis characteristics is considered to be essential in modeling the behavior of the reservoirs including the reservoir response to reinjection processes.

\section{REFERENCES}

Gruszkiewicz M. S., Horita J., Simonson J. M, and Mesmer R. E. (1996) Measurements of water vapor adsorption on The Geysers rocks. PROCEEDINGS, Twenty-First Workshop on Geothermal Reservoir Engineering, Stanford University, Stanford, CA, January 22-24, 1996.

Barrer R. M., Reay J.S.S. (1957) Interlamellar sorption by montmorillonite. In Proceedings of the Second International Congress on Surface Activity, Vol. 2, pp. 113-121, Butterworths, London.

Bertani R., Parisi L., Perini R., Tarquini B. (1996) High temperature adsorption measurements. PROCEEDINGS, Twenty-First Workshop on Geothermal Reservoir Engineering, Stanford University, Stanford, CA, January 22-24, 1996.

Gammage R. B. and Gregg S. J. (1972) The sorption of water vapor by ball-milled calcite. J. Colloid Interface Sci., 38, 118-124.

Holmes H. F., Baes Jr. C. F. and Mesmer R. E. (1978) Isopiestic studies of aqueous solutions at elevated temperatures. J. Chem. Thermodynamics, 10, 983-996.

Satik C. and Horne R. N. (1995) An experimental study of adsorption in vapor-dominated geothermal systems. PROCEEDINGS, Twentieth Workshop on Geothermal Reservoir Engineering, Stanford University, Stanford, CA, January 24-26, 1995. 
Satik C., Walters M. and Horne R. M. (1996) Adsorption characteristics of rocks from vapor-dominated geothermal reservoir at The Geysers, CA. In Proceedings of the $21^{\text {2t }}$ Workshop on Geothermal Reservoir Engineering, pp. 469-479, January 24-26, Stanford University, Stanford, CA.

Shang S. B., Horne R. N. and Ramey H. J. (1995) Water vapor adsorption on geothermal reservoir rocks. Geothermics, 4. 


\title{
CERRO PRIETO FIELD CASE STUDY
}

\author{
Marcelo J. Lippmann (1), Alfred H. Truesdell (2), and \\ Héctor Gutiérrez Puente (3) \\ (1) E.O. Lawrence Berkeley National Laboratory \\ (2) Consultant, (3) Comisión Federal de Electricidad, Mexico
}

\section{KEY WORDS}

Cerro Prieto, Salton Trough, liquid-dominated systems, reservoir response to exploitation

\section{PROJECT BACKGROUND AND STATUS}

Lawrence Berkeley National Laboratory (LBNL), with funding from the Department of Energy (DOE) and in cooperation with the Comision Federal de Electricidad de México (CFE), has studied the behavior of the Cerro Prieto geothermal field since the late 1970s. The field, currently the world largest liquid-dominated system under exploitation, is located in the southern part of the Salton Trough about $30 \mathrm{~km}$ south of the US-Mexico border. It has been under commercial production since 1973. The present installed capacity at Cerro Prieto is $620 \mathrm{MWe}$. In October 1997, CFE awarded a Build-Lease-Transfer contract for the installation of four additional $25 \mathrm{MWe}$ units in the field.

Over the years; the substantial extraction of mass has resulted in a reduction of reservoir pressure and in the entry of cooler groundwaters into the reservoir. Meanwhile, the recharge of deep hot waters has continued unabated, and perhaps has increased as reservoir pressure decreased. Since 1989, the natural fluid recharge of the reservoir has been supplemented by injection, which at present amounts to about $20 \%$ of the mass produced.

Recent (up to 1996) production, wellhead and fluid chemistry data have been analyzed to document changes in reservoir fluid enthalpy (based on geothermometry), and chemistry (mainly chloride and isotope compositions). These changes have been interpreted taking into consideration the chemistry of the geothermal fluids, cooler groundwaters and injectate, the subsurface geology, and the production/injection history of the field.

The latest study (Truesdell et al., 1997) confirms that colder groundwaters are recharging the Cerro Prieto geothermal reservoirs, not only horizontally through permeable layers, but also vertically through permeable fault zones, structures that before the start of field exploitation allowed the discharge of geothermal fluids from the system. Changes in the chemical and physical characteristics of the reservoir fluids indicate current reservoir processes like local boiling, phase segregation, steam condensation, mixing and dilution, and allow identification of the sources of the colder waters recharging the geothermal system (i.e. natural groundwater recharge versus injectate; Figures 1 and 2).

\section{PROJECT OBJECTIVES}

The main purpose of the Cerro Prieto case study is to document the changes and processes occurring in the geothermal reservoir in response to large-scale production (and injection). The experiences learned from this system will be useful in developing management procedures for geothermal fields characterized by porous or highly-fractured reservoirs, especially those in California's Salton Trough. 


\section{Technical Objectives}

- To further evaluate the effectiveness of interpretative methods that integrate geochemical and reservoir production data to identify reservoir processes in geothermal systems,

- To continue the development of methods to detect regions in geothermal fields where significant changes in reservoir fluid characteristics are taken place, which eventually might call for modifications in production and injection schemes,

- To assess physical and geochemical changes in the reservoir related to long-term fluid production, especially effects on reservoir processes due to the lack of injection or natural mass recharge,

- To assess advantages and drawbacks of injection in a matrix-dominated geothermal reservoir, and

- To assess benefits of natural fluid inflow on reservoir exploitation.

\section{Expected Outcomes}

- Conference paper discussing the data monitored at Cerro Prieto during 1996-97 and their interpretation.,

- Paper in a refereed technical journal describing the reservoir changes observed at Cerro Prieto due to production and injection since the mid-1980s, and

- LBNL report documenting chemical, isotopic and physical changes at Cerro Prieto up to the end of calendar 1996.

\section{APPROACH}

Well production, wellhead and fluid chemistry data will be interpreted to determine changes in total fluid enthalpy, reservoir temperature and liquid enthalpy, and fluid chemistry. These changes will be analyzed considering the chemistry of the geothermal fluids, ground and injection water, the subsurface geology (especially faults) and the production/injection history of the field, as well as modification in well completion. Also results from a planned deep (about $6 \mathrm{~km}$ ) exploration well (Lippmann et al., 1997) will be incorporated in the study provided they become available during FY1998.

\section{RESEARCH RESULTS}

The conceptual model of the Cerro Prieto field will be reviewed and revised, if necessary. The data bank on Cerro Prieto will be updated. Present production and injection operations in the field will be discussed with CFE and results of data interpretations described in reports and papers (see "Expected Outcomes" above).

\section{FUTURE PLANS}

The compilation, update and interpretation of production and fluid chemistry data from Cerro Prieto, as well as the collaboration with CFE and U.S. companies involved in the development of this geothermal system will continue. 


\section{INDUSTRY INTEREST}

\section{Organization}

Calpine Corporation \& Douglas Energy Company

U.S. companies involved in geothermal field development

\section{Type and Extent of Interest}

Reservoir behavior conceptual model of the Cerro Prieto geothermal system.

Field case study on reservoir management of hightemperature, liquid-dominated fields in sedimentary rocks.

\section{REFERENCES}

Lippmann, M.J., Truesdell, A.H., and Gutiérrez Puente, H. (1997). What will a $6 \mathrm{~km}$ deep well at Cerro Prieto find? Proceedings, 22nd. Workshop on Geothermal Reservoir Engineering, Stanford, CA, pp. 19-28.

Truesdell, A.H., Lippmann, M.J. and Gutièrrez Puente, H. (1997). Evolution of the Cerro Prieto reservoirs under exploitation. Geothermal Resources Council Trans., 21, 263-270, LBNL-40614.

Truesdell, A.H., Lippmann, M.J., Quijano, J.L. and D'Amore, F. (1995) Chemical and physical indicators of reservoir processes in exploited high-temperature; liquid-dominated geothermal fields. Proceedings, World Geothermal Congress, Florence, Italy, 18-31 May 1995, pp. 1933-1938.

Verma, M., Quijano, L., Gutiérrez, H., Iglesias, E. and Truesdell, A.H. (1996). Isotopic changes in the fluids of the Cerro Prieto reservoir. Proceedings 21 th Geothermal Reservoir Workshop, Stanford, CA, pp. 93-99. 


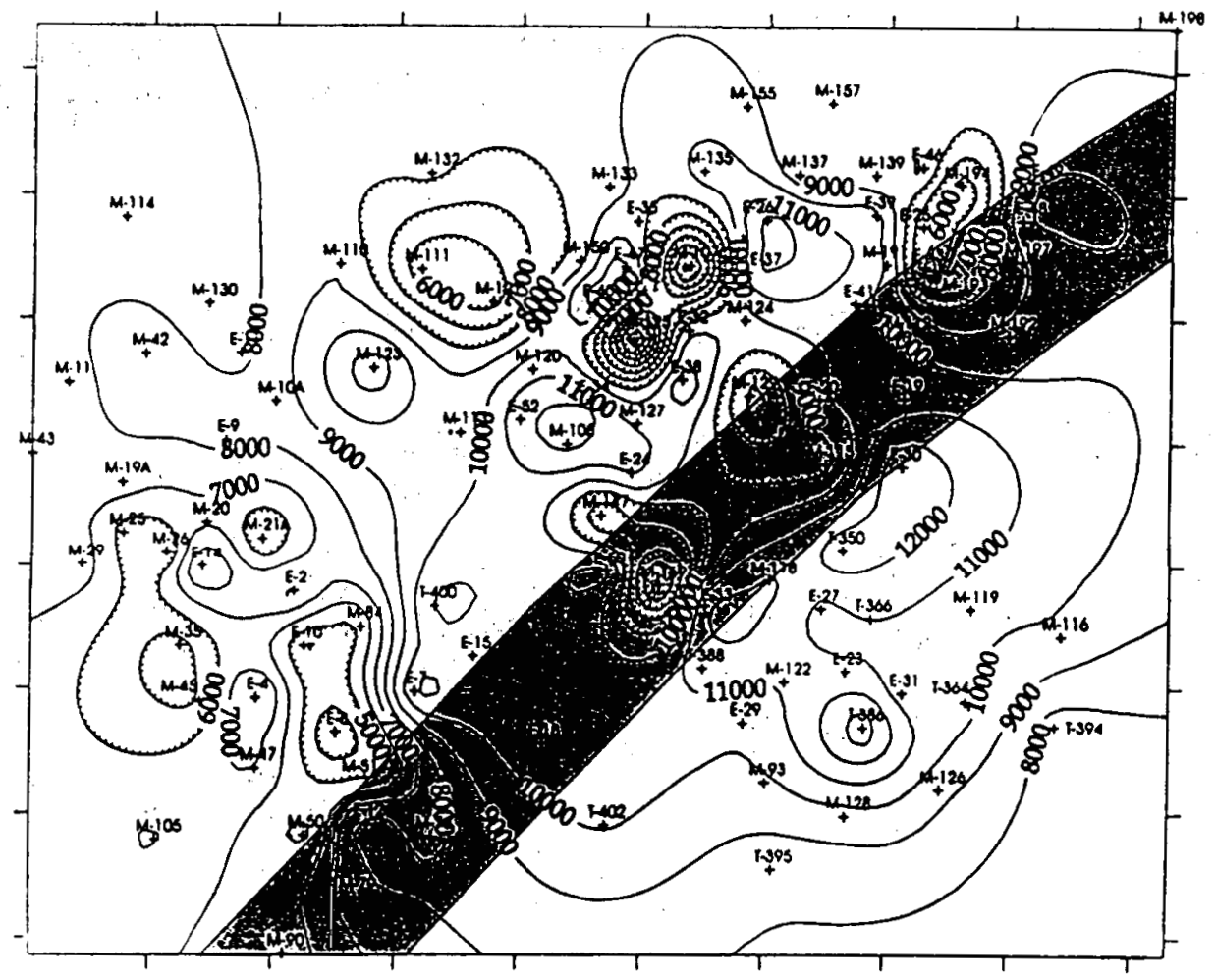

Figure 1 - 1989 reservoir concentration of chloride (in ppm) in the Cerro Prieto b (deeper) reservoir calculated from analyses of flashed fluids, measured enthalpy, and $\mathrm{NaKCa}$ reservoir temperatures. Three low-chloride anomalies are shown. The one to the northeast is due to colder groundwater inflow; the other two are from well condensation. The shaded area corresponds to the normal fault $\mathrm{H}$ at the level of the reservoir top; the hanging block of the fault is to the southeast. 


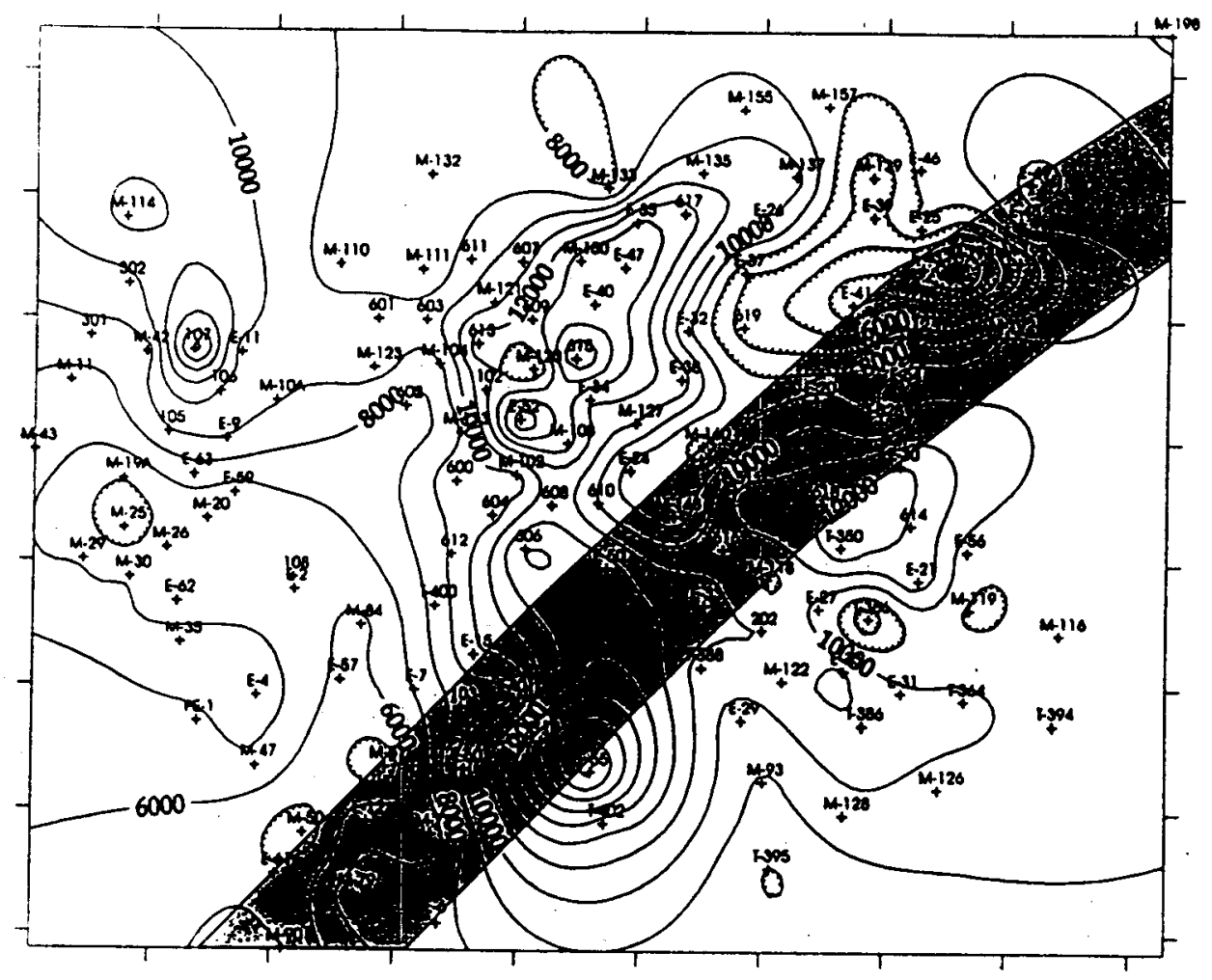

Figure 2 - 1995 chloride concentrations (in ppm) in the Cerro Prieto b reservoir (compare with Figure 1). Note the large negative and positive anomalies to the northeast and southeast, respectively, along the intersection of fault $\mathrm{H}$ with the top of the displaced reservoir. The negative anomaly is the result of groundwater recharge; the positive one, due to the inflow of injectate. 


\section{HIGHER-ORDER DIFFERENCING SCHEMES FOR GEOTHERMAL RESERVOIR SIMULATION}

Curtis M. Oldenburg and Karsten Pruess

Lawrence Berkeley National Laboratory

\section{KEY WORDS}

higher-order differencing, simulation, numerical dispersion, TVD

\section{PROJECT BACKGROUND AND STATUS}

The purpose of this project is to investigate the use of higher-order differencing schemes to reduce numerical dispersion in simulations of geothermal reservoir flow processes. In transient flow situations, it is well-known that full upstream weighting is the only scheme that gives reasonable results for the movement of saturation and concentration fronts. However, full upstream weighting is also known to cause numerical dispersion, which manifests itself as smearing of saturation and concentration fronts. Numerical dispersion can be diminished by the use of finer discretization, but improvements come at the cost of increased memory and execution times. Another approach to diminish numerical dispersion is the use of higher-order differencing schemes. We have implemented and tested higher-order differencing schemes for simulation of concentration fronts in the reservoir simulator TOUGH2 (Pruess, 1987; Pruess, 1991).

\section{PROJECT OBJECTIVES}

The objective of the project is to implement and test higher-order differencing schemes in TOUGH2.

\section{Technical Objectives}

- Identify potentially useful higher-order differencing schemes.

- Implement the higher-order differencing schemes into TOUGH2.

- Investigate the effectiveness of the new schemes in reducing numerical dispersion in the propagation of concentration fronts.

\section{Expected Outcomes}

- User-specified option of using higher-order differencing schemes in TOUGH2.

- Good understanding of the range of applicability of higher-order differencing schemes.

- Draft research paper submitted to conference proceedings. 


\section{APPROACH}

We have identified the class of higher-order schemes known as total variation diminishing, or TVD, as the most appropriate higher-order schemes. Although most of the prior work in using higher-order schemes is for explicit methods, we have implemented the same schemes into the fully implicit TOUGH2 code. To calculate the flux across an interface between two gridblocks, the standard integral finite difference method in TOUGH2 only uses information from these two connected gridblocks. Therefore TOUGH2 keeps track of the locations of the two gridblocks comprising each connection. Because the higher-order schemes require that we know the location of an additional gridblock upstream, we currently limit application of the methods to rectangular two-dimensional domains with regularly ordered gridblocks.

\section{RESEARCH RESULTS}

The higher-order differencing schemes have been verified by comparison to analytical solutions and work well with fully implicit time stepping and significantly reduce numerical dispersion for concentration fronts (Oldenburg and Pruess, 1997). We show in Figs. 1 and 2 a comparison of results calculated using upstream weighting (Fig. 1) and the Leonard TVD scheme (Fig. 2). The problem considers the injection of cold water (T $\left.=30^{\circ} \mathrm{C}\right)$ into a hot $\left(\mathrm{T}=300^{\circ} \mathrm{C}\right)$ liquid-saturated horizontal fracture zone and the production of steam and liquid from the opposite corner. The cold water injection includes an initial pulse of conservative tracer, the purpose of which is to monitor the advance of the injected water so that injection can be turned off to optimize thermal production. Clearly, accurate simulation capability is required to optimize this injection strategy. The EOS7R module (Oldenburg and Pruess, 1995) with added higher-order schemes is used for these calculations.

Shown in Figs. 1 and 2 are plots of temperature, tracer mass fraction, and liquid saturation after 6 mos. of injection, along with tracer and thermal breakthrough curves at the production well. Note that the tracer mass fraction and breakthrough curves show more smearing for full upstream weighting (Fig. 1) than for the Leonard TVD scheme (Fig. 2). The sharper front calculated using the Leonard TVD scheme allows a more accurate prediction of the thermal breakthrough. The greater accuracy of the higher-order scheme comes at a cost of more time steps as observed by the density of symbols on the breakthrough curve plots.

\section{FUTURE PLANS}

We plan to investigate the effects of higher-order schemes on phase saturation fronts.

\section{INDUSTRY INTEREST}

Higher-order differencing schemes may significantly improve numerical simulation of sharp fronts in concentration and phase saturation and therefore be of interest to all TOUGH2 users.

Improved simulation capabilities will be made available through DOE's Energy Science and Technology Software Center (ESTSC).

\section{REFERENCES}

Oldenburg, C.M., and K. Pruess, Higher-order differencing for geothermal reservoir simulation, Proceedings of the Twenty-Second Workshop on Geothermal Reservoir Engineering, Stanford University, Jan. 27-29, 1997, p. 303-308. 
Oldenburg, C.M., and K. Pruess, EOS7R: Radionuclide transport for TOUGH2, Lawrence Berkeley National Laboratory Report LBL-34868, November 1995.

Pruess, K., TOUGH User's Guide, Nuclear Regulatory Commission, Report NUREG/CR-4645, June 1987 (also Lawrence Berkeley Laboratory Report LBL-20700, June 1987).

Pruess, K., TOUGH2 - A General Purpose Numerical Simulator for Multiphase Fluid and Heat Flow, Lawrence Berkeley Laboratory Report LBL-29400, May 1991. 

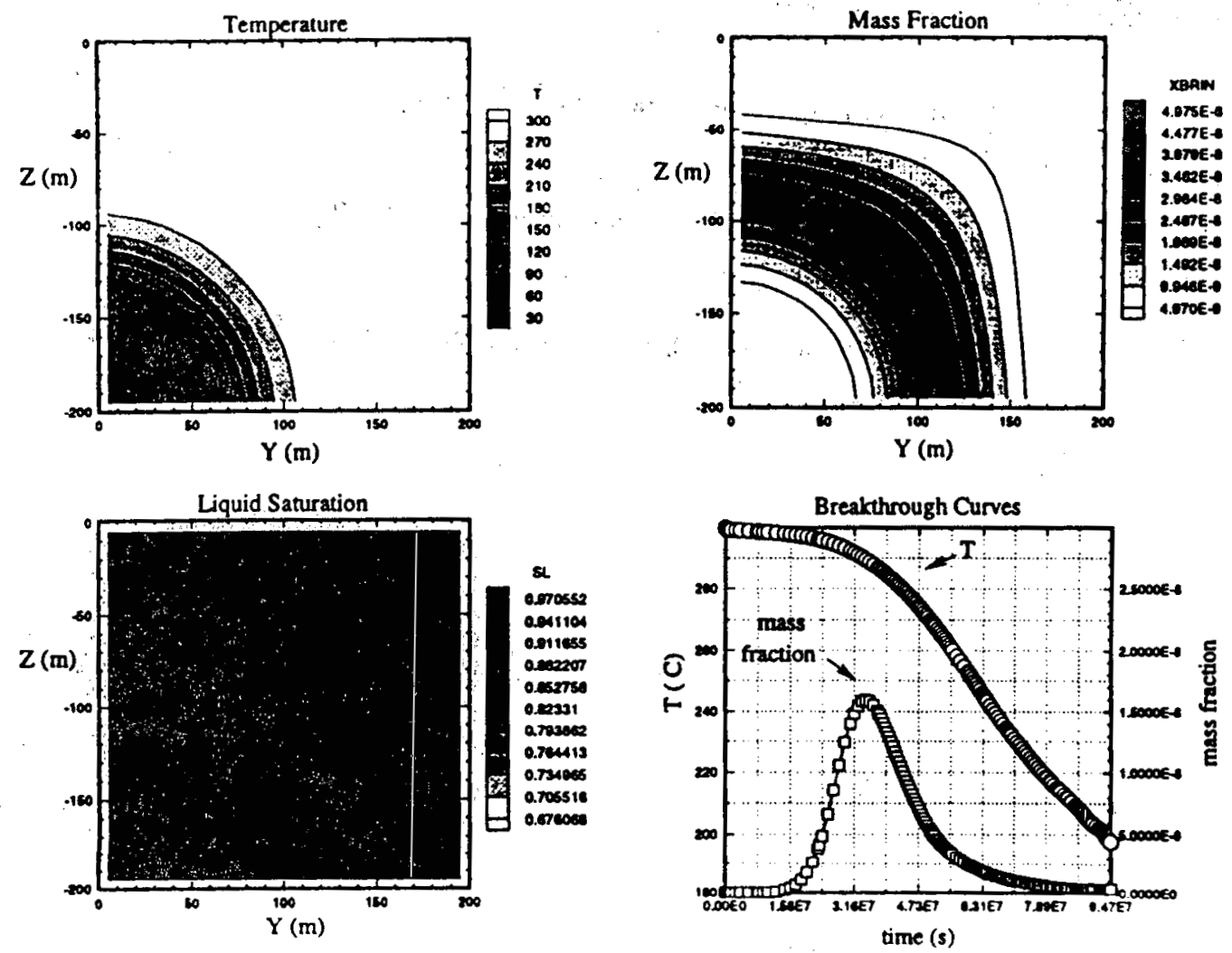

Higure 1. Resuits at six months calculated using upstream weighting for two-dimensional geothermai
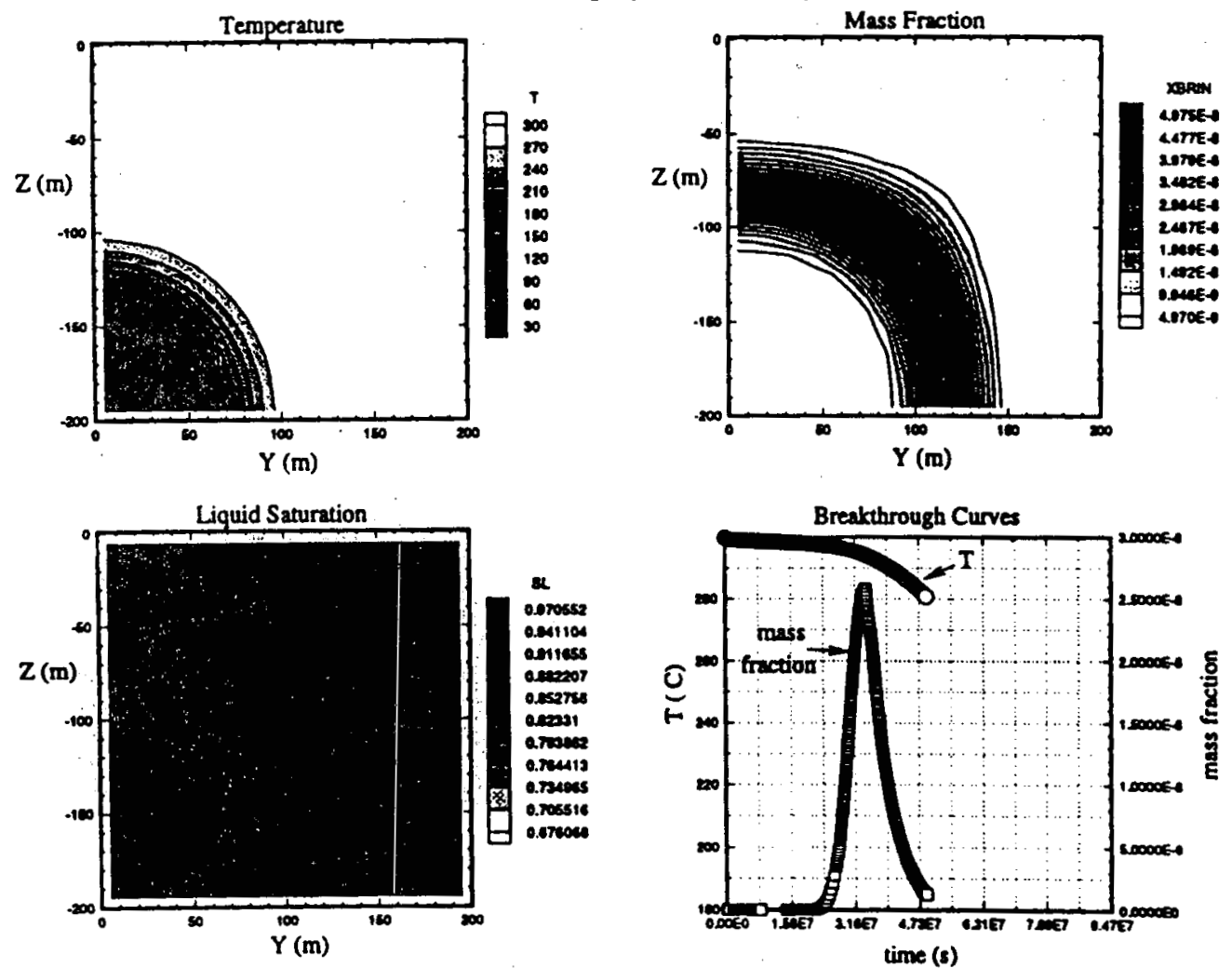

Figure 2. Results at six months calculated using the Lconard TVD scheme for geothermal reinjection. The breakthrough curve shows the run was stopped after the tail of the tracer pulse was detected. 


\title{
T2SOLV: AN ENHANCED PACKAGE OF SOLVERS FOR THE TOUGH2 FAMILY OF CODES
}

\author{
George J. Moridis and Karsten Pruess \\ E. O. Lawrence Berkeley National Laboratory
}

\section{KEY WORDS}

numerical modeling, matrix solvers, matrix preprocessing, conjugate gradients, grid numbering schemes

\section{PROJECT BACKGROUND AND STATUS}

The TOUGH2 general-purpose fluid and heat flow simulator is capable of modeling most of the processes arising in the natural state of geothermal reservoirs and in response to production and injection operations. It can handle the appearance and disappearance of liquid and vapor phases, boiling and condensation, multiphase flow due to pressure, gravity, and capillary forces, vapor adsorption with vapor-pressure lowering, heat conduction, and heat exchange between rocks and fluids. It is applicable to flow systems of arbitrary geometry from one to three dimensions, and has special provisions for flow in fractured-porous media. The equations and methods used in TOUGH2 are given in a number of reports (e.g., Pruess, 1991, 1995; Pruess et al., 1996, 1997), and on the web at URL http://ccs.lbl.

gov/TOUGH $2 /$.

In the current TOUGH2 version, T2CG1 (Moridis and Pruess, 1995), a package of Preconditioned Conjugate Gradient (PCG) solvers, complements the MA28 direct solver (Duff, 1977). T2CG1 is a reliable and fast solver package for most TOUGH2 simulations (Moridis and Pruess, 1995). In limited cases, however, the PCG solvers in T2CG1 are challenged by classes of certain very demanding numerical simulation problems, as well as by limitations in the underlying algorithms of the PCG (such as occasional oscillatory behavior as steady-state is approached). Moreover, MA28 has not well defined memory requirements and is limited to impractically small problems.

T2SOLV is an enhanced package of matrix solvers for the TOUGH2 family of codes. It includes all the PCG solvers used in T2CG1, the current solver package, as well as LUBAND, a new direct solver, and DLUSTB, a PCG solver based on the BiCGSTAB method. Additionally, T2SOLV includes the Alternating Diagonal D4 grid numbering scheme (Price and Coats, 1974) and two sets of matrix preprocessors.

\section{PROJECT OBJECTIVES}

The objective of this research is to improve the power and reliability of the TOUGH2 family of reservoir simulation codes in geothermal applications by developing enhancements to its matrix solving capabilities. These enhancements include a new PCG solver based on the BiCGSTAB algorithm, a new direct solver, and the D4 numbering scheme. A particular focus of this effort is the development of matrix preprocessors to improve the performance of the PCG methods and make possible the solution of a class of geothermal problems which were previously tractable only with direct solvers. 


\section{Technical Objectives}

- Expand T2CG1 by adding a new PCG solver based on the BiCGSTAB(m) algorithm (Sleijpen and Fokkema, 1993).

- Replace the MA28 solver (Duff, 1977) with an improved direct solver.

- Expand the capabilities of direct solvers by adding the D4 grid-numbering scheme.

- Develop matrix preprocessors to improve the performance of the PCG methods.

- Develop matrix preprocessors to make possible the PCG solution of a particular class of challenging geothermal problems previously tractable only with direct solvers.

\section{Expected Outcomes}

- More powerful and reliable numerical simulation capabilities, shorter execution times, smaller memory requirements, larger tractable problems and more realistic simulations

- Better evaluation and development of geothermal resources, as well as improved geothermal reservoir management.

\section{APPROACH}

DLUSTB is a PCG subroutine/solver based on the BiCGSTAB(m) algorithm (Sleijpen and Fokkema, 1993). It was developed to address the problem of irregular convergence behavior of the PCG solvers in situations where the iterations are started close to the solution (e.g., when approaching steady state). This is a weakness which afflicts most PCG solvers, and may lead to severe residual cancellation and errors. DLUSTB uses the BoeingHarwell matrix storage scheme of TOUGH2, and has the same architecture as the other routines in T2SOLV. As in all other PCG solvers in T2SOLV, it uses a modified LU decomposition for preconditioning. Its memory requirements increase linearly with the order $m$ of the Minimal Residual polynomial. The optimum value of $m$ is calculated internally in DLUSTB.

LUBAND is a direct solver which replaces the MA28 solver currently used in the TOUGH2 family of codes. It is derived from routines in the LAPACK (1993) package, which have been enhanced and extensively modified to conform to the TOUGH 2 architecture and memory management approach. It is based on a LU decomposition with partial pivoting and row interchange, and allows the solution of systems with a large number of zeroes on the main diagonal. Unlike MA28, LUBAND is a banded matrix solver, and as such it capitalizes on the significantly lower and well defined memory requirements of this class of solvers. LUBAND can be applied without any problem in the current TOUGH 2 version and is fully backward compatible with all older input data files.

The D4 scheme for gridblock ordering was added as an option to T2SOLV. D4 is a matrix-banding technique, which derives its benefits from the numbering of the grid points. D4 numbering reduces the order of the matrix by $50 \%$ while not increasing the bandwidth. Depending on the grid geometry, D4 makes possible execution speed improvement by a factor ranging between 2 and 5.85 (Price and Coats, 1974) over standard ordering in direct solvers. Moreover, it reduces storage requirements by a factor of two. 
A family of matrix preprocessors, the O-preprocessors, was developed for matrices with non-zero entries on the main diagonal and aim to improve the PCG solver performance by improving the matrix conditioning. Four such preprocessors, $\mathrm{O} 1$ through $\mathrm{O} 4$, are available in $\mathrm{T} 2 \mathrm{SOLV}$. The $\mathrm{O} 1$ option eliminates the lower half of the maindiagonal submatrix, and thus removes NEQ-1 subdiagonals from the global matrix (where NEQ is the number of equations per gridblock). In the $\mathrm{O} 2$ option, in addition to $\mathrm{Ol}$ the upper half of the main-diagonal submatrix is eliminated, resulting in a diagonal submatrix and eliminating an additional NEQ-1 superdiagonals from the global matrix. Compared to the original, the O2-preprocessed matrix is significantly sparser and betterconditioned and the performance of the PCG solvers can be enhanced. The $\mathrm{O} 3$ option involves normalization of the $\mathrm{O} 2$ matrix, resulting in a unity main diagonal. $\mathrm{O} 3$ does not further increase matrix sparsity, but may improve the matrix conditioning. Finally, the $\mathrm{O} 4$ option is identical to the $\mathrm{Z} 4$ option discussed in below.

Some of the most numerically challenging matrices arising in TOUGH2 simulations involve a large number of zero entries on the main diagonal of the Jacobian. Such matrices are quite common in non-isothermal, twocomponent systems (such as modeling of two-water geothermal systems using the EOS1 module) and result in at least $50 \%$ non-zero entries on the main diagonal of the matrix. Such matrices pose no problem for the LUBAND direct solver. The iterative solvers, however, are directly affected by the diagonal dominance of the matrix and the relative number of the zero entries on the main diagonals. Up to $10 \%$ zero elements have little discernible effect on the PCG solvers in T2SOLV. Matrices with as many as 30\% (and occasionally up to $50 \%$ ) zero elements are tractable without any special treatment, but usually require a large number of iterations for convergence. The four Z-preprocessors implemented in T2SOLV enhance the performance of the PCG solvers in matrices with a large number of main-diagonal zeroes. These preprocessors are invoked only when (a) PCG solvers are used to solve, (b) the matrices have main diagonals populated with a large number of zeroes and (c) the number of the primary variables NEQ $>1$.

The first preprocessing option, $\mathrm{Zl}$, replaces the zeroes with a small number (typically, $10^{-25}$ ), and can substantially decrease the number of iterations for convergence in matrices with as many as $50 \%$ zero maindiagonal elements. The second preprocessing option, $\mathrm{Z} 2$, is more computationally intensive and involves linear combinations of the flow equations in each gridblock. $\mathrm{Z} 2$ includes a search algorithm which identifies the appropriate equation to be added to the equation corresponding to the zero main-diagonal element. Z2preprocessing can suffer from poor conditioning because of persisting lack of diagonal dominance and large differences in the magnitude of the added elements. The problem can sometimes be alleviated by the Z3 option, which precedes the linear combination with normalization with respect to the largest element in the corresponding row. The Z4 option is somewhat more computationally intensive than Z3. It creates unit main-diagonal submatrices through multiplication by the inverse matrix, computed by the method of determinants. The PCG performance improvement delivered by $\mathrm{Z} 4$ can be affected by roundoff errors; under favorable conditions, it matches those of $\mathrm{Z} 2$ and $\mathrm{Z3}$.

Further details of this work are given in Moridis and Pruess (1997).

\section{RESEARCH RESULTS}

Without any matrix preprocessing, DLUSTB is shown to be a fast and efficient solver which outperforms the other PCG routines. It is the fastest and the most robust solver in T2SOLV and is shown to be practically free of stagnation, oscillation, and divergence problems.

The use of the Z-preprocessors makes possible the solution of problems which were previously intractable to all the PCG solvers. The combination of the Z-preprocessors with the BiCGSTAB routine gives the best performance in such problems. 
In problems which are known to confound the other PCG solvers, DLUSTB converges smoothly but slowly to a solution without invoking the matrix-preprocessing facility.

The O-preprocessors are shown to improve the robustness and decrease the number of iterations to convergence, but their effect depends on the PCG solver in T2SOLV. DLUSTB appears to be the solver most consistently responsive to the $\mathrm{O}$-preprocessors. In well-behaved problems the effect of the $\mathrm{O}$-preprocessors on the execution speed is not significant.

LUBAND is shown to be consistently faster and more reliable than MA28, and can solve much larger problems.

The gains in execution speed when the D4 scheme is used in regular grids are shown to be significant (especially compared to the direct solution). D4-direct seems to be competitive (in speed) to the PCG solvers in mediumsized problems.

\section{FUTURE PLANS}

We plan a future release of T2SOLV after the conclusion of its beta-testing process. In addition, we plan continued development efforts in the area of the matrix solving capabilities of TOUGH2 in an effort to maintain the code in the forefront of general-purpose reservoir simulators.

\section{INDUSTRY INTEREST}

The TOUGH 2 reservoir simulation codes are currently in use by approximately 150 geothermal and nongeothermal organizations in 23 countries.

\section{REFERENCES}

Duff, I.S. (1977) MA28 - A set of Fortran Subroutines for Sparse Unsymmetric Linear Equations, AERE Harwell Report R 8730.

LAPACK (1993), Univ. of Tennessee, Univ. of California at Berkeley, NAG Ltd., Courant Institute, Argonne National Lab., and Rice University, Version 1.1.

Moridis, G.J. and K. Pruess (1995), T2CG1: A package of preconditioned conjugate gradient solvers for the TOUGH2 family of codes, Lawrence Berkeley Laboratory report LBL-36235.

Moridis, G.J. and K. Pruess (1997), T2SOLV: An enhanced package of solvers for the TOUGH2 family of reservoir simulation codes, paper submitted to Geothermics (Lawrence Berkeley Laboratory report LBLN40933).

Price, H. S. and K. H. Coats (1974), Direct methods in reservoir simulation, Trans. SPE of AIME (SPEJ), 257, 295-308.

Pruess, K (1991), TOUGH2 - A general-purpose numerical simulator for multiphase fluid and heat flow, Lawrence Berkeley Laboratory report LBL-29400.

Pruess, K., editor (1995), Proceedings of the TOUGH Workshop '95, Lawrence Berkeley Laboratory Report LBL-37200. 
Pruess, K., A. Simmons, Y.S. Wu and G. Moridis (1996), TOUGH2 Software Qualification, Lawrence Berkeley National Laboratory Report LBL-38383.

Pruess, K., S. Finsterle, G. Moridis, C. Oldenburg, and Y.S. Wu (1997), General-Purpose Reservoir Simulators: The TOUGH2 Family, GRC Bulletin, pp. 53-57, February 1997 (also: Lawrence Berkeley National Laboratory Report LBL-40140).

Sleijpen, G.L.G. and D. Fokkema (1993), BiCGSTAB(m) for linear equations involving unsymmetric matrices with complex spectrum, Electronic Transactions on Numerical Analysis, 1, 11-32. 


\title{
FURTHER DEVELOPMENTS IN MULTIPHASE INVERSE MODELING
}

\author{
Stefan Finsterle (1), Karsten Pruess (1), and Alfredo Battistelli (2) \\ (1) E. O. Lawrence Berkeley National Laboratory \\ (2) AQUATER S.p.A., San Lorenzo in Campo, Italy
}

\begin{abstract}
KEY WORDS
inverse modeling, parameter estimation, optimization, ITOUGH2
\end{abstract}

\section{PROJECT BACKGROUND AND STATUS}

The project aims at developing and improving automatic history matching and optimization techniques for multiphase flow simulations of geothermal reservoirs. While multiphase reservoir simulation has reached a high level of sophistication, there is an increasing need for determining the numerical values of the parameters that enter these models. Automatic calibration of the process model provides a means to obtain site-specific, modelrelated parameters on the scale of interest.

The general-purpose multiphase reservoir simulator TOUGH2 (Pruess, 1991) is extensively used in geothermal reservoir engineering, and is continuously updated to enhance the process description and to improve numerical efficiency (Pruess et al., 1997). An inverse modeling code named ITOUGH2 (Finsterle, 1997) has been developed for sensitivity analysis and parameter estimation by automatic calibration of TOUGH2 models. ITOUGH2 has been applied to a number of geothermal problems on different scales (White, 1995; Finsterle and Persoff, 1997; Finsterle et al., 1997), and has been repeatedly revised to account for modifications in TOUGH2. Moreover, the robustness and efficiency of the optimization algorithm has been further improved.

\section{PROJECT OBJECTIVES}

The general objective of the project is to adapt the ITOUGH2 code to specific needs of geothermal applications, and to demonstrate its usefulness for the determination of hydrogeologic and thermal properties.

\section{Technical Objectives}

- Incorporate newly developed TOUGH2 modules into ITOUGH2.

- Increase the robustness of ITOUGH2 inversions by reducing the impact of outliers in the data and systematic modeling errors.

- Improve the efficiency of ITOUGH2 inversions by parallelization and automatic parameter selection strategies.

- Apply ITOUGH2 to geothermal problems on different scales:

- Investigate the possibilities of using ITOUGH2 for solving reservoir management problems. 


\section{Expected Outcomes}

- Release of a fully documented inversion program (ITOUGH2) based on the widely used TOUGH2 simulator.

- Demonstrate the suitability of the code for solving optimization problems relevant to geothermal reservoir engineering.

- Make inversion capabilities available to all process modules currently developed for TOUGH2 to allow the use of the same model for both calibration and subsequent prediction runs.

- Combine simulation and optimization techniques to improve project economics.

\section{APPROACH}

We continue to adapt TOUGH2 modules to the architecture of ITOUGH2. Data from laboratory and field experiments are analyzed. Interpretations of inverse modeling results are critically evaluated, and improvements are sought to increase the robustness of the inversions.

\section{RESEARCH RESULTS}

- A new fluid property module (EWASG) for variably saline brines with non-condensible gas has been developed by . Battistelli et al. (1997). EWASG includes the modeling of mineral precipitation and dissolution, and calculates the associated porosity and permeability changes. This module has been adapted for use with ITOUGH2, making possible the estimation of parameters associated with permeability changes.

- A gas-pressure pulse-decay (GPPD) experiment performed on a graywacke core plug from The Geysers geothermal reservoir has been analyzed in great detail using ITOUGH2. The study showed that accurate estimates of hydrogeologic parameters including the Klinkenberg gas-slip factor can be obtained by concurrently inverting pressure data from three GPPD experiments performed at three different pressure levels (Figure 1). The error and residual analyses revealed parameter correlations and the presence of a systematic error (Figure 2). An experimentally confirmed leak in the apparatus was successfully accounted for during the analysis by parameterization. The results are discussed in detail in Finsterle and Persoff (1997).

- The potential use of ITOUGH2 for the solution of a synthetic management optimization problem was examined. The framework of inverse modeling allows optimizing operational parameters such as the reinjection rate into a geothermal reservoir. An optimum injection scenario is determined by minimizing a cost function which includes injection costs, revenue from energy production, and other factors. The approach is described in Finsterle and Pruess (1997).

- A parallel version of ITOUGH2 for the Cray T3E supercomputer has been developed and successfully tested. Work is underway to make ITOUGH2 run in parallel on a heterogeneous network of workstations.

- The usage of ITOUGH2 commands has been documented in the report "ITOUGH2 Command Reference, Version 3.1" (Finsterle, 1997). A Web-page describing ITOUGH2 and its applications has been created (http://www-esd.lbl.gov/ITOUGH2). 


\section{FUTURE PLANS}

We continue the development of ITOUGH2 based on the experiences gained during the initial applications of the code to geothermal problems. We investigate the potential of robust estimation methods, and focus on the development of parallel computing capabilities. A report discussing a series of tutorial sample problems is in preparation.

\section{INDUSTRY INTEREST}

\section{Organization}

Stanford University

Industrial Research Ltd.

AQUATER S.p.A.

Oxbow Geothermal Corp.

\section{Type and Extent of Interest}

Analysis of boiling experiments

Beta testing of ITOUGH2; parallelization; enhancement of process description

Enhancement of process description

Analysis of tracer experiments

\section{REFERENCES}

Battistelli, A., C. Calore, and K. Pruess, The simulator TOUGH2/EWASG for modeling geothermal reservoirs with brines and non-condensible gas, Geothermics, 26, 437-464, 1997.

Finsterle, S., ITOUGH2 command reference, Version 3.1, Lawrence Berkeley National Laboratory Report LBNL-40041, August 1997.

Finsterle S., and K. Pruess, Development of inverse modeling techniques for geothermal applications, Proceedings, DOE Geothermal Program Review XV, San Francisco, CA, March 24-26, 1997, pp. 2/46-54.

Finsterle, S., and P. Persoff, Determining permeability of tight rock samples using inverse modeling, Water Resour. Res., 33(8), 1803-1811, August 1997.

Finsterle, S., K. Pruess, D. P. Bullivant, and M. J. O'Sullivan, Application of inverse modeling to geothermal reservoir simulation, Proceedings, Twenty-Second Workshop on Geothermal Reservoir Engineering, Stanford University, Stanford, CA, , January 27-29, 1997, pp. 309-316.

Pruess, K., TOUGH2 - A general-purpose numerical simulator for multiphase fluid and heat flow, Lawrence Berkeley Laboratory Report LBL-29400, May 1991.

Pruess, K., S. Finsterle, G. Moridis, C. Oldenburg, and Y:-S. Wu, General-purpose reservoir simulators: The TOUGH2 family, Geothermal Resources Council Bulletin, 26, 53-57, 1997.

White, S. P., Inverse modelling of the Kawerau geothermal reservoir, NZ, Proceedings, 17th New Zealand Geothermal Workshop, Auckland, New Zealand, pp. 211-216, 1995. 


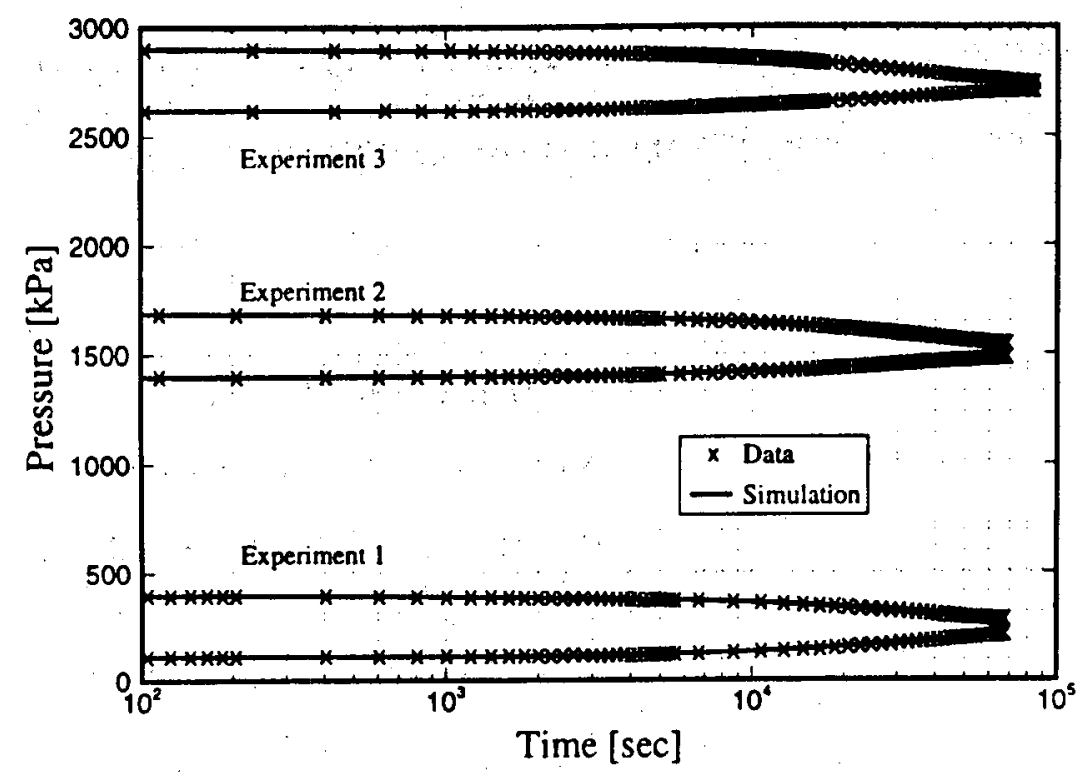

Figure 1 - Comparison between measured and calculated pressure transient curve from three simultaneously inverted gas-pressure pulse-decay experiments.

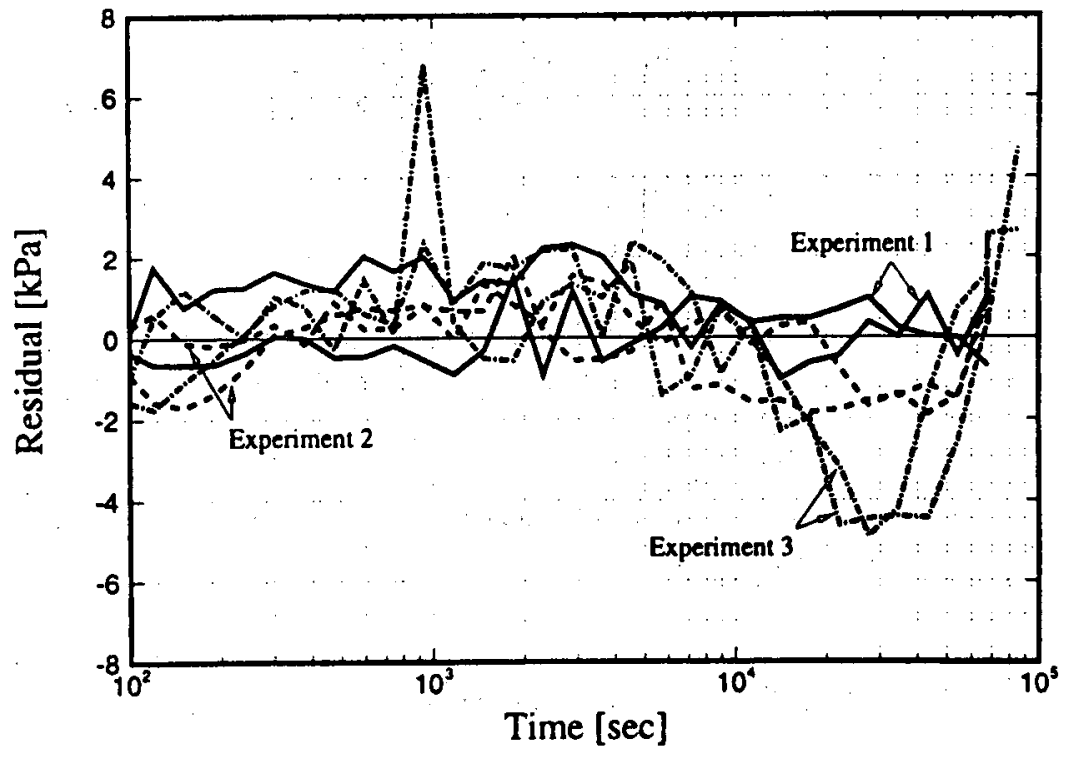

Figure 2 - Residuals as a function of time, showing systematic errors due to gas leak in experimental apparatus. 


\title{
DECLINE CURVE ANALYSIS OF VAPOR-DOMINATED RESERVOIRS
}

\author{
D. D. Faulder \\ Idaho National Engineering and Environmental Laboratory
}

\section{KEY WORDS}

vapor-dominated, decline curve, The Geysers, Fetkovich, transient production, permeability-thickness, interference

\section{PROJECT BACKGROUND AND STATUS}

This project was started in 1994 to extend the Fetkovich method of production decline type-curve analysis to vapor-dominated reservoirs. The focus of this method was the transient production response, from which an estimate of the drainage volume-weighted permeability-thickness product, or kh, can be obtained. While a great deal of reservoir modeling has been performed at The Geysers, very little attention has been paid to developing and refining a permeability-thickness model of the reservoir. Work completed to date includes a derivation of the dimensionless terms for pressure, rate, decline time, and decline rate, treating steam as a real gas, the numerical validation of these terms, and the application of this technique to over 250 production wells in The Geysers. A permeability-thickness distribution has been determined for the study area (Faulder, 1996a,b, 1997a) and the results published (Faulder, 1997b).

The current work is focusing on completing the analysis for the remaining 200 production wells with data in the public domain, and creating a database of well surface and downhole locations and steam entries. This information will be used to analyze reservoir heterogeneity with geostatistical methods. The Geysers analysis is approximately $65 \%$ completed and will be completed in FY -98 .

\section{PROJECT OBJECTIVES}

The objectives of this project are to extend the Fetkovich method of production decline type-curve analysis to vapor-dominated reservoirs, and to use the transient production data to estimate the permeability-thickness product of a well. Secondary objectives are to examine the depletion behavior to characterize the behavior of a production well responding to offset production and injection interference and to use geostatistics to characterize the reservoir heterogeneity.

\section{Technical Objectives}

- Extend the Fetkovich method to vapor-dominated, geothermal reservoirs.

- Estimate the permeability-thickness product of a well using production data.

- Analyze the field $\mathrm{kh}$ for reservoir heterogeneity using geostatistics.

- Prepare a field-wide kh map, using public domain production data, as a primary input for future reservoir modeling activities. 


\section{Expected Outcomes}

- A $25 \%$ improvement in the reliability of decline curve forecasting and remaining reserves estimation.

- A field wide kh map of The Geysers.

\section{APPROACH}

The technical approach: modified the analytic Fetkovich method for vapor-dominated geothermal systems, verified the derived analytic expressions using a reservoir simulator to evaluate the ideal reservoir response for different sets of reservoir properties, and analyzed in detail the actual production data from wells at The Geysers. The integration of analytic and numerical techniques using a single porosity reservoir model, and the review of actual production data provides an excellent test of the practicality, reliability, and repeatability of this method. This work uses publicly available production data from the California Division of Oil and Gas, \& Geothermal Resources.

\section{RESEARCH RESULTS}

The dimensionless terms for pressure, rate, decline rate, and decline time have been analytically derived and validated with a numerical simulator. Over 250 wells have been reviewed and the permeability-thickness product estimated from the transient production response. The results of this initial effort compare very favorably with published ranges of $\mathrm{kh}$ for The Geysers. Regions of high $\mathrm{kh}$ have been delineated and generally correspond to areas having favorable, historical injection response. Many of the production wells have undergone both production and injection interference. Use of this technique can identify time periods of interference. Reinitialization of the production data gives repeatable kh. A histogram of the kh results for 180 wells is presented in Figure 1.

\section{FUTURE PLANS}

The production decline response of the remaining open-file wells at The Geysers will be analyzed to determine the permeability-thickness product within each well's drainage radius. The results of this analysis will be used to prepare a map of reservoir $\mathrm{kh}$. The field wide information will be analyzed geostatistically to characterize the reservoir heterogeneity. Operators of other vapor-dominated reservoirs will be contacted to assess their interest in applying this technique. The Fetkovich method will be further extended for dual-porosity, vapor-dominated geothermal reservoirs. The application of this technique to liquid-dominated reservoirs will be reviewed.

\section{INDUSTRY INTEREST}

\section{Organization}

Calpine Corp.

NCPA

\section{Type and Extent of Interest}

Improved decline curve methodology

Extension of Fetkovich method to vapor-dominated systems 


\section{REFERENCES}

Faulder, D. D. , 1996a. Production Decline Cunve Analysis at The Geysers, California Geothermal Field, M.Sc. Thesis, Colorado School of Mines, $97 \mathrm{p}$.

Faulder, D. D., 1996b. "Permeability-Thickness Determination from Transient Production Response at the Southeast Geysers," Geothermal Resources Council Transactions, v. 20, p. 797-807.

Faulder, D.D., 1997a. "Decline Curve Analysis of Vapor-dominated Reservoirs," DOE Program Review 15, San Francisco, CA, March 25-26.

Faulder, D.D., 1997b. “Advanced Decline Curve Analysis in Vapor-dominated Geothermal Reservoirs," SPE 38763, Annual Technical Conference, San Antonio, TX, Oct. 5-8, p. 139-150. 


\section{Histogram of Results}

$$
n=180 \text { wells }
$$

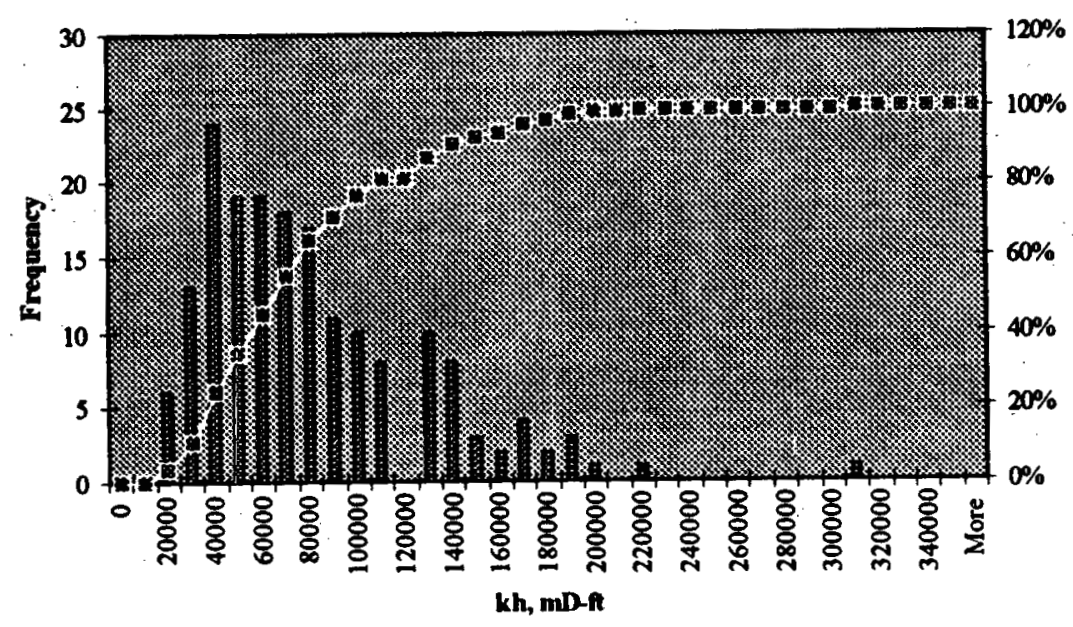

Figure 1 


\title{
NUMERICAL MODELING OF THE GEYSERS UNIT 18 COOPERATIVE INJECTION PROJECT
}

\author{
K. K. Bloomfield, G. M. Shook, and D. D. Faulder \\ Idaho National Engineering and Environmental Laboratory
}

\begin{abstract}
KEY WORDS
injection, The Geysers, numerical simulation

\section{PROJECT BACKGROUND AND STATUS}

Due to pressure declines in The Geysers, efforts have focused on improving our understanding of the physics of steam production from the field, with the goal of devising an optimal program of fluid recharge by injection of produced fluid and/or fresh water. By development of a regional, numerically efficient model that can more closely characterize the mechanics of water injection, benefits of injection can be measured. With the advent of the SE Geysers Effluent Pipeline and Injection Project, a better understanding of the mechanisms for reservoir recharge/pressure support becomes even more important.

In FY 1996, the Unit 18 cooperative injection project was initiated. This cooperative project included Geothermal Technology Organization members, Pacific Gas \& Electric (PG\&E), UNOCAL Corp, Northern California Power Agency (NCPA), and Calpine Corporation and the Idaho National Engineering and Environmental Laboratory, and was cost-shared by the Department of Energy (DOE). The goal of this project was to increase the understanding of response to injection in a known production area within The Geysers. Technical tools used in this study included monitoring production response, tracer studies, geochemistry, microseismisity, and numerical modeling.

\section{PROJECT OBJECTIVES}

The objectives of this project are to develop better understanding of injection behavior using field scale data and to develop a reservoir model using the field data. This model will be used to expand and improve the methods of reservoir characterization and injection utilization.

\section{Technical Objectives}

- Develop numerical simulation as a dependable method for estimating reservoir response to water injection projects.

- Incorporate developed methods of defining reservoir heterogeneity into numerical simulation techniques.

- Evaluate various injection scenarios in order to develop an improved understanding of optimizing use of injectate. 


\section{Expected Outcomes}

- Identify key parameters that reduce the risk and expense of expanding water injection into more areas of The Geysers.

- Develop computationally efficient field scale models to validate project benefits.

\section{APPROACH}

A numerical model was constructed that included the Unit 18 injection project area. The model was developed using data supplied by Geysers operators UNOCAL, NCPA, and Calpine Corp. The data included deviated well surveys, steam entry data, and production data. Maps for top of steam and top of felsite published in the Monograph on The Geysers Geothermal Field were used as proxies for top and bottom of reservoir, respectively. The study area (see Figure 1) was $9000 \mathrm{ft}$. by $9000 \mathrm{ft}$., and was modeled areally by a 20 by 20 grid. Model thickness was $5000 \mathrm{ft}$. The vertical grid used was 6 layers of varying thickness. For the initial pass at modeling this area, no-flow boundaries were used on all sides of the domain (the north and west sides of the domain should be flow boundaries). Attempts at relaxing this assumption indicate that additional production across those boundaries must also be accounted for in order to use more realistic boundary conditions. This will be done in coming years.

Dual porosity, with uniform permeability and porosity in both fractures and matrix was used in the study. Fracture spacing was assumed to be $150 \mathrm{ft}$. A uniform initial liquid saturation was established, and the model was initialized for 20 years prior to exploitation to adjust to vapor-static conditions. The non-uniform structure in the study area resulted in non-uniform initial liquid saturations, with a small amount of mobil liquid ponding in the bottom of the domain. Sensitivity studies were conducted on the initial saturations in order to minimize mobil liquid in the lower layers. Average initial liquid saturations in the study area were $75 \%$ in the matrix and $6 \%$ in the fracture domain.

The model was then calibrated to match observed production in the 43 wells within the study area through well productivity index manipulation. After obtaining a successful history match of the production, the injection well was turned off in the model and a comparison was made in simulated production between the base case and a "no injection" scenario.

\section{RESEARCH RESULTS}

The Geysers Unit 18 injection study area model has been constructed using diverse data from steam producers. Production rates and wellhead pressures were successfully matched for all 43 wells in the study area. In particular, early response to injection - in both timing and magnitude of response - was matched very well for all wells. Later response to injection was overpredicted to some extent, probably due to the boundary conditions used.

By comparing the base case simulation with the "no injection" case, and converting steam production to power generation $(20 \mathrm{klb} / \mathrm{hr}=1 \mathrm{MWe})$, we can also compare observed response to injection with simulated response. The results of this, reduced to a per-operator basis are given below. 
Operator

UNOCAL

NCPA

Calpine Corp
Observed Response MWe

2.0

1.0

0.0

\section{Simulated Response MWe}

2.8

0.8

0.7

\section{FUTURE PLANS}

We plan to continue the model study by developing and implementing three techniques to characterize the study area. The three techniques are:

- Use a better permeability distribution from the Fetkovich decline analysis method of (Faulder, 1996).

- Identify methods of relaxing the boundary conditions to incorporate what is happening outside the study area.

- Incorporate tracer tests results into the numerical simulation.

The study area is a candidate to receive water from the Lake County Waste Water Project. A study of long term steady state injection into a detailed reservoir description will help develop a better understanding of fluid flow and heat transfer processes during water injection.

\section{INDUSTRY INTEREST}

This project's results are presented at conferences and data sets are shared with the GTO participants for review.

\section{REFERENCES}

Antunez E. U., Bodvarsson G. S., Walters M. A. "Numerical simulation study of the northwest geysers geothermal field, a case study of the Coldwater Creek steamfield," Geothermics, 1994, Vol. 23, No. 2, pp.127141.

Voge E., Koenig B., Smith B., Enedy S., Beall J. J., Adams M. C. Haizlip J., "Initial findings of the The Geysers Unit 18 cooperative injection project," Geothermal Resource Council Transactions, 1994, Vol. 18 pp. 154-159.

Faulder D. D., "Model study of Historical Injection in the southeast geysers,"1992, Seventeenth Workshop on Geothermal Reservoir Engineering. Stanford University pp.111-119.

Bloomfield K. K., et al, 1997, "Progress presentation of Numerical Modeling of The Geysers Unit 18 Cooperative Injection Project" Geothermal Resource Conference.

Thompson R.C., "Structural Stratigraphy and Intrusive Rocks at The Geysers Geothermal Field," Monograph On The Geysers Geothermal Field pp.59-63. 
Thompson R.C., Gunderson R. P., "The Orientation of Steam-Bearing Fractures at The Geysers Geothermal Field", Monograph On The Geysers Geothermal Field pp.65-68.

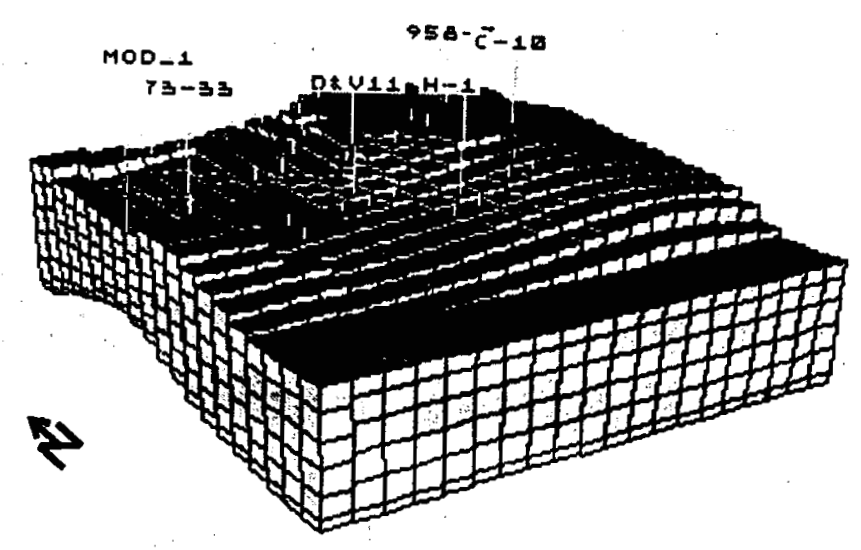

Figure 1 -- Structure of study area and partial display of wells. 


\title{
ELECTRICAL GENERATING CAPACITIES OF GEOTHERMAL SLIM HOLES
}

\author{
John W. Pritchett \\ Maxwell Technologies
}

\section{KEY WORDS}

slim holes, wellhead generators, downhole pumps, off-grid power, village power, minigeothermal, rural electrification

\section{PROJECT BACKGROUND AND STATUS}

A growing market exists for off-grid electrification projects in the developing countries of the world. Small geothermal generating plants (from 100 to 1000 kilowatts capacity) offer promise in various areas around the Pacific Rim, particularly Latin America, Indonesia, the Philippines, and isolated islands. Typically, these remotearea installations would consist of single production wells driving generating equipment located immediately adjacent to the wellhead. Entingh et al. (1994) have examined the economic feasibility of such projects and have concluded that small plants of this type can compete favorably with existing off-grid electrification techniques in this capacity range (mainly diesel generators) and also with other proposed renewable sources (photovoltaic solar, wind, hybrids).

For geothermal projects in the $100-1000 \mathrm{kWe}$ range, the costs of drilling and completing the production well dominate the economics. Entingh et al. assumed that the well would be drilled using conventional practice (133/8 inch casing to 750 feet, 9-5/8 inch casing below that depth). Conventional geothermal wells of this type are usually capable of delivering enough steam to generate several megawatts of electricity. If a slim hole could be used instead, considerable savings in drilling costs and final electricity price would be realized. Slim-hole drilling costs are typically only about one-third (per foot) of those of conventional drilling practice in the geothermal industry (Combs and Dunn, 1992). For remote applications, additional advantage would be realized by the relative portability of slim-hole rigs. Furthermore, the environmental impact and land-use requirements of slimhole drilling operations are generally much more benign.

The principal shortcomings of slim holes for electrical power production are (1) the capacity of a slim hole to produce fluid is substantially less than that of a conventional production well (Pritchett, 1993), and (2) if a downhole pump is required, small diameter downhole pumps suitable for high-temperature operation are not presently commercially available. The absence of a suitable downhole pump mostly reflects lack of demand; no major technical obstacles exist in principle to scaling down designs for existing lineshaft pumps to fit into wells as small as six inches inside diameter. Recent developments in downhole submersible pumps are also very promising for slim-hole applications.

The remaining problem is to establish whether or not slim holes can deliver enough hot geothermal fluid to the wellhead to be of practical interest for off-grid electrification projects. About three years ago, the author undertook a preliminary study of this question (Pritchett, 1995a), using theoretical techniques to mathematically model the fluid flow within geothermal wells of various diameters and to forecast their probable electrical generating capacity. This study was far from exhaustive, and employed several simplifying assumptions to render the problem tractable with minimum effort. Two generating schemes were considered: binary-type generating 
equipment supplied by wells containing downhole lineshaft pumps, and single-flash steam turbogenerators (both condensing and backpressure types) fueled by self-discharging wells.

These results encouraged the U. S. Department of Energy (DOE) to provide subsequent support for elaboration and extension of the feasibility study, relaxing a number of the more restrictive assumptions and approximations. The purpose is to provide more quantitative results concerning the probable generating capacities of individual geothermal wells (both self-discharging wells and pumped wells), and how these capacities depend upon various pertinent parameters including well diameter, feedpoint depth, productivity index, reservoir pressure, reservoir temperature, and reservoir fluid composition.

The DOE study has been subdivided into a number of separate phases. In the first phase (completed; Pritchett, 1995b), self-discharging wells supplying single-flash steam turbogenerators (both backpressure and condensing designs) were examined. Extension of this work to treat self-discharging wells driving more complex wellhead generators, including double-flash steam turbines and flash/binary hybrid designs, is presently nearing completion. A mathematical model for the performance of a geothermal well containing a downhole pump (of either lineshaft or submersible design) has been devised and computerized (Pritchett, 1997). Using this model, work is now in progress to characterize the capacities of geothermal wells of various diameters driving a variety of wellhead generators.

\section{PROJECT OBJECTIVES}

The purpose of this project is to evaluate the utility of slim holes for producing sufficient geothermal fluids for off-grid rural electrification projects in developing countries using small individual wellhead generators.

\section{Technical Objectives}

- Develop a theoretical methodology for forecasting the fluid-delivery capacities of geothermal wells as functions of reservoir conditions and well parameters (diameter, depth), both under self-discharging conditions and when equipped with a downhole pump (lineshaft or submersible type).

- Couple the wellhead characteristics obtained (relations among wellhead pressure, water discharge rate and steam discharge rate as functions of reservoir conditions and well design) with realistic theoretical representations of wellhead generating equipment of various designs.

- For each set of parameters (reservoir parameters / well parameters / power plant design) considered, compute the maximum net electrical generating capacity attainable and the wellhead and power plant design parameters (i.e. wellhead pressure, turbine inlet pressures, heat exchanger inlet temperatures etc.) at which the maximum output is attained.

\section{Expected Outcomes}

- Evaluate the electrical capacity of geothermal production wells of various diameters using various types of electrical generating equipment (backpressure turbines, single- and double-flash condensing turbines, binary plants, etc.) as functions of reservoir conditions (depth, pressure temperature, and dissolved gas content).

- Provide practical guidelines for selection of well completion and power plant design as functions of reservoir parameters. 


\section{APPROACH}

For self-discharging wells (wells flowing naturally, without the need for a downhole pump), analysis of wellhead discharge characteristics as functions of reservoir pressure, reservoir temperature, reservoir fluid composition, well productivity index, well depth and well inside diameter employed well-established techniques (Pritchett, 1985). Conditions within the flowing well were integrated numerically up the borehole from the feedpoint to the wellhead, using the pipe-friction correlation of Dukler et al. (1964), the interphase slip velocity correlation of Hughmark (1962), and a well/formation conductive heat loss formulation based on the results of Minkowycz and Cheng (1976). This general approach is in routine use to predict wellhead flowing characteristics in the geothermal industry, and has been used in numerous studies to match both measured wellhead characteristics and measured downhole flowing profiles. Numerous calculations of internal flowing conditions were carried out for each configuration corresponding to various values of the total discharge rate (water and steam together) to establish the relations among wellhead pressure and wellhead discharge rates. To make the number of cases manageable, only vertical wells of uniform inside diameter (ID) were considered. Even so, a total of 15,018 different well/reservoir configurations were examined, with parameters taking on the following values:

- Well ID: six values between $75 \mathrm{~mm}$ and $300 \mathrm{~mm}$.

- Feedpoint depth: four values $(300,600,900$ and $1200 \mathrm{~m})$.

- Productivity index: three values $(2 \mathrm{~kg} / \mathrm{s} / \mathrm{bar}, 4 \mathrm{~kg} / \mathrm{s} / \mathrm{bar}$, infinity).

- Reservoir pressure: six values of piczometric surface depth, from zero to 250 meters.

- Reservoir temperature: 31 values between $100^{\circ} \mathrm{C}$ and $240^{\circ} \mathrm{C}$.

- Reservoir fluid $\mathrm{CO}_{2}$ content: four values between 0 and $1 \%$ by mass.

Next, a particular "power plant design" was selected. For example, for a single-flash backpressure steam turbine, the amount of electrical power that can be generated increases with increasing steam inlet pressure and with available steam supply, whereas the steam supply available from the well decreases as wellhead pressure increases. Accordingly, an "optimum" valuc of the wellhead pressure exists at which the electrical generating capacity reaches a maximum. In general, this value of the wellhead pressure and the electrical generating capacity thereby obtained are both functions of the above six parameters. As noted above, the analysis is already complete for single-flash backpressure steam turbogenerators and single-flash condensing steam turbines. Work is presently nearing completion which considers more complex power plant designs, including double-flash plants, binary plants, and flash-steam/binary hybrids.

At low reservoir temperatures (below $150^{\circ} \mathrm{C}$ or so), it is very difficult to attain sustainable self-discharge from geothermal wells (particularly small-diameter slim holes) owing to insufficient gas-lift provided by the steam phase. Under these conditions, to generate electricity at practical rates, it will usually be necessary to resort to downhole pumps. Even at higher temperatures; a downhole pump may be advantageous under certain conditions by raising the generating capacity of the well over self-discharge rates sufficiently to compensate for the electrical load imposed by the pump motor. To calculate the discharge characteristics of wells equipped with downhole pumps, it was first necessary to evaluate the practical design envelope of available downhole pumps, then to estimate the characteristics of hypothetical downhole pumps designed for slim-hole geothermal applications.

Two designs were considered - "lineshaft" pumps in which the downhole impeller assembly is driven by an electric motor located at the wellhead using a long vertical coaxial mechanical lineshaft, and "submersible" pumps in which the electric motor is located downhole adjacent to the impeller assembly. An engineering study was carried out (Pritchett, 1997) to estimate how the pump characteristics would vary with well diameter, pump emplacement depth, etc., and then a mathematical model was constructed to describe the performance characteristics of a well equipped with a pump of either design. In this analysis, several mathematical constraints 
and assumptions were imposed, including a requirement that the pump impose sufficient pressure head to maintain the fluid in an all-liquid condition at the wellhead (to avoid scaling and corrosion of downhole pump components), that the pump be operated at a flowrate that yields maximum hydraulic efficiency, and that lineshaft-type pumps employ four-pole (1800 RPM) motors whereas submersible pumps use two-pole (3600 RPM) motors, as is current industry practice. The computational model, in addition to flow characteristics, also yields the pump's electrical requirements.

The above model for a well containing a downhole pump was then combined with various models for geothermal power plants, as before, to estimate the electrical generating capacity of various plant designs. Ranges of independent variables were similar to those for the self-discharging-case calculations:

- Well ID: $100 \mathrm{~mm}$ to $300 \mathrm{~mm}$ (submersible pumps); $150 \mathrm{~mm}$ to $300 \mathrm{~mm}$

- Feedpoint depth: four values $(300,600,900,1200 \mathrm{~m}$ as before).

- Productivity index: same three values $(2 \mathrm{~kg} / \mathrm{s} / \mathrm{bar}, 4 \mathrm{~kg} / \mathrm{s} / \mathrm{bar}$, infinity).

- Reservoir pressure: piezometric surface depth from zero to $250 \mathrm{~m}$.

- Reservoir temperature: $100^{\circ} \mathrm{C}$ to $240^{\circ} \mathrm{C}$.

- Reservoir $\mathrm{CO} 2$ content: zero to $1 \%$ by mass.

As noted above, in Phase I of this study the various self-discharging well models are examined using backpressure and condensing single-flash steam turbines. The remaining calculations (involving wells with downhole pumps and more elaborate power plant designs) are now nearing completion. The various power plant designs being considered include:

- Backpressure single-flash steam turbine.

- Condensing single-flash steam turbine.

- Condensing double-flash steam turbine.

- Single-component liquid-brine hydrocarbon binary plant with recuperation.

- Condensing steam / binary hybrid plant.

All five designs will be evaluated using self-discharging wells, wells with lineshaft pumps, and wells with submersible pumps. For application of the binary plant to a self-discharging well, a separator is used and the separated steam is mixed with exhaust (cooled) brine to augment the hot brine supply.

\section{RESEARCH RESULTS}

An extensive compilation of computed results from Phase I has been prepared (Pritchett, 1995b), and is available from DOE/NNEL. Briefly, these results (for single-flash steam turbogenerators) clearly indicate that slim holes have considerable promise for supplying small off-grid steam turbogenerators, even without downhole pumps. Wells of $100 \mathrm{~mm}$ (four inch) inside diameter can produce over one megawatt of electricity if the reservoir temperature is $240^{\circ} \mathrm{C}$. Electricity output of $100 \mathrm{kWe}$ is possible with $100 \mathrm{~mm}$ holes for reservoir temperatures as low as $150^{\circ} \mathrm{C}$ or so, using low-pressure condensing steam turbines.

Backpressure turbogenerators, while cheaper and simpler, are much less efficient than condensing turbines, and will usually produce less than half the electricity from the same well. They are also frequently unacceptable from an environmental standpoint. For slimhole applications, backpressure turbines will generally be restricted to reservoir temperatures of $175^{\circ} \mathrm{C}$ or more for practical purposes. At a reservoir temperature of $240^{\circ} \mathrm{C}$, a $100 \mathrm{~mm}$ ID slim hole can produce around $500 \mathrm{kWe}$ using a backpressure turbine. For a reservoir temperature of $180^{\circ} \mathrm{C}$, the generating capacity of a $100 \mathrm{~mm}$ hole declines to around $80 \mathrm{kWe}$ using optimized backpressure techniques. 
The same well geometry will produce more electrical power from a reservoir that is $30^{\circ} \mathrm{C}$ colder using a lowpressure condensing turbine.

Flash-steam generating techniques for reservoir temperatures in the $100^{\circ} \mathrm{C}$ range, however, will require downhole pumps and sub-atmospheric separator pressures. Self-discharge of geothermal wells (of any diameter) is simply not possible at these temperatures for the reservoir pressures likely to be encountered in practice. Furthermore, these calculations indicate that, at least for reservoir temperatures below $240^{\circ} \mathrm{C}$ or so, the operating inlet pressures of condensing steam turbines should be lower than what is now common practice in the geothermal industry (usually 50 psig or more). This observation is not necessarily restricted to the small, remote-site off-grid applications of particular interest in the present study. For a reservoir temperature of $240^{\circ} \mathrm{C}$, absolute inlet pressures around three bars ( $30 \mathrm{psig})$ appear to be optimum under most conditions. If the reservoir temperature is $200^{\circ} \mathrm{C}$, the optimum operating pressure is around 1.8 bars $(11 \mathrm{psig})$. For reservoir temperatures less than about $170^{\circ} \mathrm{C}$, sub-atmospheric turbines (inlet pressures less than one atmosphere) should be employed.

Conventional applications of downhole pumps in geothermal wells have largely been restricted in the past to lineshaft-type pumps of "twelve inch" size in large-diameter wells (the "size" of a downhole pump - i.e. 12-inch refers to the diameter of the casing pipe within which the pump will fit). Both submersible and lineshaft pumps of smaller diameters have, however, been in routine use for non-geothermal applications. An extensive investigation was carried out to estimate the operating characteristics of downhole lineshaft and submersible geothermal pumps as functions of pump diameter. Consideration was given to frictional head losses in the column, optimum flowrate through the impeller/bowl assembly, motor power limitations, shaft strength limitations, effects of dynamic loads on the shaft, maximum temperatures for electrical components and lubricants, hydraulic efficiencies, motor efficiencies, bearing efficiencies, cable electrical transmission losses, pressure constraints arising from material-strength limitations, and practical pump-fabrication issues. This investigation indicates that, while lineshaft pumps are probably the most practical for large-diameter wells $(\sim 300$ $\mathrm{mm}$ ), they are completely impractical below about $150 \mathrm{~mm}$ well diameter (six inches), and that submersible pumps will be more practical for relatively small diameter wells. Even using submersible pumps, well diameters significantly below six inches may be difficult to accommodate. A few results for maximum design limitations for both designs ("LS" = lineshaft; "SB" = submersible) are as follows:

\begin{tabular}{|l|c|c|c|c|c|c|}
\hline \multirow{2}{*}{ Well ID } & \multicolumn{2}{|c|}{ Maximum Pump Depth } & \multicolumn{2}{c|}{ Maximum Flow Rate } & \multicolumn{2}{c|}{ Maximum Pumping Head } \\
\cline { 2 - 7 } & $L S$ & $S B$ & $L S$ & $S B$ & $L S$ & $S B$ \\
\hline $300 \mathrm{~mm}$ & $715 \mathrm{~m}$ & Large & $139 \mathrm{l} / \mathrm{s}$ & $64 \mathrm{l} / \mathrm{s}$ & $75 \mathrm{bars}$ & $75 \mathrm{bars}$ \\
\hline $250 \mathrm{~mm}$ & $407 \mathrm{~m}$ & Large & $69 \mathrm{l} / \mathrm{s}$ & $40 \mathrm{l} / \mathrm{s}$ & $55 \mathrm{bars}$ & 75 bars \\
\hline $200 \mathrm{~mm}$ & $238 \mathrm{~m}$ & Large & $29 \mathrm{l} / \mathrm{s}$ & $36 \mathrm{l} / \mathrm{s}$ & $33 \mathrm{bars}$ & $46 \mathrm{bars}$ \\
\hline $150 \mathrm{~mm}$ & $157 \mathrm{~m}$ & Large & $10 \mathrm{l} / \mathrm{s}$ & $19 \mathrm{l} / \mathrm{s}$ & $17 \mathrm{bars}$ & $40 \mathrm{bars}$ \\
\hline $100 \mathrm{~mm}$ & $84 \mathrm{~m}$ & Large & $2 \mathrm{l} / \mathrm{s}$ & $5 \mathrm{l} / \mathrm{s}$ & $7 \mathrm{bars}$ & $35 \mathrm{bars}$ \\
\hline
\end{tabular}


It should be noted that the performance advantages of the submersible pumps are offset to some degree by their significantly higher capital costs. Typically, the electrical motor alone for a submersible downhole pump costs as much as (or more than) an entire lineshaft pump assembly.

\section{FUTURE PLANS}

Work on this project is now nearing completion. A final technical report will be prepared for the Department of Energy later this year.

\section{INDUSTRY INTEREST}

At present, there is no "minigeothermal industry" as such; the main purpose of the present study is to establish whether or not such an approach is practical for off-grid electrification projects in developing countries, and therefore whether or not such an industry would be viable. Interest has been expressed, however, by various organizations who might serve to supply various needs of such an industry, should it develop. These include manufacturers of small wellhead-type geothermal power plants (Barber-Nichols, Geothermal Power Company, Ormat International, Rotoflow), manufacturers of downhole pumps (Johnson Pump, Gould Pump, Reda Pumps), and organizations promoting slim-hole drilling (Sandia National Laboratory, Tonto Drilling, Nabors Drilling).

\section{REFERENCES}

Combs, J. and J. C. Dunn (1992), "Geothermal Exploration and Reservoir Assessment: The Need for a U. S. Department of Energy Slim-Hole Drilling R\&D Program in the 1990's", Geothermal Resources Council Bulletin vol. 21 , no. 10 , p. 329.

Dukler, A. E., M. Wicks III and R. G. Cleveland (1964), "Frictional Pressure Drop in Two-Phase Flow -- B. An Approach Through Similarity Analysis", A. I. Ch. E. J. v 10, p. 44.

Entingh, D. J., E. Easwaran and L. McLarty (1994), "Small Geothermal Electric Systems for Remote Powering", Geothermal Program Review XII: Geothermal Energy and the President's Climate Change Action Plan, U. S. Department of Energy, San Francisco.

Hughmark, G. A. (1962), "Holdup in Gas-Liquid Flow", Ch. E. Progr. v. 53, p. 62.

Minkowycz, W. J. and P. Cheng (1976), "Free Convection about a Circular Cylinder Embedded in a Porous Medium", Int. J. Heat and Mass Transfer v. 19, p. 805.

Pritchett, J. W. (1985), "WELBOR: A Computer Program for Calculating Flow in a Producing Geothermal Well", S-Cubed Report No. SSS-R-85-7283.

Pritchett, J. W. (1993), "Preliminary Study of Discharge Characteristics of Slim Holes Compared to Production Wells in Liquid-Dominated Geothermal Reservoirs", Proc. Eighteenth Workshop on Geothermal Reservoir Engineering, Stanford, California, January 1993.

Pritchett, J. W. (1995a), "Preliminary Estimates of Electrical Generating Capacity of Slim Holes - A Theoretical Approach", Proc. Twentieth Workshop on Geothermal Reservoir Engineering, Stanford, California, January 1995. 
Pritchett, J. W. (1995b), "Electrical Generating Capacities of Geothermal Slim Holes. Phase 1: Self-Discharging Wells Supplying Single-Flash Steam Turbines", S-Cubed Report No. SSS-DTR-95-15162.

Pritchett, J. W. (1997), "Mathematically Modeling Downhole Pump Performance in Geothermal Wells from 150 to 300 Millimeters Inside Diameter", Maxwell Federal Division Report MFD-DTR-97-15798. 


\title{
INTEGRATED RESERVOM STUOY OF THE BEOWAWE HYDROTHERMAL SYSTEM
}

\author{
D. D. Faulder (1) and S. D. Johnson (2) \\ (1) Idaho National Engineering and Environmental Laboratory \\ (2) Oxbow Power Systems, Inc.
}

\section{KEY WORDS}

Beowawe, reservoir characterization, modeling, injection, temperature decline, Basin and Range

\section{PROJECT BACKGROUND AND STATUS}

This project was initiated in 1996 to identify the cause(s) of temperature declines experienced over the last nine

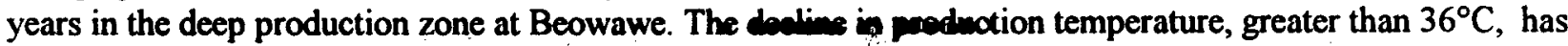
necessitated several remedial actions by the operator, including drilling of a new production well, relocation of injection, and close monitoring of the field oporminims. The field operator would like to develop a better understanding of the cause(s) of the cooling trend. A numical revoir model has been developed by the INEEL to assist the operator in forecasting future conling therior, to imestigate the likely causes of cooling, and to develop reservoir management strategies to mitigate the coeling of deep production zones. Potential reasons for cooling include injection and thermal breakthrowd, inmu of wher, shallow meteoric water, widespread shallow boiling in response to exploitation-induced pressure declime, and coning of thermally stratified water in the Malpais Fault zone.

The operator has provided access to field data for the comstmation of a numerical reservoir model. The model covers an area of over 16 square miles and integrates the structural geology, geochemistry, hydrology, and reservoir engineering information into a conceptual model of the Roowawe hydrothermal system. This conceptual model has been developed into a numerical model and is currently being used to conduct a native state history match prior to a detailed investigation of the observed reservoir cooling, (Faulder et al., 1997). The relocation of injection by the field operator in early 1994 appears to have moderated the thermal decline in the deep production zone (Benoit, 1997).

\section{PROJECT OBJECTIVES}

The objective of the study is to gain insight into the likely cauces of cooling in single fault-dominated, liquid reservoirs in response to exploitation. Insight gainad into his problem in Basin and Range reservoirs can be used to provide a basis for technology transfer and recervoir management/mitigation plans.

\section{Technical Objectives}

- Integrate the geoscience and production data into a conceptual and numerical model of the Beowawe hydrothermal system.

- Conduct a numerical model study to history mateh the chinerved cooling and to examine potential causes of the cooling. 
- Evaluate options to mitigate or remediate the cooling of the deep production zone.

- Gain insight into the problem of reservoir cooling of single fault-dominated, Basin and Range reservoirs.

- Examine hydrologic interaction between the thermal system and regional hydrology.

\section{Expected Outcomes}

- A numerical model to evaluate the likely causes of reservoir cooling and to forecast future cooling trends.

- A reservoir management plan to mitigate the cooling trend at Beowawe.

- A $15 \%$ improvement in the recovery of heat from single fault, liquid-dominated reservoirs.

\section{APPROACH}

The conceptual approach to this problem relies on the internally consistent integration of geologic, geochemical, hydrologic, and reservoir engineering data to develop a model of the Beowawe hydrothermal system: A numerical model is used to test the conceptual model and to investigate the cause(s) of cooling. Geochemical, production, and tracer response data will be used to calibrate the numerical model and to test the proposed causes of reservoir cooling.

\section{RESEARCH RESULTS}

Integration of the structural geology, geochemistry, hydrology, and reservoir engineering data been completed. The native state model has been completed and calibration has been performed using data from a three month well test program conducted in 1981 . The model sludy is currently history matching the exploitation history from 1986 to 1997 . Results are still preliminary, however the model indicates that the primary source of cooling is associated with the shallow meteoric influx in the region of the sinter terrace. The relocation of injection in early 1994 and the corresponding increase in reservoir pressure have appeared to moderate the thermal decline in the deep production zone. An additional observation is that the active hydrothermal system associated with the Malpais Fault is very narrowly focused.

\section{FUTURE PLANS}

Future activities are to complete a history match of the exploitation, and to use the extensive pressure transient data collected at Beowawe with the numerical model to refine the reservoir description. The model is being used to examine the proposed causes of cooling and to identify the likely mechanisms for cooling. Further study is needed to better characterize the complex geology and hydrology in the sinter terrace region of the Beowawe hydrothermal system. The history matched model will be used to forecast a base case cooling trend. Alternative reservoir management strategies will be investigated to determine the most favorable course of action. The results will be published for dissemination to the geothermal community. 


\section{INDUSTRY INTEREST}

Organization

Oxbow Power Services, Inc.

Basin and Range operators
Type and Extent of Interest

Provision of proprietary data and interest in strategies to mitigate cooling.

A better understanding of Basin and Range geothermal systems.

\section{REFERENCES}

Faulder, D.D., Johnson, S.D., and Benoit, W.R., 1997. "Flow and Permeability Structure of the Beowawe, Nevada Hydrothermal System," Proceeding, Twenty-Second Workshop on Geothermal Reservoir Engineering, Stanford University, January 27-29, in press.

Benoit, W.R, 1997. "Injection-Driven Restoration of the Beowawe Geothermal Field," GRC Transactions, Vol. 21 , p. 569-575. 


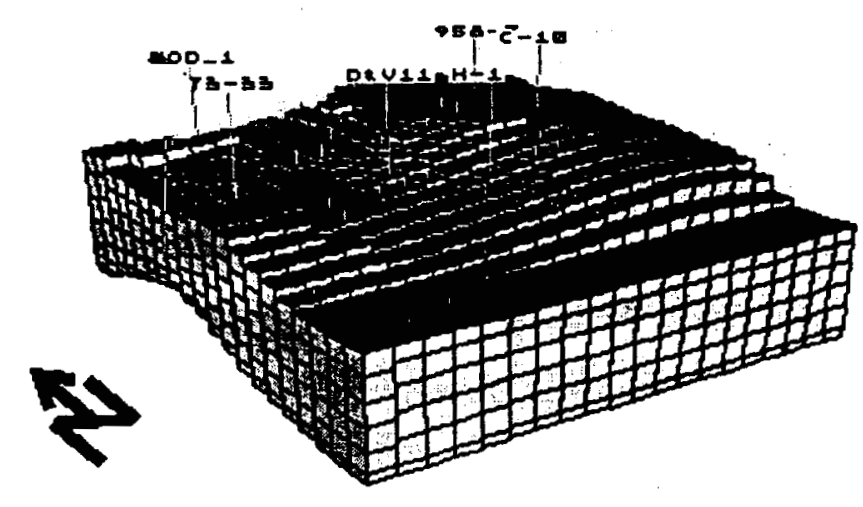

Figure 1 -- Structure of study area and partial display of study area. 


\title{
GEOTHERMAL DATA CONVERSION PROJECT
}

\author{
Jeffrey L. Wagoner and Oscar Nazario \\ Lawrence Livermore National Laboratory (LLNL)
}

\section{KEY WORDS}

database, images, geothermal production database, geothermal injection database, geothermal, CADOGGR

\section{PROJECT BACKGROUND AND STATUS}

The California Division of Oil and Gas and Geothermal Resources (CADOGGR) has been the principal state regulatory agency for geothermal well drilling and field production activities since 1965 . Records, consisting of notices, summaries, histories, and geophysical logs, have been filed and maintained in hardcopy form. Currently, there are an estimated 115,000 pages of records and 2500 geophysical well logs on file with CADOGGR. The original CADOGGR electronic geothermal production and injection database was created in 1980, as part of a project to assess the geothermal resources at The Geysers in California. Staff entered data from hardcopy reports for all geothermal fields into a mainframe database maintained at the Teale Data Center. A great deal of effort was expended to make this first database as clean and error-free as possible.

Early on, CADOGGR met with geothermal operators to discuss standards and, subsequently, distributed the first of the standard reporting forms and operator manuals. Later, in a cooperative effort, the California Office of the Bureau of Land Management and CADOGGR jointly amended CADOGGR's forms and standards, and continue to use the same forms today.

In 1990, the entire production management system was changed. A PC-based system was developed, and the database was transferred to PCs in each district office. All of the data-integrity-checking programs written in COBOL were rewritten in Smart database programming code. The DOS Smart Database program is part of a suite of DOS programs developed by Innovative Software, Inc. The CADOGGR copy of the Smart program is dated 1986. Innovative Software, Inc., ceased the development and support of Smart in the early 1990s. Consequently, the entire system is dated and obsolete.

Lawrence Livermore National Laboratory (LLNL) is reengineerng CADOGGR's geothermal data processing programs, and is developing a closed network, a well file viewing system, and a system to facilitate electronic filing of well records by geothermal operators. These efforts will, in aggregate, cut costs, improve regulatory efforts, increase efficiencies, and serve as a 21 st Century model for other geothermal agencies and the geothermal industry.

CADOGGR's engineers will be able to track geothermal production and injection, check data integrity, query the database, generate reports, and analyze statistics. Engineers will be able to electronically access virtually all of the geothermal production and injection data through a closed local area network (Intranet). This network can be easily converted to an open network (Internet), depending on future requirements. Using the same closed local area network, engineers will also be able to electronically access raster images of notices, summaries, histories, and geophysical logs from the more than 1400 geothermal wells and temperature-gradient holes. Images will be stored on CD-ROM and will be updated periodically. Geothermal companies will have the option to electronically file the forms and required reports. This will decrease permit response time, which is an added benefit to well operators. 
Finally, an industry advisory group will be formed, which will review project plans and provide input during the initial developmental phases of the project.

\section{PROJECT OBJECTIVES}

\section{Technical Objectives}

- Convert hardcopy well files to Adobe Acrobat .pdf files.

- Archive images on CD-ROM.

- Populate a relational database with geothermal data.

- Develop application to access data and images on the Internet (closed Intranet).

- Redesign the existing Smart database system, using updated technology.

- Incorporate electronic filing.

\section{Expected Outcomes}

- An integrated data system that will help cut costs, improve regulatory efforts, increase efficiencies, and serve as a 21 st Century model for other geothermal agencies and the geothermal industry.

\section{APPROACH}

LLNL is currently leading a large group of organizations that has designed an inexpensive mechanism for on-line access to all of the nonconfidential oil and gas data currently available at CADOGGR. This project, called the Oil and Gas Data Infrastructure Project (OGDIP), provides cost-effective access through the existing Internet infrastructure. Eventually, widespread use of the system by oil and gas operators will facilitate electronic filing of the documentation and permit applications required in California. Geothermal well files are very similar to oil and gas well files. In fact, the files are so similar that CADOGGR sees an expansion of applicability to its oil and gas program. This geothermal project will leverage OGDIP. The California Bureau of Land Management and Nevada Bureau of Mines are very interested in this proposal because they have similar needs.

LLNL will develop a data model for the types of data commonly encountered in the geothermal industry. The project will also redesign the existing Smart database system, using updated technology. LLNL will develop this application in Windows NT/SQL Server and Java.

To make the well file data available on-line, hardcopy data is being converted to an electronic form. Hardcopy records, including drilling histories, summaries, and geophysical well logs are being scanned. LLNL researchers have developed a systematic procedure for digitizing and indexing well records. These images are archived on CD-ROM, and nonconfidential subsets of the data will be sold at cost to the geothermal industry and the public. To guarantee confidentiality and security, the public will not have direct access to the database. 


\section{RESEARCH RESULTS}

We are continuing to scan geothermal well files at CADOGGR in Sacramento. The scanning is being accomplished by a graduate student from San Francisco State University. We have completed scanning 785 well files in District II. Archiving of the records on CD-ROM has also started at CADOGGR. LLNL developers are continuing to convert the oil and gas application to Java, using the new tools developed by Symantec (Visual Cafe). The geothermal project will leverage this effort when code development starts in the second quarter of FY98.

\section{FUTURE PLANS}

The project will be extended to develop the means for automating the filing of forms required of operators by CADOGGR. The automated remote-submission system will allow electronic filing of monthly reports and a number of other required forms. Security, encryption, and user authentication will be a priority during the development phase. Electronic filing will allow automated updating of the pilot database system, decreasing the time required before data become available to users. The pilot system will also provide for electronic issuing of permits and electronic mailing of other correspondence between the state agencies and industry.

\section{INDUSTRY INTEREST}

The project will have applicability beyond the needs and use of CADOGGR's geothermal program. A copy of the computer programs will be made available to operators for their use. Special CD-ROMs containing the companies' production and injection data and the imaged well records that are not subject to confidentiality will also be made available. Geothermal companies will be able to access production and injection data and the images as easily as CADOGGR. The public will be able to purchase CD-ROMs containing raster images of subsets of the nonconfidential data. District engineers will handle requests for data items, guaranteeing the confidentiality of proprietary data.

The universal computer programs will also be made available to other state and federal agencies, such as the Nevada Bureau of Mines and the U.S. Bureau of Land Management. These agencies have expressed interest in and support for this project.

Besides serving as a national geothermal standard, the computer programs developed will be very similar and will have the same functionality as projects being developed for the oil and gas industry and funded by the U.S. Department of Energy (DOE). From the beginning, the project has been designed to be consistent with the existing DOE/LNLL/ CADOGGR oil and gas data infrastructure project. Another attractive feature of this project is that it will leverage the work already completed and result in major cost savings to the DOE. 


\title{
HEAT-FLOW STUDIES IN THE AREA OF THE GEYSERS GEOTHERMAL FIELD, CALIFORNIA
}

\author{
Colin F. Williams \\ U.S. Geological Survey
}

\section{KEY WORDS}

heat flow, The Geysers, thermal conductivity, high temperature reservoir, pressure

\section{PROJECT BACKGROUND AND STATUS}

This project originated with industry concern over the unexpectedly rapid decline of steam production from The Geysers geothermal field. Pioneering studies of The Geysers geothermal field modeled the system as a nearly isothermal $\left(-245^{\circ} \mathrm{C}\right)$ vapor-dominated reservoir (hereafter referred to as the "normal" reservoir - NR) underlying an impermeable, liquid-filled caprock of varying thickness. In the early 1980's, exploration and development of the northwestern Geysers revealed the presence of a second, higher temperature vapor dominated reservoir (HTR) underneath the normal reservoir (Walters et al., 1988). Although a number of wells penetrate the HTR, there is little information from the HTR, and the nature of the NR-HTR transition is a matter of speculation. In addition, the nature and extent of the heat source underlying The Geysers is poorly constrained.

The absence of precision temperature and pressure data from the deeper portions of The Geysers system severely limits research into these problems. Consequently, the primary focus of this project has been the acquisition of equilibrium temperature and pressure logs from idle wells at The Geysers. The first phase of the project involved detailed studies in the caprock of the reservoir and revealed variations in conductive heat flow due to temporal variations in the Geysers system (Williams et al., 1993). The second phase focused on measuring the thermal properties of Geysers caprock and reservoir rock at temperatures and pressures equivalent to in situ conditions (Williams and Sass, 1995; Williams and Sass, 1996). These measurements are necessary for the determination of heat flow variations with depth in the system. The third phase of the project involves detailed thermal studies near the southwestem boundary of The Geysers in a coupled investigation of the processes controlling the lateral extent of the geothermal field and the existence of the HTR. The project is scheduled to be completed in early 1998.

\section{PROJECT OBJECTIVES}

The overall objective of this project is to acquire thermal data from The Geysers geothermal field in order to develop an accurate and comprehensive understanding of the nature and evolution of the system. The primary research objectives are investigations of the High Temperature Reservoir (HTR) which underlies the northwestern part of The Geysers and the factors controlling the lateral extent of the field. This translates into four primary technical objectives.

\section{Technical Objectives}

- Obtaining precision temperature and pressure logs from wells at The Geysers; particularly those penetrating the High Temperature Reservoir and those defining the limits of the geothermal system. 
- Measuring the thermal conductivity of selected core samples of Geysers reservoir and caprock at temperatures and pressures representative of in situ conditions.

- Combining the above measurements into vertical profiles of heat flow and utilizing these profiles to develop models for heat transfer through the base of The Geysers system. Applying these models to understand the heat source at The Geysers and its role in determining both the extent and nature of the Normal and High Temperature Reservoirs.

- Promoting use of the heat flow database for The Geysers for use in regional studies and local exploration efforts.

\section{Expected Outcomes}

- An analysis of the vertical and lateral variation of heat transfer at the boundaries of the field and an accompanying interpretation of coupled structural and hydrothermal processes controlling the limits of the producing reservoir.

- A refined, integrated model of the nature of the High Temperature Reservoir, along with the implications of this model for future research and exploitation.

- Transfer of precision temperature and pressure data to appropriate industrial partners.

- Use of The Geysers heat flow database as a tool for understanding the tectono-thermal processes which led to the development of the natural vapor-dominated system. Williams and Lachenbruch (1997) report recent work on this topic.

\section{APPROACH}

The technical approach applied in this research involves the acquisition of precision, equilibrium temperature and pressure logs from idle wells in The Geysers. These data are combined with thermal properties measurements on cores and cuttings for a determination of the temporal and spatial variability of heat transfer above and within the steam reservoir. Collaborative arrangements with other research groups and Geysers steam producers are necessary for the success of this effort.

\section{RESEARCH RESULTS}

\section{Phase I}

In 1991 and 1992 temperatures and pressures were measured in a number of wells in the NW Geysers. The temperature data were combined with thermal conductivity measurements on drill cores and cuttings in a vertical profile of heat flow. Results of this initial study were published in the Transactions of the Geothermal Resources Council (Williams et al., 1993). Rock thermal conductivity is significantly temperature-dependent, and room temperature conductivity measurements on cuttings were transformed to in situ values via the method of Sass et al. (1992a). In order to establish confidence in these original estimates of in situ thermal conductivity, measurements on core plugs from The Geysers were made in a new high temperature and pressure apparatus capable of simulating in situ conditions. 


\section{Phase II}

In areas with large geothermal gradients, the successful use of near-surface heat flow measurements to predict temperatures at depth depends upon accurate corrections for the variation of thermal conductivity with temperature. During the second phase of this project we developed a technique for measuring the thermal conductivity of water-saturated rocks at the temperatures from 20 to $350^{\circ} \mathrm{C}$ and confining pressures up to 100 MPa (Sass et al., 1992b; Williams and Sass, 1994, 1996). Application of this technique to samples of Franciscan graywacke from The Geysers revealed a significant change in thermal conductivity with temperature. At reservoir-equivalent temperatures of $250^{\circ} \mathrm{C}$, the conductivity of the graywacke decreases by approximately $25 \%$ relative to the room temperature value. Where heat flow is constant with depth within the caprock overlying the reservoir, this reduction in conductivity with temperature leads to a corresponding increase in the geothermal gradient. Consequently, reservoir temperatures are encountered at depths significantly shallower than those predicted by assuming a constant temperature gradient with depth. We have derived general equations for estimating the thermal conductivity of most metamorphic and igneous rocks and some sedimentary rocks at elevated temperature from knowledge of the room temperature thermal conductivity. Application of these equations to geothermal exploration should improve estimates of subsurface temperatures derived from heat flow measurements.

These measurements alter the corrections applied in Williams et al. (1993) but confirm the observations of vertical variations in heat transfer in the caprock above the reservoir in the Northwest Geysers. The interpretation of this decrease in terms of the transient thermal effects of a recent intrusion is consistent with studies of the evolution of the vapordominated system through investigations of fluid inclusions (Moore, 1992) and steam chemistry (Truesdell et al., 1993).

\section{Phase III}

This phase started in 1996 with a logging effort in selected idle wells in the inactive Unit 15 area of The Geysers. The value in studies in the Unit 15 area follows from the large number of deep production wells idled for more than seven years and located near the southwestern edge of the producing field. The decrease in heat flow and the deepening of the reservoir near the edges of the field reflects some combination of variations in the permeability structure of the reservoir and caprock with changes in the nature and geometry of the heat source (perhaps reflected in the geometry of the underlying felsite body).

Pioneering studies of The Geysers and other vapor-dominated systems identified the importance of low permeability boundaries in the development and maintenance of vapordominated conditions. The nature of these permeability barriers is generally tied to some combination of contrasting lithologies (usually due to faulting) and mineral precipitation from the fluids of earlier hydrothermal systems. Recent well abandonment activities in the Unit 15 area of The Geysers geothermal field have provided a unique opportunity to investigate equilibrium thermal conditions to depths as great as $1.7 \mathrm{~km}$ near the southwestern boundary of the system (Williams and Grubb, in review): The southwestern boundary of The Geysers is characterized by a decrease in surface heat flow over a distance of less than $1 \mathrm{~km}$ from more than $400 \mathrm{MW} / \mathrm{m}^{2}$ within the limits of the producing field to less than $250 \mathrm{MW} / \mathrm{m}^{2}$ outside the field and runs parallel to a series of northwest-trending faults which juxtapose various lithologic elements of the Franciscan complex. The new thermal data reveal a complex relationship between variations in near-surface $(<200 \mathrm{~m})$ heat flow, $\operatorname{decp}(>1 \mathrm{~km})$ heat flow, and the top of the vapor-dominated reservoir $(>1.5 \mathrm{~km})$. The southwestern boundary of the reservoir at depth is characterized by an abrupt change in heat flow, and this change appears to correlate with the subsurface projection of mapped fault zones. This is best illustrated in Figure 1 by comparison of temperature gradients in well FIL2 below $1.4 \mathrm{~km}$ and in all of well RA25 with gradients in well FIL2 above $1.4 \mathrm{~km}$ and in wells RA14 and RA22. Both RA25 and FIL2 cross fault 
zones in the deep subsurface and consequently exit the primary geothermal reservoir. Preliminary analyses suggest that advective heat transport along the fault zones may be significant, with heat flow in the units below these faults approximately equal to the surface heat flow found outside the reservoir. This lower value of heat flow presumably reflects the deep conductive heat source underlying The Geysers, whereas the higher value of heat flow above the reservoir reflects convective heat transfer within the vapor-dominated system. Modeling of the variation of heat flow with depth should yield detailed constraints on the geometry of this boundary.

\section{FUTURE PLANS}

Plans for the current fiscal year are focused on two objectives. The first objective involves continued logging of wells at The Geysers to establish lateral and vertical variations in heat flow through the caprock and reservoir. This study will also include additional conductivity measurements under in situ conditions. Operations to clean out obstructions in selected wells may also take place. Removing existing obstructions will enable temperature and pressure logging of reservoir conditions at a number of locations. The second objective is a continuation of our efforts to model heat transfer within and at the boundaries of The Geysers. Successful thermal modeling will provide a reliable explanation for the observed heat flow variations, perhaps establishing an explanation for the nature of the NR-HTR transition.

\section{INDUSTRY INTEREST}

\section{Organization}

NCPA

Unocal

Calpine

CCPA

Calif. DOGGR
Type and Extent of Interest

Assistance with Unit 15 logging

Interest in models of HTR

Interest in models of HTR

Possible access to geothermal wells

Collaboration on Unit 15 logging

\section{REFERENCES}

Moore, J.N., Thermal and chemical evolution of The Geysers geothermal system, California, Proc. 17th Workshop Geoth. Res. Engr., Stanford, 1992.

Sass, J.H., Lachenbruch, A.H., Moses, T.H., Jr., and Morgan, P., Heat flow from a scientific research well at Cajon Pass, California, J Geophys. Res., 97, 5017-5030, 1992a.

Sass, J.H., Kennelly, J.P., Jr., Williams, C.F., and Lachenbruch, A.H., Thermal conductivity of water-saturated crystalline rocks as a function of temperature: Thermal Propertics of Crustal Materials Conf., Bad Honnef, Germany, April 1-3, 1992.

Truesdell, A., Walters, M., Kennedy, M., and Lippmann, M., An integrated model for the origin of The Geysers geothermal field, Trans. Geoth. Resour. Coun., v. 17, p. 273-280, 1993. 
Walters, M.A., Sternfeld, J.N., Haizlip, J.R, Drenick, A.F., and Combs, J., A vapordominated reservoir exceeding $600^{\circ} \mathrm{F}$ at The Geysers, Sonoma County, California, Proc. 13th Workshop Geoth.. Res. Engr., Stanford, 73-81, 1988.

Williams, C.F., Galanis, S.P., Moses, T.H., and Grubb, F.V., Heat-flow studies in the NW Geysers geothermal field, California, Trans. Geoth. Resour. Coun., v. 17, p. 281-288, 1993.

Williams, C.F., and Grubb, F.V., Thermal constraints on the lateral extent of The Geysers vapor-dominated reservoir, 22nd Stanford Geothermal Workshop, in review.

Williams, C.F., Lachenbruch, A.H., and Castillo, D.A., Seismic and thermal constraints on the evolution of the California Coast Ranges south of the Mendocino Triple Junction, EOS, v. 78, n. 46, p. 708, 1997.

Williams, C.F., and Sass, J.H., The role of temperature-dependent thermal conductivity in heat transfer at The Geysers geothermal field, California, Proc. 27th IASPEI General Assembly, 1994.

Williams, C.F., and Sass, J.H, The thermal conductivity of rock under hydrothermal conditions, 21st Stanford Geothermal Workshop, p. 335-341, 1996. 


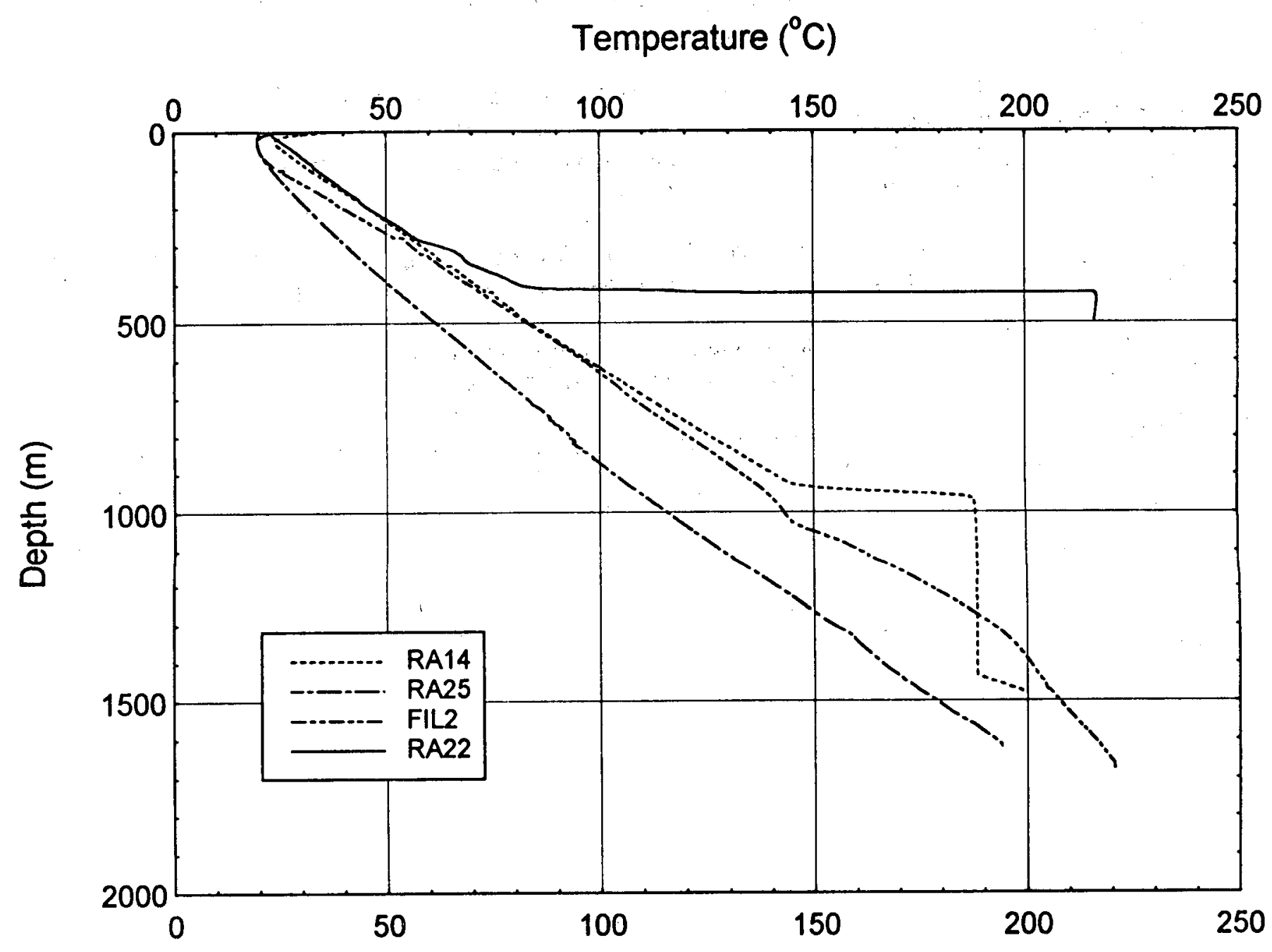

Figure 1 - Unit 15 temperature profiles. Isothermal sections of wells represent zones of upflow within the wellbore. 


\title{
THERMAL HISTORY AND AGE OF THE FELSITE UNIT, THE GEYSERS GEOTHERMAL FIELD, FROM THERMAL MODELING OF ${ }^{40} \mathrm{Ar} /{ }^{39} \mathrm{Ar}$ INCREMENTAL HEATING DATA
}

\author{
G. Brent Dalrymple \\ College of Oceanic \& Atmospheric Sciences \\ Oregon State University
}

\section{KEY WORDS}

The Geysers geothermal field, ${ }^{40} \mathrm{Ar} /{ }^{39} \mathrm{Ar}$ Dating, geochronology, felsite unit, thermal history

\section{PROJECT BACKGROUND AND STATUS}

The background and rationale for this work was summarized by Dalrymple (1992), from which most of the following is taken.

The felsite unit is a complex silicic batholith that intrudes the overlying Franciscan Complex (Late Jurassic to Late Cretaceous) and underlies The Geysers Geothermal Field, northern California (Schriener and Suemnicht, 1981; Thompson, 1989; Thompson, 1991). The felsite unit is only found in the subsurface but it appears to be an elongate body whose axis trends northwest-southeast and whose surface is shallowest in the southeast part of the field (Figure 1). It ranges in composition from granite to granodiorite (Schriener and Suemnicht, 1981; Thompson, 1991; Hulen and Nielson, 1993, 1996).

The apparent coincidence of the heat flow anomaly within The Geysers field (Walters and Coombs, 1989) with the distribution of felsite within and below the zone of steam production suggests that the felsite unit may be the primary source of heat. Presently available K-Ar ages ( 0.9 to $2.7 \mathrm{Ma}$ ) suggest, however, that the felsite unit may be too old to be the primary source of heat for the present thermal activity. Resolution of this apparent paradox should be of interest for the purposes of both exploration and field management. If the felsite unit is young $(<1$ $\mathrm{Ma}$ ), for example, then it should be hot wherever it is found except, perhaps, at its margins. If the felsite unit is old ( $>1 \mathrm{Ma})$, on the other hand, then it may be relatively cold outside of the region of present production. The felsite unit may be a complex body emplaced over a significant interval of time with both older and younger parts. Regardless of its age, the felsite unit appears to play an important role in the geothermal field, either as a heat source or as a conduit for heat from below and its age of emplacement and thermal history is of considerable interest.

The age of the felsite unit is not well known. Schriener and Sueminicht (1981) reported K-Ar ages of $1.6 \pm 0.4$ $\mathrm{Ma}$ on sanidine, $2.7 \pm 0.3 \mathrm{Ma}$ on biotite, and $2.5 \pm 0.4 \mathrm{Ma}$ on whole rocks felsite. The samples for their study came from cuttings recovered from wells that penetrate the felsite unit in the subsurface. Thompson (1991) mentions unpublished age measurements, presumably $\mathrm{K}-\mathrm{Ar}$, of as young as $0.9 \mathrm{Ma}$. McLaughlin and others (1983) reported a K-Ar age of $0.69 \pm 0.03 \mathrm{Ma}$ on adularia separated from veins that intrude Franciscan rocks above, and presumably associated with, the felsite unit. The details of these limited age studies have not been published and it is, therefore, difficult to evaluate their significance. Recently, Hulen and others (1997) have measured ${ }^{40} \mathrm{Ar} /{ }^{\beta 9} \mathrm{Ar}$ age spectra for two samples from the felsite unit and concluded that the felsite, at least in one location, has an age of $1.09 \pm 0.04 \mathrm{Ma}$. 
The K-Ar method is remarkably reliable in simple systems, e.g., volcanic rocks. In more complex systems, however, it is subject to errors from Ar. loss due to thermal events and alteration, and (rarely) from extraneous ${ }^{40} \mathrm{Ar}$ due to contamination, incomplete degassing, and elevated ${ }^{40} \mathrm{Ar}$ partial pressures (Dalrymple and Lanphere, 1969). The felsite has been, and continues to be, subjected to elevated temperatures, fluid and gas flow, and alteration over an extended period of time, perhaps since its emplacement. It is, therefore, a complex system and cannot be reliably dated by conventional K-Ar methods. Also unknown is the degree to which the dated cuttings might have been contaminated with material from the older Franciscan rocks.

The ${ }^{40} \mathrm{Ar} /{ }^{39} \mathrm{Ar}$ incremental heating method is a variation of the $\mathrm{K}-\mathrm{Ar}$ method and is considerably more robust. It has the advantage of providing information about the degree to which the system has been disturbed or contaminated. In many instances it is possible to determine a crystallization age for a sample that has lost a significant fraction of its radiogenic ${ }^{40} \mathrm{Ar}$ due to thermal or chemical (alteration) disturbance. Even where Ar loss has been severe, it is possible to determine a minimum crystallization age for a disturbed sample. Regardless of the degree of disturbance, the method nearly always gives information about the reliability of the sample as a geochronometer and so the apparent ages measured in this way are easily evaluated. By appropriate modeling techniques, it is also possible to extract thermal history information from the ${ }^{40} \mathrm{Ar}{ }^{\beta 9} \mathrm{Ar}$ age spectrum that results from the incremental heating analysis. A preliminary study of feldspar separated from core samples from the felsite unit has indicated that it is possible to extract good quality ${ }^{40} \mathrm{Ar} /{ }^{99} \mathrm{Ar}$ age spectra from these samples and that such spectra should be suitable for thermal modeling (Dalrymple, 1992). This conclusion has been validated by the recent work of Hulen and others (1997) on two samples from The Geysers felsite unit.

In 1992 a preliminary feasibility study of four Geysers felsite core samples was completed and the results reported (Dalrymple, 1992). The Department of Energy through the U.S. Geological Survey's Geothermal Program provided funding. At the time the study was begun, the Principal Investigator was an employee of the U.S. Geological Survey. The work was done in cooperation with J.B. Hulen, of the Energy and Geoscience Institute, University of Utah, who has been working on the petrology of the felsite and assisted the Principal Investigator in sample acquisition and selection. The preliminary study resulted in precise ${ }^{40} \mathrm{Ar} /{ }^{\beta 9} \mathrm{Ar}$ age spectra for the four samples and a minimum age of 1.3-1.4 Ma for the parts of the felsite unit sampled. As expected, all four age spectra show that the feldspar of the felsite unit is a disturbed K-Ar system.

Shortly after completion of the preliminary study and publication of the preliminary report a comprehensive geochronological study of the felsite unit was begun with the intent of determining the age and thermal history of the felsite unit. A large number of cuttings samples recovered from the felsite unit by drilling were examined macroscopically. Most of the samples were available in only very small (gram) amounts, limiting the choice of sample material for the ${ }^{40} \mathrm{Ar} /{ }^{\beta 9} \mathrm{Ar}$ study severely. Nevertheless, a number of samples for which there was adequate material were selected. Feldspar and biotite were separated from 14 samples, additional to the original four, from several wells and from a variety of depths (Table 1). These samples are from cuttings that sampled the felsite unit within the geothermal reservoir. Late 1993 had completed the mineral separations, which were extraordinarily time-consuming because of the extremely small samples available, and the samples irradiated in the U.S.G.S. TRIGA reactor.

In May of 1994 the Principal Investigator retired from the U.S. Geological Survey to accept his present position as Professor and Dean of the College of Oceanic \& Atmospheric Sciences (COAS) at Oregon State University. At that time, M.A. Lanphere (U.S.G.S.) joined the Principal Investigator on the project as a Co-Investigator and, in consultation with the Principal Investigator, continued the laboratory analytical work on the irradiated samples. This phase of the project, which resulted in high quality age spectra for the additional 14 samples, was completed in March, 1996. 
Funding to complete this project was received from DOE on 1 September 1997 and final data reduction for the analyses indicated in Table 1 has begun and will be completed by 1 January 1998 . Several of the analyzed samples have been selected for reanalysis in order to provide more optimal ${ }^{40} \mathrm{Ar} /{ }^{39} \mathrm{Ar}$ data for thermal modeling phase of the study. These were irradiated in September-October of 1998 and the ${ }^{40} \mathrm{Ar}{ }^{39} \mathrm{Ar}$ analyses will be done at UCLA in cooperation with Prof. T.M. Harrison over the next few months. Thermal modeling of all ${ }^{40} \mathrm{Ar} /{ }^{\beta 9} \mathrm{Ar}$ data is expected to begin in January of 1998 and should be completed by 1 June 1998 . We expect to have a draft manuscript prepared by the current project end date in August of 1998 or shortly thereafter.

\section{PROJECT OBJECTIVES}

\section{Technical Objectives}

- To obtain a precise ${ }^{40} \mathrm{Ar} /{ }^{\beta 9} \mathrm{Ar}$ emplacement age for the felsite unit that underlies The Geysers geothermal field.

- To obtain a narrow range of permissible thermal histories, from its time of emplacement to the present, for the felsite unit based on thermal modeling of the ${ }^{40} \mathrm{Ar} /{ }^{39} \mathrm{Ar}$ age spectra.

\section{Expected Outcomes}

- To determine whether the felsite unit is the source of heat for The Geysers geothermal field or a conduit for heat from below.

\section{APPROACH}

The ${ }^{40} \mathrm{Ar} /{ }^{39} \mathrm{Ar}$ age spectrum analyses were done at the USGS and will be done at UCLA using state-of-the-art ${ }^{40} \mathrm{Ar} /{ }^{\beta 9} \mathrm{Ar}$ equipment and methods. The individuals involved in these analyses (G.B. Dalrymple, M.A. Lanphere, and T.M. Harrison) are recognized experts in this field and have developed many of the standard methods employed in ${ }^{40} \mathrm{Ar} /{ }^{\beta 9} \mathrm{Ar}$ studies worldwide.

The thermal modeling will be done using the latest algorithm of $\mathrm{T}$ : M. Harrison and $\mathrm{O}$. Lovera (personal communication, 1996) for thermal modeling of ${ }^{40} \mathrm{Ar} /{ }^{39} \mathrm{Ar}$ age spectra. This model does not require assumptions about the time-temperature gradient, and thus allows evaluation of a family of plausible thermal histories that may involve both cooling and heating. In contrast, earlier thermal age spectrum models require the assumption of monotonic cooling. The model; however, is processor intensive, requiring many hours per run (typically an entire day) on a desk top SparcStation. To increase the efficiency of the modeling, the computer code for the model will be adapted to the Sparc 5000, one of four parallel supercomputers in the College of Oceanic \& Atmospheric Sciences. This will greatly reduce run time per sample and will allow a more thorough exploration and evaluation of the permissible thermal history envelope.

\section{RESEARCH RESULTS}

Dalrymple (1992) reported preliminary results. There will be no further results to report until data reduction for the data in hand are completed next year. 


\section{FUTURE PLANS}

There are currently no plans to continue this work beyond completion of the present project outlined above.

\section{INDUSTRY INTEREST}

It is expected that the above approach will yield results of interest to both geothermal and volcanic hazards researchers and to operators in The Geysers geothermal field. It is not anticipated that this work will result in any new technology.

\section{REFERENCES}

Dalrymple, G. B., 1992, Preliminary report on ${ }^{40} \mathrm{Ar} /{ }^{39} \mathrm{Ar}$ incremental heating experiments on feldspar samples from the felsite unit, Geysers geothermal field, California: U.S. Geological Survey Open-File Report, v. 92-407, p. $1-15$.

Dalrymple, G. B., and Lanphere, M. A., 1969, Potassium-Argon Dating: San Francisco, W.H. Freeman and Co., $258 \mathrm{p}$.

Hulen, J.B., and Nielson, D.L., 1993, Interim report on gcology of The Geysers felsite, northwestern California: Geothermal Resources council Transactions, v. 17, p. 249-258.

Hulen, J.B., and Nielson, D.L., 1997, The Geysers felsite: Geothermal resources Council Transactions, v. 20, p. 295-305.

Hulen, J.B., Heizler, M.T., Stimac, J.A., Moore, J.N., and Quick, J.C., 1997, New constraints on the timing of magmatism, volcanism, and the onset of vapor-dominated conditions at The Geysers steam field, California: Proceedings, Twenty-second Workshop on Geothermal Reservoir Engineering, Stanford University, Stanford, CA, January 27-29, 1997, p. 75-82.

McLaughlin, R. J., Moore, D. E., Sorg, D. H., and McKee, E. H., 1983, Multiple episodes of hydrothermal circulation thermal metamorphism, and magma injection beneath The Geysers steam field, California: Geological Society of America Abstracts with Programs, v. 15, no. 5, p. 417.

Schriener, A., and Suemnicht, G. A., 1981, Subsurface intrusive rocks at The Geysers geothermal area, California, in Silberman, M. L., Field, C. F., and Berry, A., eds., U.S. Geological Survey Open-File Report: Proceedings of the symposium on mineral deposits of the Pacific northwest, Corvallis, OR, 1980, p. 295-302.

Thompson, R. C., 1989, Structural stratigraphy and intrusive rocks at The Geysers geothermal field: Geothermal Resources Council Transactions, v. 13, p. 481-485.

Thompson, R. C., 1991, Structural stratigraphy and intrusive rocks at The Geysers geothermal field: Geothermal Resources Council Special Report 17, Monograph on The Geysers geothermal field, p. 59-63.

Thompson, R. C., and Gunderson, R. P., 1991, The orientation of steam-bearing fractures at The Geysers geothermal field: Geothermal Resources Council Special Report 17, Monograph on The Geysers Geothermal Field, p. 65-68. 
Walters, M., and Coombs, J., 1989, Heat flow regime in The Geysers-Clear Lake area of northern California: Geothermal Resources Council Transactions, v. 13, p. 491-502. 
Table 1. Samples for which ${ }^{40} \mathrm{Ar}{ }^{39} \mathrm{Ar}$ age spectra have been measured.

\begin{tabular}{lll}
\hline Well/Sample & Interval & $\begin{array}{c}\text { Mineral } \\
\text { (feet below surface) }\end{array}$ \\
\hline ANG-1-11,380 & $11,380-11,400$ & $\begin{array}{l}\text { K-feldspar } \\
\text { biotite }\end{array}$ \\
ANG-1-11,420 & $11,420-11,440$ & $\begin{array}{l}\text { K-feldspar } \\
\text { biotite }\end{array}$ \\
DV-2B & $3,708-3,718$ & K-feldspar \\
DV2E & $3,708-3,718$ & K-feldspar \\
FF52-32-ST2-9040 & $9,040-9,060$ & K-feldspar \\
& & biotite \\
FF52-32-ST2-9140 & $9,140-9,160$ & K-feldspar \\
& & biotite \\
GDC-5-7240 & $7,240-7,260$ & K-feldspar \\
& & biotite \\
& & plagioclase \\
GDC-5-7800 & 7,800 & K-feldspar \\
GDC-21 & $5,864-5,868$ & K-feldspar \\
LF-23-9,540 & $9,540-9,560$ & K-feldspar \\
LF-23-9,800 & $9,800-9.820$ & K-feldspar \\
LF-48 & $8,089-8,096$ & K-feldspar \\
& & \\
& &
\end{tabular}




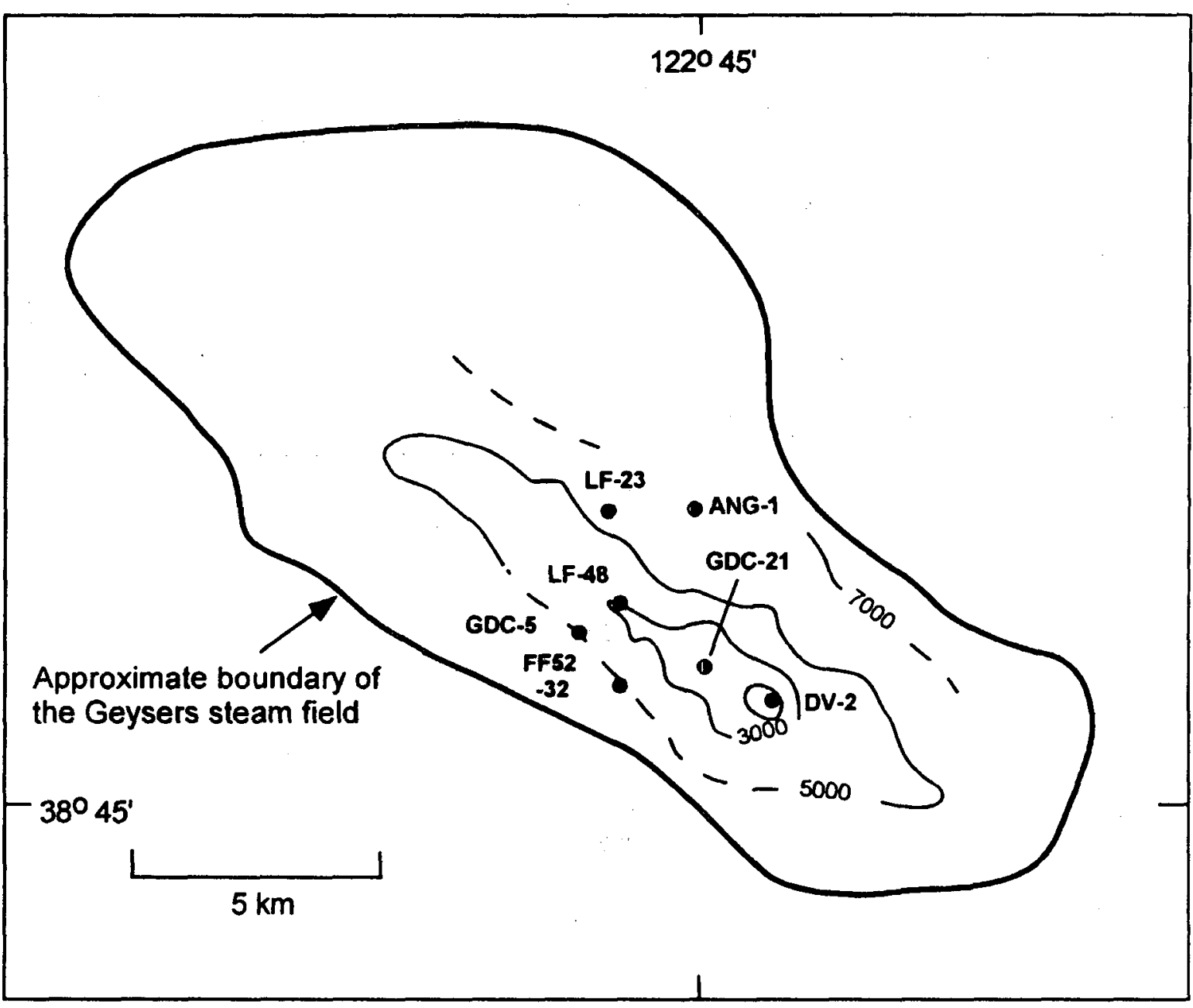

Figure 1. Location map showing wells from which samples for ${ }^{40} \mathrm{Ar} \beta 9 \mathrm{Ar}$ age spectrum and themal modeling studies were taken. Contours show the top of the Felsite Unit in feet below sea level. After J.B. Hulen (personal communication, 1992) based on data prepared cooperatively by the Geysers steam-field operators for the 1989 annual meeting of the Geothermal Resources Council. 


\title{
MICROSEISMIC MONITORING AT THE GEYSERS
}

\author{
A. Kirkpatrick, E.L. Majer and J.E. Peterson, Jr. \\ E.O. Lawrence Berkeley National Laboratory
}

\section{KEY WORDS}

microearthquakes, seismicity, seismic velocity, injection, geothermal monitoring

\section{PROJECT BACKGROUND AND STATUS}

Unocal has operated an analog seismic array over a large area of The Geysers since the mid 1980s. Data from this array have yielded some useful results, such as demonstration of spatial and temporal correlation between seismicity and injection (Stark, 1992) and have suggested that the use of higher resolution, digital, threecomponent arrays in denser configurations could provide more detailed microearthquake (MEQ) information potentially of use in characterizing more detailed reservoir structure and in contributing to a better understanding of reservoir processes.

Thus in 1988, a 16-station, digital, three-component seismic array was installed at the Northwest Geysers by the Coldwater Creek Operating Company, and in 1990 Lawrence Berkeley National Laboratory (LBNL) began processing and analyzing the data. This work revealed a correlation between injection and seismicity superimposed upon a more general pattern of seismicity probably related to steam withdrawal. Threedimensional P- and S-wave velocities ("Vp" and "Vs," respectively) and attenuation models were obtained. It was found that areas of high and low Vp and Vs correlated with the known geology, and that areas of low Vp/Vs were associated with the steam reservoir (Romero et al., 1995, 1997).

In 1993, 13 high-resolution, digital, three-component MEQ monitoring stations were installed at the Southeast Geysers, in portions of the Unocal, Calpine, and NCPA lease areas. Eight stations were installed and operated by LBNL, and five by Lawrence Livermore National Laboratory. In January 1994, the two arrays were consolidated, and LBNL began collecting and processing all data from the combined network, which operated through the fall of 1995 . Work in previous fiscal years has centered on developing streamlined processing methods for hypocentral and source parameter determination, developing a preliminary three-dimensional Vp and Vs model for the SE Geysers to locate events, and analyzing seismicity patterns and source characteristics in relation to generalized patterns of injection; steam withdrawal and reservoir parameters such as pressure (Kirkpatrick et al., 1995, 1996).

During the FY 1997, the P- and S-wave seismic velocity model for the SE Geysers was finalized, and interpretation of the results in terms of reservoir structure and parameters was begun. The results were reported on at the 1997 Stanford Geothermal Workshop (Kirkpatrick et al., 1997). Additionally, the SE Geysers network was reinstalled, and data collection resumed in August 1997 in preparation for the monitoring activities associated with the SE Geysers Effluent Pipeline and Injection Project (Dellinger, 1997).

\section{PROJECT OBJECTIVES}

The general objective of the project is to evaluate the utility of high-resolution MEQ monitoring as a reservoir management tool. Understanding the relationship between reservoir production activities and MEQ generation 
and occurrence, may help elucidate the effects of these activities on the reservoir and provide information useful for optimal management of the geothermal resource.

\section{Technical Objectives}

- Develop three-dimensional P- and S-wave seismic velocity and attenuation models for the SE Geysers.

- Locate hypocenters of MEQs occurring within the SE Geysers and characterize seismicity patterns.

- Determine MEQ source parameters such as size (magnitude, moment), stress drop, and focal mechanisms (moment tensors).

- Relate all of the above to reservoir parameters and processes such as lithology, location and nature of fracturing, steam occurrence, steam withdrawal, liquid injection, and reservoir pressure, temperature and degree of saturation.

\section{Expected Outcomes}

- Velocity structure and seismicity pattems to be used to characterize the subsurface in areas not sampled by other means, and to evaluate these areas as possible drilling targets.

- Monitoring changes in velocity structure, seismicity patterns, and source mechanisms through time to be used to devise optimal withdrawal and injection strategies.

- Greater understanding of the nature of seismicity in vapor-dominated geothermal systems, and of the physical effects of steam withdrawal and liquid injection .

\section{APPROACH}

In 1994 and 1995, the MEQ array at the SE Geysers consisted of 13 stations located over a $7 \mathrm{~km}$ by $4 \mathrm{~km}$ area. Vertical and horizontal ground velocity was continuously monitored at each station by three-component, $4.5 \mathrm{~Hz}$ geophones installed on the surface, and digitized at $480 \mathrm{samples} / \mathrm{s}$. The data were telemetered to a central site where the full waveform data for triggered events were recorded on tape, and later brought to LBNL for processing. Starting August 1997, data have been collected at 12 stations, and a switch to new, 8- $\mathrm{Hz}$ geophones is planned. The new geophones are more water resistant and will reduce station downtime during the winter due to moisture problems.

Automatic picking and locating is applied to all triggered events; $\mathrm{P}$ - and S-wave arrival times are then manually picked for all events located within the SE Geysers study area. The events are then re-located using the handpicked arrival times. and a three-dimensional Vp and Vs model. Source parameters are obtained from the amplitudes and polarities of the $P$ - and $S$-wave pulses, using a moment tensor inversion procedure. Summaries of these results are sent to representatives of The Geysers operators (Unocal, Calpine, and NCPA) and collaborative work is performed in relating the information to reservoir parameters.

Much of the work during FY 1997 focused on finalizing the velocity model for the SE Geysers. A data set consisting of $2860 \mathrm{P}$-arrival times and $1637 \mathrm{~S}$-arrival times from 297 events recorded in the first six months of 1994 was selected. The data were inverted to obtain P- and S-wave seismic velocities at 240 nodal points located within the study volume, spaced one $\mathrm{km}$ apart horizontally, and $0.5 \mathrm{~km}$ vertically (Figure 2). The progressive 
inversion method of Thurber (1983), as modified by Michelini and McEvilly (1991), was used. The method uses damped least squares to determine the perturbations to an initial estimated velocity model, which minimize the travel time residuals (the difference between the measured arrival times and the arrival times calculated through the estimated velocity model).

The velocity model was compared to the geologic structure (specifically to the position of the felsite intruding the main graywacke and other units), and to the known horizontal and vertical extent of the steam reservoir. These interpretations were partly based on laboratory measurements of seismic velocity in Geysers core material as a function of saturation recently performed by Boitnott (1995) and Boitnott and Boyd (1996), and described by Boitnott and Kirkpatrick (1997).

\section{RESEARCH RESULTS}

The three-dimensional seismic velocity results are shown in Figure 3. Generally, the northwest portion of the inversion volume is characterized by high $\mathrm{Vp}$ and high $\mathrm{Vs}$, and the southeastern portion with lower $\mathrm{P}$ - and $\mathrm{S}$ velocities. A distinct high P- and S-velocity anomaly appears to be associated with the felsite, also shown in Figure 3. A distinct low P-velocity anomaly at the -0.5 and $-1.0 \mathrm{~km}$ msl levels (approximately 1.0 to $1.5 \mathrm{~km}$ below the surface) seems to correspond to the steam reservoir.

The $\mathrm{Vp} / \mathrm{Vs}$ ratio results are low in general, with the average at each depth level ranging from 1.60 to 1.67 . The lowest $\mathrm{Vp} / \mathrm{Vs}$ ratios are at the $-0.5 \mathrm{~km}$ msl level, corresponding to the uppermost part of the steam reservoir. Low $\mathrm{Vp} / \mathrm{Vs}$ ratios have consistently been associated with the steam reservoir in other areas of The Geysers (Romero et al., 1995; Julian et al., 1996); Zucca et al. (1993) found low Vp associated with the reservoir. Generally, it has been thought that occupation of fractures and of matrix pore spaces by a vapor phase, as opposed to an incompressible fluid phase, lowers the bulk modulus which reduces $\mathrm{Vp}$, but not $\mathrm{Vs}$. This view tends to be supported by our SE Geysers results, which show a large low-Vp anomaly but only a small low-Vs anomaly corresponding to the lateral extent of reservoir.

Complicating the issue, however, are laboratory measurements that have shown that Vs increases with desaturation in Geysers core samples, probably due to a "shear strengthening" effect as the clay fraction is dried out (Boitnott and Boyd, 1996). This may contribute to a high average Vs at the $-0.5 \mathrm{msl}$ level, and the resultant overall low in $\mathrm{Vp} / \mathrm{Vs}$ at that depth. It also reveals the difficulty of separating out the effects of mineralogy and lithology from those of saturation, and indicates that interpretations of spatial $\mathrm{Vp} / \mathrm{Vs}$ variations must be made cautiously. It does indicate, however, that changes in $\mathrm{Vp} / \mathrm{Vs}$ ratios over time may be useful in monitoring changes in saturation that result as steam is extracted, pressure declines, and liquid in the matrix is converted to the vapor.

Figure 3 also shows the interrelationship between low velocity, earthquake occurrence, and the steam reservoir. The steam reservoir is characterized by high fracture density; which may play a part in causing the low seismic velocity, and may cause the observed diffuse seismicity pattern by providing many MEQ failure planes.

Figure 4 gives an enlarged view of the position of the felsite and the steam reservoir at the $-0.5 \mathrm{~km}$ msl level, and of the locations of the MEQs occurring in the depth interval between -0.25 and $-0.75 \mathrm{~km} \mathrm{msl}$. The P-velocity model at that level is also shown. The association of the felsite with the high $\mathrm{Vp}$-anomaly is clearly seen, as is the association of low $\mathrm{Vp}$ with the steam reservoir. We have previously reported that most events at the SE Geysers are confined to the producing part of the steam reservoir, except for deep events occurring in vertically linear trends beneath some injection wells (Kirkpatrick et al., 1995, 1996). Figure 4 indicates that most of the events at this depth occur within the steam reservoir (and the low-velocity zone), but that some appear on the flanks of the high-velocity anomaly, to the north and south of the felsite. These events are occurring above the 
top of the mapped steam reservoir in this location, and are thought to be associated mainly with liquid injection into several Unocal wells.

A synthetic test was conducted to investigate whether the data was capable of resolving the expected velocity contrast between the felsite and the intruded rock. The felsite is expected to have a higher velocity because it is less fractured than the intruded material. Additionally, a vertical seismic profile conducted in a well penetrating the felsits: measured $10 \%$ greater $\mathrm{Vp}$ in the felsite than in the material directly above it (J. Beall, pers. comm.). The synthetic test demonstrated that a velocity contrast of as little as $5 \%$ could be imaged, and that furthermore, the calculated seismic signature of such a contrast in the location of the mapped felsite, matches the inversion result to a remarkable degree.

\section{FUTURE PLANS}

We have begun to collect data from the re-installed network, in order to monitor seismicity that may be associated with increased injection due to the S.E. Geysers Effluent Pipeline and Injection Project. We plan to further analyze the seismicity patterns and source parameters of the 1994 and 1995 data, as well as the new data for relationships between injection, withdrawal, and reservoir parameters. Past work has tended to focus on generalized analysis of the SE Geysers; in the next year we plan to look at several SE Geysers sub-areas in more detail. To do this, we will be making some refinements to the moment tensor inversion and the magnitude determination methods.

Because of the potential of using changes in $\mathrm{Vp}, \mathrm{Vs}$, and $\mathrm{Vp} / \mathrm{Vs}$ ratios to monitor changes in saturation, a velocity inversion will be performed on the 1997 or 1998 data and the results compared to the 1994 velocity model. If changes are indicated, other methods may be used to elucidate the details and confirm the result.

\section{INDUSTRY INTEREST}

The project is a joint DOE-Industry (Unocal, Calpine, and NCPA) project. The companies provide field support, injection and production data, as well as a list of MEQs recorded by the Unocal network. Meetings are held periodically to discuss research results, directions, and priorities.

\section{REFERENCES}

Boitnott, G. N. (1995), Laboratory measurements on reservoir rocks from The Geysers geothermal field, Proc. 20th Workshop on Geothermal Reservoir Engineering, Stanford University, pp. 107-114.

Boitnoth, G. N., and P. J. Boyd (1996), Permeability, electrical impedance, and acoustic velocities on reservoir rocks from The Geysers geothermal field, Proc. 21st Workshop on Geothermal Reservoir Engineering, Stanford University, pp. 343-350.

Boitnott, G. N., and A. Kirkpatrick (1997), Interpretation of field seismic tomography at The Geysers geothermal field, California, Proc. 22nd Workshop on Geothermal Reservoir Engineering, Stanford University, pp. 391-398.

Dellinger, M. (1997), Status of the S.E. Geysers Effluent Pipeline \& Injection Project, Proc. Geothermal Program Review XV, March 24-26, 1997, San Francisco, CA, pp. 6/3-11.

Julian, B. R, A. Ross, G. R. Folger, and J. R. Evans (1996), Three-dimensional seismic image of a geothermal reservoir: The Geysers, California, Geophys. Res. Lett., 23, 685-688. 
Kirkpatrick, A., E. L. Majer, and J. E. Peterson, Jr. (1995), Microearthquake monitoring at the Southeast Geysers using a high-resolution digital array, Proc. 20th Workshop on Geothermal Reservoir Engineering, Stanford University, pp. 79-89.

Kirkpatrick, A., J. E. Peterson, Jr. and E. L. Majer (1996), Source mechanisms of microearthquakes at the Souteast Geysers geothermal field, California, Proc. 21st Workshop on Geothermal Reservoir Engineering, Stanford University, pp. 359-366.

Kirkpatrick, A., J. E. Peterson, Jr. and E.L. Majer (1997), Three-dimensional compressional- and shear-wave seismic velocity models for the Southeast Geysers geothermal field, California, Proc. 22nd Workshop on Geothermal Reservoir Engineering, Stanford University, pp. 399-410.

Michelini, A. and T. V. McEvilly (1991) Seismological studies at Parkfield: I. Simultaneous inversion for velocity structure and hypocenters using cubic b-splines parameterization, Bull. Seismol. Soc. Am. 81, 524-552.

Romero, A. E., T. V. McEvilly, E.L. Majer, and D. Vasco (1995), Characterization of the geothermal system beneath the Northwest Geysers steam field, California, from seismicity and velocity patterns, Geothermics, 24, 471-487.

Romero, A. E., T. V. McEvilly, E.L. Majer (1997), 3-D microearthquake attenuation tomography at the Northwest Geysers geothermal region, California, Geophysics, 62, 149-167.

Stark, M. A. (1992) Microearthquakes - a tool to track injected water in The Geysers reservoir, Geotherm. Resour. Counc. Special Report No. 17, 111-117.

Thurber, D. H. (1983) Earthquake locations and three-dimensional crustal structure in the Coyote Lake area, Central California, J. Geophys. Res. 88, 8826-8236.

Zucca, J. J., L. J. Hutchings, and P.W. Kasameyer (1993), Seismic velocity and attenuation structure of The Geysers geothermal field, California, Geothermics, 23, 111-126. 


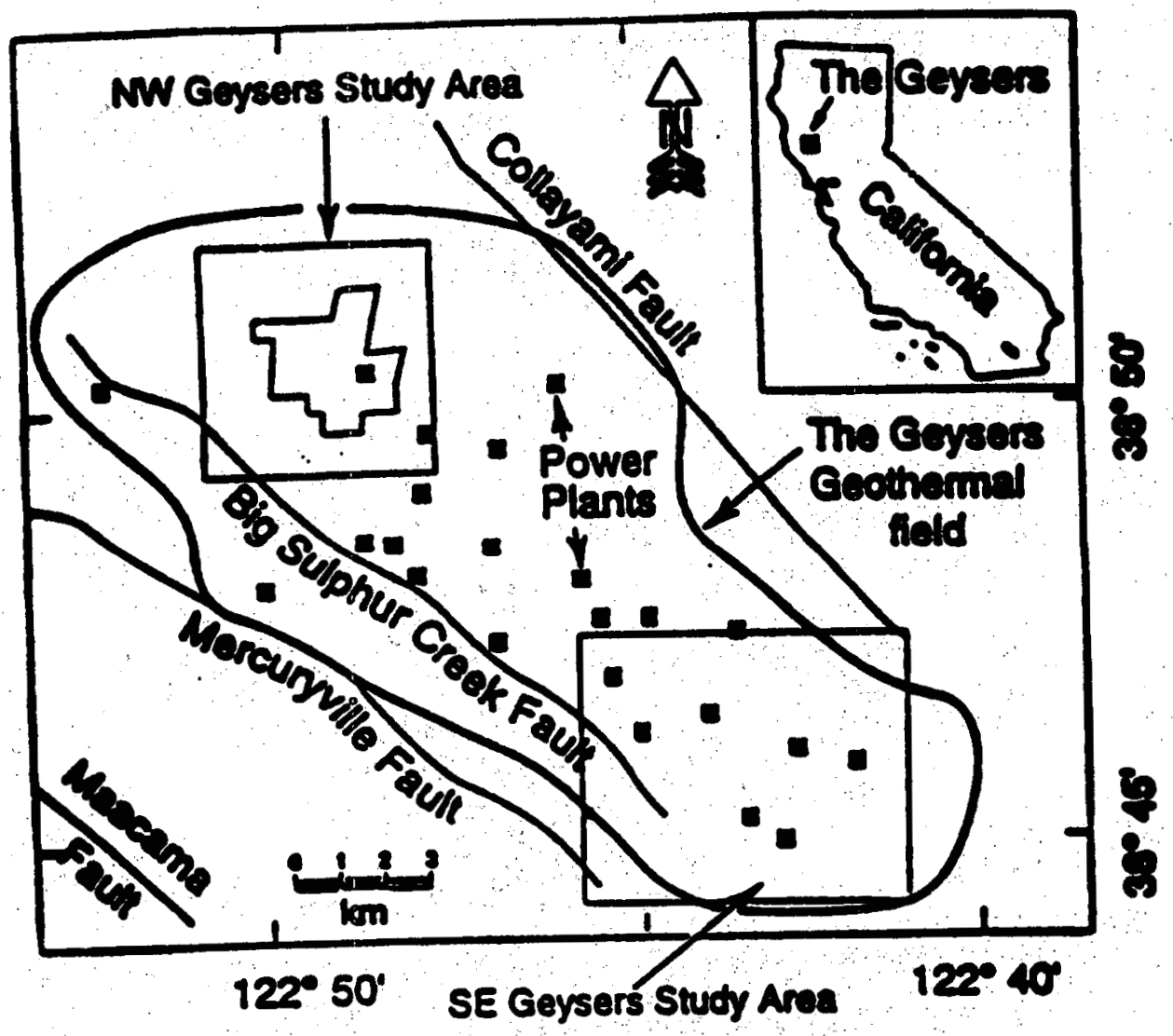

W

8

4

Q.

1.

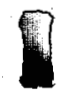

Figure 1 - Location of the Northwest (NW) and Southenst (SE Geyeors) study wees. 
(a)

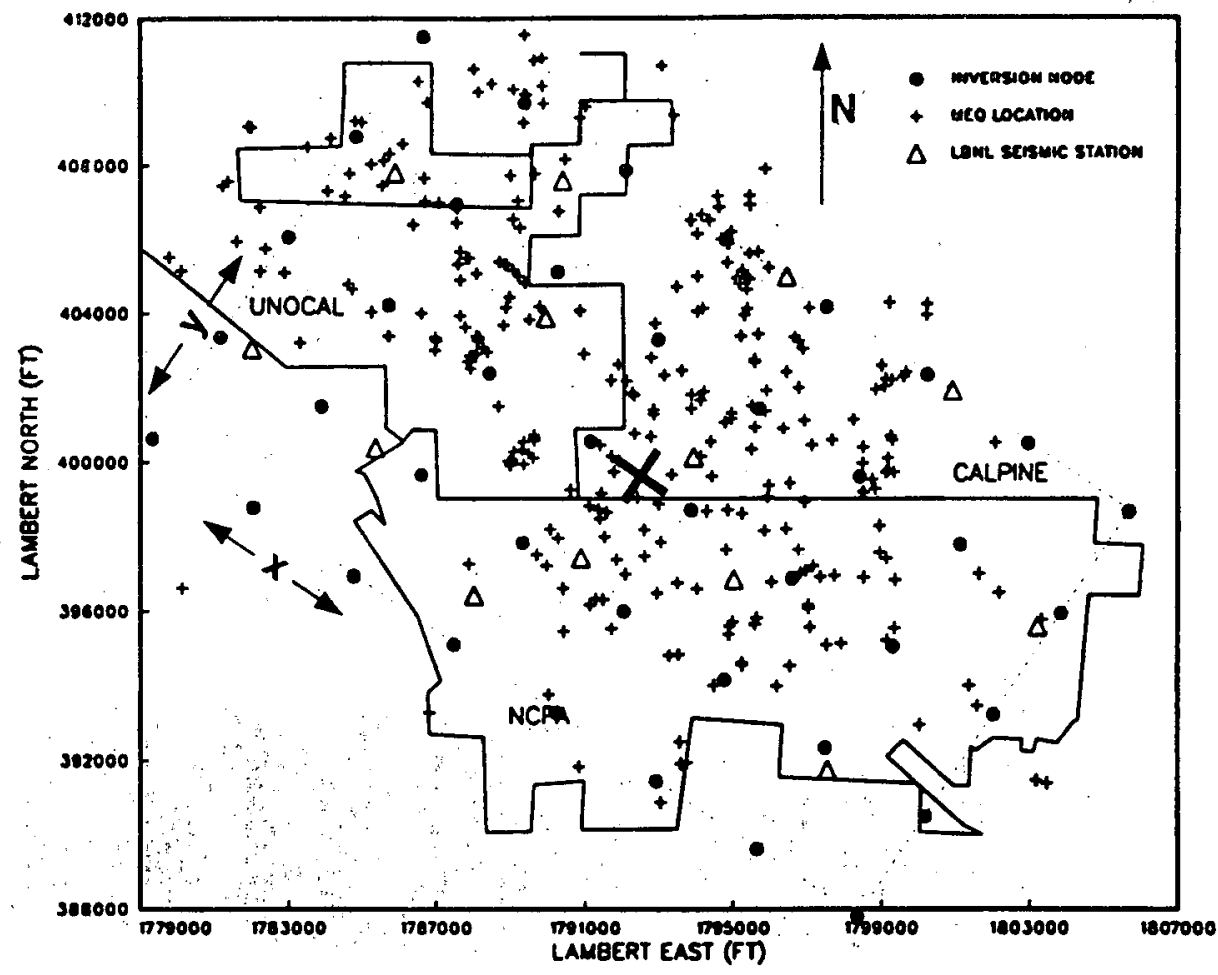

(b)

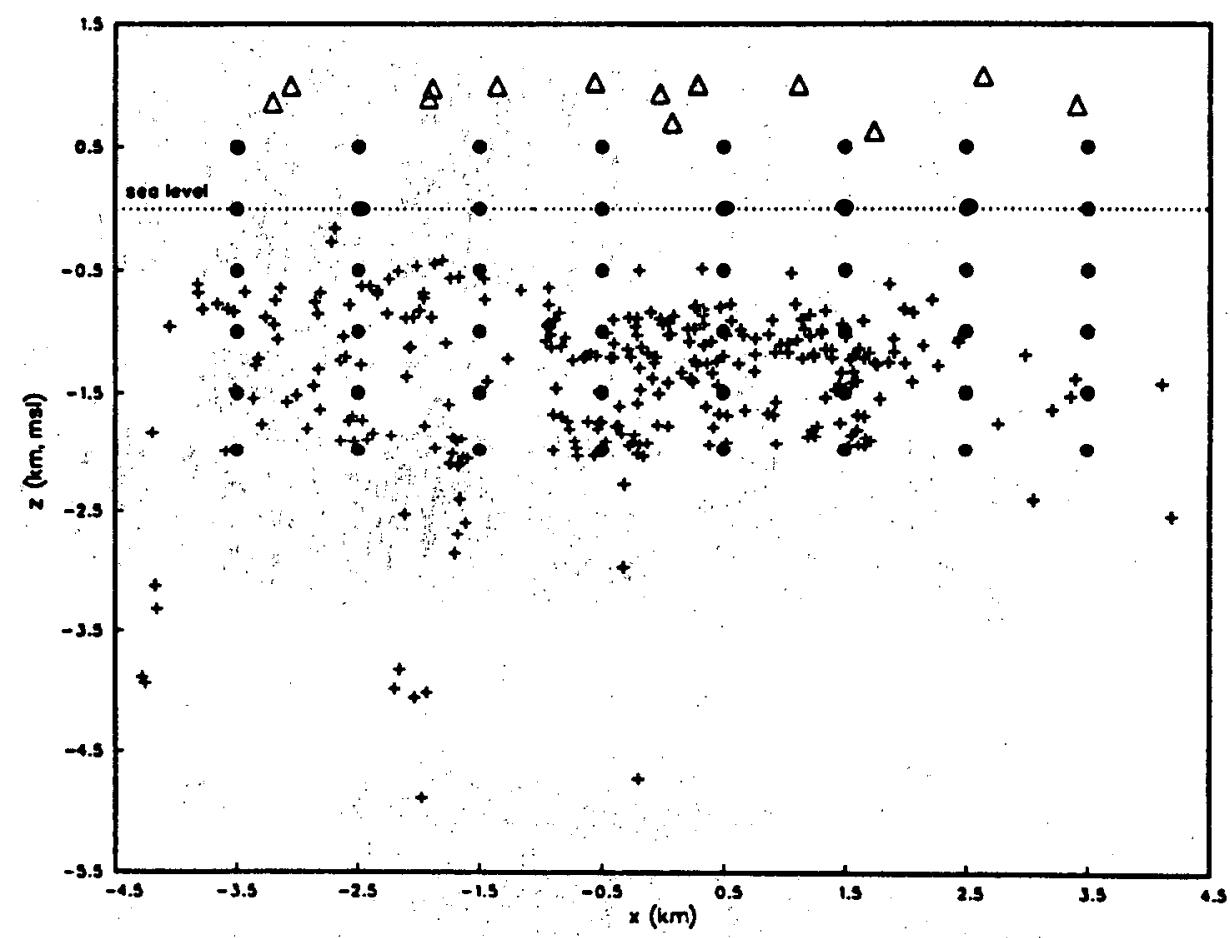

Figure 2 - Location of LBNL seismic network stations, inversion nodes, and MEQs used in the seismic velocity inversion. (a) The black cross denotes the center of the inversion grid $(x=0, y=0)$ (the $x$-axis is rotatcd $34^{\circ}$ clockwise from E-W). The rectangle defined by the inversion nodes is shown in Figures 3 and 4 . (b) Projection of MEQs, nodes, and stations onto the vertical plane along the $x$-axis of the inversion. 


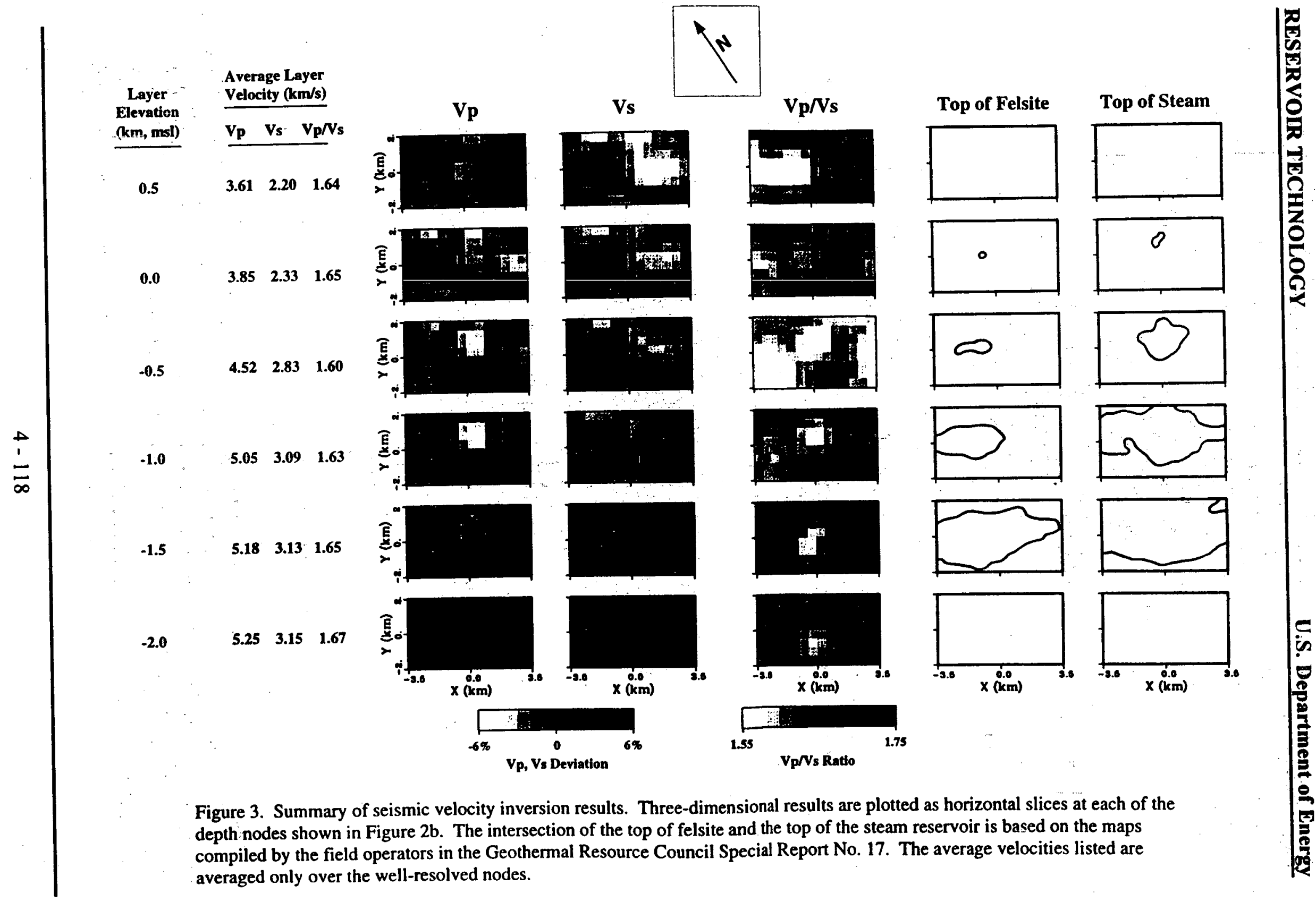




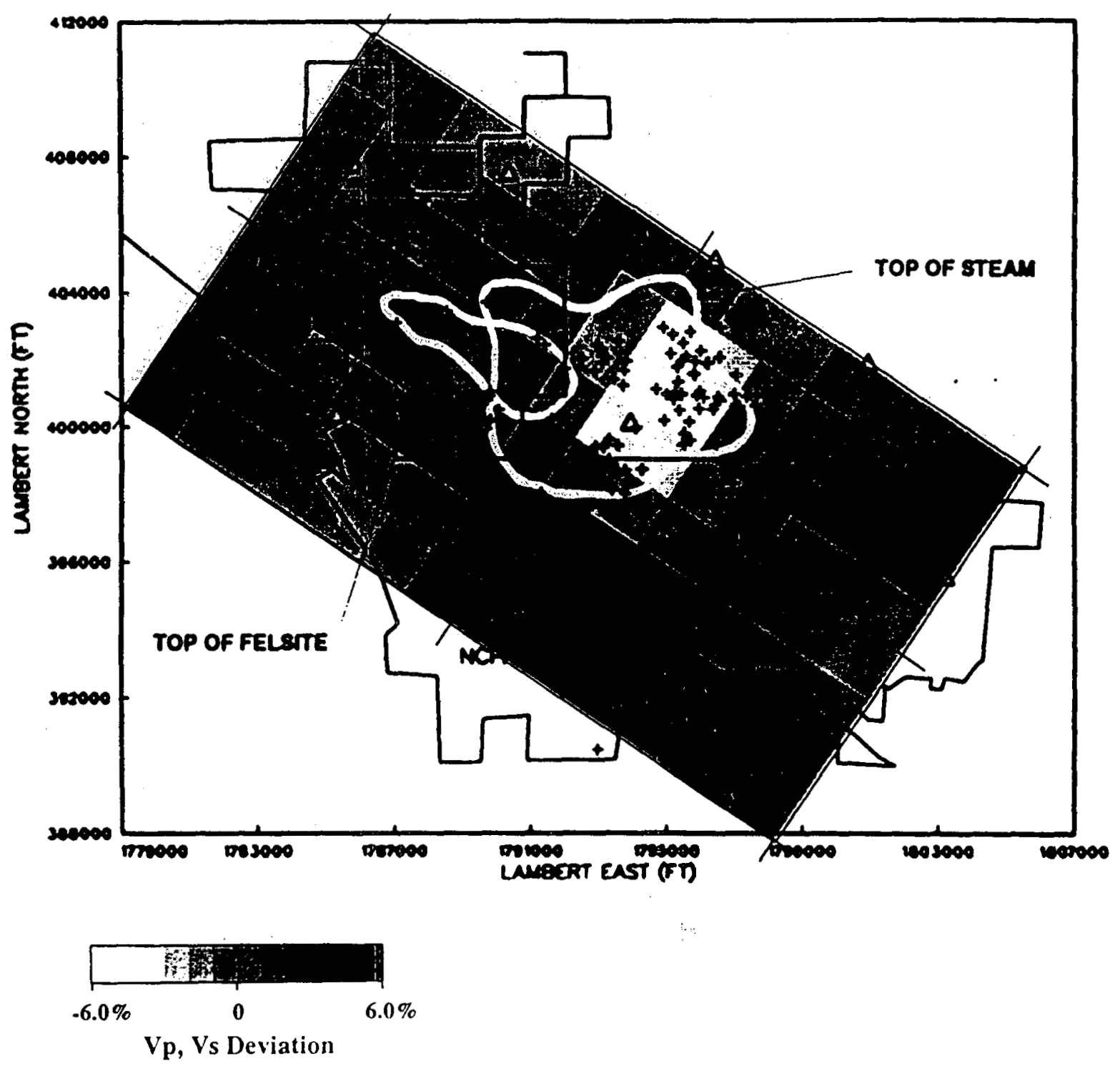

Figure 4 - Lateral variations in P-wave seismic velocity at the $-0.5 \mathrm{msl}$ depth level, plotted as relative deviation from the average P-velocity of $4.52 \mathrm{~km} / \mathrm{s}$. The white lines denote the extent of the steam reservoir and of the felsite at $-0.5 \mathrm{~km}$ msl, and the crosses show the MEQs located between -0.25 and $-0.75 \mathrm{~km}$ msl in 1994 . Note the association of the high-velocity anomaly with the felsite, and the low-velocity anomaly with the steam reservoir. The events occurring on the flanks of the high-velocity anomaly are thought to be associated with injection into two Unocal wells, while the MEQs in the low-velocity zone are thought to be associated with steam withdrawal. 


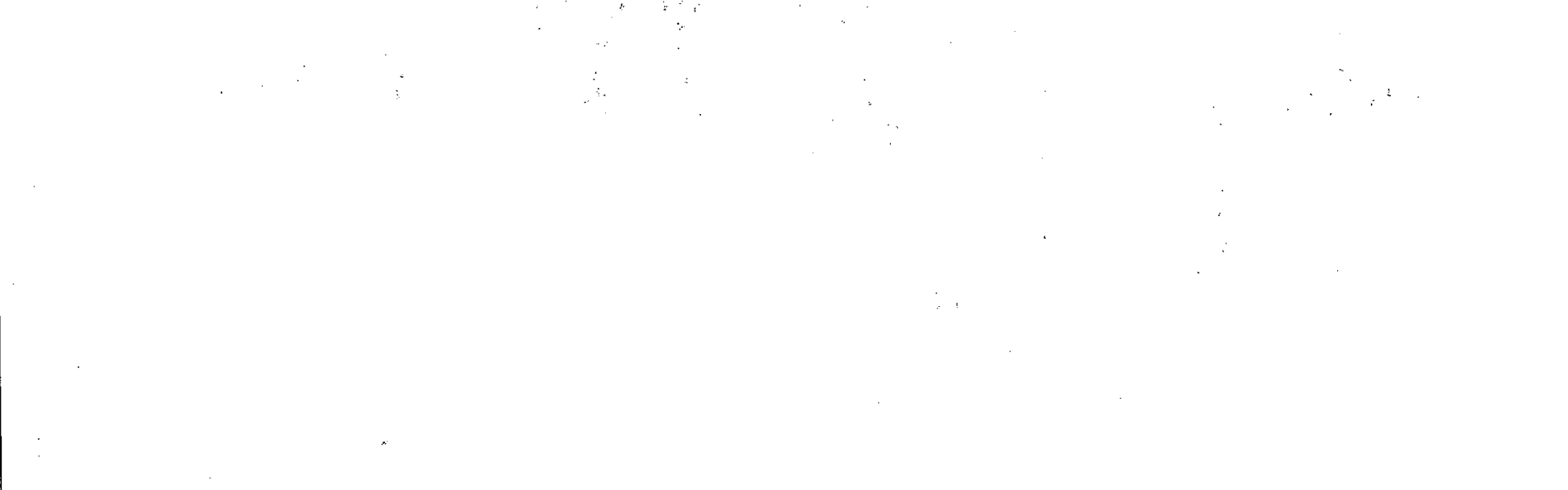




\title{
A COMPREHENSIVE STUDY OF FMACTURE PATTERNS AND DENSITIES IN THE GEYSERS GEOTHLRMAL RESERVOIR USING MICROEARTHQUAKE SHEAR-WAVE SPLITTING TOMOGRAPHY
}

\author{
E. Shalev, P.E. Malin \\ Division of Earth and Ocean Sciences, NSOE \\ Duke University
}

KEY WORDS

Shear-wave Splitting, crack-density, tomography, fracture, The Geysers

PROJECT BACKGROUND AND STATUS

The project started in September 1996, and during the first year we gathered data for about 6,000 microearthquake events from the Lawrence Berkeley National Laboratory (LBNL). All necessary computer facilities to identify shear-wave splitting from those microearthquake seismograms have been established. We have identified approximately 1000 split shear waves from almost 600 selected microearthquake events. We have discovered the dominant polarization of those shear waves and established the pervasive orientation of cracks in the geothermal field (Lou et. al. 1997).

From time delays of those split shear waves we have perfermed a preliminary tomographic inversion for crack density distribution at The Northwest Geysers (Figure 1). We emphasize, that this is only a preliminary inversion demonstrating the feasibility of our method. A more detailed tomographic inversion will be performed when more split shear-wave data have bcen identified.

\section{PROJECT OBJECTIVES}

The goal of this project is to produce 3-dimensional maps of crack-density and crack orientation in geothermal or hydrocarbon reservoirs utilizing shear-wave splitting.

\section{Technical Objectives}

- Determination of fracture pattern: Mapping the predominant crack direction in the geothermal field.

- Detailed 3-D tomography for crack-density: Construct a crack-density map of the subsurface with $1 \mathrm{~km}$ resolution.

- Develop a shear-wave splitting tomographic metho to simultaneously invert for crack-density and crack-orientation: This method can be cmployed in areas where not all cracks are align in the same direction.

\section{Expected Outcomes}

- Crack orientation map of the Geysers area: To be published in a scientific journal.

- Detailed crack-density map of the Geyser area: To be published in a scientific journal. 


\section{APPROACH}

Shear-wave anisotropy and shear-wave splitting due to aligned cracks in the crust have been observed world-wide. Shear-wave splitting occurs in variety of tectonic settings and data gathering experiments, ranging from earthquake monitoring [e.g. Lou and Rial 1994] to controlled source seismic profiling. It has been recognized that the polarization of the fast split shear-wave is usually parallel to the local strike of cracks. Further, the time delay between the fast and the slow shear waves is directly related to the intensity of aligned crack-induced anisotropy in the medium [Crampin 1987, Cramping and Lovell 1991]. Therefore, the recording and inverting of shear-wave splitting is an important diagnostic tool for finding the direction and density of subsurface cracks in energy reservoirs [Muller 1991, Sato et. al. 1991, Medow and Winterstein 1994].

Shear-wave splitting can be identified by direct examination of polarization diagrams of the two horizontal orthogonal components of shear-wave arrivals. In anisotropic media, almost all shear-wave first arrivals are observed to have linear polarization. After a time delay (usually hundredths of a second in a microearthquake survey), the first motions are followed by abrupt changes in direction that evolve into elliptical motion, or further linear motion along different polarization directions, provided the time delay is long enough to separate the late signal from the initial arrival.

Inverting for the location and density of cracks in rock bodies is similar to local earthquake tomography for Pwave velocity structure (c.g Thurber 1983; 1989; Michlini and McEveilly 1991; Shalev 1998). The time difference between fast and slow split shear-wave is the fundamental observation needed for this inversion. We assume that this time delay between fast and slow rays is caused by aligned cracks in the subsurface.

Crack density is defined as $\epsilon=\mathrm{Na}^{3} / \mathrm{V}$ where $\mathrm{N}$ is the number of cracks of average radius a in volume $\mathrm{V}$. Assuming, as a first order approximation, that the symmetric axis is the same across the field, and that each ray azimuth stays the same during its flight. We can express each split shear-wave observation as a function of: the ray angle, the S-wave velocity along the ray path, and the crack-density along the ray path. After inverting for S-velocity, we can invert for the crack density.

\section{RESEARCH RESULTS}

During the first year of the project, we gathered data for about 6,000 microearthquake events from the LBNL Geysers database. We identified approximately 1,000 splitis shear waves from nearly 600 selected microearthquake events. The polarization of those leading shear waves is predominantly $\mathrm{N} 10^{\circ}-40^{\circ} \mathrm{E}$, implying that the shear-wave splitting is mainly caused by pervasive, north-northeast aligned anisotropy at The Northwest Geysers field. Time delays between the leading and second shear waves can be as large as $10 \mathrm{~ms} / \mathrm{km}$ to $30 \mathrm{~ms} / \mathrm{km}$. We suggest that the direction and magnitude of this shear wave splitting is due to the presence of typical secondary fractures along the northwest-trending right-lateral fault systems in The Geysers. We published a scientific paper (Lou et. al. 1997) based on the work completed during the first year.

From time delays of those split shear waves we performed a preliminary tomographic inversion for crack density distribution at The Northwest Geysers. Figure 1 shows six horizontal slices of relative crack density distribution at $0.5 \mathrm{~km}$ depth interval. Light color indicates high crack density and dark color indicates low crack density. However, this inversion result is mainly to demonstrate the effectiveness of our shear-wave splitting tomographic method, since it has a low resolution $(1.5 \mathrm{kmX1} .5 \times 0.5 \mathrm{~km})$, and is limited to an area covered only by about 560 split shear wave raypaths recorded within a shear-wave splitting window. 


\section{FUTURE PLANS}

In the next year we plan to developed a two parameters inversion, inverting for 3-D crack orientation and crack density at the same time, thus enabling the method to be employed at areas with varied crack orientation. We also plan to automate at least part of the shear-wave splitting

\section{INDUSTRY INTEREST}

Organization

DOE, Geothermal industry

Oil Industry

\section{Type and extent of interest}

3-D crack-density map and crack orientation

Application to hydrocarbon reservoirs

\section{REFERENCES}

Crampin, S., Geological and industrial implications of extensive-dilatancy anisotropy, Nature, 328, 491-496, 1987.

Crampin, S., A review of the effects of crack geometry on wave propagation through aligned cracks, Canadian Journal of Exploration Geophysics, 29, 03-17, 1993.

Crampin, S and J. Lovell, A decade of shear-wave splitting in the Earth's crust: what does it mean? what use can we make of it? and what should we do next?, Geophys. J. Int. 107, 387-407, 1991.

Lou, M and J.A. Rial, Characterization of the crack geometry at the Coso, California geothermal reservoir by analyzing shear-wave splitting from microearthquakes, Proceedings of the Nineteenth

Lou, M., E. Shalev, and P.E. Malin, Shear-wave splitting and fracture alignments at the northwest Geysers, California, Geophys. Res. Lett. 24, 1895-1898, 1997.

Meadows, M.A. and D.F. Winterstein, Seismic detection of a hydraulic fracture from shear-wave VSP data at Lost Hills Field, California, Geophysics, 59, 11-26, 1994.

Michelini, A. and T.V. McEvilly, Seismological study at Parkfield. I. Simultaneous inversion for velocity structure and hypocenters using cubic B-splines parameterization: Bull. Seismol. Soc. Am. 81,524-552, (1991).

Mueller, M.C, Prediction of lateral variability in fracture intensity using multicomponent shear-wave surface seismic as a precursor to horizontal drilling in the Austin Chalk, Geophys. J. Int., 107, 409-415, 1991.

Shalev, E., and J.M. Lees, Cubic B-splines tomography at Loma Prieta, Accepted by BSSA, 1998.

Thurber, C. H., Earthquake locations and three-dimensional crustal structure in the Coyote Lake area, Central California., J. geophys. Res., 88, 8226-8236., 1983. 

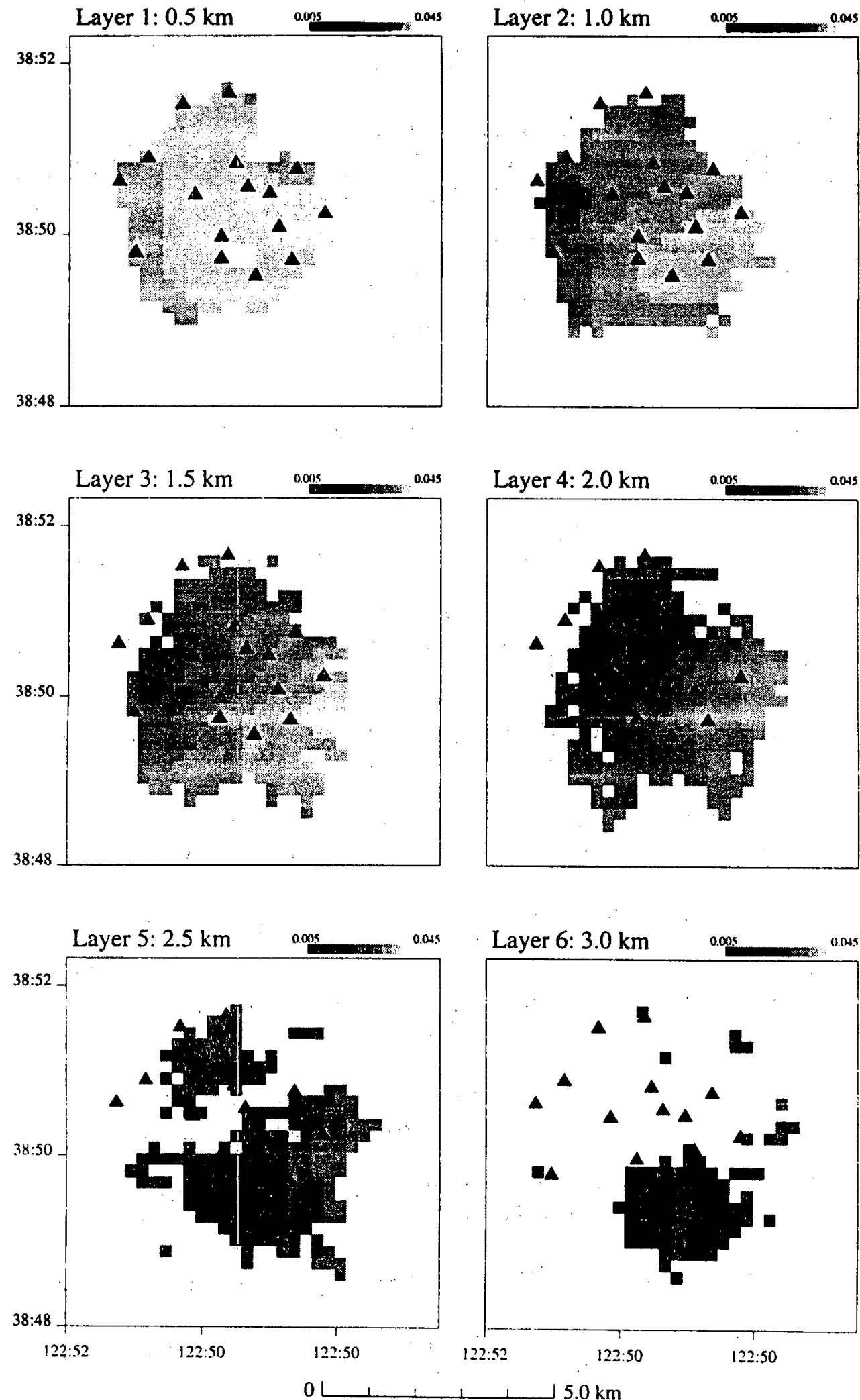

Figure 1 - Preliminary tomographic inversion result for the crack density at $0.5 \mathrm{~km}$ interval horizontal slices at The Northwest Geysers. Light color indicates high crack density and dark color indicates low crack density. The inversion is limited to those area covered by split shear waves. 


\title{
CHARACTERIZATION OF FRACTURE PATTERNS AND DENSITIES IN THE GEYSERS GEOTHERMAL RESERVOIR BY ANALYZING SHEAR- WAVE SPLITTING FROM MICRO-EARTHQUAKES
}

\author{
J.A. Rial \\ Wave Propagation Laboratory \\ University of North Carolina at Chapel Hill
}

\author{
KEY WORDS \\ fracture patterns, The Geysers, shear-wave splitting

\section{PROJECT BACKGROUND AND STATUS}

This project began in September, 1996. During the first year of this contract we have analyzed approximately 192 seismic events (88 from year 1994 and 104 from year 1988) at 16 stations from The Geysers geothermal field region and processed 9,216 individual components in search for indications of shear wave splitting. A total of 141 split shear wave paths with clear polarization directions were found and plotted. In addition, an important part of the time and effort financed by the grant to UNC-Chapel Hill went to the training and support of graduate students under the P.I.'s supervision. An important human resource is thus being formed with the training of geophysics students in the techniques of shear wave splitting.

Another important development has been the acquisition of a full-wave finite difference modeling code that will be used in the continuation of this project in order to resolve a number of difficult questions motivated by the results obtained so far. The uses and possible outcomes related to this new computational facility are discussed in more detail below. Second Year (September 1997-September 1998) During the second year it is planned to continue the analyses and processing of The Geysers data to complete the characterization of the crack patterns. An important part of the effort this time will be dedicated to confirming the effects of anisotropy and to determine the limits of the methodology by forward modeling of the seismograms with a full-wave finite difference code that allows 3-D complete description of the (isotropic) medium, and complete description of vertical and lateral heterogeneities.

With this code we will be able to identify effects due to free-surface reflection/conversion, P-to-SV conversions that mask the splitting, and more importantly, we shall be able to assess which is the optimum range for the angle of incidence at each receiver that minimizes interference and masking of the split shear wave, a condition that to date has been based upon theoretical calculations only. This approach is potentially very useful because it will also help us determine whether data collected at the free surface are clean enough to be processed for shear-wave splitting. Besides making the identification of splitting unambiguous, this is an unprecedented approach, since it has not been clearly demonstrated that the method as it is presently used can be extended to incorporate data recorded at the free surface. If this is shown to be possible, and in which circumstances, a much more extensive data set will become automatically available, since shear-wave splitting could be done in areas of The Geysers field that do not have down-hole instrumentation.

\section{PROJECT OBJECTIVES}

The ultimate goal of this project is to determine orientation and three-dimensional distribution of crack density in geothermal or hydrocarbon reservoirs through the analysis of shear-wave splitting. In order to transfer this 
technology to the geothermal industry, we will incorporate our existing shear-wave splitting processing and interpretative techniques into a user-friendly, graphics-oriented computer software package that will allow interactive determination of main fracture orientations and fracture density distributions in geothermal or hydrocarbon reservoirs. For the present period of funding the objectives are:

\section{Technical Objectives}

- Determination of fracture patterns: Continuing the construction of rose diagram maps of polarizations of the leading shear waves.

- Full-wave modeling (isotropic, heterogeneous medium): of the entire seismogram to estimate the effects of heterogeneity, as compared to the observed shear wave splitting. The synthetic seismograms will also allow us to determine the exact dimensions of the angle of incidence window required in each receiver to obtain a clean shear wave split record, including surface-collected data, wherever possible.

- Simulation (forward modeling) of the effects of anisotropy. This will be complementary to and a verification tool for the inversion approach used by the Duke University group.

\section{Expected Outcomes}

- Crack orientation maps for the NW area of The Geysers (In collaboration with the Duke group). The combined results will be published in scientific journals.

- Methodology to clean the observed seismograms of undesirable noise related to free surface reflection/conversion using full-wave synthetic seismograms. This will also be published in relevant journals.

- Verification of models obtained with the results of inversion of the Duke group. This will be a joint publication, UNC-Duke.

\section{APPROACH}

\section{Shear-Wave Splitting Technique}

Shear-wave splitting due to the stress-aligned cracks in the crust has been widely observed in a variety of earthquake recordings or controlled-source seismic data. It has also been recognized that the polarization of the leading split shear wave is usually parallel to the local strike of cracks (or normal to the direction of the minimum horizontal stress), and the time delay between fast and slow shear waves is directly related to the intensity of crack-induced anisotropy in the medium (see also Crampin 1987, Crampin and Lovell 1991). Therefore, the interpretation of shear-wave splitting is an important diagnostic tool to determine the direction and evaluate the bulk density of subsurface fractures in hydrocarbon or geothermal reservoirs (Sato et. al. 1991).

Shear-wave splitting can be often identified by direct examination of polarization diagrams of the two horizontal orthogonal components of shear-wave arrivals. In anisotropic media, almost all shear-wave first arrivals are observed to have linear polarization. After a time delay (usually hundredths of a second in a microearthquake survey), the first motions are followed by abrupt changes in direction that evolve into elliptical motion, or further linear motion along different polarization directions, provided the time delay is long enough to separate the late signal from the initial arrival (for example, see Figure 1). To quantitatively determine the polarization and time 
delay of split shear waves, the following processing method is used: First, the two horizontal components of the shear wave seismograms are numerically rotated to search for the orientation along which the ratio of the projections of the particle displacement reaches a maximum. In a time window that contains only the fast shearwave arrival, the azimuth at which this maximum ratio occurs is taken as the polarization direction of fast shear wave (Shih et. al, 1989). Second, after the appropriate rotation of the seismogram components to the azimuth angle previously determined has been performed, the time delay between the split shear waves is measured by cross-correlation. Although straightforward, the analysis of shear-wave splitting for the purpose of seismic imaging must be based on a large set of shear-wave seismogram data. The behavior of shear-wave splitting above small earthquakes is usually very complicated, because of the complexity of the source signal, subsurface geology structure, and surface topography. One major restriction to the analysis of shear-wave splitting is that in order to obtain correct interpretation of split shear-waves, the recording site needs to be within a shear-wave window. The shear-wave window beneath a recording site is defined by the critical angle arcsin (Vs/Vp), where Vs and $\mathrm{Vp}$ are the $\mathrm{S}$-wave and $\mathrm{P}$-wave velocities, respectively. For angles of incidence greater than the critical angle (measured from the vertical-down direction), shear waves strongly interact with any free surface or interface, and thus, all similarities with the incoming waveform are irretrievably lost (Booth and Crampin 1985).

\section{Crack Orientations}

One important parameter to characterize fracture patterns of geothermal reservoirs is the orientation or strike of fracture. To determine the local strike of cracks from the polarization direction of the leading split shear waves, we can plot rose diagrams of the fast shear-wave polarization directions vs. their relative frequency for each seismic station. The local strike of fracturing of direction of the maximum horizontal stress then can be inferred from the dominant polarization directions of the rose diagrams (Lou and Rial 1994). Crack density/intensity. Besides crack orientation, crack density is another important parameter to characterize subsurface crack patterns. Crack density (e) is defined by the expression (Hudson, 1981): $e=3 \mathrm{DNa} / \mathrm{V}(\mathrm{l})$ where $\mathrm{N}$ is the number of cracks of average radius a in volume $V$. From the time delays of split shear waves, we can estimate e along each ray path. If we assume that anisotropy is caused by aligned water-filled cracks contained in an otherwise isotropic homogeneous medium, where each crack is a thin, disk-like opening with radius much smaller than the typical wavelength of shear-waves. Tomographic inversion of crack density. In order to determine the three-dimensional crack density distribution, we propose a nonlinear tomographic method to invert seismic shear-wave splitting anisotropy. Since the seismic tomographic principle is very general, we can adopt a varies of existing tomographic methods, which has been widely used in local earthquake tomography for P-wave inversion (Shalev 1992, Lees and Lindley 1994).

\section{RESEARCH RESULTS}

During the first year we have analyzed approximately 192 seismic events (88 from year 1994 and 104 from year 1988 ) at 16 stations from The Geysers geothermal field region and processed 9,216 individual components in search for indications of shear wave splitting. A total of 141 split shear wave paths with clear polarization directions were found and plotted. Figures 1 and 2 in the Appendix show selected typical examples of the recordings that were used to compose the map of polarizations of the fast shear wave shown in Figure 3. Note the outstanding quality of the data. Many of the polarizations found are textbook examples of shear-wave splitting and confirm that the method is appropriate for The Geysers. Figure 4 shows the simulations carried out to understand wave propagation phenomena using a full-wave simulator. The synthetic seismograms provide clues as to which angles of incidence for the approaching $S$-wave can be expected to be contaminated with surface reflected-converted phases and thus unusable. This will allow an unambiguous determination of crack directions at any of the array stations. 


\section{FUTURE PLANS}

In the next year it is anticipated that anisotropic description of the medium will be incorporated in the finite difference code, making the forward modeling complete, which will enable us to check the results of the inversion procedures and to produce complete inversions of seismographic data for anisotropy.

\section{INDUSTRY INTEREST}

Organization

DOE, Unocal

Oil Industry

\section{Type and Extent of Interest}

Shear-wave splitting technique

Applications to hydrocarbon reservoirs

\section{REFERENCES}

Aster, R. C., P. M. Shearer, and J. Berger, Quantitative measurements of shear wave polarizations at the Anza seismic network, Southern California: Implications for shear-wave splitting and earthquake prediction, J. Geophys. Res., 95, 12,449-12,473, 1990.

Babuska, V and M. Cara, Seismic Anisotropy in the Earth, Kluwer Academic Pub., London, 1991.

Booth, D.C. and S. Crampin Shear-wave polarizations on a curved wave front at an isotropic free-surface, Geophys. J. R. astr. Soc., 83, 31-45, 1985.

Cliet, Ch., L. Brodov, A. Tikhonov, D. Marin and D. Michon, Anisotropy survey for reservoir definition, Geophys. J. Int., 107, 417-427,1991. Crampin, S., A review of wave motion in anisotropic and crack edelasticmedia, Wave Motion, 3, 343-391, 1981.

Crampin, S., Geological and industrial implications of extensive-dilatancyanisotropy, Nature, 328, 491-496, 1987.

Crampin, S and J. Lovell, A decade of shear-wave splitting in the Earth's crust: what does it mean? what use can we make of it? and what should we do next?, Gcophys. J. Int. 107, 387-407, 1991.

Hudson, J.A., Wave speeds and attenuation of elastic waves in material containing cracks, Geophys. J. R. astr. Soc., 64, 133-150, 1981.

Julian, B. R., A. Prisk, G. R. Foulger, and J. R. Evans, Three-dimensional images of geothermal systems: local earthquake P-wave velocity tomography at the Hengill and Krafa geothermal areas, Iceland, and the Geysers, California. Trans. Geother. Resour. Counc., 17, 113-121, 1993.

Julian, B. R., A. Ross, G. R. Foulger, and J. R. Evans, Three-dimensional seismic image of a geothermal reservoir: The Geysers, California, to appear in Geophysical Research Letters, 1996.

Lees, J.M. and Lindley, G.T., Three-dimensional attenuation tomography at Loma Prieta: inverting for $\mathrm{t}^{*}$ and $\mathrm{Q}$, J. Geophys. Res., 99, 6843-6864,1994. 
Lou, M and J.A. Rial, Characterization of the crack geometry at the Coso, California geothermal reservoir by analyzing shear-wave splitting from micro carthquakes, Proceedings of the Nineteenth Workshop on Geothermal Reservoir Engineering, Stanford University, SGP-TR-147, 15-20,1994.

Lou, M. and J.A. Rial Modeling elastic wave propagation in homogeneous anisotropic media by the pseudospectral method, Geophysical Journal International, 120, 60-72, 1995.

Majer, E. L. and T. V. McEvilly, Seismological investigations of the Geysers geothermal field, Geophysics, 44, 246-269, 1979.

O'Connell, D. R. and L. R. Johnson, Progressive inversion for hypocenters and P-wave and S-wave velocity structure: application to The Geysers, California, geothermal field, J. geophys. Res., 96, 6223-6236, 1991.

Romero, A. E., T. V. McEvilly, E. L. Majer, and D. Vasco, Characterization of the geothermal system beneath the Northwest Geysers steam field, California, from seismicity and velocity patterns, Geothermics, 23, 111-126, 1995.

Sato, M., N. Matsumoto and H. Niitsuma, Evaluation of geothermal reservoir cracks by shear-wave splitting of acoustic emission, Geothermics, 20,197-206, 1991.

Shalev, E., and M. Lou, Tomographic inversion for crack density, EOS, 76, 1995.

Shalev, E., Three-dimensional seismic investigation of the crust in central New Hampshire and Loma Prieta, California, Ph.D. Thesis, Yale University, 1992.

Shih, X.R., P. Meyer, P. and J.F. Schneider, An automated, analytical method to determine shear-wave splitting. Tectonophysics, 165, 271-278,1989.

Zucca, J.J., L. J. Hutchings, and P. W. Kasameyer, Seismic velocity and attenuation structure of the Geysers geothermal field, California, Geothermics, 23, 111-126, 1994. 


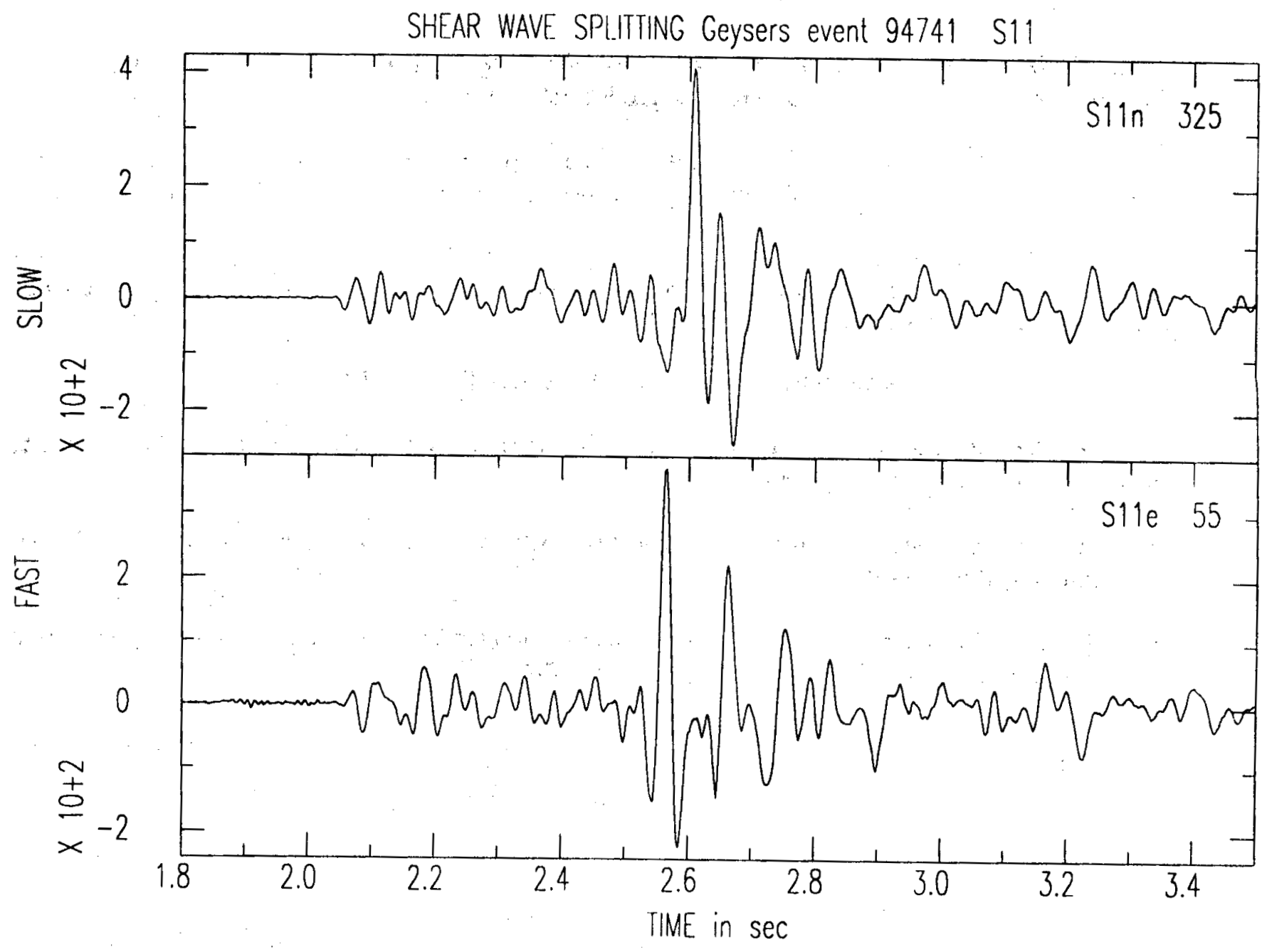

Figure 1 - The rotated horizontal components of an event clearly show the splitting of the shear wave in a fast (bottom) and a slow (top) waves. The time delay is of the order of 30 milliseconds. 


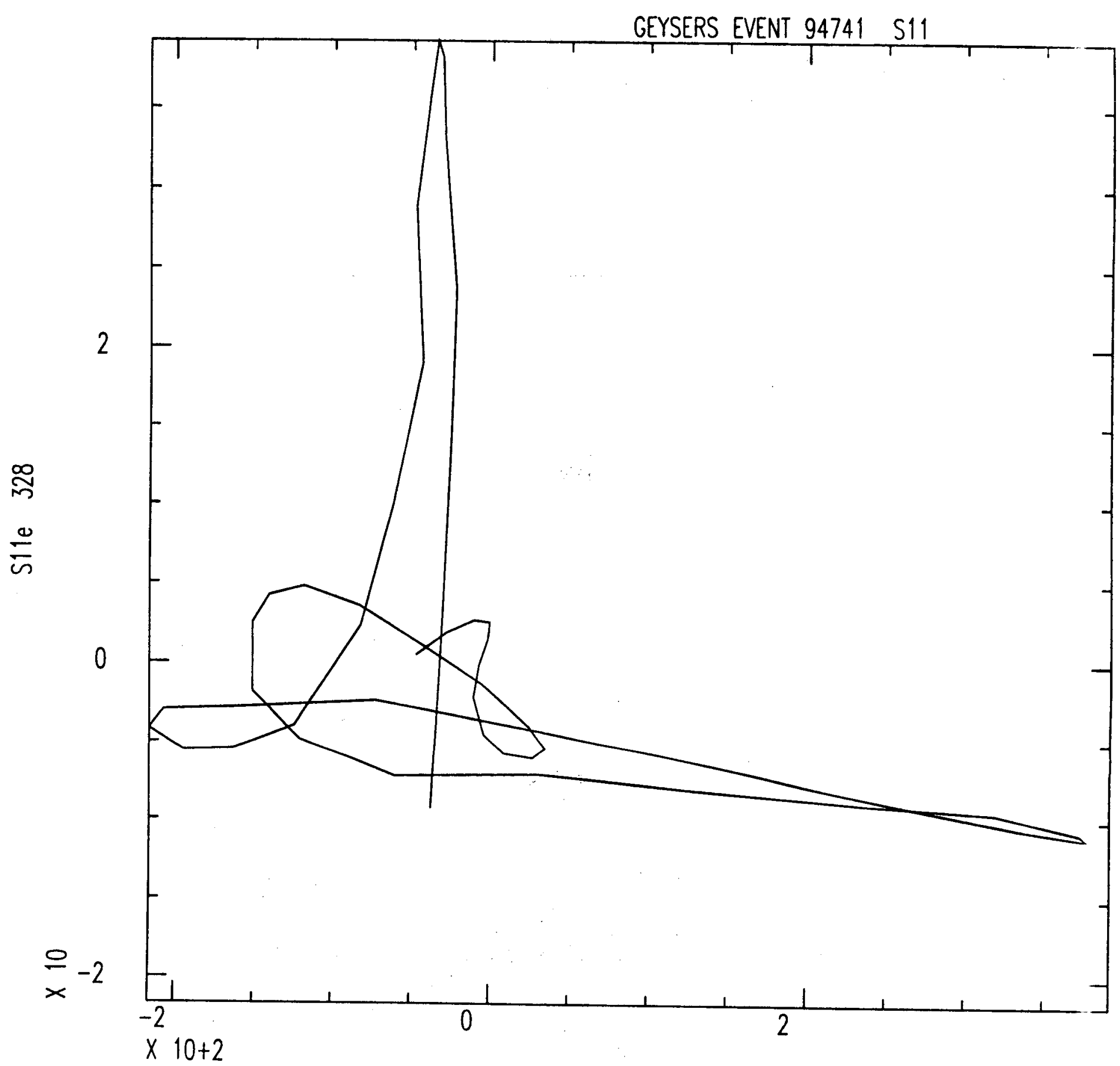

Figure 2 - The polarization directions of the fast and slow waves of Figure 1. Note the clarity of the recording and the perpendicularity between the two split waves. 


\section{Polarization of Fast S-waves in NW Geysers}

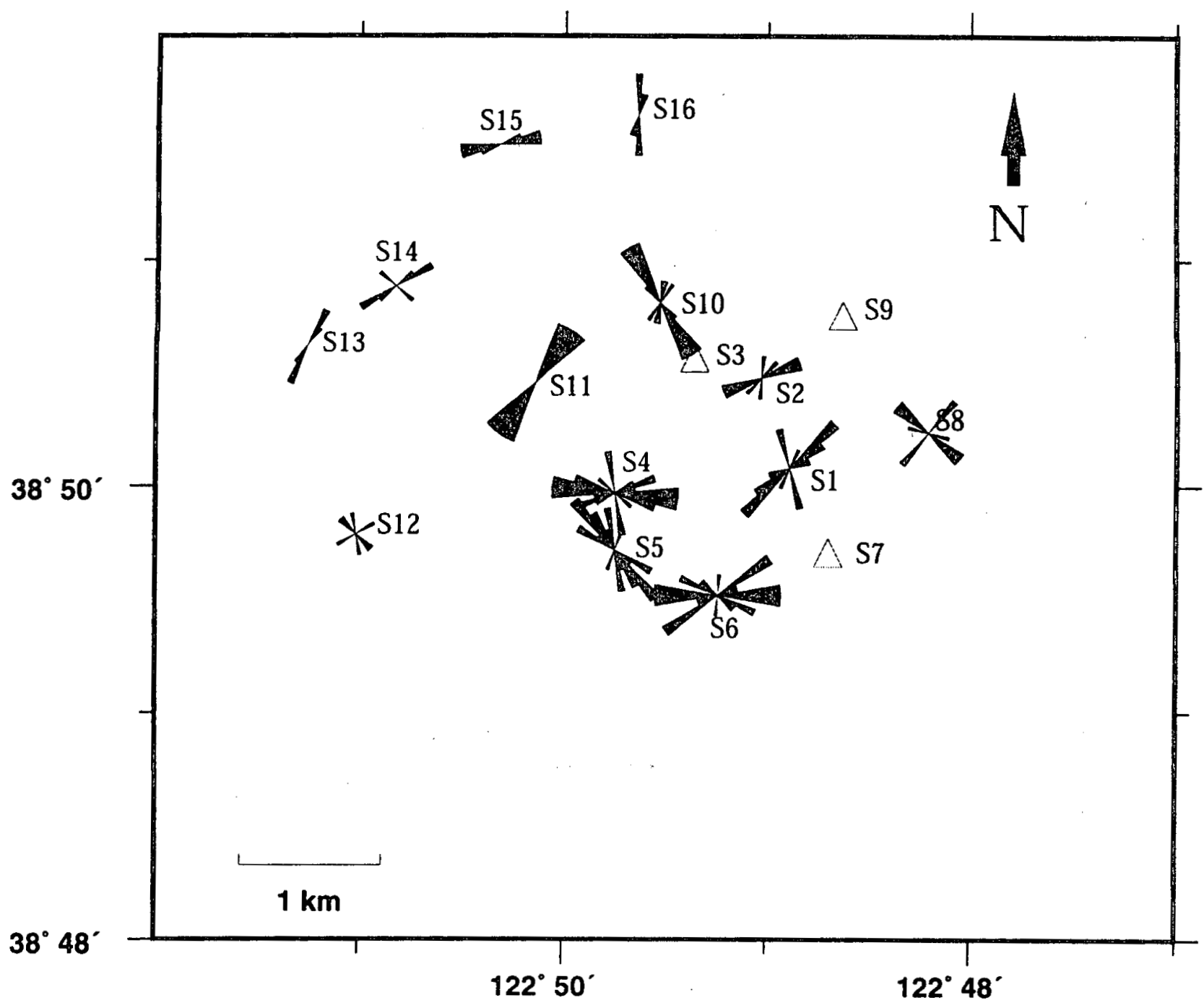

Figure 3 - Preliminary map of crack directions in The Geysers. Data are from 1988 events. Incorporation of the 1994 data is in progress. 


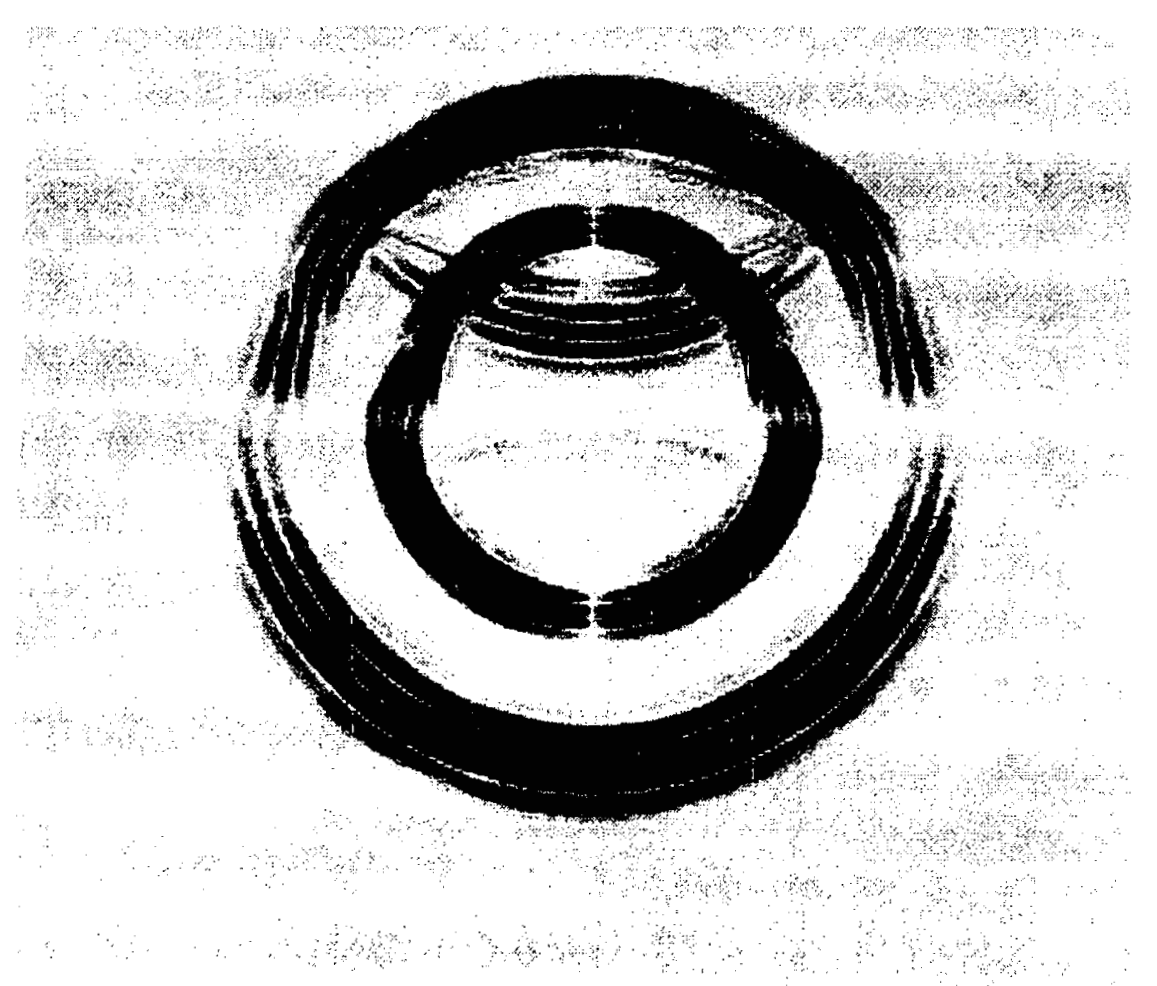

Figure 4a - Snapshot of the $P$ and $S$ wavefronts emerging from an earthquake in a simulated model of The Geysers. The event hypocenter is 2.0 kilometers below the surface. Receivers are located at the surface, $30 \mathrm{~m}$, $70 \mathrm{~m}, 100 \mathrm{~m}$, and $200 \mathrm{~m}$ below the surface. 


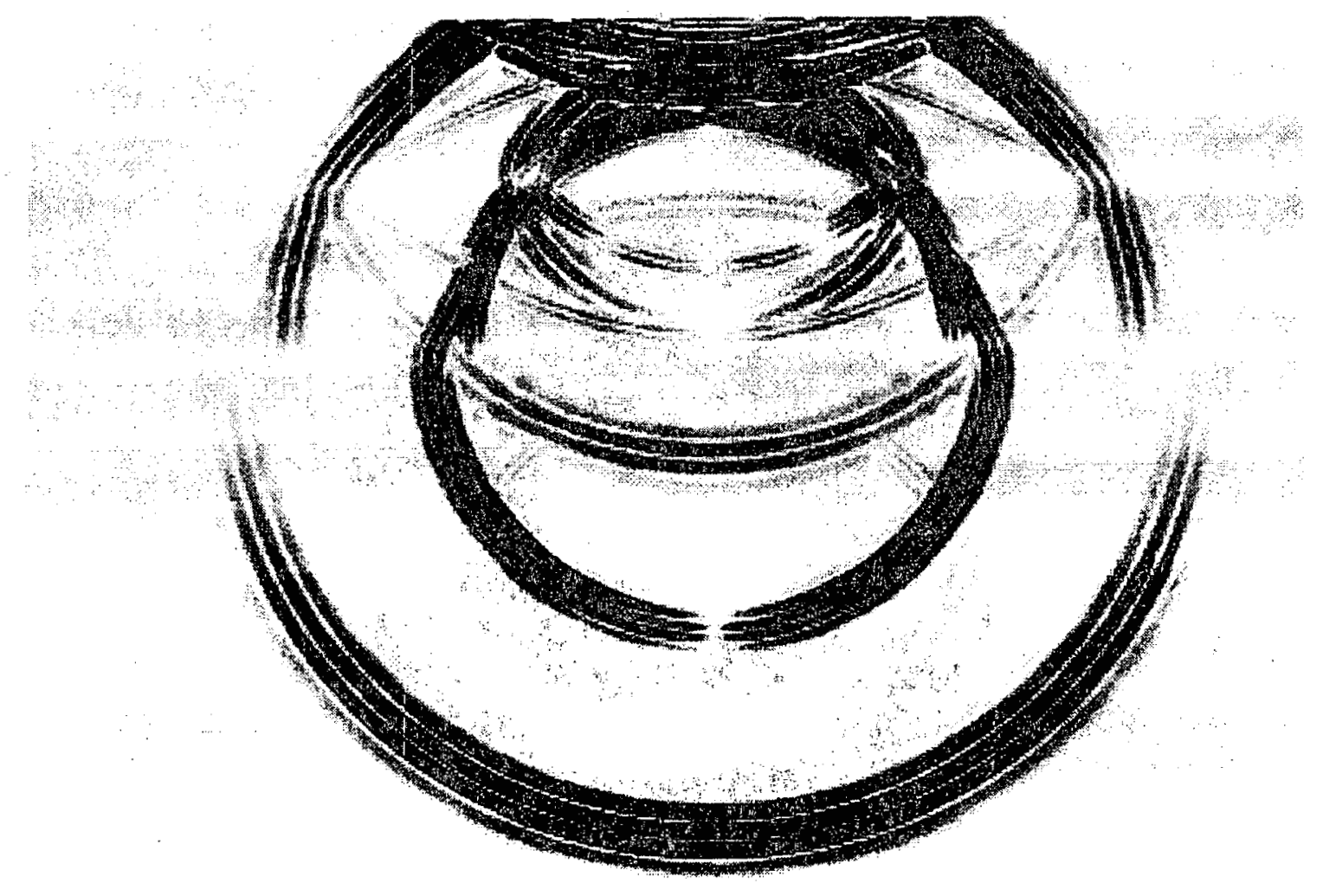

Figure 4b - Snapshot of the $P$ and $S$ wavefronts emerging from an earthquake in a simulated model of The Geysers. The event hypocenter is 2.0 kilometers below the surface: Receivers are located at the surface, $30 \mathrm{~m}$, $70 \mathrm{~m}, 100 \mathrm{~m}$, and $200 \mathrm{~m}$ below the surface. 
GEYSERS S-WAVE TEST

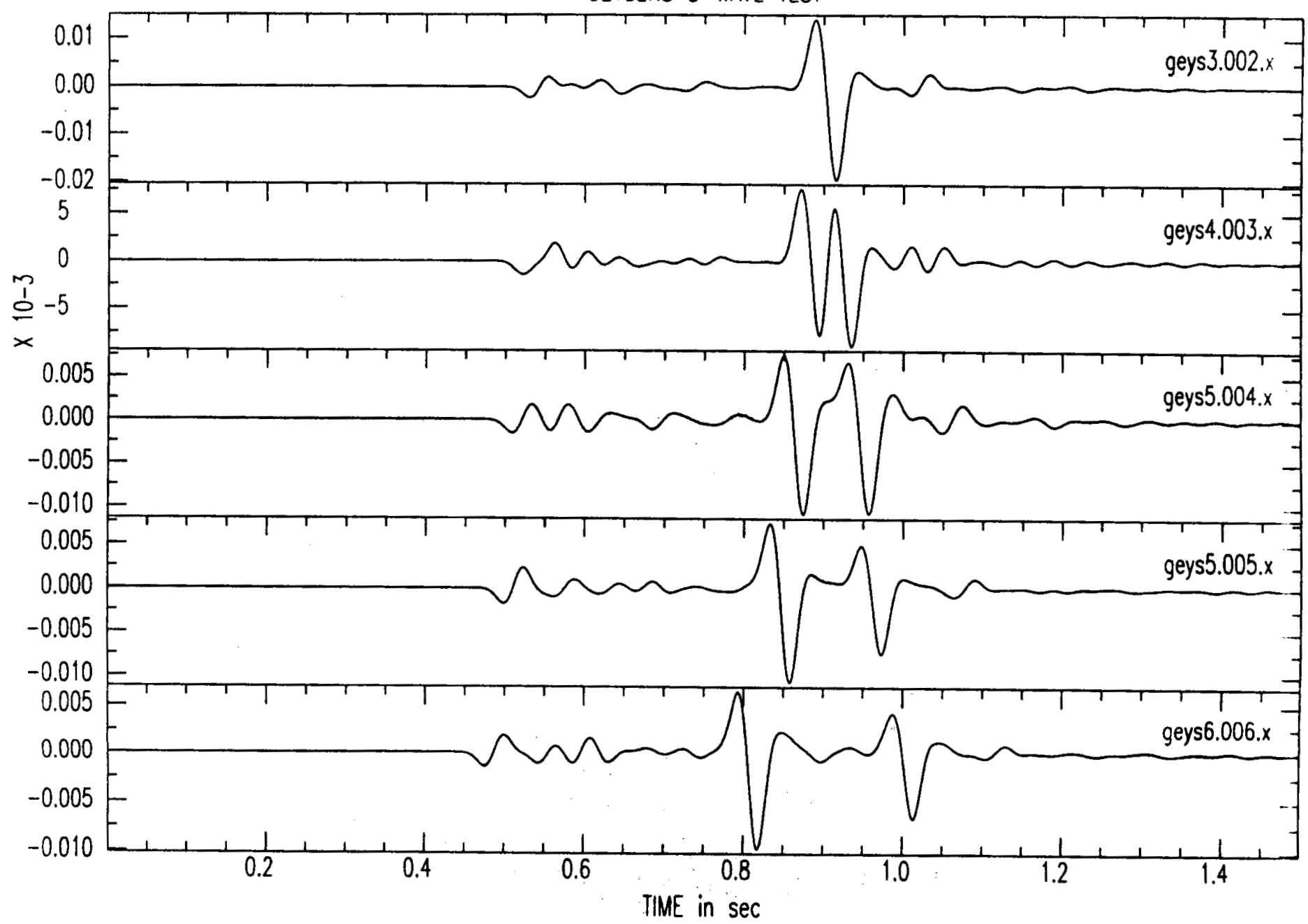

Figure 4c - shows the synthetic seismograms (horizontal component) computed for these receivers. Note that the second arrival at most receivers (except the free surface) may interfere with a split shear wave and cause misreading or misinterpretation of the data. Simulating the seismogram this way allows the interpreter to subtract the effect of the surface reflection. 


\title{
ESTIMATED RELATIVE PERMEABILITY CURVES FOR CORE PLUGS FROM THE GEYSERS WELL SB-15-D
}

\author{
Peter Persoff and Stefan Finsterle \\ E.O. Lawrence Berkeley National Laboratory
}

\section{KEY WORDS}

pressure-pulse decay, relative permeability, slip flow, capillary pressure, vapor-pressure lowering, Klinkenberg effect, mineralogy, The Geysers

\section{PROJECT BACKGROUND AND STATUS}

At The Geysers geothermal field of Northern California the reservoir rock matrix is of extremely low permeability. Thus, the rate of energy extraction from the subsurface is limited by the transport of stored liquid water from the interior of matrix blocks to the fracture network. Plans for field operations will, therefore, depend upon accurate descriptions of the fracture and matrix properties.

Matrix properties measured in this work include porosity, absolute permeability, Klinkenberg (slip flow) factors, and capillary pressure curves. The capillary pressure curves contain information about the distribution of pore sizes, and were used to estimate relative permeability curves for Geysers rocks.

At the early stages of the project, we designed and constructed a pressure pulse decay apparatus to allow measurement of absolute permeabilities as low as 0.1 nanodarcy $\left(10^{-22} \mathrm{~m}^{2}\right)$, and made measurement on several cores from well SB-15-D of The Geysers Coring Project (Hulen, 1996). We also used a vapor-pressure-lowering technique to obtain capillary pressure curves up to $200 \mathrm{MPa}(29,000 \mathrm{psi})$. Both the permeability and capillary pressure techniques represent extremes of measurability.

During FY 1996, this work was complemented by the development of analytical and numerical techniques that improved the interpretation of laboratory data (Finsterle and Persoff, 1997; Finsterle et al., 1997; Wu et al., 1997), and additional permeability measurements were done using a steady-state method. This year, we completed the estimation of relative permeability curves for these rocks using the methods of van Genuchten (1980) and Brooks and Corey (1964). The experimental and mathematical techniques are now available to be applied to other geothermal cores, such as those expected from the Awibengkok, Indonesia, field.

\section{PROJECT OBJECTIVES}

The objectives of this project are to measure and determine important properties of reservoir rocks that will assist The Geysers operators in the planning their field operations.

\section{Technical Objectives}

- Measure matrix absolute permeability.

- Measure Klinkenberg slip-flow factor.

- Determine capillary pressure curves. 
- Estimate relative permeability curves.

- Determine mineralogy of the samples and relate it to their hydrologic properties.

\section{Expected Outcomes}

- Laboratory techniques that will permit measurement of hydrologic properties of extremely tight rocks, not measurable by other methods.

- Analytic solutions and numerical methods to improve the interpretation of laboratory and field test data.

- Measured and interpreted rock properties for numerical simulation studies used in the design of The Geysers field operations.

- Correlations between rock mineralogy and hydrologic properties.

\section{APPROACH}

LBNL's gas-pressure-pulse decay permeameter is capable of measuring permeabilities as low as $10^{-22} \mathrm{~m}^{2}$. In this method, the sample is initially equilibrated with small-volume $(2 \mathrm{~mL})$ reservoirs at each end. A pressure pulse is applied to one end of the sample at the start of the test. Pressures in both reservoirs, and the differential pressure between the reservoirs, are recorded automatically, and the permeability is calculated from the rate at which the pressure differential decays (i.e., the rate at which gas flows through the sample).

In small pores, when the mean free path of gas molecules approaches the pore size, gas permeability is enhanced by "slip flow," which is quantified by the Klinkenberg $b$ factor. Permeability measurements were done at pressures ranging from ambient up to $3.4 \mathrm{MPa}(500 \mathrm{psi})$ to calculate this factor. Capillary pressure curves were measured for 18 small plugs by equilibrating them with controlled humidity atmospheres and calculating saturation from measured weight gain. Finally, the capillary pressure data were fit by the Male-van Genuchten (M-vG) model (van Genuchten, 1980) and by the Brooks-Corey-Burdine (B-C-B) model (Brooks and Corey, 1964); these two models differ in their descriptions of the geometry and interconnectedness of the pores. The fitting constants for both models were used to estimate the relative permeability curves.

In addition to the measurement of hydrologic properties, samples were taken immediately adjacent to the core plugs and analyzed for mineralogy by powder X-ray fluorescence and thin-section microscopy.

\section{RESEARCH RESULTS}

The matrix permeabilities measured were quite low ( 0.2 to 3 nanodarcy for well SB-15-D, and 16 to 40 nanodarcy for well NEGU-17). The capillary pressures (moisture tension) measured were high (100's of MPa) at moderate liquid saturations. Full data and mineralogical description of the cores will be published in 1998 (Persoff and Hulen, 1997). Figure 1 shows capillary pressure measurements for run 26, a typical core plug from SB-15-D, with resulting estimated relative permeability curves. In this figure, the data corresponding to the solid circles were measured in the wetting direction and the those to the open circles, in the drying direction. Only wetting-direction points were used to fit the curves. The curves show the fitted capillary pressure and estimated relative permeability by the $\mathrm{M}-\mathrm{vG}$ model, (solid lines) and the B-C-B model (dashed lines). Relative permeabilities are calculated in terms of effective saturation (i.e., liquid saturation minus residual liquid saturation); a residual liquid saturation of $20 \%$ was assumed to convert liquid saturation to effective saturation. 
Several samples with mineral-filled veins were no more permeable than others without veins. Mineralogy of all samples were similar, as were the hydrologic properties. The principal difference observed was the alteration of clay minerals, which can be used to differentiate between steam reservoir and cap rock samples.

The results of his work will be published in a special Geothermics issue on the Geysers Coring Project (tentative publication date: 1998).

\section{FUTURE PLANS}

The new and sensitive techniques developed at LBNL for measuring the permeability and capillary pressure curves of The Geysers core samples extended the limits to which these measurements can be made. New techniques were also developed for laboratory data interpretation. These techniques will be applied to the continuous core recently recovered at Awibengkok, Indonesia. Core logs indicate that, unlike The Geysers core, the Awibengkok core is quite heterogeneous. Hydrologic measurements will be made on all major rock types encountered in the core, and related to the mineralogy. Core plugs will be taken in coordination with other studies (e.g., mineralogy) to provide the most useful suite of measurements.

In our studies of The Geysers core samples we found mineral-filled, impermeable veins. The existence of such formerly permeable fractures indicates that natural fractures have a finite productive life. Two mechanisms recognized to seal fractures are mineral precipitation and fracture closing due to rock creep. We propose to initiate a new project to measure the rate of fracture closure due to (i) dissolution and reprecipitation of silica and (ii) the ductility of rock at reservoir temperature and stress conditions. An existing high pressure coreflood apparatus will be modified to permit temperatures up to $400^{\circ} \mathrm{C}$ and confining pressures up to 2 kilobars. Fracture permeability will be measured during an extended period to determine the rate and mechanisms of fracture closure.

\section{INDUSTRY INTEREST}

The newly developed laboratory techniques to determine the hydrologic properties of the matrix of reservoir rocks is of significant interest to the geothermal industry since it will assist in the development of reservoir management plans. Unocal Geothermal has shown interest in the application of these methods to cores obtained from their wells.

\section{REFERENCES}

Brooks, R.H., and Corey, A.T. Hydraulic properties of porous media.Hydrology Paper 3, Colorado State University, Fort Collins, Colorado, 1964, pp. 22-27

Finsterle, S., and P. Persoff, Determining permeability of tight rock samples using inverse modeling, Water Resour. Res. 33(8), 1803-1811, 1997 (LBNL-39296).

Finsterle, S., Pruess, K., Bullivant, D.P., and O'Sullivan, M.J. Application of inverse modeling to geothermal reservoir simulation, Proceedings, Twenty-second Workshop on Geothermal Reservoir Engineering, Stanford University, January 27-29, 1997, p. 309-316 (LBNL-39869).

Hulen, J.B. (ed.) Symposium on Research Results from The Geysers Coring Project, August 28, 1996, Santa Rosa, CA. Earth Sciences and Resources Institute, University of Utah, Report ESRI-27945-96/3. 
Persoff, P. and Hulen, J. B. Hydrologic Characterization of Six Cores from The Geysers Geothermal Field. Paper submitted to Geothermics for publication in The Geysers special issue (LBNL-38187 revised).

van Genuchten, M. Th. A closed-form equation for predicting the hydraulic conductivity of unsaturated soils. Soil Sci. Soc. Am. J. 44, 892-898, 1980.

Wu, Y.-S., Pruess, K. and Persoff, P. Steady and Transient Solutions for Gas Flow in Porous Media with Klinkenberg Effects, submitted to Transport in Porous Media ,1997. 


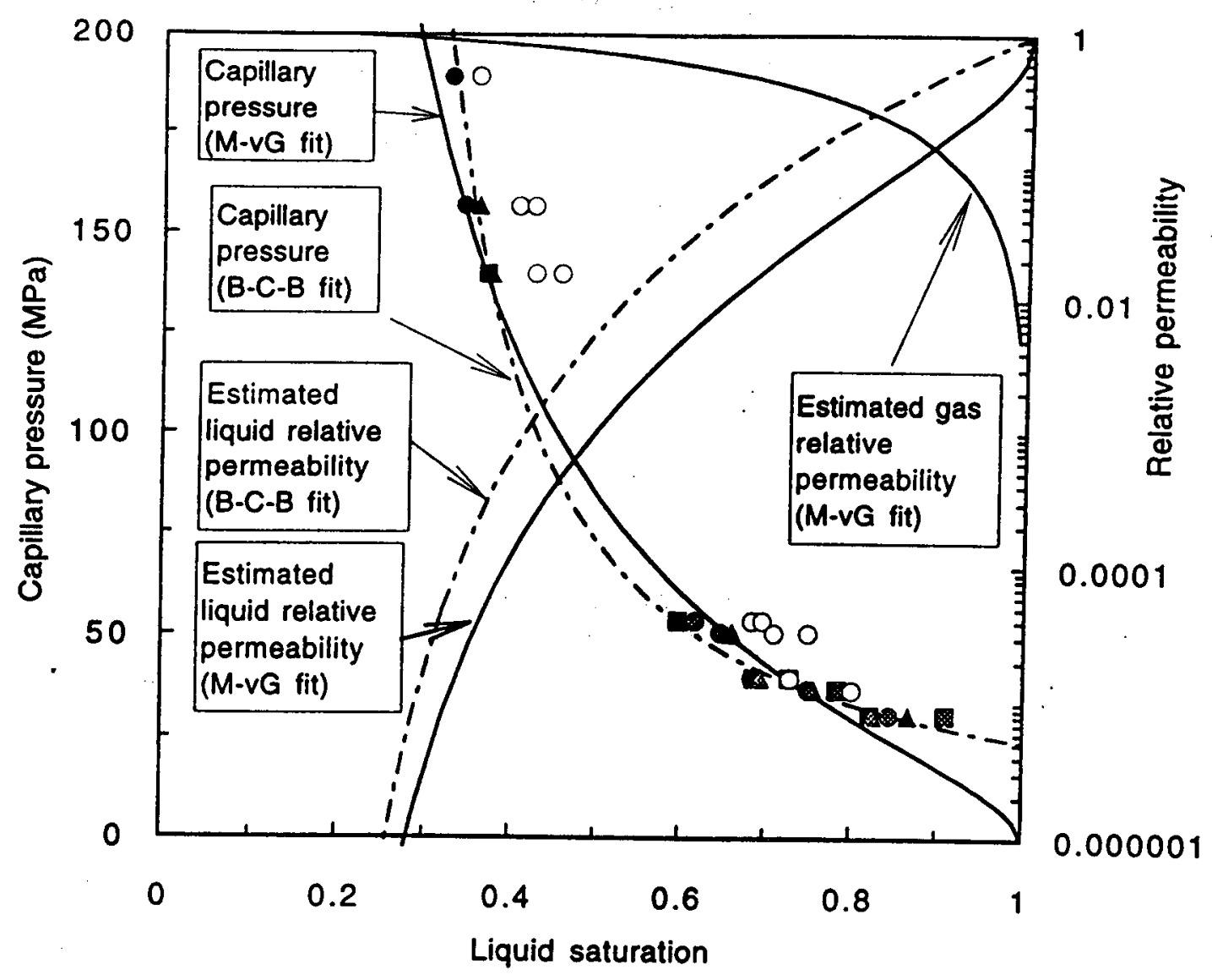

Figure 1 - Observed capillary pressure data with fitted curves and estimated relative permeability curves for SB-15-D, run 26. 


\title{
FRACTURE ANALYSIS AT THE GEYSERS
}

\author{
Dennis L. Nielson \\ Energy \& Geoscience Institute \\ University of Utah
}

\section{KEY WORDS}

Thematic Mapper, Geographic Information System, structural heterogeneity, fluid-flow architecture, strike-slip faults

\section{PROJECT BACKGROUND AND STATUS}

The continued economic viability of The Geysers is going to depend upon an effective program of fluid injection. By its nature, such a program should be based on a much more detailed understanding of the fracture permeability than currently exists. A review of the literature on fracture permeability at The Geysers geothermal field has been completed (Nielson and Hulen, submitted). This review demonstrated that there are many different opinions in the literature concerning fracture orientation and genesis, but no comprehensive models. The writing of that paper resulted in a re-evaluation of the structural setting of the field that incorporated results from the SB-15D corehole as well as satellite imagery. The imagery has proven to be particularly useful in definition of the structural setting. Combining the satellite images and other data sets with a Geographic Information System allows us to draw some important conclusions concerning reservoir controls. A paper outlining this work was presented at the 1997 GRC meeting (Nielson and Nash, 1997).

Our approach to studying fracturing at The Geysers is holistic, with our own work being done in the context of a number of important and detailed studies of the field and surrounding areas that have been completed over the years. Listed below are some of the aspects that a tectonic and structural model of The Geysers should address.

- Unique location of "The Felsite". It is clear that the plutonic event responsible for the composite pluton known as the "felsite" has not been repeated in northern California although the tectonic environment has remained the same for a period of about $3 \mathrm{Ma}$.

- Structural Heterogeneity. The structural environment is very complex and probably is an integrated result of a number of structural influences over the tectonic history of the area.

- Fluid-Flow Architecture. How efficient are different types of fractures as fluid flow conduits in the context of both production and injection of fluids? Evidence would suggest that highly productive zones are developed along the principal displacement zones of faults whereas associated damage zones serve as reservoir storage.

- Structural Influence of Felsite. 


\section{PROJECT OBJECTIVES}

\section{Technical Objectives}

- Determine the character of fracturing that controls permeability under both production and injection at The Geysers.

\section{Expected Outcomes}

- Increase efficiency of production and injection wells

- Development of a comprehensive plan for The Geysers

\section{APPROACH}

Satellite image analysis has proven to be extremely valuable in identifying structural elements in The Geysers field. The field itself is characterized by rugged topography, heavy vegetation and poor exposure. In addition, many of the features we feel are important are simply too large to be recognizable at scales normally used in geologic mapping.

Continuous core from SB-15D has demonstrated a number of important structural aspects of The Geysers geothermal system (Hulen and Nielson, 1995; Nielson and Hulen, submitted). Our approach in studying this core has been detailed logging followed by appropriate mineralogical study.

A comparative study of The Geysers and Larderello fields is nearing completion (Giannelli and Nielson, in prep.). The common features of The Geysers and Larderello are that they are both very large vapor-dominated systems that lie above young plutons of batholithic proportions. Other important features are not the same; for example, The Geysers lies within the strike-slip system of the San Andreas fault while Larderello is within an environment undergoing normal faulting. Aspects of development are also similar, in that some see injection as the means for extending the economic life of both systems. While ENEL is continuing to drill deep wells at Larderello, drilling has virtually ceased at The Geysers. In addition, exploration methods are being applied at Larderello that have not been used at The Geysers, including seismic reflection and borehole image log analysis. Thus, this comparative study is not only addressing the geological aspects of the two systems, we can also compare methodologies applied to attempt to increase the efficiency of bringing new production on line either through injection or the discovery of additional fluids in place.

\section{RESEARCH RESULTS}

The Geyser geothermal system is located within the zone of active tectonics of the San Andreas fault system that marks the boundary between the North American and Pacific Plates. However, strain is being accommodated over a $100 \mathrm{~km}$ wide zone that is displaced continent-ward of the plate boundary. A regional fault map shows that the NW trending features we relate to the San Andreas system extend into the zone of active convergence in Oregon and Washington (Kelsey and Carver, 1988). Seismic evidence suggests strike-slip faulting north of The Geysers is accommodated along pre-existing thrust faults that dip steeply to the NE (Castillo and Ellsworth, 1993). A number of investigators have remarked on the significance of the southern edge of the Gorda Plate where the sense of deformation changes from strike-slip to thrust. 
Several researchers have also suggested that the Mendocino Fracture Zone (MFZ) was at about the latitude of The Geysers system approximately $3 \mathrm{Ma}$, and that this positioning of tectonic elements had a profound influence on the development of the geothermal system. So, in order to understand the processes going on at that time, we need a more comprehensive understanding of the deformation associated with the MFZ today.

The bounding faults for The Geysers geothermal system and the elongation of "the felsite" intrusive heat source are not parallel to the prevailing strike-slip faults of the San Andreas system. Whereas, on a regional basis, the San Andreas system has an orientation of $\mathrm{N} 36^{\circ} \mathrm{W}$, the controlling structures of the system range from $\mathrm{N} 60^{\circ} \mathrm{W}$ to N70 W (Fig. 1). Nielson and Nash (1997) raised the possibility that the geothermal system is located along a major regional structure whose geometry suggests that it is the former location of the landward extension of the Mendocino Fracture Zone. Satellite images provide the opportunity to test this hypothesis by sampling and analyzing specific field sites.

Another fracture trend that is of importance in The Geysers is NE extensional faulting. Nielson and Nash initially recognized the Cobb Creek fault zone from satellite images, and Stanley et al. (1997) present other data that is consistent with this interpretation.

Corehole SB-15D helped us figure out a number of important aspects of the geology of The Geysers system (Nielson and Hulen, submitted). One of the important conclusions of that investigation is that the fractures within and above the reservoir have steep orientations (Fig. 2). Also, this analysis showed that there was really no change in fracturing from the reservoir through the cap and up to the surface.

Geothermal systems have a vertical zonation (Nielson, 1996, 1997) that extends from the surface to the magmatic heat source. Within a vertical section in the presence of steep thermal gradients, the character of fracturing changes with active fluid circulation in those open fractures between the cap and the brittle-ductile transition. At The Geysers, the depth of this transition is estimated at about $4.7 \mathrm{~km}$, and in some cases, lies within the felsite. This lower part of the geothermal system represents a tremendous heat source that could eventually be mined by deep injection.

The fractures at The Geysers respond differently under production versus injection (Nielson and Brown, 1990; Nielson and Hulen, submitted). Under production conditions, pressure sinks have formed along the northwest trend of the Big Sulphur Creek fault and the northeast trend of the Cobb Creek fault (Hulen and Nielson, 1996) and the extensional zone of Stanley et al. (1997). However, a number of injection tests using chemical tracers have shown that injection transport directions trend to the NNE, perpendicular the present orientation of the least principal stress (Nielson and Brown, 1990).

\section{FUTURE PLANS}

As always, future plans depend upon the resources available to carry out this research. Initially, the Geysers/Larderello study will be completed. We believe that sufficient data is available to evaluate the evolution of stress orientation in the geothermal system. Field studies can be done along identified structures to verify development history and character.

An important addition to our knowledge of The Geysers geothermal system would be a deep corehole that was designed to sample through the normal graywacke reservoir into the high-temperature reservoir. This type of hole would aid in developing the knowledge base necessary for the planning of programs of deep injection. 


\section{INDUSTRY INTEREST}

\section{REFERENCES}

Castillo, D. A. and Ellsworth, W. L.,1993, Seismotoctonics of the San Andreas fault system between Point Arena and Cape Mendocino in northem California: implications for the development and evolution of a young transform. Journal Geophysical Research, v. 98, p. 6543-6560.

Gianelli, G., 1994, Nature of deep seated geothermal resources in Italy: Extended abstracts of Workshop on Deep-seated and Magma-ambient Geothermal Systems 1994, New. Energy Industrial Technology and Development Organization (NEDO), Tsukuba, Japan, p. 27-36.

Giannelli, G. and Nielson, D. L., in prep., Comparison of The Geysers and Larderello geothermal systems: Geothermics.

Hulen, J. B. and Nielson, D. L., 1995, The nature of faults and hydrothermal veins in corehole SB-15-D, The Geysers steam field, California: Geothermal Resources Council Transactions, v. 19, p. 181-188.

Hulen, J. B. and Nielson, D. L., 1996, The Geysers felsite: Geothermal Resources Council Transactions, v. 20, p. 295-306.

Kelsey, H. M. and Carver, G. A., 1988, Late Neogene and Quaternary tectonics associated with northward growth of the San Andreas transform fault, northern California. Journal Geophysical Research, v. 93, p. 4797-4819.

Nielson, D. L., 1996, Natural analogs for enhanced heat recovery from geothermal systems: Proceedings, $21^{\text {st }}$ Workshop on geothermal reservoir engineering, Stanford University, p. 43-49.

Nielson, D. L. and Brown, D.,1990, Thoughts on stress around The Geysers geothermal field: Geothermal Resources Council Transactions, v. 14, p.1685-1690.

Nielson, D. L. and Hulen, J. B., submitted, Fracture permeability in The Geysers geothermal field - a contribution from corehole SB-15D: Geothermics.

Nielson, D. L. and Nash, G. D.,1997, Structural fabric of The Geysers: Geothermal Resources Council Transactions, v. 21, p. 643-649.

Stanley, W. D., Benz, H. M., Walters, M. A. and Rodriguez, B. D., 1997, Tectonic controls on magmatism and geothermal resources in The Geysers-Clear Lake region, California: integration of new geologic, earthquake tomography, seismicity, gravity, and magnetotelluric data: UȘGS Open-File Report 97-95, 40p. 

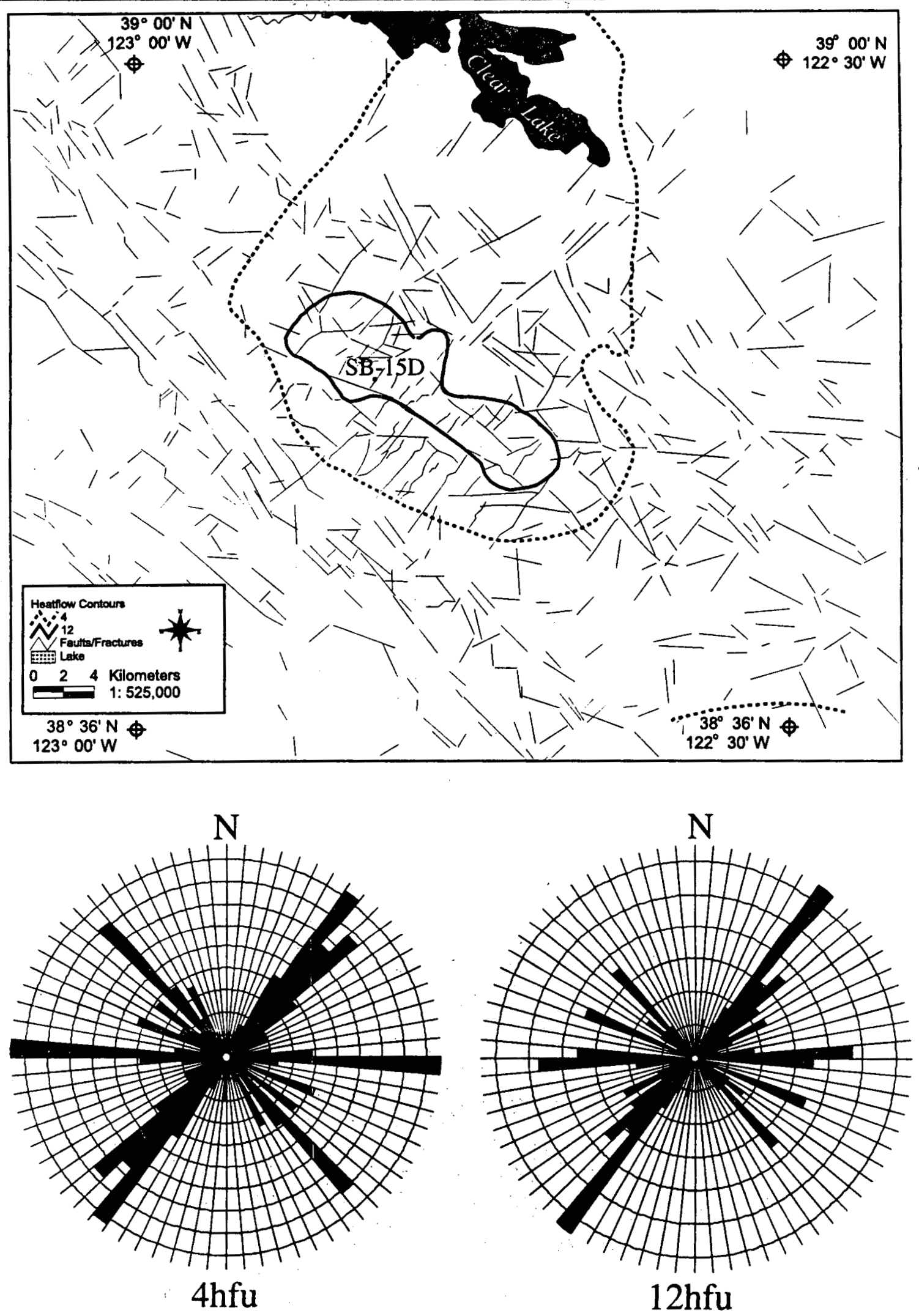

Figure 1 -- Lineation in the Geyser Geothermal Field and compilation of orientation with respect to the 4 and 12 heat flow unit contours (Nielson and Nash, 1997) 

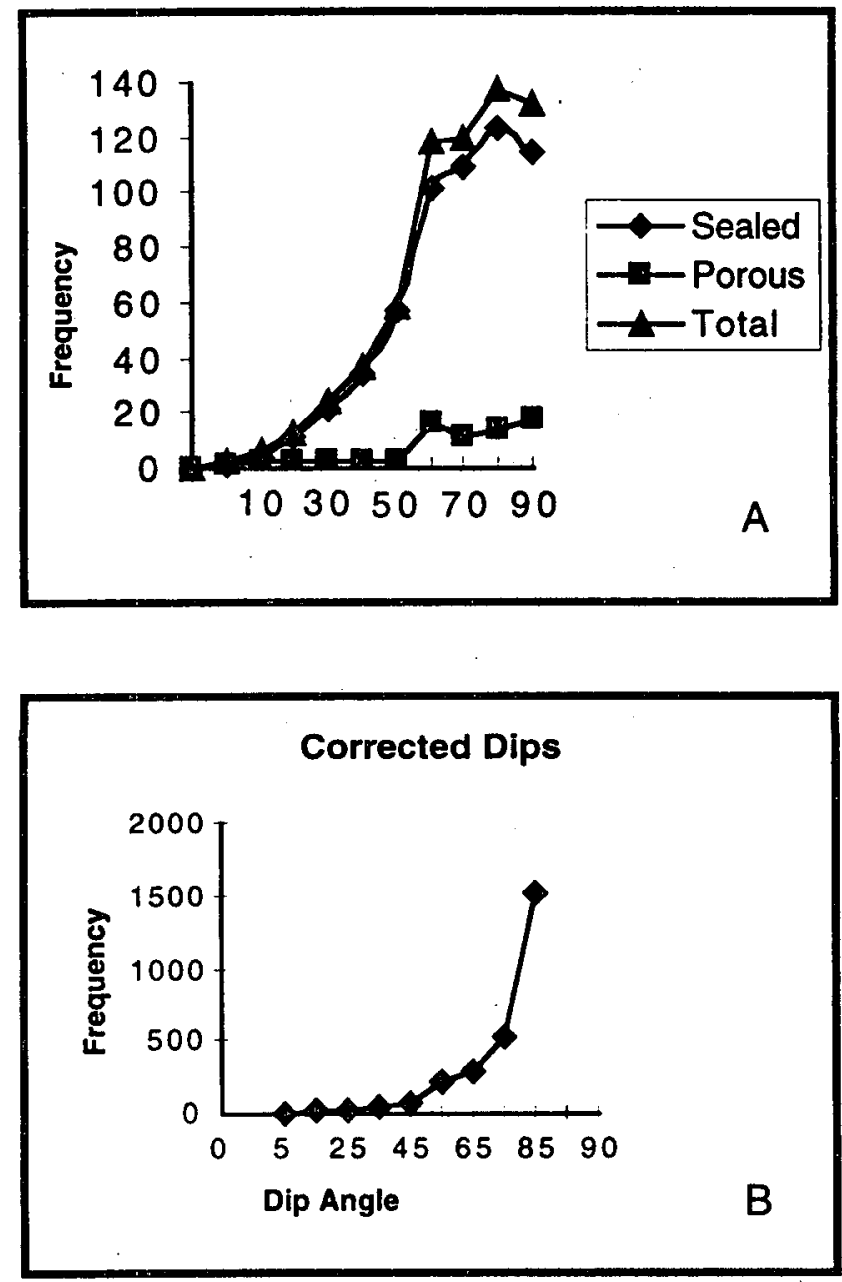

Figure 2. Measured dip angle of fracture (A) and corrected dips (B) from SB-15D.

Figure 2 -- Measured dip angle of fracture (A) and corrected dips (B) from SB-15D. 


\title{
THE APPLICATION OF FLUID-INCLUSION GASES TO TRACING FLUID SOURCES AND RESERVOIR PROCESSES: A CASE STUDY OF THE GEYSERS, CALIFORNIA
}

\author{
Joseph N. Moore', David I. Norman², B. Mack Kennedy ${ }^{3}$ \\ 'Energy \& Geoscience Institute, University of Utah \\ ${ }^{2}$ New Mexico Tech, Socorro \\ ${ }^{3}$ Center for Isotope Geochemistry, Lawrence Berkeley Laboratory
}

\section{KEY WORDS}

The Geysers, fluid-inclusions, gas analyses

\section{PROJECT BACKGROUND AND STATUS}

During the past five years, a significant amount of progress has been made in our understanding of The Geysers' history and its transition from a liquid- to vapor-dominated system. Recent studies by Moore and Gunderson (1995) have documented fluid temperatures and salinities associated with the early liquid-dominated system that formed in response to the emplacement of the "felsite" beneath the field at 1 to $1.5 \mathrm{Ma}$ (Dalrymple 1992; J. Hulen, pers. comm, 1997). They concluded that mature heat pipes had developed by the time temperatures had dropped to about $265^{\circ} \mathrm{C}$. The geometry of the individual intrusive phases that form the felsite was established by Hulen and Walters (1993). Hulen et al. (1997) used ${ }^{40} \mathrm{Ar} /{ }^{99} \mathrm{Ar}$ spectrum dating of adularia and fluid-inclusion data from well SB-15-D to constrain the onset of vapor-dominated conditions in the central Geysers to the period between 0.28 and $0.25 \mathrm{Ma}$. Numerical simulations by Shook (1995) are consistent with these observations and show that the present temperature profiles could have developed in response to catastrophic boiling of the system. The sources of the modern fluids and the impact of recent magmatic activity were established by Truesdell et al. (1991) and Kennedy and Truesdell, (1996).

Although we have been able to show that the early hydrothermal fluids were dominantly connate in origin, there is evidence from fluid-inclusion temperature-salinity relationships that both meteoric and magmatic fluids have circulated through the system. However, the significance of individual fluid sources and in particular, the extent of the magmatic contributions could not be determined from these data. Recent advances in the measurement of small quantities of fluid-inclusion gases by mass spectrometry have provided an additional means of tracing the sources of these fluids. The Geysers provides a unique natural laboratory to test these techniques and develop appropriate interpretational methods because the compositions and origins of the steam are well known (Truesdell et al, 1987), hypersaline fluid-inclusions provide independent evidence of the past existence of a magmatic fluid, ${ }^{3} \mathrm{He} /{ }^{4} \mathrm{He}$ ratios document the presence of a contemporary magmatic contribution to the steam (Kennedy and Truesdell, 1996), and the inclusion fluids provide evidence of being derived from multiple sources that have characteristic noble and major gas chemistries (Kennedy et al.,1985; Norman et al., 1996). 


\section{PROJECT OBJECTIVES}

\section{Technical Objectives}

- The primary objective of this project is to develop methods and techniques needed for interpreting fluidinclusion gas data. We are particularly interested in utilizing these data to trace fluid sources and evaluate the effects of mixing and boiling.

- A second objective is to determine how the composition of the hydrothermal fluids in active geothermal systems has changed over time.

- The final objective is to establish criteria for evaluating the magmatic contribution, if any, to the geothermal fluids.

\section{Expected Outcomes}

- The results will help to develop improved conceptual models of geothermal systems. This will assist exploration geologists in siting drill holes and predicting the natural behavior of geothermal systems.

- The presence of acid magmatic fluids can have a major financial impact on a geothermal project in volcanic terrains because wells that produce acid fluids may not be usable. Improved means of evaluating and predicting the distribution of these fluids can help reduce drilling costs.

\section{APPROACH}

The overall approach of this project has been to utilize well characterized samples whose mineral paragenesis, position within The Geysers field, and fluid-inclusion temperatures and salinities have been established. This information is necessary to remove as much ambiguity in the interpretation of the gas data as possible.

Broad-spectrum gas analyses were obtained by quadrapole mass spectrometry at New Mexico Tech. The gases were liberated from the inclusions using two different methods, crushing and thermal decrepitation. Each method has advantages. Both methods were used on splits of the same samples to compare the results. Multiple analyses were performed on the same spilt to determine the range of compositions recorded by each sample. Preliminary interpretations were made based on the concentrations of the gas species. Selected samples were then analyzed for their noble gas contents by mass spectrometry at LBNL to test hypotheses regarding the origins of the gases and the processes that have affected them. In addition, we are comparing the results from The Geysers to data from other well characterized geothermal and fossil hydrothermal systems (e.g Tiwi, Philippines; Broadlands, New Zealand; Mexican epithermal veins) to assess similarities and differences that may be related to geologic conditions and reservoir processes.

\section{RESEARCH RESULTS}

This project has demonstrated the utility of combining rapid broad spectrum fluid-inclusion gas analyses with analyses of their noble-gas contents as a means of tracing the sources and quantifying the effects of fluid mixing and boiling. The importance of magmatic, connate or metamorphic, and meteoric fluids during the evolution of The Geysers hydrothermal system was established. Inclusion populations of a dominantly magmatic origin are found in tourmaline-bearing veins in the biotite hornfels sampled in the present-day high-temperature vapordominated reservoir by well OF27A-2 ST1. These inclusions are characterized by high temperature halite- 
saturated brines, $\mathrm{N}_{2} / \mathrm{Ar}$ ratios much greater than air, and He isotopic ratios of approximately $6 \mathrm{Ra}$. Hightemperature hypersaline fluid inclusions were also observed in biotite-bearing veins from the high-temperature reservoir penetrated by well L'esperance-2, and in tourmaline + quartz veins found in the plutonic rocks in DV-2. Although veins in L'esperance-2 are characterized by high $\mathrm{N}_{2} / \mathrm{Ar}$ ratios, the associated He isotopic ratio of 0.5 $\mathrm{Ra}$ indicates overprinting of the magmatic signature by connate or metamorphic fluids and demonstrates that high $\mathrm{N}_{2}$ /Ar ratios do not in themselves indicate a magmatic influence. It is noteworthy that inclusions in L'esperance-2 not only have one of the highest $\mathrm{N}_{2} / \mathrm{Ar}$ ratios, they also have one of the highest $\mathrm{CH}_{4}$ contents. The fluid inclusions in DV-2 have high water contents $\left(\mathrm{H}_{2} \mathrm{O}>99\right.$ mole percent) and $\mathrm{N}_{2} / \mathrm{Ar}$ ratios similar to meteoric water, suggesting that meteoric recharge may have occurred in the southeast part of The Geysers prior to the onset of vapor-dominated conditions at approximately 0.28 to $0.25 \mathrm{Ma}$ (Hulen et al., 1997).

Ternary plots of $\mathrm{N}_{2}, \mathrm{Ar}$, and $\mathrm{CH}_{4}$ demonstrate a striking similarity between the compositions of the modern steam and fluid-inclusion gases from the normal vapor-dominated reservoir and the overlying cap rock. Steam and inclusion gases from the Northwest Geysers have the highest $\mathrm{N}_{2} / \mathrm{Ar}$ ratios and $\mathrm{CH}_{4}$ contents. Lower $\mathrm{N}_{2} / \mathrm{Ar}$ ratios are found in the southeast and central Geysers. Variations in these ratios are compatible with gradients in the isotopic compositions of the steam (Truesdell et al., 1987) and imply higher contributions of meteoric recharge in the southeast compared to the northwest. Water/rock ratios based on whole-rock $8{ }^{18} \mathrm{O}$ values are generally yield the lowest values in the northwest (Moore and Gunderson, 1995; Walters et al., 1996), consistent with low integrated water/rock ratios in this portion of the geothermal reservoir. Taken together, the $\mathrm{CH}_{4}, \mathrm{~N}_{2} / \mathrm{Ar}$, and isotope data imply that permeabilities have always been highest in the southeast and central Geysers.

Despite variations in the salinities, gas compositions, and temperatures of the inclusions, or their relative distance from the pluton, noble gas analyses document widespread flux of magmatic gas through the hydrothermal system. He isotopic ratios of the inclusion gases in most samples are near $6 \mathrm{Ra}$ and, thus, require the input of a magmatic fluid. The presence of a magmatic component in the inclusion fluids raises the possibility that other gases, including $\mathrm{CO}_{2}, \mathrm{H}_{2} \mathrm{~S}$ and $\mathrm{H}_{2}$ also have a magmatic origin.

\section{FUTURE PLANS}

We anticipate applying the interpretational techniques developed during this study to investigations of the hightemperatures portions of The Geysers. These studies will combine mineralogic and fluid-inclusion investigations with new age determinations on hydrothermal minerals. These techniques will also be applied to other geothermal systems, including those from the Philippines, Indonesia, and New Zealand.

\section{INDUSTRY INTEREST}

Our studies of The Geysers represent joint projects with Unocal, Calpine, and NCPA, who have supplied samples, steam analyses, and other production data. Both Unocal and Calpine have demonstrated a continuing interest in the application of fluid-inclusion data by providing samples and information on other fields. Thesc studies will be conducted during the coming year. In addition, California Energy Co. Inc., has indicated an interest in the application of these techniques. Discussions with researchers from New Zealand, Japan, and Italy have demonstrated their interest in developing similar capabilities and joint projects are likely in the future.

The results of The Geysers studies have been presented at the VII International Symposium on the Observation of the Continental Crust Through Drilling (Norman and Moore, 1994), Stanford Reservoir Engineering Conference (Norman et al., 1996), the Geothermal Resources Council annual meeting (Moore et al., 1997), and the $9^{\text {th }}$ International Water-Rock Interaction Conference (Norman and Moore, in prep.) 


\section{REFERENCES}

Dalrymple G. B. (1992) Preliminary report on ${ }^{40} \mathrm{Ar} /{ }^{39} \mathrm{Ar}$ incremental heating experiments on feldspar samples from the felsite unit, Geysers geothermal field, California: USGS Open-File Rept. 92-407.

Hulen J. B. and Walters M. A. (1993) The Geysers felsite and associated geothermal systems, alteration, mineralization, and hydrocarbon occurrences in Active geothermal systems and gold-mercury deposits in the Sonoma-Clear Lake volcanic fields, California (ed. J. J. Rytuba): Guidebook Series, Society of Econ. Geologists, v. 16, p. 141-152.

Hulen, J. B., Hitzler, M., and Moore, J. N. (1977) New constraints on the timing of magmatism, volcanism, and the onset of vapor-dominated conditions at The Geysers steam field, California: Proc. 22th Wkshp. on Geotherm. Reservoir Eng., Stanford Univ., p.75-82.

Kennedy, B. M. and Truesdell, A. H. (1996) The Northwest Geysers high-temperature reservoir: evidence for active magmatic degassing and implications for the origin of The Geysers geothermal field: Geothermics, v. 25 , p. 365-387.

Kennedy, B. M., Lynch, M. A., Reynolds, J. H., and Smith, S. P. (1985) Intensive sampling of noble gases in fluids at Yellowstone: I. Early overview of the data; regional patterns. Geochem. Cosmochim. Acta.: v. 49, p. 1251-1261.

Moore, J. N. and Gunderson, R. P. (1995) Fluid inclusion and isotope systematics of an evolving magmatichydrothermal system: Geochem. Cosmochim. Acta., v, 59, p. 3887-3907.

Norman D. I. and Moore J. N. (1994) Fluid source tracing via fluid inclusion gas analysis in an evolving magmatic system: The Geysers California (abs.): VII International Symposium on the Observation of the Continental Crust Through Drilling, Santa Fe, N.M., April 25-30.

Norman D. I. and Musgrave, J. (1993) $\mathrm{N}_{2}$, Ar, and He in fluid inclusions: Tracers of hydrothermal fluids: Geochem. Cosmochim. Acta., v. 58, p. 119-1131.

Norman D. I., Moore, J. N., Yonaka, B., and Musgrave, J. (1996) Gaseous species in fluid inclusions: A tracer of fluids and indicator of fluid processes: Proc. 21 th Wkshp. on Geotherm. Reservoir Eng., Stanford Univ., p. 233-240.

Shook G. M. (1995) Development of a vapor-dominated reservoir with a 'high-temperature' component: Geothermics, in press.

Truesdell A. H., Haizlip J. R., Box W. T. JR, and D'Amore F. (1987) Fieldwide chemical and isotopic gradients in steam from The Geysers: Proc. 11 th Wkshp. on Geotherm. Reservoir Eng., Stanford Univ., p. 241-246.

Walters, M. A., Moore, J. N., Nash, G. D., and Renner, J. L., 1996, Oxygen isotope systematics and reservoir evolution of the Northwest Geysers, Ca.: Transactions, Geothermal Resources Council, v. 20, p. 413-422. 


\title{
THE MECHANISM AND TIMING OF THE TRANSITION FROM HOT-WATER- TO VAPOR-DOMINATED CONDITIONS AT THE GEYSERS
}

\author{
${ }^{1}$ Jeffrey B. Hulen, 'Joseph N. Moore, ${ }^{2}$ Matthew T. Heizler, and ${ }^{3}$ Jeffrey C. Quick \\ 'Energy \& Geoscience Institute at the University of Utah \\ ${ }^{2}$ New Mexico Geochronological Research Institute \\ ${ }^{3}$ Utah Geological Survey
}

\section{KEY WORDS}

The Geysers, veins, fluid inclusions, vitrinite, geothermometry, age-dating, paleotopography, hydrothermal history, natural hydraulic fracturing, venting

\section{PROJECT BACKGROUND AND STATUS}

Of critical importance to The Geysers steamfield operators are the geological parameters controlling the storage and transmission of thermal fluids in the modem vapor-dominated geothermal system (e.g. Hulen et al., 1997a). Fractures are clearly of paramount importance for steam delivery at high rates and volumes, but the nature of those fractures has remained a controversial topic. The principal reason is that most samples from the steam reservoir are air-drilled cuttings, the production of which obliterates all but subtle clues to fractures in the penetrated rocks. Relying on statistical relationships between the inclination of boreholes and steam-entry frequencies in different parts of The Geysers, Beall and Box (1989) and Thompson and Gunderson (1989) determined that most productive fractures were low-angle in the metagraywacke-hosted portion of the reservoir, but high-angle in the underlying Geysers "felsite," a batholith-sized, late Cenozoic felsic intrusive complex (Fig. 1; Hulen and Nielson, 1996). The statistical approach is rigorous, and there would seem little reason to question the fracture-orientation data it supplies. However, it is intriguing to note that almost all the "spot" cores collected from all parts and depths of the steam field are disnupted by high-angle fractures, many of which are vuggy and permissibly could serve as fluid conduits (e.g. Nielson et al., 1991). Such open, high-angle fractures are even more prevalent in core from The Geysers Coring Project (Fig. 1; Hulen et al., 1995); and several are associated with documented steam entries (Hulen and Nielson, 1995).

In the absence of oriented core or borehole-imaging data, the nature and orientation of potentially steamtransmitting fractures must be ascertained in part indirectly. In a huge, high-energy, magmatic-hydrothermal system like The Geysers, one plausible mechanism of fracture formation is natural hydraulic rock rupture. Hebein (1985, 1986) considered such a mechanism likely, and Hulen and Nielson (I 996) discussed its merits as a Geysers fracturing mode. Still, its importance in creating new fractures at The Geysers has remained speculative. Textures once presumed diagnostic of this type of fracturing. (e.g. "jigsaw-puzzle" breccias) have been noted in Geysers cores, but these are now known to develop also by implosion into and around dilational voids along faults (e.g. Sibson, 1996). However, for at least one sector of the steam field, Sulphur Bank (Fig. 1), we believe we have found good evidence for past hydraulic rock rupture from the application of multiple and seemingly disparate research and analytical techniques: In the process, we have been able to show (again, for the Sulphur Bank area) that this fracturing mechanism may have been directly responsible for initiation of the vapordominated conditions which still prevail. As an unexpected but important benefit of the work, we have also been able to constrain closely the timing of The Geysers liquid- to vapor-dominated transition at Sulphur Bank, and will suggest that it could have been a relatively catastrophic event triggered by explosive, hydrothermal rock 
rupture. Finally, as an outgrowth of the research, we have the opportunity to investigate the "high-temperature" Geysers steam reservoir in one area where it may have formed in the very recent past.

\section{PROJECT OBJECTIVES}

\section{Technical Objectives}

- Improve understanding of the nature and origin of fracture porosity and permeability in the Sulphur Bank area of The Geysers steam field.

- Investigate the mechanisms and timing of the transition from hot-water-to vapor-dominated conditions, at least in this relatively high-elevation sector of the steam field.

- Assess the utility of the reflectance of organic matter (vitrinite and pyrobitumen) in The Geysers metaclastic rocks for gauging the maximum paleotemperature to which these rocks have been heated. Also test the applicability of this technique for establishing paleotemperatures in the typical situation at The Geysers where air-drilled borehole samples are too small to permit temperature estimation by fluid-inclusion microthermometry.

\section{Expected Outcomes}

- Improved knowledge of the nature of steam-transmitting fracture porosity and permeability in the Sulphur Bank area and probably other sectors of The Geysers reservoir.

- More effective exploitation of remaining steam reserves

- Maximization of future injection strategies for mining the impressive amounts of heat still stored in the rocks and thus significant enhancement of steam production.

- Refined modeling of the origin and evolution of The Geysers magmatic-hydrothermal system, particularly the "switchover" from liquid- to vapor-dominated conditions.

- A new technique (for The Geysers) based on organic-matter reflectance, useful in mapping the distribution of past and present thermal regimes in the steam field and throughout the greater Clear Lake volcanic field:

\section{APPROACH}

For this investigation, we were fortunate to be able to draw upon a breadth of excellent and germane prior publications (e.g. Moore and Gunderson, 1995). However, the work also required application of two new (for The Geysers) and surprisingly interrelated methods: (1) ${ }^{40} \mathrm{Ar} /{ }^{39} \mathrm{Ar}$ incremental-heating age dating and thermalhistory modeling (see summary by Hulen et al.); and (2) vitrinite and pyrobitumen petrography and reflectance measurement. J. Moore also supplied voluminous new data on fluid-inclusion systematics for vein minerals in core from borehole SB-15D, while J. Hulen refined the corresponding petrographic and paragenetic database -in particular the age relationships among age-datable potassium-bearing phases and the temperature-sensitive expandable interlayer content of mixed-layer clay minerals -- and integrated the results of all the foregoing investigations to yield a refined model of The Geysers' hydrothermal history. 
The basics of the ${ }^{40} \mathrm{Ar} /{ }^{39} \mathrm{Ar}$ dating method as applied to this study are briefly summarized in the accompanying fiscal-year 1997 research summary (Hulen et al., 1998). Methods of fluid-inclusion and petrographic analysis as applied to The Geysers are detailed in such papers as Moore and Gunderson (1995). The vitrinite- (and pyrobitumen-) reflectance method of assessing paleotemperature is based upon the fact that the reflectance of these organic materials increases systematically and irreversibly with time (sluggish, linear response) and temperature (rapid and geometrically increasing response) (Barker and Pawlewicz, 1994). Organic-matter reflectance can be measured very precisely and used to estimate the maximum temperature to which a rock has been subjected. The technique has been used for this purpose in several high-temperature geothermal systems around the world (summarized in Browne, 1993); the first geothermal application of organic-matter reflectance was by Barker and Elders (1981) for the Salton Sea field in southern California. Details of pyrobitumen- and vitrinite-bearing sample preparation and measurement techniques are presented in Hulen et al. (1997b).

\section{RESEARCH RESULTS}

In the preceding research summary (Hulen et al., 1998), it was demonstrated through a combination of age-dating, geochemical, and petrographic techniques that the bulk of The Geysers hydrothermal system was likely initiated at about $1.1 \mathrm{Ma}$, when the ground surface, believed to be low-relief terrain of relatively uniform elevation, was roughly a kilometer above modem mean sea level. With these relationships as background, we can focus on details of The Geysers' hydrothermal evolution. Critical to this evaluation, however, are vitrinite- and pyrobitumen-reflectance (VR and PBR) values and corresponding peak paleotemperatures for cores from the entire Geysers field. The locations, elevations, sample types, and geothermometry for these samples are presented in Figure 1. Peak paleotemperatures were obtained from corresponding VR and PBR values utilizing an empirical reflectance-temperature relationship derived through combination of the work of Jacob (1989), Landis and Castano (1995), Bertrand (1993), Barker (1991) and Barker and Pawlewicz (1994) with application to hydrothermally heated organic materials. The relevant equation is as follows:

$$
T_{\text {peak }}=132.8 \ln (V R / 0.356)
$$

It is important to realize that this value represents the very highest temperature the host rock has ever experienced. Thus, the VR/PBR technique can often be superior to fluid-inclusion microthermometry, since an analyzed vein mineral in a rock may well have been emplaced long after a rock has reached its temperature maximum.

The VR and PBR values for The Geysers cores ranged from 3.14 to $6.15 \%$, equivalent to peak paleotemperatures of $289-410^{\circ} \mathrm{C}$ (Table 1 ). These values are consistent with the range of paleotemperatures obtained from fluidinclusion microthermometry by Moore and Gunderson (1995), and much higher than regional values for analogous Franciscan metaclastic rocks (e.g. Underwood, 1974). When both of these paleotemperature data sets are plotted relative to hypothetical boiling point curves for the pre-vapor-dominated hydrothermal system, however (Fig. 2), they reveal for the first time that fluids in this system may have been intermittently overpressured by several $\mathrm{MPa}$ (please refer to the foregoing research summary by Hulen et al. for the rationale behind the illustrated [Fig. 2] upper paleosurface). We believe that this overpressuring may be intimately related to creation of the vapor-dominated conditions which still exist at The Geysers.

Also shown on Figure 2 are two BPC originating at the $1.1 \mathrm{Ma}$ paleosurface. One BPC is appropriate for coldhydrostatic pressures; the other for the pressure theoretically required to hydrofracture the reservoir rock in an extensional tectonic regime like The Geysers. It can be seen at a glance that about a third of the peak paleotemperatures fall within the overpressured zone between the two BPC. It is equally clear, however, that if these peak temperatures were achieved only when the paleosurface was at its highest, then fluid pressures would have been insufficient to break the rock hydraulically. 
We believe the pressures could have been high enough for hydraulic fracturing at $0.57 \mathrm{Ma}$ (the age of an early vein adularia; details of its age-dating and thermal-history modeling will appear later in the present summary) in the Sulphur Bank area of The Geysers. On Figure 3, the paleotemperature data of Figure 2 are plotted relative to BPC originating at a lower ground surface which we feel is appropriate for this time and this sector of the field. This ground surface, $810 \mathrm{~m}$, is based on the feldspar age and an assumed constant erosional rate between $1.1 \mathrm{Ma}$ and now, when the ground surface is $570 \mathrm{~m}$ above mean sea level (Fig. 3). When considered relative to the BPC for this lower paleosurface, many more of the peak paleotemperatures from fluid-inclusion microthermometry and VR/PBR fall within the overpressured zone. Most of those from SB-15-D, in fact, slightly exceed the pressures required for hydraulic rock rupture.

Cores from the Sulphur Bank area are intensely disrupted by mineralized, essentially vertical, latestage veins, most of which show no sign of prior tectonic shear (Hulen and Nielson, 1995). They are fragile "pull-apart" extensional features, and are consistent with development of the host fractures by natural hydraulic fracturing under stress conditions similar to those which now occur at The Geysers (see Nielson and Brown, 1990). There are no unambiguous hydrothermal breccias (for example, with attrition-rounded clasts) in The Geysers core, but we believe that this could reflect the position of SB-15-D outside the focus of hydrothermal explosive activity (Fig. 4, explained below).

From the data of Figures 2 and 3, it appears that $0.57 \mathrm{Ma}$ Geysers hydrothermal system at higher elevations, particularly in the Sulphur Bank area, was at least intermittently overpressured by up to $10 \mathrm{MPa}$. If the corresponding elevated temperatures were maintained at these high levels (up to $300^{\circ} \mathrm{C}$ ) for extended periods of time (and assuming maintenance of an effective top-seal on the system), then the overpressuring would progressively increase as overburden was stripped away. At some point, then, the fluid pressures could exceed the strength of that overburden and induce a hydrothermal enuption. Alternatively, breaching of the overpressured system by tectonic fracturing could have similar consequences, that is, relatively rapid venting of a significant amount of the fluid in place. We envision just such a scenario for the Sulphur Bank area.

The Sulphur Bank area of The Geysers represents the highest reaches of the vapor-dominated geothermal system -- productive steam entries in this oldest part of the field occurred as shallow as $200 \mathrm{~m}$ below ground level (as opposed to the typical case, >1000 m; B. Koenig, pers. comm., 1997, and, for example, Beall and Box, 1989). The Sulphur Bank sector of the field is also the site of the most extensive and intense surficial and near-surface acid-sulfate alteration (above the present-day steam reservoir). This patch of alteration is distinctly lozengeshaped (Hulen and Walters, 1993), and conceivably could be developed in a zone of enhanced porosity and permeability within a "rhombiform" dilational jog along the Big Sulphur Creek fault zone. Shearing along this jog in the past could have weakened the rocks by inducing extension fractures, which in turn could have fostered venting of the overpressured hydrothermal system, with likely accompanying hydrothermal eruption.

If this analysis is correct, then we automatically know the orientations of the induced fractures, since regional and local stresses are well known and unlikely to have varied much during the past half million years. The fractures will form parallel to the plane defined by the vertical stress and the maximum horizontal stress (Fig. 4). Thus, even in the absence of direct evidence for the orientation of steam-bearing fractures here (though we know they are steep from results of The Geysers Coring Project), we can infer that they will strike northerly (Fig. 4). This information should be useful to steamfield operators in targeting the best water-injection pathways in the future.

Pruess (1985) and Shook (1995) each have modeled the creation of vapor-dominated geothermal systems in turns of relatively rapid venting of as little as $7 \%$ of the total water initially in place in the reservoir rock. These models are consistent with the venting scenario outlined above for the Sulphur Bank area -- in other words, we believe 
this is an ideal place for the venting to have been focused. When did the transition from liquid- to vapordominated conditions take place?

We have arrived at what we believe is a good first estimate of this timing from a combination of agedating and thermal-history modeling of vein adularia constrained by vein-mineral paragenesis, fluidinclusion systematics, and VR geothermometry (Hulen et al., 1997b). The incremental-heating ${ }^{40} \mathrm{Ar} /{ }^{39} \mathrm{Ar}$ age spectrum for vein adularia from a depth of $472 \mathrm{~m}$ in corehole SB- 15-D is shown as Figure 5 (bottom). The spectrum lacks a well-defined plateau like the one obtained for biotite from The Geysers granodiorite (see previous research summary; Hulen et al., 1998), indicating that the adularia was thermally disturbed following its precipitation. Extraction of the true age of deposition as well as the thermal history of the feldspar is technically possible through comparison of plausible heating models with the actual age spectrum (Fig. 5, bottom). This is only possible, however, if the feldspar was not heated above its "blocking temperature" after precipitation; fortunately we have a way to check. The sample from which the age-dated adularia was extracted contains abundant vitrinite, the reflectance of which, applying methods described above, yields a maximum possible paleotemperature of $330^{\circ} \mathrm{C}$, or $45^{\circ} \mathrm{C}$ less than the feldspar's calculated blocking temperature (Hulen et al., 1997b).

Only two of the numerical thermal-history models (2 and 3; Fig. 5) approximate the real age spectrum of the adularia, but they do so equally well. How do we decide the more realistic match? There is no mineralogic or fluid-inclusion evidence for the temperature "spike" of model 3, so we select 2 as the more likely. This model calls for precipitation of the feldspar at $0.57 \mathrm{Ma}$ and $330^{\circ} \mathrm{C}$, followed by gradual cooling until about $0.28 \mathrm{Ma}$ (a not unlikely scenario above a huge potent heat source like The Geysers felsite). At this point the temperature begins to drop rapidly, reaching $260^{\circ} \mathrm{C}$ by about $0.25 \mathrm{Ma}$, then resumes a gradual decline to the modem $230^{\circ} \mathrm{C}$.

J. Moore has observed large, relatively low-pressure carbon-dioxide-rich fluid inclusions which could only have formed in a vapor-dominated environment; coexisting primary liquid-rich inclusions were trapped at about $290^{\circ} \mathrm{C}$. These inclusions, we believe, record the onset of vapor-dominated conditions. Note on preferred thermalhistory model 2 that $290^{\circ} \mathrm{C}$ occurs only between 0.28 and $0.25 \mathrm{Ma}$. Accordingly, we believe it very likely that this 30,000 year interval marked the transition from liquid to vapor-dominated conditions in the Sulphur Bank area.

\section{FUTURE PLANS}

As appealing in its simplicity as the foregoing hydrothermal history might be, it is based largely upon the agedating and thermal-history modeling of one secondary feldspar sample. For a truly rigorous analysis, we believe at least 7-10 additional such analyses for the Sulphur Bank area and other parts of The Geysers are required. Working with Brian Koenig of Unocal, and with permission from that organization, we have collected likely adularia-bearing vein samples from all existing cores from Unocal's leaseholdings, and submitted them to the New Mexico Geochronological Research Institute. Along with refined petrographic and fluid-inclusion analysis as well as organic-matter reflectance and geothermometry of the cores, the results of incremental heating experiments of these samples should near-definitively constrain the hydrothermal history of the world's largest vapordominated geothermal system.

Of particular interest will be the relationship of mineralization age, organic-matter reflectance, fluidinclusion geothermometry, and thermal-history modeling for the core from the high-temperature portion of the Aidlin sector of The Geysers. Here, it appears from preliminary analysis that the peak paleotemperature determined from vitrinite and pyrobitumen reflectance is equivalent to the modern temperature of about $290^{\circ} \mathrm{C}$. This is in sharp contrast to other samples from the high-temperature reservoir, in which fluid-inclusion trapping temperatures and VR/PBR paleotemperatures alike exceed the modern temperature by more than $100^{\circ} \mathrm{C}$. If the Aidlin past peak 
and modern temperature relationship withstands further scrutiny, it means that we have an opportunity to investigate a sector of the "high-temperature" Geysers steam reservoir perhaps at its very inception.

\section{INDUSTRY INTEREST}

Besides being of extreme academic interest in the study of magmatic-hydrothermal systems, results of this research bear directly upon determination of the origin, character, and geometry of fractures in The Geysers reservoir. This information should have direct relevance not only for current reservoir management, but also in the selection of the most optimum water-injection sites for the augmentation of future steam production. Geysers operating companies which should benefit most directly from this research are Unocal, Calpine, and NCPA. The results and the approach used to achieve them should be applicable to the study of any active or fossil hydrothermal system but especially those circulating through rocks containing indigenous and/or introduced organic matter.

\section{REFERENCES}

Barker, C.E., 199 1, Implications for organic maturation studies of evidence for a geologically rapid increase and stabilization of vitrinite reflectance at peak temperature, Cerro Prieto geothermal field, Mexico: American Association of Petroleum Geologists Bulletin, v. 75, p. 1852-1863.

Barker, C.E., and Elders, W.A., 1981, Vitrinite reflectance geothermometry and apparent heating duration in the Cerro Prieto geothermal field: Geothemics, v. 10, p. 207-223.

Barker, C.E., and Pawlewicz, M.J., 1994, Calculation of vitrinite reflectance from thermal histories and peak temperatures - A comparison of methods in Vitrinite reflectance as a maturity parameter (P.K. Mukhopadhyay and W.G. Dow, editors): American Chemical Society, Symposium Series, No. 570, p. 216-229.

Beall, J.J., and Box, W.T., 1989, The nature of steam-bearing fractures in the south Geysers reservoir: Geothermal Resources Council, Transactions, v. 13, p. 441-448.

Bertrand, R., 1993, Standardization of solid bitumen reflectance to vitrinite in some Paleozoic sequences of Canada: Energy Sources, v. 15, p. 287-296.

Browne, P.R.L., 1983, Application of mineralogical methods to assess the thermal stabilities of geothermal reservoirs: Stanford University, Eighteenth Workshop on Geothermal Reservoir Engineering, Proceedings, p. 7378.

Hebein, J.J., 1985, Historical hydrothermal evolutionary facets revealed within the exploited Geysers steam field: Geothermal Resources Council Bulletin, June 1985, p. 13-16.

Hebein, J.J., 1986, Conceptual schematic geologic cross sections of The Geysers steam field: Stanford University, Eleventh Workshop on Geothermal Reservoir Engineering, Proceedings, p. $251-257$.

Hulen, J.B., and Nielson, D.L., 1995, The nature of faults and hydrothermal veins in corehole SB-15D, The Geysers steam field, California: Geothermal Resources Council, Transactions, v. 19, p. 181188.

Hulen, J.B., and Nielson, D.L., 1996, The Geysers felsite: Geothermal Resources Council, Transactions, v. 20, p. 295-306. 
Hulen, J.B., and Walters, M.A., 1993, The Geysers felsite and associated geothermal systems, alteration, mineralization, and hydrocarbon occurrences in Active geothermal systems and goldmercury deposits in the Sonoma-Clear Lake volcanic fields, California (J.J. Rytuba, editor): Society of Economic Geologists, Guidebook Series, v. 16, p. 141-152.

Hulen, J.B., Koenig, B.A., and Nielson, D.L., 1995, The Geysers Coring Project, Sonoma County, California, USA -- Summary and initial results: Florence, Italy, World Geothermal Congress, Proceedings, p. 1415-1420.

Hulen, J.B., Nielson, D.L., Moore, J.N., and Quick, J.C., 1997a, Geologic research at The Geysers in Federal geothermal research program update, fiscal year 1996: Report Prepared for U.S. Department of Energy, Office of Geothermal Technologies, by Princeton Economic Research, Inc., p. 4-123 to 4-13 1.

Hulen, J.B., Heizler, M.T., Stimac, J.A., Moore, J.N., and Quick, J.C., 1997b, New Constraints on the timing of magmatism, volcanism, and the onset of vapor-dominated conditions at The Geysers steam field, California: Stanford University, Twenty-second Workshop on Geothermal Reservoir Engineering, Proceedings, p. 75-82.

Hulen, J.B., Quick, J.C., and Moore, J.N., 1997c, Converging evidence for fluid overpressures at peak temperatures in the pre-vapor-dominated Geysers hydrothermal system: Geothermal Resources Council, Transactions, v. 21, p. 344-351.

Jacob, H., 1989, Classification, structure, genesis, and practical importance of natural solid oil bitumen: International Journal of Coal Geology, v. 11, p. 65-79.

Landis, C.R., and Castano, J.R., 1995, Maturation and bulk chemical properties of a suite of solid hydrocarbons: Organic Geochemistry, v. 22, p. 137-149.

Moore, J.N., and Gunderson, R.P., 1995, Fluid-inclusion and oxygen-isotopic systematics of an evolving magmatic-hydrothermal system -- The Geysers, California: Geochimica et Cosmochimica Acta, v. 59, p. 38873907.

Nielson, D.L., and Brown, D., 1990, Thoughts on stress around The Geysers geothermal field: Geothermal Resources Council, Transactions, v. 14, p. 1685-1690.

Nielson, D.L., Walters, M.A., and Hulen, J.B., 1991, Fracturing in the northwest Geysers, Sonoma County, California: Geothermal Resources Council, Transactions, v. 15, p. 27-33.

Pruess, K., 1985, A quantitative model of vapor-dominated geothermal reservoirs as heat pipes in fractured porous rock: Geothermal Resources Council, Transactions, v. 9, p. 335-361.

Shook, G.M., 1995, Development of a vapor-dominated reservoir with a "high-temperature" component: Geothermics, v. 24, p. 489-505.

Sibson, R.H., 1986, Brecciation processes in fault zones .. Inferences from earthquake rupturing: Pure and Applied Geophysics, v. 124, p. 159-175.

Thompson, R.C., and Gunderson, R.P., 1989, The orientation of steam-bearing fractures at The Geysers geothermal field: Geothermal Resources Council, Transactions, v. 13, p. 481-485. 
Underwood, M.B., 1974, Temporal changes in geothermal gradient, Franciscan subduction complex, northern California: Journal of Geophysical Research, v. 94, p. 3111-3125. 


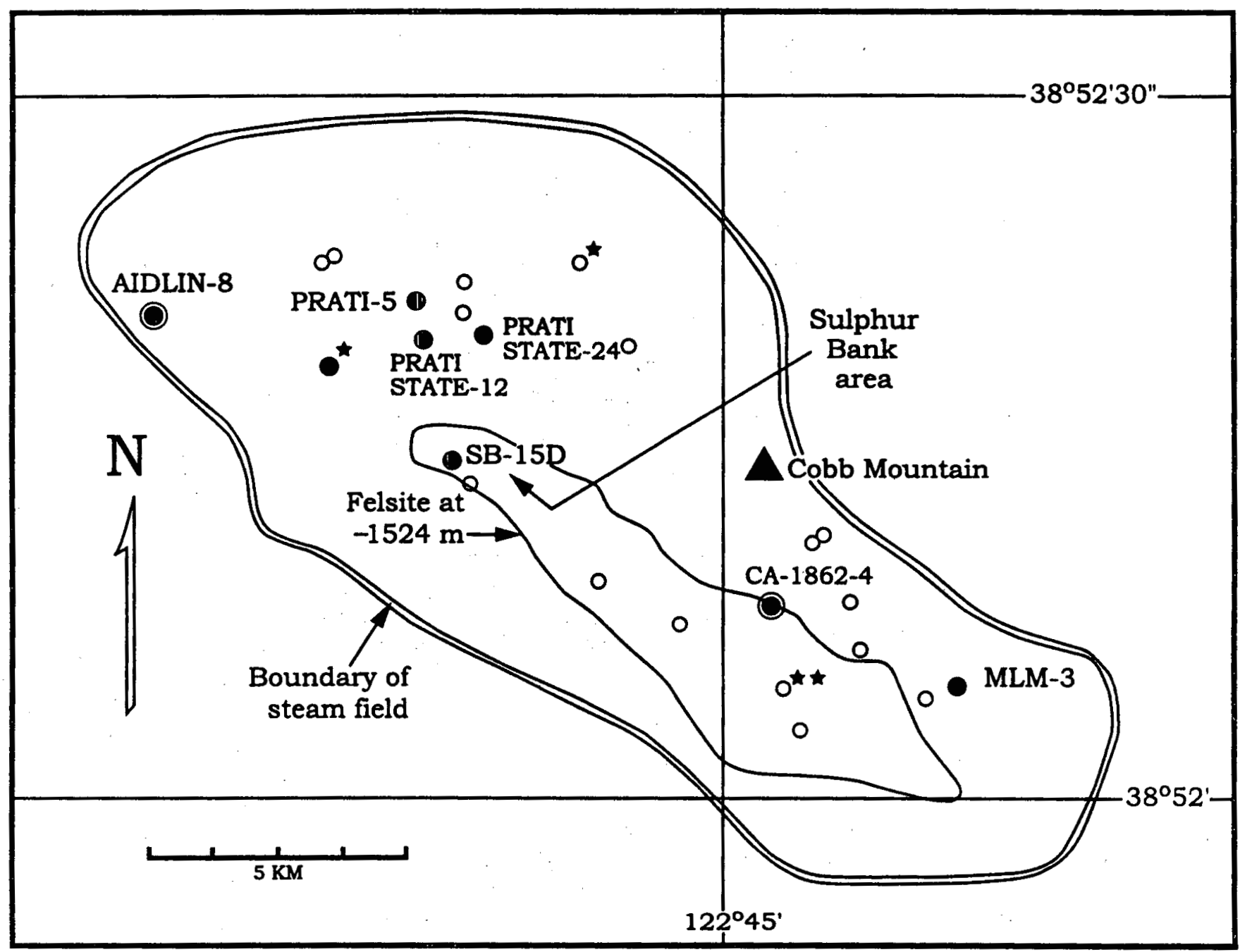

Peak paleotemperatures from:

- Hornfelsic metagraywacke

Microgranite porphy (all other samples metagraywacke).
- Organic - matter reflectance (OMR) and fluid - inclusion trapping temperatures $\left(T_{t}\right)$

OMR only

- $T_{t}$ only (from Moore and Gunderson, 1995)

Figure 1 - Location map, showing positions, at drilled depths, of samples measured for their paleotemperatures using either organic-matter reflectance or fluid-inclusion microthermometry. 


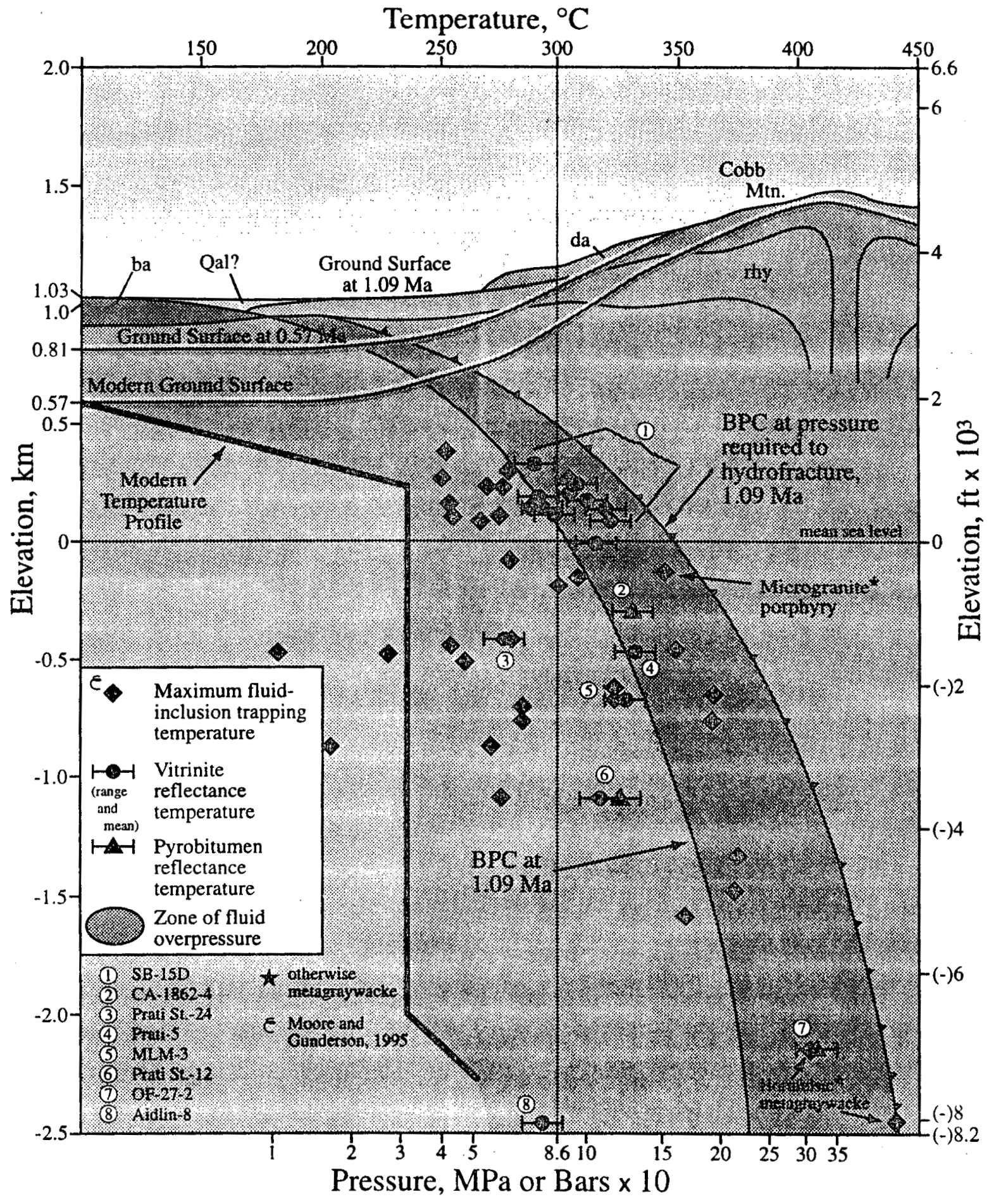

Figure 2 - Paleotemperatures vs depth for The Geysers hot-water-dominated hydrothermal system (antecedent to the modem steam reservoir). Shown for reference are boiling-point-with-depth curves (BPC) originating at the calculated palcosurface for $1.1 \mathrm{Ma}$, the probable age at which the bulk of the hydrothermal system was initiated. One of the two BPC is appropriate for cold-hydrostatic pressures; the other for pressures required to nupture the reservoir rock by natural hydraulic fracturing. Note that about a third of the peak paleotemperatures fall within the overpressured zone bracketed by the two curves. 


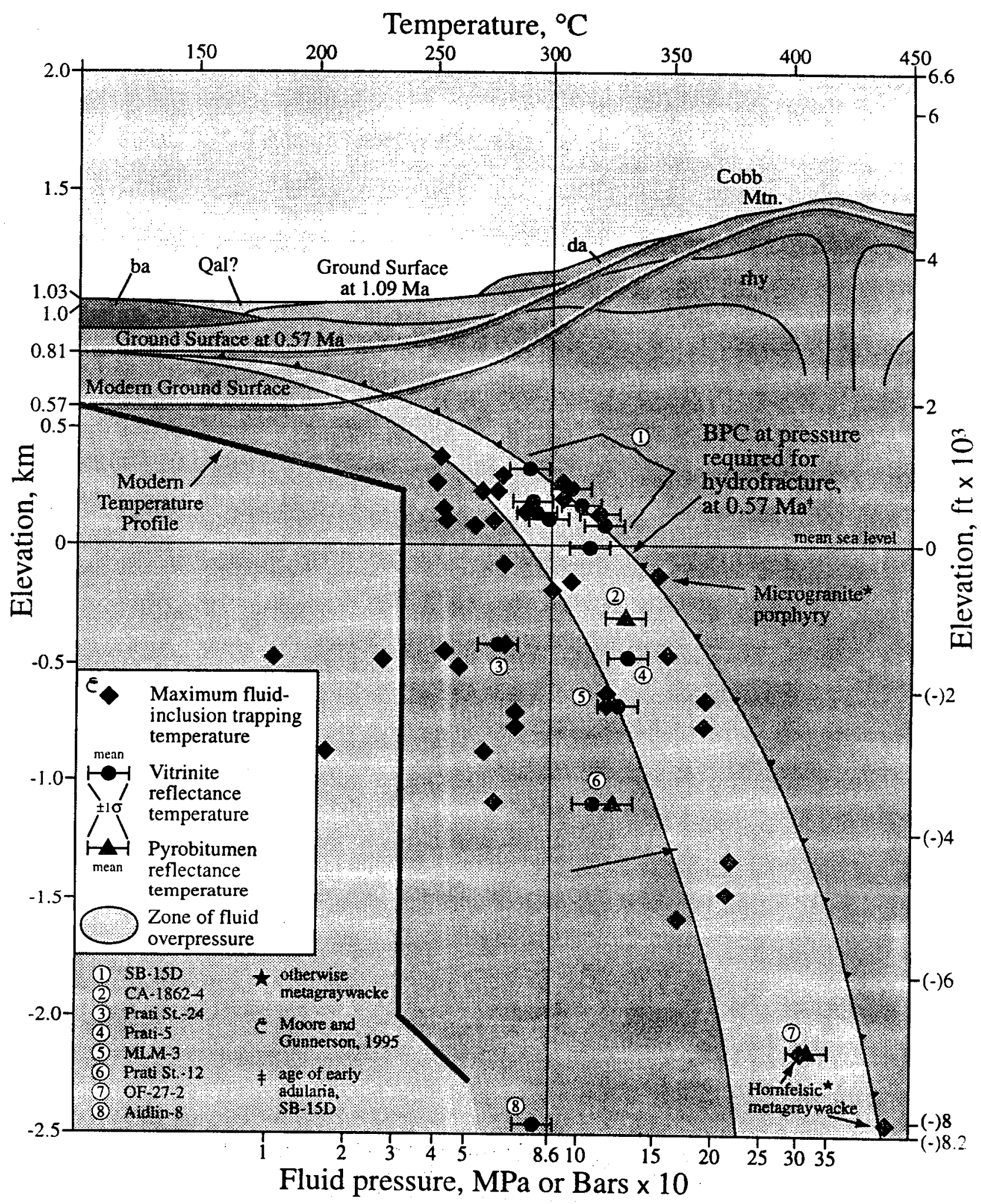

Figure 3 - Same as Figure 2, but with the two BPC originating from the presumed paleosurface at $0.57 \mathrm{Ma}, 810$ $\mathrm{m}$ above mean sea level. Note that many more of the peak paleotemperatures are within the overpressured zone, and that those for corehole SB-15-D (see Fig. 1 for location) were theoretically just high enough to induce hydrothermal brecciation. 


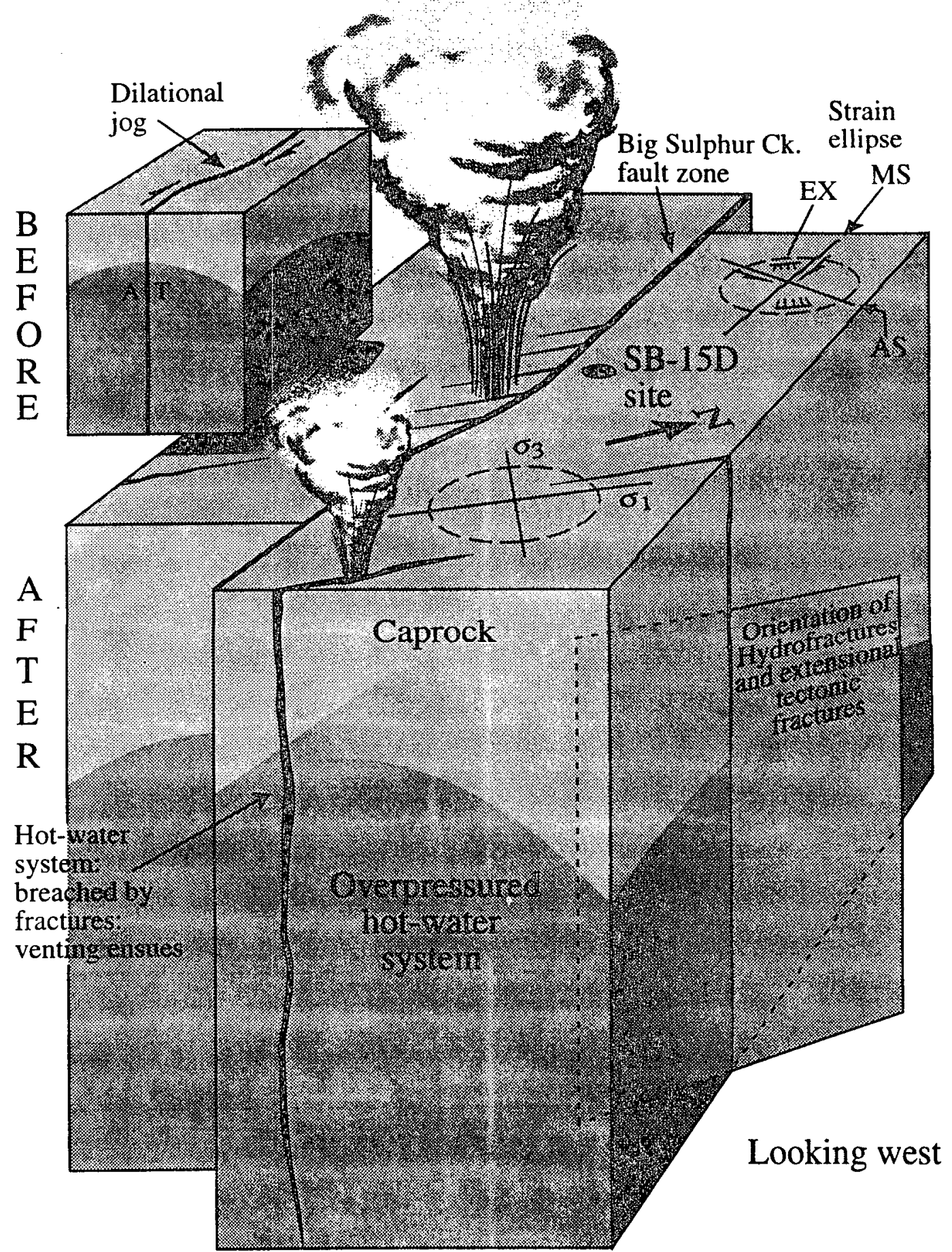

Figure 4 -- Conceptual diagram of the Sulphur Bank area of The Geysers at or later than $0.57 \mathrm{Ma}$, showing rupture of caprock and venting of the overpressured hot-water-dominated geothermal system. This event, which may have taken place in the narrow time interval $0.28-0.25 \mathrm{Ma}$ (see text for explanation), may have led directly to formation of the vapor-dominated conditions still in existence today. Caprock rupture could have been caused by extensional fracture within and around a deeply-penetrating dilational jog in the Big Sulphur Creek fault zone. Alternatively, the overpressured hydrothermal system itself may have triggered natural hydraulic rock nupture. By whichever mechanism the fractures were induced, because of the prevailing stress field they would be steeply dipping and trend approximately north. 

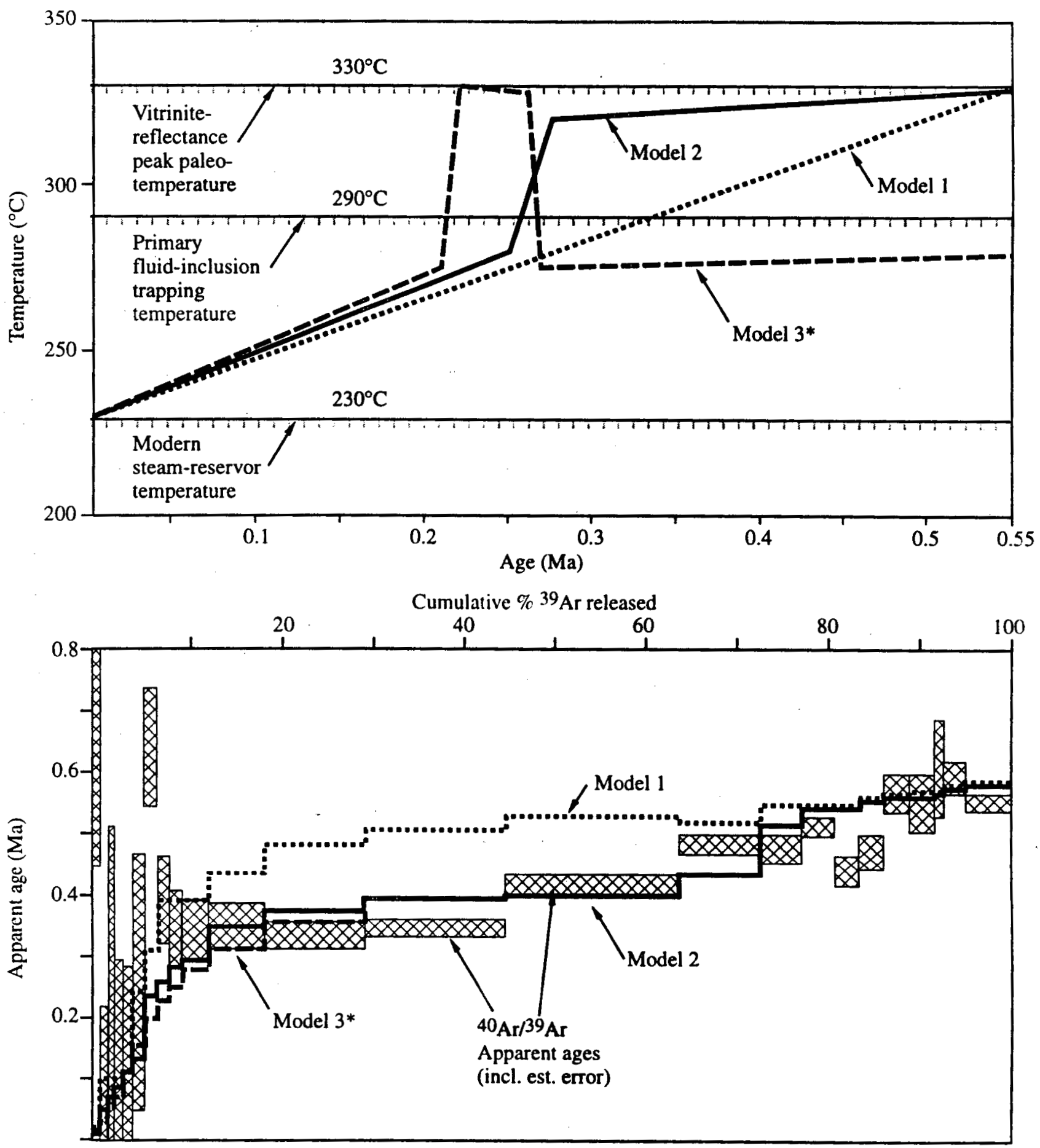

* Yields age spectrum nearly identical to that produced by model 2

Figure 5 - Three alternative thermal histories (top) and corresponding age spectra relative to the measured age spectrum (bottom) for adularia from a depth of $471.8 \mathrm{~m}$ in Geyser Coring Project corehole SB-15-D. Although models 2 and 3 both match closely the measured spectrum, model 2 is believed to be the more geologically realistic. 


\title{
AGE, PETROGENESIS, AND EMPLACEMENT OF FELSIC PLUTONIC AND VOLCANIC ROCKS AT THE GEYSERS: NEW AND CONFIRMED CONSTRAINTS ON THE INCEPTION AND EVOLUTION OF THE GEYSERS HYDROTHERMAL SYSTEM
}

\author{
Jeffrey B. Hulen ', James A. Stimac ${ }^{2}$, Matthew T. Heizler ${ }^{3}$ \\ 'Energy \& Geoscience Institute at the University of Utah \\ ${ }^{2}$ Unocal Geothermal \\ ${ }^{3}$ New Mexico Geochronological Research Institute
}

\section{KEY WORDS}

The Geysers, felsite, granodiorite, dacite of Cobb Mountain, petrogenesis, geochemistry, age-dating, boiling point curves, geothermometry, natural hydraulic fracturing

\section{PROJECT BACKGROUND AND STATUS}

This study is an outgrowth of The Geysers felsite project (Hulen and Walters, 1993; Hulen and Nielson, 1993, 1996), complete except for final journal publication at the end of the previous fiscal year (Hulen et al., 1997a). The governing aim of that undertaking was to map in detail, in three dimensions, the lithology, hydrothermal alteration, mineralization, and structural disruption of "the felsite", a large, late Cenozoic igneous intrusive body still cooling beneath the productive steam field. Prior to the early 1980's, because of sampling limitations (smalldiameter drill cuttings), the felsite necessarily was envisioned as a monolithologic pluton. However, commencing with the work of Schriener and Suemnicht (1981), it became apparent that the felsite was a composite igneous body. This being the case, it seemed possible that certain phases of the pluton, rather than the felsite en masse, might be selectively associated with higher quality and/or higher-volume steam production. Likewise, the chance existed for analogous correlations between favorable reservoir-rock volumes and felsite-induced contact metamorphism, alteration, and vein mineralization. The felsite study confirmed some of these relationships while surprisingly but convincingly disproving others; the details are summarized by Hulen et al. (1997a).

As a late component of The Geysers felsite study, ${ }^{40} \mathrm{Ar} /{ }^{39} \mathrm{Ar}$ age-dating and thermal-history modeling were completed on the largest and locally the freshest (that is, unaltered) phase of the pluton. This work was designed to complement the felsite age-dating work of Dalrymple (1992). Broad-spectrum, trace-element geochemical analyses of the felsite and overlying rhyolitic and dacitic volcanic rocks were obtained in support of this work. The combined results of these efforts have enabled us to show conclusively that one portion of the felsite -- The Geysers granodiorite -- and an overlying extrusive dacite dome -- are chemical and temporal equivalents. This in turn has allowed us to establish, with a reasonable degree of confidence, the elevation of the ground surface at the time this youngest major part of the felsite was emplaced and began to stimulate circulation of The Geysers (hot-water-dominated) geothermal system. This is critical information, because the postulated ground surface would have been the maximum elevation of the contemporaneous water table, the level of which, as first estimated by Moore and Gunderson (1995) constrains (1) the probable positions, through time, of boiling-pointwith-depth curves (BPC) relevant for the precursor liquid-dominated phase of The Geysers; and (2) the nature of a variety of porosity-inducing processes, for example natural hydraulic fracturing. 


\section{PROJECT OBJECTIVES}

\section{Technical Objectives}

- Determine, with high-precision, the geochemical composition, age, and thermal history of The Geysers granodiorite, the intrusive previously determined (e.g. Hulen and Nielson, 1996) to have been the principal magmatic engine for The Geysers hydrothermal system. Test the assumed but hitherto unproven relationship between the granodiorite and the mineralogically similar extrusive dacite of the overlying Cobb Mountain volcanic center in the southern Clear Lake volcanic field.

- Reliably establish the most probable maximum elevation of the water table at the time the granodiorite was emplaced and when this magma body activated the pre-vapor-dominated Geysers hydrothermal system.

- Utilize the foregoing information to help constrain aspects of The Geysers' hydrothermal history and evolution of the field's essential secondary porosity.

\section{Expected Outcomes}

- Enhanced understanding of The Geysers' magmatic-hydrothermal history, especially as related to the creation of reservoir porosity and the nature and timing of the transition from hot-water- to vapordominated conditions.

- New insight into the mechanisms of fracture formation associated with late Cenozoic magmatism and related hot-water circulation through time at The Geysers. In turn, more informed prediction of fracture geometry in various sectors and lithologic variants of the steam reservoir and its caprocks.

\section{APPROACH}

Much of the groundwork for this investigation had already been completed as part of The Geysers felsite study (Hulen et al., 1997a), entailing detailed petrographic and petrologic analysis of hundreds of cutting samples and numerous "spot" cores of the felsite collected from the entire explored length, breadth, and depth of the pluton (Fig. 1). This survey enabled us to focus on the The Geysers granodiorite, the portion of the felsite almost certainly responsible for the bulk of the hydrothermal alteration and mineralization enveloping the pluton (...and evidence of the system which evolved to form the modern steam reservoir). The new work entailed (1) refined petrographic and mineralogic study of selected corcs of the granodiorite as well as judiciously collected surface samples of dacite from the Cobb Mountain volcanic center (Fig. 1); (2) detailed major- and trace-element analyses of the granodiorite and dacite; and (3) high-precision argon-argon incremental-heating age dating and numerical thermal-history modeling of the granodiorite. Corresponding age-dates for the Cobb Mountain volcanic center had been measured by Donnelly-Nolan et al., (1981), Turrin et al. (1994), and Hearn et al. (1995).

The argon-argon age-dating method has several distinct advantages over conventional K-Ar techniques (Dalrymple et al., 1981; McDougall and Harrison, 1988). For one thing, the sample does not require total fusion for analysis, but rather can, as the name suggests, be incrementally heated. The argon/argon ratio can be measured for each heating increment and fraction of argon released, and this allows for the generation of age spectra, which can be numerically modeled in conjunction with all available geologic constraints to yield a sample's most geologically plausible thermal history. For complete background on the argon-argon method and related geochronology and thermochronology, the reader is referred to Dalrymple et al. (1981), Heizler and Harrison (1988), and McDougall and Harrison (1988). 


\section{RESEARCH RESULTS}

A genetic relationship between The Geysers felsite and spatially related Cobb Mountain volcanic center (Fig. 1) had been reasonably assumed since publication of mineralogical and geochemical comparisons between the two by Schriener and Suemnicht (1981). Hulen and Nielson (1993) further showed that Geysers granodiorite was virtually identical in terms of its major-element geochemistry to the dacite of Cobb Mountain or the dacite of Cobb Valley (Fig. 1). On the basis of these comparisons, and on a 0.95-1.19 argon-argon age for the granodiorite obtained by Pulka (1991), Moore and Gunderson (1995) modeled the evolution of The Geysers hydrothermal system in terms of emplacement of the granodiorite and inception of The Geysers hydrothermal system at about $1 \mathrm{Ma}$, beneath a ground surface averaging about $1 \mathrm{~km}$ in elevation. Dalrymple (1992), however, concluded from argon-argon incremental-heating age-dating of selected cores of the felsite that the pluton must be older than 1.31.4 Ma, and therefore (at least for those cores dated) an unlikely source for the Cobb Mountain volcanics. The present study was undertaken in part to resolve these discrepancies and ambiguities.

From its geometric relationship to the other major felsite rock types, The Geysers granodiorite clearly appears to be the youngest as well as the largest. Magmatic-hydrothermal alteration at The Geysers is also systematically zoned more closely in association with the granodiorite than with the other felsite phases (Hulen et al., 1997a). Therefore, we reasoned that a precise and reliable age date for the granodiorite ideally should also help refine estimates of the timing of the onset of The Geysers hydrothermal system. Accordingly, we selected visually unaltered magmatic orthoclase and coexisting biotite for argon-argon incremental-heating age-dating, which was carried out at the New Mexico Geochronological Research Laboratory under the direction of Matt Heizler (Hulen et al., 1997b).

The age spectra of biotite and orthoclase from the granodiorite are shown as Figure 2. The biotite shows a welldefined "plateau" age spectrum at $1.09 \mathrm{Ma}$. The orthoclase lacks such a plateau, but shows the same "terminal age" (corresponding to the highest temperature heating increments) anchoring an age gradient with a lower limit at about $0.7 \mathrm{Ma}$ (Fig. 2). The coincidence of the biotite plateau and the orthoclase terminal age, and the largely unaltered character of this sample of the granodiorite make it likely that the $1.09 \mathrm{Ma}$ age accurately records the time of emplacement. The results of this study thus confirm the age range for the same rock obtained by Pulka (1991), and show, at least for a portion of the felsite, that the igneous body is likely not uniformly older than 1.31.4 Ma.

The $1.09 \pm 0.04 \mathrm{Ma}$ age for the granodiorite, within error limits, encompasses the reported $\mathrm{K}$-Ar ages for the (rhyo)dacite of Cobb Mountain (1.05-1.06 $\pm 0.02 \mathrm{Ma}$ ) and the stratigraphically higher dacite of Cobb Mountain $(1.08 \pm 0.03 \mathrm{Ma})$ (Hearn et al., 1995; Donnelly-Nolan et al., 1981)(Fig. 1). In order to determine which of the two dacites, if either, might be the more likely equivalent of the granodiorite, we analyzed all three for their fullspectrum trace-element compositions. A complete reporting of the analytical results is beyond the scope of this summary, but the especially diagnostic rare-earth-element (REE) signatures for all three are shown as Figure 3. Note the close correspondence among the patterns for all three rocks. The dacite of Cobb Valley pattern matches the granodiorite most closely, but is depleted in light REE relative to the granodiorite. The reasons for the divergence remain to be determined, but considering that a big plutonic body like the granodiorite would certainly have retained heat and probably remained partially liquid long after its extrusive counterpart cooled and solidified, we believe that the match among these REE patterns is remarkably close.

The partially molten state and retention of heat following extrusion of the dacite could explain one final piece of evidence bearing on the granodiorite-dacite relationship. Intricate zoning of plagioclase phenocrysts in the granodiorite is matched very closely by zoning of plagioclase phenocrysts in the Cobb Mountain center. The 
granodiorite plagioclases, however, have an extra, sodic "rind" presumably acquired during latest-stage crystalmelt interaction.

This evidence, as intimated earlier, enables us to establish firmly the position of the ground surface in the Cobb Mountain area when part of the granodiorite here was sparingly extruded to form the Cobb Mountain dacite. The corresponding ground surfaces of other late Cenozoic volcanics in The Geysers area are all at about the same elevation, a little more than a $\mathrm{km}$ above sea level. Rytuba et al. (1993), however, have noted that a restored surface connecting these "scabs" is inclined slightly to the northeast; this could reflect either post-emplacement tilting, as they contend, or deposition of the volcanics on a mildly northeast-dipping erosional surface. In any case, the coincidence among these volcanic substrates in an area of several hundred square $\mathrm{km}$ suggests that the depositional surface was more in the nature of a low-relief plain than the ruggedly dissected terrain which prevails today.

The rationale for the foregoing geological analysis: Realizing that the initial Geysers ground surface was likely fairly flat makes it much easier to model the evolution of the felsite-driven hydrothermal system in conjunction with erosional rates obtained by subtracting modern elevations from the one deduced for 1.09.Ma. Accordingly, Moore and Gunderson (1995) determined to their satisfaction the highest possible water table at the time the prevapor-dominated Geysers hydrothermal system was circulating -- information critical for comparison of fluidinclusion temperatures with hypothetical temperatures along paleo-BPC. Likewise, Hulen et al. (1997c; see also the following research summary) utilized this datum to help deduce the timing of mineralization, the nature of fracturing (and the likely orientation of fractures), and the mechanism as well as the timing of transition from liquid- to vapor-dominated conditions.

\section{FUTURE PLANS}

Hulen and Stimac will submit a paper on the intrusive/extrusive relationship between The Geysers granodiorite and the Cobb Mountain dacite (and the implications of that relationship for the nature and evolution of The Geysers hydrothermal system) to the journal Geology during the first quarter of 1998 . This will be followed by an expanded treatise on emplacement history, petrogenesis, and hydrothermal alteration/mineralization of the felsite to be submitted to a journal (to be determined) during the first half of the year.

\section{INDUSTRY INTEREST}

The real value of knowing with confidence the timing and relationship between intrusive and extrusive rocks at The Geysers is in helping to constrain mechanisms of fluid-rock interaction and physical disruption of the reservoir rocks to create new porosity and permeability. The granodiorite-dacite connection fixes the highest likely elevation of the water table at the time the plutonic variant was emplaced, and this provides a datum for comparison of paleo-BPC at different times with paleotemperatures from mineral- and organic-based geothermometers. Such comparisons have led to the realization that fluid overpressuring and attendant natural hydraulic rock rupturing were likely common processes during the hot-water-dominated stage of The Geysers hydrothermal system. The fractures and breccias formed by this process will have developed specific textures and orientations governed in part by the prevailing regional and local stresses, all reliably established by other investigators. This information will aid Geysers steamfield operators (Unocal, Calpine, NCPA) in effectively modeling reservoir performance, and in predicting optimum sites for injection and consequently enhanced steam production. G.B. Dalrymple, of Oregon State University, and Marvin Lanphere, USGS, are completing agedating and thermal-history modeling of selected cuttings and other cores of the felsite; their work is a natural complement to the research reported in this summary. 


\section{REFERENCES}

Dalrymple, G.B., Alexander, E.C., Jr., Lanphere, M.A., and Draker, G.P., 1981, Irradiation of samples for ${ }^{40} \mathrm{Ar} /{ }^{\beta 9} \mathrm{Ar}$ dating using the Geological Survey TRIGA reactor: U.S. Geological Survey, Professional Paper 1176 , $73 \mathrm{p}$.

Dalrymple, G.B., 1992, Preliminary report on argon/argon incremental-heating experiments on feldspar samples from the felsite unit, Geysers geothermal field, California: U.S. Geological Survey, Open-File Report 92-407, $15 \mathrm{p}$.

Donnelly-Nolan, J.M., Hearn, B.C., Jr., Curtis, H., and Drake, R.E., 1981, Geochronology and evolution of the Clear Lake Volcanics in Research in the Geysers-Clear Lake geothermal area, northern California (R.J. McLaughlin and J.M. Donnelly-Nolan, editors): U.S. Geological Survey, Professional Paper 1141, p. 47-60.

Hearn, B.C., Jr., Donnelly-Nolan, J.M., and Goff, F.E., 1995, Geologic map and structure sections of the Clear Lake volcanics, northern California: U.S. Geological Survey, Miscellaneous Investigations Series Map I-2362, scale 1:24,000.

Heizler, M.T., and Harrison, T.M., 1988, Multiple trapped argon-isotope components revealed by ${ }^{40} \mathrm{Ar} /{ }^{39} \mathrm{Ar}$ isochron analysis: Geochimica et Cosmochimica Acta, v. 54, p. 1295-1303.

Hulen, J.B., and Nielson, D.L., 1993, Interim report on geology of The Geysers felsite, northwestern California: Geothermal Resources Council, Transactions, v. 17, p. 249-258.

Hulen, J.B., and Nielson, D.L., 1996, The Geysers felsite: Geothermal Resources Council, Transactions, v. 20, p. 295-306.

Hulen, J.B., and Walters, M.A., 1993, The Geysers felsite and associated geothermal systems, alteration, mineralization, and hydrocarbon occurrences in Active geothermal systems and gold-mercury deposits in the Sonoma-Clear Lake volcanic fields, California (J.J. Rytuba, editor): Society of Economic Geologists, Guidebook Series, v. 16, p. 141-152.

Hulen, J.B., Nielson, D.L., Moore, J.N., and Quick, J.C., 1997a, Geologic research at The Geysers in Federal geothermal research program update, fiscal year 1996: Report Prepared for U.S. Department of Energy, Office of Geothermal Technologies; by Princeton Economic Research, Inc., p. 4-123 to 4-131.

Hulen, J.B., Heizler, M.T., Stimac, J.A., Moore, J.N., and Quick, J.C., 1997b, New Constraints on the timing of magmatism, volcanism, and the onset of vapor-dominated conditions at The Geysers steam field, California: Stanford University, Twenty-second Workshop on Geothermal Reservoir Engineering, Proceedings, p. 75-82.

Hulen, J.B., Quick, J.C., and Moore, J.N., 1997c, Converging evidence for fluid overpressures at peak temperatures in the pre-vapor-dominated Geysers hydrothermal system: Geothermal Resources Council, Transactions, v. 21, p. 344-351.

McDougall, I., and Harrison, T.M., 1988, Geochronology and thermochronology by the ${ }^{40} \mathrm{Ar} /{ }^{39} \mathrm{Ar}$ method: Oxford University Press, 322 p. 
Moore, J.N., and Gunderson, R.P., 1995, Fluid-inclusion and oxygen-isotopic systematics of an evolving magmatic-hydrothermal system -- The Geysers, California: Geochimica et Cosmochimica Acta, v. 59, p. 3887 3907.

Pulka, F.S., 1991, Subsurface geology at Ford Flat, Geysers geothermal field, northern California: Houghton, Michigan Technological University, M.S. Thesis, $324 \mathrm{p}$.

Rytuba, J.J., Donnelly-Nolan, J.M., and McLaughlin, R.J., 1993; Day two -- The Geysers geothermal area and mercury deposits in the Clear Lake volcanic field (road log) in Active geothermal systems and gold-mercury deposits in the Sonoma-Clear Lake volcanic ficlds, California (J.J. Rytuba, editor): Society of Economic Geologists, Guidebook Series, v. 16, p. 153-170.

Turrin, B.D., Donnelly-Nolan, J.M., and Hearn, B.C., Jr., $1994,{ }^{40} \mathrm{Ar} /{ }^{39} \mathrm{Ar}$ ages from the rhyolite of Alder Creek, California -- Age of the Cobb Mountain normal-polarity subchron revisited: Geology, v. 22, p. 251-254.

Schriener, A., Jr., and Suemnicht, G.A., 1981, Subsurface intrusive rocks at The Geysers geothermal area, California in Proceedings of the symposium on mineral deposits of the Pacific Northwest (M.L. Silberman and C.L. Field, editors): U.S. Geological Survey, Open-File Report 81-355, p. 295-302. 


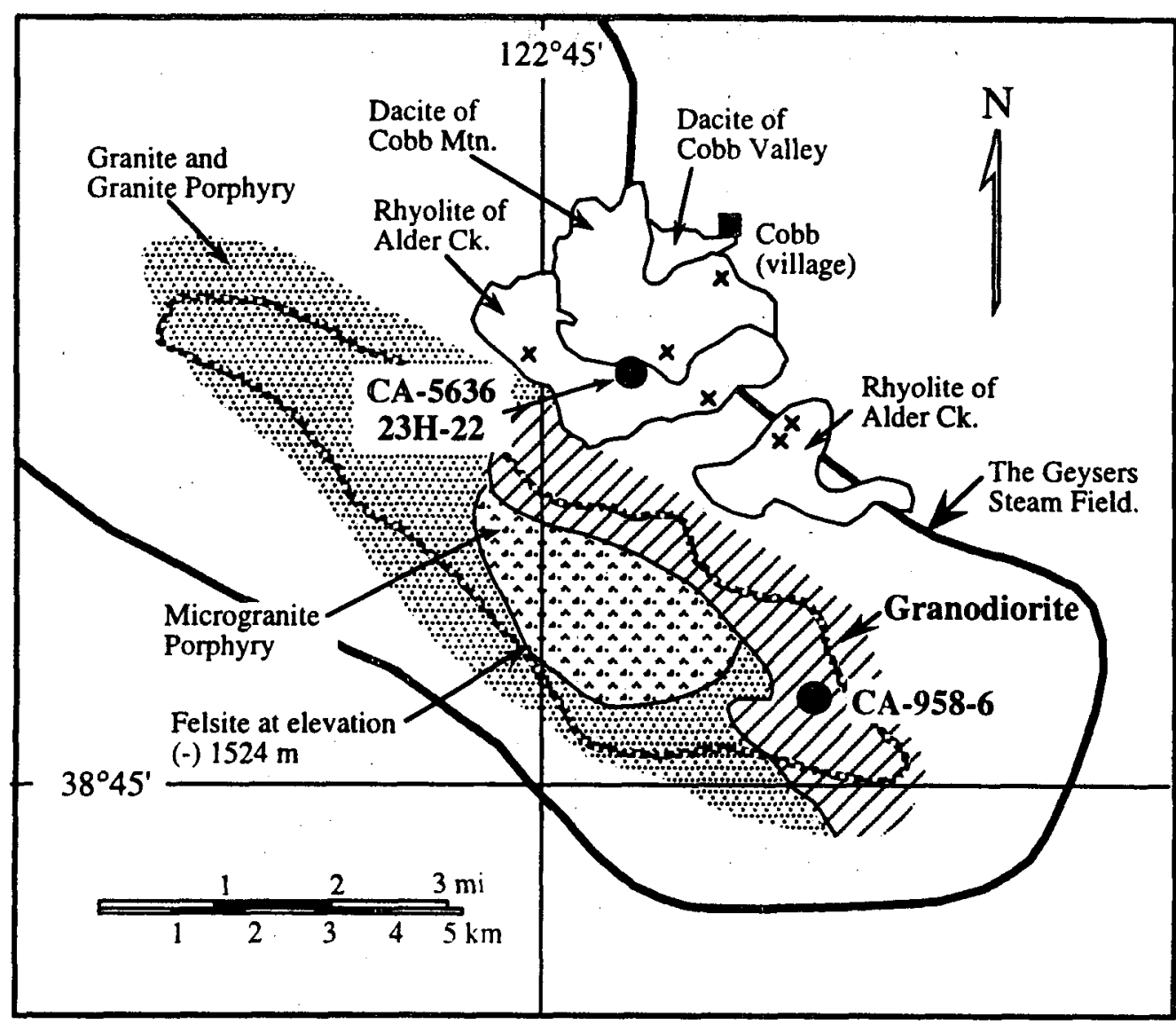

New ${ }^{40} \mathrm{Ar} / 39 \mathrm{Ar}$ age dates (this study); well location at sample depth

$x$ Previously dated volcanic rocks (please refer to text)

Figure 1 - Location map of the central and southeastern Geysers steam field, showing the three units of the Cobb Mountain volcanic center in relation to the configuration of plutonic phases at the top of The Geysers felsite. New age-dating and thermal-history modeling as well as high-precision trace-element analysis of some of these igneous rocks has confirmed that the granodiorite and one or both of the two Cobb Mountain dacite units are intrusive/extrusive equivalents. This fixes with a high degree of confidence the position of the paleosurface at the time the granodiorite intruded and stimulated circulation of The Geysers hydrothermal system. 


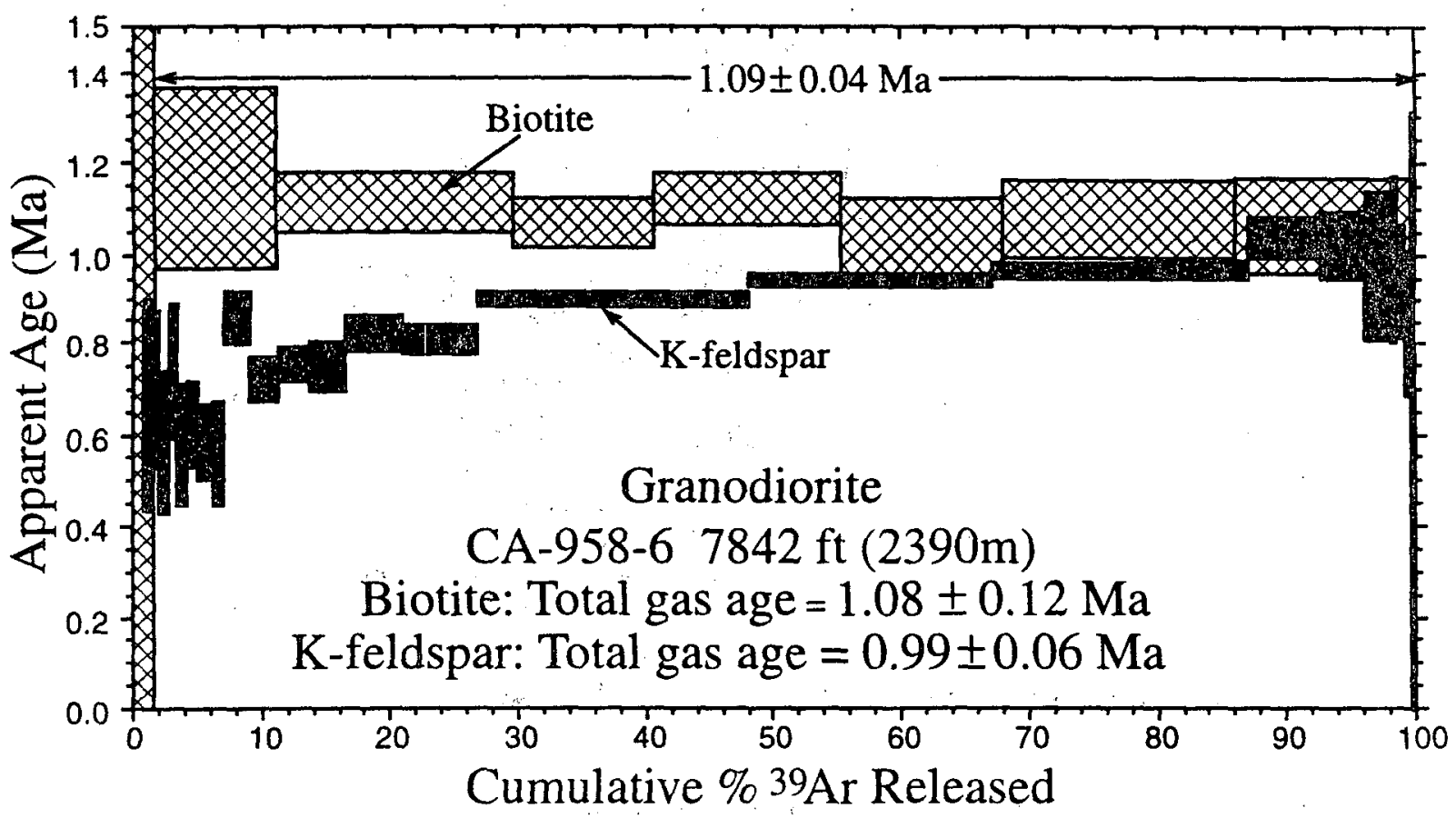

Figure 2 - Argon-Argon incremental-heating age spectra for primary biotite and orthoclase from The Geysers granodiorite. The "plateau" aspect of the biotite spectrum suggests little or no thermal disturbance or alteration of the biotite since it cooled below its "blocking temperature". The orthoclase, on the other hand, although it has a "terminal age" similar to that of the biotite, has been thermally perturbed, yielding an age gradient. The biotite pattern strongly suggests that its plateau age is the true age of crystallization. Please refer to text for further explanation. 


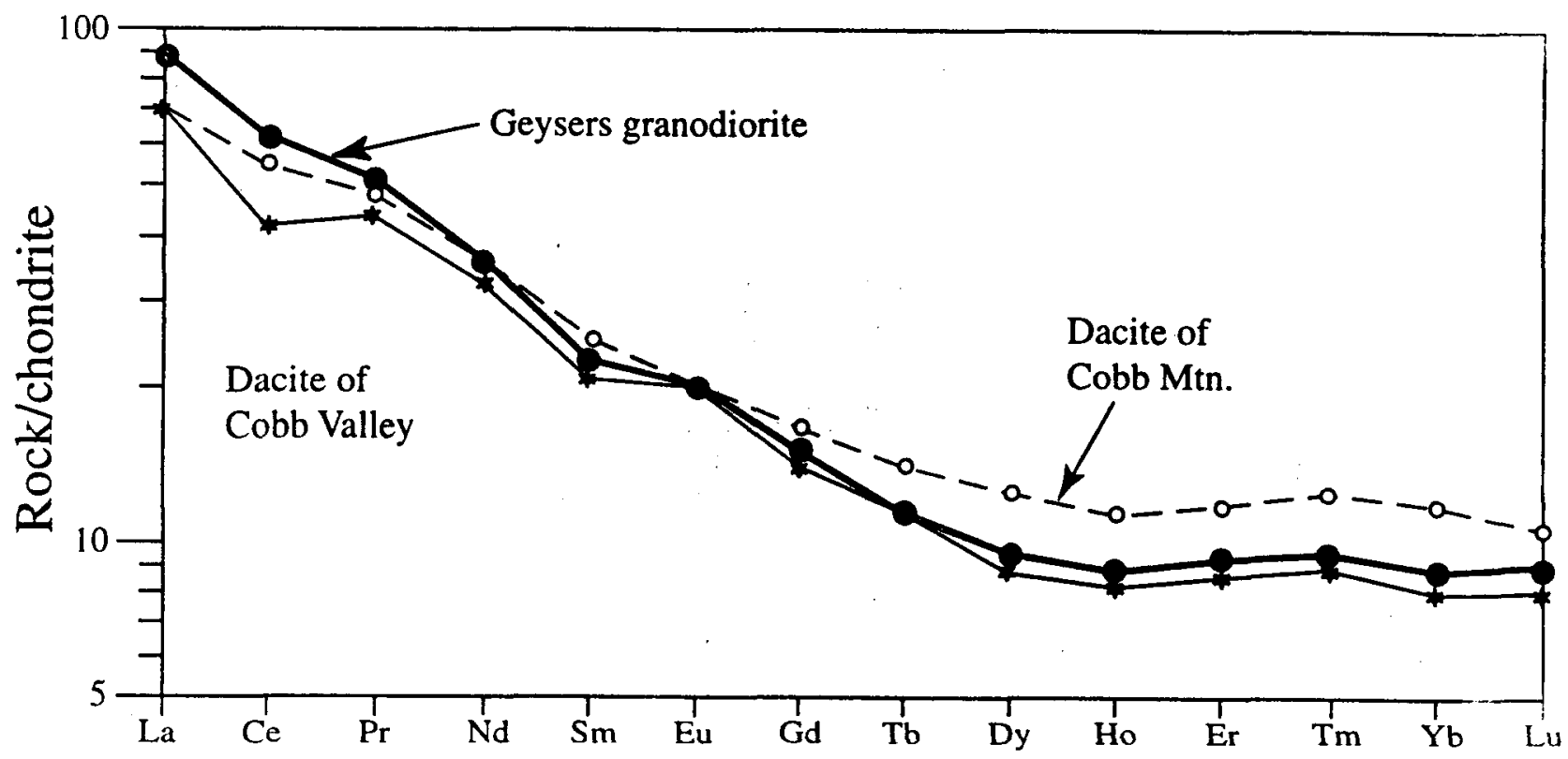

Figure 3 - Chondrite-normalized rare-earth-element distribution diagram for The Geysers granodiorite and the overlying dacites of Cobb Valley and Cobb Mountain (Fig. 1). The patterns closely match (though not perfectly), strengthening the genetic relationship strongly implied by mineralogic and temporal affiliations. 


\title{
RESISTIVITY DURING BOILING IN THE SB-15-D CORE FROM THE GEYSERS GEOTHERMAL FIELD: THE EFFECTS OF CAPILLARITY
}

\author{
Al Duba, Jeff Roberts, Brian Bonner, and Paul Kasameyer \\ Lawrence Livermore National Laboratory (LLNL)
}

\section{KEY WORDS}

capillarity, The Geysers geothermal field, electrical properties of rocks, geothermal reservoir, electrical resistivity, pore size, pore fluid content

\section{PROJECT BACKGROUND AND STATUS}

In a laboratory study of cores from borehole SB-15-D in The Geysers geothermal area in California, we measured the electrical resistivity of metashale with and without pore-pressure control, with confining pressures up to 100 bars, and with temperatures between 20 and $150^{\circ} \mathrm{C}$, to determine how the pore-size distribution and capillarity affected boiling. We observed a gradual increase in resistivity when the downstream pore pressure or confining pressure decreased below the phase boundary of free water. For the conditions of this experiment, boiling, as indicated by an increase in resistivity, is initiated at pore pressures of approximately 0.5 to 1 bar $(0.05$ to 0.1 $\mathrm{MPa}$ ) below the free-water boiling curve, and it continues to increase gradually as pressure is lowered to atmospheric. A simple model of the effects of capillarity suggests that at $145^{\circ} \mathrm{C}$, less than $15 \%$ of the pore water can boil in these rocks. If subsequent experiments bear out these preliminary observations, then boiling within a geothermal reservoir is controlled not just by pressure and temperature but also by pore-size distribution. Thus, it may be possible to determine geothermal reservoir characteristics by monitoring changes in electrical resistivity as reservoir conditions change.

\section{PROJECT OBJECTIVES}

The general objective of the project is to collect accurate data on the electrical resistivity of geothermal rocks in a laboratory environment which closely simulates that expected in the geothermal-reservoir environment. Important parameters to control are pore pressure, confining pressure, and temperature.

\section{Technical Objectives}

- Measure electrical resistivity of reservoir-fluid-saturated rocks as steam is produced in laboratory simulations of reservoir conditions. This objective has been met; however, data quality could be improved considerably with automated control of pore- and confining-pressure.

- Construct a state-of-the-art system for control of pore pressure and confining pressure while steam is being generated in a geothermal-reservoir rock on which electrical resistivity measurements are being made.

- Determine the effect of pore-size distribution on boiling-point elevation in these cores.

\section{Expected Outcomes}

- Laboratory data that permit delineation of steam-saturated, geothermal-reservoir rocks from field surveys. 
- A better understanding of the effect of pore-size distribution on boiling in geothermal-reservoir rocks.

\section{APPROACH}

The electrical properties of rocks are sensitive to factors such as the nature and amount of pore saturant, temperature, and pressure (Llera et al., 1990). Of these, the amount of the pore saturant and its nature (i.e., whether it is liquid water, other fluids, steam, and other gases) are the most important factors. Most dry rocks are excellent insulators in vacuo, but saturation with distilled water decreases resistivity by 8 orders of magnitude and more (Duba et al., 1978). For most rocks, high confining pressure closes off cracks and diminishes pore size, thereby increasing the electrical resistivity of saturated rocks by as much as an order of magnitude at $1 \mathrm{kbar}(100$ $\mathrm{MPa}$; Brace et al., 1967). In water-saturated rocks, increasing temperature from 25 to $250^{\circ} \mathrm{C}$ decreases the electrical resistivity by about an order of magnitude (Llera et al., 1990). To determine rock properties at geothermal reservoir conditions, we performed resistivity measurements on samples from The Geysers geothermal area. In analyzing the electrical resistivity data, we observed that boiling, as indicated by an increase in electrical resistivity, did not occur at the pressures and temperatures expected for bulk water. With bulk water, resistivity increases abruptly when the steam field is entered by reducing pore pressure below that of the liquid-gas transition at a specific temperature. Instead, in this study, we observed a gradual increase in electrical resistivity. After further analysis, we propose that the capillary pressure of the fine pores effectively changes the pressure and temperature at which boiling occurs. Such phenomena have been reported in studies of heat transfer in porous media (Udell, 1983) and are commonly included in models of heat transfer in finely porous materials (Vershinin et al., 1992).

We present a model of heterogeneous boiling where a decrease in pore pressure at a constant temperature results in the largest pores boiling first, followed by boiling in successively smaller pores. We then relate these observations to measurements of pore-size distribution in the sample rocks. Samples were taken in a laboratory study of geothermal-reservoir rocks from borehole SB-15-D of The Geysers to determine how electrical resistivity changes when the pore saturant boils. Because pore saturant has such a significant effect on electrical resistivity, it may be possible to distinguish steam-rich from water-filled zones using field electrical techniques and to assess-and monitor changes in - the geothermal potential of portions of a steam-dominated geothermal system such as that at The Geysers. Systematic laboratory studies of the electrical response of geothermal-reservoir rocks to changes in pore-fluid content can aid in interpreting data from field electrical surveys at the surface or within and between boreholes.

\section{RESEARCH RESULTS}

The implication of our laboratory measurements is that it is possible to observe reservoir behavior by monitoring changes in electrical resistivity as reservoir conditions change. By detecting large changes in bulk resistivity for small changes of fluid saturation, we demonstrated that boiling fronts and high-temperature zones can be tracked by monitoring the resistivity of a formation. Thus, some form of electrical monitoring may be useful to track changes in geothermal reservoirs during production. For shallow reservoirs, such monitoring may involve surface measurements, but for deeper reservoirs, it would likely include logging or cross-hole measurements. We observed (Duba et al., 1997) that boiling, indicated by increases in resistivity as pore pressure is lowered at constant temperature, happens at higher temperatures in the rocks than it would in a vessel at the same pressure. We were able to correlate this to pore-size distribution measured in these rocks. To explain the apparent change in the pressure and temperature at which boiling occurs, we introduce the helerogeneous boiling model. First, we report additional data that indicate the need for such a model, then we develop the model used to explain our observations. 
We measured resistivity as a function of pore pressure at $147^{\circ} \mathrm{C}$ and a confining pressure of $\sim 50$ bars for sample 13. The downstream, or low-side, pore pressure was varied, while the pore pressure on the upstream side of the sample was held to $\sim 16.3$ bars. Based on the data of Haas (1971), both water and $\mathrm{NaCl} 2 \%$ aqueous solution boil at -4.4 bars when the temperature is $147^{\circ} \mathrm{C}$. Because steam has a higher resistivity than water, if all of the water boiled at once, we should have observed an abnupt increase in resistivity when the pressure was lowered to permit steam to form. Instead, resistivity increases gradually with decreasing pore pressure rather than abruptly as expected at the water-steam phase-boundary pressure. These results are in basic agreement with the experiment performed without explicit pore-pressure control, in that decreasing the pore pressure causes an increase in resistivity at high temperature.

We propose that this gradual increase in resistivity is the result of boiling first in large pores and then in successively smaller pores. Small pores retain the fluid as a liquid because their capillary suction is strong. Increasing the capillary suction decreases the pore pressure required to maintain water in the liquid state for a given temperature. Boiling over a range of temperatures could indicate that the sample has a range of pore sizes, which thus would account for the increase in slope at lower pressure. This hypothesis is developed in (Roberts et al., 1997).

To the extent that heterogeneous boiling model is correct, then the formation factor, which is the ratio of the resistivity of the rock sample to the resistivity of its fluids, should depend only on the pressure below the water boiling point and on how the rock matrix controls boiling and bulk conduction. In this study, we found that the change in formation factor is typically twice as large when pore pressure at both ends is below boiling than it is when pressure at only one end is below boiling.

We also analyzed the microstructure using mercury injection porosimetry, which indicated that fine porosity dominates in the samples from borehole SB-15-D. We estimated a capillary pressure of $\sim 0.02$ bars for $100-\mu$ m-diameter pores (which would have negligible effect on boiling pressure) and $>300$ bars for the smallest pores. These capillary pressures are consistent with those measured in SB-15-D rocks (Persoff and Hulen, 1996). At $147^{\circ} \mathrm{C}$, only 9 to $12 \%$ of the pores by volume (depending on whether we use the pore distribution curve for metashale 3 or 6 ) would boil at the lowest pressures reached during the experiment. This implies that boiling occurs in pores $-0.43 \mu \mathrm{m}$ in diameter and larger.

For our experiment, the confining pressure and the upstream and downstream pore pressures are known. There appears to be little or no communication through the sample during the experiment because pressure does not increase on the low side when the other side is held to a much higher pressure. Thus, a pressure gradient exists across the sample, but its exact nature is unknown. The boiling region exists only at the end of the sample, and the large pores constrict a short distance into the sample. These findings are reasonable because (1) the sample is dominated by fine porosity and (2) the low permeability of the sample indicates that large pores are limited in extent. Boiling occurs first in the largest pores at the low-pressure end of the sample. We can only qualitatively describe the change of resistivity within this thin zone, because we do not know its geometry. However, we do know that its resistivity continues to change as pore pressure is lowered, indicating that boiling continues over the pressure range of this experiment. Also, the changes in resistivity in the thin zone must be much larger than the changes we observe in whole-rock resistance.

\section{FUTURE PLANS}

The idea that the temperature required to boil might be higher in fine pores could significantly affect assessments of reservoir potential. However, further investigation is needed, with more accurate temperature and pressure measurement, before a definitive statement can be made. If subsequent experiments bear out these preliminary 
observations, then boiling within a geothermal reservoir is controlled not just by pressure and temperature but also by pore-size distribution. Increased capillary pressure as pore size decreases prevents the fluid boiling when the applied temperatures are those derived from steam tables that do not consider this pressure. Because of the low permeability of these rocks and the distribution of very fine pore sizes, quantitative studies of this phenomenon are difficult. Pore and confining pressures must be kept constant for longer times than our present apparatus was designed to sustain, and a method must be derived to estimate the profile of boiling going into the rock sample.

\section{INDUSTRY INTEREST}

We discussed our results with UNOCAL engineers at the Stanford Workshop in January 1997 and with attendees of that workshop as well as the Geothermal Resources Council Meeting in San Francisco in October 1997.

\section{REFERENCES}

Brace, W. F., Orange, A. S., and Madden, T. R. (1967) The effect of pressure on the electrical resistivity of water-saturated crystalline rocks. J. Geophys. Res. 70, 5669-5678.Duba, A., Piwinskii, A. J., Santor, M., and Weed, H. C. (1978) The electrical conductivity of sandstone, limestone and granite. Geophys. J. R. Astron. Soc.. $53,583-597$.

Duba, A. G., Roberts, J. J., and Bonner, B. P. (1997) Electrical properties of geothermal reservoir rocks as indicators of porosity distribution. In Twenty-second Annual Stanford Geothermal Reservoir Engineering Workshop, 383-389.

Haas, J. L. Jr. (1971) The effect of salinity on the maximum thermal gradient of a hydrothermal system at hydrostatic pressure. Economic Geol. 66, 940-946.

Llera, F. J., Sato, M., Nakatsuka, K., and Yokoyama, H. (1990) Temperature dependence of the electrical resistivity of water-saturated rocks. Geophysics $55,576-585$.

Persoff, P., and Hulen, J. B. (1996) Hydrologic characterization of four cores from The Geysers Coring Project. In Twenty-first Annual Stanford Geothermal Reservoir Engineering Workshop, pp. 313-317.

Roberts, J., Duba, A., Bonner, B., Kasameyer, P. (1997) Resistivity during Boiling in the SB-15-D Core from The Geysers Geothermal Field: The Effects of Capillarity, Lawrence Livermore National Laboratory, Livermore, CA, URCL-JC-127468.

Udell, K. S. (1983) Heat transfer in porous media heated from above with evaporation, condensation, and capillary effects. J. Heat Transfer 105, 485-492.

Vershinin, S. V., Fershtater, Y. G., and Maidanik, Y. F. (1992) Effect of the thermal contact resistance on heat transfer during boiling from fine porous capillary structures. High Temperature 30, 668-673. 


\title{
STRUCTURAL AND TECTONIC SETTING OF THE DIXIE VALLEY GEOTHERMAL FIELD, NEVADA
}

\author{
Gabriel L. Plank \\ Richard A. Schweickert \\ University of Nevada Reno \\ Ardyth M. Simmons \\ E. O. Lawrence Berkeley National Laboratory \\ Dick Benoit \\ Oxbow Geothermal Corporation
}

\section{KEY WORDS}

Dixie Valley, Stillwater escarpment, geothermal reservoir, permeability, seismic reflection

\section{PROJECT BACKGROUND AND STATUS}

The complexity and uniqueness of Dixie Valley geology is nearly unmatched in northern Nevada, and data from many new wells within or near the Dixie Valley geothermal reservoir are difficult to interpret. Because the potential exists for further development of the geothermal system, it is important to obtain a better understanding of the structural geology of the area; particularly, detailed structural geometry and rock types on both sides of the Stillwater range front fault, which seems to control permeabilities in the geothermal reservoir.

This project began in August 1995. A two-year study was outlined in which the geology of the geothermal area would be mapped in detail and one or more seismic lines would be reprocessed. Phase I (first year) consisted of geologic mapping and structural analysis, well-log analysis, a survey of regional geological literature, and compilation of existing seismic data. Phase 11 (second year) entails refinement of structural models developed in Phase 1, production of maps and cross-sections, advanced reprocessing of selected seismic lines, and integration of seismic images with structural models of the reservoir. Phase I has been completed (Plank and Schweickert, 1996); Phase II will be completed in December 1997.

The work expands upon previous research in the area of the Dixie Valley geothermal reservoir. Aspects of the stratigraphy, structure, and tectonics of the Stillwater Range were mapped and assessed by Speed (1976) and Silberling (1968). Lithologic logs from geothermal wells in the field record differences in depths to and thicknesses of rock units. These variations are interpreted to reflect Tertiary high-angle faults within the reservoir that are exposed within the Stillwater Range and are related to the main Stillwater range front fault. Burke's (1967) mapping of the Quaternary geology of Dixie Valley indicated that the geothermal area lacks surface expression of these faults. Dilek and Moores (1995) studied the petrology of the Jurassic Humboldt gabbroic complex. Within the last two years, groups from Stanford University, the

University of Utah, the U.S. Geological Survey, the U.S. Department of Energy, and CEMAT (Consortium for Economic Migration and Tomography) at the University of Nevada Reno (UNR) have been working in conjunction with Oxbow Geothermal Corporation to improve understanding of the geothermal reservoir. The detailed mapping and structural analysis of this study complements these other projects. An interim assessment of results obtained by the groups mentioned was provided during a field trip to Dixie Valley in May 1997 and 
a workshop held in Reno in August 1997. Mapping results and seismic interpretations from this study provided a foundation and framework for workshop discussion of hydrologic flow pathways in the reservoir.

\section{PROJECT OBJECTIVES}

The objective of this research is to develop the local tectonic history of Dixie Valley and to further constrain the three-dimensional geometry of the geothermal reservoir. The ideal exposure of the footwall along the Stillwater range front offers a method of reservoir analysis which is unique to the Dixie Valley site. This structural approach will incorporate a large body of valuable borehole and geophysical data.

\section{Technical Objectives}

- Constrain three-dimensional geometry of the Dixie Valley geothermal reservoir

- Locate structural features causing permeability in order to suggest future areas for geothermal exploratory drilling for production and injection wells

- Constrain shape and extent of non-productive rock units

\section{Expected Outcomes}

- Refined interpretation of tectonic setting of Dixie Valley geothermal reservoir

- Improved understanding of sources of production and non-production

- Suggested future areas of exploration in the Dixie Vallcy area

- Extrapolation, if possible, of results of structural analysis to similar areas of the Basin and Range province

\section{APPROACH}

\section{Detailed Mapping}

This study combines geologic mapping, surface geophysics, and borehole geology to produce well-constrained cross-sections through both the footwall and hanging wall of the Dixie Valley fault, which coincides in this area with the Stillwater range front fault. The process of construction of cross-sections is explained in Plank et al. (1996). The study concentrates around a length of the Stillwater segment of the Dixie Valley fault, along a northeast-trending corridor $8 \mathrm{~km}$ long and $5 \mathrm{~km}$ wide which encompasses parts of both the Stillwater escarpment and the Dixie Valley Geothermal Area (Figure 1). The Stillwater escarpment, defined by Plank (in progress), is the precipitous section of the range front along the southeast flank of the Stillwater Range from Mississippi Canyon on the southeast and to the northeast as far as Fencemaker Pass. Geologic mapping of the Stillwater escarpment above the Dixie Valley geothermal area was accomplished between October 1995 and August 1996. The geology was mapped on four 1:24,000 scale topographic base maps with the aid of color-infrared aerial photographs of the same scale. Figure 2 shows the location of seismic surveys and geothermal wells with respect to the mapped area.

The selected area mapped was based primarily upon availability of exposures of Mesozoic thrust faults and folds which have Triassic and Jurassic lithologies. Detailed surface measurements of the range front faults were taken 
along fault surfaces. In order to determine the kinematics of thrusting and normal faulting and to determine the ratio of strike-slip to dip-slip motion along the Stillwater Range front fault. With this knowledge it was possible to model the three-dimensional geometry and extent of the gabbro in the concealed hanging wall of the range front fault, In addition, the location of the geothermally non-productive Triassic siltstone and argillite could be inferred.

\section{Reprocessing and Reassessment of Subsurface and Surface Geophysical Data}

Based on detailed mapping of the range front and the production of subsurface models, industry geophysical data provided by Oxbow Geothermal Corporation was used to substantiate footwall structures reflected in the hanging wall. Seismic reflection data was reprocessed at the UNR Seismological Department's SUN computer facility, using the in-house processing package under the guidance of Professor John Louie. Other geophysical data available from Oxbow was reassessed as necessary to corroborate structural findings in the footwall with those in the hanging wall. These included drill hole logs and cuttings, and data from magnetotelluric, aeromagnetic, gravity, and shallow temperature surveys.

\section{Estimation of Permeability Variations}

When the structural model is in place and is supported by geophysical evidence, the top of the brittle rocks that control permeability will be projected to depth from surface exposures and geophysical evidence. This will be contoured showing depth to the Boyer Fault as the top of the impermeable rocks. Finally, suggestions will be made as to the most promising areas to drill production wells.

\section{RESEARCH RESULTS}

Results of Phase I investigations (Plank and Schweickert, 1996) provided critical new information about structural relations of reservoir rocks (the Humboldt gabbroic complex and the Boyer Ranch Formation) where they are exposed along the range front up-dip from the reservoir. In addition, newly recognized imbricate range front normal faults cut into the footwall of the Stillwater Range front fault, and this may have implications for hanging-wall structure. Finally, based on results of Phase 1, a new interpretation has been made regarding the nature of the Boyer fault.

The Boyer fault was originally mapped as a thrust fault (Speed, 1976); however, Miocene dikes which are truncated by the fault are known to be Middle Miocene in age (14.5 Ma by Ar-Ar method; Dilek and Moores, 1995) and thus the Boyer fault must be entirely a Tertiary fault. Evidence from the overall dip of the fault plane, the rotated shear bands, and the slickensides suggest that the Boyer fault is a low-angle, top-to-the-southwest, Tertiary normal fault.

Subsidiary faults splay from the range front and cut through the exposed bedrock of the Stillwater escarpment, and indicate that the Dixie Valley fault is not a single fault but instead is a zone of complexly related, northeaststriking normal faults. Rocks between the splays are highly fractured. These subsidiary fault splays are not only exposed along the escarpment, but also crop out as alluvial scarps in the piedmont (Caskey et al., 1996). Furthermore, they are known to be present in the subsurface; as indicated at depth by geophysical surveys and well bores (Plank, in progress). The zone of the Dixie Valley fault therefore consists of a system of large and small offset faults, which cut rocks in both the foot wall and the hanging wall of the range front fault.

Detailed mapping has provided a better understanding not only of the geometry of rocks in the Stillwater Range, but also of the association of local geology with regional Mesozoic tectonic events. Four phases of deformation have been discerned in the rocks; in addition, we have found and are dating felsic dikes which may place a 
maximum age on the Fencemaker deformation. In dating the Fencemaker deformation and mapping the Stillwater escarpment above the geothermal site, the study has thus contributed a great amount to a poorly understood Mesozoic tectonic era in northern Nevada.

The emphasis in Phase 11 of this project has involved reprocessing of seismic data to image the normal fault system in the subsurface and integration of field, borehole, and seismic data. Sixteen seismic reflection surveys have been shot in the geothermal area along lines parallel, perpendicular, and oblique to the range front fault. Data from nine of these lines were made available. Although the scope of the study allowed for reprocessing of only one seismic line, a related project at UNR will process the other lines as well. Advanced seismic velocity modeling and pre-stack migration techniques have been developed at UNR (Pullamannappillil and Louie, 1993). These techniques have been designed and proven to be able to image high-angle fault planes.

We have reprocessed one Dixie Valley seismic line to constrain the locations of subsurface faults, so that reconstructions of the geology of the geothermal reservoir would be more accurate. However, as a result of our cooperation with CEMAT, the whole suite of seismic lines donated by Oxbow Geothermal have been reprocessed. This work has resulted in the identification of shallow, buried normal faults in the subsurface of the geothermal site (Unruh et al., 1997). These faults are permeable structures, one of which provides the majority of Oxbow's geothermal production fluids. Other faults identified by the seismic reprocessing may, in the future, be drilling targets. Our work builds on CEMAT's results by extrapolating the faults to reservoir depths, by relating the faults to diverse borehole stratigraphy, and by constraining even deeper levels of the reservoir by knowledge of the surface and subsurface structural geometry. Phase II will be completed by the synthesis of all map, borehole, and seismic data into detailed cross-sections through the range and reservoir, both parallel and perpendicular to the range front fault. In addition, the subsurface structural data will be projected onto the map as fault traces and structural contours of the top of the reservoir rocks. The cross-sections, which present the synthesis of all the subsurface data, are nearly finished, and will be available in Plank's University of Nevada Master's thesis (in progress).

\section{FUTURE PLANS}

Many studies in Dixie Valley could be carried out to increase the geothermal industry's interest in the area, as well as to improve knowledge of tectonics in the Basin and Range from the early Mesozoic to the present. Although the proposed age of the Dixie Valley fault system, $15 \mathrm{Ma}$ (Thompson and Burke, 1973), is within reason for typical Basin and Range faulting, the long-term slip and uplift rates for the fault are poorly defined. Future scientific studies related to the development of the Dixie Valley geothermal field would do well to address the long-term uplift and slip rates of the Stillwater segment of the fault. These studies could use cosmogenic isotopes to obtain exposure ages, and could use fission track dating to understand the uplift of the Stillwater Range in more detail.

Cross-sections through the geothermal reservoir which are constrained by reassessed borehole, geophysical, and surface geological data, will be useful in identifying drilling targets and understanding the dynamics of reservoir fluid flow. The cross-sections will.also be used to assemble three-dimensional models of the subsurface, a task which is already scheduled for completion by CEMAT. The present study is nearly completed. Commitments which remain are: 1) to constrain the timing of Mesozoic and Tertiary tectonic events, and 2) to distribute copies of G. Plank's thesis to parties involved in Dixie Valley research. 


\section{INDUSTRY INTEREST}

\section{Organization}

Oxbow Geothermal Corp.

Other geothermal developers with leases or interests in the Basin and Range Province

\section{Type and Extent of Interest}

Structural model of geothermal reservoir

Geologic history and characteristics of Basin and

Range Province

\section{REFERENCES}

Burke, D. B. (1967) An aerial photograph survey of Dixie Valley (Churchill and Pershing Counties, west-central Nevada, M. S. thesis, Stanford University, p. 81.

Caskey, S. J., S. G. Wesnousky, P. Zhang, and D. B. Slemmons (1996) Surface faulting of the 1954 Fairview Peak $\left(M_{s}, 7.2\right)$ and Dixie Valley $\left(M_{s}, 6.8\right)$ earthquakes, central Nevada, Bulletin of the Seismological Society of America, v. 86, pp. 761-787.

Dilek, Y. M., and Moores, E. M. (1995) Geology of the Humboldt igneous complex, Nevada, and tectonic implications for the Jurassic magmatism in the Cordilleran Orogen, in Miller, D. M., and B. Cathy, eds., Jurassic magmatism and tectonics of the North American Cordillera. Volume Special Paper-Geological Society of America, v. 299, (p. 229-248): Geological Society of America (GSA), Boulder, Colorado.

Plank, G. L. (1997, in progress) Structure, stratigraphy, and tectonics of the Dixie Valley geothermal area, Dixie Valley, Nevada, University of Nevada Reno, M.S. thesis.

Plank, G. L., and R. A. Schweickert (1996) Structure, stratigraphy, and tectonics of the Dixie Valley geothermal area, Dixie Valley, Nevada: Phase I /Year one report, Department of Geological Sciences, University of Nevada Reno, 18 p.

Plank, G. L., R. A. Schweickert, A. M. Simmons, P. L. Williams, and D. Benoit (1996)

Structural and tectonic setting of the Dixie Valley geothermal field, Nevada, Federal Geothermal Research Program Update - Fiscal Year 1996, U.S. Department of Energy, Office of Geothermal Technologies, March 1997, pp. 4/133-136.

Pullammanappallil, S. K., and Louie, J. N., 1993, A generalized simulated-annealing optimization for inversion of first arrival times: Bulletin of the Seismological Society of America, v. 84, pp. 1397-1409.

Silberling, N. J. (1968) Effects of basement relief beneath Triassic rocks of the Humboldt Range and nearby parts of northwestern Nevada (abs.), Geological Society of America, Special Paper 101, pp. 334-335.

Speed, R. C., 1976, Geologic map of the Humboldt Lopolith and surrounding terrane, Nevada: Geol. Soc. Am., Map Chart Series, v. Mc-14, p. 4.

Thompson, G. A. and D. B. Burke (1973) Rate and direction of spreading in Dixie Valley, Basin and Range Province, Nevada, Geological Society of America Bulletin 84, pp. 627-632.

Unruh, J. R., W. Honjas, and S. K. Pullammanappallil (1997) Re-evaluation of tectonic structure in northern Dixie Valley, Nevada, from reprocessed seismic reflection profiles: implications for subsurface permeability, 
handout presented at Geothermal Resource Council 1997 Annual Meeting, October 12-15, 1997, Burlingame, California. 


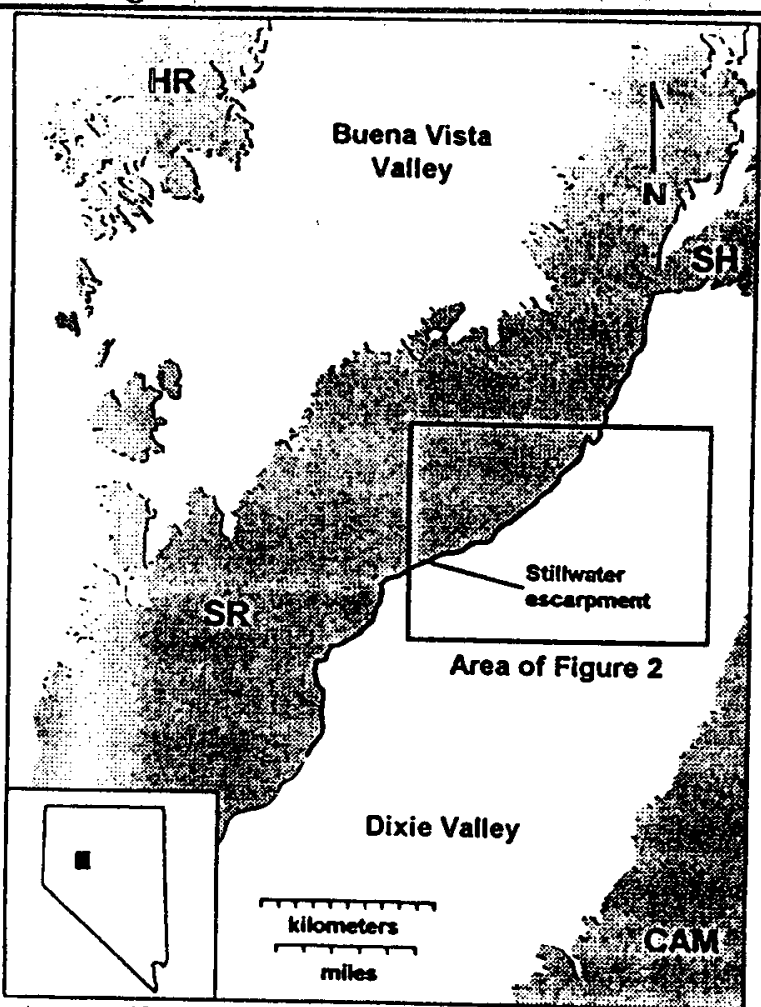

Figure 1 - Location of the study area (from Plank, in progress). CAM, Clan Alpine Mountains; HR, Humboldt Range; SH, Sou Hills: SR, Stillwater Range.

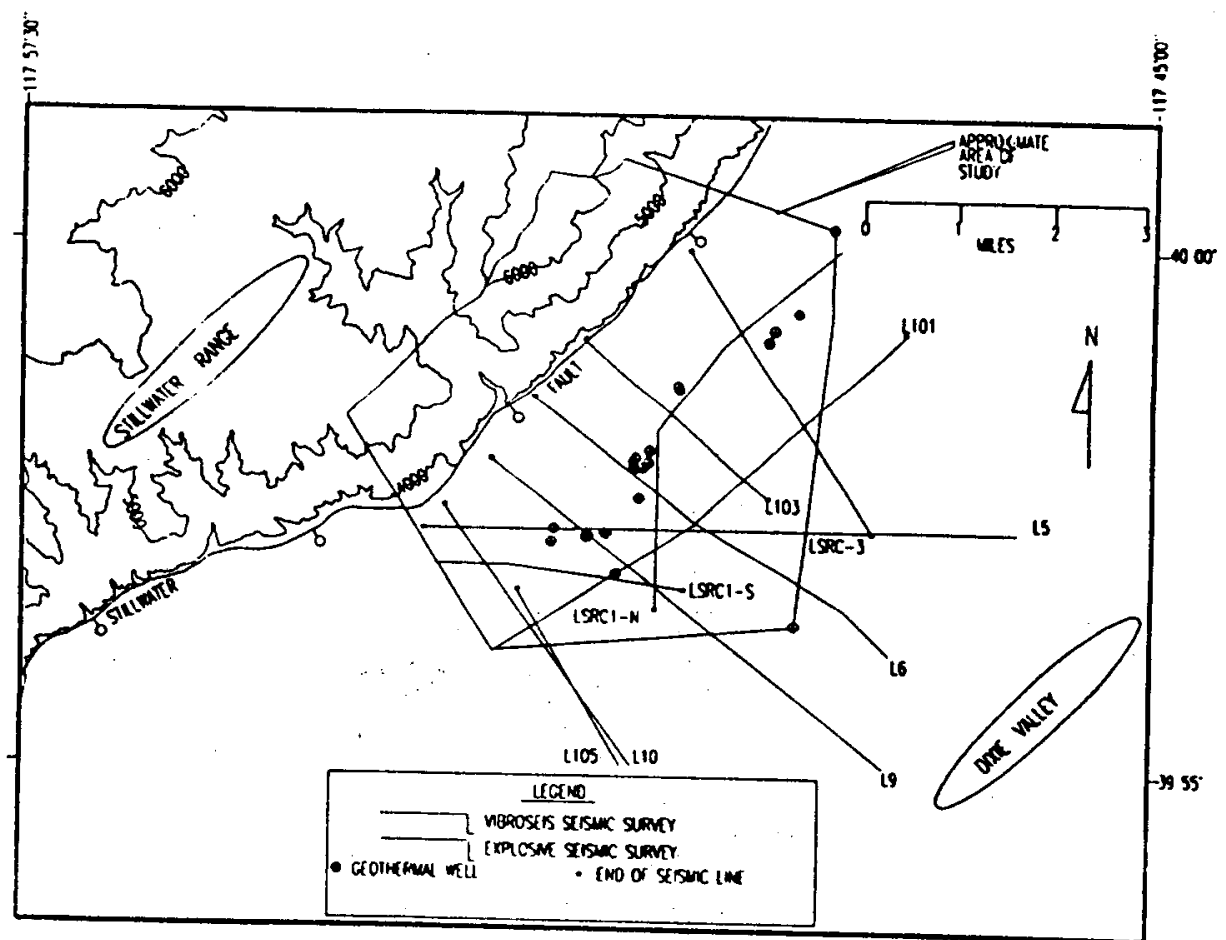

Figure 2 -- Simplified map of the study area, showing the map area, location of seismic surveys, and location of geothermal wells (from Plank, in progress). 


\title{
FRACTURE PERMEABILITY AND IN SITU STRESS IN THE DIXIE VALLEY, NEVADA, GEOTHERMAL RESERVOIR
}

\author{
Stephen Hickman, John Sass, Colin Williams, Roger Morin \\ U.S. Geological Survey \\ Colleen Barton, Mark Zoback \\ Stanford University \\ Dick Benoit \\ Oxbow Geothermal Corporation
}

\section{KEY WORDS}

permeability, fractures, stress, faulting, geothermal reservoir, heat flow, fluid flow

\section{PROJECT BACKGROUND AND STATUS}

It is generally accepted that fractures control hydrologic properties in crystalline rocks. Therefore, understanding fluid flow in fractured, low-porosity rock requires detailed knowledge of fracture and fault orientations and hydraulic properties as well as the in-situ state of stress. Although it is well known that relatively few fractures and faults in fractured rock masses often serve as the primary conduits for fluid flow, the reasons why some fractures and faults are much more permeable than others are poorly known. Understanding the origins and hydrologic characteristics of these fractures and faults requires analysis of the local fracture and fault systems in the context of the local and regional tectonic stresses.

To help determine tectonic and geochemical controls on the hydrology of a fracture-dominated geothermal reservoir at Dixie Valley, NV, we are conducting an integrated study of fracturing, stress, hydrology and heat flow in geothermal wells drilled into and near the Stillwater fault zone (Figure 1). This fault is a major, active, range-bounding normal fault located in the western Basin and Range province, Nevada, in an area characterized by active seismicity, high heat flow and late Cenozoic extensional faulting and volcanism. The Stillwater fault zone comprises the main reservoir for a $\sim 62 \mathrm{MW}$ geothermal electric power plant operated by Oxbow Geothermal Corporation. Although earthquakes have not ruptured this segment of the Stillwater fault in historic times, large $(\mathrm{M}=6.8-7.7)$ earthquakes have occurred within the past 80 years along range-bounding faults $\sim 20 \mathrm{~km}$ to the northeast and southwest of the Dixie V.alley Geothermal Field (DVGF), and geologic evidence shows that the Stillwater fault abutting the DVGF experienced two or more faulting episodes (total offset $\sim 9 \mathrm{~m}$ ) during the past 12,000 years.

The principal goal of this study is to define the nature, distribution and hydraulic properties of fractures associated with the DVGF, and to characterize the manner in which these fractures, and hence the overall reservoir hydrology, are related to the local stress field. This project was initiated with a workshop and field trip co-hosted by the US Geological Survey (USGS) and Oxbow. Geothermal in May 1995 on unresolved problems pertaining to the development of geothermal energy at Dixie Valley and other geothermal reservoirs associated with active faults. Since then we have conducted an extensive open-hole logging program at Dixie Valley, conducting borehole televiewer, temperature and flowmeter logging and hydraulic fracturing stress measurements from wells within the primary zone of geothermal production (transmissivities on the order of $1 \mathrm{~m}^{2} / \mathrm{min}$ ) and from wells within a few $\mathrm{km}$ of the producing zone that were relatively impermeable and, hence, not commercially viable 
(transmissivities of about $10^{-4} \mathrm{~m}^{2} / \mathrm{min}$ ). The measurements made in these wells makc possible a systematic, comparative study of the effects of in situ stress on fracture permeability along producing and nonproducing segments of the Stillwater fault zone (see Barton et al., 1997; Hickman and Zoback, 1997; Hickman et al., 1997; Williams et al., 1997).

\section{PROJECT OBJECTIVES}

The objective of this study is to obtain a comprehensive suite of thermal, hydrologic and stress data from widely spaced wells within and adjacent to the DVGF. These data should allow us to determine if it is possible to predict which faults or fault segments are likely to be hydraulically conductive in a given stress field, and to provide input on decisions related to redrilling of wells or abandonment of an area or prospect. At some future date it is hoped these methods can be used to locate future production and injection wells and to design enhanced recovery programs for less-than-commercial wells within geothermal reservoirs. By comparing and contrasting data from productive and non-productive wells, we hope to determine if a relationship exists between the contemporary in-situ stress field, fault slip history and reservoir productivity. These data are essential to answering a number of fundamental problems pertaining to the development of geothermal energy at Dixie Valley and other fault-hosted geothermal reservoirs.

\section{Technical Objectives}

- Determine variations in temperature, fluid flow, stress and heat flow together with the distribution and orientation of faults and fractures in selected wells within the Dixie Valley geothermal field.

- Document systematic relationships between fracture orientation and hydrologic properties (e.g. permeability) to provide a framework for interpretation of the hydrology of reservoir rocks associated with the Stillwater fault zone.

- Identify differences in fracture patterns, the orientation and magnitude of in-situ stresses, or other factors that might be responsible for variations in reservoir permeability.

\section{Expected Outcomes}

- Understanding of the factors controlling spatial variations in permeability and large-scale fluid flow along the Stillwater fault zone and other fracture-dominated geothermal reservoirs located in tectonically active areas.

- Possible techniques for predicting spatial variations in permeability and the nature and orientation of permeability anisotropy in geothermal prospects or producing reservoirs using surface-based or borehole measurements (or combinations of the two).

- Development of efficient and cost-effective procedures to induce permeability in dry holes or connect those holes to permeable zones by hydraulic fracturing, thereby increasing the productivity of a given geothermal reservoir. Development of routine strategies for measuring in-situ stresses and fracture orientations which might indicate if redrilling of a dry well is a wise course of action.

\section{APPROACH}

Three basic efforts comprise the approach to this study: 
(1) Obtain borehole televiewer (BHTV), temperature/pressure/spinner (TPS) and precision temperature logs from producing (i.e., highly permeable) as well as non-producing wells to provide information on the current stress, hydrologic and thermal regimes of the Dixie Valley geothermal field. TPS and temperature logs will be conducted under static conditions and during fluid injection and withdrawal.

(2) Conduct hydraulic fracturing stress measurements in producing and non-producing wells, to determine the magnitude of the least horizontal principal stress (see Hickman and Zoback, 1983). When hydrofrac tests are conducted over large open-hole intervals, conduct TPS logs during the last cycle of a test to accurately determine the appropriate test depth.

(3) Use BHTV logs to locate and orient faults, fractures and drilling-induced (cooling) fractures in these wells Using these logs, determine the orientation and geometry of stress-induced borehole breakouts, both for stress orientations and for bounds on the magnitude of the greatest horizontal principal stress. Analyze temperature and TPS logs to identify permeable zones and quantitatively determine their permeabilities. Analyze hydraulic fracturing tests to determine variations in least principal stress magnitudes with depth Relate stress orientations and magnitudes, fluid flow indicators and bulk reservoir hydrologic properties to the orientations and relative apertures of fractures and faults to see if changes in stress regime (i.e., proximity to failure), fracture orientations or other parameters might be responsible for variations in reservoir productivity.

\section{RESEARCH RESULTS}

\section{In-Situ Stress, Fracture Orientations and Fluid Flow}

Since this project was begun in FY 1996, we have conducted BHTV and TPS logs and hydraulic fracturing stress measurements in a total of eight wells at Dixie Valley (Figure 1); results from the first of these wells tested (73B-7) were discussed in last year's Geothermal Program Update. With the exception of a 550-m-deep water well drilled $\sim 1 \mathrm{~km}$ northeast of well $73 \mathrm{~B}-7$ (well $24 \mathrm{~W}-5$ ) and a 3.4-km-deep observation well (62-21) drilled toward the center of Dixie Valley, all of these wells penetrate the Stillwater fault zone at depths of 2 to $3 \mathrm{~km}$. Three of these wells (73B-7, 82A-7 and 74-7) penetrated the highly permeable (i.e., producing) segment of the fault zone constituting the main geothermal reservoir. The other two wells (66-21 and 45-14), which failed to encounter enough permeability to be viable production wells, penetrated segments of the Stillwater fault located approximately 8 and $20 \mathrm{~km}$ southwest of the main reservoir. Data recently acquired from an additional producing well at the northern end of the main reservoir (well 37-33) have not yet been analyzed in detail and will not be discussed here.

Producing Wells (73B-7, 74-7 and 82A-7): Televiewer logs from the three wells penetrating the highly permeable (i.e., producing) segment of the Stillwater fault zone revealed extensive drilling-induced tensile fractures (e.g., Figure 2c). As discussed by Moos and Zoback (1990), these tensile fractures result from the superposition of the ambient in-situ stresses and thermal stresses induced by circulation of relatively cold drilling fluids at the borehole wall. These tensile fractures indicate that the direction of the minimum horizontal principal stress, $\mathrm{S}_{\text {hmin }}$ adjacent to the main geothermal reservoir is $\mathrm{S} 55^{\circ} \mathrm{E} \pm 15^{\circ}$. As the Stillwater fault at this location dips $\mathrm{S} 45^{\circ} \mathrm{E}$ at $\sim 53^{\circ}$, it is thus nearly at the optimal orientation for normal faulting in the current stress field (Figure 3).

Analysis of hydraulic fracturing tests from these wells (together with the shallow water well, 24W-5) shows that the magnitude of $S_{\text {hmin }}$ is very low relative to the calculated vertical stress, $S_{v}$, with $S_{\text {hmin }} / S_{V}$ ranging from 0.45 -0.62 at depths of $0.4-2.5 \mathrm{~km}$ (Figure 4 ). The fluid pressure, $P_{p}$, was derived by integrating the equation of state 
for water for the appropriate geothermal gradient and using the pre-production reservoir water table; $S_{V}$ was calculated using geophysical density logs conducted in nearby wells. Upper bounds to the magnitude of the maximum horizontal principal stress, $S_{1 \text { max }}$, obtained using estimates of the compressive strength of rocks encountered in this well and the observed absence of borchole breakouts (see Moos and Zoback, 1990), indicate a normal faulting stress regime (i.e., $S_{\mathrm{Hmax}}<\mathrm{S}_{\mathrm{v}}$; see Figure 4).

Since the producing segment of the Stillwater fault is nearly at the optimal orientation for normal faulting, the stress magnitudes from the hydraulic fracturing tests can be analyzed in terms of the potential for slip on this fault. In accordance with the Coulomb failure criterion, we calculated the critical range of $S_{\text {hmin }}$ magnitudes for frictional failure (i.e., normal faulting) on optimally oriented faults given the calculated vertical stress and in-situ fluid pressure (Figure 4a). This analysis indicates that $S_{\text {hmin }}$ in these wells is close to that predicted for incipient normal faulting on the Stillwater and subparallel faults, using laboratory measurements of coefficients of friction of $0.6-1.0$ (after Byerlee, 1978) and the formation fluid pressure that existed prior to geothermal reservoir production. Similar results (not shown) were obtained from the "background" well 62-21, adjacent to the productive segment of the Stillwater fault but closer to the center of Dixie Valley (Figure 1), indicating that these near-failure loading conditions persist to some distance from the fault

Televiewer data recorded in these wells show pervasive macroscopic fractures with a wide range of orientations throughout the logged intervals. Although fractures imaged in the BHTV logs from the permeable wells 73B-7 and 74-7 exhibit considerable scatter in orientation, they generally strike between north and east, with shallow to moderate dips $\left(15-70^{\circ}\right)$ toward the southeast (Figure 5). These fractures tend to become steeper and larger in apparent aperture with depth.

Fluid flow into or out of relatively permeable fractures intersected by the boreholes will create perturbations to the measured temperature profiles. We have analyzed precision temperature logs to determine the locations of these flow horizons in each of the borcholes (sec Barton ct al., 1995). Figures $2 \mathrm{a}$ and $\mathrm{b}$ show examples of BHTV and temperature gradient logs over the interval 1901 to $1906 \mathrm{~m}$ in well $73 \mathrm{~B}-7$, where a flow anomaly associated with a permeable fracture at $1903.5 \mathrm{~m}$ was detected. The orientations of these hydraulically conductive fractures are distinct from the overall fracture population, and are near-optimally oriented for normal faulting in the measured stress field (Figure 5). We have also used TPS logs conducted at different injection rates to identify the primary producing fractures within the permeable segment of the Stillwater fault zone and to determine their permeabilities (see Molz et al., 1989). This analysis indicates that production within the DVGF is dominated by only a few fractures: typically between 3 and 6 fractures in any given well. We found that the permeability of these fractures is extremely high, ranging from about $2-5 \times 10^{-11} \mathrm{~m}^{2}$ (i.e., $20-50$ Darcies), and that these fractures (termed large-scale flow anomalies) are oriented roughly parallel to the local trend of the Stillwater Fault (see Figure 5 inset).

Using the stress orientations and magnitudes measured in these wells together with fracture orientations obtained from the BHTV logs, we then calculated the shear and normal stress on each of the fracture planes and used the Coulomb failure criterion to determine whether or not each plane was a potentially active fault. Based upon laboratory measurements of the frictional strength of prefractured rock (Byerlee, 1978), we assumed that fractures with a ratio of shear to normal stress $\geq 0.6$ are optimally oriented to the stress field for frictional failure. This analysis was performed on both hydraulically conductive fractures and on a control population of non-hydraulically conductive fractures extracted from the total fracture population (see Barton et al., 1995).

The results of this analysis are illustrated in Figures $6 \mathrm{a}$ and $\mathrm{b}$ for well 73B-7. As indicated by the Coulomb failure lines for $m=0.6$ and $m=1.0$, most of the hydraulically conductive fractures in this well are critically stressed, potentially active faults in frictional equilibrium with the current stress field. In contrast, the majority of fractures 
not associated with temperature anomalies (i.e., non-hydraulically conductive) lie below the Coulomb failure curves and therefore do not appear to be critically stressed shear fractures (Figure 6b). Furthermore, the highly permeable fractures identified from the TPS logs (i.c., large-scale flow anomalies) are subparallel to the local orientation of the Stillwater fault zone and are thus also critically stressed for failure (Figure 6a). This analysis indicates that the hydraulically conductive fractures observed in these wells are - like the Stillwater fault itself - critically stressed, potentially active shear planes in the current north-northwest extensional stress regime at Dixie Valley.

Permeability reduction and the establishment of fault scals would be expected along this segment of the Stillwater fault, given the high measured reservoir tempcratures $\left(-220-250^{\circ} \mathrm{C}\right.$ at $\left.2.3-3.0 \mathrm{~km}\right)$; surface observations of hydrothermal alteration, mineralization and pressure-solution deformation within and adjacent to the fault zone (e.g., Seront et al., 1997); and thermal evidence for up-dip transport of hydrothermal fluids along the productive fault segment (Benoit, 1996; D. Blackwell, pers. comm, 1997). In particular, analysis of fluid samples recovered from the Stillwater fault zone prior to reservoir production indicate a decrease in silica concentration of about 120 $\mathrm{ppm}$ as these fluids ascend from 3.0 to $2.3 \mathrm{~km}$. This loss of silica might be expected to seal fractures within the Stillwater fault zone at this location over geological time scales, thereby destroying the high overall fault-zone permeability. However, the observation that the permeability of fractures within and adjacent to the highly productive segment of the Stillwater fault zone is quite high and that these fractures are favorably aligned and critically stressed for normal faulting in the current stress field suggests that ongoing fault slip in response to high differential stresses (i.e., $S_{v}-S_{h \min }$ ) is sufficient to counteract the expected permeability reduction.

Non-Producing Wells (66-21 and 45-14): Similar data were collected in the two wells (66-21 and 45-14) penetrating relatively impermeable segments of the Stillwater fault zone, located 8 and $20 \mathrm{~km}$ southwest of the main reservoir. Unlike the wells adjacent to the productive fault segment, BHTV logs from both of these wells showed the development of stress-induced borehole breakouts (e.g., Figure 2d). These breakouts, which result from compressive rock failure in response to the concentration of tectonic stresses at the borehole wall (see Moos and Zoback, 1990), show that the direction of $S_{\text {hmin }}$ in wells $66-21$ and $45-14$ is $S 20^{\circ} \mathrm{E} \pm 15^{\circ}$ and $S 41^{\circ} \mathrm{E} \pm 12^{\circ}$, respectively. Thus, the Stillwater fault is optimally oriented for frictional failure near well $66-21$ but severely missoriented for failure at site 45-14 (Figure 3). Hydraulic fracturing tests conducted in these wells indicate that $\mathrm{S}_{\text {hmir }} / \mathrm{S}_{\mathrm{V}}$ adjacent to the non-producing segment of the Stillwater fault ranges from 0.55 to 0.64 at depths of 1.9 to $2.2 \mathrm{~km}$ (Figure $4 \mathrm{~b}$ ), which is higher than the values of 0.45 to 0.51 observed immediately above the Stillwater fault zone in producing wells to the northeast (i.e., at depths of 2.4 to $2.6 \mathrm{~km}$; see Figure $4 \mathrm{a}$ ).

Interestingly, fluid pressures in wells 66-21 and 45-14 are artesian, in contrast to the subhdydrostatic pressures encountered within the main geothermal reservoir. Coulomb failure analysis, taking account of these elevated fluid pressures and the appropriate rock densities, indicates that the magnitude of $S_{\text {hmin }}$ in well 66-21 is not low enough to induce frictional failure, even on optimally oriented faults (Figure 4b). Thus, at this site, the Stillwater and subparallel faults are optimally oriented - but not critically stressed - for normal faulting. In contrast, Coulomb failure analysis indicates that the $S_{\text {hmin }}$ magnitude measured in well 45-14 is low enough to result in incipient frictional failure on optimally oriented normal faults (Figure $4 \mathrm{~b}$ ).

The observation that breakouts were present in these relatively impermeable wells, but absent in wells drilled into the productive main reservoir, indicates a significant increase in the magnitude of $S_{\mathrm{H} \max }$ going from the producing to nonproducing segments of the fault. Although the magnitude of the compressive stress concentration at the borehole wall depends on both horizontal stress magnitudes, it is most sensitive to $S_{\mathrm{Hmax}}$ and increases rapidly with increasing $S_{\mathrm{Hnax}}$ magnitude. We used theoretical analyses of the conditions necessary for breakout initiation (e.g., Moos and Zoback, 1990) to place lower bounds on the magnitude of $S_{\mathrm{H} \max }$ in wells 66-21 and 45-14. In so doing, we extrapolated our measurements of $S_{\text {hmin }}$ magnitudes in these wells to the depths over which breakouts 
were observed (assuming constant $S_{\mathrm{Hmax}} / \mathrm{S}_{\mathrm{v}}$; see Figure $4 \mathrm{~b}$ ) and used estimates of the compressive strength of rocks encountered at these depths (after Lockner, 1995). In this manner, we determined that the magnitude of $S_{\mathrm{Hmax}}$ in these non-productive wells is greater than $S_{V}$ (Figure $4 \mathrm{~b}$ ). This is in marked contrast to wells penetrating the permeable main reservoir, where $S_{\mathrm{Hmax}}$ is less than $S_{v}$ (Figure $4 a$ ).

BHTV logs conducted in wells 66-21 and 45-14 revealed extensive natural fracturing, with the dominant fracture set in each well striking parallel to the local trend of the Stillwater fault (Figure 5). Analysis of TPS and precision temperature logs acquired in these wells under naturally flowing conditions and during injection indicates that hydraulically conductive fractures along the non-producing segment of the Stillwater fault have much lower permeabilities and are fewer in number than observed in wells 74-7 and 73B-7. Coulomb failure analysis performed on individual hydraulically conductive fractures from the non-producing well 66-21 indicate that neither these fractures nor the nearby Stillwater fault zone are critically stressed for frictional failure (i.e., these fractures and the Stillwater fault lie below the $m=0.6$ failure line in Figure $6 \mathrm{c}$ ). Similar analysis for well $45-14$ indicates that some - but not all - of the hydraulically conductive fractures in this well are critically stressed for frictional failure (Figure 6d). However, the combined effects of an increase in $S_{\text {Hmax }}$ magnitudes relative to $S_{v}$ (when compared to the producing fault segment) and the extreme misorientation of the Stillwater fault zone with respect to the principal stress directions near well 45-14 (Figure 3), leads to a decrease in the proximity of the Stillwater fault zone itself to Coulomb failure (Figure 6d). These observations suggests that a necessary condition for high reservoir permeability is that both the local state of stress and the orientation of the Stillwater fault zone be such that the overall fault zone be critically stressed for frictional failure.

Continuing analysis of precision temperature logs acquired in wells bordering the DVGF provided additional information on coupled heat and fluid flow at the reservoir-scale (Williams et al., 1997). In well 62-21, $4 \mathrm{~km}$ southeast of the current producing limits of the DVGF, and 76-28, $2 \mathrm{~km}$ northeast of the DVGF (see Figure 1), heat flow above the fault is close to the regional average of approximately $100 \mathrm{~mW} / \mathrm{m}^{2}$, despite the presence of moderately permeable fractures at depth. In wells 66-21 and 45-14, located southwest of the main geothermal reservoir, corrections for the thermal effect of water flowing from hydraulically conductive fractures into the boreholes yield estimates of undisturbed heat flow ranging from $130-140 \mathrm{~mW} / \mathrm{m}^{2}$. These values reflect the combined thermal effect of flow along the Stillwater fault zone and the background conductive heat flow. Taking measurement and modeling uncertainties into account, these results suggest that water flowing up the Stillwater fault in the vicinity of the non-productive wells $66-21$ and $45-14$ increases the measured heat flow by only 20 $50 \%$ over the regional value, which is in contrast to measurements exceeding four times the regional value in the center of the producing reservoir. Simple two-dimensional analytical models for the thermal effects of water moving up the Stillwater fault yield estimated flow rates of $4.4-11.0 \mathrm{~m}^{3} / \mathrm{yr}$ for each meter of fault length along the non-productive segment of the fault. This contrasts with estimated flow rates of $23-46 \mathrm{~m}^{3} / \mathrm{yr}$ for each meter of fault along the highly permeable segment of the fault close to well 73B-7 (Benoit, 1997) and no detectable flow up the fault $2 \mathrm{~km}$ northeast of the main reservoir (76-28) or $4 \mathrm{~km}$ southeast of the reservoir (62-21). The limited spatial extent of anomalous heat flow, particularly at 62-21, which is located approximately $6 \mathrm{~km}$ above the downdip extension of the fault, requires that enhanced permeability within the Stillwater fault is not only localized along strike but also limited to depths less than 3 to $4 \mathrm{~km}$.

\section{FUTURE PLANS}

In the coming year we will complete our analysis of hydraulic fracturing stress measurements, TPS logs and BHTV logs acquired in well 37-33 and conduct Coulomb failure analyses on the highly permeable fractures encountered in this well. We also propose to conduct laboratory measurements of uniaxial compressive strength on rocks penetrated by wells 73B-7, 66-21 and 45-14 to better constrain the magnitudes of $S_{\mathrm{Hmax}}$ using breakout analysis. Finally, we are proposing to conduct and analyze an integrated set of stress, fracture orientation, fluid 
flow and heat flow measurements in well 82-5 to see if an explanation can be found for this well's failure to encounter high fault-zone permeability, in spite of the fact that it was drilled in close proximity to highly permeable production and injection wells (see Figure 1). These data will also be used to determine if and in what manner a reservoir stimulation experiment (e.g. massive hydrofrac) should be conducted in well 82-5 at a latter date.

\section{INDUSTRY INTEREST}

\section{Organization}

Oxbow Geothermal Corporation

Unocal Corporation

California Energy Company

Sandia National Labs

Geothermal Energy Association

\section{Type and Extent of Interest}

Improved understanding of the relationship between in-situ stress, fault slip and reservoir productivity in fracture-dominated geothermal reservoirs.

New or improved techniques for geothermal energy exploration and/or reservoir enhancement in tectonically active areas.

The main conduit for the transfer of the information gained in this study is the publication and presentation of the results of this study to appropriate audiences. A major goal is to transfer any technological advances in the area of fracture/stress analysis and reservoir enhancement made at Dixie Valley to the geothermal industry through timely publication, oral presentation, and poster sessions at technical meetings, particularly the Annual Meeting of the Geothermal Resources Council and the annual Stanford Geothermal Workshop.

\section{REFERENCES}

Barton, C.A., M.D. Zoback and D. Moos, Fluid flow along potentially active faults in crystalline rock, Geology, 23,8, p. 683-686, 1995.

Barton, C.A., S. Hickman, R.H. Morin, M.D. Zoback, T. Finkbeiner, J. Sass, and R. Benoit, Fracture permeability and its relationship to in-situ stress in the Dixie Valley, Nevada, geothermal reservoir, Proceedings 22nd Workshop on Geothermal Reservoir Engineering, Stanford Univ., Stanford, CA, p. 147-152, 1997.

Benoit, W.R., Injection of geothermal fluid in Nevada as typified by the Dixie Valley project, in Deep Injection Disposal of Hazardous and Industrial Wastes, J. Apps and C.-F. Tsang (eds.), Academic Press, San Diego, p. 449-464, 1996.

Byerlee, J.D., Friction of rocks, Pure Appl. Geoph., 1/6, p. 615-629, 1978.

Hickman, S. H., and M. D. Zoback, The interpretation of hydraulic fracturing pressure-time data for in-situ stress determination, in Hydraulic Fracturing Stress Measurements, edited by M. D. Zoback and B. C. Haimson, National Academy Press, Washington D. C., p. 44-54, 1983.

Hickman, S., and M.D. Zoback, In-situ stress in a fault-hosted geothermal reservoir at Dixie Valley, Nevada, Proceedings 22nd Workshop on Geothermal Reservoir Engineering, Stanford Univ., Stanford, CA, p. 141-146, 1997. 
Hickman, S., C.A. Barton, M.D. Zoback, R. Morin, J. Sass, and R. Benoit, In situ stress and fracture permeability in a fault-hosted geothermal reservoir at Dixie Valley; Nevada, Transactions Geothermal Resources Council, v. 21, Burlingame, CA, p.181-189, 1997.

Lockner, D.A., Rock Failure, in Rock Physics and Phase Relations: A Handbook of Physical Constants, T. Ahrens (ed.), American Geophysical Union, Washington, DC, p. 127-147, 1995.

Molz, F.J., R. Morin, A. Hess, J. Melville, and O. Guven, The impeller method for measuring aquifer permeability variations: Evaluation and comparison with other tests, Water Resources Research, 25, 1677-1683, 1989.

Moos, D., and M. D. Zoback, Utilization of observations of well bore failure to constrain the orientation and magnitude of crustal stresses: Application to continental, Deep Sea Drilling Project, and Ocean Drilling Program boreholes, J. Geophys. Res., 95, p. 9305-9325, 1990.

Seront, B., T.-F. Wong, J.S. Caine, C.B. Forster, and J.T. Fredrich, Laboratory characterization of hydromechanical properties of a seismogenic normal fault system, Journal of Structural Geology (in press), 1998.

Williams, C.F., J.H. Sass, and F.V. Grubb, Thermal signature of subsurface fluid flow in the Dixie Valley geothermal field, Nevada, Proceedings 22nd Workshop on Geothermal Reservoir Engineering, Stanford Univ., Stanford, CA, p. 161-168, 1997. 


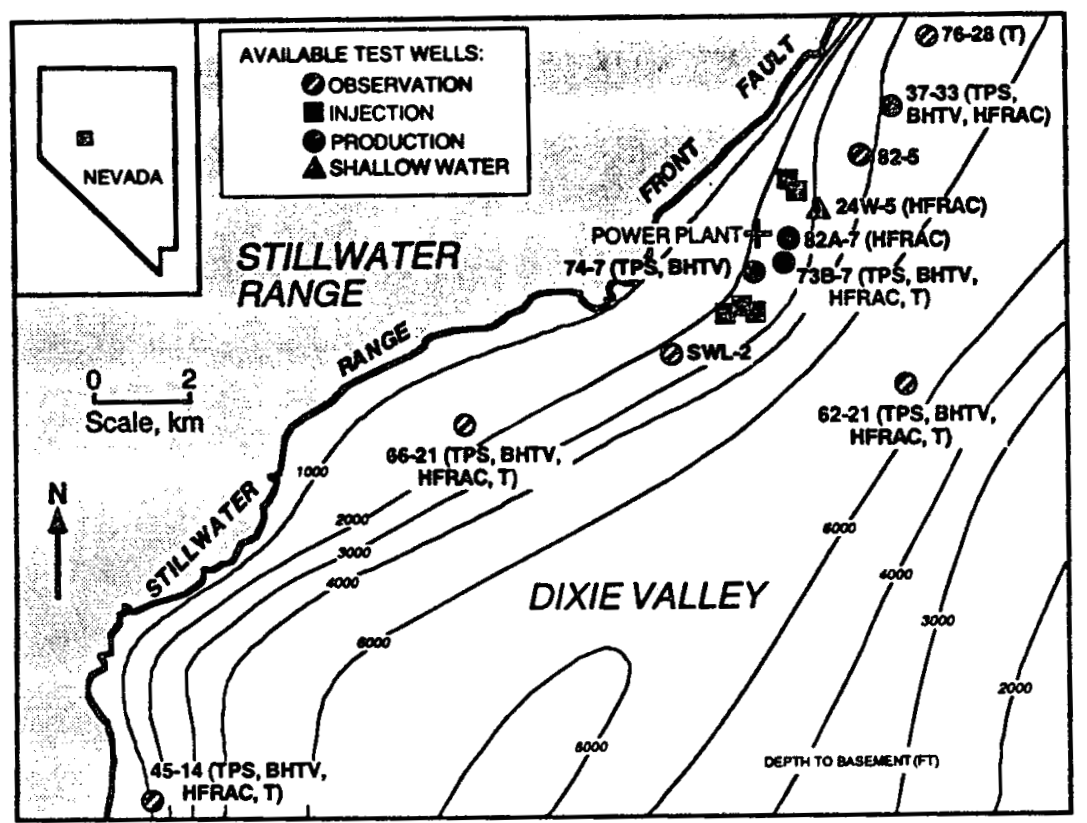

Figure 1. Map showing geothermal wells in Dixie Valley, Nevada. Injection and production wells penetrated highly permeable portions of the southeast-dipping Stillwater fault zone, whereas observation wells failed to encounter sufficient permeability to be of commercial value. Measurements conducted in these wells are TPS: Temperature/pressure/spinner log; BHTV: borehole televiewer log; HFRAC: Hydraulic fracturing stress measurement, T: temperature log.
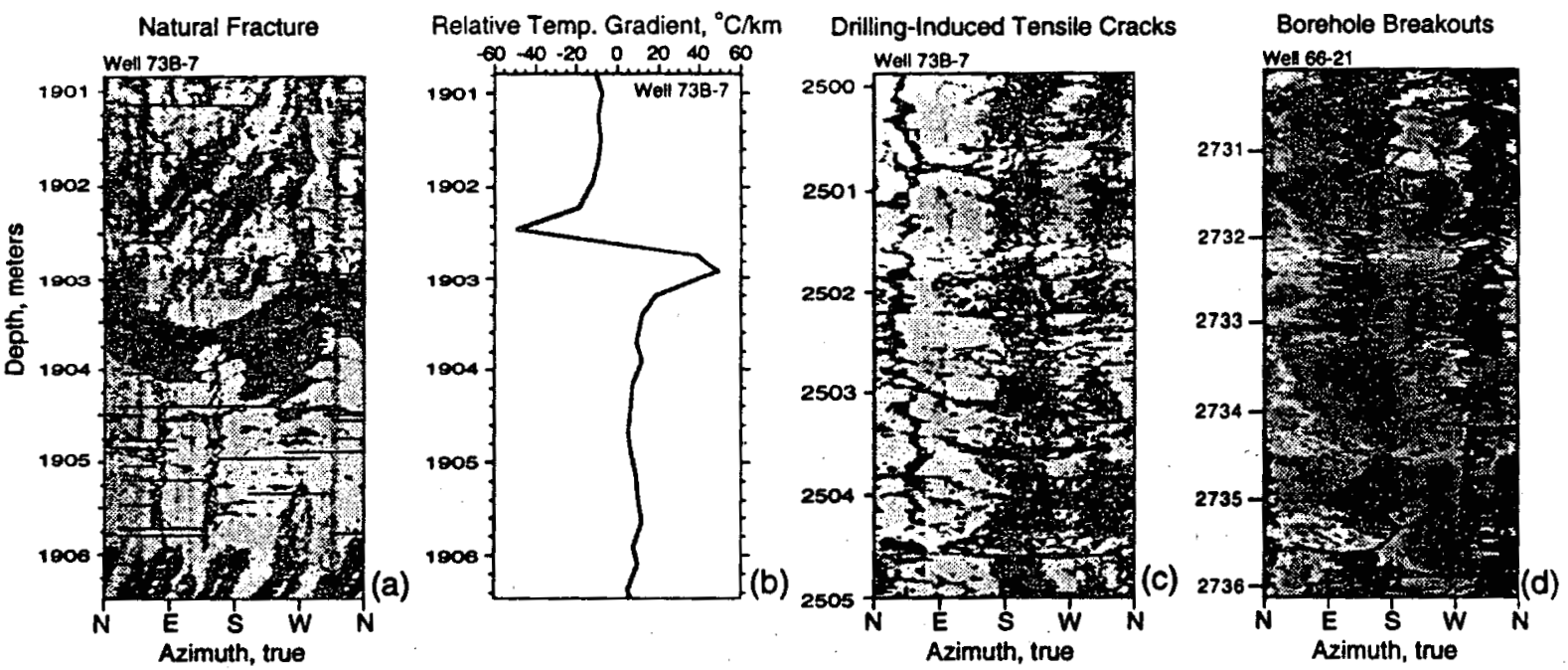

Figure 2. (a) BHTV image from well $73 \mathrm{~B}-7$, oriented relative to true North, showing a large fracture zone (sinusoid) intersecting the borehole at $1903.5 \mathrm{~m}$ and (b) relative temperature gradient (i.e., difference between the instantaneous and average gradients) over the same interval. (c) BHTV log from well 73B-7 showing drilling-induced (cooling) fractures, imaged as undulating vertical features occurring on diametrically opposed sides of the borehole and aligned in a northeast-southwest direction. (d) BHTV log from well 66-21 showing the development of stressinduced breakouts (discontinuous dark bands) on diametrically opposed sides of the borehole. 


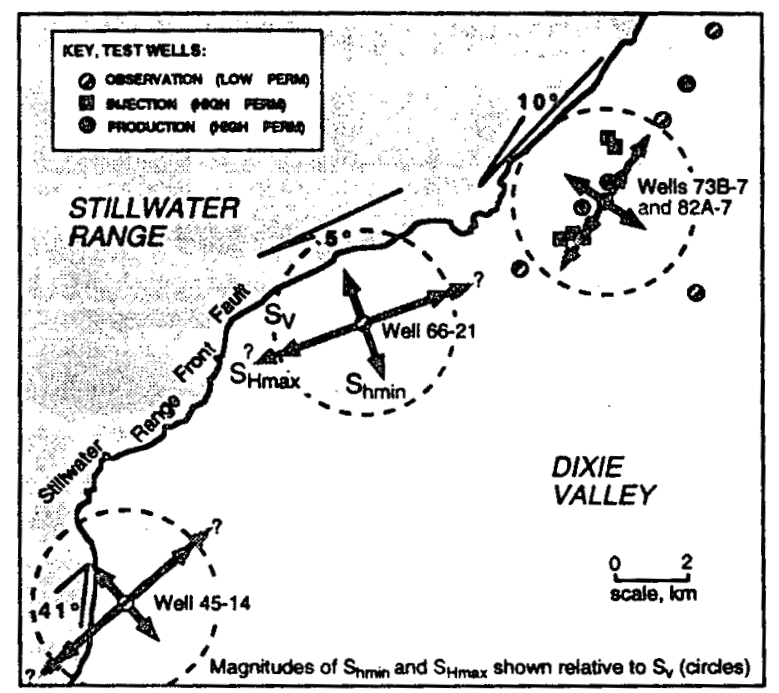

Figure 3. Orientations and relative magnitudes of the least horizontal principal stress, $S_{\text {hmin }}$, and the greatest horizontal principal stress, $S_{H \max }$, at Dixie Valley. The length of each arrow is proportional to the magnitude of the corresponding stress, normalized to the magnitude of the vertical stress $S_{v}$ (dashed circle) appropriate for that well and test depth. Lower and upper bounds on $S_{\mathrm{Hmax}}$, determined through analysis of conditions for breakout formation (see Figure 4), are depicted as dark and light gray arrows, respectively. Stresses shown for wells 73B-7 and 82A-7 are average values from three measurements at 1.7 to $2.5 \mathrm{~km}$ depth. Also shown is the extent (in degrees) to which the Stillwater fault is locally deviated from the optimal orientation for normal faulting.
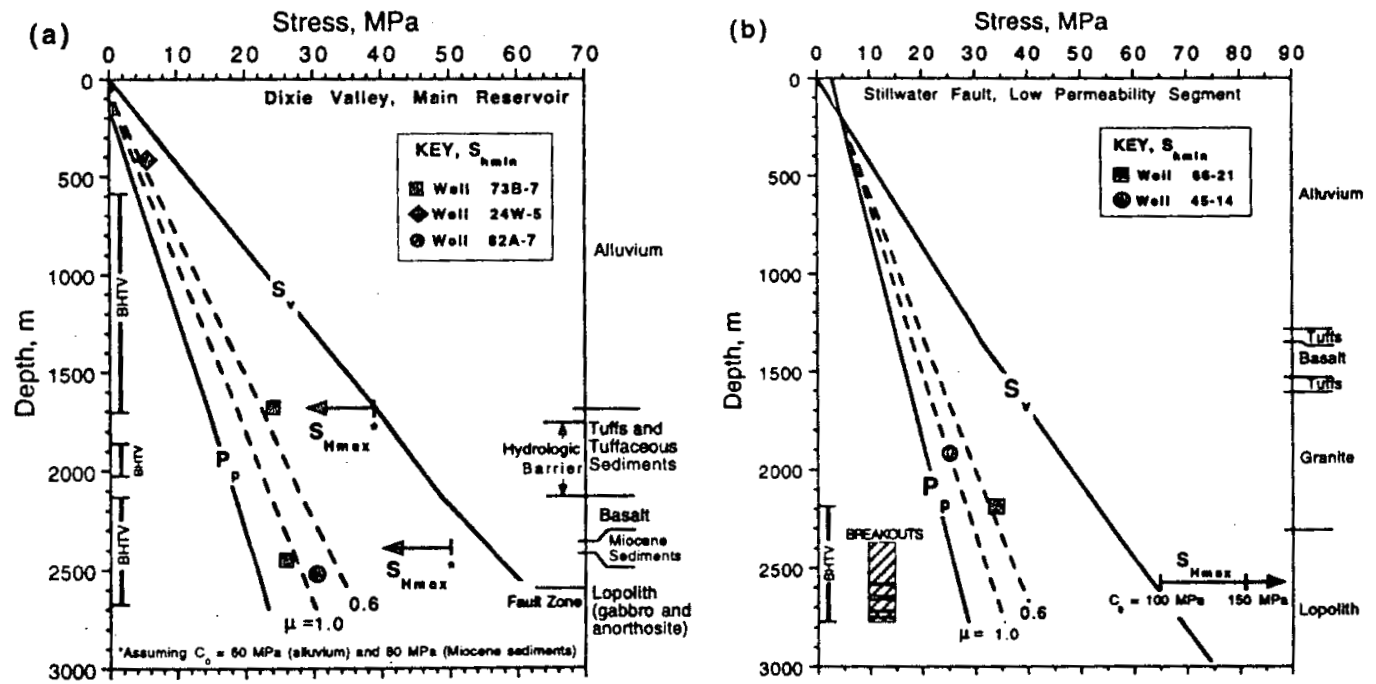

Figure 4. (a) Stress magnitudes from wells adjacent to the highly permeable segment of the Stillwater fault. Upper bounds to $S_{\mathrm{Hmax}}$ in well 73B-7 were determined from the absence of borehole breakouts, using indicated values for the compressive rock strength $\mathrm{C}_{\mathrm{o}}$. The dashed lines indicate the range of $S_{h m i n}$ at which frictional failure would be expected on optimally oriented faults for coefficients of friction of 0.6 to 1.0. (b) Same as Figure a, but for wells adjacent to the relatively impermeable segment of the Stillwater fault. The lithology, $S_{v}, P_{p}, B H T V$ coverage and breakout distribution shown are from well 66-21; although the frictional failure lines are drawn for well 66-21, they are also accurate for well 45-14 to within $2 \%$. Breakouts were either discontinuous (hachured pattern) or continuous (solid lines). Lower bounds to $S_{\text {Hmax }}$ were obtained using a breakout initiation criteria and estimates of $C_{0}$, only bounds from well 66-21 are shown. 


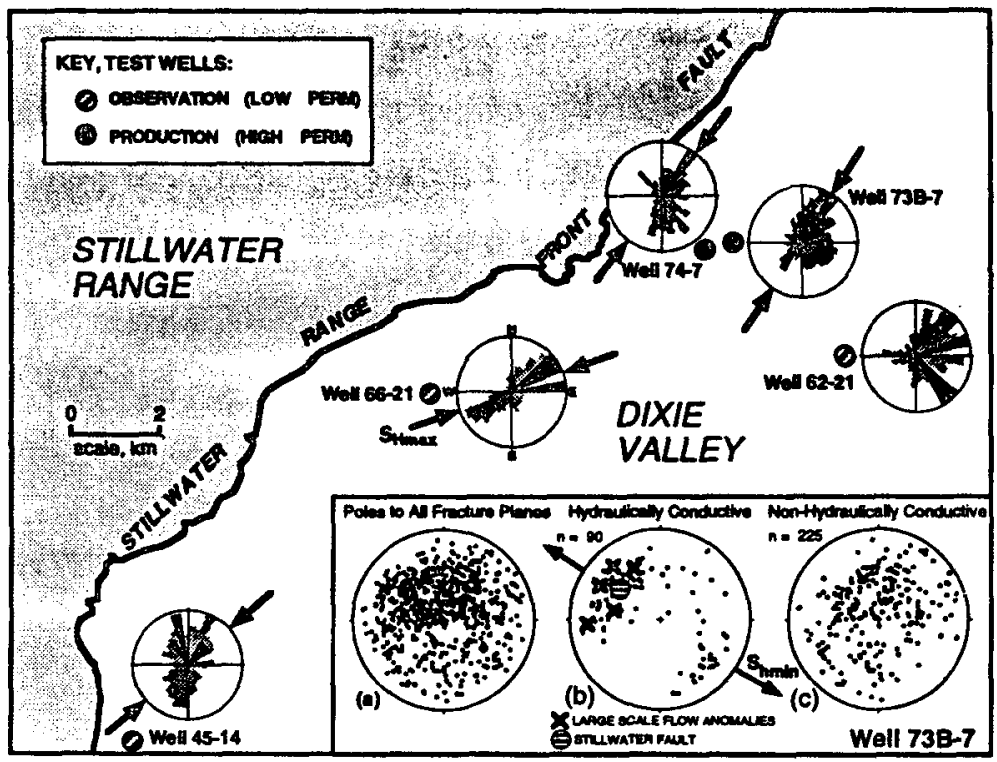

Figure 5. Rose diagrams showing the strike of all fractures imaged in BHTV logs from Dixie Valley (gray sectors) compared with the strike of hydraulically conductive fractures (solid black sectors). Also shown are the $S_{H \max }$ directions determined in these wells. Inset: (a) Lower hemisphere, equal area projection of poles to all fractures in well 73B-7 at 1.8-2.6 km, and subset of those fractures that are either (b) hydraulically conductive or (c) non-hydraulically conductive. The most permeable fractures encountered in well 73B-7 (large scale flow anomalies), the local orientation of the Stillwater fault zone and the azimuth of $S_{h \min }$ are also shown in Figure $b$.
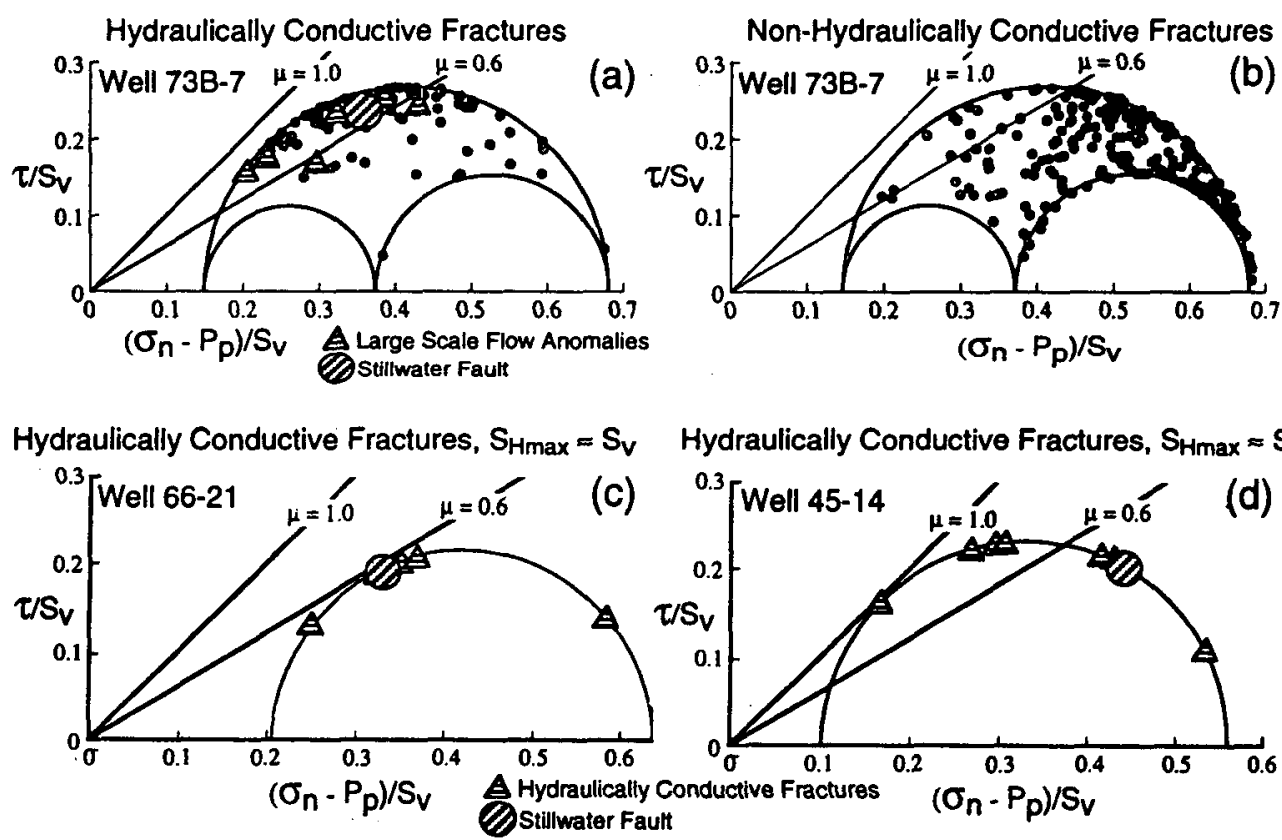

Figure 6. Shear stress versus effective normal stress, normalized to $S_{v}$, for (a) hydraulically conductive and (b) non-hydraulically conductive fractures in well 73B-7. Stresses on the Stillwater Fault adjacent to this well and on fractures primarily responsible for geothermal production (large scale flow anomalies) are also shown. Coulomb failure lines are drawn for coefficients of friction of 0.6 and 1.0. (c), (d) Same as Figure a, but for hydraulically conductive fractures encountered in non-producing wells 66-21 and 45-14, calculated assuming $S_{H \max }=S_{v}$. 


\title{
SEASONAL VARIATION IN BIG GREASEWOOD SPECTRAL BLUE SHIFTING, DIXIE VALLEY, NEVADA
}

\author{
Gregory D. Nash \\ Energy \& Geoscience Institute \\ University of Utah
}

\section{KEY WORDS}

vegetal-spectral, faults, blue-shift, Dixie Valley, Nevada, seasonal variation, geobotany, biogeochemistry

\section{PROJECT BACKGROUND AND STATUS}

This report centers on one of the results of a geobotanical study being done in Dixie Valley, Nevada. The purpose of this study, in general, is to determine if vegetation stress, related to the hydrothermal convection system, can be detected spectrally. This study has been initiated as (1) a cost-effective method for hydrothermal convection system detection that can be used over large areas is needed, (2) a need exists for a method of hidden fault/fracture detection, and (3) vegetation anomalies over producing fields can aid in field management through prediction of surficial-environmental effects from production. The feasibility of this study was determined from the results of prior similar studies at Kyle Hot Springs, Nevada; Gabbs Valley, Nevada; and Cove FortSulphurdale, Utah (Nash and Wright, 1996).

This project started during mid-July, 1996, when field spectra were acquired from Sarcobatus vermiculatus (big greasewood) near the Oxbow Power Services, Inc. geothermal power plant. More field spectra were acquired during early June 1997, thus creating the opportunity to study temporal-seasonal changes in the spectra. The temporal-seasonal change project is expected to be completed during spring, 1998.

\section{PROJECT OBJECTIVES}

The general objectives of this study are to determine if vegetal-spectral data can be used in geothermal exploration and field management. To this end the following specific objectives are guiding the study:

- Determine if geobotanical anomalies exist and are they spatially related to the hydrothermal convection system.

- If existing, are the geobotanical anomalies related to the hydrothermal convection system or other phenomena, or both.

- If existing, can the geobotanical anomalies be detected spectrally.

- If existing, can the geobotanical anomalies be detected from airborne hyperspectral data.

- To develop a methodology to apply the results of this study, if warranted, to other areas in a costeffective manner. 


\section{Technical Objectives}

- The technical objective of this study is to determine what methods and techniques can be successfully used in applied remote sensing for exploration and geothermal field management projects.

\section{Expected Outcomes}

- That geobotanical anomalies exist over the hydrothermal convection system in Dixie Valley and that they can be mapped both biogeochemically and spectrally.

- That multiple factors will be found to be causal agents in the development of geobotanical anomalies in the study area.

- That subtle changes in vegetation reflectance will be detectable near permeable faults/fractures over the hydrothermal convection system.

- It is also expected that a methodology will be developed that will allow the constraint of nonhydrothermally related vegetation stress.

\section{APPROACH}

This description of the approach will be limited to that which is directly related to the specific project result being addressed by this report. Vegetal-spectral data were collected during mid-July, 1996 and early June 1997 along the transect shown in Figure 1 at 0.1 mile intervals. Although other transects were used for data collection in 1997, only the transect shown in Figure 1 produced multitemporal data. Spectra were collected from big greasewood using a GER 2100 spectroradiometer with a sampling interval of $10 \mathrm{~nm}$. Reference spectra were collected at each sample station using a Spectralon $(\mathbb{R})$ standard. The reference spectra were used to convert the vegetation spectra to reflectance. The reflectance data were then normalized between 0 and 1 for further processing.

The normalized reflectance data were analyzed to determine if a blue-shift of the red-edge could be detected. This phenomenon is the effect of chlorophyll change on the spectral curve (Curtiss and Maecher, 1991). Chlorophyll is absorptive in the visible red with an absorption minimum at about $765 \mathrm{~nm}$ (Figure 2). A rapid increase in chlorophyll reflectance is seen in the longer wavelengths of the near infrared with a reflectance maximum between about $860-900 \mathrm{~nm}$. The area of most rapid rise between the red minimum and the near infrared maximum is known as the red-edge. The position of the red-edge has been shown to shift toward shorter wavelengths (blue shifting) in stressed vegetation (Chang and Collins, 1983).

The blue-shift phenomenon has been used to map stressed vegetation. However, it must be remembered that many factors can cause vegetation stress. The results described in this report are the comparisons of the two spectral data sets acquired during early and midsummer based on the blue-shift phenomenon. Blue shifting has beers characterized by finding the point-of-inflection of the red-edge and determining its spectral position in nanometers.

\section{RESEARCH RESULTS}

Blue shifting has been found to be present in both the data sets from early summer and midsummer. The early summer data had a point-of-inflection range from $707 \mathrm{~nm}$ to $724 \mathrm{~nm}$. The midsummer data had a point-of- 
inflection range from $699 \mathrm{~nm}$ to $716 \mathrm{~nm}$. This clearly shows that the blue shift was more prevalent in the midsummer data. The greasewood appeared to be more stressed visually during midsummer field work where the diurnal high temperature averaged $\sim 105^{\circ} \mathrm{F}$. and conditions were very dry. The vegetation was considerably greener and more vigorous during the early summer field work where diurnal high temperatures ranged between $-65^{\circ} \mathrm{F}$. and $85^{\circ} \mathrm{F}$. with occasional rain. Descriptive statistics for the data sets follow:

Early summer (1997)

Average $=720 \mathrm{~nm}$

Standard Deviation $=5.0$

Range $=17$

Midsummer (1996)

Average $=711 \mathrm{~nm}$

Standard Deviation $=5.5$

Range $=17$

These statistics show a general overall increase in blue shifting in the midsummer data set.

Figure 1 indicates which samples produced a blue-shift, or not, for both sample dates. These data are overlain on relative plant arsenic concentrations. There were 34 sample stations with multitemporal data. The endpoints are represented by data from 1997 only.

Inspection of Figure 1 shows that only $55 \%$ of the spectral data showing blue shifting in midsummer also show blue shifting in the early summer data. This indicates that climatic factors were probably the principal cause of the blue-shift in the other $45 \%$ of the cases. It is probable that temporally correlative blue shifting in samples collected on both dates is related to mineralization from past hydrothermal activity or perhaps the current hydrothermal convection system, or both. The best cluster of samples showing blue shifting correlates well with high plant As values on the hanging wall of the Buckbrush fault. However, definitive correlations among biogeochemical and soil-geochemical data and blue-shifted spectral data have not been made. It is logical to conclude, however, that in samples with multitemporally correlative blue-shifts, factors other than seasonality are likely suspects.

\section{FUTURE PLANS}

Future plans include a multivariate statistical analysis of all of the data sets mentioned in this report with correlation of the results. Plans are also underway to test other factors that may affect spectral blue shifting.

\section{INDUSTRY INTEREST}

\section{Organization}

Oxbow Power Services, Inc

\section{Type and Extent of Interest}

Exploration and field management

\section{REFERENCES}

Chang, S. and W. Collins, Confirmation of the airborne biogeophysical mineral exploration technique using laboratory methods: Economic Geology, Vol. 78, p. 723-736. 
Curtiss, B., and Maecher, A. G., 1991, Changes in forest canopy reflectance associated with chronic exposure to high concentrations of soil trace metals, in ERIM, Proceedings of the Eight Thematic Conference on Geologic Remote Sensing, Denver, CO: Environmental Research Institute of Michigan, p. 337-347.

Nash, G. D. and P. M. Wright, 1996, Remote sensing and geographic information systems (GIS) - tools for geothermal exploration in the Great Basin, U. S. A.: Final Report, Sandia National Laboratories, contract \#AB$6807,74 \mathrm{p}$. 


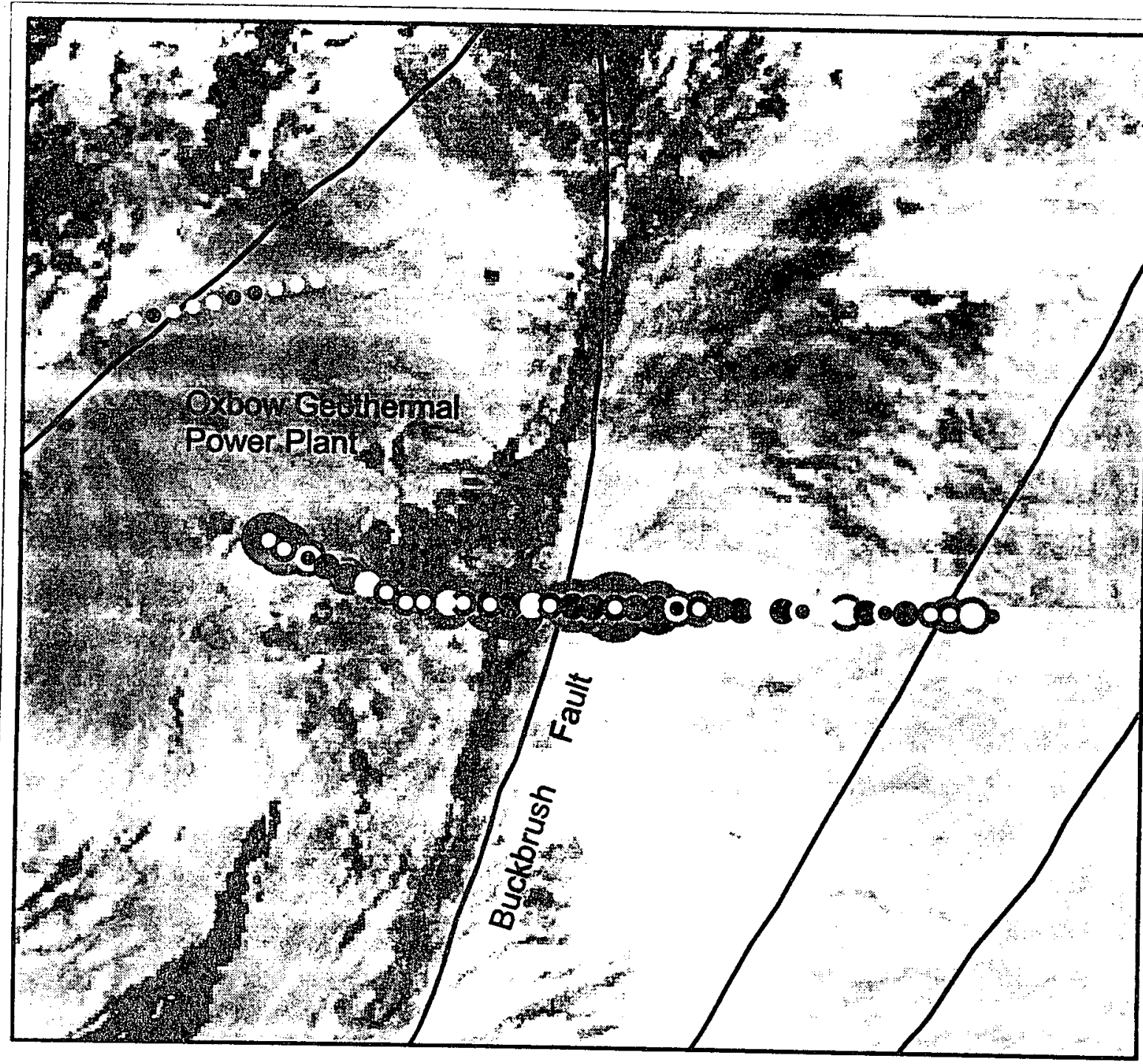

Early summer blue shifting Biogeochemistry - As

O no

Midsummer blue shifting

O no

yes

^Fault
-1 - 0 Std. Dev.

o Mean

$0-1$ Std. Dev.

1 - 2 Std. Dev.

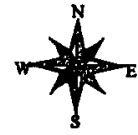

$1000 \quad 0 \quad 1000$ Meters

2 - 3 Std. Dev.

Figure 1 -- Multitemporal blue shifting overlain on relative biochemical As concentrations. 


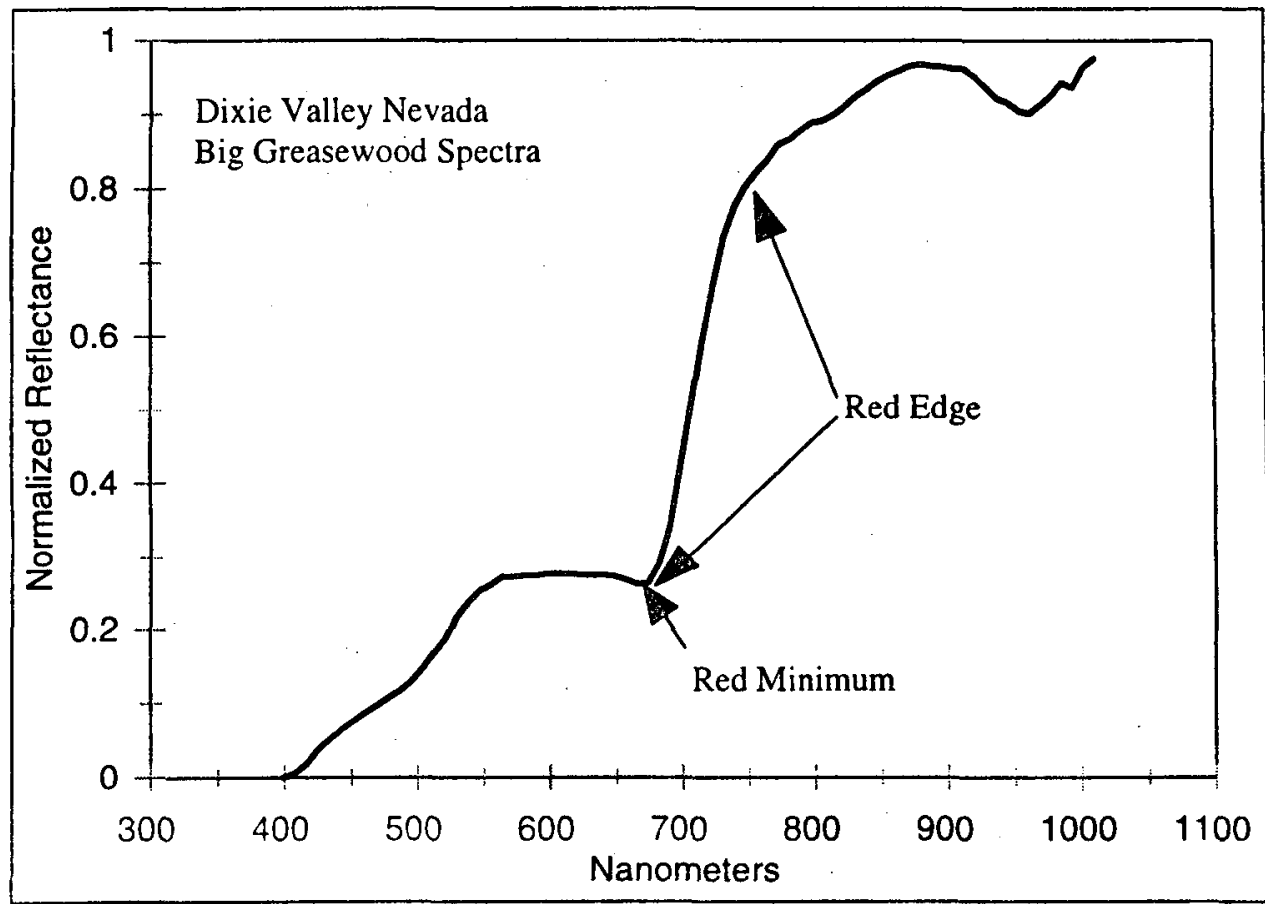

Figure 2 -- Big Greasewood spectra. 


\title{
ALTERATION HISTORY OF JURASSIC RESERVOIR ROCKS IN THE DIXIE VALLEY GEOTHERMAL FIELD, NEVADA
}

\author{
Susan J. Lutz and Joseph N. Moore \\ Energy and Geoscience Institute (EGI) at the University of Utah
}

\section{KEY WORDS}

Dixie Valley, Stillwater Range, normal faults, Basin and Range, tectonostratigraphic history, alteration mineralogy, X-ray diffraction, fluid inclusions

\section{PROJECT BACKGROUND AND STATUS}

Dixie Valley is a fracture-dominated geothermal system located on the east side of the northern Stillwater Range in west-central Nevada. With a 62 megawatt power plant (operated by Oxbow Power Corp.), Dixie Valley is the largest non-volcanic geothermal system in the Basin and Range province. Although the circulation of geothermal fluids within the field is dominantly controlled by fracture permeability along the present rangefront fault, most wells produce from a zone of fractured Jurassic-age rock located above the trace of the main fault. These Jurassic rocks have undergone a long and complicated structural history that includes both Mesozoic compressional and Cenozoic extensional events. Our studies have focussed on the post-Oligocene alteration of these rocks, and the relationship and cumulative effect of these alteration events upon the permeability of the current geothermal reservoir. From our petrographic and fluid inclusion work, we now recognize six major mineral assemblages that represent alteration events associated with the early stages of Basin and Range extension and the evolution of the Dixie Valley geothermal system.

This summary describes the history of alteration in the Jurassic rocks from wells both in the geothermal field and outside of the main producing area. X-ray diffraction, petrographic and fluid inclusion analyses have been used to characterize the alteration events and the kinds of fluids that produced the alteration minerals. We have also done reconnaissance mapping in the Stillwater Range adjacent to the Dixie Valley geothermal field in an attempt to relate discrete alteration assemblages to major structural features in the area.

\section{PROJECT OBJECTIVES}

The primary objective of this project is to develop better conceptual models of geothermal reservoirs associated with normal fault zones in extensional terrains.

\section{Technical Objectives}

- Describe the alteration mineralogy associated with recent geothermal activity along the Stillwater Fault and older hydrothermal events along earlier Basin and Range normal faults.

- Determine the temporal and spatial relationships between older hydrothermal events and the tectonostratigraphic history of the geothermal reservoir.

- Characterize the mineralizing fluids in order to understand the history of fluid flow along faults that have affected the permeability of Jurassic rocks in the area. 


\section{Expected Outcomes}

- Assist explorationists and developers in targeting geothermal wells along large-scale normal faults common to the Basin and Range Province. This will reduce the number of hot, but dry holes located along these faults, and their development costs.

- Develop an improved understanding of the distribution and evolution of permeability in normal fault zones through time.

- Integrate permeability models based on reservoir geology and petrographic work with fluid flow and other numerical reservoir models based on tracer injection studies.

- Use our knowledge of the geochemistry of the present production fluids to aid in understanding scale mineralogy and formation, especially in injection wells.

\section{APPROACH}

The objectives of this study have been attained by careful petrographic and geologic logging of outcrop material from the Stillwater Range and from cutting samples from the Dixie Valley geothermal wells. The samples were studied in thin section to determine rock type and the distribution and paragenetic relationships among the secondary minerals. X-ray diffraction techniques were used to characterize the clay minerals and to determine the percentages of mineral phases in the rock. Mineral geothermometers are compared with downhole thermal measurements to assess the evolutionary changes that have occurred since the secondary minerals were formed. Fluid-inclusion analyses indicate the temperature and salinity of the fluids that produced the alteration minerals.

These studies represent a collaborative effort between EGI and Oxbow Power Corp., the operator of the Dixie Valley field.

\section{RESEARCH RESULTS}

The main reservoir in the Dixie Valley geothermal field is hosted in a package of fractured Jurassic rocks located within the hanging wall of the Stillwater fault. Six stages of post-Oligocene alteration can be recognized on the basis of mineral paragenesis, rock associations, fluid-inclusion temperatures and apparent salinities. The paragenetic sequence from oldest to youngest consists of: Stage I) epidote-chlorite-calcite veins; Stage II) illite; Stage III) wairakite-quartz-calcite-potassium feldspar-epidote veins; Stage IV) mixed-layer illite-smectite and quartz-calcite veins; Stage V) chalcedonic quartz-dolomite-calcite-chlorite/smectite-barite-hematite veins; and Stage VI) quartz-calcite veins. Fluid-inclusion data yield the following temperatures and apparent salinities in weight percent $\mathrm{NaCl}$ equivalent for each stage: Stage I) $270^{\circ}$ to $325^{\circ} \mathrm{C}$ and 1.4 to $1.6 \%$; Stage II) $220^{\circ}$ to $270^{\circ} \mathrm{C}$ and 1.6 to $1.9 \%$; Stage III) $230^{\circ}$ to $240^{\circ} \mathrm{C}$ and $1.2 \%$; Stage IV) $180^{\circ}$ to $220^{\circ} \mathrm{C}$ and 0.4 to $0.5 \%$; Stage V) $<160^{\circ} \mathrm{C}$ and $0.0 \%$; and Stage VI) $200^{\circ}$ to $270^{\circ} \mathrm{C}$ and 0.0 to $0.5 \%$.

Stage I through $V$ assemblages appear to be associated with hydrothermal systems that developed during Basin and Range extension, prior to the development of the modern geothermal system. Field relationships and petrographic analyses suggest that the Stage II sericite and Stage III wairakite veins represent Miocene alteration events associated with NNW faulting and intrusion of andesitic dikes. The fluids associated with these events are represented by moderate-salinity fluid inclusions ( 1.2 to $1.9 \mathrm{wt} \% \mathrm{NaCl}$ equivalent) with homogenization temperatures in the $220^{\circ}$ to $270^{\circ} \mathrm{C}$ range. Descent of the hanging wall of the NE-trending Stillwater fault occurred after the deposition of Miocene basalt flows and dike intrusion. Low-salinity Stage IV and V fluid 
inclusions suggest the presence of cool fluids at shallow depths along the Stillwater fault. Stage VI quartz and calcite veins appear to have been deposited by the modern geothermal system (Tmax $=248^{\circ} \mathrm{C}$, salinity $=0.1-0.2$ wt \%) after the Jurassic rocks descended to their present depth of $2-3 \mathrm{~km}$ along this still-active fault.

Although homogenization temperatures for fluid inclusions in wairakite veins from well $45-33\left(\mathrm{Th}=233^{\circ} \mathrm{C}\right)$ are similar to the temperature of the production fluids in this well $\left(\operatorname{Tmax}=248^{\circ} \mathrm{C}\right)$, the salinity data indicate that the inclusion fluids were too saline (up to $1.2 \mathrm{wt} \% \mathrm{NaCl}$ equivalent) to have been produced by the modern geothermal system $(0.1$ to $0.2 \mathrm{wt} \% \mathrm{NaCl})$. In addition, our petrographic work in well $66-21$ outside of the main producing area indicates an abundance of wairakite veins that appear to be related to the presence of Miocene dikes in the Jurassic section. Maximum measured temperatures in this well are about $180^{\circ} \mathrm{C}$ but wairakite is generally thought to form at minimum temperatures of $230-240^{\circ} \mathrm{C}$. Hence, the wairakite clearly formed as a result of an older, hotter hydrothermal event.

Present-day fluid inclusions deposited in wellbore scale yield homogenization temperatures of about $200^{\circ} \mathrm{C}$ and salinities of 0.0 to $0.4 \mathrm{wt} \% \mathrm{NaCl}$ equivalent. Geochemical modelling by Bruton et al. (1997) indicates that Dixie Valley production fluids would precipitate calcite and minor quartz. Although our petrographic analyses do not clearly identify late-stage open-space vein fillings, low-salinity fluid inclusions from our Stage VI quartz-calcite veins do suggest their deposition from modern geothermal fluids. In well 45-33, part of the low-salinity inclusion population exhibits homogenization temperatures of up to $270^{\circ} \mathrm{C}$. Since the maximum fluid temperature in this well is about $248^{\circ} \mathrm{C}$, this suggests some cooling of the modern geothermal system since its emplacement along the Stillwater Fault.

\section{FUTURE PLANS}

We plan to continue to our petrographic investigation of the Dixie Valley geothermal field and adjacent areas in the Stillwater Range in FY 98. We will continue to use fluid-inclusion and X-ray diffraction analyses of outcrop samples to compare them with data from the geothermal wells. In FY98, we want to look at the spatial relationships between important structural features in the area (the low-angle Boyer normal fault and possibly related NNW normal faults; Plank, 1996; Honjas et al., 1997) and associated hydrothermal alteration assemblages. We would like to confirm our interpretation of the alteration paragenesis with radiometric dating on suitable minerals. For example, we are curious about the actual age of : wairakite veins in the well cuttings (assumed to be Miocene based on rock associations), sericite along NNW structures and the Boyer Fault close to the geothermal field (assumed to be the same Miocene age as sericite at the Dixie Comstock mine; Vikre; 1994), alunite at the intersection of the NNW faults with the NE-trending Stillwater Fault, and biotite-homblende bearing dikes in both the wells and in the Stillwater Range. The goal is to integrate the alteration history with the structural history, to recognize the major structural features in the boreholes based on the stratigraphic relationships, and to understand the history of faulting and fluid flow in the evolution of permeability in the present geothermal reservoir.

The results of our integrated alteration mineralogy and fluid inclusion studies at Dixie Valley have been presented at the Rocky Mountain Section of the AAPG in Denver on August 25th, to fellow researchers at the Dixie Valley Workshop in Reno during August 26th-27th, and at the annual GSA convention in Salt Lake City on October 20th, 1997.

\section{INDUSTRY INTEREST}

We have worked very closely with Oxbow Power Corp. but our work will also benefit other geothermal companies that are active in the Basin and Range Province. Caithness Corp. and Far West Capitol, who operate 
Steamboat Springs (NV) and have drilled a hot, but dry hole just to the south of Dixie Valley have also shown strong interest in this work. The operators of Roosevelt Hot Springs (UT) and Coso (CA), CalEnergy, will benefit from this study because of its focus on the alteration and kinematic history of normal faults.

We will continue to work with other research groups in order to gain a mutual understanding of how fault-hosted geothermal reservoirs work. Some current associated studies include: tectonic history and earthquake mechanics (U.S.G.S.- National Earthquakes Hazard Reduction Program; University of Nevada-Reno, Center for Neotectonic Studies and Seismological Laboratory), fluid flow and alteration mineralogy in seismogenic normal fault systems (University of Utah, Department of Geology and Geophysics), geothermal tracer development and testing (EGIP. Rose and M. Adams), structural mapping and interpretation in extensional terrains (University of NevadaReno, Department of Geological Sciences; LBL), fracture permeability and in-situ stress (U.S.G.S., Stanford University- Department of Geophysics), and geochemical modelling of geothermal fluids (LLNL).

\section{REFERENCES}

Bruton, C.J., Counce, D., Bergfield, D., Goff, F., Johnson, S.D., Moore, J.N., and Nimz, G., 1997 Preliminary investigation of scale formation and fluid chemistry at the Dixie Valley geothermal field, Nevada: Geothermal Resources Council Transactions, v. 21, p. 157-164.

Honjas, W., Pullammanappillil, S.K., Lettis, W.R., Plank, G.L., Louie, J.N., and Schweichert, R., 1997: Predicting shallow earth structure within the Dixie Valley geothermal field, Dixie Valley, Nevada using a nonlinear velocity optimization scheme: Proceedings of the 22nd Workshop on Geothermal Reservoir Engineering, Stanford University Report SGP-TR-155, p. 153-160.

Lutz, S.J., Moore, J.N. and Benoit, D., 1996, Alteration mineralogy of the Dixie Valley geothermal system, Nevada: Geothermal Resources Council, Transactions, Volume 20, p. 353-362.

Lutz, S.J., Moore, J.N. and Benoit, D., 1997, Gcologic framework of Jurassic reservoir rocks in the Dixie Valley geothermal field, Nevada: Implications from hydrothcrmal alteration and stratigraphy: Proceedings of the 22nd Workshop on Geothermal Reservoir Engineering, Stanford University Report SGP-TR-155, p. 131-139.

Lutz, S.J. and Benoit, D., 1997, Alteration history of Jurassic reservoir rocks in the Dixie Valley geothermal field, Nevada: abstract, AAPG Bulletin, v. 81, n. 7, p. 1229.

Lutz, S.J., Moore, J.N. and Benoit, D., 1997, Cenozoic hydrothermal alteration in Dixie Valley and northern Stillwaer Range, Nevada: GSA Abstracts with Programs, 1997 GSA Annual Meeting, Salt Lake City, p. A-50.

Plank, G.L., 1996, Structural geology and tectonic implications of a part of the northern Stillwater Range, Nevada: abstract, AAPG Rocky Mountain Section Meeting, AAPG Bulletin, v. 80/6, p. 979.

Vikre, P.G., 1994, Gold mineralization and fault evolution at the Dixie Comstock Mine, Churchill County, Nevada: Economic Geology, v. 89, n. 4, p. 707-719. 


\section{LIST OF CONTACTS FOR RESERVOIR TECHNOLOGY}

Michael C. Adams

Energy and Geoscience Institute

423 Wakara Way

Salt Lake City, UT 84108

Phone: (801) 585-7784

Fax: (801) 585-3540

e-mail: madams@egi.utah.edu

Colleen A. Barton

Department of Geophysics

Stanford University

Stanford, CA 94305

Phone: (415) 723-9831

Fax: (415) 725-7344

Pascale Benezeth

Chemical and Analytical Sciences Division

Oak Ridge National Laboratory

P. O. Box 2008, Bldg. 4500S, MS-61 10

Oak Ridge, TN 37831-6110

Phone: (423) 574-4960

Fax: (423) 574-4961

Dick Benoit

Oxbow Geothermal Corp.

5250 S. Virginia Street, Suite 304

Reno, NV 89502

Phone: (702) 825-4345

Fax: (702) 825-2838

K. K. Bloomfield

Idaho National Engineering and Environmental

Laboratory

P. O. Box 1625

Idaho Falls, ID 83415-3830

Phone: (208) 526-5250

Fax: (208) 526-0969

Brian Bonner

Lawrence Livermore National Laboratory

7000 East Ave., L-201

P.O. Box 808

Livermore, CA 94550

Phore: (510) 422-7080

e-mail: bonner1@)llnl.gov
Peggy Brookshier

U. S. Department of Energy

Idaho Operations Office

785 DOE Place, MS 1220

Idaho Falls, ID 8340 1-1563

Phone: (208) 526-1403

Fax: (208) 526-5964

e-mail: brookspa@inel.gov

Carol J. Bruton

Lawrence Livermore National Laboratory

L-219

P.O. Box 808

Livermore, CA 94550

Phone: (510) 423-1936

Fax: $\quad 510-422-0208$

e-mail: bruton1@llnl.gov

David R. Cole

Chemical and Analytical Sciences Division

Oak Ridge National Laboratory

P. O. Box 2008, Bldg. 4500S, MS-6110

Oak Ridge, TN 37831-6110

Phonc: (423) 574-5473

Fax: (423) 574-4961

Robert J. Creed Jr.

U. S. Department of Geothermal Energy

Idaho Operations Office, MS 1220

850 Energy Drive

Idaho Falls, Idaho 83401

Phone: (208) 526-9063

Fax: (208) 526-6249

Prof. G. Brent Dalrymple

College of Oceanic \& Atmospheric Sciences

104 Ocean Admin. Bldg.

Oregon State University

Corvallis, OR 97331-5503

Phone: (54I)737-5195

Fax: (541)737-2064

e-mail: gbd@oce.orst.edu 


\section{Al Duba}

Lawrence Livermore National Laboratory

7000 East Ave., L-201

P.O. Box 808

Livermore, CA 94550

Phone: (510) 422-7306

Fax: (510) 423-1057

e-mail: dubal@llnl.gov

D. D. Faulder

Advisory Scientist

Idaho National Engineering and Environmental

Laboratory

P.O. Box 1625

Idaho Falls, ID 83415-3830

Phone: (208) 526-0674

Fax: (208) 526-0969

e-mail: ddf@inel.gov

Stefan Finsterle

Earth Sciences Division, MS 90-1116

E.O. Lawrence Berkeley National Laboratory

Berkeley, CA 94720

Phone: (510) 486-5205

Fax: (510) 486-5686

e-mail: safinsterle@lbl.gov

Miroslaw S. Gruszkiewicz

Chemical and Analytical Sciences Division

Oak Ridge National Laboratory

P. O. Box 2008, Bldg. 4500S, MS-6110

Oak Ridge, TN 37831-6110

Phone: (423) 574-4965

Fax: (423) 574-4961

Stephen Hickman

U.S. Geological Survey

345 Middlefield Rd., MS 977

Menlo Park, CA 94025

Phone: (415) 329-4807

Fax: (415) 329-5163
Juske Horita

Chemical and Analytical Sciences Division

Oak Ridge National Laboratory

P. O. Box 2008, Bldg. 4500S, MS-6110

Oak Ridge, TN 37831-6110

Phone: (423) 576-2750

Fax: (423) 574-4961

Jeffrey $B$. Hulen

Energy and Geoscience Institute

423 Wakara Way

Salt Lake City, UT 84108

Phone: (801) 581-8497

Fax: (801) 585-3540

e-mail: jhulen@egi.utah.edu

S. D. Johnson

Geochemist

Oxbow Power Services, Inc.

9790 Gateway Drive, Suite 220

Reno, NV 89511

Phone: (702) $850-2248$

Fax: (702) 850-2211

e-mail: Stu_Johnson@opsi.oxbow.com

Paul Kasameyer

Lawrence Livermore National Laboratory

7000 East Ave., L-203

P.O. Box 808

Livermore, CA 94550

Phone: (510) 422-6487

Fax: (510) 423-2163

e-mail: kasameyer@llnl.gov

Ann Kirkpatrick

Earth Sciences Division

Bldg 90-1116

E.O. Lawrence Berkeley National Laboratory

Berkeley CA 94720

Phone: (510) 486-6985

Fax: $\quad(510)$ 486-5686

e-mail: akirkpatrick@lbl.gov 
Marcelo J. Lippmann

Earth Sciences Division,

Bldg. 90-1116

E.O. Lawrence Berkeley National Laboratory

Berkeley, CA 94720

Phone: (510) 486-5035

Fax: (510) 486-5686

e-mail: mjlippmann@lbl.gov

Susan J. Lutz

Energy and Geosciences Institute

University of Utah

423 Wakara Way

Salt Lake City, UT 84108

Phone: (801) 585-9688

Fax: (801) 585-3540

e-mail: sjlutz@egi.utah.edu

Ernie L. Majer

Earth Sciences Division

Bldg 90-1116

E.O. Lawrence Berkeley National Laboratory

Berkeley CA 94720

Phone: (510) 486-6709

Fax: (510) 486-5686

e-mail: elmajer@lbl.gov

Dr. Peter Malin

Duke University

Division of Earth and Ocean Sciences, NSOE

Durham, NC 27708

Phone: (919) 681-8889

Fax: (919) 684-5833

e-mail: pem@vaino.geo.duke.edu

Robert E. Mesmer

Chemical and Analytical Sciences Division

Oak Ridge National Laboratory

P. O. Box 2008, Bldg. 4500S, MS-6110

Oak Ridge, TN 37831-6110

Phone: (423) 574-4958

Fax: (423) 574-4961

Nancy Mфller

Chemistry Department

U. of Calif., San Diego, 92093

Phone: (619) 534-6374

Fax: (619)534-7244
Joseph Moore

Energy and Geoscience Institute

423 Wakara Way

Salt Lake City, UT 84108

Phone: (801) 585-6931

Fax: (801) 585-3540

e-mail: jmoore@egi.utah.edu

George Moridis

Earth Sciences Division

Lawrence Berkeley National Laboratory

Bldg. 90-1116

Berkeley, CA 94720

Phone: (510) 486-4746

Fax: (510) 486-5686

Roger Morin

U.S. Geological Survey, Box 25046

Denver Federal Center

Denver, CO 80225

Phone (303) 236-5915

Fax: (303) 236-5959

Gregory D. Nash

Energy \& Geoscience Institute

University of Utah

423 Wakara Way, Suite 300

Salt Lake City, Utah 84108

Phone: (801) 585-3889

Fax: (801) 585-3540

e-mail: gnash@egi.utah.edu

Dennis L. Nielson

Energy \& Geoscience Institute University of Utah

423 Wakara Way

Salt Lake City, UT 84108

Phone: (801) 585-6855

Fax: (801) 585-3540

e-mail: dnielson@egi.utah.edu 
Curtis Oldenburg

Earth Sciences Division

Bldg 90-1116

Lawrence Berkeley National Laboratory

Berkeley, CA 94720

Phone: (510) 486-7419

Fax: (510) 486-5686

e-mail: cmoldenburg@lbl.gov

Donald A. Palmer

Chemical and Analytical Sciences Division

Oak Ridge National Laboratory

P. O. Box 2008, Bldg. 4500S, MS-6110

Oak Ridge, TN 37831-6110

Phone: (423) 576-5109

Fax: (423) 574-4961

Peter Persoff

Earth Sciences Division

Lawrence Berkeley National Laboratory

Bldg. 90-1116

Berkeley, CA 94720

Phone: (510) 486-5931

Fax: (510) 486-7079

John E. Peterson

Earth Sciences Division

Bldg 90-1116

E.O. Lawrence Berkeley National Laboratory

Berkeley CA 94720

Phone: (510) 486-4267

Fax: (510) 486-5686

e-mail: jepeterson@lbl.gov

John W. Pritchett

Maxwell Technologies

Federal Division

8888 Balboa Avenue

San Diego, CA 92123-1506

Phone: (619) 576-7760

Fax: (619) 576-7710

e-mail: john@maxwell.com
Karsten Pruess

Earth Sciences Division

Bldg 90-1116

Lawrence Berkeley National Laboratory

Berkeley, CA 94720

Phone: (510) 486-6732

Fax: (510) 486-5686

e-mail: k_pruess@lbl.gov

Marshall Reed

U.S. Department of Geothermal Energy

Office of Geothermal Technology, EE-12

1000 Independence Avenue, SW

Washington, D. C. 20585-0121

Phone: (202) 586-8076

Fax: (202) 586-8185

e-mail: marshall.reed@hq.doe.gov

J. L. Renner

Program Manager

Idaho National Engineering and Environmental

Laboratory

P.O. Box 1625

Idaho Falls, ID 83415-3830

Phone: (208) 526-9824

Fax: (208) 526-0969

e-mail: rennerjl@inel.gov

Dr. Jose A. Rial

Wave Propagation Lab Geology

Department University of North Carolina at Chapel Hill

Mitchell Hall, CB\#3315

Chapel Hill, NC 27599-3315

Phone: (919) 966-4553

Fax: (919) 966-4519

e-mail: Jose_Rial@unc.edu

Jeff Roberts

Lawrence Livermore National Laboratory

7000 East Ave., L-201

P.O. Box 808

Livermore, CA 94550

Phone: (510) 422-7108

Fax: (510) 423-1057

c-mail: roberts17@IInl.gov 
Peter E. Rose

Energy and Geoscience Institute

423 Wakara Way

Salt Lake City, UT 84108

Phone: (801) 585-7785

Fax: (801) 585-3540

e-mail: prose@egi.utah.edu

John Sass

U.S. Geological Survey

2255 North Gemini Drive

Flagstaff, AZ 86001

Phone: (520) 556-7226

Fax: (520) 556-7169

Richard A. Schweickert

Department of Geological Sciences

University of Nevada Reno

Reno, NV 89557

Phone: (702) 784-6901

Fax: (702) 784-1833

e-mail: richschw@unr.edu

Dr. Eylon Shalev

Duke University

Division of Earth and Ocean Sciences, NSOE

Durham, NC 27708

Phone: (919) 684-4780

Fax: (919) 684-5833

e-mail: shalev@vaino.geo.duke.edu

Ardyth M. Simmons

Earth Sciences Division, B90-1116

Lawrence Berkeley National Laboratory

Berkeley, CA 94720

Phone: (510) 486-7106

Fax: (510) 486-6115

e-mail: asimmons@lbl.gov

J. Michael Simonson

Chemical and Analytical Sciences Division

Oak Ridge National Laboratory

P. O. Box 2008, Bldg. 4500S, MS-6110

Oak Ridge, TN 37831-6110

Phone: (423) 574-4962

Fax: (423) 574-4961
Alfred H. Truesdell

700 Hermosa Way

Menlo Park, CA 94025

Phone: (650) 322-6135

Fax: (650) 324-4009

e-mail: ahtruesdell@lbl.gov

John Weare

Chemistry Department

U. of Calif., San Diego, 92093

Phone: (619) 534-3286

Fax: (619)534-7244

Jeffrey L. Wagoner

Lawrence Livermore National Laboratory

7000 East Ave., L-221

P.O. Box 808

Livermore, CA 94550

Phone: (510) 422-1374

Fax: $\quad$ (510) 422-2195

e-mail: wagoner l@linl.gov

David J. Wesolowski

Chemical and Analytical Sciences Division

Oak Ridge National Laboratory

P. O. Box 2008, BIdg. 4500S, MS-6110

Oak Ridge, TN 37831-6110

Phone: (423) 574-6903

Fax: (423) 574-4961

Colin Williams

U.S. Geological Survey

345 Middlefield Rd., MS 977

Menlo Park, CA 94025

Phone: (415) 329-4881

Fax: (415) 329-5163

Mark Zoback

Department of Geophysics

Stanford University

Stanford, CA 94305

Phone: (415) 725-9295

Fax: (415) 725-7344 


\title{
$\mathrm{CO}_{2}$-RESISTANT CEMENTS IN GEOTHERMAL WELLS
}

\author{
Toshifumi Sugama \\ Brookhaven National Laboratory
}

\section{KEY WORDS}

Calcium aluminate cements, Phosphate containing compounds, Flyash, Acid-base reactions, Mechanical properties, Carbonation, Lightweight, Pumpable, Well completions.

\section{PROJECT BACKGROUND AND STATUS}

During the period 1978-84, BNL under DOE/OGT sponsorship organized and conducted a program to develop and test advanced normal weight cement formulations. This international effort coordinated through the American Petroleum Institute, which involved Universities, private industry and government laboratories, culminated in the field testing under downhole flowing brine conditions of several cement formulations cured in-situ. The $\mathrm{CO}_{2}$ content in this well was low, therefore carbonation resistance was not evaluated. The results from this effort currently serve as the basis for the selection of cements used for geothermal well completions throughout the world.

A more recently identified problem that is severely reducing well life, and has increased costs and environmental concerns, is cement deterioration due to alkali metal catalyzed reactions between $\mathrm{CO}_{2}$ containing brines and the calcium silicate hydrate (CSH) compounds and calcium hydroxide present in conventional well cements. In the former, reactions between $\mathrm{Na}$ and $\mathrm{K}$ in the brines and CSH phases lead to the formation of substituted CSH compounds such as pectolite and reyerite, both of which are susceptible to carbonation. Leaching of the resulting $\mathrm{CaCO}_{3}$ and $\mathrm{Ca}\left(\mathrm{HCO}_{3}\right)_{2}$ leads to rapid reductions in strength, increase permeability, and corrosion on the outside surface of the well casing. Cement failures attributed to $\mathrm{CO}_{2}$ are occurring in less than $5 \mathrm{yr}$, and in one case, resulted in a collapsed well casing within 90 days. In addition. low slurry densities $(\sim 1.2 \mathrm{~g} / \mathrm{cc})$ are desirable to minimize the frequency of lost circulation episodes when attempts are made to cement in weak unconsolidated rock zones with very fragile gradients. Solving these materials problems which could seriously constrain the development of the world's geothermal resources, is the goal of the current cement research activity. Design criteria established by industry and ranked in order of importance are as follows: 1) compatible with conventional field placement technologies, 2) carbonation rate $<5 \%$ after $1 \mathrm{yr}$ in brine at $300^{\circ} \mathrm{C}$ containing $500 \mathrm{ppm} \mathrm{CO}, 3$ ) compressive strength $>5 \mathrm{MPa}$ at $24 \mathrm{hr}$ age, and 4) slurry density $<1.2 \mathrm{~g} / \mathrm{cc}$. Other important characteristics needed are: 1) life expectancy $20 \mathrm{yr}$, 2) pumpability of $\sim 4 \mathrm{hr}$ at $\left.>100^{\circ} \mathrm{C}, 3\right)$ bond strength to steel $>70 \mathrm{KPa}$, and 4) $\mathrm{H}_{2} \mathrm{O}$ permeability $<0.1$ m Darcy.

As of May 1997, several cement formulations that meet many of the design criteria have been identified. Based upon laboratory evaluations performed at BNL and by our industrial collaborators Halliburton and Unocal, one cement formulation has tentatively been selected for completing geothermal wells in Indonesia. Using cement systems being formulated by Halliburton; a preliminary small-scale field test has been carried out by Unocal during a period of Jüly-September 1997, in Indonesia. The full-scale demonstration test currently scheduled for October 1997 . 


\section{PROJECT OBJECTIVES}

The objective of the project is to develop and field test lightweight, low-cost, $\mathrm{CO}_{2}$-resistant, non-portland based cementitious materials that can be used for geothermal well completions.

\section{Technical Objectives}

Design criteria for the cements being developed in this program are as follows:

- Slurry density, approximately $1.2 \mathrm{~g} / \mathrm{cc}$.

- Pumpability, $4 \mathrm{hr}$ at $100^{\circ} \mathrm{C}$.

- Carbonation rate, $<5 \%$ after $1 \mathrm{yr}$ in brine at $300^{\circ} \mathrm{C}$ containing $500 \mathrm{ppm} \mathrm{CO}_{2}$.

- Compressive strength, >5 MPa at $24 \mathrm{hr}$ age.

- Bond strength to steel, $>70 \mathrm{KPa}$.

- Water permeability, $<0.1 \mathrm{~m}$ Darcy.

\section{Expected Outcomes}

Attainment of the project objectives will result in the following:

- Decreased costs for well completions due to reductions in lost circulation control episodes.

- Increased well life to $>20 \mathrm{yr}$.

- Reduced environmental concerns regarding blow-outs.

- Permit development of higher temperature, higher $\mathrm{CO}_{2}$ content brines.

\section{APPROACH}

The project consists of five phases: 1) fundamental cement research, 2) mix design, 3) property characterization, 4) placement technology, and 5) downhole evaluations. Phases 4 and 5 are conducted as costshared efforts with industry to insure the practicability of the materials and technology transfer.

Phase 1 consists of fundamental work to synthesize non-portland cement-based materials and to elucidate the interactions that occur between them and a number of lightweight inorganic and organic microsphere fillers. State-of-the-art surface science analytical techniques are used in all parts of this phase. Phase 2 consists of the development of cement-filler mixtures and curing conditions to yield the desired properties. In Phase 3, the mechanical, physical and chemical resistance characteristics of the most promising formulation are being determined before and after autoclave exposures to $\mathrm{CO}_{2}$-containing hydrothermal fluids. The technical feasibility for use of the cement slurries in well completions using conventional placement technology is determined in Phase 4. This work includes the selection of retarding admixtures to extend pumpability, and verification of this by the performance of consistometer testing in accordance with American Petroleum 
Institute standards. Industrial assistance in the selection of retarders is contributed by a well service company. In Phase 5, which is a cost-shared activity with a well service company and a well owner, the ability to mix and place the cements on a large-scale is verified, and the long-term durability of samples cured in and exposed to downhole geothermal environments is determined.

\section{RESEARCH RESULTS}

Cost-shared R\&D between BNL, Halliburton Services and Unocal to develop cementing materials produced by acid-base reactions between flyash-blended calcium aluminate cements and phosphate-containing compounds was continued. Several candidate systems were evaluated. Studies of the cementing phases formed, microstructure developed, carbonation rate, and changes in strength and permeability after exposure to $\mathrm{CO}_{2}$ solutions at $300^{\circ}$ were completed. As a result, it was tentatively selected for use in a full-scale test to be performed in FY1997. The cement formulation consists of $23.7 \mathrm{wt} \%$ flyash; $15.8 \mathrm{wt} \%$ calcium aluminate cement, $12.6 \mathrm{wt} \%$ sodium polyphosphate, $29.1 \mathrm{wt} \% \mathrm{Al}_{2} \mathrm{O}_{3}$-shelled microspheres, and $18.8 \mathrm{wt} \%$ water. This formulation has a slurry density of approximately $1.2 \mathrm{~g} / \mathrm{cc}$, and after hydrothermal curing forms a strong, $\mathrm{CO}_{2}$-resistant cement. As an example, autoclave exposure for 120 days to a $4 \mathrm{wt} \% \mathrm{Na}_{2} \mathrm{CO}_{3}$ solution at $300^{\circ} \mathrm{C}$ produced no evidence of carbonation or strength retrogression. In contrast, class $\mathrm{G}$ cement that is conventionally used for geothermal well completions, was severely deteriorated.

The results from the preliminary small-scale field tests in Indonesia suggested that although the cement systems displayed an excellent $\mathrm{CO}_{2}$ resistance and a good mechanical strength at hydrothermal temperatures ranging from $150^{\circ}$ to $300^{\circ} \mathrm{C}$, there needed to develop new formulations that withstand to the highly concentrated $\mathrm{H}_{2} \mathrm{SO}_{4}(\mathrm{pH} \sim 2)$ environments being encountered in surface ground water of the geothermal wells at temperature of $\sim 90^{\circ} \mathrm{C}$. None of the inorganic-based acid-resistant cements that can withstand such hot acid environment are commercially available.

\section{FUTURE PLANS}

Specific topics will include: 1) post-test analyses of the downhole specimens removed from Indonesian wells, 2) development of acid-resistance flyash cements, 3) characterization of sludge/flyash blended cement systems, 4) evaluation of the effect of inexpensive and chemically inert wheat starch-based fillers on the properties of ultra-lightweight cement systems, and 5) autoclave studies to measure the long-term durability of the cured lightweight formulations to hot acid at $\mathrm{pH}-2$ in $\mathrm{CO}_{2}$ content hydrothermal environments. On-going cooperative work with Halliburton and Unocal to perform engineering-scale placement tests, economic evaluations and downhole exposures in high $\mathrm{CO}_{2}$ brines will be continued.

\section{INDUSTRY INTEREST}

\section{Organization}

Halliburton Services

Unocal

\section{Type and Extent of Interest}

Cement properties characterization, pumpability studies, economic evaluation.

Field testing. 


\section{REFERENCES}

Sugama, T. and Carciello, N., Strength Development in Phosphate-bonded Calcium Aluminate Cements , J. Am. Ceram. Soc., 74, 1023 (1991).

Schlumberger, Dowell, Geothermal Cementing , pp 4-5, (1993).

Sugama, T and Carciello, N., Carbonation of Calcium Phosphate Cements after Long-term Exposure to $\mathrm{Na}_{2} \mathrm{CO}_{3}$-laden Water at $250^{\circ} \mathrm{C}$, Cem. Concr., Res., 23, 1409 (1993).

Sugama, T. and Wetzel, E., Microsphere-filled Lightweight Calcium Phosphate Cements, BNL 48543, J. Mater. Sci., 29, 5165 (1994).

Sugama, T. and Carciello, N., Sodium Phosphate-derived Calcium Phosphate Cements, BNL 60195, Cem. Concr. Res., 25, 91 (1995).

Sugama, T., Hot Alkali Carbonation of Sodium Metaphosphate Modified Flyash/Calcium Aluminate Blend Hydrothermal Cements, Cement and Conc. Res., 26, 1616 (1996).

Sugama, T., Hydrothermal Treatment of Calcium Aluminate-Flyash-Sodium Metaphosphate Cements , Adv. Cem. Res., 9, 65 (1997). 


\title{
THERMALLY CONDUCTIVE COMPOSITES FOR HEAT EXCHANGER TUBING
}

\author{
Toshifumi Sugama and Ronald P. Webster \\ Brookhaven National Laboratory
}

\section{KEY WORDS}

Corrosion protection, Fouling coefficient, Heat transfer, Mild steel, Polymer cement composites, Antioxidant agent, Silicon carbide, Thermal conductivity, Nickel aluminide, Polyphenylene sulfide.

\section{PROJECT BACKGROUND AND STATUS}

The economic utilization of binary working fluids in geothermal energy conversion cycles would dramatically increase the size of the exploitable hydrothermal resource. A significant item of cost in a binary plant is the shell and tube heat exchangers, primarily due to the necessity of using high alloy steel tubing to prevent corrosion. Even then, excessive fouling prevents the economic use of binary processes with hypersaline brines. Both problems could possibly be solved with the development of a thin, scale resistant, thermally conductive polymer matrix composite that could be used as a liner on low cost mild steel tubing. Cost effective utilization of bottoming cycles in flash processes as a means of increasing energy conversion efficiency will also become possible.

The technical feasibility for the use of high temperature composite materials for corrosion protection was demonstrated by BNL in the early 1980s, and since then they have been used successfully by the geothermal industry. It was then shown that significant increases in the thermal conductivity of the polymer-matrix composites could be achieved by the incorporation of high conductivity materials as fillers. Conductivities approaching those of Type-410 stainless steel were obtained. It was later shown that the addition of high temperature antioxidants into the composite significantly reduced the rate of scale deposition and adhesion to the surface. Work to develop a low cost, low fouling replacement material for the high alloy steels used in geothermal heat exchange applications was then initiated.

In FY 1994, a 75-day field test of carbon steel tubing lined with a thermally conductive polymer composite (PCL) was conducted under conditions that simulated those in a bottoming cycle in a multi-stage flash geothermal process. The heat exchanger consisted of four 6-meter lengths of $2.54-\mathrm{cm}$ OD x $1.24 \mathrm{~mm}$ wall tubing lined with a $0.76-\mathrm{mm}$ layer of the PCL. The hypersaline brine inlet and outlet temperatures were $108^{\circ}$ and $89^{\circ} \mathrm{C}$, respectively. Concurrently, AL-6XN control tubes were evaluated under similar temperature, pressure, flow and brine composition conditions.

In FY 1995, analyses of the heat transfer, fouling and corrosion resistance performance of the PCL were completed. The post-test examination indicated that the base metal was fully protected by the lining. In addition, the heat transfer performance and fouling rate of the PCL tubes were similar to those of the high alloy controls. In FY 1996, preliminary design, manufacturing, and cost studies for utilizing the composite in full scale shelland-tube heat exchangers were conducted. These results established that contingent upon the development of a cost-effective method for joining PCL tubing to tube sheets, significant reductions (17 to $65 \%$ ) in the cost of a heat exchanger could be realized. A second field test using PCL modified with antioxidants and SiC-filed polyphenylene sulfide/zinc phosphate composite coatings was commenced in FY 1997. 


\section{PROJECT OBJECTIVES}

The objective of the research is to reduce the levelized cost of heat exchangers in geothermal binary power plants by $30 \%$.

\section{Technical Objectives}

The objectives of the project will be met by the development of a material meeting the following criteria:

- Heat transfer and fluid-flow characteristics similar to those of AL-6XN tubing.

- Fouling coefficient $<50 \%$ of AL- $6 \mathrm{XN}$ when used in brines typical of the Salton Sea KGRA.

- Cost not more than twice that of mild steel.

\section{Expected Outcomes}

- Electric generation capacities in geothermal flash processes could be improved by $10 \%$ with the availability of cost-effective materials for use in bottoming cycle heat exchangers.

- Low temperature geothermal resources that are currently uneconomical will become more attractive for development, thereby greatly enhancing the exploitable geothermal reserves.

- Increased plant utilization factors due to reduced scale deposition and decreased quantities of waste sludge for disposal will result from the use of binary processes with hypersaline brines.

\section{APPROACH}

The work is being performed as a collaborative effort between BNL, the National Renewable Energy Laboratory (NREL) and private industry. BNL performs the fundamental and applied research necessary to define the polymer cement formulations, determines protective coating thickness requirements, and develops methods for the placement of thin, uniform coatings on heat exchanger tubes. Post-field test evaluations are also performed at BNL.

Engineering analyses and heat transfer tests are conducted by NREL. The work includes measurements of heat transfer coefficients, cost estimates, and the management of field testing. NREL also coordinates technology transfer activities.

A geothermal company provides the field test site, operating personnel and ancillary equipment. Tests in an environment typical of that in a bottoming cycle application in a flash process are being performed. Design, manufacture method and economic studies are then conducted by a heat exchanger manufacturer.

\section{RESEARCH RESULTS}

A second large-scale field test of a PCL heat exchanger is nearing completion. BNL continued work to identify methods for improving the surface texture and scale-bonding characteristics of PCLs applied to carbon steel tubing. As part of this effort, fundamental work to elucidate the interactions that take place at PCL- or polymer/scale interfaces was performed. The results from these studies indicated that polymers containing esters, ketone, 
or ether groups should not be used directly in PCL formulations because of their susceptibility to oxidation reaction with hot brine. This reaction led to the formation of carboxylic acid groups, which subsequently reacts with $\mathrm{Ba}$ and $\mathrm{Ca}$ in geothermal brines. The $\mathrm{Ba}$ - and $\mathrm{Ca}$-complexed carboxylate salt derivatives not only acted to promote the rate of scale deposition, but also caused the development of high bond strength at the interfaces between PCL and scale. Two methods, the incorporation of antioxidant agents into the polymers and the use of polyaryl-type polymers such as polyphenylene sulfide (PPS), should significantly reduce the magnitude of the interfacial bond, thereby making it possible to remove the scale layers from the PCL surfaces by the hydroblasting method. This issue is being addressed in Field Test No.2. In addition, nickel aluminide (NiAl) alloy coatings applied by flame-spray technology were evaluated for use as corrosion/oxidation/wear-resistant barriers in protecting the interior surfaces at the ends where the heat-exchanger tube is jointed to a tubesheet by the roller expansion process. These had superior properties, such as a good plastic deformation, great wear resistance, a coefficient of thermal expansion similar to that of steels, and excellent of thermal conductivity in the range 35 to $76 \mathrm{w} / \mathrm{m}^{\circ} \mathrm{c}$, thereby possessing a high potential for use as a safe-tube end coating.

\section{FUTURE PLANS}

After completion of the second field test, analysis will be made of any scale deposited on the tubing surfaces to determine chemical composition. The extent of scale adhesion to the liner, corrosion of the underlying steel, and identification of any reaction products at the liner/steel interfaces will also be determined.

In-house studies to investigate the degree of the chemical reactivity and inertness of SiC-filled PPS and phenolic resin liners to the ionic reactants in geothermal fluid will be completed. Also, mechanical, physical and chemical analyses of the $\mathrm{NiAl}$ coatings on interior surfaces of tube ends after the rolled joint will be performed and the depth of brine penetration into them will be determined. Based upon the laboratory results, four $6-\mathrm{m}$-long tubes lined with antioxidant-modified SiC/styrene/TMPTMA, antioxidant-modified SiC/styrene/TMPTMA/zinc phosphate ( $\mathrm{Zn} . \mathrm{Ph}$ ), SiC/PPS/Zn.Ph, SiC/PPS/polytetrafluoroethylene (PTFE)/Zn.Ph, will be prepared for use in a third field test. In addition, four other tubes that contain NiAl coatings at tube ends will also be tested. The test will be conducted in a feedstream brine at a temperature of $170^{\circ} \mathrm{C}$ and a pH 2 .

\section{INDUSTRY INTEREST}

\section{Organization}

California Energy Co.

Hughes-Andersen Heat

Exchangers, Inc.

ASB Industries, Inc.

\section{Type and Extent of Interest}

Possible CRADA participant. User of technology

Heat exchanger manufacturer.

Thermal-spray coating industry.

\section{REFERENCES}

Fontana, J.J., Reams, W., and Cheng, H.C., "Potential Polymer Concrete Heat Exchanger Tubes for Corrosive Environments", BNL 38945, Proc. 5th International Conference on Polymers in Concrete, Sept. 22-24, 1987, Brighton, U.K.. 
Sugama, T. and Carciello, N., "Interfaces of Polyphenyleteretherketone (PEEK) and Polyphenylene Sulfide (PPS) Coated Zinc Phosphated Steels After Heating-Cooling Cycles in a Wet Harsh Environment", J. Coat. Tech., 66, 43 (1994).

Webster, R.P. Kukacka, L.E., and Reams, W., "Development of Polymer Concrete Liners and Coatings for Use in Geothermal Applications", BNL 48002, Sept. 1992, American Concrete Institute Special Publication, "Recent Innovations in Polymer Concrete Technology".

Sugama, T., "Zinc Phosphate Conversion Coatings", U.S. Patent No. 5,604,040 (1997).

Sugama, T., "Interfaces Between Geothermal Brine-Induced Scales and SiC-Filled Polymer Linings", Geothermic, (in press). 


\title{
COATINGS FOR HIGH TEMPERATURE APPLICATIONS
}

\author{
Toshifumi Sugama \\ Brookhaven National Laboratory
}

\section{KEY WORDS}

Corrosion protection, Polymers, Composites, Pre-ceramics, Nickel Aluminide, Piping, Well casing, Cooling towers, Vent gas blowers, Acid condensate.

\section{PROJECT BACKGROUND AND STATUS}

Corrosion problems at The Geysers have increased as steam pressures decline. These have contributed to decreases in electric power generation, increased operating costs, and safety and environmental concerns. In FY $1990, \mathrm{BNL}$ initiated cost-shared work with geothermal companies active at The Geysers which focuses on low cost solutions to these difficult materials problems. The identification of needs, performance of prototype and full-scale field evaluations, and subsequent economic studies are performed as cost-shared activities with firms active at The Geysers.

As of October 1997, one cooperative test program was completed, and several others were in progress. The former was with the Central California Power Agency (CCPA) to evaluate coating systems for well casing exposed to low $\mathrm{pH}$ steam condensate. Ongoing efforts include composite coating materials systems for pipelines with the Northern California Power Agency (NCPA) for dry cooling towers, turbine components and vent gas blowers.

\section{PROJECT OBJECTIVES}

The objective of the research is to decrease the operating costs of steam production, transmission and utilization at The Geysers by the identification and subsequent demonstration of low cost materials of construction that will withstand the highly corrosive acidic environments being encountered in some areas of the geothermal field. Design criteria for the coatings being developed are as follows:

\section{Technical Objectives}

- Ability to coat the substrate with large surface area and applicable to restoring damaged coatings.

- Capable of protecting the substrate against the attack of condensed and vaporized corrosive species at temperatures up to $300^{\circ} \mathrm{C}$.

- Displaying good adhesive behavior to substrate (tensile bond strength of $>10 \mathrm{MPa}$ ).

- Having a low coefficient of friction.

\section{Expected Outcomes}

Attainment of the project objectives will result in the following: 
- Wells that presently cannot be operated due to excessive maintenance costs or environmental/safety concern may be restarted.

- Service life expectancies of fluid production, transmission and electric generation components will be increased.

- Cost-effective methods for water conservation will be available, thereby resulting in reservoir life extensions due to increased fluid reinjection.

\section{APPROACH}

The approach being used to meet the project objectives is to optimize polymer, polymer cement composite and pre-ceramic formulations, previously developed under DOE/OGT sponsorship, for specific end-use applications at The Geysers. The identification of need, performance of prototype and full-scale field evaluations, and subsequent economic studies are performed as cost-shared activities with firms active at The Geysers. In FY1997, engineering ceramics, metal alloys, and ceramic/metal composites were added to the types of materials under investigation.

The Project consists of three phases:

- Phase 1 consists of the identification of specific materials problems, elucidation of the fluid environments, and the selection of candidate materials systems. Laboratory testing under simulated process conditions is then conducted to establish technical feasibility. Based upon these results, modifications to the systems are made to maximize corrosion resistance.

- Phase 2 consists of small-scale field testing, and contingent upon the results, prototype component testing.

- Phase 3 consists of design studies to incorporate the technology into components, cost estimates, documentation, and the identification of potential commercial suppliers of the new technology.

\section{RESEARCH RESULTS}

Laboratory and field testing efforts being performed as cost-shared activities with geothermal companies active at The Geysers were continued. Current industrial participants are the Northern California Power Agency (NCPA) and the Material Integrity Solutions, Inc., (MIS). Protection of piping system, turbine, vent gas blower, and dry cooling tower components from erosion-corrosion, fatigue and stress corrosion cracking is a recognized need in the geothermal industry. In FY 1997, a number of potential coating systems were developed by BNL and were investigated in laboratory-scale work. These included I) refractory oxides $\left(\mathrm{ZrO}_{2}, \mathrm{Al}_{2} \mathrm{O}_{3}\right.$, and $\left.\left.\mathrm{Y}_{2} \mathrm{O}_{3}\right), 2\right)$ ceramic-sealed $\mathrm{NiAl}$ alloy composites, 3) flyash-derived glass ceramics, and 4) PPS-sealed NiAl alloy composites. These materials were evaluated for use as corrosion/oxidation/abrasion-resistant coatings for mild carbon steel, stainless steel, $\mathrm{Ni}-\mathrm{Cr}$ steel and Ti-based alloys. Tests were conducted in a pH 2, hypersaline brine, steam environment at $300^{\circ} \mathrm{C}$. Sol-gel derived thin refractory oxide films ( $<5 \mu \mathrm{m}$ thick) had a very smooth surfaces and a good adherent to $\mathrm{Cr}$-based steels, leading to a low coefficient of friction and conferring resistance to corrosion and oxidation. The ceramic/NiAl composite coatings with thickness of $>1$ mil displayed a great abrasion wear resistance for all metals. Slurry-derived glass ceramic coatings not only had an excellent corrosion, oxidation, and abrasion resistance, but also adhered chemically to Ti-based alloys. 


\section{FUTURE PLANS}

dry cooling tower, turbine, and vent gas blower components will be completed. Contingent upon these results, engineering-scale tests for these applications will be initiated at MIS. Three new coating systems, the $\mathrm{Cr}_{2} \mathrm{C}_{3}, \mathrm{TiN}$ and amorphous diamond like carbon, by moderate temperature- and plasma-chemical vapor depositions (CVD) technologies, will be tested for evaluating their potential as a high-performance thin coating film that confers corrosion, oxidation, and wear resistances of the mild carbon steels.

\section{INDUSTRY INTEREST}

Organization

NCPA

MIS

\section{Type and Extent of Interest}

Research collaborators for corrosion protection for transmission piping. Potential user of technology.

Research collaborators for corrosion protection of vent gas blowers, dry cooling tower components, turbine blades, rotor housings.

\section{REFERENCES}

Sugama, T. and Carciello, N., "Interfaces of Polyphenyletheretherketone (PEEK) and Polyphenylene Sulfide (PPS) Coated Zinc Phosphated Steels After Heating-Cooling Cycles in a Wet Harsh Environment”, J. Coat. Tech., 66, 43 (1994).

Sugama, T. and Carciello, N., "The Protection of Aluminum Alloys in Harsh, Corrosive Environments by Oxidized Polyphenylene Sulfide Coatings", Polymers \& Polymer Comp., 3, 289 (1995).

Sugama, T., " $\mathrm{Y}_{2} \mathrm{O}_{3}$-Sealed NiAl Thermal Barrier Coatings for Inconel 625", J. Surf. Coat. Tech., (in press).

Sugama, T., "Yttrium Acetate-Derived Particle Coatings for Mitigating Oxidation and Corrosion of Inconel 625", J. Sol-Gel. Sci. Tech., (in press). 


\title{
COATINGS FOR PROTECTION OF EQUIPMENT FOR BIOCHEMICAL PROCESSING OF GEOTHERMAL RESIDUES
}

\author{
M.L. Allan \\ Brookhaven National Laboratory
}

\section{KEY WORDS}

Coatings, corrosion, thermal spraying, polymers, biochemical processing, adhesion, cathodic protection

\section{PROJECT BACKGROUND AND STATUS}

Barrier coatings are of critical importance in protecting geothermal plant equipment from corrosion. Synergistic combination of coatings and cathodic protection is also of interest for long-term corrosion mitigation. Brookhaven National Laboratory has been evaluating high performance polymer-based coatings that can be field or shop applied to protect metallic substrates in geothermal environments. In particular, emphasis is placed on evaluation of coated, low cost construction materials as alternatives to expensive corrosion resistant alloys.

A biochemical treatment process to detoxify geothermal brines and sludges has been developed at BNL (see Advanced Biochemical Process for Geothermal Brines). The process uses microorganisms to convert toxic metals, including radionuclides, present in geothermal residues into soluble species. The untreated residues are corrosive towards ferrous metals due to high chloride content and low $\mathrm{pH}$. The biochemical treatment process typically operates at $\mathrm{pH}$ values of $1-2$ and temperatures of $50-55^{\circ} \mathrm{C}$. Furthermore, the biocatalyst itself is corrosive. Therefore, protective contings are required to mitigate corrosion, reduce the cost of plant construction and reduce maintenance costs throughout the equipment design life.

Research in FY 97 evaluated several polymer-based coatings for protecting 316L stainless steel and mild steel from geothermal sludge, synthetic hypersaline brine and Thiobacillus ferrooxidans. Corrosion protective behavior, resistance to cathodic disbondment and residual adhesion were measured. The majority of the longterm laboratory evaluations are complete. Work in FY 98 will apply and monitor the performance of selected coatings in a pilot-scale biochemical plant set up at BNL.

\section{PROJECT OBJECTIVES}

The overall objective of this task is to reduce the construction and operating and maintenance costs for biochemical treatment of geothermal residues through delineation of coatings durable in low $\mathrm{pH}$, hypersaline environments and biocatalysts. The findings are also relcvant to low temperature geothermal environments where corrosion protection is required.

\section{Technical Objectives}

- Evaluate low cost, high performance coatings to protect biochemical processing and other geothermal power plant equipment from corrosion, with emphasis on field-applied coatings.

\section{Expected Outcomes}

- Reduced construction, operating and maintenance costs for biochemical treatment of geothermal residues 
- Economic viability of biochemical treatment process

- Identification of high performance, field-applied coatings for uses in other geothermal applications

\section{APPROACH}

Thermal sprayed ethylene tetrafluoroethylene and ethylene methacrylic acid polymers, spray-and-bake fluoropolymers and a brushable ceramic-filled epoxy were investigated as coatings to protect mild steel and $316 \mathrm{~L}$ stainless steel from geothermal sludge, synthetic hypersaline brine and Thiobacillus ferrooxidans at $55^{\circ} \mathrm{C}$. These coatings were selected on the basis of their predicted resistance to chemical attack and biodegradation, ease of large-scale application, and economics. The thermal spraying of the polymers was conducted at the Thermal Spray Laboratory, State University of New York at Stony Brook. Long-term exposure tests in simulated environments were conducted and the coating performance assessed. Residual adhesion after exposure was measured. Cathodic disbondment tests were also conducted to determine the possibility of using the coatings in conjunction with cathodic protection.

\section{RESEARCH RESULTS}

It was found that the tested coatings were resistant to chemical attack and biodegradation at the test temperature of $55^{\circ} \mathrm{C}$. The thermal sprayed ethylene methacrylic acid coatings protected $316 \mathrm{~L}$ stainless steel from corrosion in coupon tests. However, corrosion of mild steel substrates coated with ethylene methacrylic acid and ethylene tetrafluoroethylene occurred in Atlas cell tests that simulated a lined reactor operating environment and this resulted in decreased adhesive strength. Peel tests revealed that failure mode was dependent on exposure conditions. The long-term tests on the ceramic-filled epoxy are still in progress and initial indications are that this coating is a suitable candidate for pilot-scale tests. In particular, this coating displays excellent abrasion resistance. Cathodic disbondment tests in brine at room temperature indicated that ethylene methacrylic acid coatings are resistant to disbondment at applied potentials of -780 to $-1070 \mathrm{mV} \mathrm{SCE}$ for the test conditions and duration.

\section{FUTURE PLANS}

It is planned to apply and monitor the performance of selected coatings in a pilot-scale biochemical operating plant set up at BNL to permit evaluation under realistic operating cycles. Thus, the combined effects of temperature, flow, chemical and biochemical environment and thermal cycling on coating durability will be determined. Specifications for application of the best coatings on full-scale equipment will be developed. A lifecycle cost analysis of the coated processing equipment will be conducted for use in the overall economic evaluation of the biochemical treatment process.

\section{INDUSTRY INTEREST}

\section{Organization}

CET Environmental

CalEnergy

\section{Type and Extent of Interest}

Operation of full scale biochemical process for treating wastes

End-user of biochemical process 


\section{REFERENCES}

M.L. Allan, C.C. Berndt, J.A. Brogan and D. Otterson, Thermal Sprayed Polymer Coatings for Corrosion Protection in a Biochemical Treatment Process, International Thermal Spray Conference, Nice, France (in press).

M.L. Allan, Coatings for Protection of Equipment for Biochemical Processing of Geothermal Residues: Progress Report FY 97 (in press).

E.T. Premuzic, M.S. Lin , H. Lian and R.P. Miltenberger, Geothermal Brines and Sludges: A New Resource, Geothermal Resources Council Transactions, 19, 77-80, 1995. 


\title{
THERMALLY CONDUCTIVE CEMENTITIOUS GROUTS FOR GEOTHERMAL HEAT PUMPS
}

\author{
M.L. Allan \\ Brookhaven National Laboratory
}

\section{KEY WORDS}

Geothermal heat pumps, cementitious grouts, backfill, ground heat exchanger, thermal conductivity

\section{PROJECT BACKGROUND AND STATUS}

Ground heat exchangers used with geothermal heat pumps (GHPs) rely on a backfill material to provide heat transfer between the polyethylene U-tube and surrounding formation. Critical properties of the backfill grout are thermal conductivity, cost, ease of placement, impermeability, shrinkage resistance, bonding to U-tube and formation, and durability. By increasing the thermal conductivity of the grouting material the required length of the heat exchanger can be decreased and this results in decreased installation costs in addition to improved GHP performance. Bentonite grouts are typically used to backfill vertically-oriented heat exchangers. However, appropriately designed cementitious grouts offer potentially superior performance compared with bentonites, particularly in arid conditions.

In FY 97 Brookhaven National Laboratory initiated research to develop high thermal conductivity cementitious grouts for geothermal heat pumps. This rescarch is focused on cement-silica sand grouts. The effects of sand gradation and proportion on properties such as thermal conductivity, permeability, shrinkage, coefficient of thermal expansion, bond strength, leach resistance and durability have been investigated. It is intended to conduct a field trial in FY 98 to evaluate the developed grout under realistic working conditions, further examine bonding between grout, U-tube and surrounding formation and investigate nondestructive methods for detecting loss of bonding in any grouting material.

\section{PROJECT OBJECTIVES}

The objective is to develop a low cost, thermally conductive cementitious grout that will result in decreased bore length requirements, decreased GHP installation costs and improved GHP performance.

\section{Technical Objectives}

- Increase thermal conductivity of grout so that bore length can be reduced significantly.

- Specify grout mix proportions, materials and mixing procedure for thermally conductive cementitious grouts.

- Perform cost analysis of using thermally conductive cementitious grouts.

\section{Expected Outcomes}

- Reduced first cost installation of GHPs. 
- Improved heat transfer behaviour, particularly in dry conditions.

- Enhanced GHP performance and marketability.

\section{APPROACH}

Initial laboratory research has investigated the pertinent properties of a range of different cement-sand grouts. This has enabled quantitative characterization of grouts and increased understanding of material behaviour. Means of increasing the sand proportion in the grout while maintaining pumpability has been investigated so that thermal conductivity can be maximized. Candidate grouts have been subjected to a variety of tests. These include: thermal conductivity, effect of drying on thermal conductivity, permeability, shrinkage, bond strength, environmental impact, durability and coefficient of thermal expansion.

Independent cost analysis of the developed grouts is being undertaken by the University of Alabama. In addition, the University of Alabama will calculate the reduction in heat exchanger design length and resultant cost savings of using the cement-sand grouts compared with conventional grouts.

\section{RESEARCH RESULTS}

Thermal conductivities between 2.4 and $2.8 \mathrm{~W} / \mathrm{m} . \mathrm{K}$ have been achieved, depending on sand type, content and water/cement ratio. This compares with 0.84 and $0.80 \mathrm{~W} / \mathrm{m} . \mathrm{K}$. for neat cement grouts with water/cement ratios of 0.6 and 0.8 , respectively. Conventional high solids bentonite grout has a thermal conductivity around $0.75-0.8$ $\mathrm{W} / \mathrm{m} . \mathrm{K}$ and bentonite-sand grout can be expected to have a value around $1.46 \mathrm{~W} / \mathrm{m} . \mathrm{K}$. However, the thermal conductivity of neat cement and bentonitic grouts decreases significantly under drying conditions. The reduction in conductivity of cement-sand grouts depends on mix proportions and is typically $5-11 \%$ for the mixes of interest.

The permeability of the bulk cement-sand grouts is of the order of $10^{-10} \mathrm{~cm} / \mathrm{s}$. Permeability tests performed on grout cast around a length of polyethylene pipe showed that increased flow occurred due to a higher permeability pathway at the grout-pipe interface. The magnitude of permeability increase depended on mix proportions at it was found that grouts containing sand had values still of the order of $10^{-10} \mathrm{~cm} / \mathrm{s}$ whereas flow in neat cement grout-pipe specimens increased an order of magnitude. Mechanical bond strength was measured and it was found that the bond between neat cement grout and pipe was weak. Addition of sand to the grout improved bond strength significantly. Improved bonding was correlated with decreased shrinkage of the cement-sand grouts as compared to neat cement grouts. Shrinkage for the developed grouts depended on sand content, superplasticizer dosage and water/cement ratio. After 90 days the linear shrinkage of cement-sand grouts was typically 0.24 to $0.28 \%$, whereas neat cement grout with water/cement ratio $=0.8$ shrunk $0.59 \%$.

Leach tests showed that the developed grouts do not adversely water quality other than an increase in pH which tends to be mitigated with time. Quantities of heavy metals in the leachate were below the maximum levels stated in the EPA Drinking Water Standards. Resistance to sulphate attack of the grouts was evaluated since some groundwaters contain sulphates in concentrations that are deleterious to cementitious materials. It was determined that the potentially adverse effects of sulphates could be overcome by adding ground granulated blast furnace slag or fly ash to the grouts, or by using sulphate resistant cements (Types II and V). Wet-dry cycles demonstrated that conventional neat cement grouts are prone to severe cracking and that crack resistance is greatly improved by addition of sand. 


\section{FUTURE PLANS}

In FY 98 it is planned to conduct a field demonstration using one of the developed grouts. In-situ thermal conductivity measurements will be performed and compared with laboratory data. Heat pump performance will be monitored over heating and cooling seasons. The field demonstration will enable quantitative comparison of the selected cement-sand grout with conventional grouts under actual working conditions. Specifications for mixing and placing the grouts and technology transfer to the GHP industry will be undertaken. Further studies of bonding of cementitious grouts to U-tube and surrounding formation will be conducted. Analysis will be performed to determine the effect of imperfect bonding/thermal coupling on heat transfer. This analysis will be applicable to all types grouts. The potential for using nondestructive techniques to verify adequate bonding will be investigated.

\section{INDUSTRY INTEREST}

Potential for marketing the developed grout in prepackaged form exists.

\section{REFERENCES}

M.L. Allan and S.P. Kavanaugh, Thermal Conductivity of Cementitious Grouts and Heat Exchanger Length Design for Geothermal Heat Pumps, submitted to Int. J. of HVAC\&R Research, 1997.

M.L. Allan, Thermally Conductive Cementitious Grouts for Geothermal Heat Pumps: Progress Report FY 97, in preparation. 


\title{
ADVANCED BIOCHEMICAL PROCESSES FOR GEOTHERMAL BRINES
}

\author{
Eugene T. Premuzic \\ Brookhaven National Laboratory
}

\section{KEY WORDS}

biochemical processing, decontamination, metal recovery, production of silica

\section{PROJECT BACKGROUND AND STATUS}

Experimental data generated in an R\&D program, established at Brookhaven National Laboratory (BNL), to identify methods for the utilization and low cost environmentally acceptable disposal of toxic geothermal residues, have shown that a biochemical process would meet the cost requirements and produce environmentally acceptable end-products. Insoluble chemical species of toxic metals including radionuclides found in geothermal residual brine sludges can be converted into soluble species which may be re-injected into existing wells or concentrated and re-processed. To accomplish this, several unique biocatalysts have been identified which make possible the biochemical conversion of geothermal brines and sludges. The biocatalysts properties are due to biochemical activities of specific microorganisms which have served as models for the development of technically and economically feasible detoxification processes leading to advanced biochemical technology for geothermal waste treatment. The new technology reduces significantly the cost of surface disposal of sludges derived from geothermal brines. Concurrent processes for the concentration and recovery of valuable metals and salts are also being developed. Currently, the process removes better than $80 \%$ of total metal concentration in less than eight hours. The solid residue from this treatment can be subjected to a secondary treatment leading to de-pigmented high grade silica. The aqueous product from the primary process can be used for metal recovery. Economic and regulatory significance of the new technology is clearly defined by the following information.

\section{PROJECT OBJECTIVES}

\section{Technical Objectives}

- Solubilize, separate, and remove environmentally regulated constituents of geothermal sludges and brines.

- Produce a treated sludge which may be used as a feedstock for the production of revenue generating materials, for example high grade amorphous silica.

- Recover economically valuable trace metals and salts. The residues from such processing can be reinjected and/or converted to highly reduced volumes for disposal in the conventional manner.

\section{Expected Outcomes}

- Recent data generated at the laboratory pilot scale level show that a combined biochemical and chemical process is efficient and generates commercially attractive products and recyclable by-products.

- The data also indicate that further cost reduction is feasible. This will greatly enhance the rate at which U.S. geothermal resources are developed. 
- Conversion of geothermal sludges and brines into environmentally acceptable materials such as fillers, together with the metal salts recovery options, offsets the costs of initial investments associated with the installation of the biochemical processing plant(s).

- Integration of the biochemical processing recovery and recycling options into geothermal power producing plants, leads to a financial net gain with a concurrent satisfaction of regulatory requirements. This concept is illustrated by the examples given in Table 1, where high salinity geothermal sludges are converted to fillers.

\section{APPROACH}

- The experimental strategy is based on biochemical dissolution and concentration of toxic and valuable metals present in geothermal residues. Thus, the produced solution containing toxic and valuable metals can be reinjected or pooled with bulk brines and be used for concentration and recovery of metals and salts. In the recovery mode, both chemical and biochemical methods are being developed.

- Technical and economic feasibility of converting geothermal wastes from hazardous to non-hazardous wastes has been demonstrated. Laboratory-scale studies have shown that the new biochemical technology is versatile and is applicable to a variety of geothermal sludges containing few or many metals, including radionuclides such as radium, whose concentrations may exceed limiting threshold values as recommended by regulatory agencies. Metals such as chromium, copper, manganese, and others, can be removed with 80-90\% efficiencies.

- Residues from the biochemical processing are further treated and converted to a high grade silica product.

- Laboratory-scale pilot plant has been constructed and is being used for the optimization of processes used in the emerging biochemical technology. The data generated in these studies serve as a basis for the design of full scale processing scenarios and projections for field applications.

- Joint R\&D effort with CalEnergy for the development of field testing facilities is currently being renegotiated. The new joint effort will involve teams from BNL and CALEN to work at each others facilities leading to the optimization of the field efforts.

- Cooperative research and development agreement is in place between CET Environmental Inc. and BNL to jointly construct a field facility and test the BNL biochemical process at the Geysers area and elsewhere. The BNL/CET process is applicable in any of the industrial streams where the Stratford and/or a similar hydrogen sulfide abutment process is used.

- Educational and collaborative programs with academic institutions, e.g., Howard University, Washington, DC and Polytechnic University, New York, NY, assist in R\&D efforts and generate new graduate programs which enhance the Geothermal Science and Technology accomplishments.

\section{RESEARCH RESULTS}

CalEnergy is proceeding with the design and construction of progressively scaled-up (to $3000 \mathrm{lb} / \mathrm{h}$ ) plants for the processing of geothermal brines and sludges. BNL's team will assist by constructing a small $(\sim 3 \mathrm{lb} / \mathrm{h})$ laboratory plant. The system will include production of biocatalyst, multistep geosludge processing units and interfacing, leading to the commercial production of silica. 
The efforts to simplify ABPGB processes for high and low salinity brines have been intensified. Particular attention is being given to the use of a single biocatalyst, recycling and the maximum utilization of available materials (e.g., chemicals) and facilities.

The BNL laboratory pilot plant for silica production is now fully operative, producing $0.8-1.0 \mathrm{Kg}$ per run of high quality amorphous silica. The process at present is semicontinuous. We are working on a design for a continuous process which should be analogous to the larger scale process being developed by CalEnergy.

At CalEnergy's request we have sent a liquid sample of our biocatalyst to Calipatria. This has been done under our Confidentiality Agreement, however, against our advice. Biocatalyst handling and subsequent application and processing is a specialized and carefully controlled process which requires unique expertise. Testing and processing of the liquid sample without the appropriate expertise failed.

The amorphous silica production plant requires a continuous supply of the biocatalyst. Logistics for a steady production of the biocatalyst will have to be worked out. In a continuous process in which geothermal sludge is converted to amorphous silica, the total processing time (biochemical/chemical) is fast (hours), while the production of biocatalyst is slow (2-3 weeks). Therefore, a separate plant and holding facilities for the production of biocatalyst are essential. The output from these plans must be timed in such a manner that it satisfies the hourly demand of the amorphous silica production facility. For example, the $2 \mathrm{lb} / \mathrm{h}$ plant being considered as the first test requires the following: A $40 \%$ loading of sludge to liquid needs 0.6 gallons ( 2.3 liters) of biocatalyst at a concentration of $1 \times 10^{7} / \mathrm{ml}$. This volume of biocatalyst would be required for each hour of continuous production. Thus, a 24 hours operation needs 54.2 liters of biocatalyst preparation at the same concentration.

BNL has won the National Award for Environmental Sustainability for its "Advanced Biochemical Process for Geothermal Brines" in 1997. BNL has been granted a "Certificate of Environmental Achievement" and the ABPGB program is recognized in the Renew America 1997 Environmental Success Index.

Comparative economic studies for the use of multiple and single biocatalyst completed. A single biocatalyst and the use of a co-produced reagent has been recommended. The economic studies encompass silica production and the recovery of valuable metals.

Refinement of the sulfur recovery technology currently addresses the variations in temperature and pressure range. The cost-efficiency and economic analysis strategies are being defined.

\section{FUTURE PLANS}

- Optimize the semi-continuous sludge to silica process.

- Further investigate and define the silica depigmentation process.

- Initiate construction of biocatalyst production miniplant at a 1/10 scale of the FY 1997 projection.

- Construct a laboratory version of the BNL/CET plant that serves as an R\&D model for field operations.

- Cost-efficiency studies dealing with different sorbants will be initiated.

- Expand CET Environmental Services, Inc. and BNL efforts in identification of broader applications of the sulfur treatment process.

- Collaboration with CalEnergy will be expanded to field experimentation and joint R\&D effort for the construction and operation of silica processing plants.

- Continue tests of suitable materials for coating and/or construction of corrosion resistant reactor vessels and accessory equipment.

- Expand the data base essential for pilot/field scale designs. Include field input. 
- Continue "Quality Control" effort as per Salton Sea experience.

INDUSTRY INTEREST

Organization

CalEnergy

CET Environmental Services

\section{Type and Extent of Interest}

One on one collaborative effort. BNL assists the industry in their analytical needs and laboratory scale technical studies. The industry consults and exchanges materials and information. Field trials of a prototype biochemical process are currently being planned at a CalEnergy site.

CET is scaling up a modified version of BNL's biochemical process specifically geared to the type of wastes generated by the Geysers types of operations and similar $\mathrm{H}_{25}$ abatement technologies.

\section{REFERENCES}

Premuzic, E.T., Lin, M.S., Jin, J.Z, and Hamilton, K. Geothermal waste treatment biotechnology. Proceedings of the World Geothermal Congress 1995, 4, 2769-2772; Energy Sources, 19:9-17, 1997.

Premuzic, E.T., Lin, M.S., and Lian, L.H. Recent advances in biochemical technology for the processing of geothermal byproducts. Proceedings of the U.S. Department of Energy Geothermal Program Review XIV, April 8-10, 1996, Berkeley, California.

Premuzic, E.T., Lin, M.S., Lian, H., and Miltenberger, R.P. Geothermal brines and sludges: A new resource. Proceedings of the Fourth International Symposium and Environmental Issues and Waste Management, October 7-11, 1996, Cagliari, IT, pp. 1019-1025, in SWEMP, Vol. 2, Ed. R. Ciccu, DIGITA, Cagliari, Italy 1996.

Premuzic, E.T., Lin, M.S., and Bohenek, M. Advanced biochemical processes for geothermal brines--current developments. Proceedings of the U.S. Department of Energy Geothermal Program Review 15, March 25-26, 1997, San Francisco, CA.

Premuzic, E.T., Lin, M.S., Bohenek, M., Bajsarowicz, V., and McCloud, M. Advanced biochemical process for geothermal brines--current developments. Geothermal resources council transactions, Volume 20. 1997, pp. 1-5.

\section{Patents}

Premuzic, E.T. Biochemical Solubilization of Metals from Residual Geothermal Brines and Sludges. U.S. Patent No. 5,366,891 (1994).

Premuzic, E.T. and Lin, M.S. Conversion of Geothermal Brines and Sludges to Commercial Products, pending. 


\title{
GEOTHERMAL BIOCORROSION
}

\author{
P. A. Pryfogle \\ Idaho National Engineering and Environmental Laboratory
}

\section{KEY WORDS}

geothermal biocorrosion, microbially-influenced corrosion, corrosion measurements

\section{PROJECT BACKGROUND AND STATUS}

This work focuses on an investigation of microbially-induced corrosion (MIC) in geothermal power facilities. Corrosion is of particular concern in these systems due to the harsh conditions at which they operate. MIC has occurred in some systems, including the tube sheets in the condensers, as illustrated in Figures 1 and 2. Materials from the tube sheets have been analyzed and found to contain sulfur and nitrogen-reducing bacteria. Generally, any systems which are not drained are vulnerable to MIC, including condensers, lube oil coolers, fire lines and water boxes. In addition to the cost of repairing or replacing components and the associated shut-down costs, a considerable amount of money is spent on the purchase of corrosion control products. It is estimated that on the order of $100 \mathrm{~K} /$ year is expended on products for controlling MIC at some plant sites. The inability to efficiently control this type of corrosion also results in the use of more expensive alloys in the critical subsystems of some plants.

The technical goals of this effort are to develop a more detailed understanding of the development and extent of MIC at geothermal facilities. A particular difficulty in the assessment and control of this type of corrosion is related to the inability to distinguish damage caused by micro-organisms from that produced by direct chemical means. In particular, there are no reliable on-line techniques to recognize and predict the on-set of MIC. Currently, treatments are applied at plants either on an as needed basis corresponding to the evidence of microbial growth, or on a predefined schedule. As a result, there is potential for over- or under-treatment of the problem. This effort is evaluating analytical techniques to estimate and partition corrosion between microbial and other sources; and in addition, is examining the feasibility of using these techniques in the development of diagnostic tools to measure and sample biofouling in-situ in critical components. The ultimate goal of the work is to support the geothermal industry in identifying the most economical methods to prevent corrosion.

Since the start of the project in March 1997, a baseline characterization of microbial diversity at The Geysers has been initiated. This effort examines spatial and temporal differences in microbial communities from geothermal process fluids. In addition, water, sludge and biofilm samples have been collected from sites throughout the field and examined using a variety of analytical techniques to determine their chemical compositions and the physiological activity of the microorganisms. Metal coupon samples have also been deployed at various geothermal facilities and are being examined for biofilm development and the presence of corrosion products. Experiments have been designed to evaluate the biotic/abiotic partitioning of corrosive activity using native bacteria and geothermal fluids obtained from the field.

\section{PROJECT OBJECTIVES}

The objective of this project is to investigate the role MIC plays in the corrosion of critical components in geothermal power plants. This investigation involves the integration of established sampling and analysis 
procedures with new analytical techniques to predict the on-set and severity of MIC in plant subsystems. This data will be used to more accurately determine the benefit of various treatment alternatives.

\section{Technical Objectives}

- Perform baseline characterization of geothermal ficlds to determine microbial densities and metabolic diversity, and perform baseline chemical analyses to evaluate nutrient availability for microbial growth and chemical corrosion potential.

- Design and conduct abiotic/biotic partitioning experiments in the laboratory using field samples.

- Adapt these techniques into a plant monitoring capability.

\section{Expected Outcomes}

- Cross field characterization of chemical and microbial activity

- Techniques to partition and estimate the contribution of MIC to plant corrosion

- Development of more efficient and cost-effective treatment alternatives

\section{APPROACH}

Investigations are being performed on both biofilm samples exposed at the facilities and materials isolated and cultured in the laboratory. Using native bacteria and geothermal fluids in a modified electrochemical apparatus, known as a Brenda Little cell, biofilms are being cultured and studied under controlled conditions. The cell is configured with two compartments, each containing a metal coupon of the same composition as those found in geothermal systems. One half of the apparatus is kept sterile, while the other is inoculated with microorganisms from the geothermal field. An external circuit is completed between the two coupons using a zero resistance ammeter or potent-iostat, while the internal contact is maintained through a semi-permeable membrane. Biological interactions with the metal substrate are then detected as a current under short-circuit conditions, since no current will flow if both cells are maintained under sterile conditions. This device can be used to determine the partitioning between microbial and chemical corrosion.

In addition to these experiments, a number of chemical analyses, incorporating techniques such as auger electron spectroscopy (AES), Raman, secondary ion mass spectroscopy (SIMS), X-ray photoelectron spectroscopy (XPS), and confocal microscopy are being used to examine surfaces, analyze biofilms, and identify corrosion precursors and by-products.

\section{RESEARCH RESULTS}

The condensers (Figure 1) in the power plant operations were considered by all contacts in the field as a common place for slime and MIC problems (Figure 2). Therefore, initial investigations involved the collection of samples from fluids going into the condenser and the heated waters leaving the condensers after flowing through the tube sheets. These water circulation points have also been used to conduct corrosion coupon studies at each of the power plant sites. In addition to weight loss and pit formation measurements, these metal coupons are examined under scanning electron microscopy (SEM, Figure 3), phase and confocal microscopies to characterize surface 
conditions on these exposed materials. Figure 3 shows film and particulate material that has been deposited on the surface of a 316 stainless steel (SS) coupon from The Geysers.

Studies have also begun to characterize the microbial populations at The Geysers. The procedure of Most Probable Number (MPN) has been used with 4-selective medias to determine the relative cell densities at selected power plant operations. The medias are selective for either heterotrophic, denitrifying, sulfate reducing, or acid producing bacteria. Growth in these types of media represent a metabolic capability of the microbial population which is indicative of corrosion potential. When relative numbers are equal to or greater that $10^{6} \mathrm{cells} / \mathrm{mL}$, there is some concern for potential corrosion problems. Figure 4 compares the relative densities of samples collected in summer to those during a fall collection. In most cases, the numbers of heterotrophic, denitrifying, and acid producing bacteria increased in the fall sampling while the sulfate reducing bacteria numbers decreased in comparison to the summer sampling date. This data, coupled with chemical analyses from process water, sludge and coupon samples, are being studied for systematic variations that can be exploited in predictive monitoring methods for MIC.

\section{FUTURE PLANS}

The sampling and analysis work will continue and be incorporated into a database that will allow trend data on MIC to be extracted. Several analyses are also planned to determine their applicability in partitioning the chemical and microbial contributions to corrosion. These include electrochemical, organic acid and isotopic techniques. Design modifications and operational protocols for using the Brenda Little cell apparatus as an inplant monitoring system will also be investigated.

\section{INDUSTRY INTEREST}

PG\&E, CALPINE AND NCPA have expressed an interest in the technology as a potential means of reducing the cost of biological control agents by instituting predictive or on-line feedback, and also in the possibility of using less expensive alloys in some subsystems if improved control techniques can be identified.

\section{REFERENCES}

S. M. Gerchakov, B. J. Little, and P. Wagner, AProbing Microbiologically-Induced Corrosione, Corrosion 42 , 689 (1986).

H. A. Videla, Manual of Biocorrosion, CRC Lewis Publishers, Boca Ratan, Florida, 1996. 


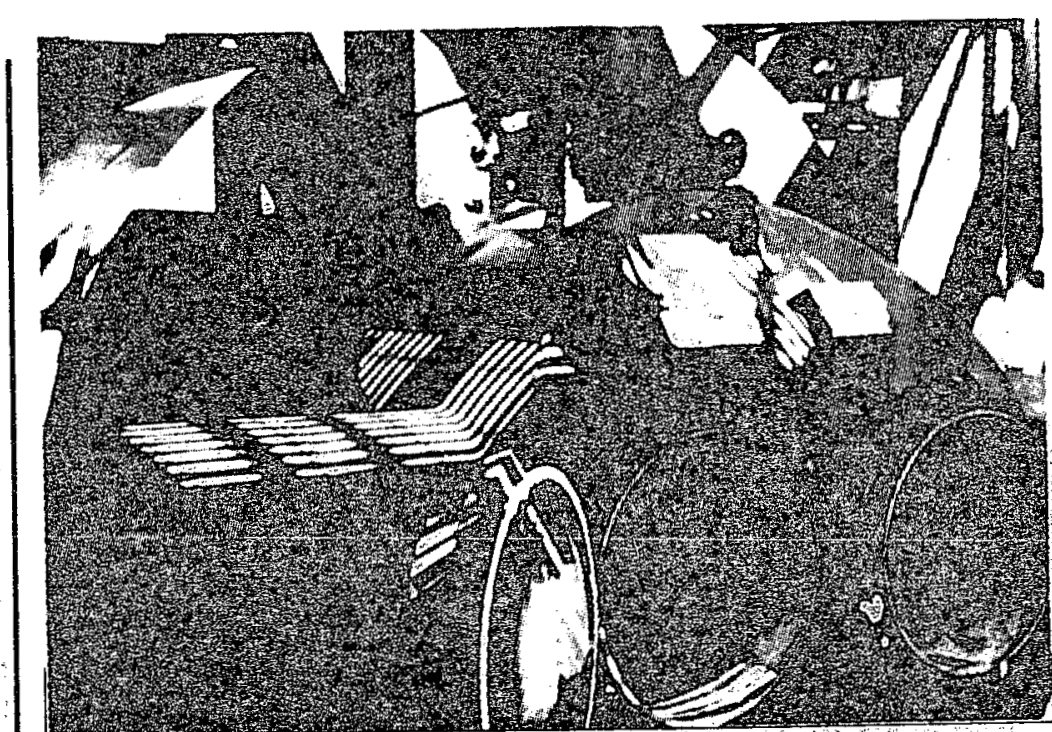

Figure 1. Condenser.

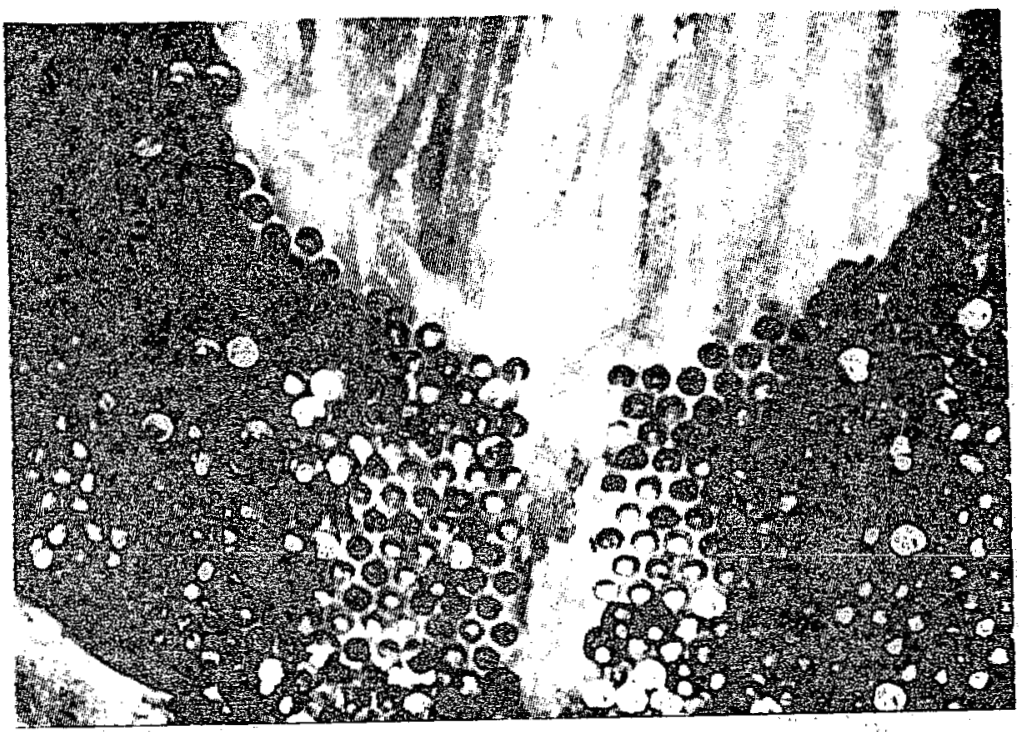

Figure 2. Tube sheet structural corrosion.

$\ddot{n}$

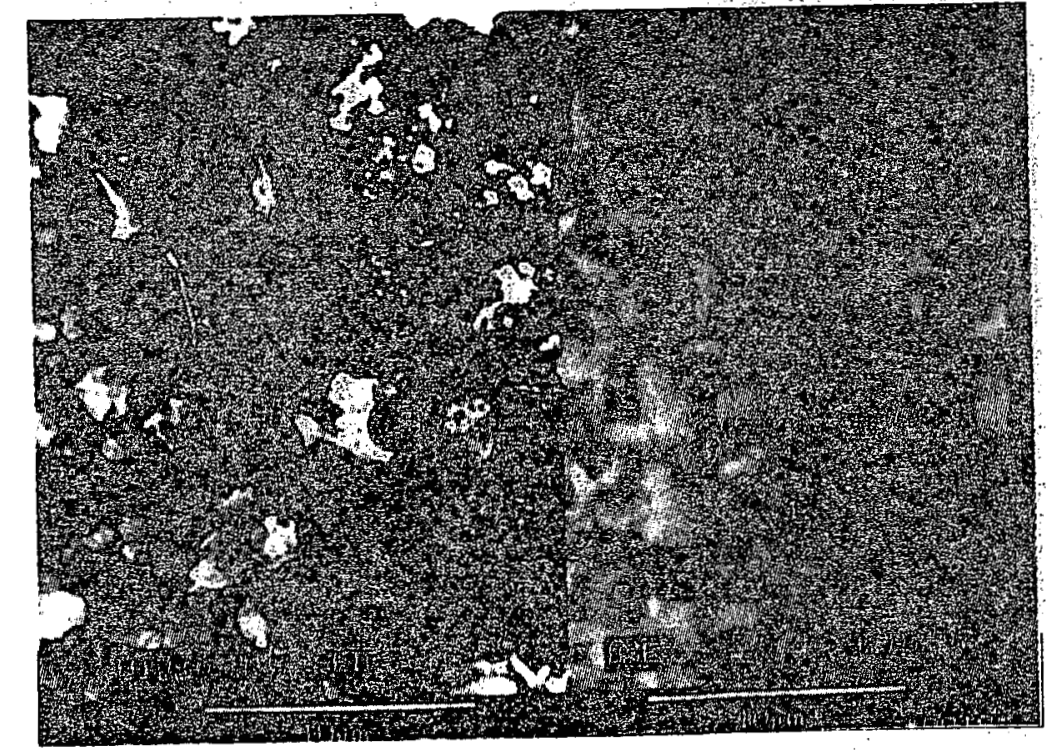

Figure 3. Scanning electron Micrograph (SEM) of biofilm development on metal coupon. 


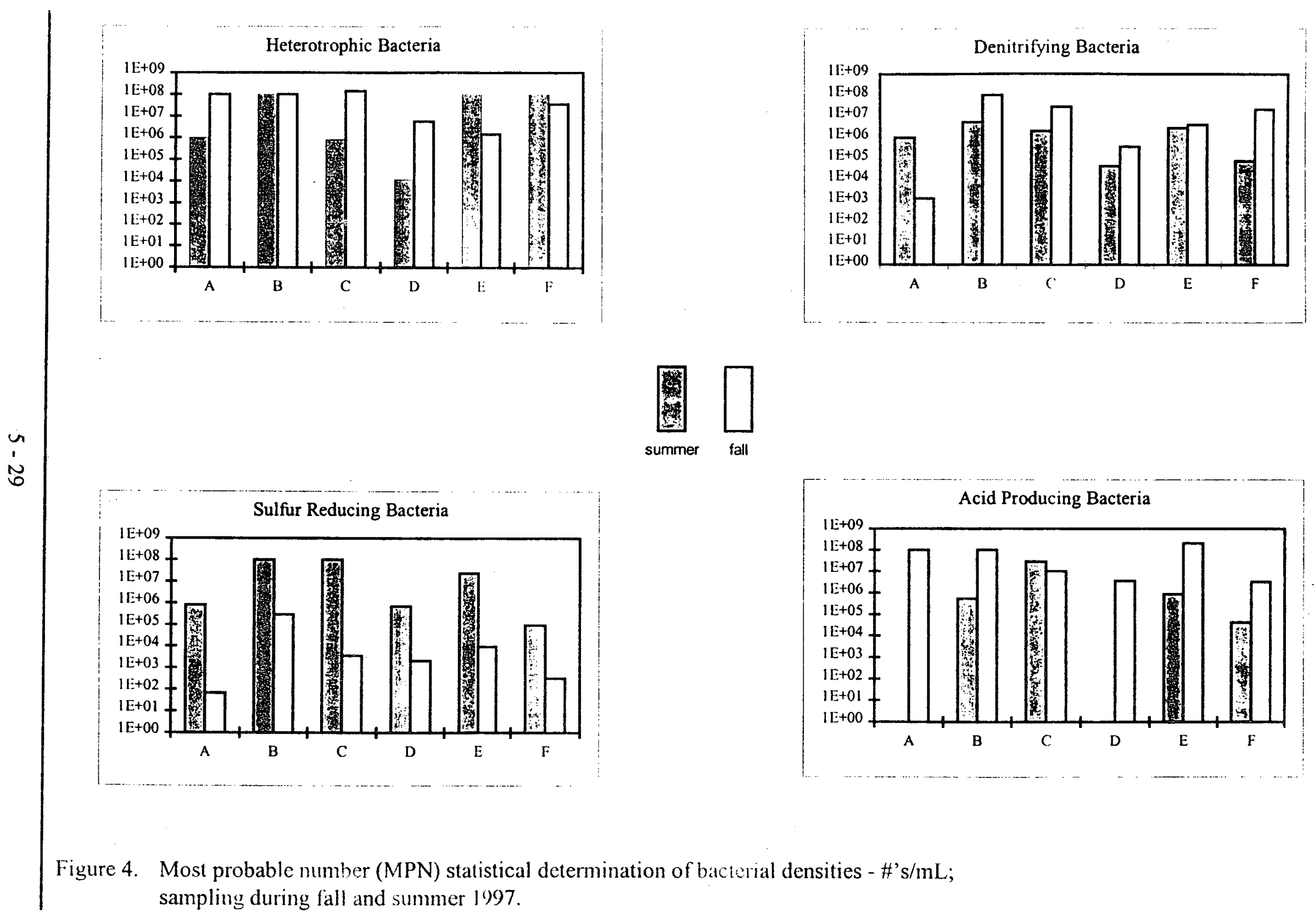




\title{
IMPROVEMENTS IN BINARY CYCLE PERFORMANCE SUPERSATURATED TURBINE EXPANSION
}

\author{
G. L. Mines \\ Idaho National Engineering and Environmental Laboratory (INEEL)
}

\section{KEY WORDS}

binary power cycles, turbines, supersaturated expansion, metastable turbine expansion

\section{PROJECT BACKGROUND AND STATUS}

Since the early 1980's the INEEL's Heat Cycle Research project has been developing technologies that support development of the nation's hydrothermal resources considered marginally feasible for electrical power production. The technologies developed allow the energy in the hydrothermal resource to be more efficiently converted into electrical power. The more efficient cycle typically results in lower power generation costs.

An INEEL study showed that the brine utilization (net power produced per unit mass flow of brine) of a supercritical binary cycle increases by $\sim 8 \%$ when the turbine inlet state points are modified to allow expansion in the turbine to "pass through" the two-phase region. This type of expansion is avoided in commercial binary plants because condensate could form in the expanding vapor causing erosional damage to the turbine, adversely affecting performance. Initial investigation of these metastable expansions confirmed they support a supersaturated vapor and did not affect turbine performance. However, these investigations were limited in duration and did not adequately resolve whether these expansions would adversely affect performance and/or damage the turbine over an extended period of operation.

This issue was addressed in an investigation conducted at Mammoth-Pacific Limited Partnership's MPI-100 facility where the turbine operated from November 1995 until May 1997 at inlet conditions producing metastable, supersaturated expansion. During this period the turbine performance was monitored with time to identify any degradation in efficiency. At the conclusion of the investigation the turbine was examined to determine whether there was any abnormal damage that could be attributed to operating in this mode. The Mammoth investigation showed that supersaturated turbine expansion could be utilized at an existing plant, and identified the conditions under which it could improve the performance in such an instance.

\section{PROJECT OBJECTIVES}

The investigation of the irappact of metastable, supersaturated expansion is to establish a mode of operation that will increase the amount of power that can be produced from a given brine flow. This is to be accomplished without damaging the turbine or adversely affecting its performance.

\section{Technical Objectives}

- Determine the degree of supersaturation or moisture content tolerated in the binary cycle turbine expansion without degrading efficiency or damaging the turbine components.

- Identify modifications necessary to maximize the performance gain when utilizing these expansions in an existing turbine. 


\section{Expected Outcomes}

- The metastable expansion of an isobutane working fluid through the two-phase region supports a supersaturated vapor and proceeds without adversely affecting turbine performance or damaging the turbine.

- Supersaturated, metastable turbine expansions increase the brine utilization by up to $\sim 8 \%$ in binary plants designed for their use.

- Metastable, turbine expansion can be utilized to improve the performance of an existing binary plant (not designed for operation with these expansions).

\section{APPROACH}

Field investigations have been used to validate the assumptions and conclusions from the analytical studies that identified the performance gain possible from using the metastable, supersaturated turbine expansion. Testing was conducted at bench scale and prototype levels to establish that the turbine expansion of interest supported a supersaturated vapor, and to determine the conditions that adversely affected turbine performance. The initial testing was conducted at supercritical inlet pressures with both pure (isobutane) and mixed (isobutane, hexane) working fluids. This duplicated the conditions for which the cycle performance improvements were projected.

To determine how this expansion would affect a turbine after an extended period of operation, an agreement was reached with Mammoth Pacific Limited Partnership (MPLP) to operate its MPI-100 turbine with the metastable expansion for a period of six months or more. Prior to initiating operation with the metastable expansion, a new rotor and set of vanes were installed in the turbine. The pretest-test condition of the components was established along with the turbine performance at normal operating conditions. Inlet conditions were then adjusted to provide the desired degree of supersaturation in the vapor expanding through the turbine. Except for abnormal periods of operation, these conditions were maintained for the duration of the test. The turbine performance was monitored to identify any degradation in efficiency with time. At the conclusion of the test, the turbine components were examined for any unusual wear or erosion.

At each phase of the investigation, industry has commented on the results and plans for subsequent phases of the investigation. As results have shown the potential benefit of operating with these expansions, turbine manufacturers, plant operators, and engineering-design firms have provided materials and services (in-kind contributions). This investigation is expected to culminate with the incorporation of the metastable turbine expansion into the operation of a commercial power plant, at the initiative of the plant operator.

\section{RESEARCH RESULTS}

In testing at the Heat Cycle Research Facility (HCRF) a supersaturated vapor was supported up to equilibrium moisture levels of $5 \%$ to $6 \%$ during the ideal expansion of isobutane though a converging-diverging nozzle. The turbines tested at the HCRF tolerated moisture in their expansions without degradation in efficiency; at maximum equilibrium moisture levels of $\sim 25 \%$ in the impulse turbine, and of $\sim 15 \%$ in the radial inflow turbine. Operating with the metastable expansion did not damage the turbines, however neither was tested for more than 200 hours.

An agreement was reached with MPLP that allowed its MPI-100 binary plant turbine to be operated with metastable expansion. In November 1995, a new turbine rotor and set of vanes were installed in the MPI-100 facility turbine, and operation resumed with the turbine inlet conditions adjusted to allow the expanding isobutane 
vapor to pass through the two-phase region producing the desired metastable, supersaturated expansion. The turbine inlet conditions during the HCRF and Mammoth investigation are shown on the temperature-entropy ( $T$-s) plot in Figure 1. Inlet conditions during a test of the HCRF impulse turbine are shown, along with the nominal operating conditions for the MPI-100 turbine and the modified conditions for the extended investigation. The dashed constant entropy lines depict an ideal expansion process in the turbine (the isobutane expansion through the turbine nozzles approaches this ideal process). As implied in Figure 1, the testing at the HCRF was conducted at supercritical pressures. The MPI- 100 turbine nominal design condition is $290^{\circ} \mathrm{F}$ and 500 psia. Prior to starting the metastable investigation, the MPI- 100 unit was operating at inlet conditions of $218^{\circ} \mathrm{F}$ and 275 psia.

The fixed equipment performance and brine conditions at the MPI-100 facility necessitated conducting the extended test at a sub-critical inlet pressure; vapor flow was throttled with the turbine vanes to raise the inlet pressure above 450 psia. The superheat entering the turbine was limited to $\sim 1^{\circ} \mathrm{F}$ to produce the desired levels of supersaturation in the expansion. Periodically MPLP modified the turbine inlet conditions to increase the nominal equilibrium moisture content in the isobutane as it expanded through the turbine. By the conclusion of the investigation, the equilibrium moisture levels in the turbine expansion were equivalent to those that produced condensate formation in the HCRF nozzle tests.

The MPI-100 turbine operated with metastable expansion through May 1997 without any measured degradation in efficiency. The efficiency varied as the turbine exhaust pressure changed in response to variations in the ambient air temperature. Because the efficiency variation is significant (up to 20 percentage points), investigators looked at changes in efficiency with time at similar air temperatures. In Figure 2, efficiency data during different months of the investigation are plotted as a function of the air temperature. Although there is some scatter in the data at a given air temperature there does not appear to be any trend with time, indicating no adverse effect from operating with metastable expansion. The efficiency during May 1997 overlies the performance data during the first few months of operation

In May 1997, the MPI-100 turbine shut down for maintenance. At that time a visual inspection of the turbine rotor and vanes was made. This inspection did not reveal any abnormal wear on or erosion of the surfaces exposed to the isobutane vapor in the turbine. The erosion found on component surfaces was typical of what MPLP personnel had observed in turbines after equivalent periods of operation. (MPLP has 8 turbines at it Mammoth facilities; all of them have had the rotors replaced at least once.) Based upon results of this inspection and plant performance during the extended investigation, MPLP began examining the feasibility of extending the use of metastable expansion to an additional facility.

Mammoth's MPI facility consists of two identical, independently operated binary power plants. While the MPI100 operated with metastable expansion, the MPI-200 plant operated with the vapor entering the turbine superheated sufficiently to assure the subsequent expansion remained completely outside the two-phase region. During the extended investigation, a $9 \%$ to $13 \%$ increase in power generation from the MPI-100 unit relative to the MPI-200 unit could be attributed to operation with the metastable; supersaturated expansion. Over the period the investigation was carried out, the MPI- 100 unit generated $\sim 4,000,000$ more KW-hrs than the MPI-200 plant.

\section{FUTURE PLANS}

Mammoth-Pacific is currently preparing to extend the use of metastable turbine expansion to its MPII facility. This decision was finalized when the visual examination of the turbine components showed no damage attributable due to using the metastable, supersaturated expansion. INEEL investigators are working with Mammoth personnel to identify changes to the control system to assure the vapor entering the turbine remains 
completely dry. In return for the assistance provided, Mammoth will provide the INEEL with operating data once the MPII facility begins operation with the metastable expansion.

INEEL investigators are examining the feasibility of using metastable turbine expansion at other opcrating facilities. The work at Mammoth has shown that these expansions can be applied to an existing plant operating at subcritical turbine inlet pressures if the plant is operating with a declining resource. The examination of the feasibility of altering the design of an existing turbine to increase the benefit of using this expansion continues. Project investigators are also examining methods of identifying when condensate is present in the vapor as it expands through the turbine.

\section{INDUSTRY INTEREST}

\section{Organization}

Barber-Nichols, Inc

Rotoflow Corp., Inc.

Ben Holt Co.

Mammoth Pacific LP

\section{Type and Extent of Interest}

Turbine manufacturer and engineering firm: assisted with the turbine testing and data evaluation at the HCRF.

Turbine manufacturer: provided equipment for the reaction turbine testing at the HCRF; provided review and comment on HCRF investigations; assisted the project in soliciting interest from geothermal plant operators for the extended test; manufacturers the turbines used by MPLP.

Engineering firm: provided review and comment on HCRF investigations; assisted the project in soliciting interest from geothermal plant operators for the extended test; provide engineering services to MPLP during the extended operation test.

Binary plant operator: made its MP-100 plant available for the extended operation with supersaturated turbine expansion; providing operational and maintenance personnel for activity at no cost; foregoing any lost revenues during shutdowns and testing

\section{REFERENCES}

Demuth, O. J., Preliminary Assessment of Condensation Behavior for Hydrocarbon Vapor Expansions Which Cross the Saturation Line Near the Critical Point, EGG-GTH-5960, July 1982.

Goswami, D. Y., Hingorani, S., and Mines, G. L., "A Laser Based Technique for Particle Sizing to Study Two Phase Expansion in Turbines", ASME Paper reprinted from Solar Engineering, Book No. H00630, 1991.

Mines, G. L., "Investigations of the Condensation Behavior of Supersaturated Turbine Expansions", Geothermal Program Review XI, April 1993, Berkeley, California, pp. 127-131.

Mines, G. L., "Field Investigations Examining the Impact of Supersaturated Vapor Expansions on Turbine Performance", Geothermal Program Review XII, April 1994, San Francisco, California, pp. 111-118. 
Hunt, J. W. and Nichols, K. E., Turbine Performance Evaluation with Supercritical Isobutane, Hexant Mixtures Expanded Through the Two-Phase Region, Report Prepared for INEEL, June 1995.

Mines, G. L., "One year of Operation of Mammoth Pacific's MPI-100 Turbine with Metastable, Supersaturated Expansions", Geothermal Program Review XV, March 1997, San Francisco, California, pp. 3-51 - 3-57. 


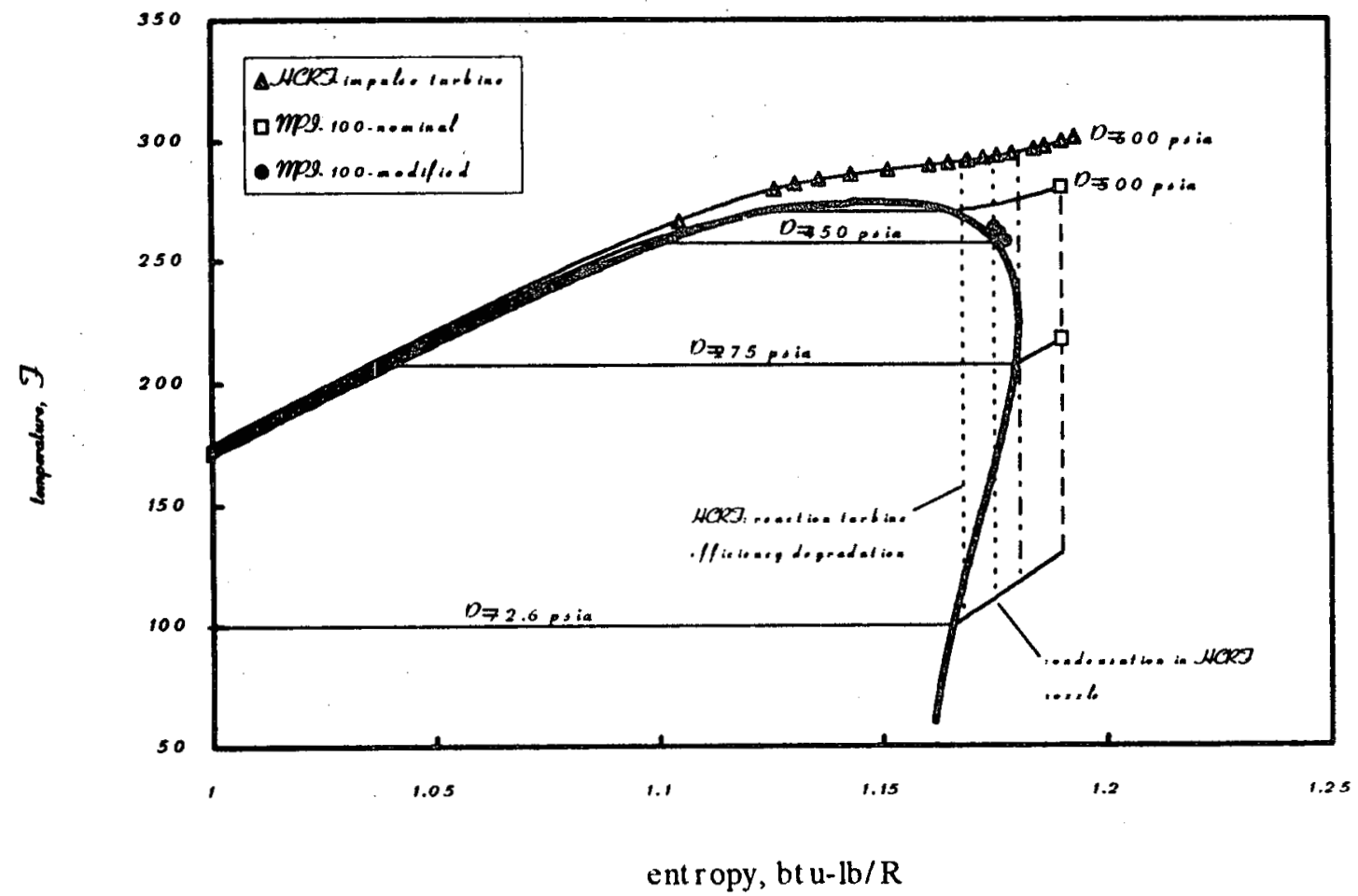

Figure 1 --Turbine Inlet Conditions During Supersaturated, Metastable Turbine Expansion Investigations

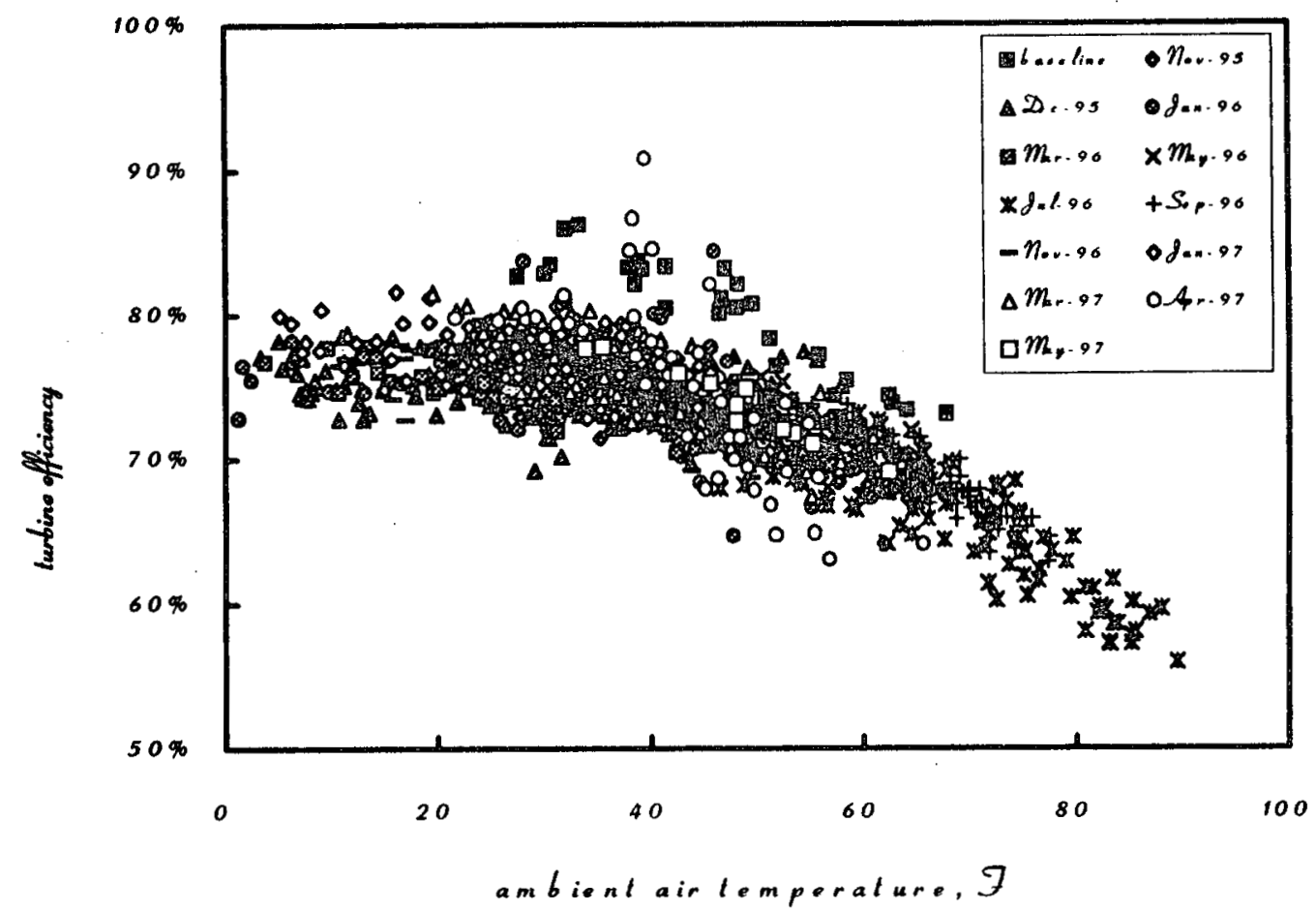

Figure 2 --MPI-100 Turbine Performance During Extended Investigation with Metastable Expansions 


\title{
BINARY CYCLE PERFORMANCE IMPROVEMENT FROM REAL-TIME PROCESS CONTROL
}

\author{
B. W. Brown, G. L. Mines, and M. M. Plum \\ Idaho National Engineering and Environmental Laboratory (INEEL)
}

\section{KEY WORDS}

binary power cycles, performance improvements, working fluid mixtures, real-time control

\section{PROJECT BACKGROUND AND STATUS}

The efficiency of a reversible system, or engine, is related to temperature difference between the heat source and heat sink. The larger the temperature difference is between the heat source and sink, the more efficient the system. In geothermal power plants, the ambient air provides the heat sink while the hydrothermal resource is the heat source. Because the temperature difference is relatively small in energy conversion systems using a liquid-dominated, hydrothermal resource (compared to fossil fuel plants), the performance of the geothermal plant is very sensitive to changes in either the heat source or heat sink temperature.

NNEEL investigators have shown that the performance of a binary cycle can be maximized for a given set of heat source and heat sink temperatures by optimally selecting the turbine inlet conditions and the working fluid. In this activity, investigators are attempting to determine whether this concept can be applied to an existing or fixed configuration power plant to minimize the impact of changes in the ambient temperature on the amount on electrical power generated. By continually adjusting the turbine inlet conditions and the composition of the working fluid mixture to account for changes in the ambient, the plant performance can be maximized. A similar process could be used for a decline in the resource productivity, though this change is considered long-term relative to the changes in the ambient and would not require continuous adjustment.

\section{PROJECT OBJECTIVES}

The objective of the Heat Cycle Research Project is to develop technologies that will reduce the cost of generating electricity from hydrothermal resources marginally feasible for economic development. This investigation examines whether the real-time adjustment of the power cycle process conditions (including working fluid composition) improves binary plant performance.

\section{Technical Objectives}

- Establish the performance improvement of a fixed configuration power plant when cycle process conditions are adjusted in real time in response to variations in the ambient air temperature.

- Determine whether the real-time control scheme is cost-effective.

- Define systems to be used for the on-line adjustment of the composition of the working fluid.

- Evaluate whether the real-time control concept can be incorporated into the operation of an existing power plant. 


\section{Expected Outcomes}

- The continuous adjustment of the process conditions minimizes the impact of variations in the ambient air temperature on the performance of binary cycles.

- Cost effective real-time control methods will be identified.

- The real-time adjustment of process conditions can be incorporated into existing power plants to improve their performance.

\section{APPROACH}

To evaluate the effect of adjusting process conditions with changes in the ambient air temperature, a $5 \mathrm{MW}_{\mathrm{e}}$ binary power plant was modeled. Plant performance for assumed heat source and heat sink temperatures was optimized, and the plant equipment sized for the corresponding process conditions. A parametric study was made to optimize the performance of this fixed configuration plant at various ambient conditions and working fluid compositions. This study identified the process conditions providing the optimum performance for the set of conditions assumed. The plant modeled utilizes air-cooled condensers. Two design heat sink temperatures were considered; one representative of the design air temperatures for the Steamboat and Mammoth facilities and the second at a higher air temperature, representative of an average summer air temperature. Different compositions of an isobutane and hexane mixture were used as the working fluid in the model. Performance was predicted for geothermal fluid temperatures of $335^{\circ} \mathrm{F}$ and $350^{\circ} \mathrm{F}$. The plant performance was modeled using both ASPEN software, and a model developed at the INEEL.

The predicted fixed plant performance for a given composition of an isobutane and hexane working fluid mixture was then applied to the 1995 hourly ambient air temperature profile for Reno, Nevada (considered to be representative of a Basin and Range application). The effect of hourly changing the working fluid composition and turbine inlet conditions on the plant output during the year was evaluated to determine the additional power for the entire year and periods having more favorable terms in a power sales agreement. For all cases, it was assumed that the plant was available for operation $100 \%$ of the time.

A value was assigned to the additional power generated based upon different power purchase agreement pricing scenarios. Additional annual revenues could be determined and an estimate made of the dollar amount that could be used to make the system upgrade to modify the fluid chemistry and turbine inlet conditions on a real-time basis. This dollar amount could then be used to assess the feasibility of making the plant modification.

\section{RESEARCH RESULTS}

Investigators utilized the plant models to optimize the power production from a plant using a pure isobutane working fluid and a fixed ambient air temperature and resource temperature. The configuration of the modeled plant was then fixed (heat exchangers, pumps, turbine, and air-cooled condensers) and its performance optimized over an air temperature range of $0^{\circ} \mathrm{F}$ to $100^{\circ} \mathrm{F}$. The turbine inlet conditions were varied for a fixed brine flow rate until a maximum net power output was achieved for a given air temperature. Hexane was then incrementally added to the working fluid changing its composition. The performance optimization was again repeated for a fixed brine flow rate over the selected ambient air temperature range. In Figure 1, the impact of modifying the fluid chemistry on a plant designed for a $335^{\circ} \mathrm{F}$ brine temperature and a $60^{\circ} \mathrm{F}$ ambient air temperature is shown. In Figure 2, the predicted impact of modifying the fluid chemistry is shown for a plant designed for a $350^{\circ} \mathrm{F}$ 
resource and the same air temperature. The results in Figure 1 were generated with the model developed at the INEEL; those in Figure 2 with the ASPEN model.

The predicted results in Figure 1 indicates there is an advantage to operating with a mixed working fluid, but suggest there is little benefit to adjusting the fluid chemistry in response to a change in the ambient air temperature. Over an air temperature range of $20^{\circ} \mathrm{F}$ to $100^{\circ} \mathrm{F}$, the modeled plant produces more power with the mixture containing $2.5 \%$ hexane (by mass) than it does with pure isobutane or with a mixture containing $5 \%$ hexane. At lower air temperatures, a pure isobutane working fluid would provide a superior performance. However for the annual air temperature profile selected, the air temperature was below $20^{\circ} \mathrm{F}$ for only 50 hours. The additional power output that could be generated over the year by continually varying composition is less than $1000 \mathrm{~kW}$-hrs. Revenues generated at high price of electricity scenarios would not justify the cost to provide the continuous adjustment of the working fluid chemistry.

The predicted performance in Figure 2 for the plant using the $350^{\circ} \mathrm{F}$ resource, indicates there is an advantage to operating with a mixture when ambient air temperatures are above $40^{\circ} \mathrm{F}$. At air temperatures up to $\sim 90^{\circ} \mathrm{F}$ a mixture containing $2 \%$ hexane provides a higher predicted power output. At higher temperatures, the addition of hexane increases the predicted power output from the modeled plant. At air temperatures below $40^{\circ} \mathrm{F}$, the predicted power output is greatest when pure isobutane is used.

In Figure 3, the incremental change in power output is shown throughout the year for different compositions in the plant designed for $a 350^{\circ} \mathrm{F}$ brine and $\mathrm{a} 60^{\circ} \mathrm{F}$ air temperature. The optimized bar reflects hourly modification of the working fluid composition to maximize the power generated. The bars for the different mixtures reflect running with that particular working fluid continuously. The delta performance, in $\mathrm{kW}-\mathrm{hr}$, is relative to the optimized plant performance with a pure isobutane working fluid. The advantage of operating with a mixture is greatest during the summer months, with a penalty incurred during the colder winter months (as one would expect given the results in Figure 2).

If the plant modeled in Figure 2 operated continually with the $2 \%$ hexane mixture, it would produce $\sim 459,000$ $\mathrm{kW}$-hrs more annually than it would operating with pure isobutane. Except for the months of December and January, i.e., the coldest months of the year, operating with the $2 \%$ mixture would always produce more power (on a monthly basis). If the composition was modified seasonally, i.e., changed to pure isobutane for these cold periods, the plant would produce $\sim 472,000 \mathrm{~kW}$-hrs more annually than it would operating with pure isobutane. If the composition was modified continuously, the plant would produce $\sim 522,000 \mathrm{~kW}$-hrs more annually than it would operating with pure isobutane. The performance advantage from continually modifying the fluid chemistry occurs primarily in the winter months. However, there is little advantage in the summer. Between May and September, the plant with a working fluid containing $2 \%$ hexane produces about the same amount of power as it would with the working composition optimized. The predicted difference in power generation for these two scenarios over this 5 month period is $\sim 1,600 \mathrm{~kW}$-hrs. During the remainder of the year, continually modifying the working fluid composition to maximize the power output would result in an additional $61,800 \mathrm{~kW}$-hrs of power generated relative to operating with the $2 \%$ hexane mixture.

These results indicate operating there is a performance improvement if the composition of the working fluid is changed from pure isobutane to a mixture containing $2 \%$ hexane. Assuming there is no adverse impact on heat exchanger performance when using the mixtures (i.e., countercurrent flow paths are maintained with integral phase changes) and a market price of $\$ 0.06$ per $\mathrm{kW}$-hr for the additional power, the plant would have an additional revenue of $\$ 27,600$. If the plant has a capacity of $\sim 50,000$ gallons, the operator would need to purchase $\sim 1,000$ gallons of hexane. Assuming a hexane cost of $\$ 2$ per gallon and $\$ 5,000$ to $\$ 10,000$ costs for 
additional storage and handling of hexane, the cost would be returned by the additional revenues in less than 6 months.

If the same market price of $\$ 0.06$ per $\mathrm{kW}$-hr were obtained for the additional power generated by continually modifying the fluid chemistry, the plant would generate $\sim \$ 3,800$ in additional revenue. Seasonally modifying the chemistry would generate less than $\$ 1,000$ from the additional power generated. (Both of these revenue increases are relative to operating continually with the $2 \%$ hexane mixture.) It is unlikely that the system to modify the composition either continually or seasonally could be paid for with the added revenue streams over a period acceptable to a facility operator.

The modeling based on a $45^{\circ} \mathrm{F}$ ambient air temperature gave similar results. Performance gains were slightly larger, however typically a single working fluid composition gave a superior performance.

\section{FUTURE PLANS}

The results of this investigation imply there is an advantage to using a mixed working fluid in a plant designed for a pure isobutane fluid. The additional power generated would likely justify the addition of the second component on a one-time basis. However, under the conditions evaluated, there is not sufficient improvement when continually or seasonally modifying the chemistry to justify the costs associated with providing this control function. The project intends to refine the models used and identify conditions and performance improvements that would warrant the additional costs to continually modify the working fluid chemistry: Investigators believe that the lack of flexibility in pumping capacity, and to a certain extent the turbine size, limit the fixed plant performance when mixtures are used, particularly at the low ambient air temperatures. Candidate systems for continually modifying the chemistry will be evaluated. The results of the study will be reported.

\section{INDUSTRY INTEREST}

Mammoth Pacific has indicated an interest in this activity as a potential means of improving the performance of existing facilities. It is anticipated that if the results are positive, it could be applied to a number of existing binary facilities, as well as new plants.

\section{REFERENCES}

Demuth, O. J., "Analysis of Mixed Hydrocarbon Binary Thermodynamic Cycles for Moderate Temperature Geothermal Resources ", Proceedings of the $17^{\text {th }}$ IECEC, Institute of Electrical and Electronic Engineers, Vol. 2, pp. 1104-1109, August 1982, Los Angeles, California.

Demuth, O. J. and Whitbeck, J. F., Advanced Concept Value Analysis for Geothermal Power Plants, EGGGTH-5821, March 1982.

Bliem, C. J., Demuth, O. J., Mines, G. L., and Swank, W. D., Supercritical Binary Geothermal Cycle Experiments with Mixed-Hydrocarbon Working Fluids and a Vertical, In-Tube, Counterflow Condenser, EGGEP-7076, December 1985.

Bliem, C. J. and Mines, G. L., Supercritical Binary Geothermal Cycle Experiments with Mixed-Hydrocarbon Working Fluids and a Near-Horizontal, In-Tube, Counterflow Condenser, EGG-EP-8800, December 1989.

Bliem, C. J. and Mines, G. L., Advanced Binary Geothermal Power Plants -- Limits of Performance, EGG-EP9207, January 1991. 


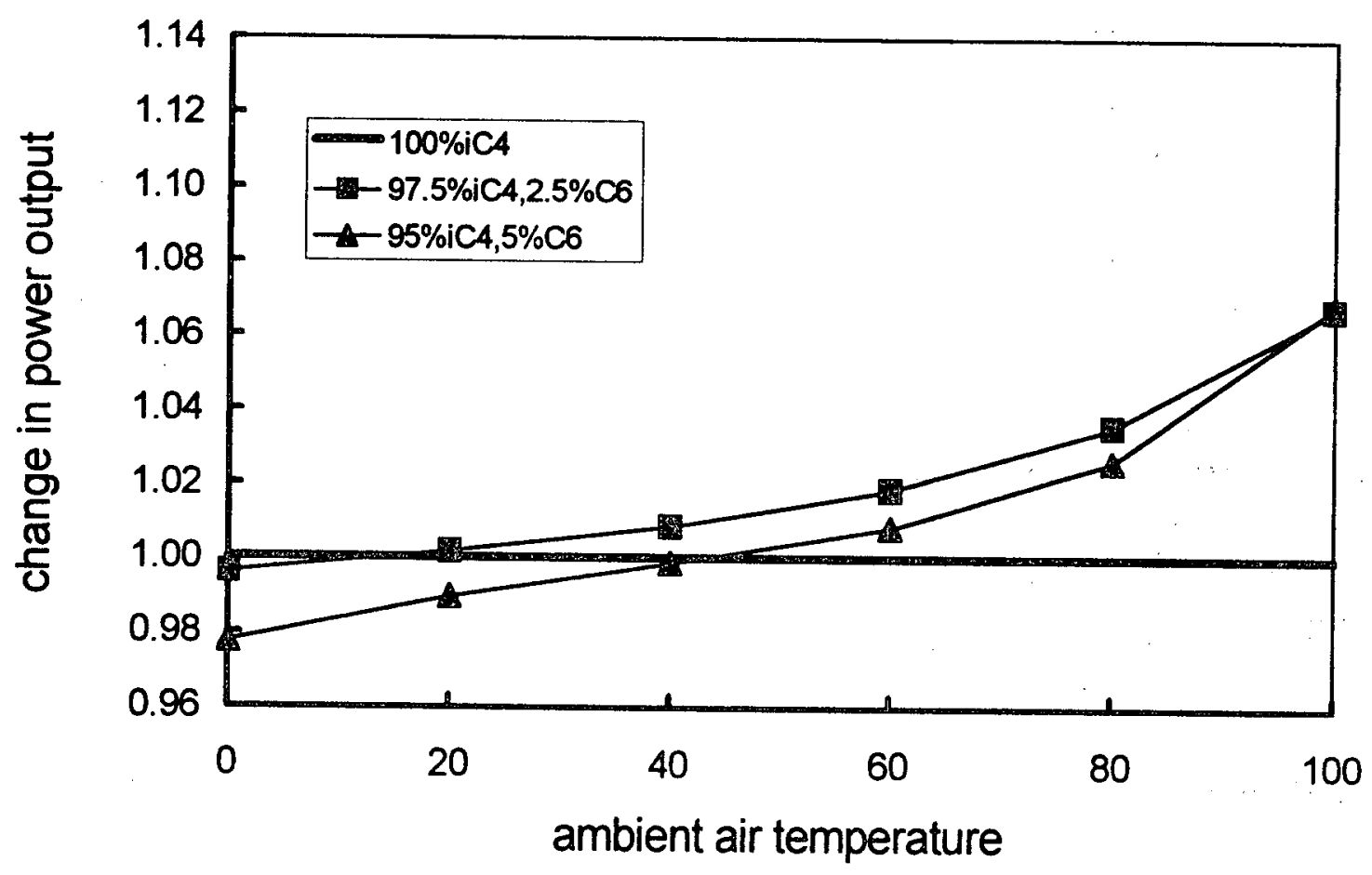

Figure 1 --Effect on changing composition on performance of binary plant designed for an isobutane working fluid, $335^{\circ} \mathrm{F}$ brine and $60^{\circ} \mathrm{F}$ air temperature. 


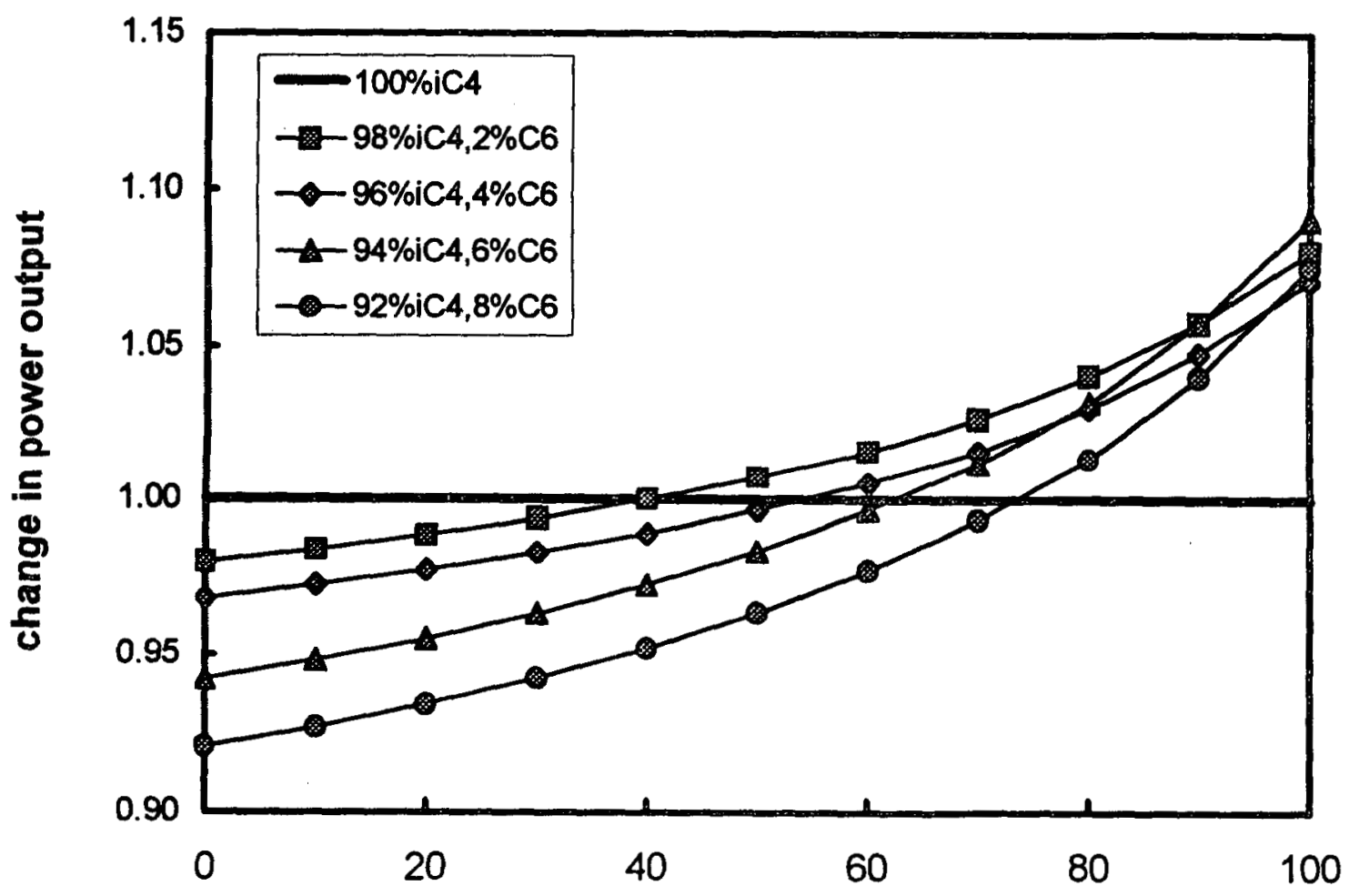

ambient air temperature, $\mathbf{F}$

Figure 2 --Effect on changing composition on performance of binary plant designed for an isobutane working fluid, $350^{\circ} \mathrm{F}$ brine and $60^{\circ} \mathrm{F}$ air temperature. 


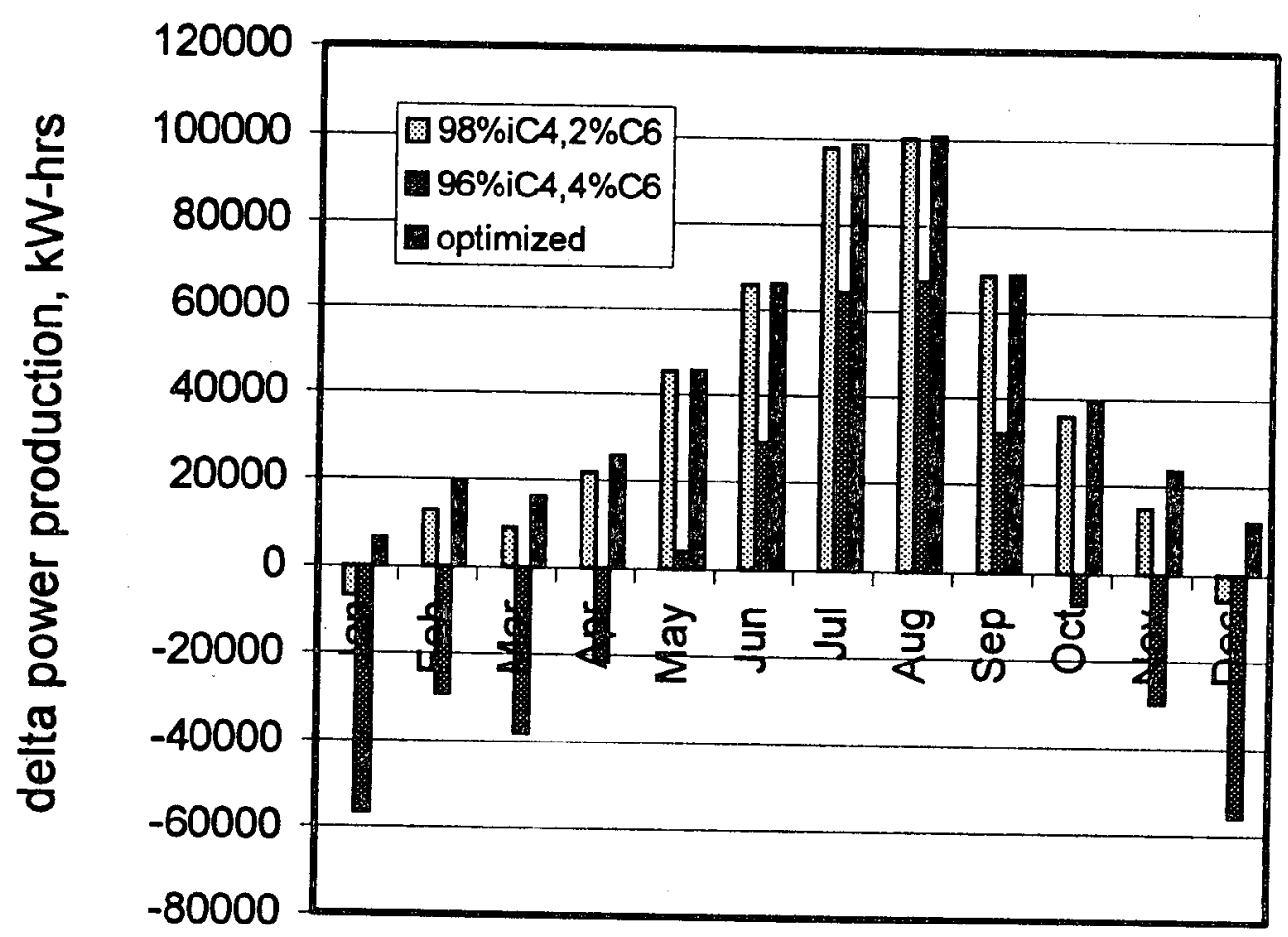

Figure 3 --The impact of optimizing working fluid composition on output of plant designed for $350^{\circ} \mathrm{F}$ brine and $60^{\circ} \mathrm{F}$ air temperature. 


\title{
TRILATERAL CYCLE FOR LOW-TEMPERATURE RESOURCES
}

\author{
B.W. Brown and G. L. Mines \\ Idaho National Engineering and Environmental Laboratory (INEEL)
}

\section{KEY WORDS}

binary power cycles, trilateral cycle, off-grid power cycles, village power

\section{PROJECT BACKGROUND AND STATUS}

Although relatively abundant, low- to moderate-temperature, liquid dominated hydrothermal resources will not be developed, except under unique circumstances, in the current domestic power market. When found in remote locations (domestically or internationally) lacking the infrastructure to deliver electrical power from conventional suppliers, an opportunity for development exists. These off-grid, or "village power" applications would be small (operate on a single well) and would require simple and rugged designs with minimal operating and maintenance costs.

The trilateral cycle proposed by I. K. Smith has characteristics that may provide both a performance and cost advantage over other types of energy conversion systems for these off-grid applications. Because the working fluid entering the turbine is a pressurized liquid (near its bubble point), the heat addition is a sensible heat exchange process between the geothermal brine and the working fluid. This allows cycle irreversibilities to be reduced and performance improved. INEEL investigators have identified similar benefits for supercritical binary cycles. In the trilateral cycle, there is no boiler or vaporizer as found in a conventional binary cycle.

The turbine is the only component in the trilateral cycle that will be dissimilar to those found in a conventional binary cycle. Any performance advantage that the cycle would have over the conventional cycle is based upon the premise that a turbine can be developed that will have an efficiency equivalent to those in current installations. Previous work has indicated a significant performance penalty is imposed on the expander when geothermal fluid is expanded directly from the well. (Douglas Energy is developing a bi-phase turbine that could reduce this performance penalty.) The specific volume of a liquid brine expanding isentropically from $320^{\circ} \mathrm{F}$ to a $100^{\circ} \mathrm{F}$ condensing temperature will increase by a factor of greater than 1500. In the trilateral cycle, the energy is transferred from the brine to a working fluid that is expanded through the turbine. These working fluids are typically more volatile than water and have much lower expansion ratios through the expander.

In this activity, INEEL investigators are examining the feasibility of using the trilateral cycle in these off-grid applications. Current efforts have focused on identifying the conditions under which the trilateral cycle would have an advantage over the conventional Rankine binary cycle.

\section{PROJECT OBJECTIVES}

This investigation is examining the potential benefits of using the trilateral cycle for low temperature hydrothermal resources. The cycle evaluation is being specifically focused towards the possible use in remote, off-grid locations. 


\section{Technical Objectives}

- Model the trilateral cycle performance for a range of resource temperatures and identify the working fluids providing the optimum performance.

- Compare the performance of the trilateral cycle with that of a conventional single-boiler Rankine cycle.

- Identify threshold expander efficiencies below which there is no performance advantage for the trilateral cycle.

- Compare the relative equipment sizes of the two cycles; use value analysis to estimate impact on cost of power.

\section{Expected Outcomes}

- The trilateral cycle performance will be superior to that of the conventional Rankine cycle over the resource temperature range considered.

- The trilateral cycle will maintain its performance advantage at efficiencies that would be expected in potential expanders.

- The trilateral cycle will prove to be a cost-effective method of generating electrical power from geothermal resources in remote, off-grid locations.

\section{APPROACH}

The energy conversion system used for the evaluation of the trilateral cycle is modeled using ASPEN software. The cycle modeled uses air-cooled condensers and heat exchangers having $10^{\circ} \mathrm{F}$ approach temperatures. Rotating equipment efficiencies were fixed at $80 \%$. The geothermal fluid was assumed to be provided from a single (slimhole) well, with a flow rate of $450 \mathrm{gpm}$ (liquid). The resource temperature range evaluated was $200^{\circ} \mathrm{F}$ to $320^{\circ} \mathrm{F}$. Higher temperatures were not considered, in part because of concerns relative to silica precipitation. Because the trilateral cycle cools the brine to temperatures approaching the condensing temperature, it would be subject to silica precipitation at the higher resource temperatures. This range of resource temperatures evaluated is not currently considered economically viable for development. This investigation is intended to determine whether this cycle could enhance this viability.

The trilateral cycle performance was modeled over this temperature range using the database of fluids available in the ASPEN software package. The net power was optimized for each of the fluids at a given brine temperature. (The fluids were no longer considered once the optimized temperature and/or pressure was greater than those at the fluid's critical point.)

Once the working fluid performance was determined, the optimum fluid could be identified at different intervals over the range of brine temperatures. This was then compared to the performance of a single-boiler, Rankine cycle. The efficiency of the trilateral cycle turbine could be varied to determine the point where the cycle no longer had a performance advantage. The relative sizes of the equipment could be predicted with the ASPEN model, and the value analysis techniques applied to determine the effect on the cost of power. 


\section{RESEARCH RESULTS}

Investigators examined 19 different working fluids using the ASPEN model. The results of this evaluation are summarized in Table 1. The pentane working huids considered in general have a superior performance than the other fluids over the range of resource temperatures cvaluated. The performance advantage however is not significant; the cycle has similar power outputs for a number of working fluids. These results are consistent with those published by Smith.

In Table 2, the expansion ratios are shown for each of the fluids. This is the ratio of the specific volumes between the turbine exhaust and the turbine inlet. Relative to water, the expansion ratios are an order of magnitude less than for water, with the exception of $R-130$ which is $\sim 1 / 3$ less than the ratio for water. The expansion ratios for the more volatile fluids are lower, but the cycles do not perform as well with these fluids. In Table 3, the UA's for the heat exchangers are shown. (UA is the product of the heat exchanger area and the overall heat transfer coefficient; it provides an indication of the relative heat exchanger size.) The more volatile fluids appear to have lower UA's at the lower resource temperatures, however in general the UA's are roughly equivalent at a given resource temperature for most of the fluids.

In Figure 1, the performance of the trilateral cycle is compared to that of a Rankine cycle using a propane working fluid with the same heat source, heat sink, and equipment assumptions. Over the range of brine temperatures considered, the trilateral cycle has a performance advantage. With the $320^{\circ} \mathrm{F}$ resource, the trilateral cycle expander efficiency would have to decrease from $80 \%$ to $70 \%$ before the Rankine cycle would have a performance advantage. At the lower resource temperatures, the trilateral cycle expander efficiency would have to decrease even more before the Rankine cycle would have a performance advantage.

\section{FUTURE PLANS}

The results indicate that the trilateral cycle has a performance advantage over the conventional Rankine binary cycle for the resource temperature range considered. Investigators will complete the evaluation of the trilateral cycle, including the economic comparison of the two cycles. Investigators will consider the optimum approach temperatures in the trilateral cycle, and will begin examining the potential types of expanders that will be ablc to maintain the expander efficiency over the expected operating range.

\section{INDUSTRY INTEREST}

Douglas Energy is actively developing a total flow expansion device for applications where the brine is expanded directly. Douglas Energy also has an agreement with Carrier where a bi-phase turbine is operated in a refrigeration system. FAS Engineering is also pursuing the development of a total flow expander for geothermal applications. The project will solicit recommendations and comments from these members of industry and others as this work continues.

\section{REFERENCES}

Smith, I. K., Development of the Trilateral Flash Cycle System, Part I: Fundamental Considerations, Proc. Instn. Mech. Engrs., Vol 207. 
Table 1: Net Work (kW) for Various Working Fluids

\begin{tabular}{|c|c|c|c|c|c|c|c|c|c|c|c|c|c|c|c|c|c|c|c|}
\hline Tw[.crit & $\begin{array}{l}n-C 4 \\
306\end{array}$ & $\begin{array}{l}\text { iC4 } \\
275\end{array}$ & $\begin{array}{l}\text { Water } \\
705\end{array}$ & $\begin{array}{l}\mathrm{C7} \\
513\end{array}$ & $\begin{array}{l}\text { C6 } \\
454\end{array}$ & $\begin{array}{l}\text { pentane } \\
436\end{array}$ & $\begin{array}{l}2 \text { methyl } \\
\text { pentane } \\
448\end{array}$ & $\begin{array}{l}3 \text { methyl } \\
\text { butane } \\
420\end{array}$ & $\begin{array}{l}\text { dimethyl } \\
\text { butane } \\
440\end{array}$ & $\begin{array}{l}\text { dimethyl } \\
\text { n-C5 } \\
386\end{array}$ & $\begin{array}{l}\text { iC5 } \\
369\end{array}$ & $\begin{array}{l}\text { neoCs } \\
321\end{array}$ & $\begin{array}{l}\text { NH3 } \\
270\end{array}$ & $\begin{array}{l}\text { R-160 } \\
369\end{array}$ & $\begin{array}{l}\text { R-150 } \\
482\end{array}$ & $\begin{array}{l}R-134 a \\
214\end{array}$ & $\begin{array}{l}R-130 \\
701\end{array}$ & $\begin{array}{l}R-40 \\
290\end{array}$ & $\begin{array}{l}\text { R-30 } \\
458\end{array}$ \\
\hline \multicolumn{20}{|l|}{ Tgf, in } \\
\hline 200 & 227 & 220 & 162 & 161 & 198 & 216 & 209 & 223 & 218 & 231 & 231 & 228 & 232 & 212 & 217 & 218 & 42 & 211 & 230 \\
\hline 220 & 365 & 355 & 286 & 267 & 343 & 346 & 350 & 362 & 351 & $37 !$ & 371 & 367 & 367 & 371 & 356 & 292 & 145 & 342 & 371 \\
\hline 240 & 497 & 514 & 452 & 431 & 506 & 519 & 514 & 528 & 520 & 538 & 528 & 531 & 527 & 536 & 521 & & 245 & 493 & 538 \\
\hline 260 & 713 & 696 & 638 & 588 & 694 & 709 & 704 & 720 & 710 & 724 & 728 & 719 & 708 & 726 & 712 & & 390 & 644 & 731 \\
\hline 280 & 922 & & 860 & 793 & 909 & 924 & 917 & 935 & 925 & 944 & 942 & 929 & & 938 & 928 & & 552 & 754 & 947 \\
\hline 300 & 1151 & & 1110 & 1017 & 1145 & 1163 & 1155 & 1174 & 1163 & 1181 & 1179 & 1129 & & 1159 & 1165 & & 758 & & 1186 \\
\hline 320 & & & 1386 & 1266 & 1405 & 1422 & 1418 & 1435 & 1426 & 1443 & 1432 & 1405 & & 1426 & 1425 & & 979 & & 1449 \\
\hline
\end{tabular}

\section{Table 2: Expansion Ratios for Various Working Fluids}

$$
2.2 \quad 2,3
$$

2 methyl 3 methyl dimethyl dimethyl

$u$
$i$
$\infty$

\begin{tabular}{lllllllllllll}
\multicolumn{2}{c}{ Tgf, in n-C4 } & iC4 & Water & C7 & C6 & pentane & pentane & butanc & butane & n-C5 & iC \\
200 & 19 & 14 & 622 & 220 & 117 & 99 & 105 & 75 & 92 & 52 & 4 \\
220 & 23 & 17 & 795 & 279 & 147 & 121 & 128 & 90 & 111 & 62 & 49 \\
240 & 24 & 19 & 962 & 332 & 172 & 139 & 149 & 104 & 130 & 71 & 5 \\
260 & 28 & 20 & 1127 & 384 & 195 & 157 & 170 & 118 & 147 & 80 & 62 \\
280 & 30 & & 1278 & 434 & 218 & 175 & 189 & 130 & 164 & 88 & 68 \\
300 & 32 & & 1425 & 480 & 238 & 191 & 206 & 142 & 179 & 95 & 74 \\
320 & & & 1572 & 523 & 256 & 205 & 223 & 152 & 192 & 101 & 78
\end{tabular}

\section{Table 3: Heater UA Values for Various Working Fluids}

$$
\begin{array}{ll}
2,2 & 2,3 \\
\text { dimethyl } & \text { dimethy }
\end{array}
$$

2 methyl 3 methyl dimethyl dimethyl

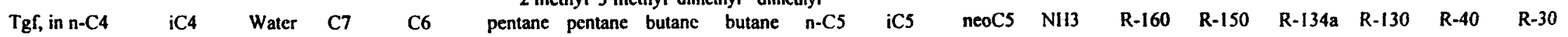

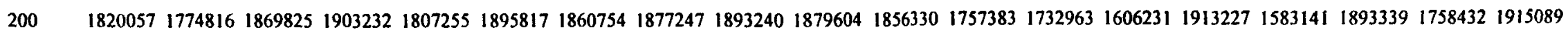

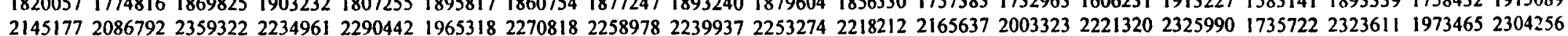

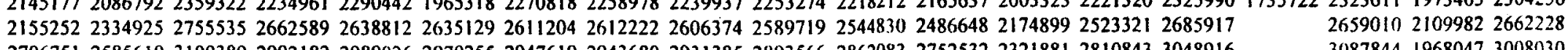
270675125856103100389299218229890262970255294761929436802931385289356628620832752532232188128108433048916 $2924947 \quad 3496789333747533155773277627325404832421013228422318329931344523003557$

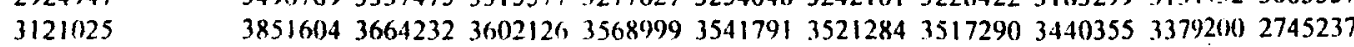
$\begin{array}{lllllllllll}38516014 & 3664232 & 3602126 & 3568999 & 3541791 & 3521284 & 3517290 & 3440355 & 3379200 & 2745237 \\ 4109480 & 3967678 & 3876759 & 3835431 & 3861371 & 3780249 & 3824980 & 3696796 & 3619630 & 3439849\end{array}$

30866253382573

$34936091600559332711 ?$

$3889552 \quad 3612428$

3612428 


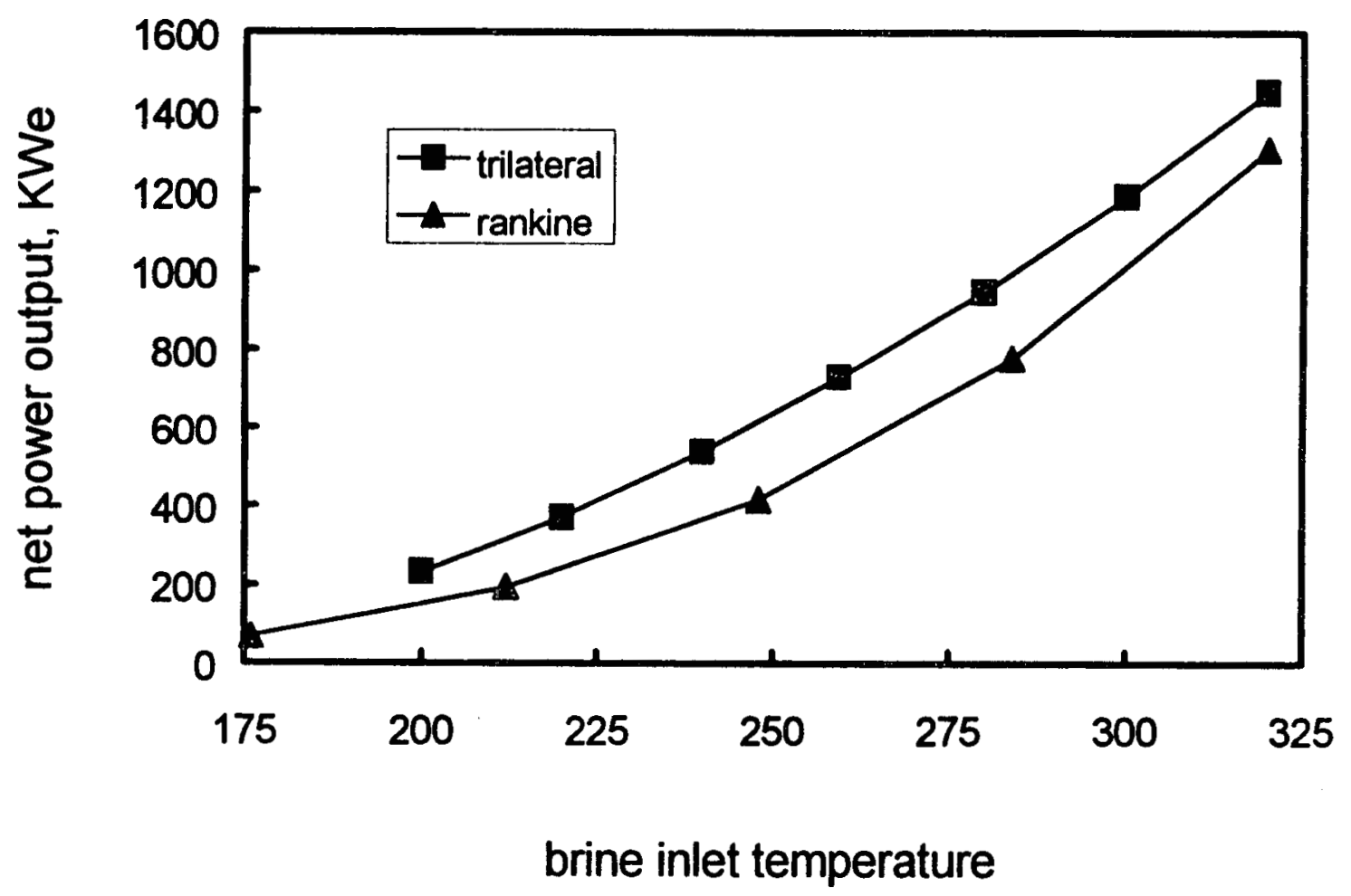

Figure 1 -- Comparison of Trilateral and Rankine Cycle Performance 


\title{
REAL-TIME $\mathrm{H}_{2} \mathrm{~S}$ MONITOR FOR APPLICATION IN GEOTHERMAL PLANTS
}

\author{
J. K. Partin \\ Idaho National Engineering and Environmental Laboratory (INEEL)
}

\section{KEY WORDS}

gas sensing, tunable diode spectroscopy, near infrared spectroscopy, real-time monitoring, hydrogen sulfide

\section{PROJECT BACKGROUND AND STATUS}

The goal of this effort is to develop and demonstrate a real-time detection system for monitoring hydrogen sulfide $\left(\mathrm{H}_{2} \mathrm{~S}\right)$ gas in geothermal plants. The system is based upon the use of near-infrared diode laser technology that offers several advantages for geothermal emission and process control operations. For this application, there is a fortuitous coincidence between the standard communications diode at 1.55 microns and the $\mathrm{H}_{2} \mathrm{~S}$ combination band at 1.578. The communication diode is easily temperature-shifted by the amount needed to access this absorption band. The spectral resolution of the diode laser is on the order of $1 \mathrm{GHz}$. This extremely narrow linewidth reduces the potential of signal contributions from interferents, such as water vapor or carbon dioxide, which can limit the sensitivity and accuracy of other types of measurements. The output from these lasers can easily be propagated over standard fused silica optical fibers. This allows for the configuration of a system in which sensitive optical and electronic components can be located in an environmentally-controlled area, and also allows multiplexing of signals so that a single device can be used to make a number of remote measurements.

The ability to perform real-time $\mathrm{H}_{2} \mathrm{~S}$ monitoring could result in several benefits, including improved air quality monitoring and compliance. Significant dollar savings could also be realized through the optimization of chemical usage, primarily iron chelates. Iron chelate is added to the circulating water to react with dissolved $\mathrm{H}_{2} \mathrm{~S}$ to form elemental sulfur. $\mathrm{H}_{2} \mathrm{~S}$ fluctuations in the incoming stream require most plants to target iron feed to obtain $75 \%$ of allowable emissions. Accurate real time stack emission monitoring would allow the lower iron chelate concentrations to obtain $90 \%$ of allowable emissions. This $15 \%$ improvement would result in annual savings of about $\$ 65 \mathrm{~K}$ to $\$ 75 \mathrm{~K}$ for a typical plant.

There are several locations within the plant at which this measurement could be made. The sites vary in environmental conditions from the main steam line which operates at a temperature of $350^{\circ} \mathrm{F}\left(175^{\circ} \mathrm{C}\right)$ and a pressure of $100 \mathrm{psig}$ to the cooling stack with a temperature of $80-100^{\circ} \mathrm{F}\left(27-38^{\circ} \mathrm{C}\right)$ at ambient pressure. $\mathrm{H}_{2} \mathrm{~S}$ concentrations vary from $0.1 \mathrm{ppm}$ to 1000 's ppm, depending upon the location. In order to establish the optimal plant location and design configuration for the monitor, a series of scoping experiments have been performed to determine the effect of pressure, temperature and water vapor on the sensitivity of the proposed technique.

\section{PROJECT OBJECTIVES}

The project objective is to investigate the applicability of frequency-modulated, near-infrared diode spectroscopy for on-line monitoring of $\mathrm{H}_{2} \mathrm{~S}$ in geothermal facilities. The data from this investigation will then be used to design a prototype for field application. 


\section{Technical Objectives}

- Laboratory testing and evaluation of frequency-modulatod, infrarod spectroscopic techniques for geothermal gas monitoring applications

- Identification of test site(s) and operational requirements

- Design and demonstration of a field prototype

\section{Expected Outcomes}

- Compact, rugged spectroscopy system for real-time monitoring of gases in geothermal plants.

- Optimization of chemical compounds used in $\mathrm{H}_{2} \mathrm{~S}$ abatement systems.

\section{APPROACH}

The monitor is based upon the use of solid-state diode lasers and frequency modulation techniques. In these types of measurements, the injection current of the diode is sinusoidally (frequency) modulated as the wavelength is tumed across the absorption line. Harmonics of the modulation frequency are recorded that are proportional to the concentration of the absorbing molecular species. The frequencies used allow the measurements to be performed where the intensity noise of the diode laser is at a minimum; and therefore, very high signal-to-noise measurements are possible. Under laboratory conditions, absorptions as low as $10^{-7}$ can be detected.

The basic components of the spectroscopy system, pictured in Figure 1, were procured from Unisearch Associates. These included a fiberoptic-coupled, distributed-feedback, laser diode which emits radiation at 1.578 microns, as well as the electronics package for tuning and modulating the diode probe and demodulating and detecting the absorbed signal. For the evaluation of the system, a stainless steel test cell, $80 \mathrm{~cm}$ long and $2.5 \mathrm{~cm}$ in diameter, was configured with sapphire windows. The cell was designed to be placed in a clam shell furnace for operation at elevated temperature $\left(200^{\circ} \mathrm{C}\right)$ and pressure $(100 \mathrm{psig})$. Water could also be added to generate steam.

\section{RESEARCH RESULTS}

The sensitivity and detectivity of the device was evaluated by filling the cell with $\mathrm{H}_{2} \mathrm{~S}$ gas from a calibration cylinder ( $5000 \mathrm{ppm}$ in nitrogen) and observing the standard deviation in the signal. Using this technique, a detection limit on the order of $25 \mathrm{ppm}$ per meter was observed with the system at atmospheric conditions. Extrapolating over the 8 meter diameter of the stack, it should be possible to detect a level of 1-2 ppm in a signal retroreflocted across the stack. Some signal noise modulation due to optical feedback into the diode was observed in the signals. It is speculatod that by improving the optical isolation in the system this limit could be improved. The technique was found to be quite sensitive to changes in pressure, exhibiting a $50 \%$ decrease in signal for every $1 / 3$ atmosphere increase in pressure. Much less sensitivity was observed to changes in temperature with changes of less than $20 \%$ recorded over a $100^{\circ} \mathrm{C}$ range. Experiments with water vapor indicate that the device is effective at excluding the contribution of water vapor in the signal, but a marked decrease in signal-to-noise is noted as droplets form which are comparable in size to the wavelength of light.

The device shows good promise for application as a stack monitor. For this application, the laser would be propagated via an optical fiber to a telescope located on the stack near the fan circulation for appropriate mixing 
to limit condensate or fog formation. A retroreflector would be placed on the stack opposite the telescope assembly and used to redirect the laser signal back across the stack and into a fiberoptic cable for transmission to the detection and data logging electronics. In view of the pressure and temperature sensitivity, direct sampling of the stream would not be effective for locations such as the main steam line. However, it would also be possible to use the tochnique for real-time monitoring in these locations by circulating a portion of the strcam into a long pass cell. The use of this configuration would allow for conditioning of the stream to a reasonable pressure and temperature prior to introducing the vapor sample into the cell for measurement, while preserving the sensitivity afforded by operation over a long pathlength.

The use of a long pass cell might also be considered if there is too much condensate to make a measurement in the stack via the open path measurement. In this scenario, the sample could be collected by installing a perforated tube across a chord of the stack. The vapor would then be pulled into the cell for measurement. (An additional water trap could be placed in the line, if needed, to eliminate droplets.) This configuration could also be used to increase the measurement sensitivity by evacuating the cell at a rate that causes a small pressure drop. In this case, the line broadening effect is reduced and the spectroscopic technique is more sensitive to the sharper absorption feature. These deployment options are shown schematically in Figure 2.

\section{FUTURE PLANS}

Modifications are currently being made to the device to upgrade it for use in either the open path or long pass configuration. When this upgrade is completed, a site for fielding the technology will be selected. It is anticipated that a field demonstration will be completed during the second quarter of FY-98.

\section{INDUSTRY INTEREST}

PG\&E, Calpine and NCPA have expressed an interest in the technology as a potential means of improving control of their operations, and thereby reducing the costs for abatement chemicals.

\section{REFERENCES}

M. D. Rogers, “ Design, Construction and Operation of Geysers Unit 18”, Monograph on The Geysers Geothermal Field, Claudia Stone, Ed., Geothermal Resources Council, 317 (1992).

Risis, D. Cooper, C. Carlisle, L. Carr, and J. van der Laan, "Frequency Modulation Spectroscopy with Tunable Diode Lasers", Proc. SPIE 2112, 12 (1992).

J. A. Silver, "Frequency-Modulation Spectroscopy for Trace Species Detection: Theory and Comparison Among Methods", App. Opt. 31, 707 (1992). 


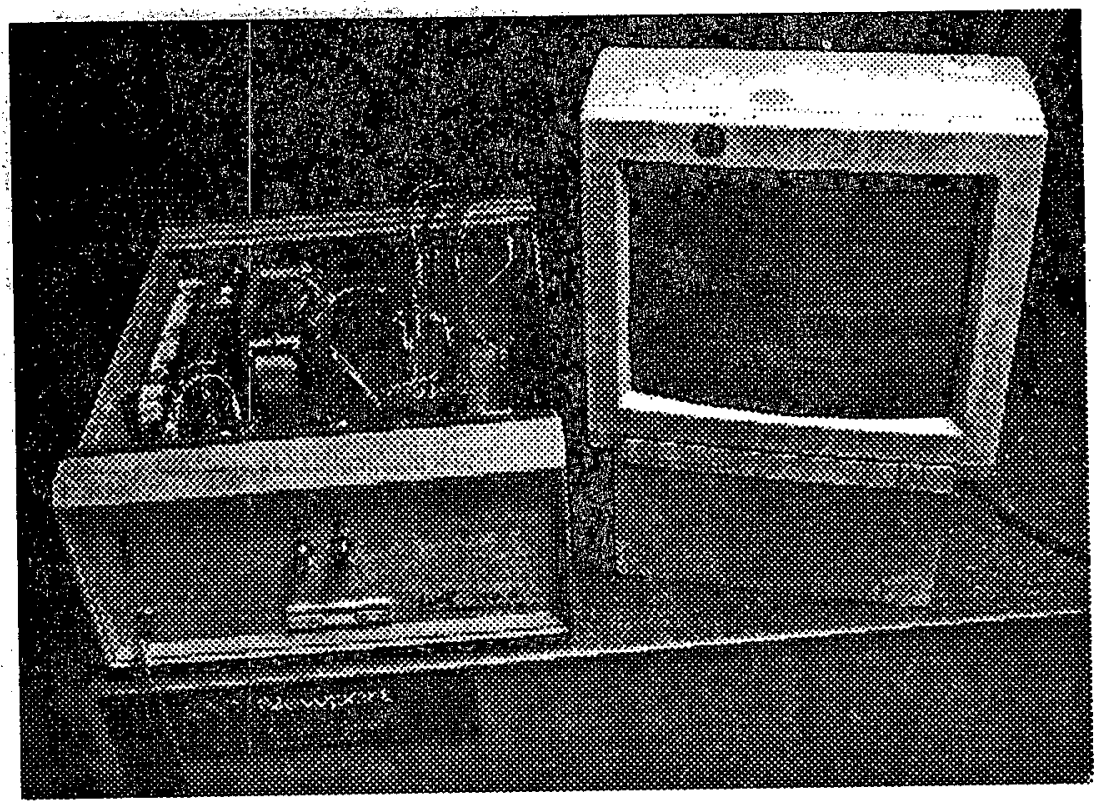

Figure 1 -- Photograph of LasIR Spectroscopy System
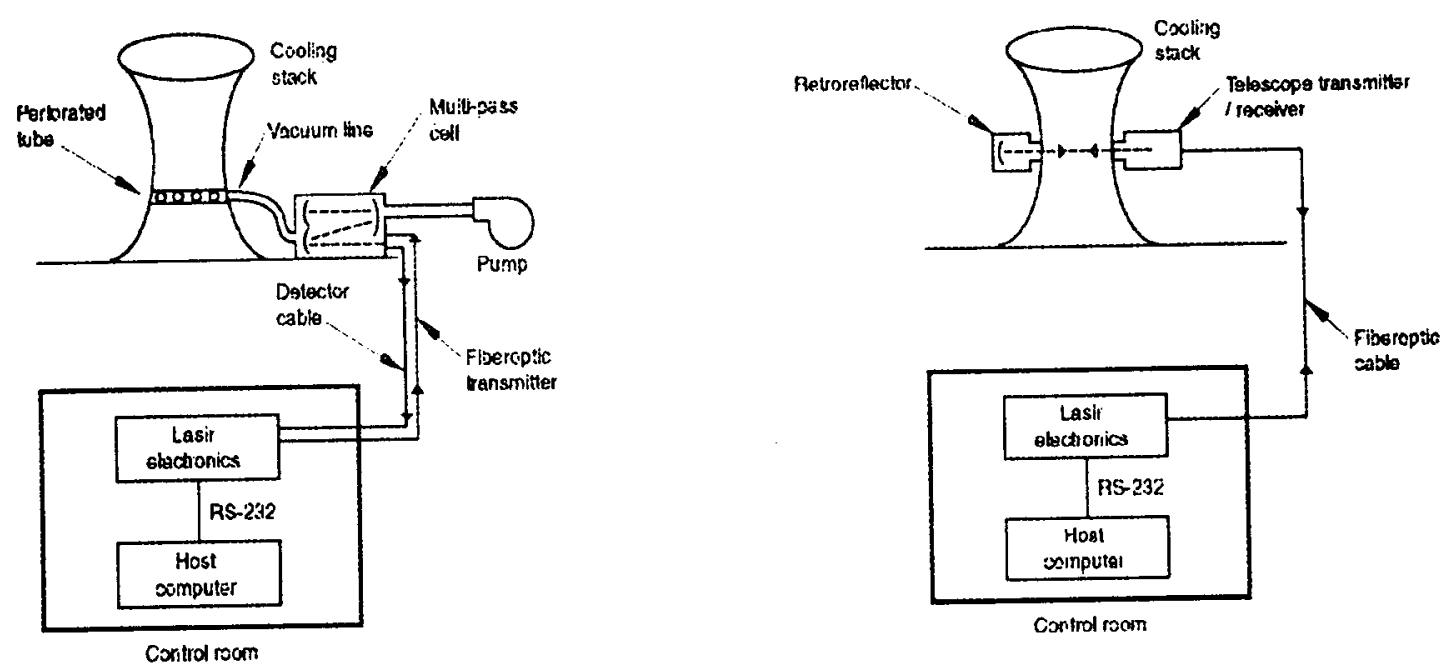

Figure 2 -- Deployment Options 


\title{
INVESTIGATION OF GEOTHERMAL POWER SYSTEMS USING MULTI-COMPONENT WORKING FLUIDS
}

\author{
Desikan Bharathan \\ National Renewable Energy Laboratory
}

\section{KEY WORDS \\ multi-component working fluids, power cycles \\ PROJECT BACKGROUND AND STATUS}

Many of the high-temperature $\left(>300^{\circ} \mathrm{F}\right)$ geothermal reservoirs have generally been identified and are already producing power using a variety of power-conversion technologies. While lower-temperature reservoirs are numerous and scattered, the cost for exploiting these resources has remained high, thus limiting their use for power production.

In order to lower the cost for power production and increase the resource utilization, the U.S. DOE geothermal program is already funding two projects which are looking into using multi-component working fluids (specifically ammonia and water). One of the project, conducted by Exergy Inc. is attempting to build a $12 \mathrm{MW}$ electric power plant. In the other project, NIST is generating experimental data and computer models for consistent estimation of ammonia/water mixture properties.

The potential use of multi-component working fluids has been documented to yield higher utilization of the resource throughout the literature. The general difficulty in their use are many, starting with the lack of adequate property information for the mixtures, to analyzing the numerous heat-exchanger arrangements in the cycle (with the primary aim of reusing the heat in its different segments), to the ultimate lack of operating experience with such systems.

In this proposed work, NREL aims to investigate power systems, such that any viable design may be built and tested within a reasonable cost and time frame, in future efforts. NREL will look into the use of the working fluid mixtures, ammonia/water mixtures and non-azeotropic hydrocarbon mixtures. The design of the overall cycle will be driven by the desire to maintain the cost of the system and especially all recuperative and other heat exchangers to a minimum.

\section{PROJECT OBJECTIVES}

In pursuit of its goal of reducing the cost of electricity from various geothermal resources, the Department of Energy (DOE) is conducting investigations to improve the performance and economic viability of geothermal power cycles. One of the DOE tasks, carried out by NREL, is to investigate the performance and cost-reduction potential through the use of multi-component working fluids in geothermal power systems.

\section{Technical Objectives}

- To investigate methods for improving the performance of small-scale geothermal power systems through the use of multi-component working fluids in closed cycle systems. 


\section{Expected Outcomes}

- Upon completion of the task, the report is expected to address the relative merits of using multi component working fluids in geothermal power systems.

\section{APPROACH}

The geothermal brine is used to generate vapor of the lighter components of the mixed working fluid in the evaporator. The vapor is allowed to pass through a turbine to generate work and then comes in contact with a cooled heavier component in the condenser. A recuperative heat exchanger is introduced in the cycle to transfer heat from the evaporator effluent to the condenser effluent.

Because of the varying temperatures occurring both in the evaporator and the condenser, a more effective, lessreversible heat transfer takes place in both, to result in a more efficient cycle.

NREL will investigate the most effective economical options. Of specific interest is the heat rejection part of the cycle. Using some innovative arrangement for the flow of lighter and heavier components, NREL researchers will attempt to generate cycle arrangements that might keep a higher fraction of the heavier component in this part of the cycle. Both a Heller-type indirect heat rejection and an air-cooled condenser option will be investigated to ascertain their potential merits.

For cycle investigations, NREL plans to use ASPEN, a commercial process modeling software.

\section{RESEARCH RESULTS}

NREL has acquired the ASPEN software and has installed it on a PC. NREL researchers are familiarizing the software use. NREL has conducted preliminary investigation of a cycle called the Maloney-Robertson cycle, using ammonia/water as the working fluid mixture.

\section{FUTURE PLANS}

NREL expects to generate a suitable set of component arrangements, cycle hardware, and operating conditions for the multi-component fluids appropriate for use with geothermal systems. NREL will provide detailed models for all the heat exchangers, turbine and pumps for quick on of the cycle for various resource temperatures, ambient conditions and any other ions that a site may impose. Such a model will allow researchers to vary components and operating conditions readily, and provide for quick evaluation of the performance potential and arriving at an estimated cost for the power system.

\section{REFERENCES}

Ibrahim, O.M. and Klein, S.A., "Absorption Power Cycles," Energy, v2 1, n 1, 1996, pp. 21-27.

Marston, C.H., "Development of the Adjustable Proportion Fluid Mixture Cycle," Mechanical Engineering, Sept. 1992, pp. 76-81. 


\title{
MODEL DEVELOPMENT AND ANALYSIS OF ADVANCED BINARY CYCLES
}

\author{
Vahab Hassani and Keith Gawlik \\ National Renewable Energy Laboratory
}

\section{KEY WORDS}

computer-aided model, binary cycle, geothermal power plant, heat rejection system, economic evaluation, thermodynamic evaluation, off-design performance, mixed hydrocarbon working fluid, binary working fluid

\section{PROJECT BACKGROUND AND STATUS}

Low- and moderate-temperature resources are abundant in the U.S., relative to high temperature resources, and their future for producing power rests on decreasing the cost of power produced from binary plants. The most promising technology for these resources is a binary cycle that uses a hydrocarbon working fluid, pure or mixed. Because of the low temperatures of these resources, the amount of heat rejected to the environment is high relative to the heat input to the cycle. The optimization of the heat rejection system, therefore, can result in large increases in cycle efficiency and decreases in levelized cost of electricity (LEC).

During the past four years, a computer model has been developed at NREL to represent binary cycles with different types of heat rejection systems. The change in the levelized cost of producing electricity from a base case was determined based on the changes in the cycle thermodynamic attributes. This modeling used Valuc Analysis, similar to that used by Demuth and Whitbeck early in the Heat Cycle Research Program. Baseline configurations were determined from the Next Generation Geothermal Power Plants (NGGPP) study conducted by CE Holt Company. The model used at NREL consists of a computer program to do the cycle thermodynamics and equipment sizing, a database of thermodynamic properties of various working fluids, and a spreadsheet to do the economic evaluation.

In FY1994, NREL began the development of the computer model and made some initial studies using a dry heat rejection system and a number of different working fluids. A program to evaluate the thermodynamic performance of a basic Rankine cycle was written and a spreadsheet for economic analysis was developed. A limited database of working fluid properties was developed. Economic information was based on studies conducted by Barber-Nichols Engineering for small power plants at low temperature (less than $300^{\circ} \mathrm{F}$ ) resources. A number of studies were made using the computer model, and the results were compared to the base line data from Barber-Nichols.

In FY1995, the computer model was enhanced by including the ability to model different types of heat rejection systems and temperatures, and to determine cycle performance during "off-design" operation. These modifications allowed NREL to conduct a number of studies of the effect of heat rejection system type and temperature on cycles under different environmental conditions.

In FY1996, further enhancements were made to the computer model and new economic information was incorporated into the model. The thermodynamic performance program was modified to allow the uninterrupted running of multiple cases over a range of heater pressure, condenser bubble point temperature, and air-cooled condenser and heater pinch points. The database of working fluid properties was expanded significantly by the use of a new program. This program, based on the NIST14 code, was developed to generate quickly all the data 
files necessary to describe a working fluid, and allowed NREL to explore many new fluids. In addition, detailed economic information from CE Holt Company, which pcrformed the NGGPP study, was obtained for a number of large $(50 \mathrm{MW})$ power plants at four low-temperature resources. This economic information was incorporated into the spreadsheet tool and became the new baseline cases for a series of cycle optimizations using dry cooling and a variety of working fluids.

In FY 1997, NREL completed its studies of the effect of type of working fluid on the performance of cycles located at different resources, and found that large reductions in LEC were possible when the plants used the optimum working fluid. The amount of LEC reduction increased as the resource temperature dropped, an important result because of the large availability of low to moderate temperature resources. The use of recuperation was also studied and found to have minimal to no effect in reducing LEC.

\section{PROJECT OBJECTIVES}

The objectives of this project are to develop a model for analysis of binary cycles and to use the model to evaluate different plant configurations and working fluids. The model is composed of two parts: a program for cycle thermodynamic performance and a spreadsheet for economic evaluation. The database of working fluids allows NREL to study a large variety of mixed and pure working fluids. Recuperation and different types of heat rejection systems can also be studied. New economic information was obtained from CE Holt Company and is included in the model. Through the use of the model, the performance of cycles using different working fluids was studied and the optimum working fluid and plant design, based on lowest LEC, for a particular resource were found. The effect of using techniques to enhance performance and reduce cost, such as adding a recuperator, is included in this study.

\section{Technical Objectives}

- This project will produce a computer model with flexibility in the types of cycles it can analyze. The model will rank the relative performance, based on LEC, of cycles that use different types of heat rejection systems and working fluids, with and without recuperation. A large number of different working fluids will be able to be used in the program. The latest economic information for large plants, from the NGGPP study, will be the basis of the economic evaluation.

- Studies will be conducted that will determine the optimum working fluid for a plant using dry cooling at a number of low temperature resources. The use of recuperation will explored.

\section{Expected Outcomes}

- A computer model will be produced that will be the main tool used to evaluate advanced systems.

- Optimal working fluids for different plant configurations and resources will be determined.

- The effect of modifying plant configuration, such as adding recuperation, on LEC will be determined. The effect of changing environmental conditions, such as varying ambient conditions or changing resource temperature, can also be evaluated using this model. 


\section{APPROACH}

The studies outlined above were conducted using the computer model described in the Background section. This model uses as baseline cases the cycle configuration and economic information from the NGGPP study. The model allows one to see what effect changing the plant configuration or working fluid has on LEC, and permits the relative ranking of different plants. The results of these studies will direct research into the most promising technologies for improving binary cycle, geothermal plant performance. The model can accommodate cycles, with or without recuperation, that use a variety of heat rejection systems. The database of working fluids includes a large number of pure and mixed hydrocarbons. The latest economic information from CE Holt Company has been included.

The model was then used to perform studies to determine the optimum working fluid and plant design for a particular resource. For each resource, a large number of pure and mixed working fluids were used in plants whose heater pressure, condenser bubble point temperature, heater pinch, and condenser pinch were allowed to vary over a wide range. The model then performed an economic analysis of the plants to estimate the LEC of power produced at each plant. The plant with lowest LEC was determined to be the best configuration for that resource, and its working fluid determined to be the optimum fluid. The effect of adding recuperation on plant performance and economics was also determined.

\section{RESEARCH RESULTS}

The results of the working fluid study show that large reductions in LEC are possible when the plants are optimized with the best fluid for the resource. Figure 1 shows a sample of the findings. Many more fluids were studied than are shown. In this figure are shown the base case results, the results for the optimized plants using the best fluid at that resource, the results for plants with lowest LEC using the base case fluid of isobutane, and the results for plants using two mixtures. At the lowest resource temperature studied, $265^{\circ} \mathrm{F}$, the plant with lowest LEC used a mixture of $98 \%$ propane and $2 \%$ isopentane. This plant had an LEC $24 \%$ lower than the base case value of $0.1022 \$ / \mathrm{kWhr}$. The geofluid effectiveness of this plant was $48 \%$ higher than the base case plant. Also, if the base case fluid is used, and the plant parameters allowed to vary to find the plant with lowest LEC, the LEC can be reduced $14 \%$. Also shown is the result that a propane mixture performed well at low resource temperatures, but an isobutane mixture was better at high temperatures. The advantage of mixtures over the base case fluid diminished as the resource temperature increased.

The effect of adding recuperation to the cycle was also studied. The economic potential of using recuperation is limited to a $1.3 \%$ reduction in LEC at the highest temperature resource studied, and a $0.9 \%$ reduction at the lowest temperature resource. No advantage to recuperation was seen at the two intermediate temperature resources. While geofluid effectiveness could be increased significantly at the $265^{\circ} \mathrm{F}$ and $375^{\circ} \mathrm{F}$ resources by using recuperation, the cost of the equipment offset this performance improvement so that the overall advantagc is slight.

A complete description of the results may be found in the last paper in the References section.

\section{FUTURE PLANS}

This concludes the advanced binary cycle modelling task. Future activities in this area will shift to experimental verification of these results at the Geothermal Energy Conversion Facility at NREL. 


\section{INDUSTRY INTEREST}

The computer model is available to industry for making similar studies. The model gives the user an accurate idea of the relative performance of an advanced systcm relative to the NGGPP baseline cases.

The results of the working fluid, operating strategies, and recuperation studies are immediately useful to industry as ways to decrease operating costs and improve plant performance are sought.

These results have been presented at the World Renewable Energy Conference in 1996, Geothermal Program Review 15, 1997 IECEC Conference, and the 1997 GRC Annual Meeting. Attendees have shown great interest in the results.

\section{REFERENCES}

Bliem, C.J., "Computer-Aided Value Analysis for Small, Low-Temperature Binary Systems (with Emphasis on Heat Rejection Systems)," Final Report for NREL Subcontract TAR-5-15085-01, December, 1995.

Bliem, C.J., and G.L. Mines, "Performance Improvements in Binary Geothermal Power Plants Using Advanced Concepts," Geothermal Energy Symposium Proceedings, pp. 329-334, ASME \& GRC, January 1988.

Brugman, J., M. Hattar, K. Nichols, and Y. Esaki, "Next Generation Geothermal Power Plants," EPRI TR106223, CE Holt Company, February 1996.

Demuth, O.J., "Analyses of Mixed Hydrocarbon Binary Thermodynamic Cycles for Moderate Temperature Geothermal Resources," EG\&G Idaho Report PG-G-80-041, February 1981.

Demuth, O.J., and J.F. Whitbeck, "Advanced Concept Value Analysis for Geothermal Power Plants," EGGGTH-5821, March 1981.

Hassani, V., Gawlik, K., "Modeling and Analysis of Advanced Binary Cycles: Summary of Results on the Development of the Computer Analysis Software Tool, Working Fluid Selection, and Recuperation Potential," National Renewable Energy Laboratory, 1997. 


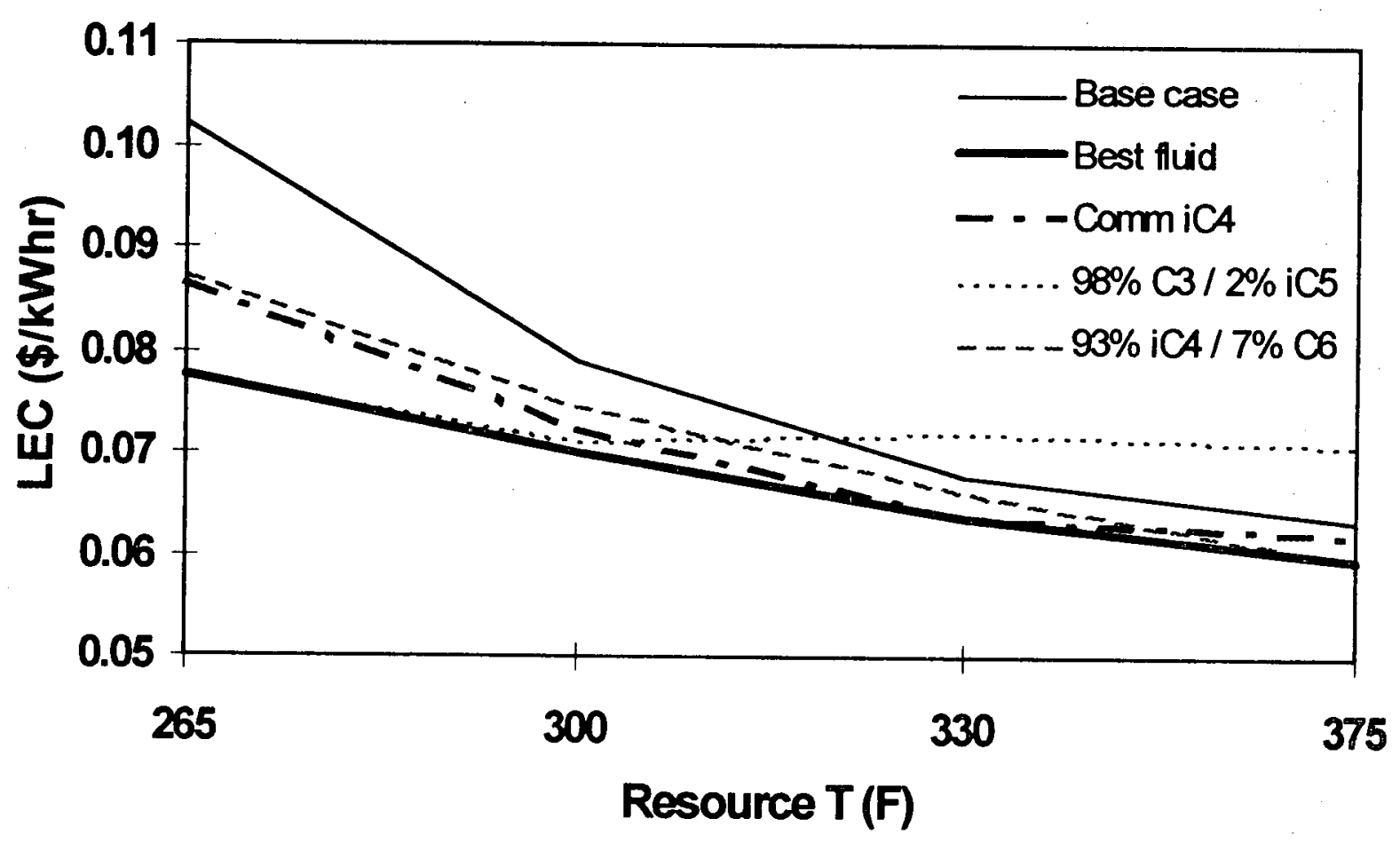

Figure 1 -- LEC results summary for all resources. 


\title{
FIELD TESTING OF THERMALLY-CONDUCTIVE, CORROSION-RESISTANT HEAT EXCHANGER LINERS
}

\author{
Keith Gawlik and Vahab Hassani \\ National Renewable Energy Laboratory
}

\section{KEY WORDS}

materials testing, materials development, polymer concrete lining, heat exchangers, industrial coatings

\section{PROJECT BACKGROUND AND STATUS}

Fouling and corrosion of heat exchangers and brine service piping is a major concern to the geothermal power industry. Increased heat transfer resistance, loss of material due to corrosion, and increased maintenance to remove scale and replace piping combine to raise the cost of power produced from geothermal resources. Traditionally, heat exchangers in highly-fouling brine service have been made from corrosion-resistant, expensive materials such as titanium, monel, and stainless steel. Reducing the cost of the heat exchanger, and potentially slowing the fouling rate, can be achieved by using polymer linings applied to low-cost carbon steel.

A collaborative effort began in 1993 between the National Renewable Energy Laboratory (NREL), Brookhaven National Laboratory (BNL), and an industry partner to evaluate the thermal, anti-fouling, and anti-corrosion characteristics of polymer linings developed by BNL. The first set of field tests, conducted at the industry partner's power plant in the Salton Sea area, compared the performance of BNL's Polymer Concrete Lining (PCL), applied to carbon steel tubes, and bare stainless steel tubes (material AL-6XN). This set of tests ended in November 1994 after a total of 75 days in brine service. The test results indicated that under similar operating conditions the overall heat transfer coefficient for the PCL tubes was about $9 \%$ lower than for the AL-6XN tubes. Similar pressure drops along both sets of heat exchanger tubes indicated that comparable rates of fouling and scale buildup existed on the PC lining and the stainless tubes. Post field test analysis at BNL proved that the PC liner fully protected the carbon steel surfaces from the corrosive brine. However, because the scale-to-PC-liner bond strength was the same order of magnitude as the liner-to-tube-wall bond strength, the PCL tubes could not be reliably hydroblasted clean without damage to the liner surface.

Since that test period, BNL has reformulated the PCL material to increase the bond strength between the liner and tube wall and to reduce the adhesion of scale to the liner. The new formulations have been applied to carbon steel tubes and a new round of tests begun. In addition, BNL has provided tubes coated with polyphenylene sulfide for testing. These tests started in September, 1997, and are anticipated to be completed by the end of December, 1997.

An economic analysis was conducted to determine the cost savings potential of PC-lined heat exchangers. A variety of methods of protecting the tube ends were investigated and cost comparisons made. It was found that if the entire heat exchanger is constructed of carbon steel and protective linings used in the tubes, on the tubesheets, and in the channels, significant savings can be realized. A unit made with PC-lined tubes and using a baked phenolic coating on the balance of the wetted surfaces is $36 \%$ of the cost of a heat exchanger made with traditional corrosion-resistant materials.

In the next fiscal year, tests of different coatings will continue. BNL will refine their coating materials based on the outcome of the current set of tests. NREL will provide phenolic tube linings tailored to the conditions 
encountered in brine service, and commercial coatings may also be tested. In addition, the construction of a new, portable test skid will be considered for use at a binary plant in the Steamboat Springs area near Reno.

\section{PROJECT OBJECTIVES}

This project's objective is to reduce the cost of brine-wetted heat exchangers and service piping at geothermal power plants by developing and testing fouling- and corrosion-resistant coating systems. These coatings are designed to be applied to low-cost carbon steel. Reducing the capital and maintenance costs of heat exchangers will lead to reduced cost of electricity generation, and increased cost competitiveness of the geothermal power industry. To this end, NREL has conducted field tests of polymer concrete coatings developed by BNL to determine the heat transfer, fouling, and corrosion properties of the materials. New coatings from BNL are currently under test, and a variety of other materials, from NREL and, possibly, commercial suppliers, will be evaluated in upcoming tests. Significant capital cost savings can be achieved if heat exchangers are constructed of coated carbon stoel rather than traditional materials such as titanium, monel, and stainless steel. In addition, the anti-fouling properties of the coatings can reduce maintenance costs.

\section{Technical Objectives}

- Evaluate polymer coatings in actual brine service to determine the materials' abilities to prevent corrosion of the base metal, reduce fouling, transfer heat, and remain adhered to the base metal. Compare these results to the performance of traditional corrosion-resistant materials.

- Use the field test results to refine the composition of current coatings and to aid in the development of new coatings.

- Determine the manufacturing issues related to the use of promising coatings, and find ways to resolve construction problems.

- Determine the economic benefits of using coated carbon steel heat exchangers against units made of corrosion-resistant metals.

\section{Expected Outcomes}

- Development of new heat exchanger polymer linings that will reduce the capital and maintenance costs and extend the life of equipment in geothermal brine service

- Provision of data, suitable for heat exchanger design, on the thermal and mechanical properties of polymer linings.

- Development of techniques for using the polymer linings in a commercial heat exchanger construction environment.

- Provision of estimates on the economic advantages of the coatings in reducing capital and O\&M costs.

\section{APPROACH}

NREL, in cooperation with industry partners, performs field tests of polymer coatings provided by BNL, researchers at NREL, and commercial suppliers. BNL has developed liner materials and coated appropriate 
lengths of heat exchanger tubing for the field tests. NREL installs the tubes in its heat exchanger test skid located at a geothermal power plant operated by the industrial partner. Temperature, pressure, and mass flow data are recorded at the site and downloaded via a modem for analysis at NREL's offices. Test skid maintenance may be performed by plant personnel or by a person under subcontract to NREL. Upcoming tests will evaluate coatings developed at NREL and by commercial industrial lining suppliers.

NREL works with industrial heat exchanger manufacturing firms to determine methods by which pre-lined heat exchanger tubes can be assembled into shell and tube heat exchangers using standard industrial processes."These manufacturing firms also help quantify the potential cost savings of using corrosion-resistant liners for carbon steel components in place of using corrosion-resistant metal components or overlays.

\section{RESEARCH RESULTS}

NREL has examined ways to protect the tube ends and tubesheets from corrosion. Since the coated tubes cannot be reliably roller expanded into the tube sheet, and since the coating must be removed from the end up to at least $1 / 2$ " depth in order to weld the tube to the tubesheet, a second coating operation to protect this area is necessary. NREL compared the costs and manufacturability issues related to four different techniques: using a corrosion resistant material, such as titanium, at the bare tube ends; applying a flame-sprayed metal coating; flooding the bare area with phenolic material and baking the coating; and spraying or brushing on the phenolic material, followed by baking. In comparison to a heat exchanger made of traditional materials, it was found that the lowest cost options were the use of the baked phenolic coatings. For the flood application, the estimated cost of the heat exchanger was $39 \%$ of the traditional unit, and for spray or brush application, $36 \%$. These results show the great potential for saving capital cost by use of polymer linings over carbon steel.

\section{FUTURE PLANS}

BNL's reformulated liner materials are currently under test and the results will become available in FY98. Additional field tests of liners from BNL, NREL, and commercial suppliers will be conducted.

A new heat exchanger test skid similar to the existing unit but more compact and transportable will be considered for use at a binary plant in Nevada. This unit has previously been designed and its cost estimated, and the cost will have to be reevaluated.

Work on the protection of the bare tube ends and tubesheets will continue as new materials are evaluated and manufacturing problems identified.

\section{INDUSTRY INTEREST}

\section{Organization \\ CalEnergy}

Oxbow Power Services

Hughes-Anderson Heat Exchangers

\section{Type and Extent of Interest}

Industry partner at whose plant the PCL brine tests are being conducted.

Geothermal power producer who may be first company to receive the new portable heat exchanger test skid.

The company that has conducted design and economic studies of polymer concrete lined heat exchangers. 


\section{REFERENCES}

Bliem, C.G., Miller, and Mines, G.L., 1993, "Results of Field Investigations Conducted with The PolymerConcrete Lined Heat Exchanger Tubes," Idaho National Engineering Laboratory.

Hassani, V., Hoo, E., 1995, "Results of Field Testing on Heat Exchanger Tubes with Polymer Concrete Lining," National Renewable Energy Laboratory.

Kindschi, M., 1995, “An Economic Analysis of the Feasibility of Using Polymer Concrete Lining in Shell and Tube Heat Exchangers Used in Corrosive Geothermal Applications," National Renewable Energy Laboratory.

Sholl, K., Hassani, V., 1997, "Field Testing of Polymer-Concrete-Lined Heat Exchanger Tubes," National Renewable Energy Laboratory.

Webster, R.P., Kukacka, L.E., 1995, "Evaluation of Field-Tested Thermally Conductive Polymer Concrete-Lined Heat Exchanger Tubing," Brookhaven National Laboratory. 


\title{
DEVELOPMENT AND TESTING OF ADVANCED DIRECT-CONTACT CONDENSERS
}

\author{
Desikan Bharathan \\ National Renewable Energy Laboratory
}

\section{KEY WORDS}

Direct-contact condensers, Hydrogen sulfide abatement, Back pressure, Non-condensable gas handling

\section{PROJECT BACKGROUND AND STATUS}

Pacific Gas and Electric Company (PG\&E) owns and operates a set of approximately 14 power plants at the Geysers, utilizing the geothermal steam resource. PG\&E produces about $750 \mathrm{MW}$ from the Geyser steam resource, making the power available to California consumers. On some of the power systems (called Units), PG\&E has experienced performance problems from existing condensers as evidenced by increased operating back pressures and a high carry-over of steam with the non-condensable gases which must be vented. Over the years, PG\&E has pursued different approaches to improve condenser performance with limited success. PG\&E recognized the potential merit of the NREL developed condenser concepts for gaining substantial improvement in the condenser performance and remains interested in developing those concepts into workable hardware.

NREL, DOE and PG\&E have agreed to carry out a collaborative research and development effort to develop field test equipment and test data which will quantify the potential heat-transfer performance and non-condensable gas handling characteristics of these advanced condenser concepts. These condenser developments will be applicable to all steam power plants with a potential for improvement of plant heat rate by as much as five percent.

NREL and PG\&E are working under a Cooperative Research and Development Agreement ( CRADA) to demonstrate the use of advanced design techniques and designs to improve thermal performance and scavenging of non-condensable gases in direct-contact steam condensers, thereby improving the utilization of geothermal steam resource and reducing emission of non-condensable gases.

The work to be carried out was divided in three Phases, with the indicated subtasks:

I. Conceptual Design Development
A. Condenser code upgrade for geothermal applications
B. Selection of packing
C. Performance projections
D. Conceptual design
E. Decision analyses for proceeding to the following phases

II. Engineering Design and Installation (pending Go/No go decision)
A. Steam, gas and water chemistry acceptability analyses
B. Engineering design
C. Procurement and Installation 
III. Operational Tests

A. Instrumentation

B. Operational tests

C. Model validation

D. Reporting

The schedule for the project was matched to accommodate the installation at the time of the scheduled major overhaul and maintenance of the selected unit.

Phase I was carried out in FY 1994 by NREL. Phase II was implemented in FY 1995, with the definition of design and costs by March 1995, and the Go/No go decision for this project was made in July by PG\&E with a go ahead for the project. Phase III was carried out during FY 1997.

\section{PROJECT OBJECTIVES}

In pursuit of its goal of reducing the cost of electricity from various geothermal resources, the Department of Energy (DOE) is conducting investigations to improve the performance and economic viability of geothermal power cycles. One of the DOE tasks, carried out by NREL, is the development and implementation of advanced direct-contact condensers, developed at NREL, which offer a potential for reduced condenser back pressure and improved non-condensable gas handling in geothermal power systems.

\section{Technical Objectives}

- To develop analytical and design methods for improving the performance of existing direct-contact condensers at the Geysers and to retrofit one of Units at the Geysers for performance verification

\section{Expected Outcomes}

- Upon retrofit of the existing condenser, the condenser back pressure will be lowered significantly; this retrofit is estimated to have a pay-back period of less than two years.

\section{APPROACH}

\section{Phase III. Engineering Design and Installation and Testing}

Initial efforts in this Phase allowed PG\&E to undertake a detailed engineering design of the proposed modifications, and initiate procurement and schedule installation. NREL participated in a continuing series of meetings with PG\&E to provide technical guidance and allow uninterrupted progression of the project from the conceptual stage to the engineering stage.

During Phase III, NREL evaluated the requirements for instrumentation to allow model validation when data can be gathered. NREL, in collaboration with PG\&E, conducted a series of pretests on the existing condenser hardware to ascertain the present performance.

Upon completion of installation and commission of the new hardware, NREL, in collaboration with PG\&E, has conducted a series of post tests in May 1997, on the new condenser hardware to ascertain its performance. PG\&E has summarized the results of the pre and post tests in a paper at the Geothermal Resources Council Meeting conducted in October 1997. 


\section{RESEARCH RESULTS}

A working version of a computer code for modeling the direct-contact condenser together with the accompanying chemical reactions has been developed by NREL. This code has been exercised by PG\&E personnel to evaluate the operation of Unit \#11 of the PG\&E power plant at the Geysers. These results have been used to develop designs for the retrofit. The project is progressing according to the original plan. However, on account of demands and pricing for electricity and other outages within the PG\&E system, the major overhaul planned for Unit 11 had to be rescheduled to December 1996.

\section{FUTURE PLANS}

Upon successful installation and demonstration of the improvements at one particular unit at the Geysers, modifications to other units may be pursued depending upon the established economic viability of the system. On account of reduced turbine back pressure, a $5 \%$ improvement in the steam utilization efficiency has been achieved at Unit 11.

\section{INDUSTRY INTEREST}

This project was initiated upon expressed interest of PG\&E. NREL, on behalf of DOE, has applied for a patent on this advanced condenser technology and associated modeling and simulation methods. With the completion of this project with validated results and a pending patent, substantial interest from condenser manufacturers to license this technology has resulted. Marketing efforts by NREL is expected to result in establishment of certain licenses with the U.S. manufacturers, to help improve the U.S. competitiveness in the geothermal power industry. This project is expected to come to a close upon successful licensing and technology transfer to the U.S. manufacturers and the U.S. industry.

\section{REFERENCES}

Bharathan, D., B.K. Parsons, and J.A. Althof, 1988, "Direct-Contact Condensers for Open-Cycle OTEC Applications - Model Validation with Fresh Water Experiments for Structured Packing," Solar Energy Research Institute, SERI/TR-252-3108, Golden Colorado.

J. Henderso and T. Bahning, "Geyser Advanced Direct-Contact Condenser Results," Geothermal Resources Council Transactions, Vol 21, October 1997, pp 507-513. 


\title{
REDUCTION OF OPERATING AND MAINTENANCE COSTS AT GEOTHERMAL POWER PLANTS
}

\author{
Charles Stevens, Joseph Rard, and Carol J. Bruton \\ Lawrence Livermore National Laboratory
}

\section{KEY WORDS}

operating and maintenance costs, geothermal power plants, $\mathrm{H}_{2} \mathrm{~S}$ abatement, $\mathrm{H}_{2} \mathrm{~S}$ stack emissions, spectrometer, The Geysers geothermal field

\section{PROJECT BACKGROUND AND STATUS}

This project addresses the economic necessity of reducing the costs of geothermal power production, especially in light of the effects of deregulation on the power generation industry. We are searching for ways to help reduce operation and maintenance costs at geothermal power plants with regard to chemistry and corrosion. Current projects focus on the need to limit the release to the atmosphere of hydrogen sulfide $\left(\mathrm{H}_{2} \mathrm{~S}\right)$, which is contained in produced geothermal steam. Hydrogen sulfide is detectable in air by its odor at several parts per billion, and is toxic at only slightly higher concentrations (Weres, 1988). Thus, considerable effort has been expended to develop technologies for its removal from steam and condensate. This remediation adds significantly to the cost of geothermal energy, and more cost effective alternatives are being sought. Power plants at The Geysers geothermal field in California must limit the atmospheric release of noncondensable $\mathrm{H}_{2} \mathrm{~S}$ gas that is contained in geothermal steam. At present, Pacific Gas and Electric (PG\&E) uses two major technologies to abate $\mathrm{H}_{2} \mathrm{~S}$ based on oxidizing the reduced sulfur in $\mathrm{H}_{2} \mathrm{~S}$ to more oxidized, less toxic forms. Sulfur is oxidized either by using an iron chelate (where HEDTA = hydroxy-ethylenediaminetriacetic acid), or by using vanadium (V) salts and anthraquinone disulfonates as dual redox catalysts in the Stretford process for oxidation of HS by oxygen in carbonate solutions. The first technology requires use of a fairly expensive chemical reagent (FeHEDTA), which requires replenishing. The Stretford process produces large amounts of an alkaline solution that contains sulfur in a variety of chemical forms, some of which, such as thiosulfate, build-up to unacceptable levels. PG\&E is interested in finding less expensive, alternative reagents for both processes, enhancing the purity and market value of elemental sulfur separated from the Stretford solutions, and destroying thiosulfate ions present in these mixtures. There is presently no way to continuously and accurately monitor $\mathrm{H}_{2} \mathrm{~S}$ emissions from cooling towers. Monitoring is not only required to ensure air quality compliance, but also to control the addition of $\mathrm{H}_{2} \mathrm{~S}$ abatement chemicals. PG\&E currently measures $\mathrm{H}_{2} \mathrm{~S}$ cmissions using portable analyzers at 36 sample points per stack on a regular basis to determine iron chelate demand. Real-time monitoring of the composition of steam from production wells is also needed to determine the demand for steam "desuperheating." Geothermal condensate is being sprayed into the main steam pipeline upstream of the power plants to scrub chlorides, which contribute to stress corrosion cracking in the steam turbine. Steam desuperheating, however, results in the generation loss of about 10 to $20 \mathrm{MW}$ at each Geysers power plant. A real-time monitor of steam chloride content could determine the need for steam desuperheating. We are currently working at The Geysers on using a cross dispersive infrared spectrometer to continuously and accurately measure hydrogen sulfide in cooling tower emissions, which would permit efficient use of abatement chemicals, and on reducing the cost of chemical processing techniques associated with $\mathrm{H}_{2} \mathrm{~S}$ abatement. 


\section{PROJECT OBJECTIVES}

Our objectives are to: (1) conduct proof-of-concept experiments in the field to demonstrate that the cross-dispersive infrared spectrometer can be used to provide accurate, reliable and continuous $\mathrm{H}_{2} \mathrm{~S}$ measurements at cooling stacks and to measure $\mathrm{H}_{2} \mathrm{~S}$ and $\mathrm{HCl}$ in incoming steam; and (2) improve $\mathrm{H}_{2} \mathrm{~S}$ chemical abatement techniques.

\section{Technical Objectives}

- Carry out laboratory tests and field tests at The Geysers to demonstrate the utility of continuous infrared spectral monitoring of $\mathrm{H}_{2} \mathrm{~S}$ emissions from cooling towers and of $\mathrm{HCl}$ and $\mathrm{H}_{2} \mathrm{~S}$ in incoming steam for both corrosion control and environmental purposes.

- Seek alternative or improved strategies for the removal of hydrogen sulfide from geothermal steam and condensate.

- Examine strategies for reducing the disposal costs for sulfur-containing waste from the Stretford treatment process.

\section{Expected Outcomes}

- Real-time monitoring of $\mathrm{H}_{2} \mathrm{~S}$ stack emissions could save an estimated $\$ 300 \mathrm{~K}$ per year by varying the addition of chelate according to changes in fluid chemistry or plant operation, while assuring continued emissions compliance.

- Real-time monitoring of steam chloride content could determine the need for steam desuperheating, which results in a generation loss of about 10 to $20 \mathrm{MW}$ at the Geysers.

- Develop a technique for enhancing the purity and market value of elemental sulfur separated from the Stretford solutions, and in minimizing the undesired build-up of thiosulfate ions in Stretford solutions. More than 100 Stretford units are in use throughout the world.

\section{APPROACH}

\section{Monitoring of $\mathrm{H}_{2} \mathrm{~S}$ Emissions}

The cross dispersive infrared spectrometer is a tool for infrared field measurements that is unique in that it has no moving parts, yet it can make spectral snapshots of the entire infrared region while being nearly immune to external vibrations. It can be over 100 times more sensitive than existing infrared instruments, and is capable of high resolution, being able to distinguish over 10,000 infrared colors. The harsh environment of the cooling towers makes it difficult to implement contact type monitors, and thus a non-contact optical monitor potentially has considerable merit in this application. $\mathrm{H}_{2} \mathrm{~S}$ has a characteristic absorption in the mid-infrared region near 4-micron wavelength. However, it is a very weak absorber, and conventional infrared spectrometers have considerable difficulty making measurements except at very high concentrations, greater than those expected at The Geysers under normal operating conditions. The echelle grating spectrometer has been developed at LLNL in a joint effort involving personnel and support from the several LLNL directorates: NAI, Energy, Engineering, and Chemistry and Materials Science. This infrared instrument is specifically designed to achieve very high sensitivity in harsh operating environments. We are working with PG\&E to properly apply the spectrometer 
system to on-site conditions at The Geysers. $\mathrm{H}_{2} \mathrm{~S}$ Removal via Chemical Processing We obtained fluid samples from PG\&E of the effluent solutions from the two currently used technologies for $\mathrm{H}_{2} \mathrm{~S}$ abatement at The Geysers and characterized their ionic and elemental composition. Complete chemical characterization of the solutions was a requisite first step in analyzing the $\mathrm{H}_{2} \mathrm{~S}$ abatement processes, from which point improvements can be considered. We are now seeking improved ways of extracting elemental sulfur and thiosulfate ions from the Stretford solutions, and of identifying less-expensive alternatives to the iron chelate oxidation technology.

\section{RESEARCH RESULTS}

\section{Monitoring of $\mathrm{H}_{2} \mathrm{~S}$ Emissions}

Experiments were conducted over three days in October 1997 to determine the minimum detectable concentration of $\mathrm{H} 2 \mathrm{~S}$ in the steam condensate just prior to its entry into the power turbines. The steam was condensed into a container by means of an aluminum coil and the headspace above the solution was allowed to equilibrate with it before the vapor was pumped through an optical flow cell for analysis. Improvements in the stability of the apparatus and in the optical coupling of the light into the spectrometer during the course of the investigation allowed us to achieve a measurement precision level of $0.014 \%$ with a one-minute sample time and a level of $0.0025 \%$ average for 30 minutes. This high level of precision provided a detection threshold level for $\mathrm{H} 2 \mathrm{~S}$ of 35 parts per million over a 1-meter path. Our detection limit for methane was approximately 20 parts per billion over the same path, illustrating the comparative sensitivity required for $\mathrm{H} 2 \mathrm{~S}$ detection. Our field study demonstrated the potential for using infrared analysis as a noncontact monitor of $\mathrm{H} 2 \mathrm{~S}$ in The Geysers plant steam condensate.

\section{$H_{z}$ S Removal via Chemical Processing}

A thorough characterization of the effluent from both processes was made using ICP/AES, ion chromatography, and inorganic and organic carbon by chemical methods. In addition, the gas produced from acidification of the very alkaline Stretford solutions was cxamined by gas chromatography/mass spectrometry. Total dissolved sulfur concentrations in the Stretford solutions were about a factor of 100 larger than in the iron chelate solution. The predominant sulfur species in the Stretford solutions was thiosulfate with lesser amounts of sulfate. Sulfate predominates over thiosulfate in the iron chelate solution. High concentrations of thiosulfate add to disposal costs. Neither sulfur dioxide nor sulfite were detected in these solutions. Analysis of the gas produced by acidification of the Stretford solution detected only carbon dioxide and sulfur dioxide; the latter was produced by decomposition of thiosulfate. The absence of hydrogen sulfide in this gas proved that polysulfide species were absent. The iron chelate catalysts in general use include NTA, EDTA, and HEDTA. All of these are slowly destroyed by oxidation, mainly by hydrogen peroxide which is a byproduct formed during the reoxidation of the iron in the chelate (Chen et al., 1995). This necessitates regular replenishing of the relatively expensive iron chelate. Free radical scavengers (including thiosulfate) slow down this degradation. It appears likely that suitable chelates can be developed to resist this oxidation (Chen et al., 1995). More stable alternative chelates for iron could provide a cost-effective alternative to FeHEDTA at some geothermal power plants, but they may be of limited benefit at The Geysers because most of the iron chelate is lost during reinjection of the condensate rather than by oxidation.A literature search was initiated to determine the feasibility of using chlorine, chlorine oxides, or oxychloride for the abatement of hydrogen sulfide. Using chlorine was rejected because of the probable formation of chlorinated methane species, and of sodium hypochloride (bleach) because of its hazardous reaction with ammonia. The most promising reagent of this type is sodium chlorite, which has recently been shown to be highly efficient for the abatement of hydrogen sulfide (de Rocher and Kellogg, 1997). It may be possible to optimize the reaction conditions to produce predominantly elemental sulfur rather than sulfate. 


\section{FUTURE PLANS}

\section{Monitoring of $\mathrm{H}_{2} \mathrm{~S}$ Emissions}

The results of our tests will be used to design an on-line H2S monitor that will be tested later this year. We will then investigate the direct monitoring of incoming steam for $\mathrm{H} 2 \mathrm{~S}$ and $\mathrm{HCl}$ content for both corrosion control and environmental purposes.

\section{$\mathrm{H}_{2}$ S Removal via Chemical Processing}

We will pursue the use of sodium chlorite for $\mathrm{H} 2 \mathrm{~S}$ abatement by determining if there are any possible hazardous side reactions with the hydrogen, ammonia, or methane present in geothermal steam and brines. If the process seems feasible, we will characterize reaction yields and products as a function of $\mathrm{pH}$ and temperature, and attempt to tailor the process to yield elemental sulfur.

\section{INDUSTRY INTEREST}

\section{Organization}

PG\&E

\section{Type and Extent of Interest}

$\mathrm{H}_{2} \mathrm{~S}$ abatement techniques, $\mathrm{H}_{2} \mathrm{~S}$ emission monitor, monitor of $\mathrm{H}_{2} \mathrm{~S}$ and $\mathrm{HCl}$ in incoming steam

\section{REFERENCES}

D. Chen, A. E. Martell, and D. McManus (1995), "Studies on the Mechanism of Chelate Degradation in Iron-based, Liquid Redox H2S Removal Processes," Can. J. Chem. 73, 264-274.

T. de Rocher and N. Kellogg (1997), "Cooling Water Hydrogen Sulfide Abatement Using Sodium Chlorite," Geothermal Science and Technology 5, 147-154.

O. Weres (1988), "Environmental Protection and the Chemistry of Geothermal Fluids," Geothermal Science and Technology, 1253-302. 


\section{LIST OF CONTACTS FOR CONVERSION TECHNOLOGY}

Dr. Marita L. Allan

Energy Efficiency and Conservation Division

Department of Applied Science

Building 526

Brookhaven National Laboratory

Upton, NY 11973

Phone: (516) 3443060

Fax: (516) 3442359

e-mail: allan@bnl.gov

Willettia Amos

Advanced Technology Division

U.S. Department of Energy

Idaho Operations Office

785 DOE Place, MS 1220

Idaho Falls, ID 83402-1562

Phone: (208) 526-4097

Fax: (208) 526-5964

e-mail: amoswd@inel.gov

Desikan Bharathan

National Renewable Energy Laboratory

1617 Cole Boulevard

Golden, Colorado

Phone: (303) 384-7418

Fax: (303) 384-7495

e-mail: Desikan_Bharathan@nrel.gov

Peggy Brookshier

Office of Program Management

U.S. Department of Energy

Idaho Operations Office

785 DOE Place, MS 1220

Idaho Falls, ID 83402

Phone: (208) 526-1403

Fax: (208) 526-6249

e-mail: brookspa@inel.gov
Blaine Brown

Idaho National Engineering \& Environmental Laboratory

Lockheed Martin Idaho Technologies Company

P.O. Box 1625

Idaho Falls, ID 83415-3625

Phone: (208) 526-9292

Fax: (208) 526-4017

e-mail: brownbw@inel.gov

Carol J. Bruton

Lawrence Livermore National Laboratory

L-219

P.O. Box 808

Livermore, CA 94550

Phone: (510) 423-1936

Fax: (510) 422-0208

e-mail: bruton1@llnl.gov

Keith Gawlik

National Renewable Energy Laboratory

1617 Cole Boulevard

Golden, CO 80401

Phone: (303) 384-7515

Fax: (303) 384-7540

e-mail: keith_gawlik@nrel.gov

Vahab Hassani

National Renewable Energy Laboratory

1617 Cole Boulevard

Golden, CO 80401

Phone: (303) 384-7464

Fax: (303) 384-7495

e-mail: vahab_hassani@nrel.gov

J. Henderson, ,

Senior Chemical Engineer

Pacific Electric and Gas Company

3400 Crow Canyon Road

San Ramon, CA 94583

Phone: (510) 866-5491

Fax: (510) 866-5681

e-mail: jmh6\%TesCe\%gsv@go01.comp.pge.com 
Dr. Allan J. Jelacic

U.S. Department of Energy

Office of Geothermal Technologies

Room 5H-072, EE-12

1000 Independence Avenue, SW

Washington, DC 20585

Phone: (202) 586-6054

Fax: (202) 586-8185

Raymond LaSala

Office of Geothermal Technologies, EE-12

U.S. Department of Energy

1000 Independence Ave., SW

Washington, DC 20585

Phone: (202) 586-4198

Fax: (202)586-8185

e-mail: Raymond.LaSala@ee.doe.gov

Greg Mines

Idaho National Engineering \& Environmental Laboratory

Lockheed Martin Idaho Technologies Company

Idaho Falls, Idaho 83415-3830

Phone: (208) 526-0260

Fax: (208) 526-0969

e-mail: minesgl@inel.gov

Judy K. Partin

Advisory Scientist

Idaho National Engineering \& Environmental

Laboratory

Lockheed Martin Idaho Technologies Company

Idaho Falls, Idaho 83415-2211

Phone: (208) 526-2822

Fax: (208) 526-2814

e-mail: jk6@inel.gov

Martin Plum

Idaho National Engineering \& Environmental

Laboratory

Lockheed Martin Idaho Technologies Company

P.O. Box 1625

Idaho Falls, ID 83415-3875

Phone: (208) 526-1108

Fax: (208) 526-8883

e-mail: plummm@inel.gov
Dr. Eugene T. Premuzic

Brookhaven National Laboratory

Department of Applied Science

Energy Science and Technology Div.

Upton, NY 11973

Phone: (516) 282-2893

Fax: (516) 282-2060

Peter A. Pryfogle

Staff Scientist

Idaho National Engineering \& Environmental

Laboratory

Lockheed Martin Idaho Technologies Company

P.O. Box 1625

Idaho Falls, Idaho 83415-2203

Phone: (208) 526-0373

Fax: (208) 526-0828

e-mail: wck2@inel.gov

Marshall Reed

Office of Geothermal Technologies, EE-12

U.S. Department of Energy

1000 Independence Ave., SW

Washington, DC 20585

Phone: (202) 586-8076

Fax: (202) 586-8185

e-mail: marshall.reed@hq.doe.gov

Joel L. Renner

Advisory Scientist

Idaho National Engineering \& Environmental

Laboratory

Lockheed Martin Idaho Technologies Company

P.O. Box 1625

Idaho Falls, Idaho 83415-3830

Phone: (208) 526-0373

Fax: (208) 526-0969

e-mail: rennerjl@inel.gov

Dr. Toshifumi Sugama

Brookhaven National Laboratory

Upton, NY 11973-5000

Phone: (516) 344-4029

Fax: (516) 344-2359

e-mail: sugama@bnl.gov 


\author{
R.P. Webster \\ Department of Applied Science \\ Building 526 \\ Brookhaven National Laboratory \\ Upton, NY 11973 \\ Phone: (516) 344-2845 \\ Fax: (516) 3442359 \\ e-mail: webster@bnl.gov
}




\title{
GEOTHERMAL DIRECT-HEAT UTILIZATION ASSISTANCE
}

\author{
John W. Lund \\ Geo-Heat Center \\ Oregon Institute of Technology (OIT)
}

\section{KEY WORDS}

aquaculture, direct use, district heating, greenhouses, heat pumps, industrial, low temperature resources, space heating, technical assistance

\section{PROJECT BACKGROUND AND STATUS}

The Geo-Heat Center, established in 1975 at Oregon Institute of Technology, conducts research, provides technical assistance and distributes general information on a wide range of applications in the area of geothermal energy. This program, the only one of its kind in the nation, provides rapid response, unbiased information to designers, developers and owners of systems ranging from geothermal heat pumps, through direct use to small power generation projects.

Research and development tasks are conceived carefully to address current industry needs in the areas of cost containment, equipment performance/application and system design.

The technical assistance program, designed to augment, not compete, with private engineering firms and developers, offers technical support for system design, equipment selection and trouble shooting for geothermal systems. This program places the unique technical expertise of the Center's staff at the disposal of designers around the country.

A major obstacle to wider use of geothermal is lack of awareness. The Center's outreach program addresses this issue with a variety of information sources. Through the publication of an industry quarterly Bulletin (2,000 subscribers), handbooks, software, Internet webpage (http://www.oit.edu/ geoheat) and a dedicated geothermal technical library (5,300 volumes) a broad spectrum of information is available to the public. Beyond this, staff activity in and publications for industry and professional groups greatly enhances technology transfer efforts.

The U.S. geothermal resource base is currently the largest of all renewables and, in fact exceeds that of the combined capacity of solar, wind and tidal power. Though growing rapidly, the use of this immense resource remains distressingly small. Continued, aggressive and cost effective support of geothermal is the key to unlocking it's potential.

\section{PROJECT OBJECTIVES}

The objectives of this project are to conduct direct-heat applied research and development, and to provide assistance to stimulate utilization of the nation's large low-to moderate-temperature $\left(<20^{\circ}\right.$ to $\left.150^{\circ} \mathrm{C}\right)$ geothermal resource base. 


\section{Technical Objectives}

- To provide tochnical assistance to developers of geothermal direct use projects for space heating, geothermal heat pumps, greenhouses, aquaculture and industrial applications;

- To perform appropriate R\&D to reduce the cost of installing and operating direct use projects;

- To publish information and educational materials, maintain a homepage and library to aid researchers and developers of geothermal direct use projects.

The success of this project will mean more rapid penetration of geothermal direct use into the energy sector:

\section{Expected Outcamex}

- Energy savings and reduced emissions of airbome pollutants and greenhouse gases due to more geothermal direct-heat projects on-line. For example, a $457 \mathrm{~m}, 82^{\circ}$ geothermal well producing $3 \mathrm{MWt}$ (500 gpm) saves $28 \mathrm{TJ} / \mathrm{yr}$ of energy and reduces $\mathrm{CO}_{2}$ by $687 \mathrm{~kg}$ per year compared to a natural gas boiler plant.

- Geothermal energy used for district heating in existing single-family homes, implemented in areas of propane, electric or fuel oil (or combinations of these with wood) resulting in a savings of about $30 \%$ per year.

- Reduced costs for geothermal greenhousc operators wishing to continue using tube type heating systems and where additional geothermal flow is not available (conventional fuel peaking offers the opportunity to reduce costs by $75 \%$ relative to conventional heating).

- Increased awereness of geothermal direct-heat dovelopments and opportunities through a Quarterly Bulletin on geothermal projects, handbooks, geothermal homepage, technical papers, software, tours, and other educational materials.

\section{APPROACH}

The Geo-Heat Center's approach is to provide technical assistance to prospective geothermal users on resource data, preliminary engineering design, analysis of operational problems and technical information. The program is designed to introduce the potential user and engineering consultant to geothermal direct-heat applications. The presence of a proven and reliable source of technical advice to the consultant is critical in promoting their initial involvement with an unfamiliar resource. The Oregon Institute of Technology provides a cost share of $10 \%$ on the project. Further, the Geo-Heat Center publishes educational materials to aid engineers in the design of direct use projects.

\section{RESEARCH RESULTS}

\section{Technical Assistance Program}

The Geo-Heat Center provides assistance to those actively involved in geothermal development. Geothermal projects are allocated a limited number of man-hours (usually eight hours/project unless prior approval for additional hours are received from DOE) for analysis. Engineering and economic assistance has been provided to a broad range of clients, from the homeowner interested in geothermal space heating and municipalities 
engaged in geothermal district heating projects, to industrial concerns adapting geothermal resources to meet their process energy needs. During FY-97, the program handled 725 requests for technical and development assistance on geothermal direct use projects and for various types of technical information. This is an increase of $44 \%$ over FY-96, with most of the request coming by e-mail.

The program's R\&D accomplishments included: (1) A Comprehensive Greenhouse Developers Package, and (2) Well Pumping in Commercial Groundwater Heat Pump Systems, which are summarized below.

\section{A Comprehensive Geothermal Greenhouse Developer Package (Rafferty and Boyd, 1997)}

The package of information is intended to provide background information for developers of geothermal greenhouses. The material is divided into seven sections covering such issues as crop culture and prices, operating costs for greenhouses, heating system design, vendors and a list of other sources of information.

Section 1 - Crop Market Prices contains recent wholesale price information for some typical vegetable and flower crops grown in greenhouses. Both national and regional prices are included along with an indication of seasonal variations for some crops. Sources for current price information are provided at the end of the section. An example of season average prices for four common greenhouse vegetables are as follows:

\begin{tabular}{|l|c|c|c|c|}
\hline & \multicolumn{4}{|c|}{ Season Average Price \$/cwt } \\
\hline Vegetable & 1992 & 1993 & 1994 & 1995 \\
\hline Tomatoes & 35.80 & 31.70 & 27.50 & 26.00 \\
\hline Bell Peppers & 26.80 & 30.20 & 29.60 & 31.10 \\
\hline Head Lettuce & 12.50 & 16.00 & 13.30 & 23.10 \\
\hline Cucumbers & 19.10 & 18.00 & 16.00 & 16.70 \\
\hline
\end{tabular}

Section 2 - Greenhouse Operating Costs outlines ranges of costs for a typical operation such as labor, utilities, plant stock and mortgage components. Cost ranges for structure construction are also provided. The total greenhouse costs (including greenhouse and operating equipment) range from $\$ 11.34$ to $\$ 14.24 / \mathrm{ft}^{2}$ of greenhouse, with an average price of $\$ 12.65 / \mathrm{ft}^{2}$. The construction costs alone were in the $\$ 7.30$ to $\$ 8.05 / \mathrm{ft}^{2}$ range with an average of $\$ 7.44 / \mathrm{ft}^{2}$.

Section 3 - Crop Culture Information provides abbreviated culture information for some typical vegetables and flower crops. Such issues as temperature requirements, $\mathrm{CO}_{2}$, lighting and disease issues are covered. For each species, an extensive list of additional information sources are provided. Detailed information is provided on tomatoes, cucumbers, hydroponic lettuce, carnations and roses.

Section 4 - Greenhouse Heating Systems consists of recently updated Chapter 15 - Greenhouses from the Geothermal Direct Use Engineering and Design Guidebook. It covers the design and performance of various heating equipment commonly used in geothermal greenhouses. The topic of peaking with conventional fuel is also covered. Construction material of glass, plastic film and fiberglass are discussed and heating systems using 
finned pipe, standard unit heaters, low-temperature unit heaters, fan coil units, soil heating and bare tube are also covered in detail using sample design calculations.

Section 5 - Greenhouse Heating Equipment Selection Spreadsheet is the supporting information and documentation for a spreadsheet based on Section 4. Included are: screens covering the selection and cost of six types of geothermal greenhouse heating systems. This material is intended for use by engineers and those very familiar with the design of heating systems.

Section 6 - Vendor Information provides a list of vendors for components of geothermal systems, and greenhouse structures and equipment. These include the name and address for greenhouse supplies, hydroponic systems, greenhouse manufacturers and suppliers, plant materials--seeds and plants, well pumps, variable-speed drives, plate heat exchangers, piping and space heating equipment.

Section 7 - Other Information Services provides an extensive list of sources for information on greenhouse operation including state extension agencies, and USDA state offices.

Well Pumping in Commercial Groundwater Heat Pump Systems (Rafferty, 1997)

Key to efficient well pumping design is the consideration of three major power consuming components of commercial groundwater heat pump systems: well pump, heat pumps and building loop pump. Careful consideration of the interaction betwcen these components and their impact upon system performance is necessary in order to minimize operating costs for the building owner.

The research considered well pump head analysis, well pump power requirements, optimum water flow requirements for the loop pump and comparison of ground-coupled heat pump system performance.

Well pump head in a groundwater heat pump (GWHP) application consists of three major components: lift, surface requirements and injection head. The vertical distance between the pumping level and the ground surface constitutes the "lift" portion of the well pump head. Surface hrad loss includes the losses in piping, the isolation heat exchanger and associated fittings and accessories. The report discusses the use of injection for disposal and how to calculate the injection pressure. If the water level remains below ground level at design flow conditions, there is no additional well pump head associated with injection.

Well pump power requirement is a function of flow, head and efficiency. Based on an overall well pump (and motor) efficiency of $60 \%$, well pump power consumption varies from $<50 \mathrm{~W} /$ ton $(@ 1 \mathrm{gpm} /$ ton and $100 \mathrm{ft}$ head) to nearly375 W/ton (@3 gpm/ton and $400 \mathrm{ft}$ head)--[0.14 W/kW (@ $1 \mathrm{~L} / \mathrm{min} / \mathrm{kW}$ and $30 \mathrm{~m}$ head) to nearly 107 W/kW (@3 L/min/kW and $120 \mathrm{~m}$ head)].

Avoidance of excessive well pump power lies in a design procedure which rests upon total system performance rather than simply heat pump unit performance.

Optimum system performance is obtained when the power consumption of the well pump, loop pump and heat pumps is minimized through careful design. At a given loop flow rate, heat pump performance is largely a function of loop water temperature. In most GWHP applications, the groundwater flow will be less than the building loop flow for optimum design. Information on total system performance for three water temperatures $\left(50^{\circ} 60^{\circ}\right.$ and $\left.70^{\circ}\right)\left(10^{\circ} 16^{\circ}\right.$ and $\left.21^{\circ}\right)$ at various well pump heads and flows were developed to show the designer that he has some latitude in loop flow selection. Figure 1 shows example curves for cooling duty with $60^{\circ}\left(16^{\circ}\right)$ groundwater. 
Properly designed groundwater heat pump systems are characterized by peak load performance comparable to, or in some cases superior to, ground-coupled systems. To achieve this performance, it is necessary to select the groundwater flow with total system performance in mind. In addition, the flow should be based upon peak block load and not installed capacity.

\section{FUTURE PLANS}

The Geo-Heat Center will continue to act as a clearinghouse to provide project technical assistance and information on geothermal direct use projects.

The Geothermal Direct Use Engineering and Design Guidebook will be revised and updated for 12 Chapters and printed.

R\&D activities for FY-98 will include: (1) Model Construction Specifications for Geothermal Wells and Well Equipment, and (2) A Comprehensive Aquaculture Developer Package.

The Bulletin will be distributed quarterly, the homepage will be maintained, new software will be developed that will enhance the ability of design engineers on geothermal direct use projects, and information about geothermal projects and other related developments will be gathered and distributed.

\section{INDUSTRY INTEREST}

The following is the number of requests for geothermal direct heat technical assistance during Fiscal Year 1997 from individuals, companies and municipalities:

\section{Type of Interest}

Geothermal Heat Pumps

Space and District Heating

Greenhouses

Aquaculture

Industrial

Resource/well

Equipment

Electric Power

Resorts/Spas

Snow Melt

General

Total

\section{Number of Requests}

232

80

34

35

14

93

53

27

14

2

141

725

Technology transfer activities included: publication of the GHC Quarterly Bulletin (Vol. 17, No. 4, and Vol. 18, Nos. 1 - 3), which includes technical articles and a geothermal progress section. Development of a geothermal homepage (www.oit.edu/ geoheat), it's main headings include: What is Geothermal, Services Offered, Publication List, Bulletin, Where are the Geothermal Direct Use Project Sites (an interactive map), Where are Geothermal Resources, Directory of Consultants and Equipment Manufacturers, Funding/Disclaimer and Other Places of Interest, and the Quarterly Bulletin. Links were added to the webpage for (1) Geothermal Energy Association, (2) Arizona Aquaculture, (3) American Tilapia Association, and (4) Hot Dry Rock Geothermal at Los Alamos 
National Lab. "An Information Survival Kit for the Prospective Residential Geothermal Heat Pump Owner" was also added. A Geothermal Library of over 5,300 volumes was maintained and can be accessed through the Intemet on the GRC homepage. A total of 1,769 publications were requested during the fiscal year, 6 technical papers were prepared and presented, 9 groups were given tours of local geothermal facilities, and 13 geothermal progress monitor reports were prepared.

\section{REFERENCES}

Rafferty, Kevin and Tonya Boyd, 1997. Geothermal Greenhouse Information Package, prepared for USDOE, Office of Geothermal Technologies, Geo-Heat Center, 72 p.

Rafferty, Kevin, 1997. Well Pumping Issues for Commercial Groundwater Heat Pump Systems, prepared for USDOE, Office of Geothermal Technologies, Geo-Heat Center, 28 p. 


\section{Effect of Groundwater Flow on EER $60 \mathrm{~F}$ Groundwater}

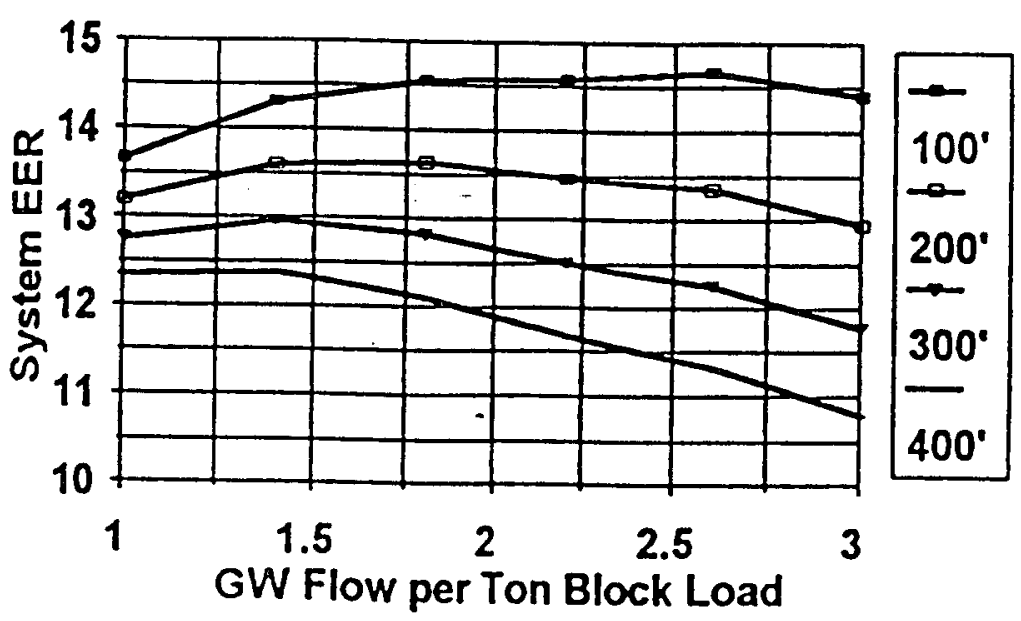

Figure 1 -- Well pump requirements as a function of flow and pump head. 


\title{
GEOTHERMAL HEAT PUMP TECHNOLOGY TRANSFER
}

\author{
J. Mark Hannifan and Joseph E. King \\ Heritage Technologies
}

\section{KEY WORDS}

heat pumps, technology transfer, marketing support, utility programs

\section{PROJECT BACKGROUND AND STATUS}

The geothermal heat pump (GHP) industry has received a boost from the formation of the Geothermal Heat Pump Consortium (GHPC) and the increased involvement of the U.S. Department of Energy's Office of Geothermal Technologies. These organizations have formed the National Earth Comfort Program (NECP) whose purpose is to promote and accelerate the market penetration of GHP technology.

For energy providers of the future to successfully compete, they must do so on the basis of cost, performance, reliability, and value-enhancement. For the GHP industry to successfully meet the installation goals established by the NECP, GHP technologies must also compete on the basis of cost, performance, reliability, and valueenhancement. GHP systems will compete favorably with other system options where installed costs can be minimized, performance can be maximized, an installation and service infrastructure is established, and the overall value of GHP systems is effectively communicated to building owners.

\section{PROJECT OBJECTIVES}

To support the goals of the NECP, the DOE-ID Geothermal Program and Heritage Technologies solicited the interest of electric utilities in developing and implementing GHP marketing programs. The primary objective was to identify and provide two utilities with the following assistance:

\section{Technical Objectives}

- Provide suggestions to the utilities to increase the number of GHPs installed in existing residential and/or commercial programs; and

- Assist the utilities in developing a comprehensive GHP program designed to achieve meaningful market penetration within $1-2$ years.

\section{APPROACH}

\section{Refine Marketing Strategies}

Heritage is providing general assistance to each sclected utility to help sharpen their marketing focus and to finalize delivery strategies of the marketing programs that may have discussed in preliminary contacts with the utilities during the selection process. This support will include helping the utilities to clearly define:

- What is their target market segment(s); 
- What is the competitive position of GHP systems vs. other HVAC-water heating options in the target market segment(s);

- Who are the utility's existing and proposed trade allics (manufacturers, distributors, dealer/installers, etc.);

- What are the information needs of staff and customers of the utility;

- What are the training needs for utility or trade ally personnel;

- What market barriers have previously hindered GHP use; and

- What financial incentives, if any, are needed to accelerate use of GHP systems.

Development of Marketing Support Information: Briefing Books

Based on the results of the above questions, Heritage is developing a briefing book for each utility that will cover a range of technical and marketing topics related to GHP systems that the utilities may use as background information for internal staff or as a starting point for marketing materials for customers. ${ }^{1}$ The briefing books will contain the following type of information:

\section{GHP System Operation}

Ground Coupling Options - What are the installation requirements and operating advantages of closed-loop (vertical/horizontal, pond) and open-loop (well, pond, reservoir) systems? What information about subsurface conditions (soil/rock, temperatures, etc.) is needed?

Heat Pump and Thermal Delivery Options - What are the installation requirements and operating advantages of water-to-air, water-to-water, DX, and other heat pump equipment? How can thermal comfort be effectively delivered to building spaces? Which heat pump equipment and delivery systems are best suited for various building types?

Integration with Water Heating And Refrigeration - To what extent can GHPs meet hot water and refrigeration loads? How does such integration affect system design, selection, and sizing? Can GHPs provide dedicated water heating and refrigeration?

\section{GHP System Specifications and Integration}

Estimating Building Loads - What noods to be known about peak (design) loads, diurnal, monthly, and seasonal building energy loads prior to considering GHPs? What tools expedite the estimation of loads, and which tools can be used to estimate GHP system performance? Which tools are appropriate for specific building types?

GHP System Selection and Sizing - Which type of heat pump equipment is best suited for residential and a variety of commercial buildings? How are GHP heat pumps sized to minimize initial cost yet maintain high efficiency? What effect do loop size and water delivery rates have on sizing and performance?

${ }^{1}$ The exact content of the briefing materials will be discussed with the DOE-ID project manager and the utilities prior to developments. 
Initial Costs (Equipment, Installation, Etc.) - Since it is a relatively new technology option, what are the associated component costs in a GHP system? What strategies exist to minimize loop installation costs? How do costs vary between new and retrofit projects? What impact does system size and configuration have on cost?

Operating and Maintenance Costs - To what extent do GHP systems reduce energy and demand? How much do other system components such as pumps and fans contribute to energy and demand requirements? What are the typical requirements for maintaining ground loops?

\section{Market Characteristics}

Building Types/Ownership - What are the predominant building types in the market(s) targeted? Are there multiple buildings owned by the same owner (e.g. retail/restaurant chains, insurance companies, GSA, etc.).

Building/Equipment Vintages - What are the predominant building/mechanical equipment combinations in the target market(s)? How do the combinations vary with building or equipment vintage?

Utility Rates (Energy and Demand) - What are the rate options available for buildings in the target market(s)? How significant is energy vs. demand in prevailing rate structures?

\section{Skill Requirements}

Field Auditing (for Existing Buildings) - What skills are need to perform simple and detailed field audits of existing buildings? What data must be gathered to allow performance and economic analyses?

Design Engineering - What tools are available to assist in the selection and sizing of GBP system components? What tools are available to estimate thermal, elcctrical, and economic performance? Where can specialized engineering skills be acquired to supplement in-house skills?

Equipment Distributors and Dealers - Who makes GHP-related equipment and how are their products delivered? What sort of support and/or service may be expected from GHP equipment vendors? What range of equipment capacities do they offer?

Installers (Drillers, Loop Installers, Etc) - What training should loop installers have? Who has responsibility with regards to loop performance - the loop installer or the design engineer? What methods are available to minimize loop cost while maintaining performance?

Maintenance Personnel - What training should maintenance personnel have? What frequency might maintenance be expected? How does maintaining a GHP system vary from other building systems?

\section{Market Risks}

Equipment Failure - What are typical operating profiles and lives of system components? How reliable is the ground loop? How can a major loop failure be corrected? What are typical warranty provisions from GHP component manufacturers?

Customer and Load Changes - What is the impact on GHP system performance and economics if a school modifies its occupancy schedule from 9 month to 12 month operation? What impact would new envelope and 
lighting upgrades have on an existing GHP system? Conversely, how would a GHP system accommodate new thermal loads?

Utility Rate Fluctuations - How might retail competition affect retail rates? What affect would these rate changes have on GHP system economics? How sensitive are GHP economics to the price of natural gas?

Availability of Parts and Service - Is there a local support infrastructure for GHP systems? Are GHP systems so specialized that parts and service are hard to come by? Can traditional HVAC service companies provide support for GHP systems?

\section{Development of Marketing Support Information: Analysis}

Heritage is providing support to each utility in developing comparative analyses of GHP and alternate HVAC/ water heating systems to demonstrate the energy and economic benefits of GHP systems. The energy analyses will be structured to use utility-specific weather and the economic assessments will investigate the financial benefits of GHP systems to the customer (with and without utility-provided incentives).

\section{Development of Marketing Support Information: Customer Information}

Once the briefing books and comparative analyses are completed, Heritage will continue to support the utilities as they finalize the details of their marketing programs. Heritage will provide assistance in the review of draft or camera-ready customer-oriented materials that the utilities may generate. Where needed, Heritage will assist the utilities in the development of conceptual or schematic illustrations to communicate to target customers the installation or operational aspects of GHP systems. Heritage will also assist the utilities in developing case study information for successful GHP systems in their service territory, if merited.

\section{RESEARCH RESULTS}

The project is just underway with a February 28, 1998 completion date. Thus, reporting of research results is premature.

\section{FUTURE PLANS}

Plans will be determine based on the results of the efforts described above.

\section{INDUSTRY INTEREST}

Organization

Southern California Edison

\section{Type and Extent of Interest}

Residential and Commercial GHP Systems Others (TBD) 


\title{
SOUTHEAST GEYSERS EFFLUENT PIPELINE PROJECT
}

\author{
Mark Dellinger, Project Manager \\ Lake County Sanitation District \\ Lake County, California
}

\section{KEY WORDS}

Injection; reservoir management; wastewater efluent; public/private partnership

\section{PROJECT BACKGROUND AND STATUS}

The project concept originated in 1990 with the convergence of two problems: 1) a need for augmented injection to mitigate declining reservoir productivity at The Geysers; and 2) a need for a new method of wastewater disposal for Lake County communities near The Geysers. A public/private partnership of Geysers operators and the Lake County Sanitation District (LACOSAN) was formed in 1991 to conduct a series of engineering, environmental, and financing studies of transporting treated wastewater effluent from the communities to the southeast portion of The Geysers via a 29-mile pipeline as shown in Figure 1. By 1994, these evaluations concluded that the concept was feasible and the stakeholders proceeded to formally develop the project, including pipeline and associated facilities design; preparation of an environmental impact statement; negotiation of construction and operating agreements; and assembly of $\$ 45$ million in construction funding from the stakeholders, and from state and federal agencies with related program goals.

The project development process culminated in its dedication on October 16,1997. As of that date the status of the project's major components were as follows:

- Pipeline: The entire 29-mile pipeline has been installed and successfully tested. Water has been moving through the pipeline to The Geysers since the end of September 1997.

- Pump stations: All six pump stations have been constructed. Final testing at the three Bear Canyon stations is underway, with completion expected before the end of 1997.

- Flow control tank: A 250,000 gallon stcel tank has been completed and successfully leak tested, and is now fully operational.

- Steamfield distribution pipelines: All of the steamfield distribution pipelines between the main effluent pipeline and injection wellheads have been completed and are operational.

- Control system: All control system components have been installed. Final adjustments and fine-tuning is underway and will be completed before the end of 1997.

- Environmental mitigation: All crosion control and standard revegetation has been completed. Maintenance of this work will occur over the winter of 1997-98. The special woody plant revegetation is approximately $50 \%$ complete, with the remainder due for full completion by Spring of 1998 . 
- Southeast regional wastewater treatment plant improvements: Upgrades to the treatment plant and two collection system pump stations were initiated in June 1997. This work is approximately $90 \%$ complete and is expected to be finished in January 1998.

The construction accomplished through November 1997 and successful start-up of operations are both in conformance with the project's original schedulc. Funds expended to date are similarly in conformance with forecasted cash flow.

\section{PROJECT OBJECTIVES}

The overall objectives of the project are to demonstrate that large-scale augmented injection is a viable reservoir management practice that can simultaneously convert the community liability of wastewater into a sustainable energy asset.

\section{Technical Objectives}

- Mitigation of reservoir productivity declines through augmented injection.

- Use of treated wastewater effluent as an injection fluid.

- Use of a public/private partnership of stakeholders to plan and implement a synergistic solution to their respective problems.

\section{Expected Outcomes}

- Construction of the 29-mile, 20-inch diameter cffluent pipeline and associated facilities on schedule and within budget.

- Delivery of 7.8 million gallons per day of wastewater effluent and lake make-up water to the Southeast Geysers for injection.

- Recovery of effluent-derived geothermal steam in an amount equivalent to approximately $70 \mathrm{MW}$ of generating capacity, or approximately $625,000 \mathrm{MWh}$ of effluent-derived electricity generation annually.

- Operation of the system for 25 years or more.

\section{APPROACH}

The project's approach to problem solving is distinguished by two characteristics: 1) a public/private partnership that includes all key stakeholders working together on a consensus basis; and 2) a comprehensive and thorough series of reservoir assessment, pipeline engineering, and environmental impact studies to insure that risks have been minimized, and that the constructed project will perform according to specifications. A strong monitoring and evaluation component will be used to verify the degree of success in attaining project goals. 


\section{RESEARCH RESULTS}

Quantified pipeline operation and reservoir injection results will not be available until the end of 1997 when full operation commences. Thereafter the project expects to issue periodic performance reports via a website which will be operational in January 1998.

\section{FUTURE PLANS}

Once full operations are completely underway, the project will monitor pipeline operations and evaluate reservoir productivity to determine if expected results have been achieved. Additionally, other communities in the region are considering disposal of their wastewater via similar pipelines if initial Southeast Geysers operations are satisfactory.

\section{INDUSTRY INTEREST}

The following geothermal industry organizations are participating with LACOSAN in the project:

\section{Organization}

Northern California Power Agency

Unocal Corp.

Calpine Corp.

Pacific Gas \& Electric Co.

\section{Type and Extent of Collaboration}

Co-funder; operator of pipeline control system; steamfield injection operator; power-plant operator.

Co-funder; steamfield operator.

Co-funder; steamfield operator.

Co-funder; power plant operator.

LACOSAN, NCPA, Unocal, and Calpine constitute the membership of the project's Joint Operating Committee (JOC). The JOC will oversee pipeline operation and maintenance, and conduct monitoring and evaluation of the project's performance.

\section{REFERENCES}

California Energy Commission, December 1991, Geysers KGRA Generating and Steam Resources Study, Docket 89-INF-1, Sacramento, CA.

CH2M-Hill, September 1995 and March 1996, S.E. Geysers Effluent Pipeline Project Final Plans and Specifications, Redding, CA.

CH2M-Hill, February 1997, S.E. Regional Wastewater Treatment Plant Improvement Final Plans and Specifications, Redding, CA.

Criterion Planners/Engineers, December 1990, Study of Water Availability and Additional Strategies for Geysers Resource Management, Lake and Sonoma Counties, CA.

Criterion Planners/Engineers, February 1992, Southeast Geysers Effluent Pipeline Preliminary Engineering and Economic Analysis, Lake County, CA. 
Criterion Planners/Engineers, 1994, Southeast Geysers Effluent Pipeline MMOP Implementation Guide, Lake County Sanitation District, Lakeport, CA.

Criterion Planners/Engineers, 1995, Southeast Geysers Effluent Pipeline Permitting \& Funding Mapbook, Lake County Sanitation District, Lakeport, CA.

Criterion Planners/Engineers, March 1996, Southeast Gcysers Effluent Pipeline Environmental Compliance Manuals, Volumes 1-4, Lake County Sanitation District, Lakeport, CA.

Dewante \& Stowell, 1991, Southeast Regional Wastewater System Facilities Plan, Lake County Sanitation District, Lakeport, CA.

Environmental Science Associates Inc., September 1994, Environmental Impact Report/Environmental Impact Statement for the Southeast Geysers Effluent Pipeline Project, Lake County Sanitation District, Lakeport, CA.

GeothermEx Inc., July 1991, Geysers Rescrvoir Productivity Decline Analysis, Lake and Sonoma Counties, CA.

Lake County Sanitation District, September 1994, Southeast Geysers Effluent Pipeline Project Mitigation, Monitoring \& Operation Plan, Lakeport, CA. 
Figure 1

PROJECT VICINITY \& MAJOR COMPONENTS

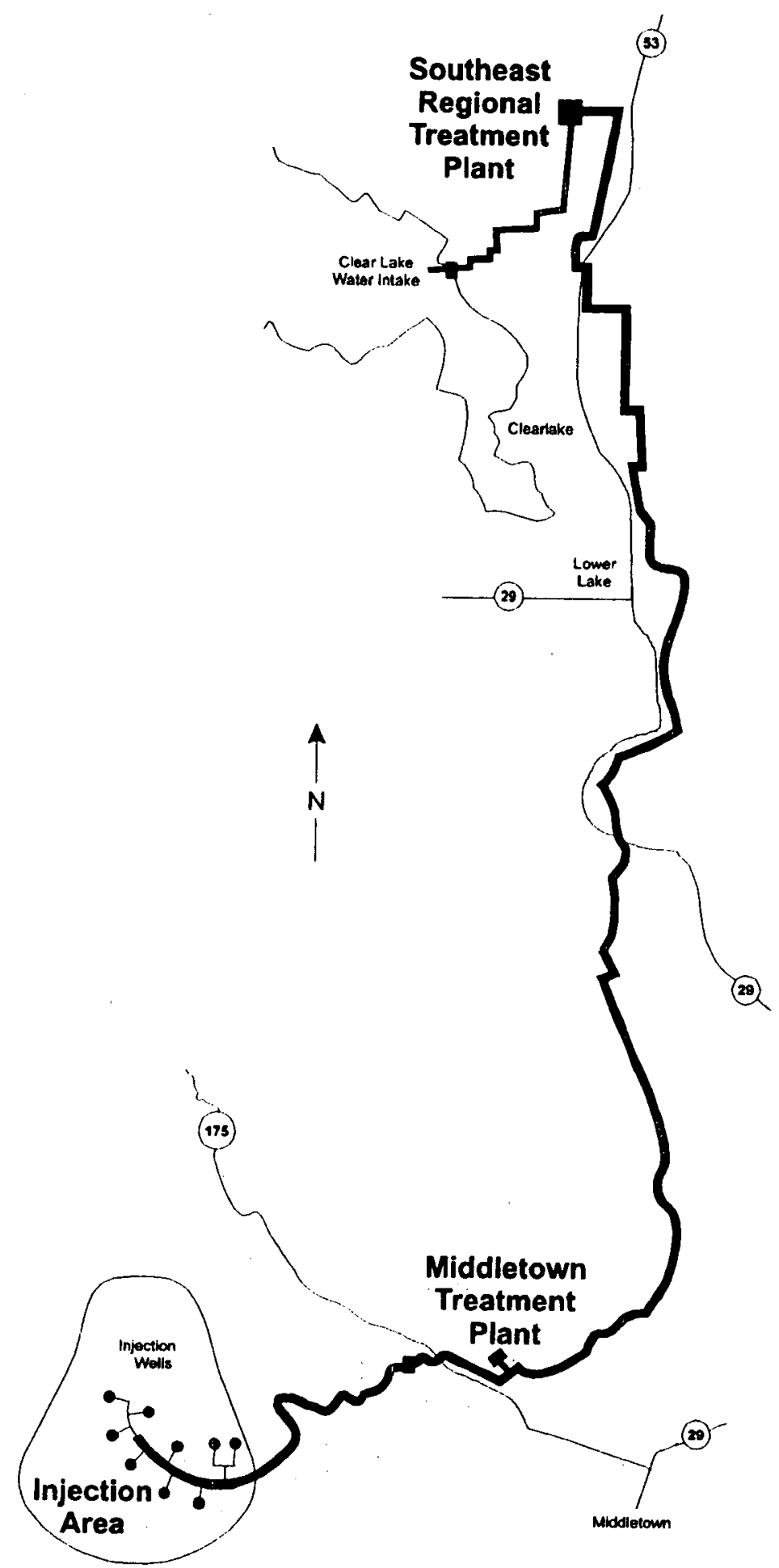




\title{
GEOTHERMAL HEAT PUMP TECHNOLOGY TRANSFER
}

\author{
Thomas F. O’Day \\ TODAY Associates
}

\section{KEY WORDS}

Geothermal heat pumps, GHP, GHP technology transfer, GHP program, GHP market penetration and implementation

\section{PROJECT BACKGROUND AND STATUS}

The Geothermal Heat Pump Technology Transfer project (Project) creates initiatives to transfer GHP technology to affect market penetration. It assists utilities in creating or expanding geothermal heat pump (GHP) programs, developing new business ventures focusing on GHP technology, and instructing utilities how to transfer their successful GHP programs to other utilities. The Project is in support of the objectives set forth by the Geothermal Heat Pump Consortium (GHPC).

President Clinton authored The Climate Change Action Plan (Plan) in October, 1993. The Plan responds to the threat of global climate change and helps guide the U.S. economy toward environmentally sound economic growth into the twenty-first century. The Plan is comprehensive and encourages the partnership of the U.S. government with American businesses to rapidly implement methods to solve environmental problems. Action \#26 within the Plan, "Form Renewable Energy Market Mobilization Collaborative and Technology Demonstrations", called for the DOE to form a collaborative with private industry to accelerate market acceptance of renewable technologies, including geothermal technology.

TODAY Associates (TODAY) has a background unique within the utility industry. Its experience is rooted in competitive business, which has made it very valuable in the utility industry as deregulation progresses. For more than 12 years, TODAY has used its comprehensive knowledge of the competitive market to conceive and implement a wide variety of GHP technology transfer programs for the utility industry and other organizations. TODAY interfaces with GHPC, national labs, IGSHPA and has made major efforts to educate national parties about market development activities for GHPs and outlined what their roles should be in that effort. Examples include:

TODAY has conducted workshops, lectures, seminars and functioned in an advisory capacity to a diverse crosssection of corporations and organizations interested in the development of GHPs. Its main focus and contribution has always been to explain concepts and principles required to capture market share with a replacement product in a competitive marketplace.

For this project, TODAY selected, and the DOE approved, two utilities which will be assisted in the expansion of their GHP programs. The utilities/holding companies are OG+E (Oklahoma City, OK), and The Southern Companies (Birmingham, AL). The Project began on September 1, 1997 and will be completed by February 1 , 1998. The project is approximately $50 \%$ complete.

\section{PROJECT OBJECTIVES}

The Project's objective is to assist two utilities in one: or more of the following ways: 
- Transfer their successful GHP program to other utilities,

- Develop a new business venture focusing on GHP technology,

- Develop a comprehensive GHP program designed to achieve meaningful market penetration within several years, and

- Increase the number of GHPs installed in its existing residential and/or commercial program.

\section{Technical Objectives}

- Assist the utility in developing a market and sales strategy to sell/transfer their programs to other utilities,

- Convince top utility management of the potential in the GHP industry,

- Develop a plan to create a new venture in the GHP industry,

- Develop a comprehensive plan for the total GHP program,

- Develop training programs for utility personnel,

- Assist the utility in designing an aggressive and effective advertising and promotional program that will educate the public on GHP technology,

- Assist in setting up systems/procedures to deal with following up on leads and handling customer questions,

- Help the utility establish an effective network of HVAC and loop contractors who are interested in installing GHP systems,

- Show the utility how to recruit HVAC and loop contractors,

- Develop GHP training courses for the HVAC and loop contractors, and

- Evaluate the utility's existing program and the results achieved to date. Re-focus the utility's efforts, if required.

\section{Expected Outcomes}

\section{For $\mathbf{O G}+\mathbf{E}$ :}

- In 1998 and 1999, obtain 60 signed contracts from commercial building owners for conversion to GHP systems. Have all 60 building converted to GHP by 2000 .

- In 1998 and 1999, install 1,050 GHP systems in new and existing homes.

- Install GHP systems in at least $10 \%$ of all new homes in OG+E's service territory by 2000 .

For The Southern Companies, goals have not yet been determined. 


\section{APPROACH}

TODAY is usig the experience it gained working with utilities, government agencies, and other affected parities in determining its approach to the current project. TODAY has solved the following GHP technology transfer problems and is applying the same problem solving approach to the Project:

- Create high volume sales to reduce prices - This technique was utilized at PSI where the high volume sales of GHP systems in residential subdivisions led to reduced prices. This principle has been used in every utility's GHP program.

- Reduce the number of HVAC and loop contractors involved in installing the GHP system to increase their incentive to perform the installations.

- Create advertising and promotion programs similar to what a high-tech company would use to attract customers.

- Develop sales methods similar to what building suppliers use in the construction industry with developers and builders.

- Utilize standardized training requirements. This was achieved through the creation of IGSHPA.

- Create an industry standard, ARI rating, for GHP equipment.

- Develop methods to transfer GHP technology to other utilities. Provide videos, hold open houses, and train personnel to make presentations.

- Develop a Ten Step Program to define the clements and identify the steps and activities necessary to implement a successful GHP program.

- Integrate national organizations into local cfforts.

\section{RESEARCH RESULTS}

The research results of the Project are not unlike the results found in previous DOE or other affected party contacts. The results show that in order for a utility to effectively implement the technology transfer of GHP systems into commercial and residential buildings, the following program elements must be in place:

\section{Create a Comprehensive Plan}

The plan must include all of the following elements, as well as specific features unique and critical to each utility. Evaluate and determine the appropriate target market for the utility based on corporate goals and the specific make-up of the utility's service territory. Focus on top management, their role in creating a successful program, and the importance of management leading by example. To generate interest and awareness, encourage top management to install GHP systems in their own homes. 


\section{Develop GHP Training Programs}

Develop GHP training programs for utility personnel to introduce the technology and benefits of the system to the company and its customers Include mid/upper management, marketing representative, and all people involved in administering the program.

\section{Education}

Educate the public on GHP technology to gain acceptance.

\section{Recruit and Develop a GHP Infrastructure}

Recruit and develop an infrastructure of HVAC contractors, drillers, and loop installers. They must be trained in the installation of GHP systems, and the utility must do whatever is necessary to assist this small number of committed contracts to be successful.

\section{Establish Contracts with Loop Contractors}

Establish contracts with loop contractors for volume installation of loops. This will significantly reduce the price for loop installations by as much as $50 \%$.

\section{FUTURE PLANS}

- TODAY plans to work with several more utilitics to create service companies dedicated to selling and installing commercial and residential GHP systems.

- TODAY will propose ways to focus efforts to affect market penetration via the assistance of government agencies and research laboratories.

- TODAY will continue to build on its efforts to train utilities in the methods to build successful GHP businesses. This may be done through the development of "packaged" implementation programs.

- TODAY plans to direct the development of national awareness efforts utilizing unique media programs.

\section{INDUSTRY INTEREST}

Electric \& Gas Utilities are interested in our technology transfer methods so they can learn how to develop and implement their own GHP programs. GHP equipment manufacturers, dealers, and contractors are interested in our ideas and methods to assist them in selling/installing more GHP systems.

\section{REFERENCES}

The Climate Change Action Plan, President William J. Clinton and Vice President Albert Gore, Jr., October, 1993.

National Plan, Geothermal Heat Pump Consortium (GHPC).

Charter, International Ground Source Heat Pump Association (IGSHPA) 


\section{LIST OF CONTACTS FOR DRILLING TECHINOLOGY}

Willetia Amos

U.S. Department of Energy

Idaho Operations Office

850 Energy Drive

Idaho Falls, Idaho 83401

Phone: (208) 526-4097

e-mail: arnoswd@inel.gov

Robert J. Creed, Jr.

U.S. Department of Energy

Idaho Operations Office - MS 1220

850 Energy Drive

Idaho Falls, ID 8340 I

Phone: (208) 526-9063

Fax: (208) 526-6249

Mark Dellinger

Project Manager

Lake County Sanitation District

230A Main Street

Lakeport, CA 95453

Phone: (707) 263-2273

Fax: (707) 263-3836

Raymond Fortuna

Office of Geothermal Technologies, EE-122

U.S. Department of Energy

1000 Independence Avenue, SW

Washington, DC 20595

Phone: (202) 586-1711

Fax: (202) 586-8185

Mark Hannifan

Heritage Technologies

5300 Denver Tech Center Parkway, Suite 265

Englewood, CO 80111

Phone: (303) 221-7410

Fax: (303) 221-7412

e-mal: hannifan@heritage-corp.com
Thomas F. O'Day

TODAY Associates

500 S. Salina St.

Suite 1030

Syracuse, NY 13202

Phone: (315) 426-7843

Fax: (315) 426-2900

e-mail: TODAYAssoc@msn.com 
AUTHOR INDEX

Adams, Michael C. $4 \cdot 27$

Allan, M.L.

$5-13,5-17$

Anovitz, L. M.

$2-49$

Barton, Colleen

$4-189$

Battistelli, Alfredo

$4-69$

Benezeth, Pascale

$4-9$

Benoit, Dick

$4-181,4-189$

Bharathan, Desikan

$5-55,5-67$

Blackwell, David D.

$2-93$

Blencoe, J. G.

$2-49$

Bloomfield, K. K.

$4-77$

Bonner, Brian

$4-177$

Brown, B.W.

$5-37,5-45$

Bruton, Carol J.

Candela, P.A.

$5-71$

Cole, David R.

$2-45$

Costain, John K.

$2-49,4-21$

Dalrymple, G. Brent

$2-1$

Dellinger, Mark

$4-103$

DePaolo, Donald J.

$6-13$

Drumheller, Douglas $\mathrm{S}$

$2 \cdot 39$

Duan, Zhenhao

$3-31$

Duba, Al

$4-35$

Faulder, D. D.

$4-177$

Finger, John $\mathrm{T}$.

$4-73,4-77,4-89$

Finsterle, Stefan

$3-25,3-43$

Gawlik, Keith

$4-69,4-137$

Glowka, David A

$5-57,5-63$

Goff, Fraser

$3-37,3-43$

Greenberg, Jerry P.

$2-33$

Gruszkiewicz, Miroslaw S.

$4-35$

Hannifan, J. Mark

$4-15,4-47$

Hassani, Vahab

$6-9$

Heizler, Matthew T.

$5 \cdot 57,5-63$

Henfling, Joseph A.

$2-15,4-153,4-167$

Hickman, Stephen $3-19$

Horita, Juske

$4-189$

Hulen, Jeffrey B. $2-49,4-21,4-47$

Janik, Cathy J.

$2-27,4-153,4-167$

Johnson, S. D.

$2-33$

Kamola, Diane L

$4-89$

Kasameyer, Paul

$2-21$

Kennedy, B. Mack

$4-177$

$2-39,4-149$ 


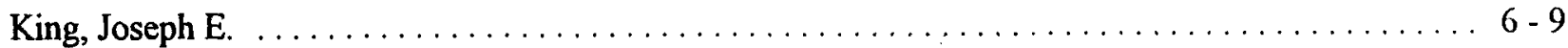

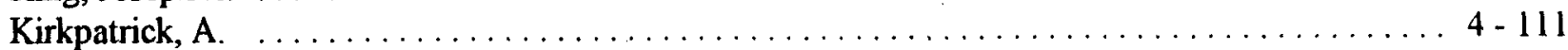

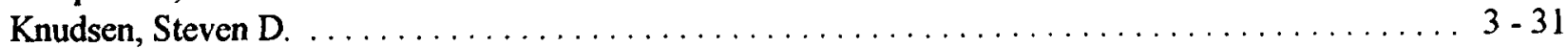

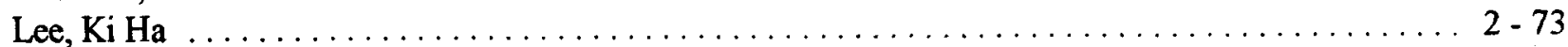

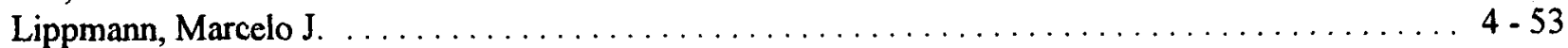

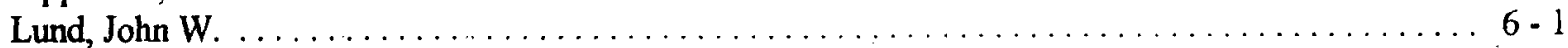

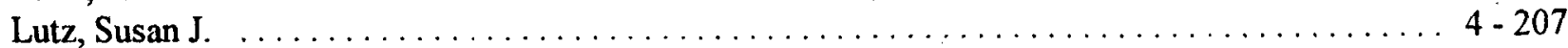

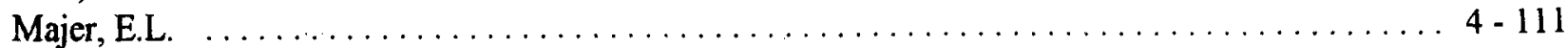

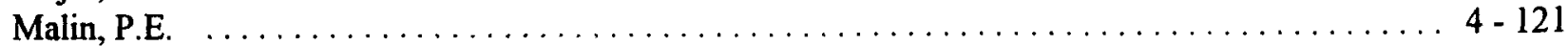

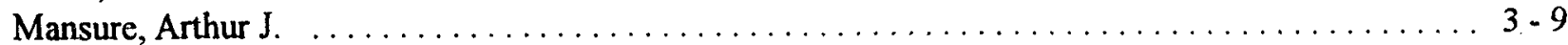

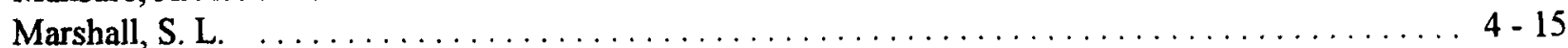

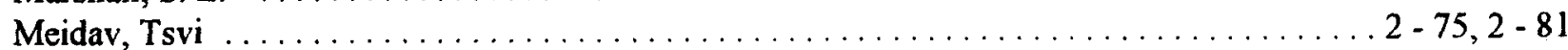

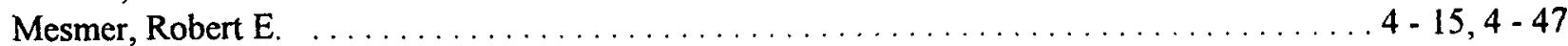

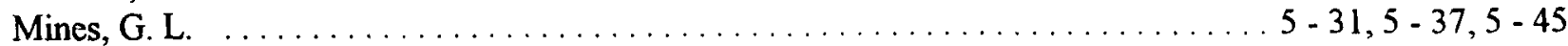

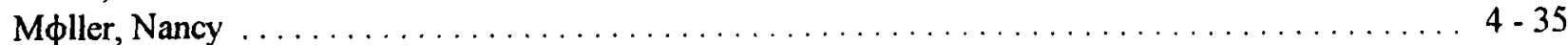

Moore, Joseph N. .............................. 2-15,4-149,4-153,4-207

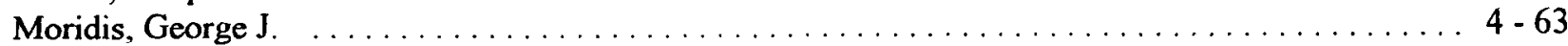

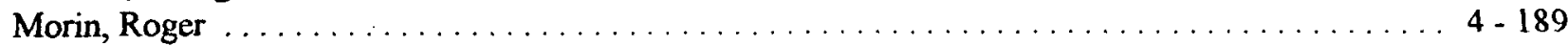

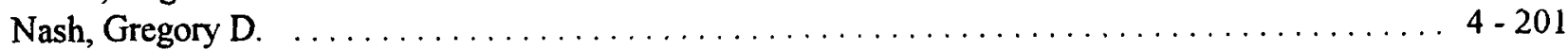

Nazario, Oscar . . ............................................ $4-93$

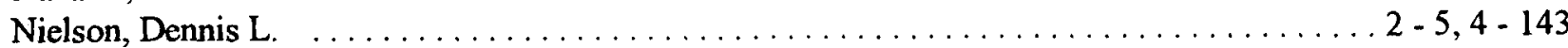

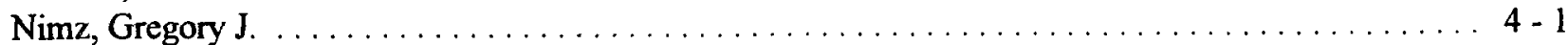

Norman, Randy A. . . . . . . . . . . . . . . . . . . . . . . . . . . . . . . . . . $3-19$

Norman, David I. . . . . . . . . . . . . . . . . . . . . . . . . . . . . . . . . 2 2-15,4-149

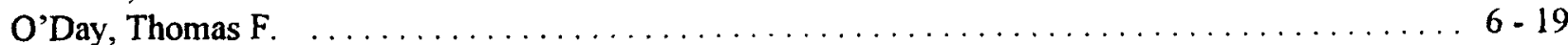

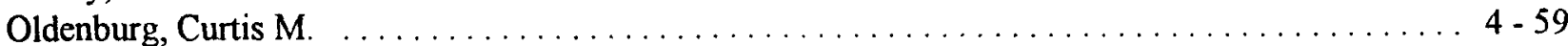

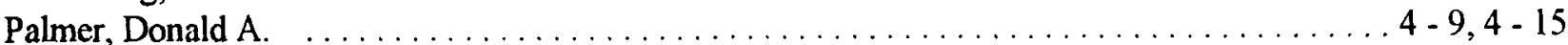

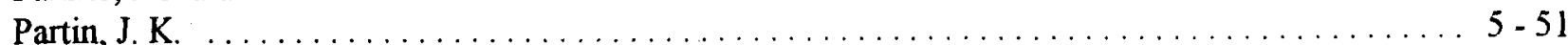

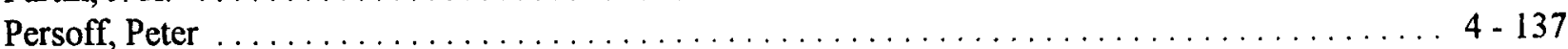

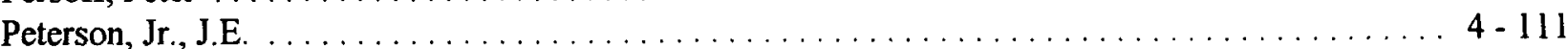

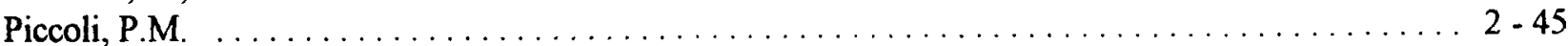

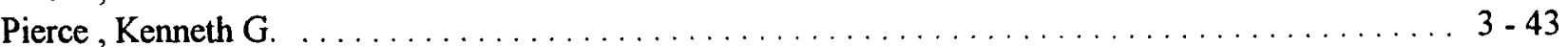

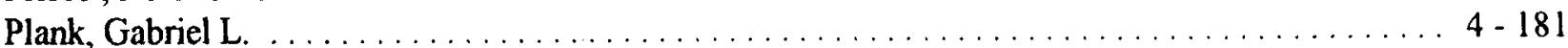

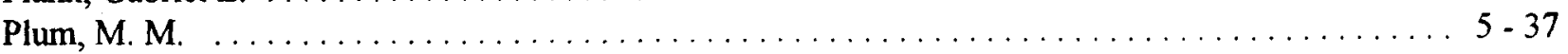

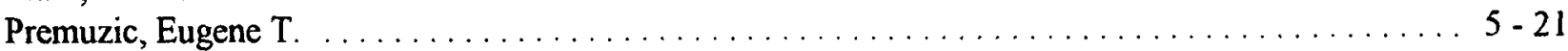

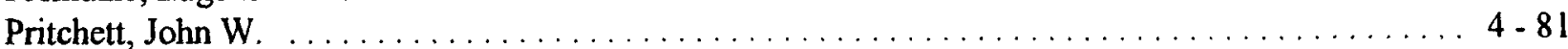

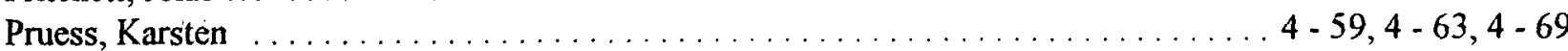

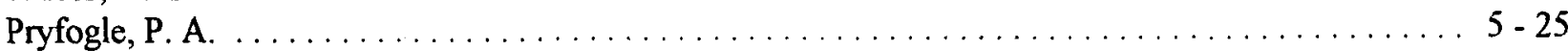

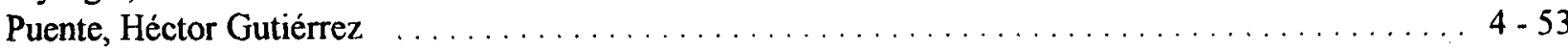

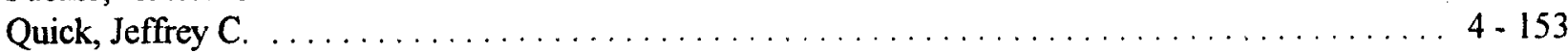

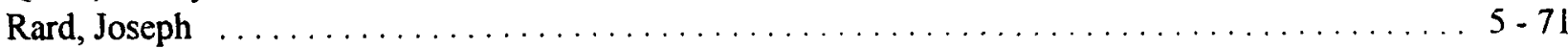

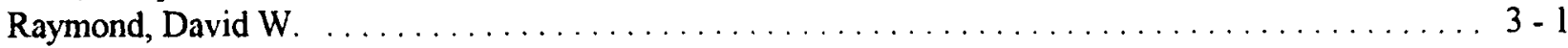

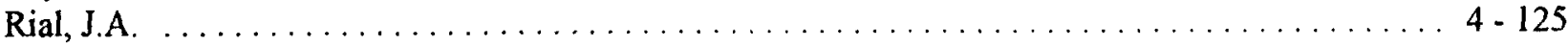


AUTHOR INDEX (continued)

Roberts, Jeff . . . . . . . . . . . . . . . . . . . . . . . . . . . . . . . . . . . . . 4 - 177

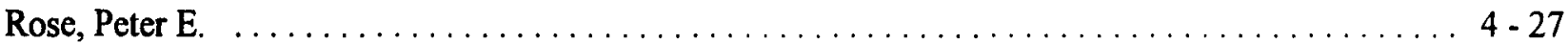

Ross, Howard P. . . . . . . . . . . . . . . . . . . . . . . . . . . . . . 2-69, 2-89

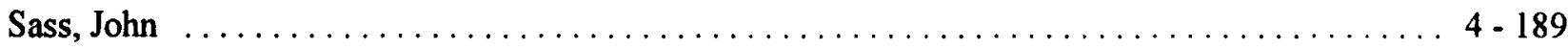

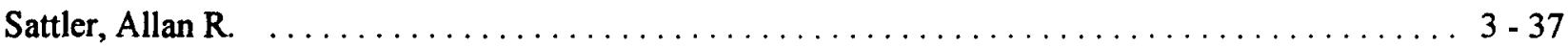

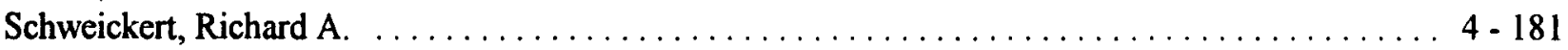

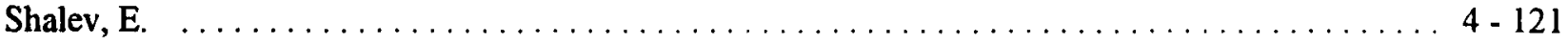

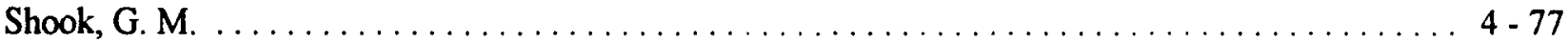

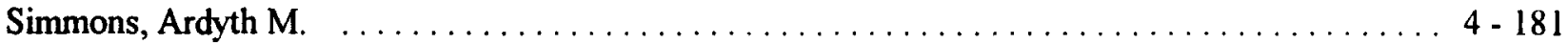

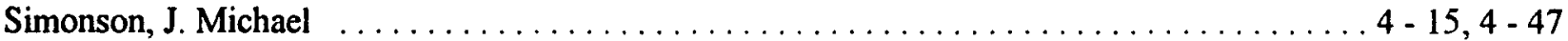

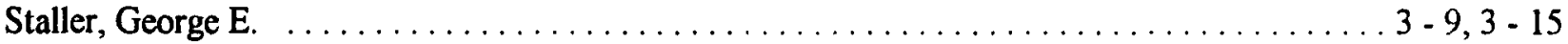

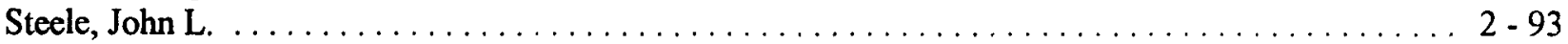

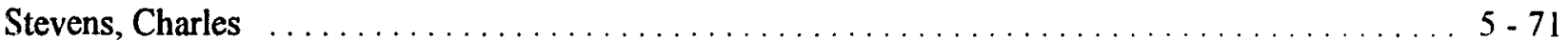

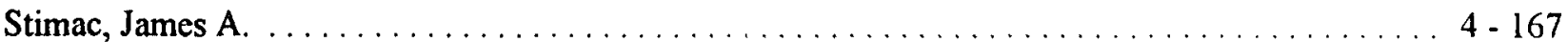

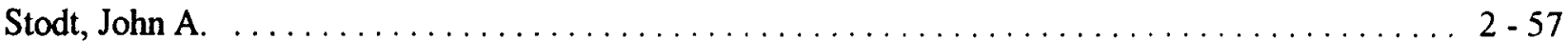

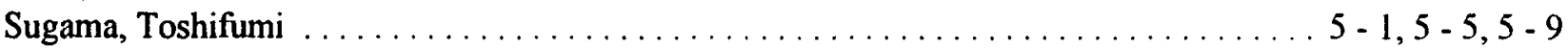

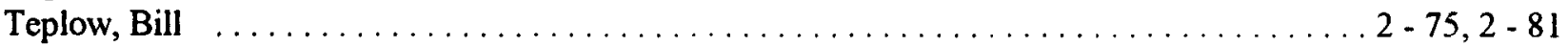

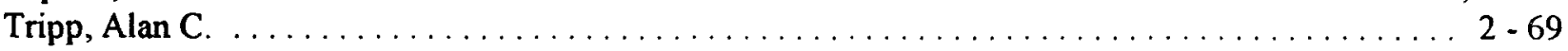

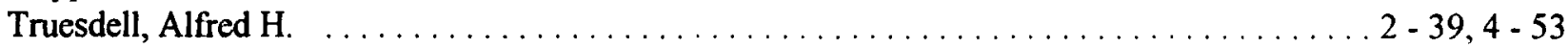

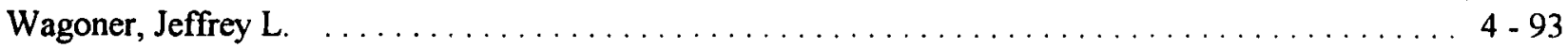

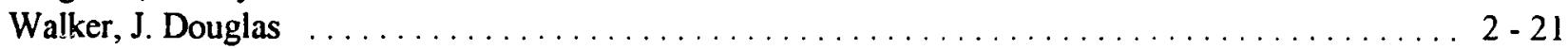

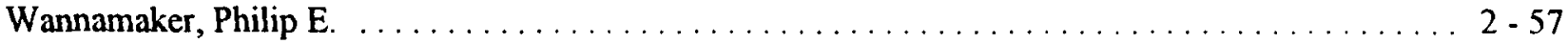

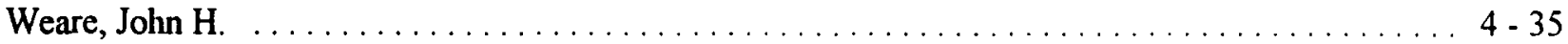

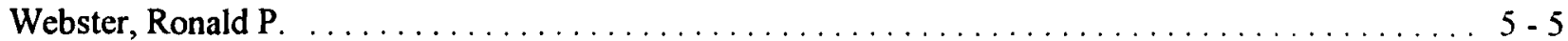

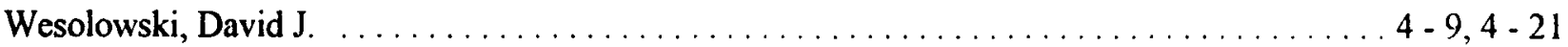

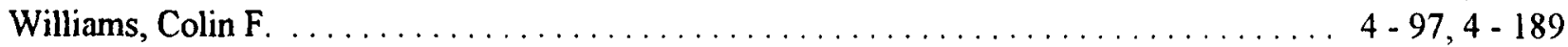

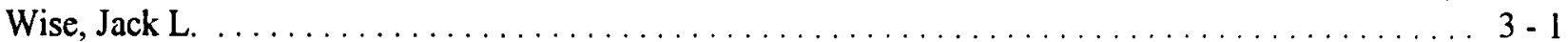

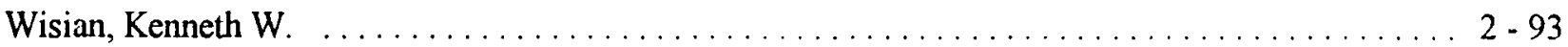

Zoback, Mark ............................................... 4.189 


\section{KEY WORD INDEX}


KEY WORD INDEX

3-D seismic reflection $\ldots \ldots \ldots \ldots \ldots \ldots .2$ - 81

40Ar/39Ar dating .............. 2-15

40Ar/39Ar Dating ............. 4 403

acid condensate ................. 5 - 9

acid-base reactions $\ldots \ldots \ldots \ldots \ldots \ldots \ldots \ldots$ 5 - 1

acidity ..................... 4 4 . 15

acoustic telemetry .............. 3-31

adhesion ..................... 5 - 13

adsorption ..................4 4 -47

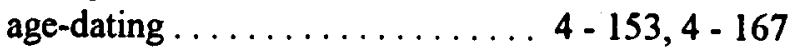

algorithms $\ldots \ldots \ldots \ldots \ldots \ldots \ldots \ldots .2$. 57

alteration mineralogy ............. 4 4-207

alteration .................. 4-9

aluminosilicates $\ldots \ldots \ldots \ldots \ldots \ldots \ldots \ldots 4$. 9

aluminum $\ldots \ldots \ldots \ldots \ldots \ldots \ldots \ldots, 4$. 9

antioxidant agent $\ldots \ldots \ldots \ldots \ldots \ldots \ldots \ldots, 5-5$

aquaculture ..................6. $6-1$

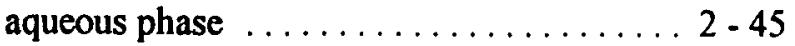

Awibengkok .......... 2 - 27, 2-39,4-1

back pressure ................. 5 $5-67$

backfill ..................... . 5 - 17

Basin and Range ....... 2 - 81, 4 - 89,4 - 207

Basin and Range Province . . . . . . . . . . . 2 - 39

Beowawe ... . . . . . . . . . . . . . . . . 4 4 - 89

binary cycle .................. 5-57

binary power cycles $\ldots \ldots \ldots 5-31,5-37,5-45$

binary working fluid $\ldots \ldots \ldots \ldots \ldots \ldots 5-57$

biochemical processing ....... 5-13,5-21

biogeochemistry ..............4-201

blue-shift ...................4 4-201

boiling point curves $\ldots \ldots \ldots \ldots \ldots \ldots 4-167$

borehole imaging logs $\ldots \ldots \ldots \ldots \ldots 2,5$

breakout .................. 4-35

brine $\ldots \ldots \ldots \ldots \ldots \ldots 2$-45,4-15,4-21

brines .....................4 $4-35$

CADOGGR .................... 4 4-93

calcium aluminate cements .......... 5-1

capillarity ..................... 4 $4-177$

capillary pressure ............... . 4- 137

carbonation $\ldots \ldots \ldots \ldots \ldots \ldots \ldots \ldots . \ldots . \ldots .1$

cathodic protection .............. 5 5.13

cementitious grouts $\ldots \ldots \ldots \ldots \ldots \ldots \ldots 5-17$
Cerro Prieto $\ldots \ldots \ldots \ldots \ldots \ldots \ldots \ldots \ldots .4-53$

chemistry ................ 4-35

chloride ....................4 4-15

coatings $\ldots \ldots \ldots \ldots \ldots \ldots \ldots \ldots \ldots, 13$

communications $\ldots \ldots \ldots \ldots \ldots \ldots \ldots, 3-31$

composites .................. 5-9

computer models ..............4 $4-35$

computer-aided model . . . . . . . . . . . 5 - 57

conjugate gradients ..............4 4-63

controlled source magnetotellurics ... . . 2 2 73

cooling towers $\ldots \ldots \ldots \ldots \ldots \ldots \ldots \ldots, 5.9$

core ....................... 2 2-27

core-tube memory logger . . . . . . . . . . . 3 -19

core-tube monitoring ............. 3-31

corrosion ..............4 $4-15,5-13$

corrosion measurements .......... 5-25

corrosion protection $\ldots \ldots \ldots \ldots \ldots \ldots 5 \cdot 5,5-9$

Coso .........................4 4-1

Coso Range $\ldots \ldots \ldots \ldots \ldots \ldots \ldots \ldots .2-21$

cost sharing ................ 3 37

Cove Fort ... . . . . . . . . . . . . . . . 2 2 89

crack-density ................4 4 - 121

CSAMT .................... 2 2-57

cutter wear testing ............. 3-1

dacite of Cobb Mountain . . . . . . . . . 4 467

database .................... 4 4-93

decline curve ................ 4-73

decontamination ............... 5-21

direct use $\ldots \ldots \ldots \ldots \ldots \ldots \ldots \ldots, 6,1$

direct-contact condensers ......... 5 5 67

district heating $\ldots \ldots \ldots \ldots \ldots \ldots \ldots 6-1$

Dixie Valley . 2 - 39, 4 - 1, 4 - 181, 4 - 201, 4 - 207

Dixie Valley geothermal system ....... 2 - 33

Doppler flow meter ................ . 3 -9

downhole pumps ...............4 4-81

downhole measurements ............ 3-19

downhole tools and materials for treating lost

circulation zones ............. 3-15

drillable straddle packer ............ $3-15$

drilling costs ................. 3-25

drilling fluid hydraulics measurement system . 3 -9

drilling systems $\ldots \ldots \ldots \ldots \ldots \ldots \ldots, 3-43$ 
drilling technology $\ldots \ldots \ldots \ldots \ldots \ldots \ldots .3-37$

drilling success ................ 2-81

Eastern United States .......... 2 - 1, 2 - 93

economic evaluation ............ 5 5 57

El Hoyo .................... 2 2 . 75

electrical resistivity $\ldots \ldots \ldots \ldots \ldots 2-89,4-177$

electrical conductivity .............2 $2-73$

electrical properties of rocks ........4 4-177

electromagnetics ................ 2-57

energy ....................... 4-35

Engineered-I. ithology Test Facility ...... $3-15$

enthalpy ..................... 4-35

EOS ..................... 4-35

equilibrium .................. 4-35

expert system ................. 3-9

exploration ................. $3-25$

exploration methods for geothermal energy . . 2-1

exsolution ..................... 2.45

extensional basins .............. 2-21

facies analysis $\ldots \ldots \ldots \ldots \ldots \ldots \ldots 2-21$

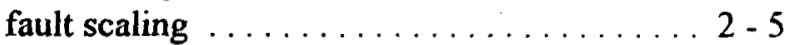

fault zone architecture $\ldots \ldots \ldots \ldots \ldots \ldots 2-5$

faulting $\ldots \ldots \ldots \ldots \ldots \ldots \ldots \ldots .4-189$

faults .................. 4-201

felsite ................... 4 4-167

felsite unit $\ldots \ldots \ldots \ldots \ldots \ldots \ldots \ldots 4-103$

Fetkovich ...................4 4-73

fluid/gas sampler ................ 3-19

fluid geochemistry .............. 2-33

fluid inclusions ........ 2 - 15, 2 - 39, 4 - 149,

$4-153,4-207$

fluid migration and storage $\ldots \ldots \ldots \ldots .2 \cdot 27$

fluid flow ................... . 4 489

fluid-flow architecture ............ 4 4 - 143

fluid-rock interactions . . . . . . . . . . . . 2 - 49

fluorescein .................... 4 4-27

flyash $\ldots \ldots \ldots \ldots \ldots \ldots \ldots \ldots \ldots, 5,1$

fouling coefficient $\ldots \ldots \ldots \ldots \ldots \ldots \ldots, 5-5$

fracture patterns ................4 4-125

fractures $\ldots \ldots \ldots \ldots \ldots \ldots \ldots 4-121,4-189$

fumaroles .................... 2-33

gas analyses $\ldots \ldots \ldots \ldots \ldots \ldots \ldots \ldots .4-149$ gas composition ............... 2-33

gas geochemistry .............. 2-15

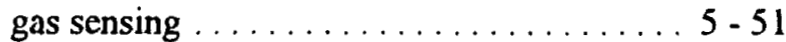

gases .................... 4-35

geobotany ................4 4-201

geochemical modeling .............4 4

geochemistry ............4 4-1,4-167

geochronology ............ 2-21,4-103

Geographic Information System ....... 4- 143

geologic studies ............... 2-21

geological exploration ............ 2-81

geophysical exploration ..... 2 - 1,2 - 75,2 - 81

geophysics ............. 2-69,2 -89

geothermal ......... 2-45, 2-73,3-25,

$4-27,4-35,4-93$

geothermal biocorrosion ........... 5-25

geothermal drilling .............. 3-1

Geothermal Drilling Organization (GDO) . . 3 - 37

geothermal exploration ..... 2-1,2 - 75, 3-43

geothermal fluids ............... 2 -49

geothermal gradient .............. 2-93

geothermal heat pumps ....... 5 - 17,6-19

geothermal injection database . . . . . . . 4 4-93

geothermal markets ............... 3-43

geothermal monitoring ............ 4-111

geothermal potential .............. 2-93

geothermal power plant ........ 5-57,5-71

geothermal production database ....... 4-93

geothermal reservoir ........ 4 - 47,4 - 177,

$4 \cdot 181,4 \cdot 189$

geothermal system .............. 2-27

geothermometer ................4-21

geothermometry ...........4 4-153.4-167

GHP ...................... 6-19

GHP market penetration and implementation $6-19$

GHP program ................... $6-19$

GHP technology transfer . . . . . . . . . . 6 6 - 19

granite ...................... 2. 49

granodiorite .................. 4-167

greenhouses $\ldots \ldots \ldots \ldots \ldots \ldots \ldots \ldots, 6.1$

grid numbering schemes $\ldots \ldots \ldots \ldots \ldots 4-63$

ground heat exchanger ............ $5-17$ 
KEY WORD INDEX (continued)

Gunung Salak ..................... 2 2 27

H2S stack emissions .............. 5- 71

H2S abatement ................... 5 - 71

hard-rock drilling $\ldots \ldots \ldots \ldots \ldots \ldots \ldots, 3-1$

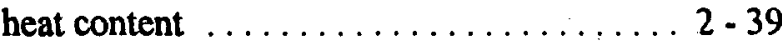

heat exchangers ................. 5-63

heat flow ........... 2 - 93,4-97,4-189

heat mining .................... 2-93

heat pumps $\ldots \ldots \ldots \ldots \ldots \ldots, 6,1,6-9$

heat rejection system $\ldots \ldots \ldots \ldots \ldots \ldots .5-57$

heat transfer ..................... 5 5 5

high temperature reservoir .......... 4 4 97

high-temperature $\ldots \ldots \ldots \ldots \ldots \ldots \ldots .29,27$

high-temperature tools .............. 3 19

higher-order differencing ............. 4-59

hydrochloric acid ................... 4-15

hydrogen ..................... 4-21

hydrogen sulfide ................. 5 - 51

hydrogen sulfide abatement .......... 5-67

hydrothermal alteration $\ldots \ldots \ldots \ldots \ldots \ldots .2-15$

hydrothermal history .............. 4-153

images $\ldots \ldots \ldots \ldots \ldots \ldots \ldots \ldots . \ldots .4-93$

impregnated-diamond bits ............. 3-1

Indonesia ...................... 2-27

industrial $\ldots \ldots \ldots \ldots \ldots \ldots \ldots, 6,1$

industrial coatings $\ldots \ldots \ldots \ldots \ldots \ldots \ldots, 5-63$

industry partners $\ldots \ldots \ldots \ldots \ldots \ldots, 3.37$

injection ........ 4 - 77,4-89,4-111,6-13

instrumentation ................... 2-57

integrated data analysis ............... 2-81

interference ...................... 4 473

inverse modeling $\ldots \ldots \ldots \ldots \ldots \ldots \ldots 4-69$

isotope $\ldots \ldots \ldots \ldots \ldots \ldots 2-39,4-1,4-21$

isotope composition .............. 2, 2,33

ITOUGH2 ................... 4.-69

joint DOE/industry ventures . . . . . . . . . 3-37

Klinkenberg effect $\ldots \ldots \ldots \ldots \ldots \ldots, 4: 137$

lightweight ................... 5-1

liquid-dominated systems $\ldots \ldots \ldots \ldots \ldots, 4-53$

logging $\ldots \ldots \ldots \ldots \ldots \ldots \ldots \ldots \ldots \ldots \ldots \ldots \ldots, 19$

logging tools $\ldots \ldots \ldots \ldots \ldots \ldots \ldots \ldots, 3-19$

low temperature resources ............ $6-1$ low-temperature applications $\ldots \ldots \ldots \ldots 2$ - 1

magma $\ldots \ldots \ldots \ldots \ldots \ldots \ldots \ldots . \ldots \ldots$

magmatic fluids $\ldots \ldots \ldots \ldots \ldots \ldots \ldots, 4-1$

magmatic gas ................... $2-39$

magnetometry $\ldots \ldots \ldots \ldots \ldots \ldots \ldots . .61$

magnetotellurics $\ldots \ldots \ldots \ldots \ldots \ldots 2-57,2-73$

marketing support $\ldots \ldots \ldots \ldots \ldots \ldots, 6-9$

materials development ............ 5-63

materials testing $\ldots \ldots \ldots \ldots \ldots \ldots \ldots, 5-63$

matrix preprocessing $\ldots \ldots \ldots \ldots \ldots \ldots, 4-63$

matrix solvers $\ldots \ldots \ldots \ldots \ldots \ldots \ldots, 4-63$

measurement while drilling (MWD) ...... 3 - 31

mechanical properties ............... $5-1$

memory tools ................... $3-19$

metal recovery ................. 5 $5-21$

metastable turbine expansion ......... 5-31

microbially-influenced corrosion ........ 5 - 25

microearthquakes ............... 4 - 111

mild steel ........................ 5 5 5

mineral .......................... 4-21

mineralogy .................. 4 457

minigeothermal ............... 4-81

mixed hydrocarbon working fluid ...... 5 - 57

modeling ..........2 - 49.4 - 9.4 - 15,4-89

MT/CSAMT ............ 2-75, 2-81

multi-component working fluids ........ 5-55

natural hydraulic fracturing ..... 4- 153, 4- 167

near infrared spectroscopy ........... 5 -51

Nevada ........................ 4-201

Nicaragua ...................... 2 -75

nickel aluminide $\ldots \ldots \ldots \ldots \ldots \ldots, 5$ - 5,5 - 9

noble gases .................... 2 - 39

non-condensable gas handling . . . . . . 5 - 67

normal faults ................. 4- 207

numerical dispersion .............. 4-59

numerical modeling ........... 2-69, $4-63$

numerical simulation ............. 4- 77

off-design performance ............ 5-57

off-grid power ................. 4-81

off-grid power cycles .............. 5 - 45

operating and maintenance costs ....... 5-71

optimization .................. 4-69 
oxygen

$4-21$

paleotopography

$4-153$

parameter estimation

$4-69$

partitioning

$4 \cdot 21$

performance improvement

$5-37$

permeability ...... 2-27,4-9,4-181, 4- 189

permeability-thickness ...........4 $4-73$

petrogenesis ................. 4-167

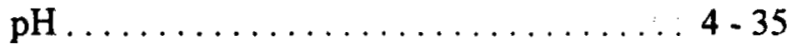

phase equilibria $\ldots \ldots \ldots \ldots \ldots \ldots \ldots .2$ - 49

phase transition ...............4 45

Philippines .................... 2 - 15

phosphate containing compounds ...... 5 $5-1$

piping ................... 5 - 9

polyaromatic sulfonates . . . . . . . . 4 4 - 27

polycrystalline diamond compact (PDC) ... . 3 - 1

polymer cement composites ............ 5-5

polymer concrete lining ............ 5 5 - 63

polymers ................ 5 5,9,5-13

polyphenylene sulfide ............ 5-5

pore fluid content ................4 $4-177$

pore size ....................4.4-177

porosity ....................... 2 2 . 27

porous materials .............. . . 4 4-47

potentiometry ................... 4 4 9

power cycles ................. 5 5 55

pre-ceramics ................... 5-9

pressure ................ 3-19,4-97

pressure-pulse decay .............4 4-137

production monitoring $\ldots \ldots \ldots \ldots \ldots \ldots 3-31$

production of silica $\ldots \ldots \ldots \ldots \ldots \ldots, 5-21$

public/private partnership ..........6 $6-13$

pump monitoring $\ldots \ldots \ldots \ldots \ldots \ldots \ldots .3-31$

pumpable .................. $5-1$

radiogenic model ................. 2-1

real-time control ................ 5 5-37

real-time monitoring $\ldots \ldots \ldots \ldots \ldots \ldots, 5-51$

recharge $\ldots \ldots \ldots \ldots \ldots \ldots \ldots \ldots \ldots 2-33$

reinjection ................. $4-1$

relative permeability $\ldots \ldots \ldots \ldots \ldots \ldots 4-137$

remote sensing ................ 2-75

reservoir reservoir characterization . . . . . . . . . . 4-89

reservoir management $\ldots \ldots \ldots \ldots \ldots \ldots 6-13$

reservoir models ................ $2-33$

reservoir response to exploitation ......4 453

reservoir simulation ............. 4-27

resistivity ................. 2-75

resource evaluation $\ldots \ldots \ldots \ldots \ldots \ldots .3-43$

rock/water interactions . . . . . . . . . . 4 4 - 35

rocks ..................... 4-47

rolling float meter $\ldots \ldots \ldots \ldots \ldots \ldots \ldots 3-9$

rural electrification . . . . . . . . . . 4 4 81

Rye Patch ................... 2 - 81

Salton Trough $\ldots \ldots \ldots \ldots \ldots \ldots \ldots .4 . \ldots .43$

scaling ............... 2-33,4-35

seasonal variation $\ldots \ldots \ldots \ldots \ldots \ldots .4-201$

seismic reflection . . . . . . . . . . . 4 4 - 181

seismic velocity . . . . . . . . . . . . . 4-11.1

seismicity .................4 4-111

self potential ......2 - 69,2 - 75,2 - 81;2 - 89

shear-wave splitting ........4-121,4-125

silicate melts $\ldots \ldots \ldots \ldots \ldots \ldots \ldots \ldots .2-49$

silicon carbide ................5 5

silicon-on-insulator . . . . . . . . . . 3-19

simulation.............. 4-35,4 - 59

single-cutter testing $\ldots \ldots \ldots \ldots \ldots \ldots, 3-1$

slim holes ................... 4 4-81

slimhole ....................... 3-25

slimhole tools ................... . . 3-19

slip flow . . . . . . . . . . . . . . . . 4 4137

solubility ...............4 4-9,4-35

source effect ................... 2-73

space heating $\ldots \ldots \ldots \ldots \ldots \ldots \ldots \ldots, 6,1$

spectral gamma ................. 3-19

spectrometer .................5-71

steam ..............4 4-15,4-21

steam fraction ................. 4 4 45

Stillwater escarpment . . . . . . . . . . 4 - 181

Stillwater Range ... . . . . . . . . . . . 4 - 207

stress ........................ . 4 - 189

strike-slip faults ...............4 $4-143$

structural heterogeneity ............4- 143

structural classification .............. 2-5 
supersaturated expansion ..........5 - 31 synthetic-diamond bits ............. 3-1 technical assistance $\ldots \ldots \ldots \ldots \ldots \ldots 6,1$ technology transfer ..............6. 6-9 tectonostratigraphic history . . . . . . . 4 4 - 207 temperature $\ldots \ldots \ldots \ldots \ldots \ldots \ldots 2-93,3-19$ temperature decline ............ 4 - 89 temperature gradients $\ldots \ldots \ldots \ldots \ldots \ldots 2-1$ temperature measurements $\ldots \ldots \ldots \ldots .2$. 75 texture $\ldots \ldots \ldots \ldots \ldots \ldots \ldots \ldots \ldots 2-45$ The Geysers ...... 2 - 39, 4 - 15, 4 - 47, 4 - 73, $4-77,4-97,4-121,4-125$, $4-137,4-149,4-153,4-167$ The Geysers geothermal field ....... 4-103, $4-177,5-71$

The Geysers-Clear Lake geothermal region . 2 - 33 Thematic Mapper .............. 4-143 thermal conductivity $\ldots \ldots \ldots \ldots \ldots 2-1,2-93$, $4-97,5-5,5-17$ thermal history ...............4 403 thermal spraying $\ldots \ldots \ldots \ldots \ldots \ldots \ldots 5-13$ thermally stable polycrystalline (TSP) $\ldots \ldots 3-1$ thermodynamic data ............. 4-35 thermodynamic evaluation ......... 5-57 thermodynamics ........... 2-49,4-15 Tiwi ................. 2- 15,2 - 39 tomography $\ldots \ldots \ldots \ldots \ldots \ldots \ldots \ldots 4-121$ tracer tests $\ldots \ldots \ldots \ldots \ldots \ldots \ldots \ldots \ldots 4-27$ tracers ...............4 4-21,4-27 transient production .............4 4.73 trilateral cycle ................. 5 5.45 tunable diode spectroscopy $\ldots \ldots \ldots \ldots \ldots 5-51$ turbines $\ldots \ldots \ldots \ldots \ldots \ldots \ldots \ldots \ldots .5 .31$ TVD ...................... 4 - 59 utility programs $\ldots \ldots \ldots \ldots \ldots \ldots \ldots \ldots 6-9$

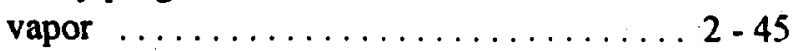
vapor-dominated $\ldots \ldots \ldots \ldots \ldots \ldots \ldots 4$ - 73 vapor-pressure lowering $\ldots \ldots \ldots \ldots \ldots 4-137$ vegetal-spectral ...............4 4-201 veins ..................... 4 4-153 vent gas blowers $\ldots \ldots \ldots \ldots \ldots \ldots \ldots \ldots 5$-9 venting $\ldots \ldots \ldots \ldots \ldots \ldots \ldots \ldots, 453$ vertical seismic profiling $\ldots \ldots \ldots \ldots \ldots 2-81$ village power $\ldots \ldots \ldots \ldots \ldots \ldots .4-81,5-45$ vitrinite ..................4 4-153 volatiles ..................... 2.45 volatility .................... 4-15 volcanic ..................... 2-45 wastewater effluent $\ldots \ldots \ldots \ldots \ldots \ldots 6-13$ water composition .............. 2-33 waveguides ................ 3-31 well casing $\ldots \ldots \ldots \ldots \ldots \ldots \ldots \ldots \ldots \ldots \ldots$ well completions ............... 5-1

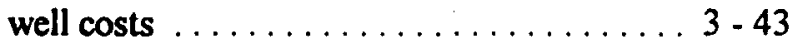
wellhead generators $\ldots \ldots \ldots \ldots \ldots \ldots \ldots 4$-81 West Java . . . . . . . . . . . . . . . . . . . . 2 2 27 Western U.S. . . . . . . . . . . . . . . 2.93 wireless telemetry $\ldots \ldots \ldots \ldots \ldots \ldots \ldots 3-31$ working fluid mixtures . . . . . . . . . . 5 - 37 X-ray diffraction .............. 4-207 
夙闻

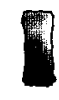

$\sqrt{7}$

1

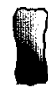

1

W

瀷 